

\section{Juventud: realidades y retos para un desarrollo con igualdad}

Daniela Trucco

Heidi Ullmann

Editoras

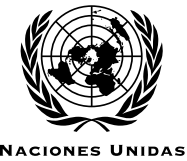

CEPA L

Comisión Económica para América Latina y el Caribe (CEPAL) Santiago, septiembre de 2015 


\section{Libros de la CEPAL}

\section{7}

Alicia Bárcena

Secretaria Ejecutiva

\section{Antonio Prado}

Secretario Ejecutivo Adjunto

\section{Laís Abramo}

Directora de la División de Desarrollo Social

\section{Ricardo Pérez}

Director de la División de Publicaciones y Servicios Web

Este libro ha sido editado por Daniela Trucco y Heidi Ullmann, Oficiales de Asuntos Sociales de la División de Desarrollo Social de la Comisión Económica para América Latina y el Caribe (CEPAL), en el marco del proyecto "Inclusión social de la juventud en contextos de creciente violencia e inseguridad con un foco en Centroamérica", financiado con cargo a la Cuenta de las Naciones Unidas para el Desarrollo.

Se agradecen muy especialmente los valiosos comentarios de todos los capítulos del libro formulados por Ernesto Rodríguez, así como el apoyo editorial de Daniela Huneeus. Se reconoce a su vez a Martín Hopenhayn, ex Director de la División de Desarrollo Social, por promover el tema de juventud en la agenda de la CEPAL y de la región, y este proyecto en particular.

Las opiniones expresadas en este documento son de exclusiva responsabilidad de los autores y pueden no coincidir con las de la Organización.

Diseño de portada: María Luisa Avaria

Publicación de las Naciones Unidas

ISBN: 978-92-1-121898-5 (versión impresa)

ISBN: 978-92-1-057227-9 (versión pdf)

ISBN: 978-92-1-358015-8 (versión ePub)

Número de venta: S.15.II.G.12

LC/G.2647-P

Copyright (C) Naciones Unidas, 2015

Todos los derechos reservados

Impreso en Naciones Unidas, Santiago

S.15-00718

Esta publicación debe citarse como: Daniela Trucco y Heidi Ullmann (eds.), Juventud: realidades y retos para un desarrollo con igualdad, Libros de la CEPAL, N 137 (LC/G.2647-P), Santiago, Comisión Económica para América Latina y el Caribe (CEPAL), 2015.

La autorización para reproducir total o parcialmente esta obra debe solicitarse al Secretario de la Junta de Publicaciones, Sede de las Naciones Unidas, Nueva York, N.Y. 10017, Estados Unidos. Los Estados miembros y sus instituciones gubernamentales pueden reproducir esta obra sin autorización previa. Solo se les solicita que mencionen la fuente e informen a las Naciones Unidas de tal reproducción. 


\section{Índice}

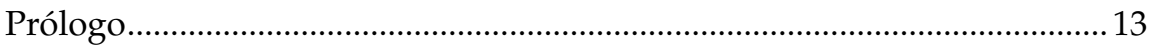

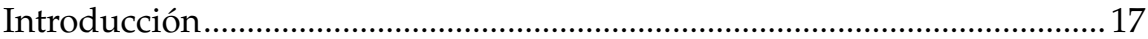

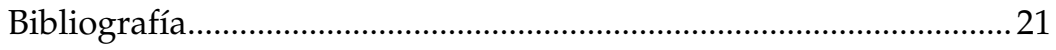

Capítulo I

La llave maestra de la inclusión social juvenil: educación y empleo

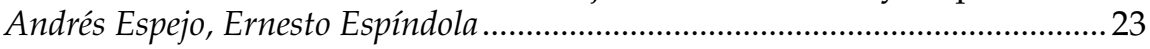

A. A qué se dedican los jóvenes: una aproximación .......................25

B. Los jóvenes que estudian: acceso y progresión

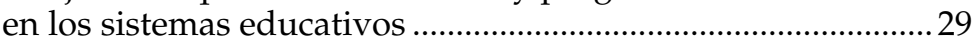

C. Empleo juvenil .................................................................................... 39

D. Los jóvenes que no están incorporados a los sistemas educativos y no tienen un empleo remunerado ...........................50

E. Sugerencias de políticas ..................................................................57

1. Disponer de una oferta educativa y formativa flexible y pertinente.

2. Fomentar la generación de procesos de transición de la educación a empleos más adecuados y de mejor calidad, y promover la existencia de un marco legal y de políticas públicas que aseguren la oportunidad de construcción de trayectorias de trabajo decente para los jóvenes

3. Promover la creación de sistemas de información que brinden evidencia suficiente para la adecuada articulación entre el sistema educativo y el mercado de trabajo 
Bibliografía. 65

Capítulo II

La salud y las juventudes latinoamericanas y caribeñas

Heidi Ullmann

Introducción

A. Panorama de la salud de los jóvenes latinoamericanos y caribeños

1. ¿De qué mueren los jóvenes en América Latina y el Caribe?

2. Juventud y morbilidad: ¿de qué se enferman los jóvenes?

B. Desigualdades en salud sexual y reproductiva entre las jóvenes de la región

C. Acceso a servicios de salud

D. Otros temas de salud en la población juvenil: el uso de drogas y la salud mental.

1. El uso de drogas lícitas e ilícitas

2. La salud mental de los jóvenes: no hay salud sin salud mental

E. Políticas y programas: promoción

de una vida saludable

1. Las políticas y los programas en materia de salud: una revisión

2. Las políticas y los programas en materia de salud: ¿qué se podría mejorar?

3. Recomendaciones

Bibliografía

Capítulo III

Inclusión y contextos de violencia

Humberto Soto, Daniela Trucco

A. Violencia y juventud ................................................................ 115

1. Multidimensionalidad de la violencia: manifestaciones en la juventud

2. Multicausalidad de la violencia: factores facilitadores

3. Ubicuidad de la violencia: espacios o ámbitos que enfrenta la juventud.

B. Género y violencia en la juventud

1. El género como factor de riesgo de ser víctima o victimario de violencia en la juventud

2. La juventud como factor en la perpetración de la violencia de género 
3. La violencia contra la mujer en las pandillas ..................... 133

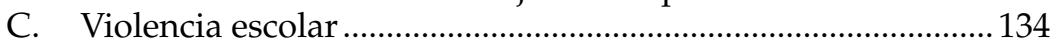

1. Violencia escolar entre pares: algunas cifras .......................137

2. El factor tecnológico en la ecuación ........................................142

D. Violencia colectiva en la ciudad .................................................. 144

1. El homicidio como la máxima expresión de la violencia directa ............................................................. 145

2. Formas organizadas de participar en la violencia: las pandillas y el narcotráfico ................................................. 150

E. Las alternativas hacia una convivencia pacífica ........................ 154

1. La visión de los jóvenes sobre un entorno libre de violencia

2. Políticas y programas que abordan la violencia en la juventud.

3. Recomendaciones para la inclusión juvenil en contextos de violencia.

Bibliografía......

\section{Capítulo IV}

El acceso de los jóvenes a la cultura en la era digital en América Latina Guillermo Sunkel.

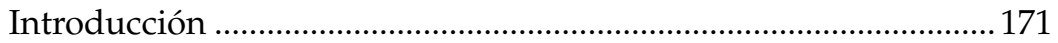

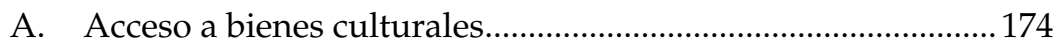

B. Acceso y uso de medios digitales …………………………....... 179

C. Acceso a bienes culturales a través

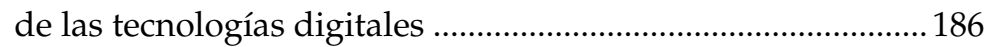

D. Programas culturales: promoción del bienestar ........................194

1. Promoción del acceso a la cultura .......................................... 196

2. El arte y la cultura como mecanismo para la inclusión social ......................................................... 197

3. Desarrollo de habilidades digitales para la producción y la expresión cultural ...........................................................200

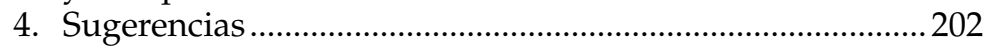

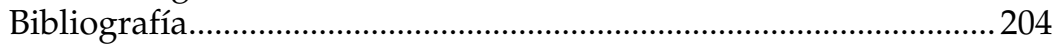

\section{Capítulo V}

Participación política, apego a la democracia y temas prioritarios de las personas jóvenes en América Latina, 2000-2013

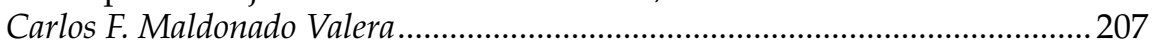

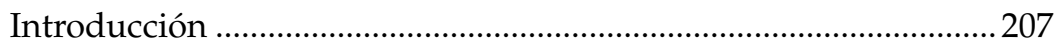

A. Participación electoral y movilización de las personas jóvenes

B. Actitudes individuales, confianza en las instituciones y apego a la democracia 
C. La participación no convencional y las nuevas plataformas de expresión, movilización

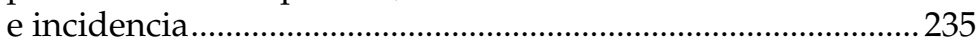

D. Temas que movilizan a la juventud y sus prioridades para la agenda pública.

E. Políticas y programas para favorecer la participación y movilización de las personas jóvenes

F. Conclusiones 247

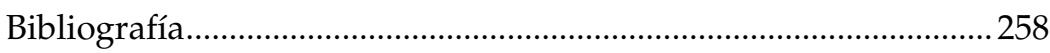

Capítulo VI

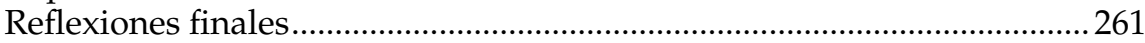

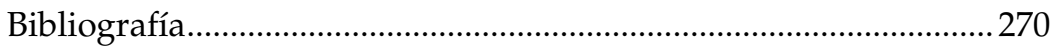

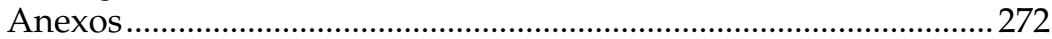

Anexo VI.A1

América Latina y el Caribe (23 países): instituciones

coordinadoras en materia de juventud

Anexo VI.A2

América Latina y el Caribe (17 países): marco jurídico

nacional en el área de juventud.

Anexo VI.A3

América Latina y el Caribe (15 países): documentos

de las políticas nacionales de juventud

Publicaciones recientes de la CEPAL_............................................................ 279

\section{Cuadros}

1 Dimensiones de inclusión social juvenil

I.1 América Latina (18 países): condición de actividad de jóvenes de 15 a 29 años, alrededor de 2012

I.2 América Latina (18 países): tasa de deserción en la enseñanza secundaria, alrededor de 2012

I.3 América Latina (18 países): tasa de asistencia al nivel terciario entre jóvenes de 20 a 24 años, alrededor de 2012

I.4 América Latina (18 países): tasas de desempleo, jóvenes de 15 a 29 años, por quintiles, alrededor de 2012

II.1 América Latina y el Caribe (33 países): principales enfermedades o problemas que contribuyen a la carga de morbilidad, por sexo y edad, 2010 ....

II.2 Políticas, programas y proyectos: salud en general y acceso .........101

II.3 Políticas, programas y proyectos: salud sexual y reproductiva

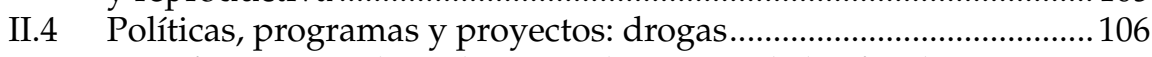

III.1 Manifestaciones de violencia en la juventud clasificadas de acuerdo con la complementariedad de las tipologías de Galtung y del modelo ecológico. 
III.2 América Latina (18 países): percepción de presencia de violencia en distintos ámbitos, población de 16 a 29 años, 2008 ..

III.3 América Latina (18 países): personas que han sufrido actos delincuenciales en los 12 meses previos a la encuesta, según tipo de acto, sexo y edad, 2012

III.4 Chile, Guatemala y Perú: jóvenes de 15 a 29 años que declaran presencia de violencia física en su escuela o lugar de estudio, según tramo de edad

III.5 América Latina y el Caribe (18 países): percepción de la incidencia de pandillas o maras en los barrios, según sus residentes, por país y tramo etario, 2012

III.6 América Latina y el Caribe (19 países): planes, leyes y programas relacionado con distintos tipos de violencia.

V.1 América Latina (18 países): promedio de las cuatro características principales que atribuyen los jóvenes a la democracia, 2013

V.2 América Latina (17 países): los dos problemas más importantes mencionados por jóvenes de 16 a 29 años, 2000 y 2013

V.3 Programas centrados en la generación de instancias y procesos de diálogo y comunicación política para las personas jóvenes

V.4 Programas que buscan promover directamente la participación política de las personas jóvenes.

V.5 América Latina y el Caribe (24 países): edad mínima para votar y para ser elegido al poder legislativo nacional.

VI.1 Paradigmas de la fase juvenil en los enfoques de políticas y programas.

\section{Gráficos}

I.1 América Latina (18 países): condición de actividad de jóvenes de 15 a 29 años, alrededor de 2012

I.2 América Latina y el Caribe (42 países): tasa neta de matrícula de nivel secundario, según sexo

I.3 América Latina (17 países): estudiantes matriculados en el nivel secundario, según tipo de programa, 2012

I.4 América Latina (18 países): tasa neta de asistencia a la enseñanza secundaria, según quintiles extremos de ingreso, alrededor de 2012

I.5 América Latina (18 países): conclusión del nivel secundario entre jóvenes de 20 a 24 años, alrededor de 2012

I.6 América Latina y el Caribe (42 países): tasa bruta de matrícula de nivel terciario, según sexo, 2000-2012. 
I.7 América Latina (15 países): tipo de estudio de los jóvenes de 20 a 24 años que se encuentran asistiendo a un establecimiento educativo, alrededor de 2012

I.8 América Latina (12 países y 18 países): jóvenes de 25 a 29 años que no se encuentran estudiando y poseen estudios terciarios incompletos, y jóvenes que concluyeron el nivel terciario

I.9 América Latina (18 países): tasas de participación laboral de jóvenes de 15 a 29 años, alrededor de 2012

I.10 América Latina (18 países): tasas de desempleo, por grupo de edad

I.11 América Latina (18 países): empleo juvenil, alrededor de 2012

I.12 América Latina (18 países): promedio de ingresos laborales mensuales de la población ocupada, alrededor de 2013

I.13 América Latina (18 países): peso del ingreso laboral de los jóvenes que están empleados en el ingreso familiar, según parentesco

I.14 América Latina (18 países): población asalariada afiliada a la seguridad social, por tramos de edad, alrededor de 2012

I.15 América Latina y el Caribe (18 países): condición de actividad de jóvenes de 15 a 29 años que no estudian ni están empleados, alrededor de 2012

I.16 América Latina y el Caribe (11 países): razones de no asistencia al sistema educativo de los jóvenes catalogados como "otros", alrededor de 2012.

I.17 América Latina y el Caribe (10 países): razones para no buscar trabajo remunerado en los jóvenes catalogados como "otros", alrededor de 2012

II.1 América Latina y el Caribe: tasas específicas de mortalidad, según edad y sexo, 2010.

II.2 América Latina y el Caribe (33 países): muertes según causas específicas, por grupos etarios y sexo, 2010

II.3 América Latina y el Caribe (33 países): muertes por lesiones, por grupos etarios y sexo, 2010.

II.4 América Latina (7 países): madres adolescentes entre mujeres de 15 a 19 años, según quintil de ingreso y zona de residencia

II.5 América Latina y el Caribe (6 países): edad de la iniciación sexual entre mujeres de 15 a 29 años, por quintil de riqueza.

II.6 América Latina y el Caribe (5 países): uso de condón en la última relación sexual entre mujeres sexualmente activas de 15 a 29 años, por quintil de riqueza 
II.7 América Latina y el Caribe (4 países): cobertura de salud entre mujeres de 15 a 29 años, por quintil de riqueza

II.8 América Latina y el Caribe (15 países): estudiantes que fumaron cigarrillos 1 o más días en los últimos 30 días .90

II.9 América Latina y el Caribe (15 países): estudiantes fumadores que probaron su primer cigarrillo a los 14 años o antes

II.10 América Latina y el Caribe (18 países): estudiantes que han consumido por lo menos un trago de alcohol 1 o más días en los últimos 30 días

II.11 América Latina y el Caribe (11 países): estudiantes que han consumido alcohol y probaron su primer trago a los 14 años o antes.

II.12 América Latina y el Caribe (18 países): estudiantes que han consumido tanto alcohol hasta quedar borrachos una o más veces en su vida

II.13 América Latina y el Caribe (15 países): estudiantes que han consumido drogas, como marihuana, cocaína o éxtasis, una o más veces en su vida

II.14 América Latina y el Caribe (17 países): estudiantes que han considerado el suicidio

II.15 América Latina y el Caribe (17 países): estudiantes que han hecho un plan de suicidio

III.1 América Latina y el Caribe (23 países): población de entre 11 y 17 años que declara haber sufrido bullying (acoso escolar) en el último mes.

III.2 América Latina y el Caribe (23 países): tipos de bullying (acoso escolar) sufridos por la población de 11 a 17 años que declara haber sido víctima en el último mes, según sexo

III.3 América Latina y el Caribe: tasa de mortalidad por violencia interpersonal, según tramos de edad, 1990-2010

III.4 Brasil, Colombia y Venezuela (República Bolivariana de): tasa de mortalidad por violencia interpersonal, según tramos de edad, 1990-2010

III.5 El Salvador, Guatemala, Honduras y México: tasa de mortalidad por violencia interpersonal, según tramos de edad, 1990-2010

IV.1 América Latina (18 países): personas que han utilizado, visto o participado en alguna actividad cultural, según tramo de edad

IV.2 Jóvenes (16 a 29 años) que han utilizado, visto o participado en alguna actividad cultural, según grupos de países

IV.3 América Latina (18 países): frecuencia de uso de la computadora, según grupos de edad 
IV.4 América Latina (18 países): frecuencia de uso de Internet, según grupos de edad

IV.5 Jóvenes (16 a 29 años): frecuencia de uso de Internet, según nivel socioeconómico

IV.6 América Latina (18 países): lugar de conexión a Internet de los jóvenes (16 a 29 años), según nivel socioeconómico

IV.7 América Latina (18 países): personas que han utilizado Internet para realizar alguna actividad cultural, según tramo de edad

IV.8 América Latina (18 países): jóvenes (16 a 29 años) que han utilizado Internet para realizar alguna actividad cultural, según grupos de países

V.1 América Latina (18 países): poco o ningún interés en la política de los jóvenes de 16 a 29 años y los adultos de 30 años y más, 2013

V.2 América Latina (17 países): jóvenes y adultos que declaran haber votado en la última elección presidencial, 2000-2013

V.3 América Latina (18 países): frecuencia de trabajo para un partido político o candidato, por tramo de edad, 2013

V.4 América Latina (17 países): jóvenes y adultos que declaran haber participado en manifestaciones al menos una vez en el último año, 2000-2013

V.5 América Latina (promedio simple de 17 países): jóvenes y adultos que declaran haber votado en la última elección y haber participado en una manifestación al menos una vez en el último año, 2000-2013

V.6 América Latina (17 países): jóvenes y adultos que no votaron en la última elección, según si declaran haber participado en una manifestación al menos una vez en el último año, 2000-2013

V.7 América Latina (promedio simple de 17 países): apreciación de la situación económica del país, 2000-2013.

V.8 América Latina (18 países): apreciación de la situación económica personal y familiar como mejor o un poco mejor para los siguientes 12 meses, según país y tramo etario, 2013

V.9 América Latina (promedio simple de 17 países): personas de 16 a 29 años y de 30 años y más que declaran tener mucha o ninguna confianza en instituciones seleccionadas, 2000-2013

V.10 América Latina (17 países): apoyo a la democracia como mejor forma de gobierno, entre los jóvenes de 16 a 29 años y los mayores de 30 años, 2013 
V.11 América Latina (17 países): evolución del apoyo a la democracia como mejor forma de gobierno, entre los jóvenes de 16 a 29 años, 2000 y 2013

V.12 América Latina (17 países): cambio en el apoyo a la democracia como mejor forma de gobierno, entre los jóvenes de 16 a 29 años, 2000-2013

V.13 América Latina (17 países): cambio en la cantidad de jóvenes de 16 a 29 años que se declaraban satisfechos con el funcionamiento de la democracia, 2000-2013

V.14 América Latina (17 países): apoyo a la democracia como mejor forma de gobierno, entre los jóvenes de 16 a 29 años, 2000-2013

V.15 América Latina (18 países): jóvenes de 16 a 29 años y adultos de 30 años y más que consideran que son los grupos poderosos y no el pueblo quienes gobiernan su país, 2013

V.16 América Latina (18 países): promedio de las cuatro características principales atribuidas por los jóvenes a la democracia, 2013

V.17 Guatemala: participación no convencional en organizaciones, según tramo etario y tipo de causa, 2011.

V.18 América Latina (promedio simple de 18 países): jóvenes de 16 a 29 años y adultos de 30 años y más que declaran estar muy dispuestos o nada dispuestos a movilizarse a favor de asuntos seleccionados, 2013

V.19 América Latina (promedio simple de 18 países): jóvenes de 16 a 29 años y adultos de 30 años y más que se declaran nada dispuestos a movilizarse a favor de asuntos seleccionados, 2013

V.20 América Latina (17 países): promedio de percepción sobre el problema más importante en el país, según los jóvenes de 16 a 29 años, 2000 y 2013

\section{Recuadros}

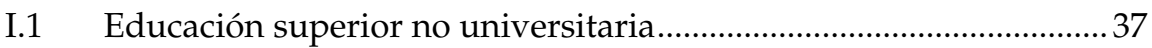

I.2 Trabajo adolescente en América Latina ............................................... 41

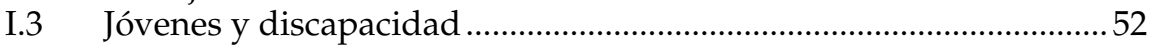

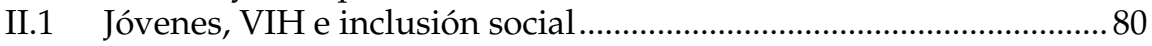

II.2 La salud de los jóvenes indígenas en la región: algunas cifras ......... 84

III.1 Tipología de violencia propuesta por Galtung, 1990........................ 117

III.2 Tipología basada en el modelo ecológico (OMS, 2002) .................... 118

III.3 Alcances sobre el bullying o matonaje escolar homofóbico en América Latina.....

IV.1 Servicios de acercamiento a la cultura a través de Internet.............189 
V.1 Algunos factores limitantes de la participación de las personas jóvenes en la vida política de las democracias contemporáneas.

V.2 Costa Rica: desapego juvenil hacia la participación electoral y la democracia, 2013

V.3 Chile: algunos rasgos de la movilización no convencional de las personas jóvenes, 2012

V.4 México: el movimiento \#yosoy132 durante la campaña presidencial de 2012

V.5 Medidas concretas orientadas a fomentar la participación política de las personas jóvenes

V.6 Intervenciones estratégicas para potenciar y fortalecer la participación y movilización política de las personas jóvenes en las distintas etapas del ciclo electoral

\section{Diagramas}

1 Ámbitos de la inclusión social en la juventud 


\section{Prólogo}

En los últimos años, la Comisión Económica para América Latina y el Caribe (CEPAL), a partir de los documentos presentados en los últimos tres períodos de sesiones — La hora de la igualdad: brechas por cerrar, caminos por abrir (2010); Cambio estructural para la igualdad: una visión integrada del desarrollo (2012) y Pactos para la igualdad: hacia un futuro sostenible (2014) -, ha postulado la consideración de la igualdad como el horizonte del desarrollo, el cambio estructural como el camino y la política como el instrumento para alcanzarlo.

Planteamos interpretar la igualdad desde una perspectiva que vaya más allá de la distribución de medios, como los ingresos monetarios, e incluya igualar oportunidades y capacidades con un enfoque de derechos. Esto significa entender la igualdad como el pleno ejercicio de la ciudadanía, en dignidad y con el reconocimiento recíproco de los actores. Avanzar en esa línea exige políticas que promuevan tanto la autonomía de los sujetos como la atención a sus vulnerabilidades.

Se ha de impulsar el reconocimiento de la igualdad en ese sentido amplio y relacional desde una perspectiva de derechos, pero también teniendo en cuenta la necesidad de mayor solidaridad colectiva, de valoración de la diversidad de grupos e identidades y del combate a la discriminación, requisitos esenciales para una sociedad más cohesionada y un desarrollo sostenible. Eso significa también tener la oportunidad de participar activamente en las decisiones que afectan el desarrollo colectivo y no solo ser su beneficiario.

Desde esta perspectiva se fortalece nuestra convicción de que la integración de la población juvenil en los procesos de desarrollo es crucial 
para avanzar hacia una sociedad más igualitaria. Por ello, el objetivo de este libro es profundizar en esa perspectiva desde una mirada centrada en la inclusión social de la juventud.

Dejando atrás una década de relativa bonanza económica, la región enfrenta un contexto externo más complejo y con menor dinamismo económico. Es preciso redoblar esfuerzos para lograr un desarrollo con horizonte estratégico a través del cambio estructural e inversión en capacidades humanas.

Como ha planteado la CEPAL (2014) en su discusión sobre pactos para la igualdad, en América Latina el estrato más productivo produce dos terceras partes del PIB (el 66,9\%) y, sin embargo, genera poco menos del $20 \%$ del empleo. En tanto, los sectores menos productivos emplean al $50 \%$ de los trabajadores, produciendo tan solo un $10 \%$ del PIB regional. Esta disparidad en el aporte de cada sector al producto y al empleo se traduce en una distribución también muy desigual en las ganancias de productividad entre los trabajadores.

Un desarrollo regional que tiene como horizonte la igualdad no puede lograrse con un pequeño grupo de empresas o sectores que producen con la mejor tecnología y compiten en los mercados globales, mientras que la mayoría de las empresas producen con tecnología poco intensiva en conocimiento, pero emplean a la mayor parte de los trabajadores en la economía.

El desarrollo de las capacidades de las nuevas generaciones se entiende como uno de los pilares básicos para transformar esa realidad, considerando a la persona joven como un agente productivo indispensable para el cambio estructural.

La CEPAL ha señalado que, junto a las persistentes brechas estructurales, hay desigualdades en el desarrollo de capacidades y en el mundo laboral. Esas inequidades, que afectan sobre todo a los y las jóvenes, requieren respuesta si se desea avanzar en el camino de la sostenibilidad con igualdad, entendiendo que la posición que ocupan los individuos en la escala social no es resultado exclusivo de las circunstancias, esfuerzos y decisiones individuales. Existe una estructura de oportunidades proporcionadas por los Estados, los mercados, las familias y las comunidades que escapan al control del individuo y condicionan sus perspectivas de movilidad social y acceso al bienestar. 
En este documento se pretende abordar los principales retos que enfrenta este segmento tan relevante de la población en su proceso de desarrollo e inclusión en la sociedad latinoamericana y se espera hacer un aporte para el fortalecimiento de las políticas de juventud de la región. En esa línea, el libro contiene los resultados del conjunto de investigaciones realizadas en el marco del proyecto "Inclusión social de la juventud en contextos de creciente violencia e inseguridad con un foco en Centroamérica", que fue financiado por la Cuenta de las Naciones Unidas para el Desarrollo e implementado por la CEPAL entre los años 2013 y 2015.

\author{
Alicia Bárcena \\ Secretaria Ejecutiva \\ Comisión Económica para \\ América Latina y el Caribe (CEPAL)
}





\section{Introducción}

Los jóvenes constituyen un segmento importante de la población de América Latina y el Caribe, de gran relevancia en los debates sobre las estrategias de desarrollo en años recientes ${ }^{1}$. Como se planteó en el prólogo, invertir en esta generación se constituye en uno de los pilares centrales para avanzar en un proceso de desarrollo que tiene como horizonte la igualdad. A pesar de que el concepto de juventud se construye socialmente de acuerdo con el contexto histórico, y no necesariamente alude a un rango de edad cerrado, en este libro, al igual que en las otras investigaciones realizadas por la Comisión Económica para América Latina y el Caribe (CEPAL), se acota a la población de 15 a 29 años.

A menudo los jóvenes no se sienten representados en los discursos, espacios y mecanismos políticos tradicionales; no participan en los ámbitos de decisión ni en los debates sobre temas socioeconómicos y políticos clave, aun cuando se consideran sensibles a las demandas de equidad y justicia social, protección medioambiental y diversidad cultural. A nivel mundial, en los últimos años han destacado los movimientos sociales liderados por la juventud, lo que supone un llamado de atención respecto de su interés de ser escuchados y de tener una participación activa en el desarrollo de las sociedades en que viven (CEPAL, 2014a). Es así como han proliferado una serie de investigaciones recientes sobre el papel de este segmento de la población en los procesos de desarrollo.

En este documento se utiliza el sustantivo genérico masculino "los jóvenes" para aludir tanto al género femenino como al masculino, a fin de evitar formas lingüísticas más largas que afecten a la fluidez de la lectura. 
La investigación presentada en este libro se fundamenta desde una perspectiva de derechos con la igualdad como aspiración. Tal como se planteó en CEPAL/UNFPA (2012), el trabajo en el campo de la juventud que promueven las Naciones Unidas se basa en los instrumentos de derechos humanos ratificados por los países de la región que ubican al joven como un sujeto de derechos. Entre los ámbitos que estos instrumentos apuntan a proteger se encuentran las familias de los jóvenes y el derecho a la educación, al trabajo, a la salud, a la participación y al desarrollo de la identidad y la cultura. En este marco, la propuesta de la CEPAL apunta a comprender el proceso de inclusión social juvenil desde una perspectiva de derechos, que trascienda el eje básico de educación y empleo y abarque otras dimensiones de inclusión social que también son clave para que los jóvenes avancen no solo en los parámetros objetivos de la inclusión, sino también en los subjetivos, y que con ello puedan sentirse parte de una sociedad que se construye en conjunto. El aporte de las políticas públicas para la juventud debería dirigirse a garantizar una serie de condiciones y seguridades mínimas para posibilitar el desarrollo de sus capacidades y potencialidades (Alvarado, Rodríguez y Vommaro, 2013). Se propone, entonces, considerar en el análisis y diseño de políticas dirigidas a la juventud una mirada multidimensional e integral que abarque los ámbitos de educación, empleo, salud, violencia, cultura y participación política (véase el diagrama 1).

\section{Diagrama 1 \\ Ámbitos de la inclusión social en la juventud}

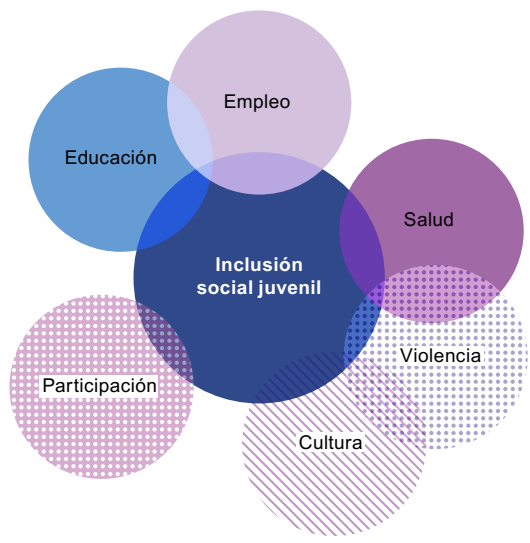

Fuente: Elaboración propia.

Pese a proponer esta visión de integralidad y multidimensionalidad sobre la vida de los jóvenes, por las propias limitaciones de la investigación y la falta de información comparable, hemos tenido que restringir el 
análisis a algunos aspectos de cada dimensión. En consecuencia, no se han considerado algunos temas de alta importancia para la inclusión social de los jóvenes de la región, como la migración, la recreación y el deporte, el medio ambiente y la religión. Además, reflexionamos sobre otros temas, como la familia y las comunidades, de una manera transversal. Si bien la unidad de análisis de la investigación es el joven, lo situamos en su contexto y valoramos la importancia de ese contexto para fomentar o complicar los procesos de inclusión de los jóvenes.

Este libro tiene por objeto ilustrar la situación que enfrentan los jóvenes en términos de oportunidades de inclusión social, teniendo en cuenta cada uno de los ámbitos considerados en el diagrama 1, pero también avanzar en materia de recomendaciones respecto de cómo mejorar esta situación a partir de políticas públicas integrales. Tal como ha sido recomendado recientemente por expertos en políticas públicas de juventud (Alvarado, Rodríguez y Vommaro, 2013), es importante promover en esta región el desarrollo y la consolidación de políticas de juventud integrales e integradas (entre los diferentes sectores), procurando dotar a todas las políticas públicas de una perspectiva generacional, operando de manera transversal e incluyendo, de mejor manera, a una mayor cantidad de jóvenes.

Sobre la base del marco general de medición de la cohesión social propuesto por la CEPAL en 2007, se propone entonces analizar la inclusión social juvenil considerando tres dimensiones fundamentales a ser contempladas por políticas y estrategias para la juventud (véase el cuadro 1). Una primera dimensión que examine el desarrollo institucional para la promoción-protección de la inclusión social de la juventud. Esta dimensión considera el fortalecimiento en capacidades de diseño, coordinación y evaluación de las instituciones coordinadoras y de la apertura al establecimiento de visiones integrales por parte de las instituciones implementadoras de políticas en materia de juventud. Una segunda dimensión que se enfoque en el cierre de las brechas objetivas de inclusión social en distintos ámbitos clave para este ciclo de la vida, con una perspectiva de igualdad y garantía de derechos, mediante la implementación de políticas sectoriales coordinadas. Por último, una tercera dimensión que contemple el ámbito subjetivo de inclusión social, donde se considere escuchar y entender las necesidades y visiones de los jóvenes con respecto a su propia inclusión social a fin de incorporar estos elementos en el diseño y la ejecución de las políticas. La puesta en práctica de políticas integrales exitosas solo puede lograrse si se consideran las tres dimensiones antes señaladas con una visión holística. En cada dimensión es importante considerar aspectos particulares que se pueden resumir en el conjunto de subdimensiones que se presentan en el cuadro 1. 
Cuadro 1

Dimensiones de inclusión social juvenil

\begin{tabular}{|c|c|c|c|}
\hline \multicolumn{4}{|c|}{ Dimensiones de análisis } \\
\hline \multirow{6}{*}{ 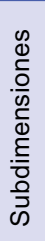 } & Desarrollo institucional & Brechas & Percepciones y valoraciones \\
\hline & Normativa (marco jurídico) & Empleo & Confianza \\
\hline & Planificación (plan sectorial/intersectorial) & Educación & Expectativas \\
\hline & Institucionalidad coordinadora & Salud & Construcción identitaria \\
\hline & $\begin{array}{l}\text { Oferta programática (instituciones } \\
\text { implementadoras) }\end{array}$ & Violencia & Solidaridad social \\
\hline & Acceso a recursos (gasto/inversión) & $\begin{array}{l}\text { Cultura } \\
\text { Participacic }\end{array}$ & \\
\hline
\end{tabular}

Fuente: Elaboración propia sobre la base de Comisión Económica para América Latina y el Caribe (CEPAL), Cohesión social: inclusión y sentido de pertenencia en América Latina y el Caribe (LC/G.2335/Rev.1), Santiago, 2007.

Los mecanismos de transmisión intergeneracional de la desigualdad están fuertemente arraigados en América Latina. La inclusión social de la juventud quizás sea uno de los retos más importantes en la actualidad, no solo por el número que representan los jóvenes en relación con el resto de la población, sino también por lo que ello implica en términos de tasas de dependencia, necesidades y problemáticas propias de este período de la vida. En promedio, las personas de entre 15 y 29 años representan una cuarta parte de la población total de la región. Por fines analíticos, los análisis de este libro se realizan para el grupo de población en este tramo de edad, entendiendo que se trata de una población muy heterogénea y que el término "juventud" esconde una diversidad de situaciones de vida, necesidades, intereses y trayectorias. Además, en algunos países, una gran parte de los jóvenes se encuentran extremadamente excluidos y marginados de los procesos económicos, políticos y sociales que se están llevando a cabo.

En virtud de este marco conceptual, se ha preparado este libro que se ordena a partir de un análisis de los principales ámbitos de inclusión social presentados en el diagrama 1, pero tomando en consideración las distintas dimensiones de análisis propuestas en el cuadro 1. En el capítulo I se trabaja sobre el eslabón educación-empleo, considerado el eje básico de inclusión social en esta etapa de la vida, ya que representa el paso de la vida dependiente a la vida autónoma. En el capítulo II se abordan las consideraciones relevantes de salud para la etapa juvenil. Como una dimensión relacionada, pero de destacada importancia actualmente en la región, en el capítulo III se trabaja el tema de la violencia. En el capítulo IV se revisa el acceso de la población joven a la cultura en la era digital, mientras que en el capítulo $\mathrm{V}$ se discute sobre la participación política de los jóvenes, como otro ámbito fundamental de sus procesos de inclusión. Para culminar, en el capítulo VI se presenta una discusión más integral sobre la política social hacia la juventud, tomando en cuenta las recomendaciones derivadas de cada ámbito, así como las consideraciones generales de institucionalidad, normativa e inversión social que existen en la región. 


\section{Bibliografía}

Alvarado, Sara Victoria, Ernesto Rodríguez y Pablo Vommaro (2013), Informe CLACSO-UNESCO: Politicas de inclusión social de jóvenes en América Latina. Situación, desafios y recomendaciones para la acción [en línea] http://www.celaju. net/informe-unesco-clacso-politicas-publicas-de-juventud-e-inclusion-socialen-america-latina-y-el-caribe/.

CEPAL (Comisión Económica para América Latina y el Caribe) (2014a), Panorama Social de América Latina, 2014 (LC/G.2635-P), Santiago.

(2014b), Pactos para la igualdad: hacia un futuro sostenible (LC/G.2586(SES.35/3)), Santiago, abril.

(2007), Cohesión social: inclusión y sentido de pertenencia en América Latina y el Caribe (LC/G.2335/Rev.1), Santiago.

CEPAL/UNFPA (Comisión Económica para América Latina y el Caribe/Fondo de Población de las Naciones Unidas) (2012), Informe Regional de Población en América Latina y el Caribe, 2011. Invertir en juventud en América Latina y el Caribe: Un imperativo de derechos e inclusión, Santiago. 

Capítulo I

\title{
La Ilave maestra de la inclusión social juvenil: educación y empleo
}

\author{
Andrés Espejo \\ Ernesto Espindola ${ }^{1}$
}

La noción de igualdad de la Comisión Económica para América Latina y el Caribe (CEPAL) va más allá de la distribución de los ingresos; incluye la igualación en la disponibilidad y el aprovechamiento de las oportunidades, así como el desarrollo de las capacidades. Esto significa que la igualdad se expresa en el ejercicio pleno de la ciudadanía, la dignidad y el reconocimiento recíproco de los actores. El progreso en este ámbito requiere de políticas que promuevan tanto la autonomía de los sujetos como la protección frente a sus vulnerabilidades. Así, la CEPAL refuerza la consideración de la igualdad como el horizonte, el cambio estructural como el camino y la política como el instrumento (CEPAL, 2010a, 2012a y 2014a).

El cambio estructural implica la modificación y diversificación de la estructura productiva de las economías de la región, con grandes innovaciones tecnológicas y la creación o el crecimiento de sectores de alta productividad, mediante la intensa incorporación de conocimiento y progreso técnico. El desarrollo de capacidades de las nuevas generaciones es uno de los pilares básicos para sustentar el camino hacia la igualdad, que necesariamente ha de complementarse con el cambio en la estructura productiva (CEPAL, 2014a).

Los autores agradecen los aportes sustantivos de Matías Sálces, Heidi Ullmann y Javiera Menchaca. 
En ese sentido, se requiere aprovechar mejor el bono demográfico, especialmente el potencial que representan los jóvenes. Aunque no son los únicos, dos grandes ámbitos se presentan como clave: la educación y el empleo. Ambos conforman los grandes eslabones del desarrollo, tanto del actual como de las nuevas formas de desarrollo que conllevan a sociedades más dinámicas e igualitarias (CEPAL, 2012a).

Para asegurar la sostenibilidad del desarrollo en el largo plazo, así como para impulsar el cambio estructural requerido, es necesario contar con una población joven de mayor nivel educativo, aprendizajes pertinentes y capacidades de innovación y manejo de la sociedad del conocimiento. En resumen, se necesita una juventud mejor preparada para el aprendizaje a lo largo de toda la vida (CEPAL/OIJ/IMJUVE, 2014). Potenciar este eslabón necesariamente debe complementarse con mejorías en el ámbito de las oportunidades de inserción laboral para su pleno aprovechamiento, tanto en términos de mayor productividad e innovación, como para fortalecer los procesos de inclusión social: el puente entre la educación y el empleo durante la juventud implica, en gran medida, el paso de la vida dependiente a la vida autónoma (Rico y Trucco, 2014).

Sin embargo, ha de reconocerse que junto con las persistentes brechas estructurales existen grandes desigualdades en la formación de capacidades, no solo en cuanto a acceso y conclusión educativa, sino también en el desarrollo de competencias de calidad suficiente para un buen desenvolvimiento en la sociedad del conocimiento. Por otra parte, la juventud se ve tensionada por una paradoja que hoy resulta más significativa que nunca: los grandes avances registrados en el ámbito educativo en las últimas décadas, aunque todavía son insuficientes, no se han plasmado en una mejor incorporación en el mercado de trabajo ni en un aprovechamiento suficiente de las nuevas capacidades de gestión e innovación adquiridas por los jóvenes.

En dicho sentido, la discusión en curso sobre los Objetivos de Desarrollo Sostenible (Agenda 2030 para el Desarrollo Sostenible) ha puesto especial énfasis en las nuevas generaciones. Entre las propuestas de metas orientadas hacia la juventud, destaca la formación de habilidades para la vida, especialmente la alfabetización y aquellas que favorezcan una mejor inserción laboral, un menor desempleo juvenil y el acceso a empleos de calidad.

En este capítulo se aborda precisamente la situación actual en materia educativa y de empleo entre los jóvenes de 15 a 29 años, sin olvidar a aquellos que, por diversas razones, no están incorporados plenamente en alguno de estos ámbitos cruciales para la inclusión social y el desarrollo. 


\section{A. A qué se dedican los jóvenes: una aproximación}

Las condiciones estructurales de desigualdad socioeconómica y espacial, las características de la oferta educativa formal y no formal, la estructura productiva y el entorno inmediato en el que se desarrollan influyen en las trayectorias y biografías de los jóvenes de la región, tanto en términos de las diversas oportunidades de inserción social a las que pueden acceder, como, y más ampliamente, en sus sentidos de pertenencia y modos de concebir la vida y el futuro dentro (o fuera) de las sociedades latinoamericanas.

Históricamente, la transición de la niñez a la vida adulta se ha entendido como un proceso lineal que atraviesa diversas etapas con roles definidos a nivel social y cultural (educación, inserción, independización, matrimonio, paternidad/maternidad). En este sentido, el proceso de emancipación y autonomía de los jóvenes se hacía visible cuando estos iban perdiendo gradualmente los roles propios de la edad e iban asumiendo otros (Filgueira, 1998, pág. 12). Sin embargo, las condiciones y oportunidades para las nuevas generaciones han tendido a generar trayectorias más heterogéneas hacia esos procesos de autonomía. Un ejemplo de ello es el alargamiento de la etapa juvenil mediante el desplazamiento de ciertos hitos asociados con el término de esta etapa, aumentando los años de estudio y aplazando la inserción al mercado del trabajo, así como la formación de una familia. Por tanto, las trayectorias de vida no se plantean en un sentido secuencial de estos hechos o sucesos vitales, en lo que podría ser una trayectoria de tipo lineal, sino de manera más dinámica y no secuencial (CEPAL/OIJ, 2004; Dávila y Ghiardo, 2005, citado en CEPAL/OIJ/ IMJUVE, 2014). Hoy ya no es posible concebir una única ruta de desarrollo personal e inserción social ni tampoco la continuidad en dicho proceso. Esta diversidad de trayectorias no responde únicamente a la voluntad o el deseo del joven de continuar sus estudios para postergar ciertas funciones y actividades que antes se asumían más temprano, sino también - y quizás principalmente- a factores estructurales que escapan al deseo de la persona, como las condiciones socioeconómicas en las que crece, tal como se plantea en el último informe iberoamericano de juventud (CEPAL/OIJ/IMJUVE, 2014). Las condiciones que rodean a los jóvenes de distintos estratos socioeconómicos y realidades generan trayectorias cada vez más oscilantes entre los sistemas educativos, el desempleo, el trabajo, las labores familiares, la inactividad y otras situaciones. Es decir, dibujan estructuras de transición irregulares, donde se va y se vuelve de una condición a otra. Hoy más que nunca cobra sentido la noción clásica de aprendizaje continuo con el impulso a la educación a lo largo de toda la vida y la necesidad de comprender que en el mundo laboral ya no existe un solo trabajo para toda la vida.

Algunas de las razones que han influido en estos cambios tienen relación con los sistemas educativos, que se han ampliado para acoger 
a una mayor proporción de la población, y con los requerimientos de sectores productivos más dinámicos y globales, que exigen procesos de capacitación permanentes. La creciente incorporación de la mujer al mercado de trabajo y las transformaciones en las estructuras familiares han promovido, a su vez, la postergación de la maternidad y la paternidad, lo que plantea menores exigencias de autonomía económica en los jóvenes a edades tempranas. En virtud de ello, preocupan los jóvenes que están quedando, aparentemente, desvinculados de instituciones clave de inclusión social, como la educación y el empleo.

El objeto de esta sección es revisar brevemente la distribución de los jóvenes según si están vinculados con el sistema educativo o tienen un empleo remunerado. Cabe tener en cuenta que la clasificación según su vinculación a ambos eslabones del desarrollo (educación y empleo) corresponde a un diagnóstico en un punto del tiempo. Es decir, se toma una fotografía (cuyo momento varía de un país a otro) que da cuenta de la situación específica de cada joven, pero oculta el hecho de que la inserción educativa, y principalmente la inserción laboral, responden más bien a un proceso que conlleva diversos cambios de estado en lo que respecta a la actividad principal realizada por los jóvenes.

Alrededor de 2012, aproximadamente el 37\% de los jóvenes de entre 15 y 29 años asistía a un centro educativo de enseñanza primaria (los más rezagados), secundaria o postsecundaria (técnico-profesional o universitaria), lo que equivale a unos 49,9 millones de jóvenes. Por otra parte, como se puede apreciar en el gráfico I.1, poco más del $50 \%$ de los jóvenes se encontraban empleados al momento de aplicarse las encuestas en los diversos países (75,7 millones). Tal como es de esperar, entre quienes estudian predominan los más jóvenes (de entre 15 y 19 años) y entre los empleados son mayoría los de edad más avanzada (de 25 a 29 años).

Entre ambos grupos hay un subconjunto que realiza ambas actividades y que corresponde solo a una décima parte de todos los jóvenes: hay 15,3 millones de jóvenes que estudian y trabajan remuneradamente ${ }^{2}$.

Por último, el $22 \%$ de las personas jóvenes declaró no realizar ninguna de estas dos actividades (29,7 millones). Es importante tener en cuenta que la no incorporación al sistema educativo y al empleo de esta población no es sinónimo de vagancia o desinterés por insertarse en la sociedad. Como se examina más adelante, la mayoría de estos jóvenes, en especial las mujeres, están dedicados a tareas de cuidado y al trabajo doméstico no remunerado, se encuentran desempleados (buscan trabajo remunerado), están esperando un empleo o tienen una discapacidad

\footnotetext{
En las encuestas de empleo se clasifica a las personas en una sola actividad principal: o se es ocupado o se es estudiante. En este caso, la medición corresponde a aquellos cuya actividad principal es estar ocupado y además declaran estar asistiendo a establecimientos educativos.
} 
que impide su inserción laboral o educativa, entre otras situaciones no asimilables a subculturas de delincuencia, consumo de drogas o formación de pandillas, leitmotiv recurrente al analizar a la juventud.

Si se atiende el desarrollo de los sistemas educativos y el acceso a dichos sistemas, así como el funcionamiento de los mercados de trabajo, los patrones de maternidad y participación femenina, y otros fenómenos que involucran a la población juvenil, se observan ciertas diferencias entre un país y otro. Por ejemplo, en países como Bolivia (Estado Plurinacional de), el Brasil, Guatemala, México, el Paraguay, el Perú y el Uruguay, el porcentaje de jóvenes que están empleados (ya sea que estudien o no) supera el 55\%, en tanto que en la Argentina, Chile y la República Dominicana esta cifra se ubica por debajo del $45 \%$. Esto está naturalmente muy relacionado con la proporción de jóvenes insertos en el sistema educativo: en la Argentina, Chile, Costa Rica, el Ecuador y la República Dominicana, más del 44\% del total de jóvenes de 15 a 29 años asiste a algún tipo de establecimiento educacional, mientras que en Bolivia (Estado Plurinacional de), Guatemala, Honduras y Nicaragua los que asisten son menos del 30\%. En el mismo sentido, los mayores porcentajes de jóvenes que no están vinculados a los sistemas educativos ni tienen un empleo se encuentran en Bolivia (Estado Plurinacional de), El Salvador, Guatemala, Honduras y Nicaragua (en todos los casos, con un quinto o más de los jóvenes), países en los que precisamente existen mayores niveles de pobreza y exclusión social.

\section{Gráfico I.1 \\ América Latina (18 países): condición de actividad de jóvenes de 15 a 29 años, alrededor de $2012^{a}$ \\ (En porcentajes)}

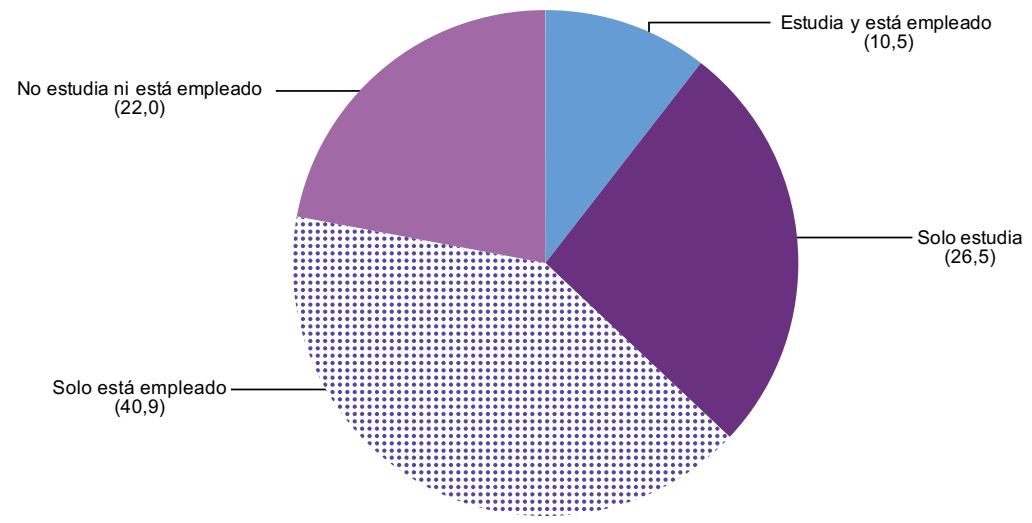

Fuente: Comisión Económica para América Latina y el Caribe (CEPAL), Panorama Social de América Latina 2014 (LC/G.2635-P), Santiago, 2014. Publicación de las Naciones Unidas, $N^{\circ}$ de venta: S.15.II.G.6.

a Los datos corresponden al promedio simple de los países. 


\section{Cuadro l.1 \\ América Latina (18 países): condición de actividad de jóvenes de 15 a 29 años, alrededor de $2012^{\text {a }}$}

(En porcentajes)

\begin{tabular}{lccccc}
\hline & $\begin{array}{c}\text { Estudia } \\
\text { y está } \\
\text { empleado }\end{array}$ & $\begin{array}{c}\text { Sólo } \\
\text { estudia }\end{array}$ & $\begin{array}{c}\text { Sólo esta } \\
\text { empleado }\end{array}$ & $\begin{array}{c}\text { No estudia } \\
\text { ni está } \\
\text { empleado }\end{array}$ & Total \\
\hline Argentina, 2012 & 10,3 & 36,1 & 34,3 & 19,3 & 100 \\
\hline Bolivia (Estado Plurinacional de), 2011 & 8,7 & 14,2 & 48,5 & 28,6 & 100 \\
\hline Brasil, 2012 & 13,1 & 22,0 & 44,0 & 20,8 & 100 \\
\hline Chile, 2011 & 6,5 & 38,2 & 32,4 & 21,8 & 100 \\
\hline Colombia, 2012 & 10,7 & 24,1 & 42,5 & 22,7 & 100 \\
\hline Costa Rica, 2011 & 15,0 & 32,2 & 34,2 & 18,6 & 100 \\
\hline Ecuador, 2012 & 8,8 & 35,5 & 38,1 & 17,7 & 100 \\
\hline Guatemala, 2006 & 10,4 & 13,9 & 50,0 & 25,7 & 100 \\
\hline Honduras, 2010 & 8,3 & 20,8 & 43,6 & 27,3 & 100 \\
\hline México, 2012 & 8,7 & 23,8 & 47,0 & 20,5 & 100 \\
\hline Nicaragua, 2009 & 7,3 & 20,7 & 43,6 & 28,4 & 100 \\
\hline Panamá, 2011 & 9,2 & 28,8 & 39,7 & 22,3 & 100 \\
\hline Paraguay, 2011 & 16,9 & 25,0 & 40,3 & 17,8 & 100 \\
\hline Perú, 2012 & 12,2 & 20,2 & 47,7 & 19,8 & 100 \\
\hline República Dominicana, 2012 & 11,6 & 33,6 & 31,1 & 23,6 & 100 \\
\hline El Salvador,2012 & 7,8 & 27,0 & 40,4 & 24,8 & 100 \\
\hline Uruguay, 2011 & 13,8 & 27,4 & 42,4 & 16,4 & 100 \\
\hline $\begin{array}{l}\text { Venezuela (República Bolivariana } \\
\text { de), 2012 }\end{array}$ & 9,6 & 33,6 & 36,3 & 20,5 & 100 \\
\hline $\begin{array}{l}\text { América Latina } \\
\text { (promedio simple) }\end{array}$ & $\mathbf{1 0 , 5}$ & $\mathbf{2 6 , 5}$ & $\mathbf{4 0 , 9}$ & $\mathbf{2 2 , 0}$ & 100 \\
\hline
\end{tabular}

Fuente: Comisión Económica para América Latina y el Caribe (CEPAL), sobre la base de tabulaciones especiales de las encuestas de hogares de los respectivos países.

a Los datos corresponden al promedio simple de los países.

En relación con el eje principal de inclusión social instituido a partir del sistema formal de educación y el mercado de trabajo, tanto entre los que participan en él como entre aquellos que se encuentran momentáneamente desvinculados, el análisis de evidencia permite visibilizar mejor la complejidad y diversidad de las situaciones y trayectorias juveniles. Esto no solo permite destacar la riqueza de información con la que se puede hacer un análisis más pormenorizado de la situación de la juventud, sino que también aporta elementos orientadores para el diseño de mejores políticas públicas que fortalezcan los sistemas educativos, regulen de forma más adecuada el comportamiento de los mercados de trabajo y planteen alternativas de inclusión entre los jóvenes que no están, al menos momentáneamente, integrados al mencionado eje. 


\section{B. Los jóvenes que estudian: acceso y progresión en los sistemas educativos}

En estudios recientes, la CEPAL (CEPAL, 2014b; CEPAL/OIJ/IMJUVE, 2014) ha hecho hincapié en que el desarrollo de capacidades mediante la educación formal constituye uno de los principales ejes de inclusión social para los jóvenes. En estos estudios se indica que más años de escolaridad no solo permiten acceder a mejores oportunidades de inserción laboral, sino que también habilitan a las personas jóvenes para tener una participación más plena en las sociedades democráticas, complejas y globalizadas que enfrentan. Además, la educación es una de las principales herramientas para romper con el círculo de reproducción intergeneracional de la pobreza.

El panorama educativo de los jóvenes de la región muestra que la conclusión de la educación primaria es prácticamente universal (94\%) y ha dejado de constituir una limitación para expandir la educación secundaria, lo que da cuenta de una fluida transición entre estos dos ciclos (UNESCO, 2013b) ${ }^{3}$. No obstante, aún es relevante el número de estudiantes que, pese a tener la edad para asistir al nivel secundario, no está matriculado en un establecimiento educacional. Según datos del Instituto de Estadística de la UNESCO, con base en información comparable de 42 países de América Latina y el Caribe, la tasa neta de matrícula en el nivel secundario aumentó del 60,4\% en 2000 al 73\% en 2012 (véase el gráfico I.2) ${ }^{4}$. Por otra parte, el proceso de expansión de la educación secundaria ha dado cuenta de importantes avances en el acceso a la educación de las mujeres en la región. Los datos indican una mayor matrícula neta entre las mujeres que entre los hombres (un $75,4 \%$ frente a un $70,7 \%$ en 2012), lo que podría explicarse, en parte, por las dinámicas de inserción laboral temprana que atentan contra las oportunidades presentes y futuras de los jóvenes del sexo masculino (CEPAL/UNFPA, 2012).

Sin duda, y pese a que se registra un incremento de más de 10 puntos porcentuales en los últimos 12 años, estas cifras aún son bajas y dan cuenta del largo camino que queda por recorrer para la universalización de la conclusión del ciclo secundario, ya que el rezago escolar en este nivel se asocia con el abandono escolar.

En general, la oferta de estudios secundarios en la región está dividida en dos modalidades: un programa común y los programas de educación técnica o vocacional. La primera de las modalidades consiste en ofrecer a los jóvenes una educación científico-humanista y los prepara para la educación superior. Por su parte, la educación vocacional fue concebida

\footnotetext{
El dato del 94\% es de la CEPAL, sobre la base de tabulaciones especiales de las encuestas de hogares de 18 países de la región alrededor de 2012.

4 Para obtener información de los países considerados por el Instituto de Estadística de la UNESCO, véase [en línea] http://www.uis.unesco.org/Education/Documents/uis-regions.pdf.
} 
como un subsistema dentro de la oferta educativa de nivel medio, que ofrece una inserción ocupacional al finalizar los estudios secundarios mediante las tecnicaturas (Briasco, 2008). En América Latina, sobre la base de información disponible para 17 países, la gran mayoría de los jóvenes se encuentra matriculado en la educación común o general (88,5\%). En Bolivia (Estado Plurinacional de), Nicaragua y el Perú, prácticamente el total de alumnos matriculados en secundaria cursa este tipo de educación (véase el gráfico I.3). Por otra parte, hay un grupo de países en donde la educación técnica es más significativa y supera el $15 \%$ del total de matriculados en el nivel secundario; tal es el caso de Guatemala (28,1\%), Chile (22,5\%), el Ecuador (21,1\%), El Salvador (18,5\%), Costa Rica (17,1\%) y México (16,6\%).

Gráfico I.2

América Latina y el Caribe (42 países): tasa neta de matrícula de nivel secundario, según sexo

(En porcentajes)

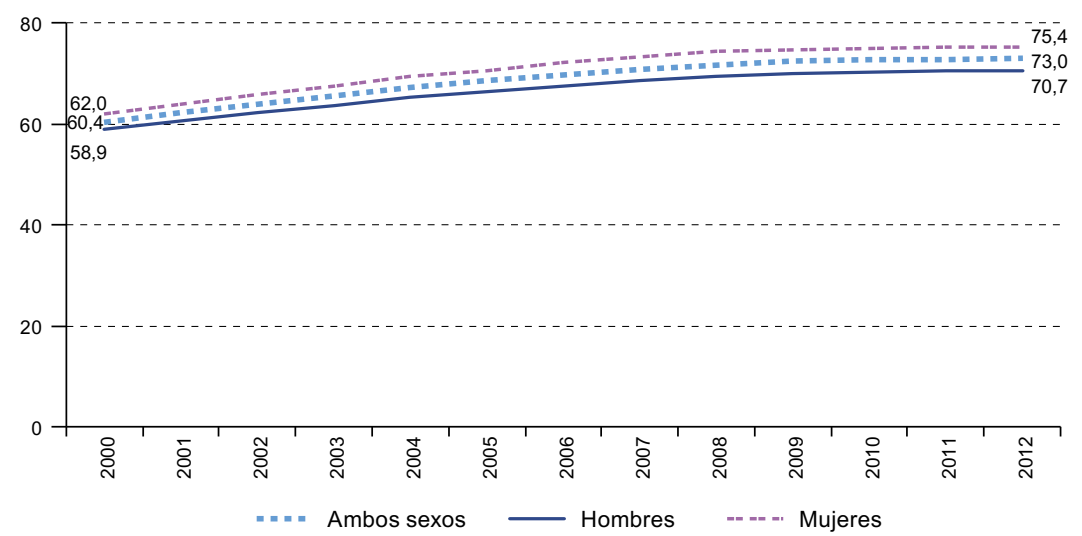

Fuente: Base de datos del Instituto de Estadística de la UNESCO [en línea] http://stats.uis.unesco.org/.

La expansión de la matrícula en la educación secundaria en la última década se debe, en gran medida, a la incorporación de grupos que históricamente se encontraban fuera del sistema escolar (Itzcovich, 2014). En la región, no obstante, todavía persisten marcadas brechas según el nivel socioeconómico de los hogares. Por ejemplo, en 2012, mientras el 80,3\% de los adolescentes y jóvenes en edad de estar matriculados en la educación secundaria del quintil de ingresos más alto estaba asistiendo a este nivel educativo, solo un $57 \%$ de los del primer quintil asistía. La situación es, por cierto, muy heterogénea al revisar los países de la región. En comparación con los países centroamericanos, la Argentina, Chile, el Ecuador, el Perú y Venezuela (República Bolivariana de) son los países que muestran menor brecha entre los quintiles extremos, lo que no solo da cuenta de una fuerte desigualdad, sino también de bajas tasas de asistencia en general (véase el gráfico I.4). 


\section{Gráfico I.3}

América Latina (17 países): estudiantes matriculados en el nivel secundario, según tipo de programa, 2012

(En porcentajes)

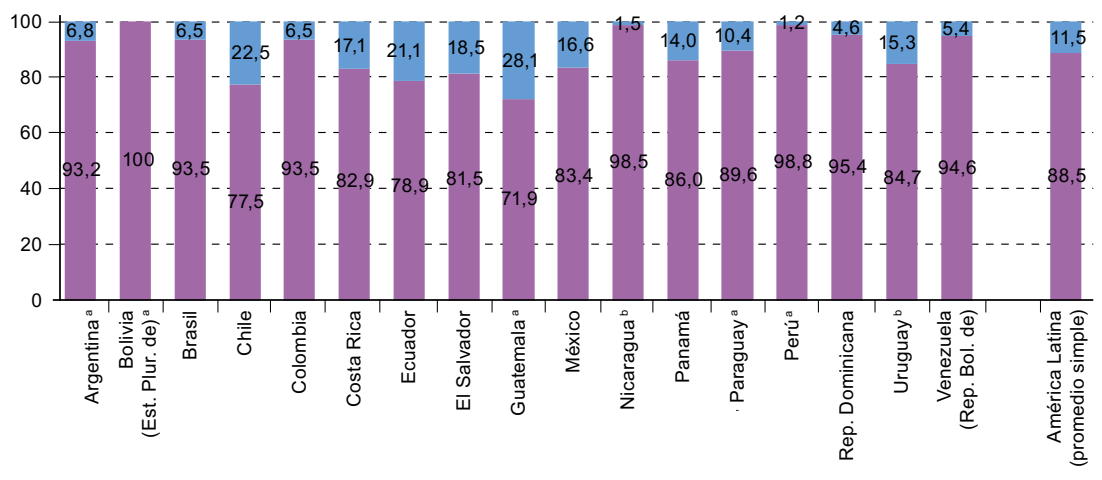

Secundaria general

Educación técnica o vocacional

Fuente: Base de datos del Instituto de Estadística de la UNESCO [en línea] http://stats.uis.unesco.org/.

a Los datos de la Argentina, Bolivia (Estado Plurinacional de), Guatemala, el Paraguay y el Perú corresponden a 2011.

b Los datos de Nicaragua y el Uruguay corresponden a 2010.

\section{Gráfico I.4}

América Latina (18 países): tasa neta de asistencia a la enseñanza secundaria, según quintiles extremos de ingreso, alrededor de $2012^{a}$

(En porcentajes)

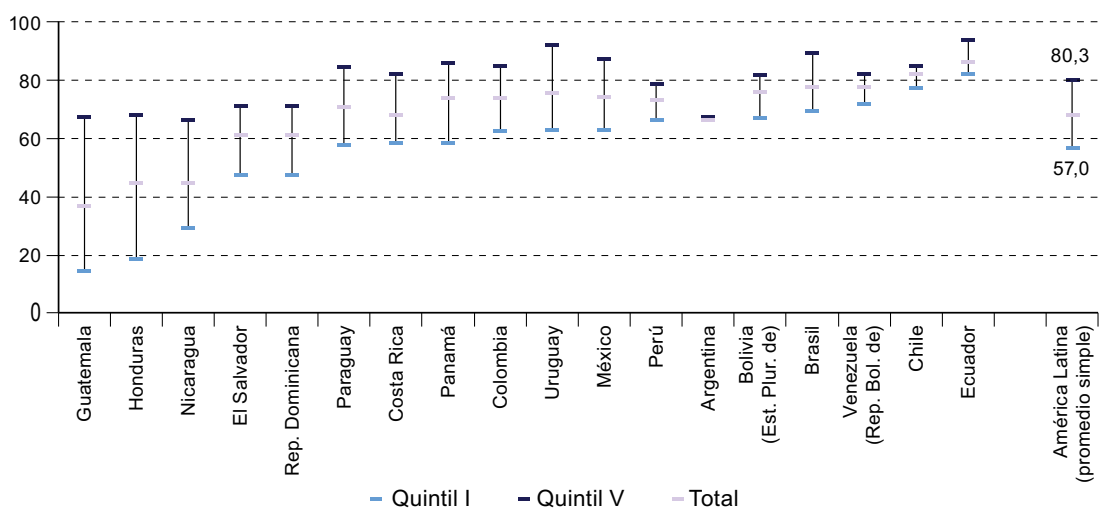

Fuente: Comisión Económica para América Latina y el Caribe (CEPAL), sobre la base de tabulaciones especiales de las encuestas de hogares de los respectivos países.

a Los datos corresponden al promedio simple de los países.

Las tasas de deserción escolar constituyen otro factor que atenta contra la progresión oportuna y la conclusión del ciclo de enseñanza secundaria ${ }^{5}$. De hecho, estas son significativas en muchos países de la

La deserción escolar se entiende como el abandono de un año en particular y no necesariamente implica una deserción definitiva del sistema escolar. 
región, en gran medida debido a que los jóvenes ya tienen oportunidades - y necesidades - para insertarse en el mercado laboral, lo que desincentiva su retención. Además, hay que considerar que en muchos países este ciclo educativo no es obligatorio (CEPAL, 2010b). Las estimaciones dan cuenta de que la tasa de deserción de la enseñanza secundaria para 2012 en América Latina era del 15,5\% (véase el cuadro I.2). Los adolescentes y jóvenes del primer quintil duplican con creces la tasa de deserción de los del quintil de mayor ingreso (un 19,1\% en el quintil 1 frente a un 8,2\% en el quintil 5). El acceso al sistema educativo no basta para garantizar que los adolescentes concluyan la educación formal, y es por esto que aumentar la capacidad de retención de los alumnos en la escuela, especialmente de los que provienen de hogares más desfavorecidos, es un imperativo de los sistemas educacionales de América Latina.

\section{Cuadro I.2}

América Latina (18 países): tasa de deserción en la enseñanza secundaria, alrededor de $\mathbf{2 0 1 2}^{\text {a }}$

(En porcentajes)

\begin{tabular}{lrrrrrr}
\hline & \multicolumn{7}{c}{ Ambos sexos } \\
\cline { 2 - 7 } & Total & Quintil I & Quintil II & Quintil III & Quintil IV & Quintil V \\
\hline Argentina & 13,5 & 18,6 & 15,0 & 11,7 & 9,9 & 5,5 \\
\hline Bolivia (Estado Plurinacional de) & 12,0 & 16,0 & 10,6 & 10,6 & 13,2 & 9,4 \\
\hline Brasil & 16,2 & 19,7 & 19,7 & 16,2 & 13,3 & 5,5 \\
\hline Chile & 10,0 & 12,2 & 11,8 & 13,5 & 7,0 & 2,2 \\
\hline Colombia & 14,6 & 17,4 & 18,7 & 15,9 & 11,0 & 6,7 \\
\hline Costa Rica & 8,5 & 7,6 & 9,5 & 7,5 & 10,9 & 6,4 \\
\hline Ecuador & 15,5 & 20,6 & 18,9 & 16,4 & 12,0 & 4,2 \\
\hline El Salvador & 19,3 & 26,8 & 24,1 & 18,8 & 16,5 & 9,2 \\
\hline Guatemala & 13,0 & 8,6 & 10,2 & 19,9 & 15,9 & 8,1 \\
\hline Honduras & 16,5 & 23,8 & 22,7 & 16,9 & 15,8 & 10,4 \\
\hline México & 28,9 & 37,3 & 32,6 & 31,1 & 27,1 & 14,8 \\
\hline Nicaragua & 19,7 & 21,5 & 17,6 & 18,5 & 24,3 & 16,5 \\
\hline Panamá & 15,7 & 20,4 & 14,8 & 16,1 & 15,4 & 9,4 \\
\hline Paraguay & 13,6 & 15,8 & 16,7 & 14,2 & 14,2 & 5,4 \\
\hline Perú & 8,8 & 7,0 & 7,5 & 10,7 & 9,9 & 9,3 \\
\hline República Dominicana & 19,3 & 26,8 & 24,1 & 18,8 & 16,5 & 9,2 \\
\hline Uruguay & 21,7 & 30,2 & 23,9 & 21,5 & 17,1 & 7,0 \\
\hline $\begin{array}{l}\text { Venezuela (República } \\
\text { Bolivariana de) }\end{array}$ & 12,1 & 14,1 & 14,1 & 11,8 & 10,7 & 7,8 \\
\hline $\begin{array}{l}\text { América Latina } \\
\text { (promedio simple) }\end{array}$ & $\mathbf{1 5 , 5}$ & $\mathbf{1 9 , 1}$ & $\mathbf{1 7 , 4}$ & $\mathbf{1 6 , 1}$ & $\mathbf{1 4 , 5}$ & $\mathbf{8 , 2}$ \\
\hline Furyyyyyy & & & & & \\
\hline
\end{tabular}

Fuente: Comisión Económica para América Latina y el Caribe (CEPAL), sobre la base de tabulaciones especiales de las encuestas de hogares de los respectivos países.

a Los datos corresponden al promedio simple de los países.

Las mediciones también indican que la situación en la región es heterogénea. Costa Rica $(8,5 \%)$, el Perú $(8,8 \%)$ y Chile $(10,0 \%)$ son los países que presentan las tasas de deserción más bajas de la región y los 
que registran una menor diferencia entre los quintiles extremos. Por su parte, México (28,9\%), el Uruguay (21,7\%), Nicaragua (19,7\%), El Salvador $(19,3 \%)$ y la República Dominicana (19,3\%) no solo presentan elevadas tasas de deserción en la enseñanza secundaria, sino que registran una marcada brecha entre los hogares de mayores y menores ingresos.

Las altas tasas de deserción escolar registradas en una gran cantidad de países de la región se traducen en un bajo número de años de educación aprobados (bastante por debajo del ciclo secundario completo). Este nivel es crucial para adquirir las destrezas básicas que requiere un mundo globalizado y que permiten al sujeto desenvolverse libremente y con capacidad para aprender por el resto de su vida (CEPAL/UNFPA, 2012). Además, según estimaciones de la CEPAL (2010b), concluir los años del ciclo secundario es el piso mínimo requerido en la mayoría de los países de América Latina para tener una menor probabilidad de vivir en condiciones de pobreza que el promedio de la población. Sin embargo, para tener ingresos laborales mayores que el promedio, en la mayoría de los países se requiere un mínimo de 13 a 14 años de estudio, es decir, algún grado de educación postsecundaria (CEPAL/OIJ, 2008, y CEPAL/OIJ/ IMJUVE, 2014).

La situación descrita se traduce en un panorama regional negativo en cuanto a la conclusión del nivel secundario. Cuatro de cada diez jóvenes de 20 a 24 años no termina este ciclo (véase el gráfico I.5) y, al no poder acceder a un empleo de calidad que otorgue ingresos mayores al promedio, sus probabilidades de continuar y reproducir las condiciones de vida precarias aumentan (CEPAL/OIJ/IMJUVE, 2014). Si se revisa lo que sucede en los países, en Chile y el Perú se observa la tasa de conclusión más alta de la región (cercana al 80\%), pero hay países que presentan porcentajes muy bajos de conclusión de la secundaria, como Honduras y Nicaragua (ambos con un $36 \%$ ) y Guatemala (25\%).

Las bajas tasas de conclusión de la enseñanza secundaria en América Latina y el Caribe, así como la necesidad de los jóvenes de obtener ingresos para que sus hogares accedan a niveles de bienestar mínimos, implican un reducido acceso a la educación postsecundaria (técnico-profesional y universitaria) y que esta se encuentre reservada a una porción relativamente pequeña de jóvenes. De allí que avanzar en el fortalecimiento de este nivel de educación sigue siendo un gran desafío en la región (CEPAL, 2010b).

Es importante mencionar que no es fácil estimar el acceso de los jóvenes al nivel educativo postsecundario (o terciario), pues la población en edad de asistir no tiene una delimitación formalmente definida (a diferencia de la educación primaria y secundaria), y las personas entran y salen de este nivel educativo en diferentes momentos de 
su vida (UNESCO, 2013b). No obstante, una forma de conocer el acceso educativo es revisar la tasa bruta de matrícula ${ }^{6}$. Sobre la base de este indicador, se puede apreciar que la matrícula en educación postsecundaria en la región se ha incrementado de manera acelerada en los últimos años y las cifras han llegado a duplicarse en el último decenio: del 22,3\% en 2000 al 42,8\% en 2012 (véase el gráfico I.6). Al igual que en la educación secundaria, son las mujeres las que más se han beneficiado del incremento de la matrícula, superando en aproximadamente 10 puntos porcentuales a los hombres.

Otra forma de aproximarse a este aspecto es analizar la tasa de asistencia al nivel postsecundario entre los jóvenes de 20 a 24 años. Este indicador muestra que, si bien se ha producido un notorio aumento en las tasas de asistencia en la región, quienes asisten siguen perteneciendo principalmente a la población de más altos ingresos. Esta es una tendencia que se observa en la mayor parte de los países, aunque con ciertos matices (véase el cuadro I.3). Hay algunos países, como el Brasil, El Salvador, Guatemala, Honduras, México, el Paraguay y la República Dominicana, donde la asistencia al nivel terciario del primer quintil se ubica en torno al $5 \%$ o por debajo, lo que da cuenta del restringido acceso a este nivel educativo para los jóvenes de los hogares de menores ingresos.

\section{Gráfico I.5 \\ América Latina (18 países): conclusión del nivel secundario entre jóvenes de 20 a 24 años, alrededor de $2012^{\text {a }}$ \\ (En porcentajes)}

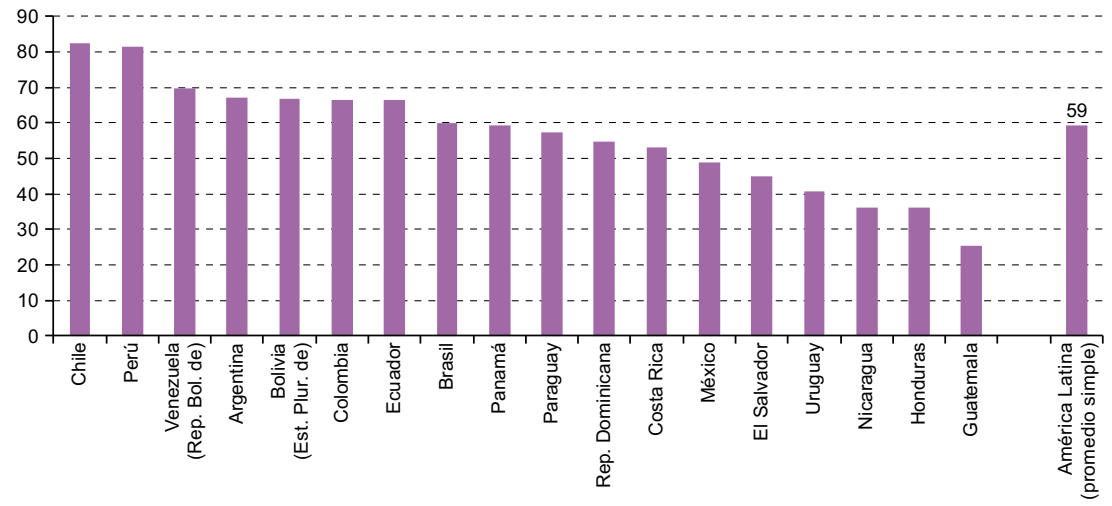

Fuente: Comisión Económica para América Latina y el Caribe (CEPAL), sobre la base de tabulaciones especiales de las encuestas de hogares de los países.

a Los datos corresponden al promedio simple de los países.

La población en edad escolar de nivel terciario representa una cohorte de cinco años derivada por país, que cubre cinco años después de la edad teórica de terminación de la educación secundaria. 
Gráfico I.6

América Latina y el Caribe (42 países): tasa bruta de matrícula de nivel terciario, según sexo, 2000-2012

(En porcentajes)

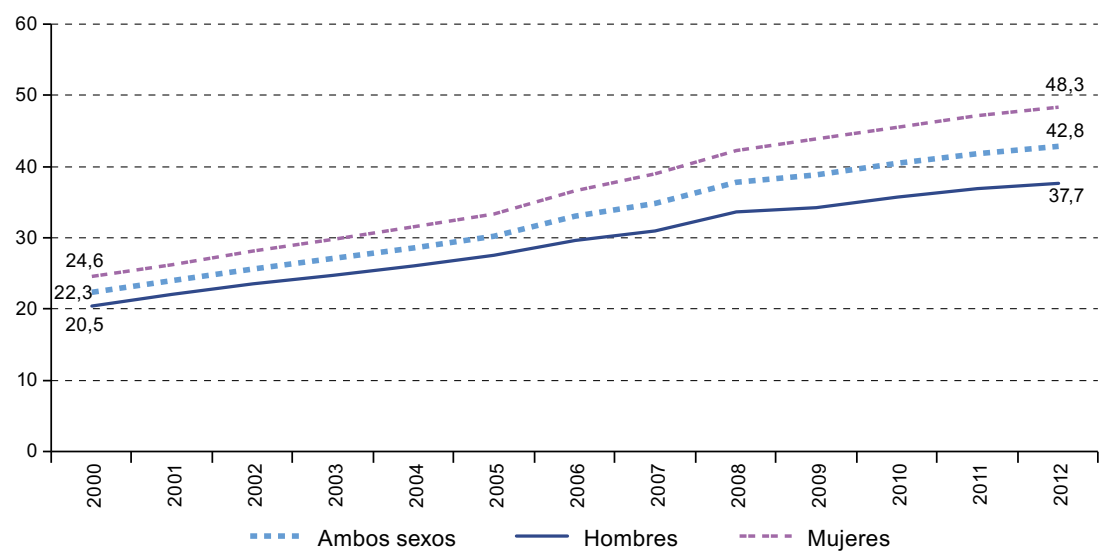

Fuente: Base de datos del Instituto de Estadística de la UNESCO [en línea] http://stats.uis.unesco.org/.

\section{Cuadro I.3}

América Latina (18 países): tasa de asistencia al nivel terciario entre jóvenes de 20 a 24 años, alrededor de $2012^{\text {a }}$

(En porcentajes)

\begin{tabular}{lrrrrrr}
\hline & \multicolumn{5}{c}{ Quintiles de ingreso per cápita } \\
\cline { 2 - 7 } & Total & Quintil I & Quintil II & Quintil III & Quintil IV & Quintil V \\
\hline Argentina & 37,4 & 27,2 & 30,5 & 38,4 & 45,2 & 51,3 \\
\hline Bolivia (Estado Plurinacional de) & 34,0 & 18,0 & 26,3 & 35,4 & 40,5 & 41,5 \\
\hline Brasil & 16,1 & 4,2 & 6,1 & 11,9 & 20,8 & 42,1 \\
\hline Chile & 33,5 & 21,1 & 27,5 & 26,4 & 35,9 & 58,6 \\
\hline Colombia & 22,3 & 6,6 & 11,3 & 17,8 & 29,3 & 44,8 \\
\hline Costa Rica & 32,3 & 15,1 & 19,6 & 26,9 & 38,1 & 58,7 \\
\hline Ecuador & 28,9 & 14,9 & 20,3 & 25,5 & 30,8 & 48,8 \\
\hline El Salvador & 15,9 & 2,0 & 5,1 & 12,0 & 20,2 & 38,7 \\
\hline Guatemala & 10,0 & 0,9 & 1,9 & 3,7 & 8,4 & 29,1 \\
\hline Honduras & 14,3 & 2,4 & 3,9 & 7,5 & 16,9 & 31,1 \\
\hline México & 22,6 & 5,6 & 14,8 & 16,8 & 27,4 & 42,2 \\
\hline Nicaragua & 15,5 & 6,8 & 8,3 & 12,2 & 16,9 & 29,3 \\
\hline Panamá & 25,5 & 8,8 & 18,3 & 25,1 & 31,4 & 41,7 \\
\hline Paraguay & 25,4 & 5,3 & 14,9 & 25,0 & 27,6 & 46,3 \\
\hline Perú & 22,7 & 14,8 & 18,2 & 21,3 & 23,2 & 33,1 \\
\hline República Dominicana & 15,9 & 2,0 & 5,1 & 12,0 & 20,2 & 38,7 \\
\hline Uruguay & 25,6 & 8,1 & 14,0 & 23,4 & 32,7 & 53,6 \\
\hline Venezuela (República Bolivariana de) & 37,9 & 29,9 & 33,2 & 38,4 & 41,0 & 47,1 \\
\hline América Latina (promedio simple) & $\mathbf{2 4 , 2}$ & $\mathbf{1 0 , 8}$ & $\mathbf{1 5 , 5}$ & $\mathbf{2 1 , 1}$ & $\mathbf{2 8 , 1}$ & $\mathbf{4 3 , 1}$ \\
\hline
\end{tabular}

Fuente: Comisión Económica para América Latina y el Caribe (CEPAL), sobre la base de tabulaciones especiales de las encuestas de hogares de los respectivos países.

a Los datos corresponden al promedio simple de los países. 
De las personas de 20 a 24 años que estudian, la gran mayoría está asistiendo a la universidad (66,3\%), seguido por un importante número de jóvenes que todavía se encuentra realizando estudios secundarios (cursos formales, de adultos o a distancia) o asisten a otro tipo de cursos con una duración menor a un año de estudio (24,3\%), y otros que cursan estudios técnico-profesionales $(9,4 \%)$ (véase el gráfico I.7). La heterogeneidad de realidades muestra diferencias de un país a otro, sobre todo en lo concerniente a la educación técnico-profesional: los países que poseen una mayor proporción de jóvenes cursando estos estudios son el Perú (27,5\%), Chile $(21,2 \%)$ y la Argentina (18,9\%). También hay un importante grupo de países (Costa Rica, Ecuador, El Salvador, Honduras, México, Nicaragua, Panamá, Paraguay, República Dominicana y Uruguay), donde el porcentaje de estudiantes técnico-profesionales es marginal en relación con el total de jóvenes de 20 a 24 años que asiste a un establecimiento educacional.

\section{Grafico I.7 \\ América Latina (15 países): tipo de estudio de los jóvenes de 20 a 24 años que se encuentran asistiendo a un establecimiento educativo, alrededor de $2012^{a}$ (En porcentajes)}

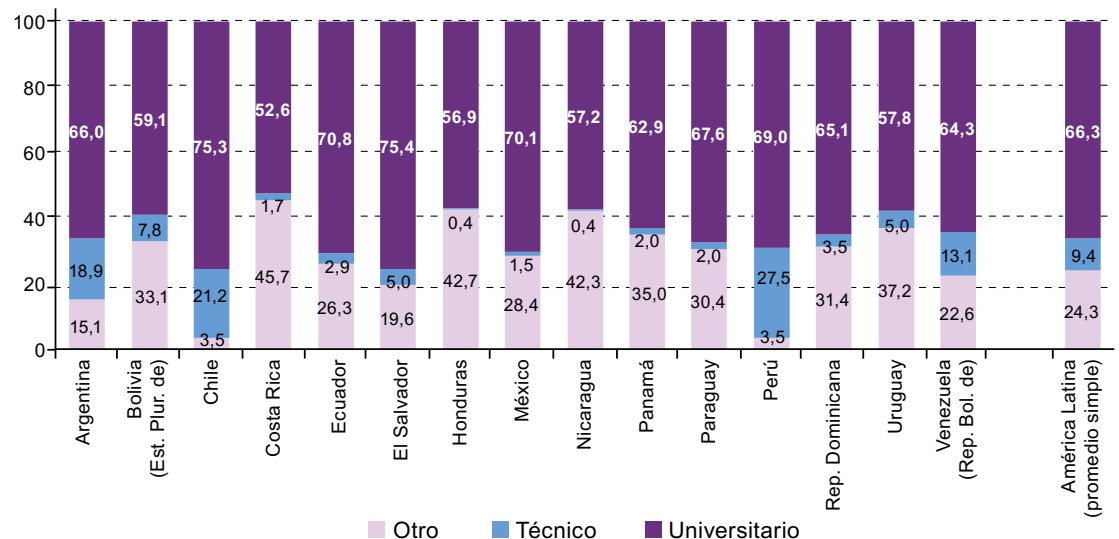

Fuente: Comisión Económica para América Latina y el Caribe (CEPAL), sobre la base de tabulaciones especiales de las encuestas de hogares de los respectivos países.

a Los datos corresponden al promedio simple de los países.

Lo expuesto da cuenta de que, pese a la importante promoción que se ha hecho de la educación superior no universitaria en los distintos países de la región, el porcentaje de jóvenes que asiste a este tipo de programas es bajo y se concentra en jóvenes provenientes de zonas urbanas de los quintiles más pobres (CEPAL, 2004). Esto no solo se debe a los problemas de cobertura que presenta este tipo de programas, sino también a la baja calidad de estas alternativas, lo que no hace más que perpetuar la baja valoración social de las carreras técnicas y tecnológicas (Llisterri y otros, 2014) (véase el recuadro I.1 ). 


\section{Recuadro I.1}

\section{Educación superior no universitaria}

Uno de los principales desafíos que enfrentan los sistemas educativos de América Latina es desarrollar alternativas de educación postsecundaria que permitan a los egresados de la educación secundaria continuar estudiando y prepararse para ingresar a un mercado laboral que se encuentra en constante cambio (Jacinto, 2013). La experiencia internacional muestra que la existencia de una oferta en educación superior no universitaria amplia y de calidad tiene un impacto positivo en el destino de los jóvenes una vez que ingresan al mercado laboral.

La disponibilidad de una educación superior no universitaria de calidad no solo tiene notables efectos en la trayectoria de los estudiantes, sino que también tiene una gran incidencia a nivel económico y social, tanto en el aumento de la productividad como en la disminución de la brecha entre oferta y demanda de mano de obra calificada y la reducción del desempleo y de la desigualdad de ingresos en los países (Bornacelly, 2013). De allí que este tipo de educación se haya constituido en una respuesta efectiva a la demanda de los sistemas productivos de los países, en constante cambio para responder a los desafíos que plantea la economía global, lo que impacta en ámbitos tan diversos como el mercado de trabajo y las tecnologías de la información y las comunicaciones (TIC) (Jacinto, 2013).

A nivel de pregrado, la educación superior no universitaria puede ser de dos tipos: técnica profesional y tecnológica. La Organización de las Naciones Unidas para la Educación, la Ciencia y la Cultura (UNESCO) y la Organización Internacional del Trabajo (OIT) recomiendan que los programas de educación técnica profesional se centren en la profundización del estudio de las tecnologías y ciencias a las cuales son afines y entreguen conocimientos prácticos, actitudes, compresión y conocimientos teóricos relacionados, según sean requeridos (Velasco, 2005). De esta forma, su fin es la profesionalización y capacitación de carácter operacional e innovador específico, requerido por el sector productivo (Bornacelly, 2013). Además, otorga más valor y reconocimiento a la experiencia laboral como parte del aprendizaje, da mayor acceso a las mujeres, lo vuelve accesible a personas con discapacidad y desarrolla la capacidad de tomar decisiones y de adaptarse a los constantes cambios en las TIC (Velasco, 2005).

En el proceso de formación, un técnico profesional adquiere habilidades para llevar a cabo tareas de carácter operativo e instrumental, y sus competencias se relacionan con la aplicación de conocimientos de actividades laborales rutinarias, altamente específicas y con un menor grado de complejidad. Este tipo de programa dura entre cuatro y cinco semestres. Por otra parte, un tecnólogo se desempeña en contextos diversos, donde las actividades suelen requerir la aplicación y práctica de conocimientos en actividades complejas y no rutinarias. El curso de las carreras tecnológicas lleva de seis a siete semestres (Bornacelly, 2013).

Fuente: I. Bornacelly, "Educación técnica y tecnológica para la reducción de la desigualdad salarial y la pobreza", Revista Desarrollo y Sociedad, N 71 , Bogotá, Universidad de los Andes, 2013; C. Jacinto, "La educación post-secundaria técnica: Contexto, interrogantes y aportes de la investigación", Incluir a los jóvenes. Retos para la educación terciaria técnica en América Latina, C. Jacinto y otros, Organización de las Naciones Unidas para la Educación, la Ciencia y la Cultura (UNESCO), 2013; C. Velasco, La educación técnica y profesional de nivel medio en siete países de América Latina. Hacia un estado del arte, Santiago, Organización de las Naciones Unidas para la Educación, la Ciencia y la Cultura (UNESCO), 2005. 
Otro hecho de relevancia es la elevada proporción de jóvenes de 25 a 29 años que, habiendo asistido a la educación terciaria, actualmente no están asistiendo y no han finalizado sus estudios. Estos jóvenes que abandonaron el sistema educativo alcanzan aproximadamente al 10\% del total de dicho grupo de edad en los países con información disponible (véase el gráfico I.8.A).

La baja matrícula y asistencia (24\% de jóvenes de entre 20 y 24 años asistiendo a estudios postsecundarios como se aprecia en el cuadro I.3), sumado al alto grado de abandono de estudios en este nivel (casi la mitad de los que ingresaron en el grupo de 25 a 29 años), evidencian que la conclusión de la educación terciaria es todavía muy baja en la región, ya que, en promedio, solo el $10 \%$ de los jóvenes ha logrado finalizar este ciclo (véase el gráfico I.8.B). En América Latina se observa una importante heterogeneidad en los niveles de conclusión de los distintos países, que varían desde alrededor del $20 \%$ de los jóvenes en la Argentina, Bolivia (Estado Plurinacional de) y el Perú, hasta menos del 5\% en Guatemala, Honduras y la República Dominicana.

En términos generales, el panorama de los jóvenes de la región en los diversos ciclos educativos muestra notables avances tanto en acceso como en asistencia, progresión y conclusión. No obstante, un examen más pormenorizado revela una gran desigualdad y da cuenta de profundas brechas que aumentan en la medida en que se avanza de nivel educativo. Muchos de los jóvenes no asisten a la escuela por razones económicas o problemas que se relacionan con la oferta o falta de establecimientos (CEPAL/OIJ/IMJUVE, 2014). Asimismo, los contextos de pobreza en el hogar llevan a estudiantes jóvenes a dejar la escuela para acceder a algún empleo remunerado, muchas veces de mala calidad (bajo ingreso, informal y sin protección laboral). El salario a temprana edad es un incentivo para acceder a un mayor bienestar de manera inmediata cuando se piensa que este permite sumar un ingreso al hogar que se pierde si el joven retorna al sistema educativo. Las jóvenes, por su parte, pueden verse obligadas a asumir roles adultos, haciéndose cargo de labores domésticas o de cuidado, o asumiendo la maternidad, por lo cual se retiran del sistema educativo.

La escasa proporción de jóvenes con educación técnica limita los procesos de modernización y el aumento de la competitividad en la mayoría de los países de la región (CEPAL/OIJ, 2008). En este sentido, urge una reformulación de la educación técnica para que esta no solo sea entendida como educación conducente a un empleo inmediato y a corto plazo, sino que proporcione a los jóvenes una plataforma hacia el aprendizaje permanente y capacidad de innovación, incluidos el empleo o el ingreso a la enseñanza y formación postsecundaria (Fretwell, 2004). 


\section{Gráfico 1.8 \\ América Latina (12 países y 18 países): jóvenes de 25 a 29 años que no se encuentran estudiando y poseen estudios terciarios incompletos, $y$ jóvenes que concluyeron el nivel terciario ${ }^{a}$ \\ (En porcentajes)}

A. Jóvenes que no completaron estudios terciarios

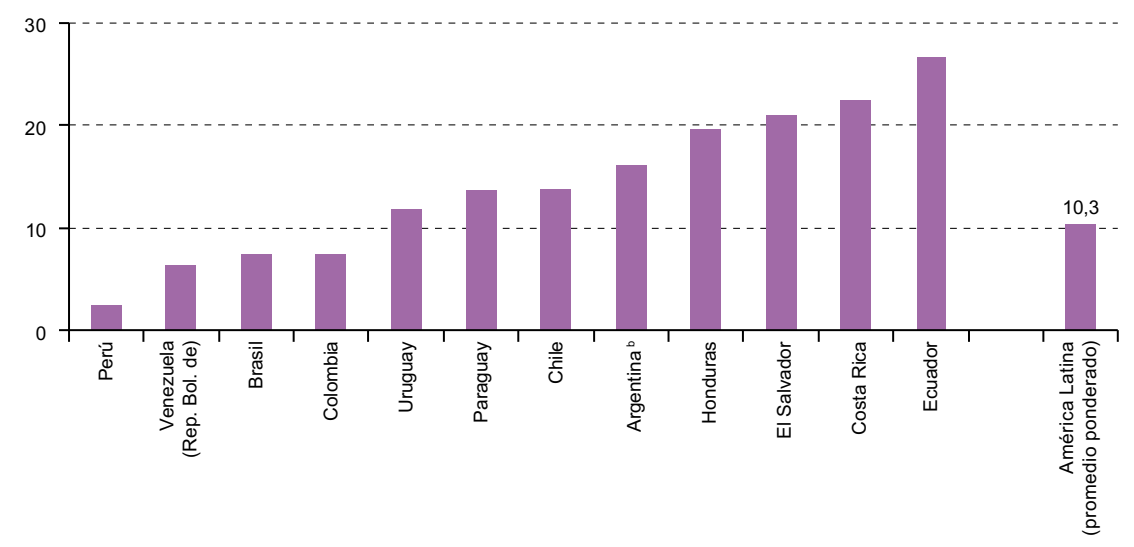

B. Jóvenes que completaron estudios terciarios

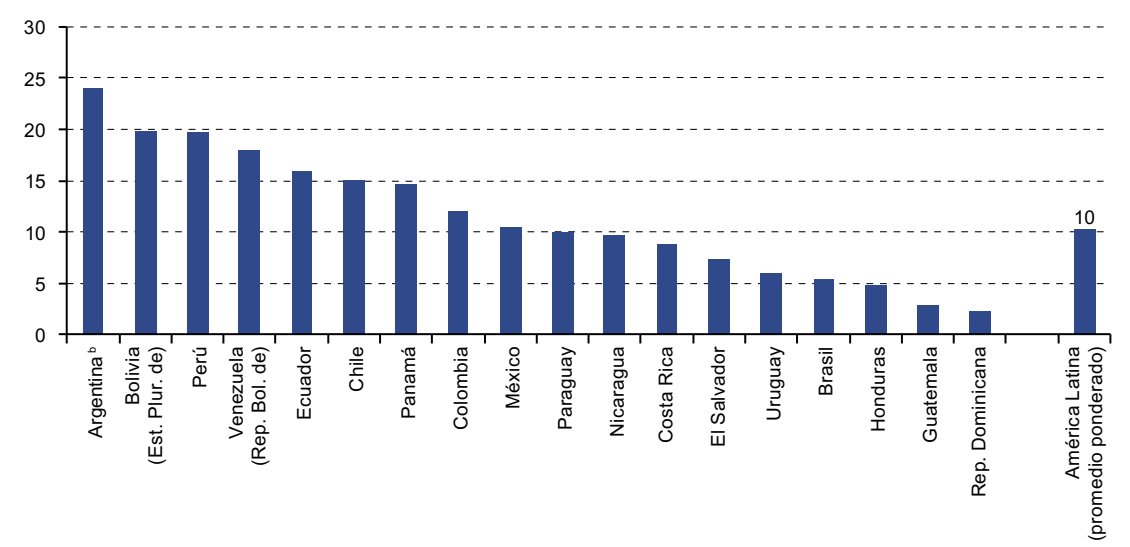

Fuente: Comisión Económica para América Latina y el Caribe (CEPAL), sobre la base de tabulaciones especiales de las encuestas de hogares de los países.

a Conclusión de al menos cinco años de estudios postsecundarios.

b Los datos corresponden a las zonas urbanas.

\section{Empleo juvenil}

Las oportunidades de inserción laboral en el período juvenil constituyen otro pilar de la inclusión social. El trabajo remunerado es el principal - sino el único- elemento que entrega independencia económica y 
familiar. En este sentido, los jóvenes aspiran a oportunidades laborales de calidad, que les permitan participar plenamente en el desarrollo ciudadano y productivo, y acceder a mejores condiciones de bienestar y desarrollo personal. La información disponible para 18 países muestra que aproximadamente 76 millones de jóvenes de entre 15 y 29 años se encuentran empleados en América Latina. Esta cifra corresponde a alrededor del $50 \%$ de los jóvenes, de los cuales, un $10 \%$ se encuentran estudiando y trabajando remuneradamente a la vez (es decir, un $20 \%$ de los jóvenes empleados).

La tasa de participación laboral de los jóvenes en América Latina aumenta con la edad (véase el gráfico I.9) (CEPAL, 2014; CEPAL/OIJ/ IMJUVE, 2014). Alrededor de 2012, los jóvenes latinoamericanos de entre 15 y 19 años presentaban una tasa de participación laboral del 39\%, mientras que en el tramo de 25 a 29 esta se elevaba al $80 \%$. Sin embargo, como se indica en los documentos citados, la menor participación laboral de quienes tienen entre 15 y 19 años no es, necesariamente, un hecho preocupante, ya que una inserción laboral más tardía propicia la oportunidad de permanecer dentro del sistema educativo y mejorar las credenciales con que se ingresará al mercado laboral.

\section{Gráfico 1.9 \\ América Latina (18 países): tasas de participación laboral de jóvenes de 15 a 29 años, alrededor de $2012^{\text {a }}$ (En porcentajes)}

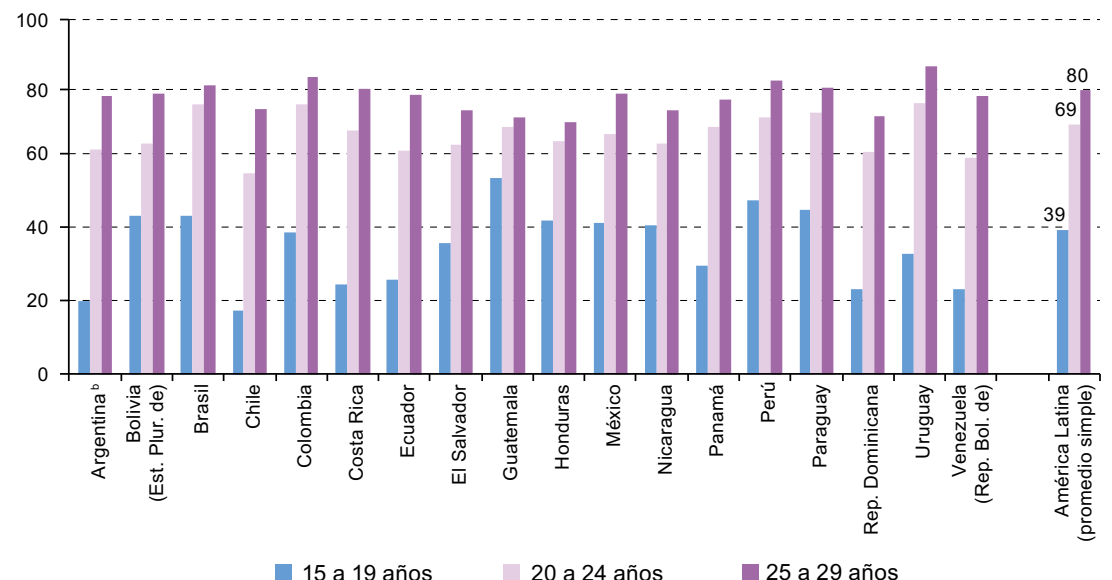

Fuente: Comisión Económica para América Latina y el Caribe (CEPAL), Panorama Social de América Latina 2014 (LC/G.2635-P), Santiago, 2014. Publicación de las Naciones Unidas, $N^{\circ}$ de venta: S.15.II.G.6.

a Los datos regionales corresponden al promedio simple de los países.

b Los datos corresponden a las zonas urbanas. 


\section{Recuadro I.2 \\ Trabajo adolescente en América Latina}

Muchos jóvenes inician su vida laboral en la adolescencia (período que va de los 12 a los 17 años), por lo que deben compatibilizar los estudios con el trabajo (remunerado y no remunerado). La promoción y el resguardo de sus derechos se sustentan en las normativas de cada país y en tres instrumentos internacionales: el Convenio sobre la Edad Mínima de Admisión al Empleo, 1973 (Núm. 138), el Convenio sobre las Peores Formas de Trabajo Infantil, 1999 (Núm. 182), y la Convención sobre los Derechos del Niño. Pese a estas iniciativas, en muchos países de la región, el trabajo adolescente, en su mayoría informal, se realiza en las peores condiciones.

Es importante recalcar que no todas las tareas realizadas por los adolescentes deben clasificarse como trabajo que se ha de eliminar. "Por lo general, la participación de los niños o los adolescentes en trabajos que no atentan contra su salud y su desarrollo personal ni interfieren con su escolarización se considera positiva" (OIT, s/f ). De manera complementaria, en el Convenio sobre la Edad Mínima de Admisión al Empleo se establece que dicha edad mínima no deberá ser inferior a la edad en que cesa la obligación escolar (14 a 15 años), aun cuando esta edad puede variar de un país a otro. Además, se establece que los niños de entre 13 y 15 años podrán realizar trabajos ligeros, siempre y cuando ello no ponga en peligro su salud, ni obstaculice su educación. En consecuencia, si bien quienes integran el grupo etario que comprende la adolescencia están sujetos a los mismos derechos que cualquier persona adulta, el del trabajo es un derecho supeditado al respeto de otros derechos, como la educación, la salud, la recreación y otros (OIT, 2010).

En América Latina (18 países), aproximadamente uno de cada seis adolescentes de entre 12 y 17 años se encuentran empleados en el mercado laboral y, de ellos, más de la mitad deben compatibilizar los estudios con el trabajo remunerado. Al revisar la situación de los adolescentes según tramos de edad, se constata que el $11 \%$ de los adolescentes de 12 a 14 años se encuentra trabajando, cifra que aumenta al doble en el tramo de 15 a 17 años.

Aunque el trabajo adolescente adopta muchas formas diferentes, una prioridad es la eliminación inmediata del trabajo peligroso. Este se refiere al trabajo que, por su naturaleza o por las condiciones en que se lleva a cabo, es probable que dañe la salud, la seguridad o la moralidad. En un estudio reciente de la OIT (2015), donde se consideran nueve países de la región (Bolivia (Estado Plurinacional de), Brasil, Costa Rica, Ecuador, El Salvador, Honduras, México, Nicaragua y Uruguay), se da cuenta de que la proporción de adolescentes de 15 a 17 años empleados en este tipo de trabajos es de aproximadamente un $60 \%$ del total de trabajos realizados por este grupo etario. Asimismo, en el estudio se pone énfasis en que en los países donde las diferencias entre la población rural y la urbana son más marcadas y donde predomina la agricultura, las tasas de trabajo peligroso son más elevadas. Por otra parte, los factores de género también parecen importantes para determinar la participación en el trabajo peligroso, en donde los hombres tienen más probabilidades, tanto en términos relativos como absolutos. 
Recuadro I.2 (conclusión)

\section{América Latina (18 países): adolescentes de entre 12 y 17 años que se encuentran empleados, según grupos de edad, alrededor de $2013^{\text {a }}$ \\ (En porcentajes)}

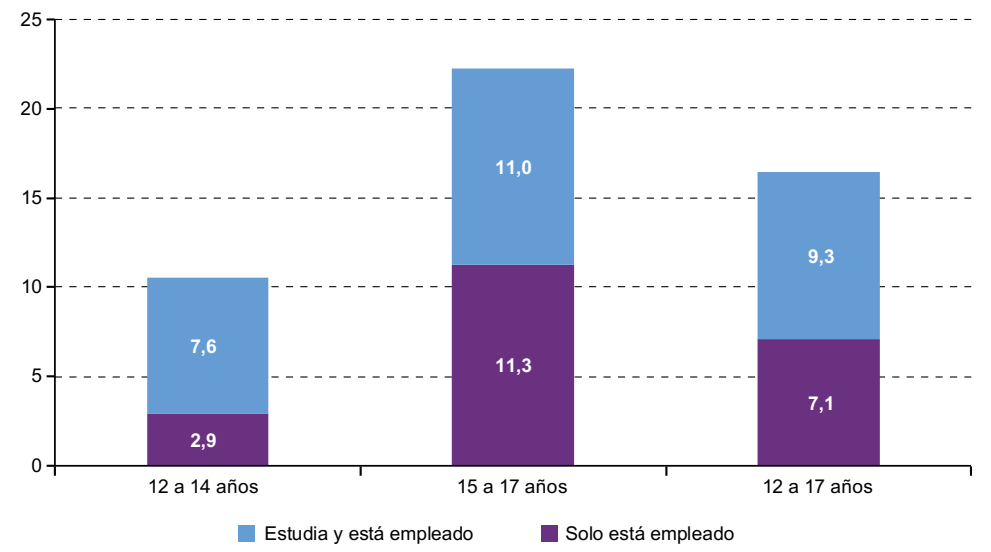

Fuente: Comisión Económica para América Latina y el Caribe (CEPAL), sobre la base de tabulaciones especiales de las encuestas de hogares de los respectivos países.

a Los datos regionales corresponden al promedio simple de los países.

Otra manifestación del trabajo realizado por los adolescentes es el trabajo doméstico no remunerado, realizado predominantemente por mujeres. Cómo mencionan Rico y Trucco (2014), es en este período donde se instala la especialización por sexo en el tipo de trabajo: los adolescentes hombres que trabajan se especializan en actividades de producción económica, mientras que las mujeres se dedican al trabajo doméstico no remunerado. Las autoras también mencionan que las adolescentes trabajan, en promedio, alrededor del triple de horas semanales en actividades domésticas que los varones, lo que supone un factor detractor de la escolaridad de las mujeres. En el caso de aquellas que viven en zonas rurales, se suma la crianza de animales pequeños y la agricultura familiar.

En virtud de las condiciones de precariedad e inseguridad que enfrentan muchos adolescentes de la región, se insta a mejorar los mecanismos que fomenten la permanencia en el sistema educativo, elaborando políticas de flexibilización laboral que permitan la conciliación entre el trabajo, la escuela y la recreación, y velando por que los trabajos que los adolescentes desempeñen se enmarquen en los regímenes especiales de protección, adoptados por las legislaciones nacionales sobre la base de los instrumentos de derecho internacional (OIT 2010).

Fuente: Organización Internacional del Trabajo (OIT), Informe mundial de 2015 sobre el trabajo infantil: Allanar el camino hacia el trabajo decente para los jóvenes, Ginebra, Oficina Internacional del Trabajo, 2015; Trabajo decente y Juventud en América Latina 2010, Lima, Proyecto Promoción del Empleo Juvenil en América Latina (Prejal), 2010; “¿Qué se entiende por trabajo infantil?”, Programa Internacional para la Erradicación del Trabajo Infantil (IPEC), s/f [en línea] http://www.ilo.org/ipec/facts/lang--es/index. htm; y María Nieves Rico y Daniela Trucco, "Adolescentes: Derecho a la educación y al bienestar futuro", serie Políticas Sociales, N 190 (LC/L.3791), Santiago, Comisión Económica para América Latina y el Caribe (CEPAL). 
La tasa de desempleo da cuenta de un comportamiento inverso a la participación laboral, ya que, conforme se avanza en los tramos de edad, tiende a descender hasta llegar a niveles similares a los de la población adulta. En promedio, no obstante, la población juvenil tiene una tasa de desempleo dos veces mayor que la población adulta (véase el gráfico I.10), lo que constituye un fenómeno de larga data y representa un problema estructural a nivel mundial (CEPAL/OIJ/IMJUVE, 2014). Además, si bien la crisis económica de mediados de la década de 2000 no tuvo un efecto mayor en los segmentos jóvenes que en los adultos en lo que respecta a la tasa de desempleo, en el período de recuperación económica posterior (20092011), la población adulta incrementó su tasa de empleo más rápidamente que la juventud. Esto indicaría que durante el período 2007-2011, la disminución en el empleo juvenil se habría compensado por una mayor permanencia de los jóvenes en el sistema educativo, especialmente en el tramo de 15 a 19 años (CEPAL, 2014b).

Gráfico I.10

América Latina (18 países): tasas de desempleo, por grupo de edad ${ }^{a}$ (En porcentajes)

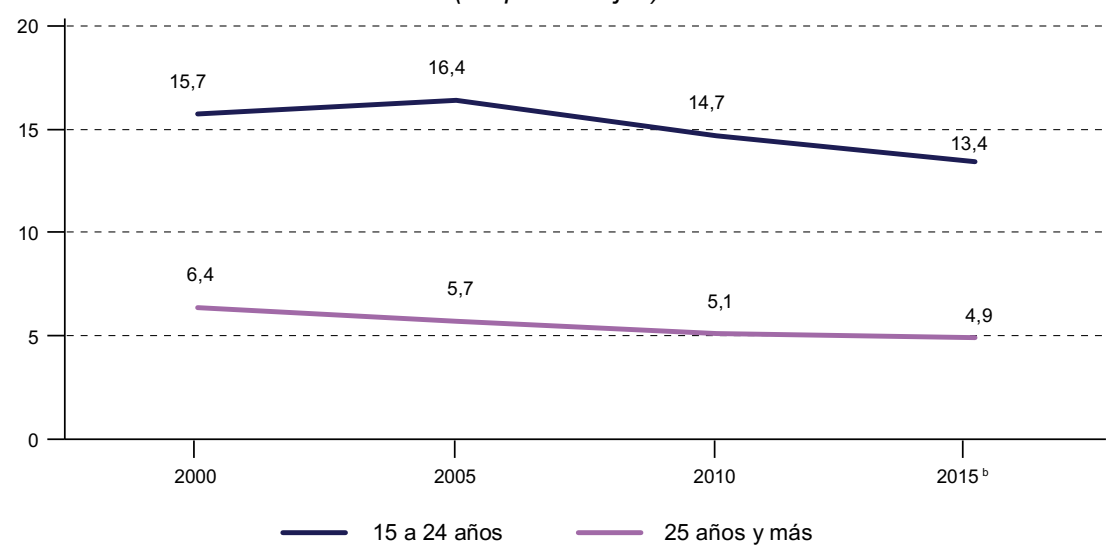

Fuente: Organización Internacional del Trabajo (OIT), Panorama Laboral 2013. América Latina y el Caribe, Lima, Oficina Regional de la OIT para América Latina, 2013.

a Los datos corresponden al promedio simple de los países.

b Los datos para 2015 corresponden a proyecciones.

En relación con el tiempo de búsqueda de trabajo entre jóvenes y adultos desocupados, los datos revisados por Weller (2007) indican que no existen grandes diferencias entre ambos grupos. Si bien los jóvenes en general no tienen más problemas de acceso al mercado del trabajo que los adultos, este hecho no es generalizable para las edades más jóvenes, en las cuales se concentran los desempleados que buscan trabajo por primera vez y aquellos a quienes les resulta más difícil acceder al mercado laboral y obtener empleos de calidad. 
Las diferencias que experimentan los jóvenes no se limitan únicamente a una cuestión de edad, sino que también hay muchos otros factores en juego, especialmente las condiciones socioeconómicas en las que crecen y se desarrollan. Como se observa en el cuadro I.4, los distintos países registran una tendencia a disminuir las tasas de desempleo a medida que se llega a los grupos de mayores ingresos. De ese modo, y considerando que son estos últimos grupos los que alcanzan un mayor nivel educativo, se releva la incidencia de la educación en el ingreso al mercado laboral y, por tanto, el menor tiempo de desempleo, así como los períodos de inactividad asociados con las dificultades de inserción (desempleo desalentado). A nivel regional, se constata que los jóvenes de los quintiles más altos de ingreso presentan una tasa de desempleo en promedio tres veces menor que los de los quintiles más pobres y en algunos países la diferencia es de hasta ocho veces (Costa Rica).

\section{Cuadro I.4}

América Latina (18 países): tasas de desempleo, jóvenes de 15 a 29 años, por quintiles, alrededor de $2012^{a}$ (En porcentajes)

\begin{tabular}{lrrrrr}
\hline País & Quintil I & Quintil II & Quintil III & Quintil IV & Quintil V \\
\hline Argentina $^{\text {b }}$ & 28,8 & 18,3 & 14,3 & 9,3 & 4,6 \\
\hline Bolivia (Estado Plurinacional de) & 5,0 & 5,5 & 5,5 & 4,7 & 3,6 \\
\hline Brasil & 23,9 & 16,3 & 9,8 & 6,2 & 5,5 \\
\hline Chile & 39,9 & 18,2 & 14,2 & 8,2 & 7,3 \\
\hline Colombia & 25,4 & 20,9 & 19,1 & 14,3 & 10,3 \\
\hline Costa Rica & 36,9 & 21,5 & 11,5 & 10,0 & 4,3 \\
\hline Ecuador & 14,4 & 11,5 & 9,3 & 9,2 & 5,3 \\
\hline El Salvador & 15,1 & 13,4 & 10,1 & 9,2 & 5,4 \\
\hline Guatemala & 1,2 & 2,6 & 3,4 & 3,4 & 3,8 \\
\hline Honduras & 3,3 & 7,6 & 8,2 & 8,3 & 6,9 \\
\hline México & 10,6 & 7,8 & 8,1 & 7,1 & 4,4 \\
\hline Nicaragua & 14,3 & 10,2 & 11,5 & 8,6 & 8,1 \\
\hline Panamá & 9,5 & 17,4 & 8,5 & 7,0 & 4,3 \\
\hline Perú & 7,2 & 9,0 & 7,9 & 7,3 & 6,5 \\
\hline Paraguay & 17,6 & 13,0 & 12,6 & 8,1 & 6,1 \\
\hline República Dominicana & 32,2 & 17,5 & 12,7 & 9,6 & 6,6 \\
\hline Uruguay & 24,0 & 16,1 & 11,7 & 8,4 & 7,3 \\
\hline Venezuela (República Bolivariana de) & 29,9 & 17,3 & 13,6 & 7,7 & 5,5 \\
\hline América Latina & $\mathbf{1 9 , 3}$ & $\mathbf{1 3 , 9}$ & $\mathbf{1 0 , 4}$ & $\mathbf{7 , 6}$ & $\mathbf{5 , 7}$ \\
\hline Fuente: Comsón Econ & & & & \\
\hline
\end{tabular}

Fuente: Comisión Económica para América Latina y el Caribe (CEPAL), sobre la base de tabulaciones especiales de las encuestas de hogares de los respectivos países.

a Las cifras regionales corresponden al promedio simple de los países.

b Los datos corresponden a las zonas urbanas.

La mayoría de los jóvenes de 15 a 29 años que se encuentran empleados son asalariados (79\%) y una menor proporción trabaja de forma independiente o por cuenta propia (19\%). Entre los trabajadores remunerados mayores de 30 años la distribución es menos marcada: un $56 \%$ y un $37 \%$, respectivamente (véase el grafico I.11) ${ }^{7}$. Este patrón es

\footnotetext{
7 Solo se mencionan las dos categorías más importantes.
} 
generalizado: a medida que se avanza en la edad y en la experiencia laboral, hay una mayor propensión a la autonomía laboral, ya sea en la forma de trabajo independiente o mediante la creación de nuevas empresas, lo que se debe principalmente al mayor conocimiento del rubro de trabajo y de las redes de proveedores y clientes en la actividad específica que se realiza. Esto tiene implicancias en cuanto al diseño de programas de capacitación; si bien el fomento del emprendimiento juvenil y el desarrollo de competencias adecuadas es importante, no es esperable que tenga efectos significativos a nivel masivo, por lo que debe considerarse como un tipo de programa complementario a los de formación para el trabajo (asalariado).

\section{Gráfico l.11 \\ América Latina (18 países): empleo juvenil, alrededor de $2012^{\text {a }}$ (En porcentajes)}

A. Situación laboral, según tramo etario

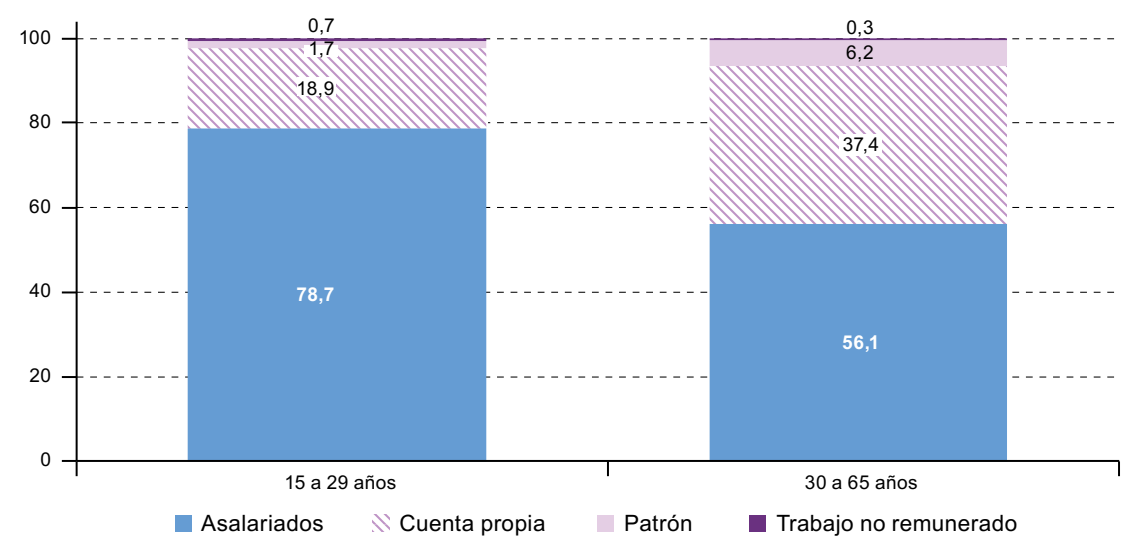

B. Rama de actividad en jóvenes de 15 a 29 años, según sexo

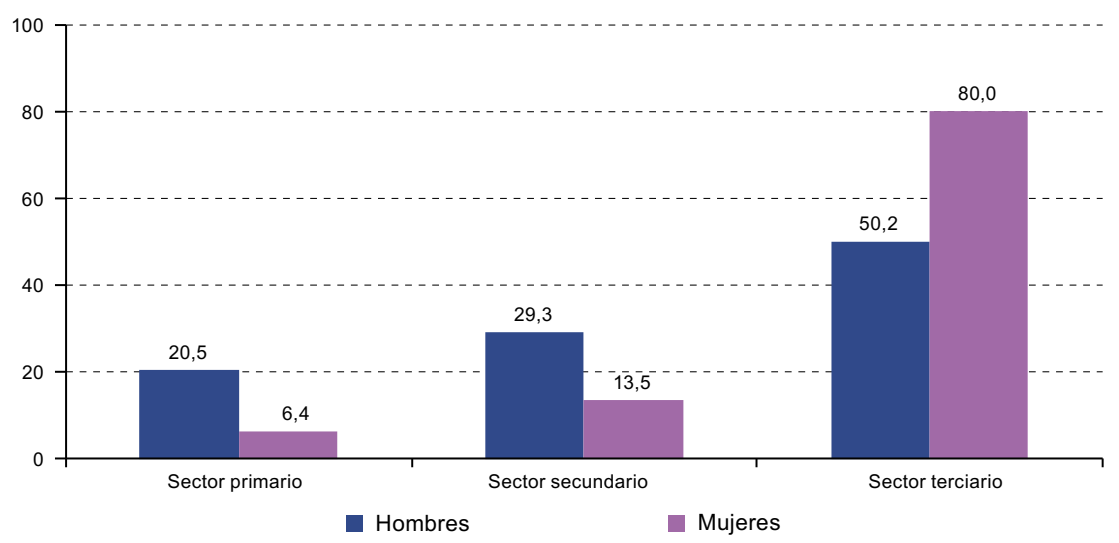

Fuente: Comisión Económica para América Latina y el Caribe (CEPAL), sobre la base de tabulaciones especiales de las encuestas de hogares de los países.

a Los datos corresponden al promedio simple de los países. 
En términos de la composición de la ocupación juvenil por ramas de actividad económica, la mayoría de los jóvenes se desempeñan en el sector terciario, donde predominan empleos con alta tasa de rotación. Esta situación no se explicaría por dinámicas propias de los jóvenes, sino por las características de estas ramas de actividad en donde se insertan (Pérez, 2007). Tal y como menciona Weller, tanto el sector agropecuario como la industria manufacturera han perdido peso en la estructura ocupacional de los jóvenes (Weller, 2001 y 2003). Esta situación genera una estructura polarizada en el sector terciario que, por una parte, está marcada por una importante cantidad de empleos altamente productivos $\mathrm{y}$ en general bien remunerados (como servicios financieros, servicios a empresas, telecomunicaciones, energía y servicios sociales), y, por la otra, empleos con bajas barreras de entrada y baja productividad (como el comercio informal y ciertos servicios personales). En ambos grupos predominan las mujeres de niveles educativos altos e intermedios.

En cuanto a los ingresos de los ocupados, se observa una marcada brecha entre jóvenes y adultos que se debe, principalmente, al valor de la experiencia. Como es esperable, la brecha se reduce con el aumento de la edad y la experiencia (CEPAL/OIJ/IMJUVE, 2004). Mientras los más jóvenes (de 15 a 19 años) perciben, en promedio, un tercio de los ingresos medios de los adultos, los de 20 a 24 años ganan aproximadamente la mitad y el tramo siguiente (de 25 a 29 años) percibe más de las tres cuartas partes de lo que ganan los adultos (véase el gráfico I.12.A). Los datos también indican que la brecha es significativamente mayor para los hombres que para las mujeres. $\mathrm{Si}$ bien este fenómeno ha sido vastamente estudiado, hay dos elementos que llaman la atención. El primero es que al comenzar la vida laboral remunerada, no se observa una brecha salarial entre ambos sexos, pero esta empieza a crecer conforme aumenta la edad. Esto podría explicarse, en parte, por el hecho de que las mujeres acumulan menos experiencia debido a la mayor carga de cuidado, que resulta en trayectorias más interrumpidas. El otro punto es que si bien las mujeres logran mejores rendimientos educativos que los hombres en todos los niveles, $\mathrm{y}$, por tanto, se capacitan para acceder al empleo, esto no se traduce en mayores ingresos laborales, lo que responde a patrones sociales y culturales de discriminación salarial de género.

Otro enfoque posible al analizar los ingresos laborales es revisar su asociación con el nivel educativo. En el gráfico I.12.B se da cuenta de una asociación positiva entre ambas variables: a medida que aumentan los años de estudio, también aumentan los ingresos. Es importante destacar que existe un marcado cambio de pendiente al concluir la educación terciaria, en donde los ingresos aumentan considerablemente. Esto parecería estar indicando lo que en la literatura especializada se denomina efecto sheepskin, que da cuenta de premios a la obtención de títulos o diplomas, o, como en este caso, a la conclusión de la educación terciaria. En América Latina 
(18 países), el conjunto de la fuerza de trabajo ocupada obtiene un ingreso medio mensual cercano a 900 dólares (a precios de 2005 en paridad del poder adquisitivo), un 30\% más que el ingreso medio de los jóvenes, que reciben aproximadamente 640 dólares. Al realizar un análisis según nivel educativo, los jóvenes de 15 a 29 años que tienen educación primaria completa o menos alcanzan un ingreso medio que apenas llega a los 430 dólares, en tanto que los que concluyeron la educación terciaria perciben remuneraciones que, en promedio, superan los 1.400 dólares mensuales.

\section{Gráfico l.12}

América Latina (18 países): promedio de ingresos laborales mensuales de la población ocupada, alrededor de $2013^{\text {a }}$

(En dólares de 2005 en paridad del poder adquisitivo)

A. Por grupos de edad y sexo

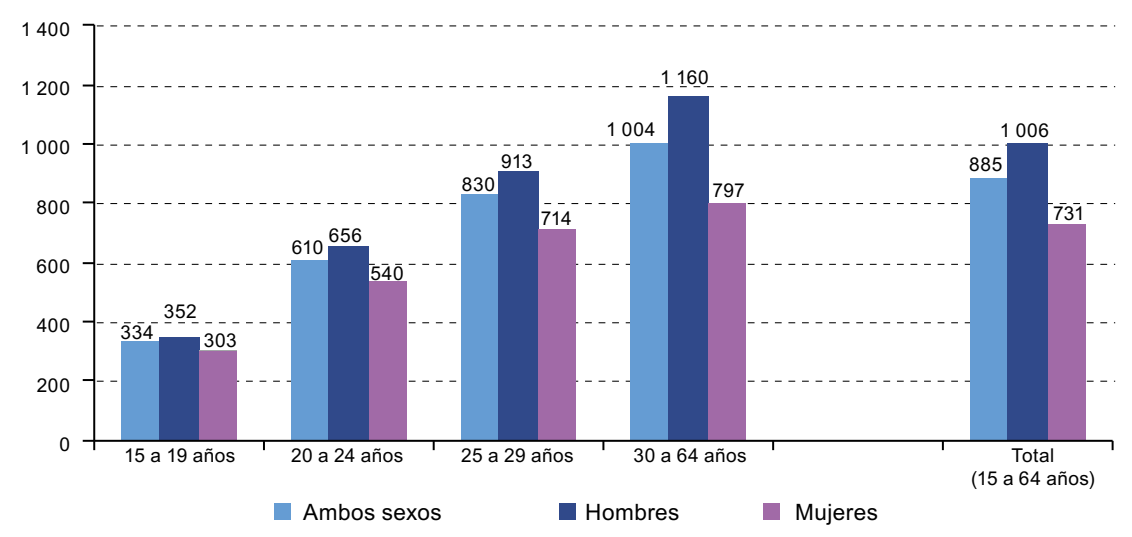

B. Por grupos de edad y nivel educativo alcanzado

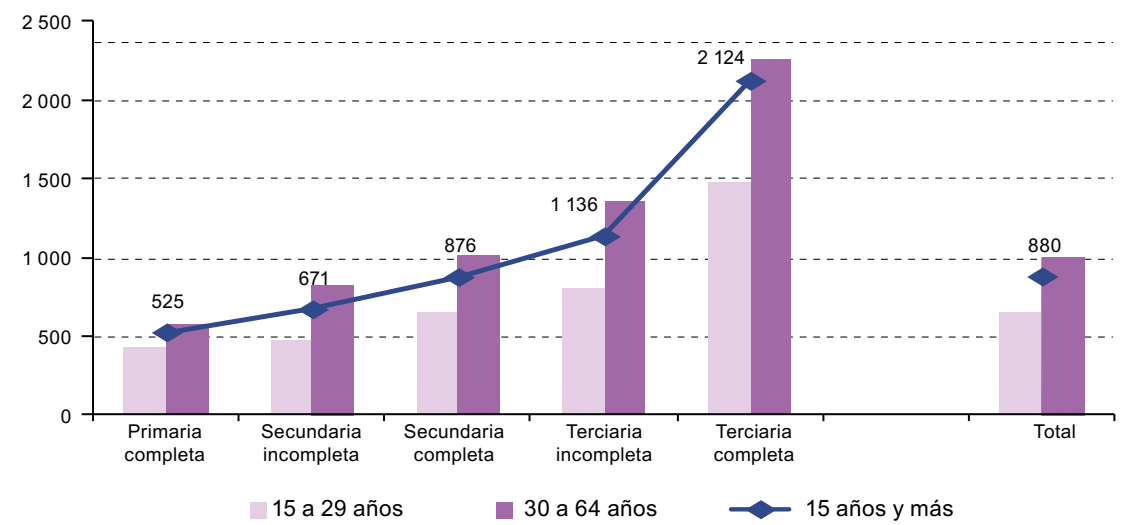

Fuente: Comisión Económica para América Latina y el Caribe (CEPAL), sobre la base de tabulaciones especiales de las encuestas de hogares de los países.

a Los datos corresponden al promedio simple de los países. 
Asimismo, y como se ha mencionado en otros estudios elaborados por CEPAL/OIJ (2004 y 2008), la presencia en el hogar de jóvenes en condición de dependencia económica puede constituirse en una carga para la familia. Si estos están empleados, pueden aportar al bienestar familiar y ayudar a prevenir la pobreza o a salir de ella en hogares de ingresos bajos. La evidencia en 18 países de la región muestra que el peso del ingreso laboral de los hijos en el total del ingreso familiar alcanza aproximadamente al 32\% y da cuenta de que el peso del ingreso de los jóvenes se vuelve más significativo conforme aumenta la edad, ya que pasa del 22,6\% en los de menor edad al $40 \%$ en el tramo de 25 a 29 años (véase el gráfico I.13). Además, se constata que el peso del ingreso del trabajo de los hogares con jefatura juvenil no dista de los hogares con jefatura adulta (aproximadamente un $80 \%$ ).

\section{Gráfico l.13}

América Latina (18 países): peso del ingreso laboral de los jóvenes que están empleados en el ingreso familiar, según parentesco ${ }^{a}$

(En porcentajes)

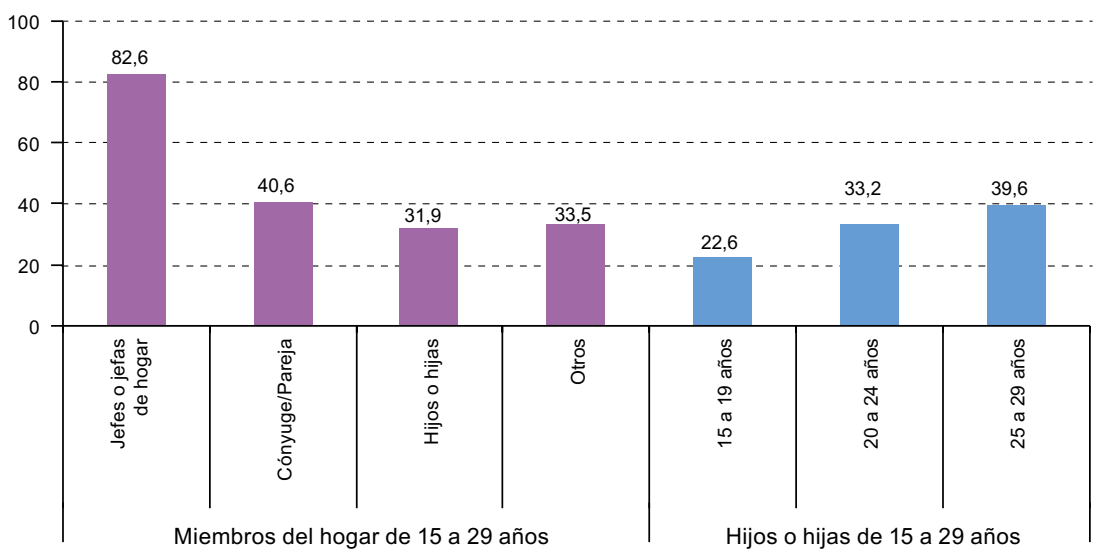

Fuente: Comisión Económica para América Latina y el Caribe (CEPAL), sobre la base de tabulaciones especiales de las encuestas de hogares de los países.

a Los datos corresponden al promedio simple de los países.

Por otra parte, la calidad del empleo entre jóvenes y adultos es diferente, ya que la mayor parte de la población joven tiene empleos precarios. Una manifestación de esta situación es el nivel de protección laboral, medida a través de la población joven asalariada afiliada a la seguridad social. La población joven, especialmente la de menos de 20 años, tiene un nivel de protección laboral sustantivamente menor que la población adulta: mientras que el $27,5 \%$ de los jóvenes asalariados de 15 a 19 años están afiliados a la seguridad social, en los adultos este porcentaje ronda el $70 \%$ (véase el gráfico I.14). A medida que se avanza en edad, la afiliación también aumenta, lo que indica que para una gran parte de la población juvenil que tiene un trabajo remunerado se 
trataría de una situación de desprotección transitoria (o inserción laboral transitoria), pero que refleja claramente una situación de discriminación en el mercado laboral hacia los trabajadores jóvenes (CEPAL, 2014b). La gravedad de esto reside en que se trata del período del ciclo de vida donde el aporte a los sistemas de seguridad cobra mayor relevancia por el tiempo de acumulación y, por tanto, la rentabilidad que tendrían dichos fondos.

Gráfico I.14

América Latina (18 países): población asalariada afiliada a la seguridad social, por tramos de edad, alrededor de 2012 ${ }^{a}$

(En porcentajes)

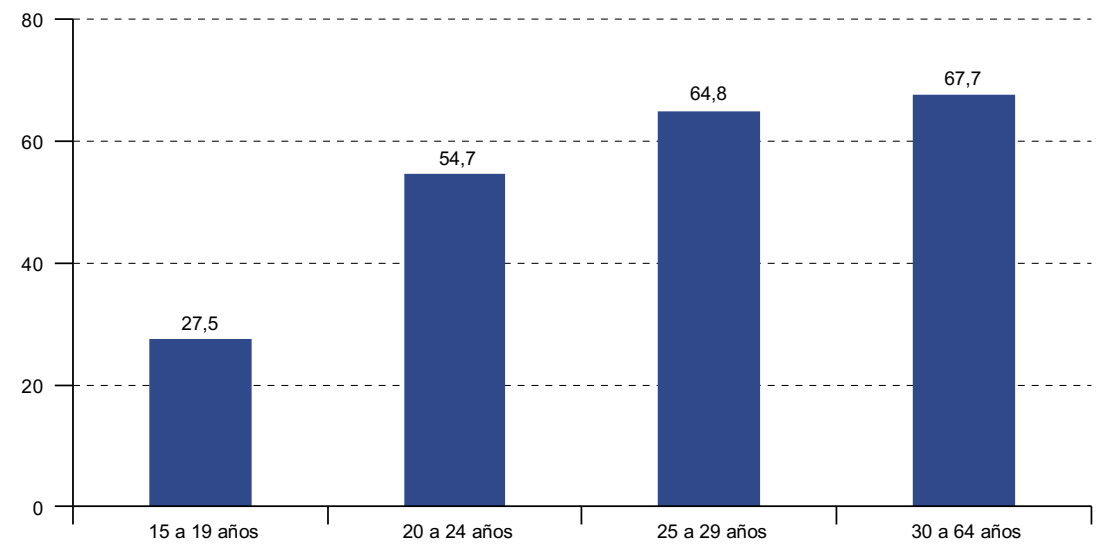

Fuente: Comisión Económica para América Latina y el Caribe (CEPAL), Panorama Social de América Latina 2014 (LC/G.2635-P), Santiago, 2014. Publicación de las Naciones Unidas, № de venta: S.14.II.G6.. a Los datos corresponden al promedio simple de los países.

Como corolario, se puede señalar que la inserción de los jóvenes en el mercado laboral se caracteriza por ser de alta rotación, segmentación y precariedad. Sin embargo, como menciona la Organización de Estados Iberoamericanos (OEI, 2012), los jóvenes consideran esta nueva normalidad laboral como un hecho dado que, en algunos casos, cumple con las expectativas de autonomía deseadas. No obstante, el mercado de trabajo actual no permite que la mayoría de ellos desarrolle trayectorias ascendentes y relaciones laborales estables. Según la OIT, esta situación laboral plantea un desafío político porque los deseos de tener un trabajo remunerado y de construir una vida autónoma tropiezan con la realidad de un mercado laboral en el cual los jóvenes deben enfrentarse a un alto nivel de desempleo e informalidad (OIT, 2013a). En síntesis, el panorama descrito reafirma lo expresado en el informe de CEPAL/OIJ/IMJUVE (2014), referido a que el empleo es el eslabón más crítico en la inclusión social de los jóvenes. En conjunto con la Organización Iberoamericana de Juventud (OIJ), la CEPAL señaló diez años atrás que, pese a los importantes logros educativos y a la mayor adaptabilidad a los cambios organizacionales y 
comunicacionales por parte de los jóvenes con respecto de los adultos, estos no habían podido plasmar dichos logros en el campo del empleo (CEPAL/ OIJ, 2004). En este sentido, para que los jóvenes puedan tener acceso a oportunidades laborales, se requiere que se expanda la generación de puestos de trabajo de calidad, pero también que la juventud esté capacitada para aprovechar dicha expansión (CEPAL/OIJ, 2008).

\section{Los jóvenes que no están incorporados a los sistemas educativos y no tienen un empleo remunerado}

Se estima que aproximadamente 30 millones de jóvenes en América Latina, equivalente al $22 \%$ del total, se encuentran desvinculados de los principales ejes de la inclusión social: el sistema educativo y el mercado laboral. Esta situación no solo implica una importante desventaja en términos presentes y futuros para no caer en condición de pobreza, o para salir de ella, sino que también lleva consigo una etiqueta negativa que los estigmatiza.

El estigma se construye en torno a la idea de que los jóvenes que no están incorporados al sistema educativo o al mercado laboral son una población de riesgo que se asocia a problemas como la vagancia, la delincuencia, el abuso de alcohol y las drogas. La realidad es que este grupo de jóvenes es muy heterogéneo y, por esta razón, se hace necesario visibilizar su complejidad y diversidad de situaciones, además de los motivos de la exclusión. Esto permitiría identificar otros caminos de integración social que está siguiendo este grupo de la población juvenil.

Como se evidenció en un reciente estudio de la CEPAL (2014b), el grupo de jóvenes desvinculados del sistema educativo y del mercado laboral está constituido en su mayoría por mujeres $(73,5 \%)$ y residentes de zonas urbanas (63,5\%); las excepciones son Guatemala y Honduras, donde la mayoría de estos jóvenes viven en áreas rurales. A pesar de que las diferencias entre tramos etarios no son muy significativas, la mayoría de los jóvenes que no estudian ni se encuentran empleados tienen entre 20 y 24 años (37,5\%) y este número disminuye en el tramo de 25 a 29 años (30,1\%), lo que da cuenta de la característica dinámica y transitoria de la condición de actividad de los jóvenes. Finalmente, se observan brechas considerables entre los quintiles de ingreso, ya que cerca del $50 \%$ de quienes no estudian ni tienen un empleo remunerado pertenecen a los dos primeros quintiles de ingreso 8 .

Más de la mitad (55\%) de los jóvenes que no estudian ni se encuentran empleados se dedican a tareas de cuidado y trabajo doméstico no remunerado (véase el gráfico I.15). Este hecho evidencia una distinción de género, ya que la gran mayoría de las personas jóvenes que se dedican a esta actividad

Véanse más detalles acerca de los jóvenes no vinculados al sistema educativo y al mercado laboral en CEPAL (2014). 
son mujeres y el tiempo que destinan a esta tarea es muy superior al de los hombres ${ }^{9}$. Tampoco debe obviarse el alto costo que esto tiene en la trayectoria de oportunidades futuras de estas mujeres, que las hace dependientes económicamente de otras personas y dificulta su inserción en el mercado laboral. Este es un costo al que los hombres jóvenes que abandonan el sistema educativo no se enfrentan en la misma medida, puesto que compensan la falta de educación formal con experiencia laboral, algo relativamente bien valorado en el mercado de trabajo (Rico y Trucco, 2014).

\section{Gráfico l.15 \\ América Latina y el Caribe (18 países): condición de actividad de jóvenes de 15 a 29 años que no estudian ni están empleados, alrededor de 2012 (En porcentajes)}

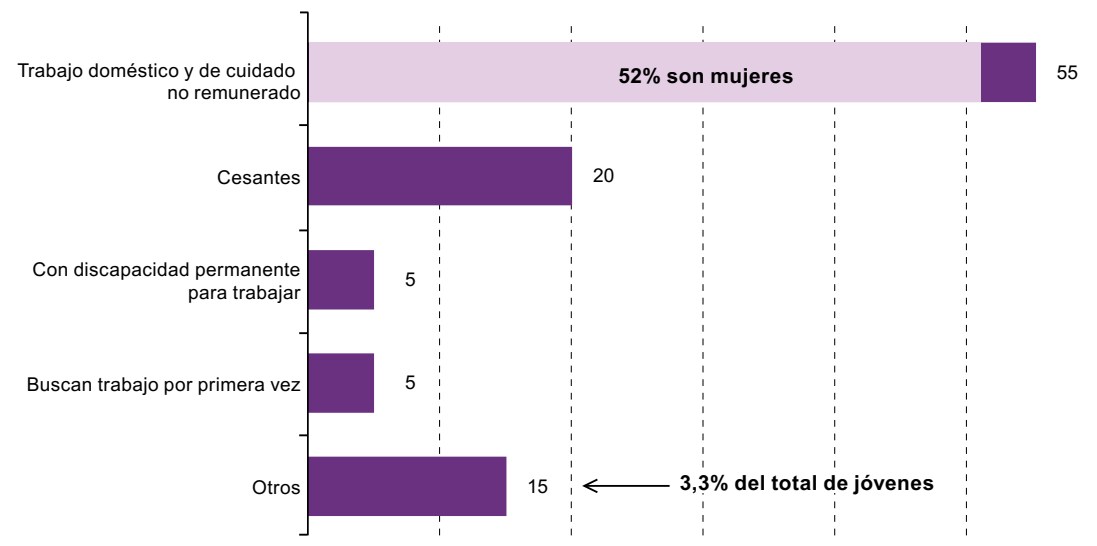

Fuente: Comisión Económica para América Latina y el Caribe (CEPAL), Panorama Social de América Latina 2014 (LC/G.2635-P), Santiago. Publicación de las Naciones Unidas, Nº de venta: S.15.II.G.6.

Esta valoración de la experiencia laboral permite entender por qué un $20 \%$ de los jóvenes que no estudian ni están empleados se encuentran buscando trabajo remunerado habiendo trabajado antes (cesantes). A esto se suma un $4,5 \%$ de jóvenes que han dejado de estudiar y se encuentran buscando trabajo por primera vez. Es posible suponer que esta sea una situación transitoria para estos jóvenes y que en algún momento lograrán insertarse en el mercado laboral.

Otro grupo de jóvenes que se encuentran inactivos, y que es importante visibilizar, es el que está conformado por jóvenes que tienen alguna discapacidad que los inhabilita de manera permanente para trabajar y que muchas veces les impide seguir una trayectoria educativa. Si bien las encuestas no permiten indagar los tipos de discapacidad, sobre la base de información disponible para 18 países se da cuenta de que el $5 \%$ de los jóvenes de 15 a 29 años que no estudia ni está empleado presenta esta condición (véase el recuadro I.3).

9 Véase más información sobre este tema en Rico y Trucco (2014). 


\section{Recuadro I.3 Jóvenes y discapacidad}

Los jóvenes con discapacidad se encuentran entre los más pobres y marginados de la población juvenil. Todos los desafíos que enfrenta la juventud, tales como el acceso a la educación, el empleo, la salud y los servicios sociales, también afectan a quienes tienen alguna discapacidad, pero de una manera mucho más compleja. El estigma y la discriminación hacen que para ellos sea mucho más difícil asistir a la escuela, encontrar trabajo o participar plenamente en la sociedad.

Como señala la CEPAL (2014b), hasta hace poco tiempo, las personas jóvenes con discapacidad eran escondidas, objeto de burlas y, en muchos casos, víctimas de violencia. En cierta medida, y gracias a algunos cambios en la concepción de la discapacidad y a la ratificación de la Convención sobre los Derechos de las Personas con Discapacidad por parte de 23 países de la región, esta situación ha mejorado, pero aún falta mucho por hacer.

La incorporación de los jóvenes con discapacidad en el ámbito escolar y en el mercado de trabajo, los dos ejes principales de la inclusión social, representa un gran desafío para todos los países de la región. Algunas estimaciones recientes permiten deducir que el $6 \%$ de la población de entre 13 y 19 años tiene al menos una discapacidad, lo que equivale a 6,5 millones de jóvenes en edad de recibir enseñanza secundaria. La mayoría de estos jóvenes tiene una discapacidad visual o de audición, seguido por dificultades de aprendizaje.

La educación es fundamental para que los jóvenes puedan realizar su potencial. Sin embargo, los niños con discapacidad tienen una menor probabilidad de asistir a la escuela y enfrentan importantes desafíos para permanecer y avanzar en las instituciones de enseñanza (OMS/Banco Mundial, 2011). La información sobre el tiempo de asistencia a centros de enseñanza de las personas con discapacidad de entre 13 y 18 años en la región revela grandes disparidades según el país y el tipo de discapacidad. No obstante, a partir de la información disponible, el promedio en 2011 era de no más de tres años de estudio en América Latina y solo algo superior en los países del Caribe de habla inglesa (CEPAL, 2013). Los establecimientos educativos no son tan accesibles como deberían, carecen de instalaciones adecuadas y no proporcionan a los estudiantes con discapacidad los ajustes necesarios o dispositivos de asistencia. Las escuelas inclusivas y accesibles son una condición esencial para promover la inclusión social, la aceptación y la igualdad de oportunidades en escuelas y colegios para los jóvenes con discapacidad. Los programas de sensibilización y de capacitación son importantes para preparar a los docentes y al personal de la escuela y de la universidad, una carencia que a menudo da pie a la exclusión de jóvenes con discapacidad de ciertas actividades (OMS/Banco Mundial, 2011).

Al no adquirir las habilidades y competencias necesarias para participar en el mercado laboral, las oportunidades de acceder a un trabajo decente e independizarse son muy limitadas para los jóvenes con discapacidad. Aunque los bajos logros educativos y la falta de habilidades pueden afectar su competitividad en el mercado laboral, las actitudes negativas acerca de la discapacidad y la discriminación son los principales obstáculos para conseguir un trabajo. Las percepciones negativas hacia las personas con discapacidad y las ideas erróneas por parte de los empleadores -como que son menos productivas que sus compañeros, que requieren demasiada ayuda, que van a afectar la imagen del empleador o la preocupación por los costos iniciales de contratación (por ejemplo, la construcción de rampas) - son barreras formidables para los jóvenes con discapacidad en busca de empleo, pese a estudios que demuestran que las personas con discapacidad son tan productivas y confiables como los trabajadores 
Recuadro I.3 (conclusión)

sin discapacidad y exhiben menos ausentismo que estos (Du Pont, 1993; Zadeck y Scott-Parker, 2003). Para las mujeres jóvenes con discapacidad la situación es aún peor, ya que tienen que enfrentar prejuicios y discriminación no solo a raíz de su discapacidad sino también en virtud del género. Incluso con un alto nivel de educación, a las mujeres jóvenes con discapacidad les toma más tiempo conseguir empleo que a los hombres jóvenes en la misma situación (Roggero y otros, 2005).

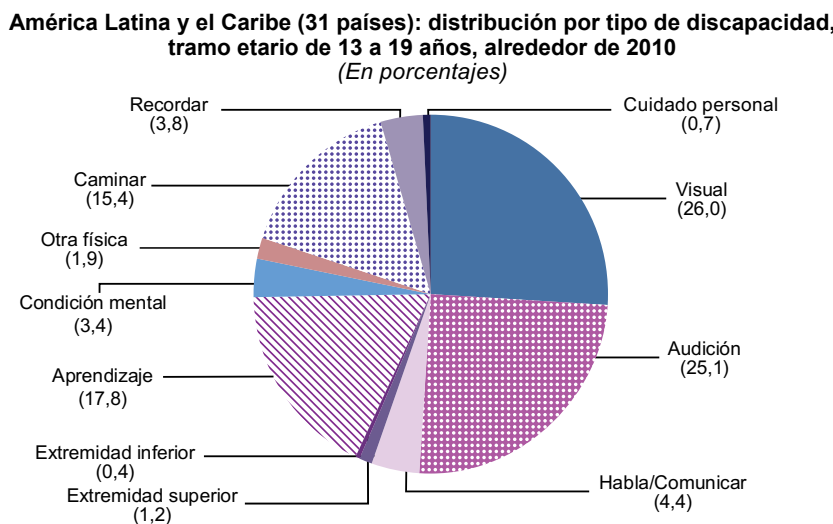

Fuente: Elaboración propia, sobre la base de: Argentina (Censo Nacional de Población, Hogares y Viviendas 2010); Aruba (Censo de Población y Vivienda, 2010); Bahamas (Censo de Población y Vivienda, 2010); Chile (Censo de Población y Vivienda, 2002); Costa Rica (Censo Nacional de Población y Vivienda, 2011); Curaçao (Censo de Población y Vivienda, 2011); Ecuador (Censo de Población y Vivienda, 2010); Granada (Censo de Población y Vivienda, 2001); Islas Caimán (Censo de Población y Vivienda, 2010); México (Encuesta Nacional de Ingresos y Gasto de los Hogares (ENIGH) 2012); Panamá (Censo de Población y Vivienda, 2010); Paraguay (Resultados preliminares Censo Nacional de Población y Viviendas, 2012); Perú (Primera Encuesta Nacional Especializada Sobre Discapacidad 2012); República Dominicana (Encuesta Nacional de Hogares de Propósitos Múltiples, 2013); San Vicente y Granadinas (Censo de Población y Vivienda, 2001); Suriname (Censo de Población y Vivienda, 2012); Venezuela (República Bolivariana de) (Censo Nacional de Población y Vivienda, 2011).

Mientras los jóvenes con alguna discapacidad sean discriminados por el rechazo a las diferencias, la pobreza, el aislamiento social, el prejuicio, la ignorancia y la falta de servicios y apoyo, no podrán ejercer sus derechos y vivir plenamente. La consecuencia no es solo un impacto social y económico negativo para los afectados y sus familias, sino que también implica altos costos y pérdidas para el conjunto de la sociedad, al no permitírseles ofrecer todo su potencial creativo y productivo.

Fuente: Comisión Económica para América Latina y el Caribe (CEPAL), Panorama Social de América Latina 2012 (LC/G.2557-P), Santiago, 2013. Publicación de las Naciones Unidas, N de venta: S.13.II.G.6; Panorama Social de América Latina 2014 (LC/G.2635-P), Santiago, 2014. Publicación de las Naciones Unidas, N de venta: S.15. II.G.6; Du Pont, Equal to the Task II: 1990 Du Pont Survey of Employment of People with Disabilities, Wilmington, Du Pont de Nemours and Company, 1993; Organización Mundial de la Salud (OMS)/Banco Mundial, Informe mundial sobre la discapacidad, 2011 [en línea] http://www.who.int/disabilities/world_report/2011/report/en/; P. Roggero y otros, Employment \& Youth with Disabilities: Sharing Knowledge and Practices, Washington, D.C., Banco Mundial, 2005; S. Zadeck y S. Scott-Parker, Unlocking Potential: The New Disability Business Case, Londres, Employers' Forum on Disability, 2003. 
Para una parte importante de quienes se encuentran fuera del sistema educativo y el mercado laboral, no obstante, no existe una razón clara que permita explicar dicha exclusión (estos son los que han sido caracterizados como "otros" en el gráfico I.15). Este grupo, que representa cerca del $15 \%$ de los jóvenes que no estudian ni están empleados y se compone de aproximadamente 4,8 millones de jóvenes de América Latina y el Caribe, es lo que la OIT ha llamado el núcleo duro de la exclusión social (OIT, 2013a).

Este es el grupo de jóvenes a quienes las estrategias vigentes de integración al sistema educacional o al mercado laboral no han logrado alcanzar; aquellos que, por diversas razones, se han visto marginados del eje de inclusión social juvenil (CEPAL, 2014b). Asimismo, este núcleo sería, en gran medida, producto de condiciones estructurales asociadas al origen socioeconómico, pero también de instituciones sociales expulsoras y discriminadoras que marginan a quienes no cumplen con las expectativas que se les imponen. Al ver truncadas sus oportunidades de inserción escolar o laboral, las opciones de inclusión social de estos jóvenes se ven disminuidas. A esto se suma el hecho de que son quienes ven más vulnerados sus derechos y los más propensos a integrarse a organizaciones y grupos alternativos a los socialmente instituidos. El análisis de este grupo da cuenta de que, a diferencia del total de quienes no estudian ni están empleados, está conformado principalmente por hombres $(59,8 \%)$, de zonas urbanas $(70,8 \%)$, de 15 a 19 años (49,1\%) y de los quintiles más bajos de ingreso (24,5\%).

Un análisis más detallado permite conocer otras razones por las que estos jóvenes se encuentran desvinculados de la educación y el empleo remunerado. Sobre la base de información disponible para nueve países de América Latina (Chile, Ecuador, Honduras, Nicaragua, Panamá, Perú, República Dominicana, Uruguay y Venezuela (República Bolivariana de)), los jóvenes que pertenecen a este núcleo indican que el principal motivo por el que no asisten a la escuela es porque no les interesa o consideran que no sirve estudiar a su edad (19,7\%) (véase el gráfico I.16). Esto tendría relación con la percepción de falta de beneficios de la enseñanza secundaria y un sistema educacional que no tiene conexión con las realidades cotidianas de los jóvenes de la región (Rico y Trucco, 2014).

Un segundo factor mencionado por los jóvenes encuestados es que ya terminaron sus estudios $(16 \%)$ y no desean continuar estudiando. Esta categoría se considera como una etapa transitoria en la que se hallan jóvenes que estarían en condiciones de incorporarse pronto al mercado laboral (situación que se analiza un poco más adelante). En tercer lugar, aproximadamente un $13 \%$ de este núcleo declara tener dificultades económicas para pagar los estudios, lo que los ha hecho desvincularse del sistema educacional. Esto no resulta sorprendente cuando se toma en cuenta que cerca del $50 \%$ de los jóvenes de este grupo pertenecen a los 
dos primeros quintiles de ingreso, lo que no les permite pagar por su educación o bien los lleva a abandonarla para tratar de incorporarse al mercado laboral y aportar con sus ingresos al hogar. El problema es que no siempre logran conseguir trabajos remunerados, ya sea por falta de preparación o de experiencia.

Gráfico I.16

América Latina y el Caribe (11 países): razones de no asistencia al sistema educativo de los jóvenes catalogados como "otros", alrededor de 2012 (En porcentajes)

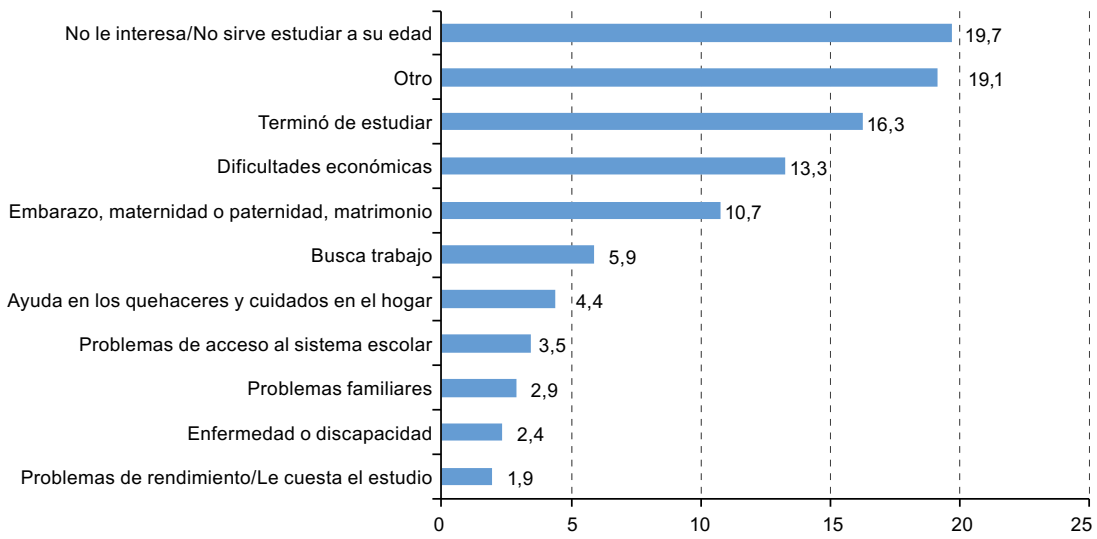

Fuente: Comisión Económica para América Latina y el Caribe (CEPAL), sobre la base de tabulaciones especiales de las encuestas de hogares de los respectivos países.

Otro factor destacado para no asistir a un centro educativo es el embarazo, la maternidad o la paternidad, mencionado por un $10,7 \%$ de los encuestados. Es importante indicar que América Latina y el Caribe sigue siendo la región de mayor fecundidad adolescente del mundo, después del África subsahariana (Rodríguez, 2014). En este sentido, la persistencia de altas tasas de embarazo, y en especial la maternidad adolescente, sobre todo no deseada, constituye en América Latina un asunto de salud pública estrechamente ligado a la falta de derechos reproductivos de las jóvenes y la exclusión social (CEPAL/OIJ, 2008). En muchos casos, esto lleva a la deserción del sistema educativo con la consiguiente reproducción de la pobreza.

Por último, hay un grupo de razones no determinadas (catalogadas como "otras") que representa a alrededor del 19\% de las personas inactivas no vinculadas al sistema educativo, a las que se suman una serie menor de causas: problemas familiares, problemas de acceso al sistema escolar, ayuda en los quehaceres del hogar o cuidado de niños, ancianos $u$ otras personas, enfermedad o discapacidad, y problemas de rendimiento que obligaron a abandonar el sistema educativo. 
Por otra parte, y sobre la base de información disponible para diez países de la región (Chile, Colombia, Ecuador, Honduras, Nicaragua, Panamá, Perú, República Dominicana, Uruguay y Venezuela (República Bolivariana de)), entre las razones que dan los jóvenes para no estar empleados ni buscar trabajo (es decir, no ser activos), hay un 20,7\% que menciona estar cansado de buscar trabajo remunerado. Estos jóvenes, desalentados por sus perspectivas futuras en materia de empleo, no solo se ven marginados del ámbito laboral, sino que también pueden tener dificultades para proseguir con sus estudios o formación, lo que les genera importantes consecuencias negativas a largo plazo, al reducirse los ingresos personales, además del estigma negativo que comporta el hecho de permanecer inactivo o apartado del mercado de trabajo durante un largo período de tiempo (OIT, 2010). En esta línea también se encuentran los jóvenes que no buscan trabajo debido a que piensan que nadie se los dará $(5,6 \%)$, ya sea por falta de educación o experiencia laboral, o por motivos de edad, sexo o raza (véase el gráfico I.17).

Otra causa relevante es la falta de interés de los jóvenes en trabajar $(17,4 \%)$. Aun cuando no existe información primaria que permita explicarlo, este desinterés podría estar relacionado con que muchos jóvenes todavía viven con sus padres y, por el momento, no tienen interés en emanciparse. También puede tratarse de un núcleo duro de autoexclusión de los mecanismos instituidos de inclusión social, donde el rechazo al sistema (como sea que este se entienda) los lleva a incorporarse a subculturas alternativas, algunas de las cuales se relacionan con el consumo de drogas, el pandillaje y la delincuencia.

\section{Gráfico I.17}

América Latina y el Caribe (10 países): razones para no buscar trabajo remunerado en los jóvenes catalogados como "otros", alrededor de 2012

(En porcentajes)

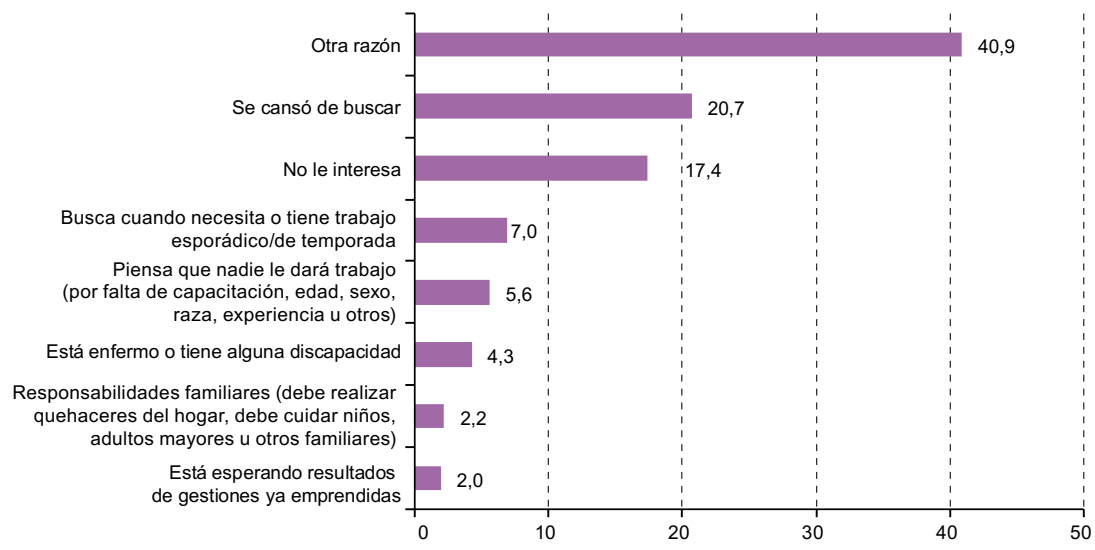

Fuente: Comisión Económica para América Latina y el Caribe (CEPAL), sobre la base de tabulaciones especiales de las encuestas de hogares de los respectivos países. 
Finalmente, los jóvenes mencionan "otra razón" para no encontrarse empleados (40,9\%). Esta categoría agrupa causas tan diversas como las relacionadas con condiciones de trabajo no convenientes, sueldos muy bajos, contar con otras fuentes de ingresos (como seguros de cesantía, mesadas, rentas o transferencias del Estado) o no disponer de la documentación necesaria para trabajar (como certificados de nacimiento y documentos de identidad). Se trata de una categoría bastante heterogénea, que debe ser tomada en cuenta para comprender este fenómeno.

Las situaciones descritas se tornan críticas cuando se tiene en cuenta que el empleo no solo permite el bienestar que significa una fuente de ingresos continua y, en algunos casos, facilita el acceso a sistemas de salud y seguridad social, sino que fortalece el sentido de pertenencia de las personas jóvenes, en la medida en que perciben su trabajo como un aporte al progreso colectivo (CEPAL/OIJ, 2008). Todo esto favorece el desarrollo interpersonal, la autoestima y el reconocimiento mutuo entre colectivos similares, algo fundamental a la hora de promover la cohesión social (CEPAL/OIJ, 2008). Es por esta razón que la desmotivación de los jóvenes para buscar trabajo y, sobre todo, la percepción de que no lograrán emplearse debe ser considerada como un problema desde la perspectiva de la inclusión social, la solidaridad y la confianza entre los grupos sociales, que son factores que impiden que los jóvenes, principalmente los de bajos ingresos, se sientan partícipes y elementos importantes de una sociedad.

El panorama regional indica que hay cerca de 4,8 millones de jóvenes que no estudian ni se encuentran insertos en el mercado laboral, situación que tiene como una de sus razones el desinterés y la desmotivación, tanto a la hora de estudiar como de buscar empleo. Para realizar acciones efectivas y adecuadas que incentiven y apoyen a estos jóvenes a la hora de continuar estudiando o buscando empleo, el diseño de estrategias de inserción social debe tomar en cuenta realidades nacionales y locales, las situaciones de vida y las trayectorias específicas a las que los jóvenes se enfrentan (CEPAL, 2014b). Además, se debe trabajar en pos de la constitución de instituciones educativas y un mercado laboral que acepten y permitan la inserción de los jóvenes. Solo de esta forma es posible generar políticas que tengan sentido para los jóvenes y permitan avanzar hacia la reducción del núcleo duro de la exclusión social juvenil.

\section{E. Sugerencias de políticas}

El examen de la multiplicidad de políticas y programas que involucran a los jóvenes sugiere la necesidad de desarrollar y consolidar visiones integrales e integradas en las políticas públicas de juventud, procurando dotar a las políticas sectoriales de una perspectiva generacional que opere transversalmente (CEPAL/UNFPA, 2012; Alvarado, Rodríguez y 
Vommaro, 2013; CEPAL/OIJ/IMJUVE, 2014). En el ámbito de la educación y el empleo, esta necesidad se traduce en el requerimiento de una mejor articulación de las políticas y los programas educativos y de empleo, no solo para lograr mayores efectos, sino también para su conciliación con la vida familiar y las demandas de cuidados hacia la población dependiente.

El análisis y diseño de políticas integrales, tanto en el ámbito de la educación como del empleo, requiere atender el desarrollo institucional especialmente necesario para la articulación entre ambas áreas, que considere el fortalecimiento en capacidades de diseño, coordinación y evaluación de los diversos programas, y la apertura a visiones integrales en materia de juventud por parte de las instituciones que implementan las políticas. Por otra parte, es urgente abordar el cierre de las brechas de inclusión educativa y de inserción laboral, con una perspectiva de igualdad y garantía de derechos, mediante la implementación de políticas sectoriales coordinadas (educativas y de capacitación, de empleo y emprendimiento juvenil, y de acceso a la seguridad social, entre otras). Además, en la elaboración y puesta en práctica de políticas y programas en estos ámbitos, debe escucharse y entenderse las necesidades y visiones de los jóvenes con respecto a su propia inclusión e inserción para incorporarlas en el diseño y la ejecución de dichas políticas y programas.

A continuación se detallan algunos lineamientos de política concretos en los ámbitos que se abordan en este capítulo, que surgen tanto de nociones normativas como de buenas prácticas observadas en diversos países y experiencias ${ }^{10}$.

\section{Disponer de una oferta educativa y formativa flexible y pertinente}

Para seguir incrementando las oportunidades educativas de la juventud en la región, es necesario reconocer la diversidad de trayectorias y ofrecer la oportunidad de continuar los estudios de manera flexible. Por este motivo, es importante disponer de una oferta de educación formal y no formal que incluya alternativas más "heterodoxas" que permitan adaptarse a las condiciones específicas de los jóvenes (por ejemplo, zonas rurales apartadas, zonas de concentración de la pobreza y la marginalidad), que compatibilicen educación y trabajo, que incluyan programas para jóvenes en situaciones especiales (como los jóvenes con discapacidad), que promuevan la no discriminación y tiendan a disminuir la segregación, y que incorporen acciones de carácter compensatorio (becas, comedores escolares juveniles, programas de transferencias condicionadas a jóvenes),

10 Véase una revisión de experiencias y programas destacados de inclusión social de jóvenes en Alvarado, Rodríguez y Vommaro (2013). 
de retención y reincorporación a la escuela, de compatibilización con las demandas de cuidado y demás (CEPAL/OIJ/IMJUVE, 2014).

Por otra parte, los jóvenes de hoy son producto de una sociedad que los exalta desde el punto de vista comercial, mediático y consumista, mientras los aísla o los estigmatiza, por lo que tienden a socializar entre sí cada vez más, sin la presencia o guía de los adultos. Crece la importancia del sentido de derechos en las culturas juveniles, que en el contexto escolar reclama por un mejor trato y un nuevo tipo de relación con los adultos (los docentes en particular). Se reclama además por una educación con sentido, que proporcione identidad y pertenencia que vincule a la cultura juvenil con la sociedad más amplia mediante un aprendizaje significativo y relevante (Rico y Trucco, 2014). La pertinencia de los contenidos educativos adquiere especial relevancia en el ámbito rural, sobre todo en lo relativo a los pueblos indígenas: no solo deben considerarse las costumbres y la cosmovisión particular de los jóvenes de estos grupos, así como su quehacer cotidiano, sino también la propia lengua, para lo cual es deseable contar con profesores que hablen y enseñen en el lenguaje autóctono, y que sería muy bueno que provengan de los mismos pueblos a los que prestan servicios de enseñanza y aprendizaje.

También es necesario mejorar la articulación entre los diversos subsistemas de educación y capacitación, de forma que no solo se adapten a la diversidad de trayectorias juveniles que existen en la actualidad (incluidas las necesidades particulares de quienes ejercen la maternidad y paternidad en la etapa juvenil), sino que también permitan el adecuado flujo de estudiantes entre programas de capacitación, de educación técnica, educación profesional y universitaria, y faciliten que los jóvenes puedan continuar o retomar sus estudios, tanto para la actualización como para la profundización y especialización en diversas áreas del conocimiento a lo largo de toda la vida.

En cuanto a la flexibilidad de los sistemas formales de educación, particularmente los de nivel secundario, es adecuado tener en cuenta diversas experiencias exitosas:

- Sistema de escuelas itinerantes, que se adaptan principalmente a las necesidades de los jóvenes rurales y compatibilizan los ciclos agrícolas con las demandas curriculares propias del programa, ya sea con modalidades lectivas de fin de semana o por temporada. La modalidad itinerante está dada por el hecho de que una misma unidad docente o "escuela móvil" puede ser una alternativa de oferta educativa para varias zonas.

- En zonas de gran dispersión geográfica y poca densidad poblacional, las escuelas itinerantes pueden combinarse con la 
modalidad de escuelas multigrado o con un único docente (o unos pocos) para cubrir la demanda educativa primaria, y sobre todo secundaria, en las zonas rurales.

- Fortalecimiento de los programas de educación nocturna, habitualmente diseñados como programas de educación para adultos, y extensión a los grupos en edad de asistir a la educación formal, ya sea en modalidades programáticas comprimidas (dos o tres años en uno) o extendidas.

- Diseño e implementación de programas educativos flexibles y adaptados a grupos de jóvenes en situación de vulnerabilidad social, que apunten a fortalecer su vínculo con las comunidades educativas a partir tanto de actividades programáticas como extraprogramáticas (por ejemplo, escuelas de fútbol, clubes de lectura, talleres de música), de forma de generar alternativas de (re)integración social en el marco de una de las instituciones que mayor presencia tiene a nivel territorial en todos los países de la región, como es la escuela.

Con respecto a los sistemas de educación no formal y de capacitación para el trabajo:

- Fortalecer la oferta de programas de capacitación, tanto en lo referido a diversidad programática (vinculada con las demandas laborales) como a las coberturas totales de dichos programas. Una de las consideraciones para avanzar en esta línea es el fortalecimiento de la institucionalidad regulatoria y de articulación de las diversas ofertas públicas de capacitación, a fin de poder tener mejores herramientas de información para planificar en forma coordinada las múltiples ofertas de capacitación de conformidad con las necesidades del mercado de trabajo y los volúmenes reales de beneficiarios potenciales.

- Estrechar las alianzas público-privadas para mejorar la pertinencia de los programas de capacitación respecto de la estructura productiva actual y proyectada partiendo del nivel local. Esto facilita que los contenidos de la capacitación en cada territorio se adapten a los mercados de trabajo locales y no se transformen en ofertas que no cumplen las expectativas de empleo de los beneficiarios ni son útiles a los sistemas productivos existentes en las áreas donde se desenvuelven los jóvenes.

- A la diversidad programática de la capacitación para el trabajo se agrega la necesidad de una oferta programática variable en cuanto a duración, en modalidades sustitutivas y complementarias al trabajo (diurnas y vespertinas). También es adecuado articular 
los programas de capacitación dentro de una misma área de especialización para que sean compatibles entre sí (convalidación de contenidos entre programas) y se transformen en una posibilidad de acumulación de conocimientos y formación continua que facilite a jóvenes y adultos la participación regular en dichos programas.

- Desarrollar o fortalecer los programas de certificación de competencias laborales y articular dicha certificación con la oferta programática mencionada anteriormente. Esto permite generar acreditaciones de la adquisición de competencias en el desempeño del trabajo (facilitando el reconocimiento, por parte de los empleadores, de la especialización adquirida y con los consecuentes beneficios salariales y no salariales asociados) y promover la especialización adicional y continua de los trabajadores jóvenes (y adultos).

Además, se requiere un fortalecimiento significativo de los sistemas nacionales de educación técnico-profesional:

- Desarrollar o fortalecer la educación técnico-profesional a partir del fortalecimiento de su institucionalidad: organismos nacionales que brinden, coordinen o regulen la oferta de educación técnica tanto durante la educación secundaria como en el nivel postsecundario.

- Los programas técnico-profesionales deben responder a las necesidades presentes y futuras de los sistemas productivos nacionales, lo que requiere tanto alianzas público-privadas como el análisis conjunto de las necesidades del mercado de trabajo y proyecciones a futuro de la demanda laboral. Así, se facilita una adecuada planificación de la oferta programática, en contenidos, diversidad de programas y estructura de dicha oferta según niveles de especialización y potencialidades reales de absorción de mano de obra por parte del mercado de trabajo.

- Como ocurre con los programas de capacitación, es necesario articular y compatibilizar los programas de educación técnica secundaria, postsecundaria técnica y profesional, y educación terciaria (universitaria), de forma de otorgar a los jóvenes (y adultos) la posibilidad de continuar con sus estudios a partir de programas compatibles e intercambiables entre sí (que, a la vez, incluyan salidas intermedias acreditadas). También debe facilitarse la acumulación de contenidos especializados sin que sea necesario cumplir con el conjunto total de contenidos programáticos si ya se han adquirido algunos de estos en especializaciones anteriores. 


\section{Fomentar la generación de procesos de transición de la educación a empleos más adecuados y de mejor calidad, y promover la existencia de un marco legal y de políticas públicas que aseguren la oportunidad de construcción de trayectorias de trabajo decente para los jóvenes}

El eslabón entre el sistema educativo y el mercado laboral debe reforzarse tomando en cuenta ámbitos tan importantes como los espacios de formación técnica y vocacional, particularmente al final de la secundaria (CEPAL, 2014b). A su vez, se sugieren estrategias que apunten a mejorar la empleabilidad mediante educación, formación y competencias, programas de inserción laboral (pasantías y aprendizajes), y programas de iniciativa empresarial y empleo por cuenta propia (OIT, 2013a). Estas iniciativas deben buscar la articulación de la variada oferta educativa (y de capacitación) con las demandas proyectadas de fuerza laboral con diversos tipos de calificación, como se mencionó anteriormente. Convendría, en ese sentido, impulsar la evaluación de programas de emprendimiento juvenil, su diversificación y diagnósticos adecuados acerca de la masividad de su impacto para ajustar la oferta programática, y mejorar la articulación con otros programas de capacitación o formación y con las demandas efectivas del mercado.

Por otra parte, se requieren marcos legales que incluyan especialmente a las mujeres jóvenes, los indígenas, los afrodescendientes y las personas con discapacidad, y den sustento a las políticas públicas orientadas a estos grupos. Se aboga por el reconocimiento de las dificultades que tienen las jóvenes para compatibilizar las oportunidades educativas y de empleo con la maternidad y las responsabilidades familiares y de cuidado. Al respecto, se plantea la necesidad de reconocer el trabajo doméstico no remunerado y la economía del cuidado, así como de incorporar políticas que promuevan la corresponsabilidad de hombres y mujeres en ese ámbito y apoyen el balance con la vida familiar para ambos sexos.

También es muy importante diseñar programas y mecanismos de incentivo para la contratación de jóvenes en empleos protegidos (que incluyan la afiliación a seguridad social, sistemas de salud y seguros de desempleo).

A continuación se plantean algunas recomendaciones específicas en cuanto a las políticas y los programas de promoción del empleo juvenil.

- Es importante incorporar las diversas iniciativas bajo una sola institucionalidad pública permanente $\mathrm{o}$, al menos, una institucionalidad articulada, que evite la histórica fragmentación de los diversos programas de promoción de la empleabilidad, 
generación de empleo, autoempleo y emprendimiento, y mejore las condiciones de trabajo y los niveles de formalización y protección social de los jóvenes trabajadores. En la misma línea, es adecuado diseñar planes nacionales de empleo juvenil (en el marco de los planes nacionales de desarrollo que, explícita o implícitamente, tienen los programas de gobierno), en tanto instrumentos de articulación y consolidación de las políticas y estrategias de promoción del empleo juvenil, y así evitar la dispersión de esfuerzos y duplicidad de acciones.

- En el ámbito legislativo, se hace necesario que las leyes que apuntan a la promoción del empleo y el trabajo decente para los jóvenes sean coherentes tanto con las leyes generales de juventud como con la legislación laboral en general. También es imprescindible elaborar iniciativas legislativas que favorezcan diferentes modalidades de adquisición de experiencia laboral y de formación de empresas, entre otros temas.

- Las políticas de empleo juvenil deben ser concordantes con las políticas nacionales en materia macroeconómica y de crecimiento, y con las políticas de educación, trabajo y desarrollo juvenil en general, ya que la generación de empleos para jóvenes y otros grupos requiere, en muchos casos, reformas estructurales que estimulen la generación de empleos formales y garanticen que los sistemas educativos doten a los jóvenes de las competencias que el mercado demanda.

- En el caso de los programas de promoción laboral, es adecuado que aquellos destinados a jóvenes en situación de vulnerabilidad social sigan modelos integrales y amplíen el área de atención no solo a la capacitación y eventual inserción laboral, sino también al entorno psicosocial de los jóvenes. Esto se debe a que la mayor empleabilidad no se logra exclusivamente con el desarrollo de habilidades técnicas específicas, sino también mejorando el modo de relacionamiento de los jóvenes con su entorno social y, particularmente, el entorno laboral (empleadores, supervisores, compañeros de trabajo, eventuales subordinados). Esto también incluye el desarrollo de habilidades "blandas" para el trabajo, entendidas como habilidades sociales, liderazgo, empatía, asertividad y otras.

- La debida articulación de los programas de empleo juvenil requiere, desde su diseño, el concurso de las organizaciones de empleadores, de trabajadores y de jóvenes, los órganos rectores en materia de empleo juvenil, el sector público y el sector 
privado en general, así como el fortalecimiento de diversos mecanismos de consulta, retroalimentación y diálogo social con dichos actores durante el diseño y la ejecución de los programas.

- Respecto de los programas de promoción del emprendimiento y autoempleo, es necesario que los jóvenes beneficiarios puedan acceder a los diversos servicios financieros, en particular créditos, capitales semilla y sistemas de garantías. Dependiendo de las características del sistema financiero, en ocasiones puede ser necesario crear nuevos productos que se adapten a las necesidades y dinámicas juveniles para facilitar la consolidación de sus emprendimientos.

- Por último, es relevante poner en práctica políticas, programas y acciones que apunten a la formalización y generación de nuevos empleos formales para los jóvenes, que incluyan mecanismos de protección social y de cumplimiento de los derechos laborales (que se extiendan a los que son independientes). En este marco, es necesario estimular la afiliación juvenil a los sistemas de seguridad social y fortalecer los mecanismos de inspección laboral para garantizar los derechos en el trabajo.

\section{Promover la creación de sistemas de información que brinden evidencia suficiente para la adecuada articulación entre el sistema educativo y el mercado de trabajo}

Cada vez es más necesario fortalecer las capacidades institucionales, no solo para tener adecuados diagnósticos, sino también para efectuar un seguimiento de los jóvenes participantes, tanto en los diversos programas educativos como en el mercado de trabajo. Aunque en la región han mejorado ostensiblemente los sistemas de información relacionados con el sistema educativo formal y, en menor medida, los observatorios laborales y de seguridad social, se requieren datos que no solo diagnostiquen, sino que también proyecten los requerimientos de los mercados de trabajo futuros para poder mejorar la planificación y el incentivo para el desarrollo de ofertas educativas acordes a las necesidades actuales y futuras de los sistemas productivos, con miras no solo a responder a dichas demandas sino también a cerrar las brechas de productividad de los distintos sectores económicos. En este sentido, la necesaria articulación entre la educación y el trabajo requiere, fundamentalmente, sistemas de información también interconectables y que se nutran unos de otros para poder orientar los requerimientos a la hora de establecer un diseño articulado de políticas en dichos ámbitos. 


\section{Bibliografía}

Alvarado, Sara Victoria, Ernesto Rodríguez y Pablo Vommaro (2013), Informe CLACSO-UNESCO: Politicas de inclusión social de jóvenes en América Latina. Situación, desafios y recomendaciones para la acción [en línea] http://www.celaju. net/informe-unesco-clacso-politicas-publicas-de-juventud-e-inclusion-socialen-america-latina-y-el-caribe/.

Bornacelly, Iván (2013), “Educación técnica y tecnológica para la reducción de la desigualdad salarial y la pobreza", Revista Desarrollo y Sociedad, N 71, Bogotá, Universidad de los Andes.

Briasco, Irma (2008), “ ¿Hacia dónde va la educación técnico profesional en América Latina?", Andamios, No 1, Buenos Aires, Fundación UOCRA, abril-junio.

Bucheli, Marisa (2006), "Mercado de trabajo juvenil: Situación y políticas", serie Estudios y Perspectivas, $\mathrm{N}^{\circ} 6$ (LC/L.2642-P), Montevideo, Oficina de la CEPAL en Montevideo. Publicación de las Naciones Unidas, $\mathrm{N}^{\circ}$ de venta: S.06.II.G.168.

CEPAL (Comisión Económica para América Latina y el Caribe) (2014a), Pactos para la igualdad: Hacia un futuro sostenible (LC/G.2639), Santiago.

(2014b), Panorama Social de América Latina 2014 (LC/G.2635-P), Santiago. Publicación de las Naciones Unidas, $\mathrm{N}^{\circ}$ de venta: S.15.II.G.6.

(2012a), Cambio estructural para la igualdad. Una visión integrada del desarrollo (LC/G.2524(SES.34/3)), Santiago.

(2012b), Eslabones de la desigualdad. Heterogeneidad estructural, empleo y protección social (LC/G.2539), Santiago, julio.

(2010a), La hora de la igualdad: Brechas por cerrar, caminos por abrir (LC/G.2432(SES.33/3)), Santiago.

(2010b), Panorama Social de América Latina 2010 (LC/G.2481-P), Santiago. Publicación de las Naciones Unidas, $\mathrm{N}^{\circ}$ de venta: S.11.II.G.6.

(2004), Panorama Social de América Latina 2004 (LC/G.2259-P), Santiago.

Publicación de las Naciones Unidas, $\mathrm{N}^{\circ}$ de venta: S.04.II.G.148.

CEPAL/OIJ (Comisión Económica para América Latina y el Caribe/Organización Iberoamericana de Juventud) (2008), Juventud y cohesión social en Iberoamérica. Un modelo para armar (LC/G.2391), Santiago, octubre.

(2004), La juventud en Iberoamérica: Tendencias y urgencias (LC/L.2180), Santiago.

CEPAL/OIJ/IMJUVE (Comisión Económica para América Latina y el Caribe/ Organización Iberoamericana de Juventud/Instituto Mexicano de la Juventud) (2014), Invertir para transformar. La juventud como protagonista del desarrollo, Santiago, octubre.

CEPAL/OIT (Comisión Económica para América Latina y el Caribe/Organización Internacional del Trabajo) (2012), Coyuntura Laboral en América Latina y el Caribe, $N^{\circ} 7$, Santiago, octubre.

CEPAL/UNESCO (Comisión Económica para América Latina y el Caribe/ Organización de las Naciones Unidas para la Educación, la Ciencia y la Cultura) (2009), "Impacto social y económico del analfabetismo: Modelo de análisis y estudio piloto" (LC/W.299), Santiago.

CEPAL/UNFPA (Comisión Económica para América Latina y el Caribe/Fondo de Población de las Naciones Unidas) (2012), Informe regional de población en América Latina y el Caribe 2011: Invertir en Juventud (LC/G.2391), Santiago. 
Dávila, Oscar y Felipe Ghiardo (2005), “Trayectorias, transiciones y condiciones juveniles en Chile", Revista Nueva Sociedad, N²00, noviembre-diciembre.

Feijoó, María del Carmen y Margarita Poggi (coords.) (2014), Educación y políticas sociales: Sinergias para la inclusión, Buenos Aires, Instituto Internacional de Pleaneamiento de la Educación (IIPE)-Organización de las Naciones Unidas para la Educación, la Ciencia y la Cultura (UNESCO).

Filgueira, Carlos (1998), "Emancipación juvenil: Trayectorias y destinos" (LC/MVD/R.154.Rev.2), Montevideo, Oficina de la CEPAL en Montevideo, junio.

Fretwell, David (2004), "Enseñanza secundaria: Preparar a los jóvenes para el mercado del trabajo en la economía del conocimiento", Las reformas de la enseñanza técnica y de la formación profesional en la economía del conocimiento, París, Centro Internacional de Estudios Pedagógicos.

Itzcovich, Gabriela (2014), "La expansión educativa en el nivel medio. América Latina, 2000-2010", Cuadernos, $\mathrm{N}^{\circ}$ 19, Sistema de Información de Tendencias Educativas en América Latina (SITEAL).

Llisterri, J. y otros (2014), “Educación técnica y formación profesional en América Latina. El reto de la productividad", serie Políticas Públicas y Transformación Productiva, $\mathrm{N}^{\circ} 13$, Banco de Desarrollo de América Latina.

Martínez, Rodrigo, Daniela Trucco y Amalia Palma (2014), “El analfabetismo funcional en América Latina y el Caribe: Panorama y principales desafíos de política", serie Políticas Sociales, N 198 (LC/L.3841), Santiago, Comisión Económica para América Latina y el Caribe (CEPAL).

OEI (Organización de Estados Iberoamericanos) (2012), "Estado del arte sobre empleo juvenil en América Latina y Europa", documento presentado en el Encuentro Intersectorial de Intercambio y Programación "Inserción laboral de los jóvenes. Estrategias innovadoras para facilitar la transición escuela- trabajo".

OIJ/CEPAL/PNUD/UNFPA/UNESCO (Organización Iberoamericana de Juventud/ Comisión Económica para América Latina y el Caribe/Programa de las Naciones Unidas para el Desarrollo/Fondo de Población de las Naciones Unidas/ Organización de las Naciones Unidas para la Educación, la Ciencia y la Cultura) (2012), 20 buenas prácticas en políticas públicas de juventud, noviembre.

OIT (Organización Internacional del Trabajo) (2013a), Trabajo decente y juventud en América Latina. Políticas para la acción, Lima, Oficina Regional de la OIT para América Latina y el Caribe.

(2013b), Panorama Laboral 2013. América Latina y el Caribe, Lima, Oficina Regional de la OIT para América Latina y el Caribe.

(2010), "El empleo de los jóvenes ante la crisis. Documento de antecedentes para la Reunión Informal de Ministros de Trabajo y Asuntos Sociales que se celebrará durante la 99a reunión de la Conferencia Internacional del Trabajo", Ginebra, 15 de junio.

OIT/OIJ (Organización Internacional del Trabajo/Organización Iberoamericana de Juventud) (2014), “Trabajo decente para los jóvenes: El desafío de las políticas de mercado de trabajo en América Latina y el Caribe", Boletín OIJ-OIT.

Pérez, Pablo (2007), "El desempleo de los jóvenes en Argentina. Seis hipótesis en busca de una explicación", Revista Estudios del Trabajo, № 34, Buenos Aires.

Rico, María Nieves y Daniela Trucco (2014), "Adolescentes: Derecho a la educación y al bienestar futuro", serie Políticas Sociales, N 190 (LC/L.3791), Santiago, Comisión Económica para América Latina y el Caribe (CEPAL) [en línea], http:/ / www.unicef.org/lac/Adolescentes_derecho_educacion_bienestar_futuro.pdf. 
Rodríguez V., Jorge (2014), “La reproducción en la adolescencia y sus desigualdades en América Latina. Introducción al análisis demográfico, con énfasis en el uso de microdatos censales de la ronda de 2010", Documento de Proyecto (LC/W.605), Santiago, Comisión Económica para América Latina y el Caribe (CEPAL).

UNESCO (Organización de las Naciones Unidas para la Educación, la Ciencia y la Cultura) (2013a), “¿Progresa la Región en el cumplimiento de los objetivos de la educación para todos?", Educación Post 2015, N 1, Santiago, octubre. (2013b), Situación educativa de América Latina y el Caribe: Hacia la educación de calidad para todos al 2015, Santiago, Oficina Regional de Educación para América Latina y el Caribe.

UNESCO/IESALC (Organización de las Naciones Unidas para la Educación, la Ciencia y la Cultura/Instituto Internacional para la Educación Superior en América Latina y el Caribe) (2006), Informe sobre la educación superior en América Latina y el Caribe 2000-2005. La metamorfosis de la educación superior, Caracas.

Weller, Jürgen (2007), “La inserción laboral de los jóvenes: Características, tensiones y desafíos", Revista de la CEPAL, N 92 (LC/G.2339-P), Santiago, agosto. (2003), "La problemática inserción laboral de los y las jóvenes", serie Macroeconomía del desarrollo, $\mathrm{N}^{\mathrm{2}} 28$ (LC/L.2029-P), Santiago, Comisión Económica para América Latina y el Caribe (CEPAL). Publicación de las Naciones Unidas, $\mathrm{N}^{\mathrm{o}}$ de venta: S.03.II.G.192. (2001), "Procesos de exclusión e inclusión laboral: La expansión del empleo en el sector terciario", serie Macroeconomía del desarrollo, No 6 (LC/L.1649-P), Santiago, Comisión Económica para América Latina y el Caribe (CEPAL). Publicación de las Naciones Unidas, $\mathrm{N}^{\mathrm{o}}$ de venta: S.01.II.G.187. 

Capítulo II

\section{La salud y las juventudes latinoamericanas y caribeñas}

Heidi Ullmann ${ }^{1}$

\section{Introducción}

Entender y responder a las necesidades de salud de los jóvenes es imperativo, ya que la salud es una condición que favorece el desarrollo de capacidades al facilitar la asistencia a centros de estudio y la inserción laboral, con lo que se promueve la inclusión social. A su vez, como señala la CEPAL, "la inclusión social permite la realización y el disfrute progresivos de derechos que son fundamentales para alcanzar muchas de las aspiraciones de una sociedad segura, saludable y próspera en todo el planeta, garantizando altos niveles de seguridad alimentaria y nutricional, de salud y de bienestar" (CEPAL, 2014a).

El concepto de salud ha recorrido un largo camino de redefiniciones: ha pasado de una noción de ausencia de enfermedad a un estado ideal de bienestar físico, mental y social consagrado en la constitución de la Organización Mundial de la Salud (OMS) (OMS, 1948). Se le considera un fenómeno multidimensional que comprende al individuo en interacción con su contexto sociocultural. Esta definición conceptual ha permitido abrir el debate no solo en torno a la definición de salud, sino también en lo referente a las políticas y programas que se pueden derivar de ella.

La autora agradece los aportes de Matías Salcés, Sebastián Moller y Alicia Sánchez, y el apoyo bibliográfico de Mirian Ramírez. 
A pesar de que las personas jóvenes tienden a enfermarse menos y mueren en menor cantidad que aquellas que se encuentran en otras etapas de la vida, conforman el grupo poblacional que enfrenta mayores riesgos de salud asociados a factores exógenos. También es cierto que muchos de los hábitos nocivos para la salud adquiridos durante la juventud no se manifiestan en morbilidad o mortalidad sino hasta unos años después (Maddaleno, Morello e Infante-Espíndola, 2003).

Aunque la salud está muy condicionada por procesos genéticos, los entornos económicos y sociales tienen gran influencia en el desarrollo de las enfermedades, su identificación y su tratamiento. La pobreza, la desigualdad y la exclusión social tienen un impacto significativo en la salud de la población joven. Tanto en países ricos como en países pobres, los jóvenes excluidos y de estrato socioeconómico bajo (ya sea que se mida por ingreso, nivel de educación u otras variables) tienen peor estado de salud y tasas de mortalidad más altas que los jóvenes más aventajados. Por otra parte, las sociedades más desiguales suelen tener peores índices de salud (Marmot y Wilkinson, 2006).

El principal paradigma para entender las desigualdades socioeconómicas es el de los determinantes sociales de la salud. Existe una muy amplia literatura que explora los determinantes sociales de diversas condiciones de salud, además de análisis y reflexiones sobre la relación entre el estado socioeconómico y la salud de un individuo, como la teoría de causas fundamentales propuesta por Link y Phelan (1995).

Si bien la investigación sobre los determinantes sociales de la salud se ha posicionado como un enfoque central dentro de la salud pública, aún falta mucho por recorrer en la implementación efectiva de medidas para reducir las inequidades sanitarias. La situación es particularmente sensible entre los adolescentes y jóvenes, ya que gran parte de la investigación se ha centrado en la influencia que tienen los determinantes sociales de la salud en la primera infancia sobre la vida adulta, sin considerar los aspectos específicos de la adolescencia y juventud como una importante etapa del ciclo vital en la sociedad moderna (Viner y otros, 2012).

Entre las limitaciones que se reconocen en el análisis de la salud de los jóvenes se observan dos grandes elementos. Por una parte, las políticas y programas de salud, cuando no aluden a la población adulta, se centran en la población infantil y adolescente. Por otra parte, las acciones dirigidas a la juventud suelen centrarse en temas de salud sexual y reproductiva. $\mathrm{Si}$ bien es cierto que la maternidad adolescente y las infecciones de transmisión sexual son temas de gran relevancia para la población joven, sobre todo entre los jóvenes marginados, este sesgo crea una invisibilidad del tema de la salud de los jóvenes desde una perspectiva más amplia y holística. Esta invisibilidad lleva a la omisión no solo de las necesidades de salud de los jóvenes, sino también de sus derechos en materia de salud.

Teniendo todo esto en cuenta, y para realizar un abordaje más integral, en este capítulo se propone analizar la salud de los jóvenes en 
América Latina y el Caribe contrastándola con la salud de los adultos de la región y destacando las disparidades que existen en la población joven. Siempre desde la perspectiva de la exclusión social y la desigualdad, se comienza con una investigación de los grandes rasgos de la mortalidad y morbilidad entre los jóvenes para después examinar temas específicos como la salud sexual y reproductiva, el acceso a un seguro de salud, el uso abusivo de drogas lícitas e ilícitas, y la salud mental. El capítulo concluye con una revisión de las políticas en materia de salud y la propuesta de recomendaciones para fortalecerlas.

\section{A. Panorama de la salud de los jóvenes latinoamericanos y caribeños}

\section{1. ¿De qué mueren los jóvenes en América Latina y el Caribe?}

Antes de responder a esta pregunta, es necesario señalar que las tasas de mortalidad de los jóvenes son inferiores a las de los adultos y los niños (véase el gráfico II.1). En general, las tasas tienden a descender durante la infancia y alcanzan el punto más bajo alrededor de los 10 años. Después, la tasa de mortalidad empieza a aumentar paulatinamente hasta los 35 años, cuando el crecimiento es más acelerado. Este patrón se observa tanto para los hombres como para las mujeres, aunque los hombres tienen tasas de mortalidad superiores en todas las edades.

\section{Gráfico II.1}

América Latina y el Caribe: tasas específicas de mortalidad, según edad y sexo, 2010

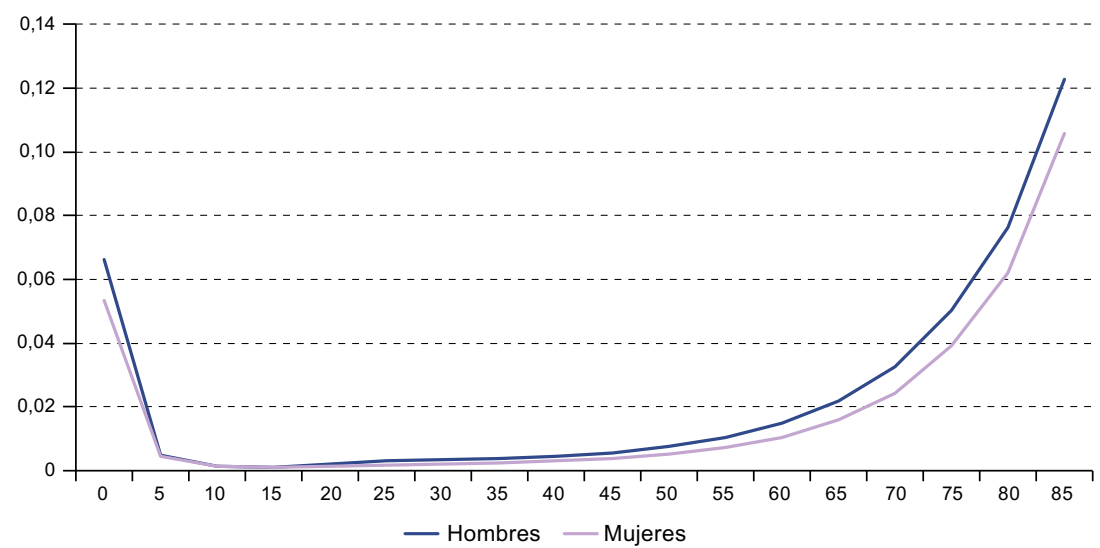

Fuente: Comisión Económica para América Latina y el Caribe/Centro Latinoamericano y Caribeño de Demografía-División de Población de la CEPAL (CEPAL/CELADE), "Mortalidad", Observatorio Demográfico, N 9 (LC/G.2490-P), Santiago, abril de 2010. Publicación de las Naciones Unidas, $\mathrm{N}^{\circ}$ de venta: S.11.II.G.34. 
Además de tener tasas de mortalidad más bajas que la población adulta, las causas específicas de mortalidad en este rango etario muestran patrones particulares. Como se observa en el gráfico II.2, las lesiones constituyen la principal causa de muerte entre los jóvenes - tanto hombres como mujeres-, lo que quiere decir que la mayoría de ellos muere por causas prevenibles. A medida que avanza la edad, no obstante, disminuye el peso relativo de las muertes por lesiones y van cobrando más importancia las enfermedades no transmisibles, especialmente entre las mujeres.

\section{Gráfico II.2}

América Latina y el Caribe (33 países): muertes según causas específicas, por grupos etarios y sexo, 2010

(En porcentajes)

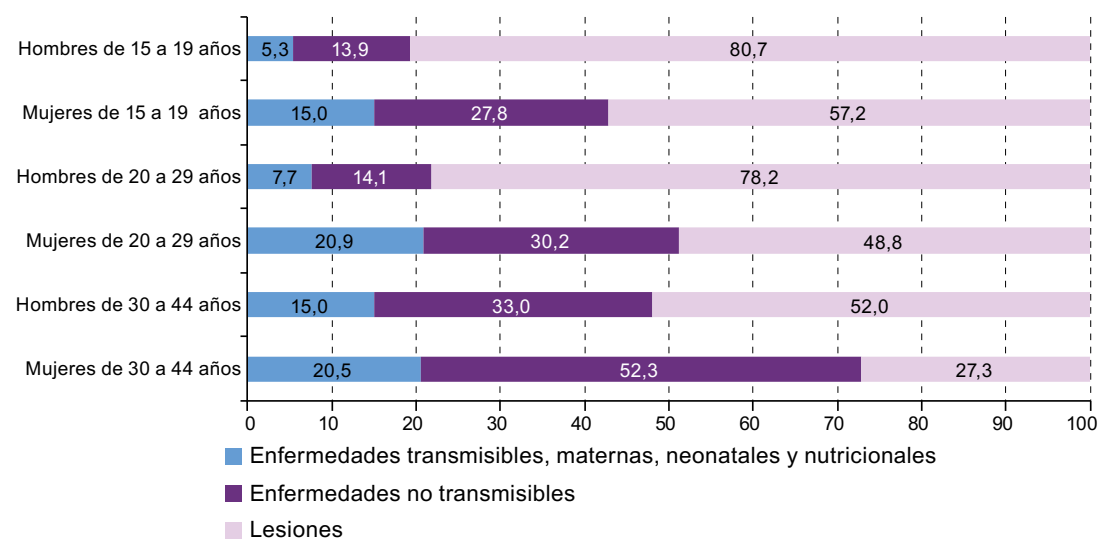

Fuente: Institute for Health Metrics and Evaluation [en línea] http://vizhub.healthdata.org/gbd-compare.

Un análisis de la categoría de muertes causadas por lesiones (véase el gráfico II.3) revela patrones diferenciados para hombres y mujeres $y$, nuevamente, entre jóvenes y adultos. Aunque la violencia es la principal causa de muerte en la categoría de lesiones para los hombres, los adultos presentan una mayor proporción de muertes por otros tipos de lesiones, como las lesiones no intencionales. En contraste, la mayoría de las muertes entre las mujeres en la categoría de lesiones son causadas por exposición a las fuerzas de la naturaleza, una tendencia que aumenta con la edad. Finalmente, vale destacar que los accidentes de tránsito son una importante causa de muerte tanto entre hombres como entre mujeres de todas las edades. Según un informe de la Organización Panamericana de la Salud (OPS), los peatones, motociclistas y ciclistas son los más vulnerables y las principales víctimas fatales de los traumatismos por accidentes de tránsito en la mayoría de los países del continente (OPS, 2015). Ante este preocupante escenario, los Estados Miembros de la OPS aprobaron el Plan de Acción de Seguridad Vial, que ayudará a los países de la región a alcanzar 
las metas establecidas en el Decenio de Acción para la Seguridad Vial, una iniciativa lanzada en mayo de 2011 por el sistema de las Naciones Unidas, que busca brindar asesoría y apoyo en legislación, campañas de medios de comunicación, recolección de datos y asistencia para quienes sufren accidentes, entre otros.

\section{Gráfico Ill.3 \\ América Latina y el Caribe (33 países): muertes por lesiones, por grupos etarios y sexo, 2010}

(En porcentajes)

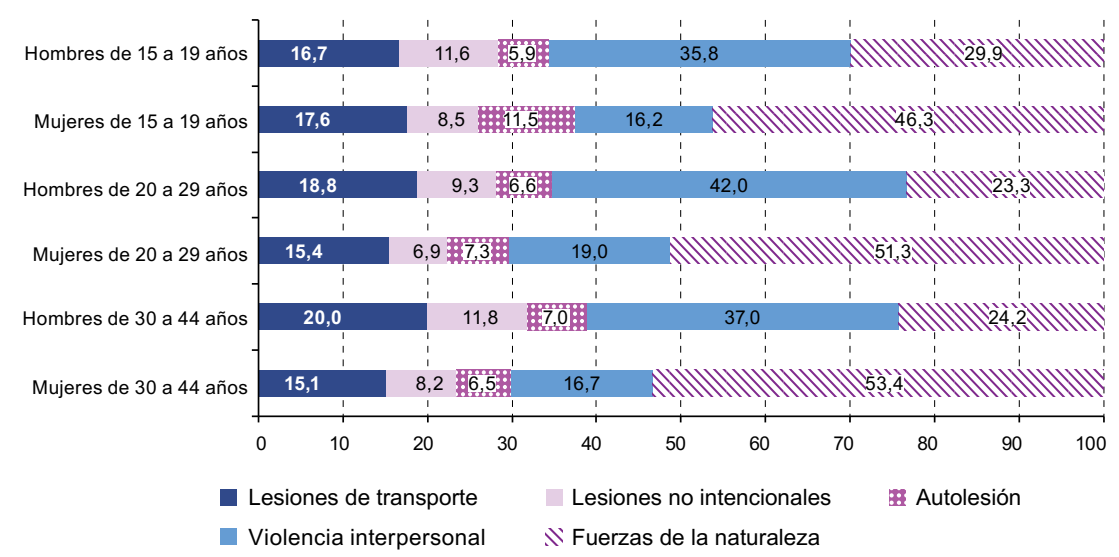

Fuente: Institute for Health Metrics and Evaluation [en línea] http://vizhub.healthdata.org/gbd-compare.

Un hallazgo significativo y novedoso que se desprende del gráfico II.3 es la importancia de las fuerzas de la naturaleza como causa de muerte. Huracanes, inundaciones y terremotos son fenómenos que ocurren con frecuencia en América Latina y el Caribe, con efectos catastróficos para quienes habitan en países con infraestructura débil y sobre todo para quienes se encuentran en condición de pobreza y residen en viviendas precarias. Las diferencias en la vulnerabilidad ante las fuerzas de la naturaleza entre hombres y mujeres ha sido documentada a nivel mundial (véanse, por ejemplo, Neumayer y Plümper, 2007; Nishikiori y otros, 2006).

Como señalan Neumayer y Plümper (2007), las diferencias biológicas y fisiológicas entre los hombres y las mujeres pueden poner en desventaja a estas últimas en su respuesta inmediata frente a un desastre. En segundo lugar, ciertas normas sociales también pueden aumentar la vulnerabilidad de las mujeres ante las catástrofes naturales. Por ejemplo, el rol tradicional de las mujeres como cuidadoras de niños y adultos mayores puede limitar sus posibilidades de escapar. También es cierto que en algunos países es más probable que ellas se encuentren en casa durante los desastres naturales, y si las viviendas son precarias, a diferencia de los lugares de 
trabajo de los hombres, los efectos del desastre pueden recaer con más fuerza sobre las mujeres. Por último, los desastres pueden implicar escasez de recursos lo que genera un aumento de la competencia entre individuos y exacerba las formas existentes de discriminación de género.

\section{Juventud y morbilidad: ¿de qué se enferman los jóvenes?}

Aunque la mortalidad es un reflejo del estado general de salud de los jóvenes en la región, es una medida insuficiente, pues no considera las enfermedades que restringen las posibilidades de vida de las personas en esta etapa de la vida, pero no llevan a la muerte.

Otra manera de conceptualizar la salud es mediante los años de vida ajustados en función de la discapacidad (AVAD). Aunque existen fuertes y merecidas críticas a esta métrica (véase, por ejemplo, Anand y Hanson, 1997), sobre todo críticas a sus fundamentos éticos y valóricos, resulta útil para conceptualizar y medir, de una manera sintética, la salud de una población e identificar las causas que evitan que esta disfrute de una condición de salud plena. La OMS define un AVAD como un año de vida sana perdido. En particular, este valor refleja el impacto de los diferentes riesgos sobre la mortalidad y la morbilidad. La suma de los AVAD en una población, o la carga de morbilidad, representa la brecha entre el estado de salud actual y el estado ideal de salud de la población, donde todos viven hasta una edad avanzada, libres de enfermedad y discapacidad ${ }^{2}$.

Según datos recientes (véase el cuadro II.1), los AVAD relacionados con la salud mental juegan un papel importante en el total de la carga de morbilidad para los jóvenes. Si examinamos los AVAD para las mujeres en el rango etario de 15 a 19 años, los problemas de salud mental destacan entre las principales enfermedades o problemas y contribuyen a la carga de morbilidad (trastornos depresivos unipolares, trastornos depresivos mayores y trastornos de ansiedad). Este patrón varía un poco en el grupo de edad entre 20 y 29 años, pero los trastornos depresivos unipolares siguen ocupando el primer lugar. Para las adultas de 30 a 44 años, los trastornos depresivos unipolares siguen siendo importantes, pero las enfermedades cardiovasculares, las neoplasias y la diabetes son las principales enfermedades que contribuyen a la carga de morbilidad.

En el caso de los hombres, la violencia, la exposición a las fuerzas de la naturaleza y los accidentes de tránsito figuran entre las tres principales enfermedades y problemas que contribuyen al AVAD en todos los tramos etarios considerados. A estos les siguen los problemas de salud mental

Para mayor información véase [en línea] http://www.who.int/healthinfo/global_ burden_ disease/metrics_daly/en. 
(trastornos depresivos unipolares, trastornos depresivos mayores y trastornos por consumo de drogas), con una alta presencia entre los jóvenes. En tanto, los factores que más contribuyen a la carga de morbilidad de los adultos son el VIH/SIDA, la tuberculosis y las enfermedades cardiovasculares.

\section{Cuadro II.1}

América Latina y el Caribe (33 países): principales enfermedades o problemas que contribuyen a la carga de morbilidad, por sexo y edad, 2010

\begin{tabular}{|c|c|}
\hline \multicolumn{2}{|c|}{15 a 19 años } \\
\hline Hombres & Mujeres \\
\hline Violencia & Trastornos depresivos unipolares \\
\hline Exposición a las fuerzas de la naturaleza & Exposición a las fuerzas de la naturaleza \\
\hline Lesiones por accidentes de tránsito & Trastornos depresivos mayores \\
\hline Lesiones no intencionales & Trastornos de ansiedad \\
\hline Trastornos depresivos unipolares & Enfermedades de la piel y del tejido subcutáneo \\
\hline \multicolumn{2}{|c|}{20 a 29 años } \\
\hline Hombres & Mujeres \\
\hline Violencia & Trastornos depresivos unipolares \\
\hline Exposición a las fuerzas de la naturaleza & Exposición a las fuerzas de la naturaleza \\
\hline Lesiones por accidentes de tránsito & Trastornos depresivos mayores \\
\hline Trastornos por consumo de drogas & $\begin{array}{l}\text { Diabetes y enfermedades urogenitales } \\
\text { y endocrinas }\end{array}$ \\
\hline Trastornos depresivos unipolares & Trastornos de ansiedad \\
\hline \multicolumn{2}{|c|}{30 a 44 años } \\
\hline Hombres & Mujeres \\
\hline Violencia & Enfermedades cardiovasculares y circulatorias \\
\hline Exposición a las fuerzas de la naturaleza & Neoplasias \\
\hline Lesiones por accidentes de tránsito & $\begin{array}{l}\text { Diabetes y enfermedades urogenitales } \\
\text { y endocrinas }\end{array}$ \\
\hline VIH/SIDA y tuberculosis & Trastornos depresivos unipolares \\
\hline Enfermedades cardiovasculares y circulatorias & $\begin{array}{l}\text { Infecciones respiratorias bajas, meningitis } \\
\text { y otras enfermedades infecciosas comunes }\end{array}$ \\
\hline
\end{tabular}

Fuente: Institute for Health Metrics and Evaluation [en línea] http://vizhub.healthdata.org/gbd-compare.

En términos generales, hemos visto que las lesiones son la principal causa de muerte entre los jóvenes de la región, y dentro de esta categoría los varones tienden a morir a causa de la violencia, en tanto las jóvenes mueren más por causas asociadas a las fuerzas de la naturaleza. Aunque las lesiones $-\mathrm{y}$, dentro de esta categoría, la violencia- representan la principal causa de muerte en los hombres adultos, las enfermedades no transmisibles también constituyen un tercio de la muertes en ese grupo. Para las mujeres adultas, las enfermedades no trasmisibles son la principal causa de muerte.

En cuanto a la morbilidad, las enfermedades no transmisibles, y entre ellas los problemas de salud mental, son las que impiden que las jóvenes de 
la región gocen de plena salud. Los trastornos de salud mental contribuyen de manera importante a la carga de morbilidad entre las jóvenes, mientras que en el caso de las adultas, la mayor importancia la tienen los problemas asociados a enfermedades crónicas. Las lesiones -específicamente relacionadas con la violencia, la exposición a las fuerzas de la naturaleza y los accidentes de tránsito- son las principales enfermedades y problemas que contribuyen a la carga de morbilidad de los hombres en los tres tramos etarios considerados. Sin duda, la violencia es una amenaza a la salud de los jóvenes y adultos en la región, tanto como causa de muerte como de morbilidad, en particular cuando provoca una discapacidad permanente.

No obstante, como se verá a continuación, los patrones de mortalidad y morbilidad muestran grandes brechas según el nivel socioeconómico. La pobreza, la falta de educación, el hacinamiento, la nutrición deficiente, las privaciones de agua potable y saneamiento, y la marginación y discriminación no solo condicionan la exposición de los jóvenes a agentes patógenos, sino que también crean un contexto de exclusión que puede generar las condiciones para el desarrollo o agravamiento de problemas de salud mental o relaciones abusivas con drogas. Por otra parte, la exclusión social limita el acceso a la atención médica, tanto para el diagnóstico como para el tratamiento de enfermedades. En contextos de exclusión, resulta particularmente importante contar con factores de protección - como una vida familiar estable, fuertes vínculos con la escuela y buenos modelos a seguir - para promover el desarrollo sano de los jóvenes y reducir los efectos de la exclusión.

\section{B. Desigualdades en salud sexual y reproductiva entre las jóvenes de la región}

Si bien el análisis de mortalidad y morbilidad nos ofrece un panorama general del estado de salud de la juventud en América Latina, hay que tener en cuenta que la distribución de la salud en la población no es homogénea y que en la región existen importantes disparidades en este ámbito: por área de residencia (rural y urbana), por pertenencia a pueblos indígenas o afrodescendientes, y por nivel socioeconómico. Las brechas socioeconómicas en salud se manifiestan muy claramente en la salud sexual y reproductiva.

Dadas las consecuencias para el momento de la vida que están transitando, su futuro y el de sus hijos, los riesgos reproductivos que enfrentan los jóvenes son una preocupación creciente. En particular, el embarazo en adolescentes ha generado inquietud a nivel regional por las grandes y variadas repercusiones negativas en el desarrollo integral de las mujeres, los hombres, los hijos, las familias y las sociedades involucradas. Aún más preocupante es el hecho de que, pese a los esfuerzos realizados 
para reducir las tasas de maternidad adolescente, en muchos países de la región este indicador se ha estancado en niveles altos (Rodríguez, 2014). Según un estudio del Banco Interamericano de Desarrollo (BID) (NäslundHadley y Binstock, 2011), la tasa de fecundidad de las adolescentes de la región es mayor a 80 por cada 1.000. Esta cifra, superada solamente por África, es cerca de un $50 \%$ más alta que el promedio mundial, que alcanza a 55 por cada 1.000 jóvenes de entre 15 y 19 años. Dado el nivel de desarrollo económico y social, y la etapa de transición demográfica de la región, estas tasas de embarazo adolescente son muy superiores a lo que se esperaría (Guzmán y otros, 2006).

El embarazo en adolescentes no solo constituye un fenómeno demográfico, sino que también es un fenómeno social complejo que tiene un efecto negativo en la región. La CEPAL y el Fondo de las Naciones Unidas para la Infancia (UNICEF) han destacado una serie de problemas sociales asociados a la reproducción temprana (CEPAL/UNICEF, 2007). Por ejemplo, la maternidad adolescente puede truncar los logros educativos, alterar los planes de vida y restringir el ejercicio de derechos de las jóvenes madres. Además, mediante estos y otros canales, perpetúa la transmisión intergeneracional de la pobreza.

Si una joven queda embarazada por carecer de acceso a métodos de planificación familiar, estamos ante un atentado contra sus derechos sexuales y reproductivos. También hay que considerar, no obstante, que es problemático que la joven quede embarazada por no tener un plan de vida o porque las oportunidades para llevar a cabo su proyecto eran pocas o nulas, lo que refleja una serie de inequidades y desafíos estructurales. Subyacente a este último punto radica el hecho de que en la categoría "fecundidad en adolescentes" hay embarazos planificados y no planificados. Siguiendo esta línea, Rodríguez (2012) identifica tres grupos vulnerables a la maternidad temprana. En el primer grupo están las jóvenes de los grupos tradicionales, incluyendo los pueblos indígenas; para estas jóvenes la maternidad temprana se vincula con una unión temprana, arraigada en prácticas culturales. En el segundo grupo se encuentran las jóvenes de estratos socioeconómicos bajos, particularmente de áreas urbanas, en los cuales la alta fecundidad en adolescentes está asociada con la falta de alternativas y proyectos de vida, combinado con la ausencia de intervenciones públicas de prevención del embarazo. Por último se encuentran las jóvenes de los grupos socioeconómicamente más favorecidos, que reconocen los riesgos de la maternidad temprana, pero no logran prevenir el embarazo por falta de acceso a métodos preventivos o comportamientos que les permitan hacer uso de ellos.

Aunque existe cierta diversidad de trayectorias que pueden resultar en un embarazo adolescente, este fenómeno ocurre de manera 
desproporcionada en los estratos bajos y la fecundidad en adolescentes se ha asociado históricamente con la pobreza (Rodríguez, 2008). Más allá del criterio de estratificación socioeconómica utilizado (zona de residencia, nivel educativo o nivel de riqueza del hogar), se aprecia una relación inversa entre las tasas de fecundidad en adolescentes y el nivel socioeconómico.

Sobre la base de las rondas censales más recientes, en el gráfico II.4 se presenta el porcentaje de madres adolescentes en siete países de la región. Las jóvenes que residen en áreas rurales son sistemáticamente más proclives a ser madres adolescentes que las que viven en áreas urbanas $y$, dentro de cada zona, son las jóvenes del quintil más pobre de ingresos las que registran los más altos porcentajes de maternidad adolescente.

\section{Gráfico II.4 \\ América Latina (7 países): madres adolescentes entre mujeres de 15 a 19 años, según quintil socioeconómico y zona de residencia}

(En porcentajes)

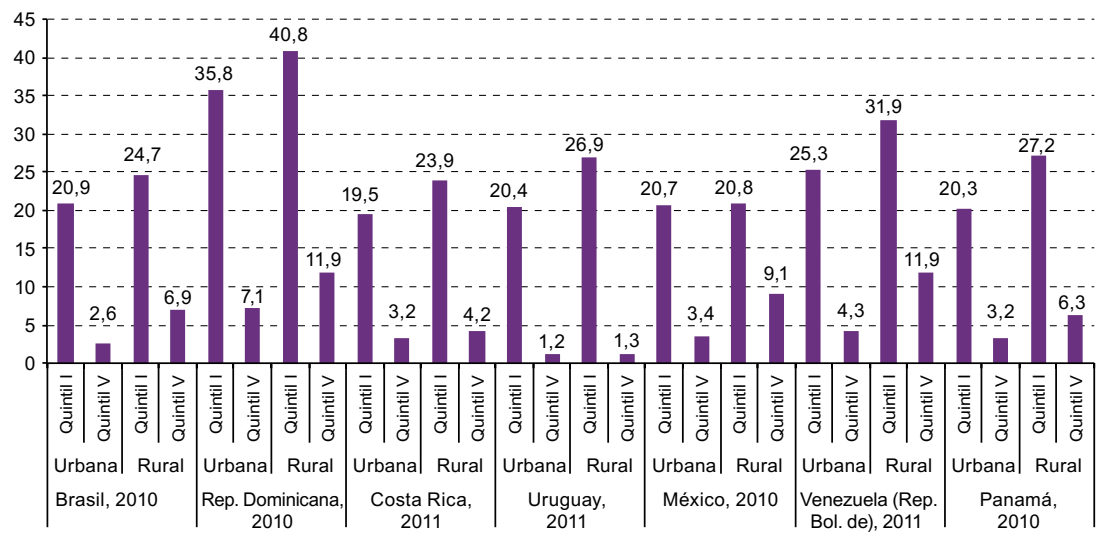

Fuente: Jorge Rodríguez, "La reproducción en la adolescencia y sus desigualdades en América Latina. Introducción al análisis demográfico, con énfasis en el uso de microdatos censales de la ronda de 2010", Santiago, 2014, Comisión Económica para América Latina y el Caribe (CEPAL).

Una manera de abordar la relación entre situación socioeconómica y maternidad adolescente es mediante un análisis de los comportamientos que inciden sobre la probabilidad de quedar embarazada: al tener comportamientos diferenciados, el riesgo de quedar embarazada también es diferente. La edad de la iniciación sexual y el uso de anticonceptivos son dos variables que se relacionan directamente con la probabilidad de quedar embarazada, y en estos comportamientos se aprecian importantes diferencias según nivel socioeconómico (medido aquí como quintil de riqueza).

Como se observa en el gráfico II.5, la edad de iniciación sexual es consistentemente más precoz entre las jóvenes del quintil más pobre de riqueza. En ausencia del uso de anticonceptivos, esto claramente 
las expone al riesgo de embarazo. En algunos casos, la brecha entre las jóvenes del quintil más bajo y el quintil más alto llega a los dos años. La tendencia de las jóvenes de estratos socioeconómicos más altos a postergar la iniciación sexual y evitar el embarazo posiblemente se vincula con que tienen proyectos de vida que incluyen estudios superiores o viven en entornos familiares que actúan como barreras contra la iniciación sexual a edades más tempranas (tienen, por ejemplo, mayor supervisión parental). Por último, algunas investigaciones en el Caribe han mostrado que tener fuertes vínculos con la escuela es un factor muy asociado con la postergación de la iniciación sexual (Pilgrim y Blum, 2012).

\section{Gráfico II.5}

América Latina y el Caribe (6 países): edad de la iniciación sexual entre mujeres de 15 a 29 años, por quintil de riqueza (En años)

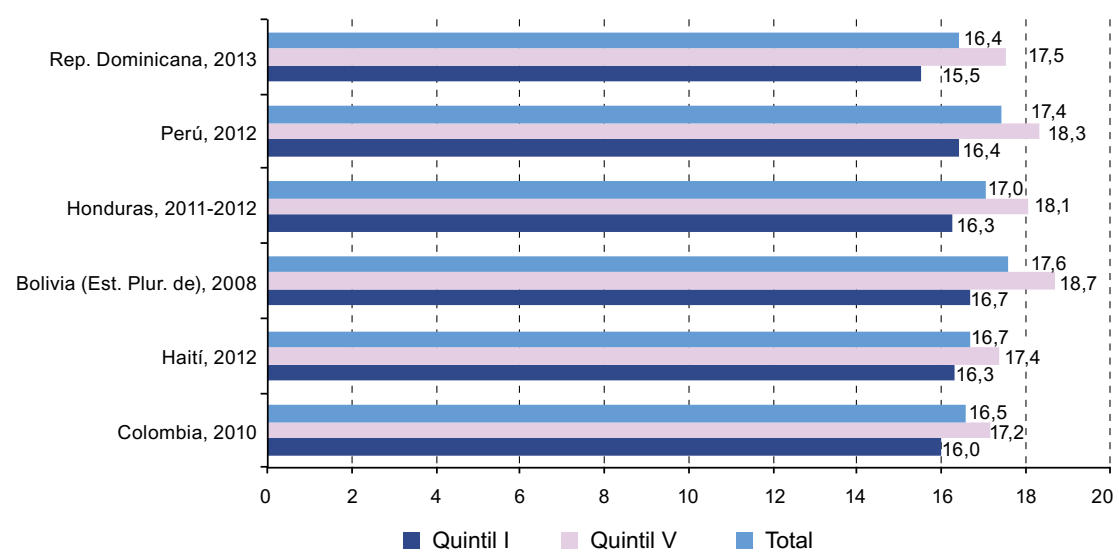

Fuente: Elaborado a partir de datos de las Encuestas de Demografía y Salud de los respectivos países.

El uso de un condón en la última relación sexual también muestra marcadas diferencias entre las jóvenes según nivel socioeconómico (véase el gráfico II.6). En casi todos los casos, el porcentaje de mujeres jóvenes en el quintil más rico que usó condón en la última relación sexual es, por lo menos, el doble del de las jóvenes pobres. Este hallazgo se puede relacionar con falta de acceso a métodos de planificación familiar, como los condones, asimetrías de poder en las relaciones de pareja y, desde luego, diferencias en los planes de vida. Además, partiendo del hecho de que el uso de condón en la última relación sexual es bajo, hay grandes diferencias entre un país y otro: un 30,7\% en Haití frente a un $11,8 \%$ en Honduras. Esto claramente tiene implicancias no solo para la probabilidad de quedar embarazada, sino también en el riesgo de contraer una infección de transmisión sexual, como el VIH, que tiene su propia dinámica en torno a la exclusión social de los jóvenes (véase el recuadro II.1). 


\section{Gráfico II.6 \\ América Latina y el Caribe (5 países): uso de condón en la última relación sexual entre mujeres sexualmente activas de 15 a 29 años, por quintil de riqueza ${ }^{a}$ \\ (En porcentajes)}

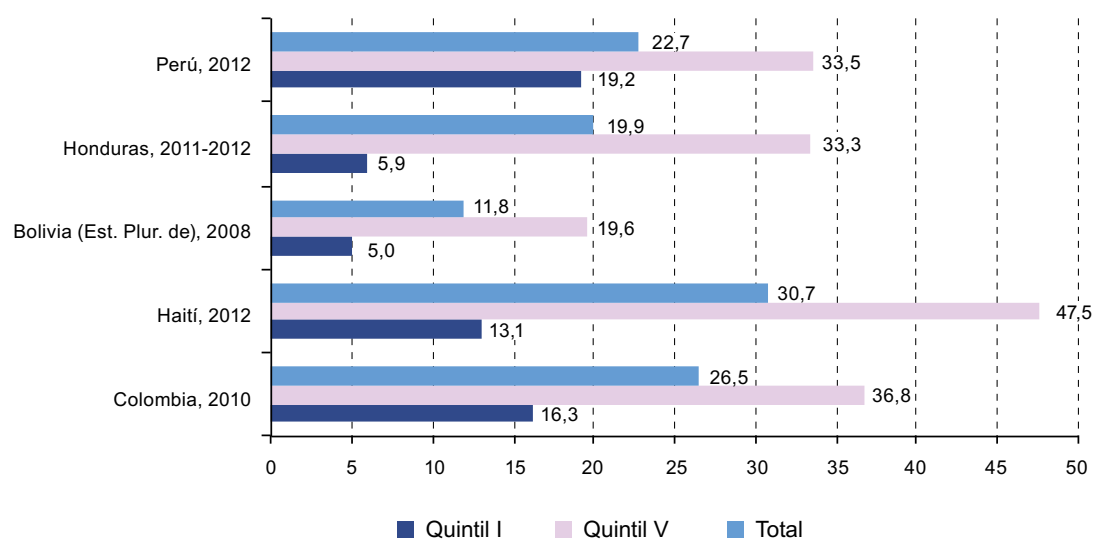

Fuente: Elaborado a partir de datos de las Encuestas de Demografía y Salud de los respectivos países.

a Sexualmente activas se define como haber tenido relaciones sexuales en las cuatro semanas previas a ser encuestadas.

\section{Recuadro II.1 \\ Jóvenes, VIH e inclusión social}

Una de las metas del área de salud en la Agenda 2030 para el Desarrollo Sostenible es acabar con la epidemia del virus de la inmunodeficiencia humana $(\mathrm{VIH})$ para 2030. Para lograrlo en América Latina, es necesario concentrar los esfuerzos en las poblaciones que han sido marginadas de la respuesta frente al VIH, específicamente la juventud.

Pese a la escasa información sobre la epidemia del VIH en los jóvenes, los datos disponibles muestran un panorama alarmante. En América Latina, solo el $30 \%$ de los jóvenes identifica correctamente cómo prevenir la transmisión sexual del $\mathrm{VIH}^{\mathrm{a}}$. Esto muestra las falencias de los servicios de prevención dirigidos a esta población y de los programas sobre educación integral en sexualidad. También se estima que un tercio de las nuevas infecciones en América Latina ocurre en jóvenes de entre 15 y 24 años, lo que evidencia la vulnerabilidad de este grupo etariob.

Para mejorar la respuesta dirigida a los jóvenes, aún hay varios desafíos pendientes. Uno de ellos se refiere al estigma y la discriminación relacionados con el $\mathrm{VIH}$ y las poblaciones que enfrentan un mayor riesgo ante el virus (hombres que tienen relaciones sexuales con hombres, personas transexuales, personas que se dedican al trabajo sexual y personas usuarias de drogas). Un segundo desafío alude a la necesidad de superar la falta de información estratégica que visibilice el impacto de la epidemia del VIH en la juventud. También se detecta poca inclusión de los jóvenes en los espacios políticos de toma de decisiones de la respuesta frente al VIH. 
Recuadro II.1 (continuación)

El problema es aún más grave si se consideran los determinantes sociales de la salud que inciden en el aumento del riesgo y la vulnerabilidad de los adolescentes y jóvenes frente al $\mathrm{VIH}$. La pobreza, la violencia social, el origen étnico, la edad, el género (incluidas la orientación sexual y la identidad de género) y el lugar de origen, entre otros, son factores que determinan la acogida y el nivel de acceso a los servicios de prevención y atención del VIH.

En nuestra región, el $\mathrm{VIH}$ afecta especialmente a las poblaciones que son consideradas clave para la epidemia y para la respuesta. El segmento joven de estas poblaciones es el más vulnerable frente a las nuevas infecciones. La prevalencia de $\mathrm{VIH}$ en hombres que tienen relaciones sexuales con hombres menores de 25 años alcanza al 7,3\% en Chile, el $8,8 \%$ en el Ecuador, el $4,1 \%$ en Honduras, el $12,4 \%$ en México, el $13,1 \%$ en el Paraguay y el $10,5 \%$ en el Perúc.

En agosto de 2008 se adoptó en México, D.F., la Declaración Ministerial "Prevenir con educación", en virtud de la cual, los ministros de Salud y Educación de América Latina y el Caribe se comprometieron a alcanzar metas específicas para responder a la epidemia del VIH en jóvenes y adolescentes mediante sinergias entre los ministerios de salud y educación y la sociedad civil. En 2012, cuatro años después de adoptada la declaración, la región mostraba un avance del $58 \%$ en la implementación de la Declaración Ministerial ${ }^{d}$.

En la región existen barreras legales que dificultan el acceso de los jóvenes a servicios relacionados al VIH y la salud sexual y reproductiva. Pese a que las relaciones sexuales son consentidas en la mayoría de los países desde los 14 años, en varios países, los menores de edad requieren del consentimiento de sus padres o tutores legales para solicitar ciertos servicios de salud sexual, incluida la prueba del VIH. Estas normativas son contradictorias pues durante la juventud las personas son más propensas a los embarazos no deseados y a contraer enfermedades de transmisión sexual, entre otras consecuencias.

En relación con las brechas de género, se destaca que aproximadamente un $70 \%$ de los hombres jóvenes que tuvieron más de una pareja sexual en los últimos 12 meses declararon haber usado condón durante su última relación sexual, cifra que disminuye al $43 \%$ entre las mujeres de 15 a 19 años y al $30 \%$ entre las mujeres de 20 a 24 añose $^{e}$. Estos datos muestran la dificultad que tienen las mujeres jóvenes para negociar el uso del condón a causa de los estereotipos de género e incluso debido a la violencia. A estas bajas cifras de uso se suma que solo cinco países de la región (Brasil, Colombia, Costa Rica, Ecuador y México) contemplan la distribución gratuita del condón femenino.

Para mejorar la inclusión social de los jóvenes que viven con VIH y los que pertenecen a las poblaciones más afectadas por la epidemia en la respuesta nacional al $\mathrm{VIH}$, es importante considerar las siguientes acciones:

- aumentar la participación de los adolescentes y jóvenes que viven con $\mathrm{VIH}$ y de las poblaciones más afectadas por la epidemia en los espacios de toma de decisiones políticas de la respuesta frente al virus (esto implica considerar a los jóvenes como socios y líderes, más que como meros beneficiarios, en la formulación e implementación políticas y programas para abordar el VIH y la salud sexual y reproductiva); 
Recuadro II.1 (conclusión)

- incrementar la inversión en programas de prevención y atención dirigidos a jóvenes, con especial énfasis en la captación de adolescentes y jóvenes de las poblaciones clave;

- eliminar las barreras legales que dificultan el acceso de los adolescentes y jóvenes a servicios de prevención y atención del VIH y la salud sexual y reproductiva;

- expandir los programas de protección social existentes para incluir a los adolescentes y jóvenes de las poblaciones más afectadas y a quienes viven con $\mathrm{VIH}$, de modo de reducir la brecha en el acceso a servicios de prevención y atención (esto incluye el fomento de la educación y el empleo digno para estas poblaciones);

- hacer cumplir las leyes y políticas existentes sobre la no violencia o discriminación por razón de $\mathrm{VIH}$, orientación sexual e identidad de género.

Fuente: Programa Conjunto de las Naciones Unidas sobre el VIH/SIDA (ONUSIDA).

a AIDSinfo Online Database, sobre la base de Programa Conjunto de las Naciones Unidas sobre el VIH/SIDA (ONUSIDA), Global AIDS Response Progress Reporting 2013, Ginebra, 2013.

b Programa Conjunto de las Naciones Unidas sobre el VIH/SIDA (ONUSIDA), The Gap Report 2014 [en línea] http://www.unaids.org/sites/default/files/en/media/unaids/ contentassets/documents/unaidspublication/2014/UNAIDS_Gap_report_en.pdf.

c Ibídem 1.

d IPPF, Evaluación de la Implementación de la Declaración Ministerial, Prevenir con Educación. Del acuerdo a la Acción: Avances en Latinoamérica y el Caribe, 2012.

e Ibídem 1.

Vemos entonces que en dos comportamientos determinantes para el embarazo adolescente - la iniciación sexual y el uso de condónlas jóvenes de estratos socioeconómicos bajos sistemáticamente tienen conductas que las predisponen a un embarazo.

Las diferencias en el papel de la maternidad como rol identitario para las mujeres constituyen otra explicación de la brecha en la maternidad joven entre mujeres de diferentes estratos socioeconómicos. Desde esta perspectiva, el embarazo en la adolescencia es el resultado de condiciones como la pobreza, la desmotivación o el fracaso escolar (frecuentemente debido a la mala calidad de la educación), las pocas expectativas de que una educación completa las ayude a conseguir un empleo bien remunerado, las reducidas posibilidades de movilidad social y la ausencia de otros proyectos de vida. En este contexto, ser madre es una manera de tener actividades, roles y preocupaciones, y de ser incluida y visibilizada en su familia y comunidad (Oviedo y García, 2011; Näslund-Hadley y Binstock, 2010).

Teniendo en cuenta lo expuesto, y tal como destacan Rico y Trucco (2014), las implicancias sobre las políticas son distintas y deben avanzar más allá de la prevención del embarazo como un problema de educación sexual y reproductiva, y la disponibilidad y uso de anticonceptivos. Si bien 
estos son elementos necesarios para la prevención del embarazo temprano, no son condición suficiente y se requieren estrategias que expandan las oportunidades para las jóvenes y las apoyen en el logro de sus metas.

Finalmente, como se mencionó al principio de esta sección, la maternidad adolescente también puede ser entendida desde las prácticas culturales tradicionales de algunos grupos, por ejemplo, los pueblos indígenas. Como señala la CEPAL/OPS (2011), las mujeres indígenas forman una unión estable e inician la reproducción en una etapa de la vida que sería considerada adolescencia según un criterio cronológico occidental. Los comportamientos, las experiencias y el significado de la sexualidad y el embarazo en la juventud indígena están fuertemente determinados por las normas sociales y culturales. Esta relativización cultural complejiza la noción generalizada de la maternidad adolescente como "problema".

\section{Acceso a servicios de salud}

Otro ámbito de exclusión en el campo de la salud entre los jóvenes es su limitado acceso a servicios sanitarios. El hecho de que muchos jóvenes en la región no estén cubiertos por un seguro de salud (véase el gráfico II.7) puede estar asociado a varios factores. Por una parte, los jóvenes dejan de estar cubiertos por los seguros de salud de sus padres al cumplir cierta edad y subestiman sus necesidades de atención médica y de seguro de salud al percibir que su riesgo de enfermarse es bajo. Además, la inserción laboral de los jóvenes - en trabajos inestables, de tiempo parcial y en el mercado informal - no les permite acceder a un seguro de salud. Aunque este es un patrón generalizado para la población juvenil, claramente se manifiestan notorias brechas entre jóvenes de diferentes estratos económicos. En virtud de que el empleo de los padres es una vía principal para la afiliación a la seguridad de salud entre los jóvenes, es razonable pensar que los jóvenes de estratos económicos bajos carecen de seguro de salud porque sus padres también están desafiliados. Además de las diferencias en la cobertura de salud, el acceso desigual al sistema de salud puede deberse a una combinación de barreras: económicas, geográficas, culturales y lingüísticas.

Los jóvenes que tienen acceso también pueden sentirse alienados del sistema de salud por diversas razones. Los servicios de salud pueden no responder a las características de atención requeridas, ya sea porque hay un desfase entre la oferta y la demanda de servicios o porque la manera de entregar estos servicios no es adecuada; el personal de salud puede demostrar prejuicios contra la juventud o no estar capacitado para tratar con esta población; y la falta de confidencialidad puede desincentivar a los jóvenes a buscar atención médica, sobre todo en las áreas de salud sexual y reproductiva y salud mental. 


\section{Gráfico II.7 \\ América Latina y el Caribe (4 países): cobertura de salud entre mujeres de 15 a 29 años, por quintil de riqueza \\ (En porcentajes)}

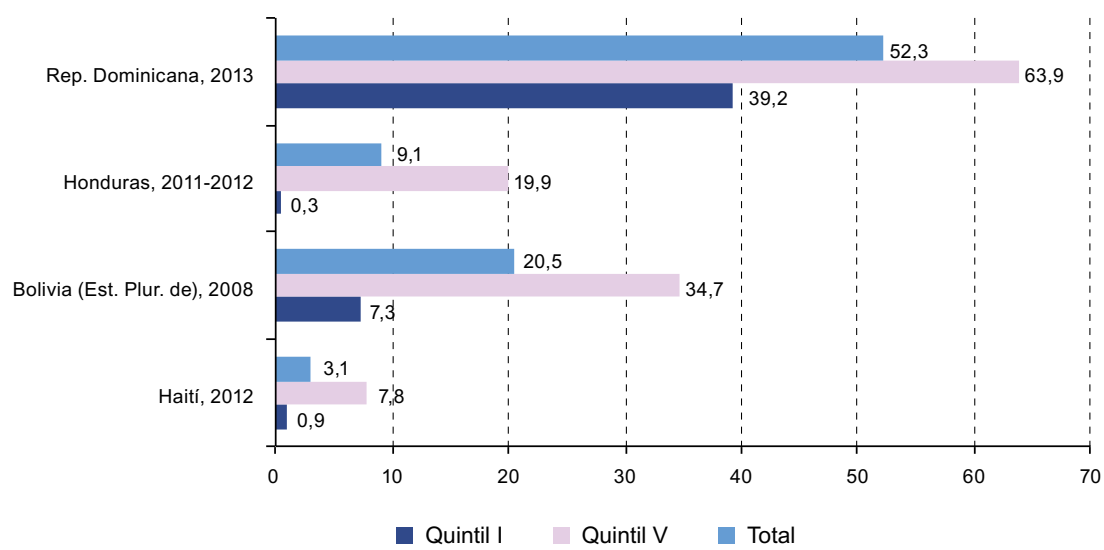

Fuente: Elaborado a partir de datos de las Encuestas de Demografía y Salud de los respectivos países.

Recuadro II.2

\section{La salud de los jóvenes indígenas en la región: algunas cifras}

Como se ha destacado a lo largo de este capítulo, las situaciones de exclusión, discriminación y marginación crean contextos que dan origen a problemas de salud. Ello también restringe el acceso a la atención médica, lo que produce notables brechas en salud entre los jóvenes, según su posición socioeconómica, raza, etnia, sexo, lugar de residencia u orientación sexual. Ante este escenario, se vuelve imperativo y visibilizar estas brechas y situaciones de inequidad.

En América Latina viven por lo menos 10 millones de adolescentes y jóvenes indígenas de entre 10 y 24 años, la mayoría de los cuales residen en zonas rurales (CEPAL/OPS, 2011)a. Los jóvenes indígenas de la región enfrentan desigualdades vinculadas con los determinantes estructurales, así como próximos, de la salud. Esto los coloca en una posición de mayor vulnerabilidad respecto de los jóvenes no indígenas (CEPAL/OPS, 2011), la que se vuelve más aguda en el caso de las jóvenes indígenas.

La desnutrición crónica (definida como el déficit de talla para la edad) refleja la acumulación de consecuencias debidas a la falta de una alimentación y nutrición adecuada durante los años más críticos del desarrollo. Es una condición que tiene importantes consecuencias a corto y largo plazo, como efectos en la morbilidad y la mortalidad, así como implicancias en los logros educativos y la productividad, lo que constituye uno de los principales mecanismos de transmisión intergeneracional de la pobreza y la desigualdad. Para el grupo etario de interés, en plena edad fértil, la desnutrición también puede tener efectos perjudiciales directos en las futuras generaciones. Aunque este hallazgo no es nuevo, como señalan Martínez y Palma (2014), urge profundizar en el relevamiento de más y mejores indicadores que permitan conocer con mayor claridad la relación entre etnia y desnutrición. 
Recuadro II.2 (continuación)

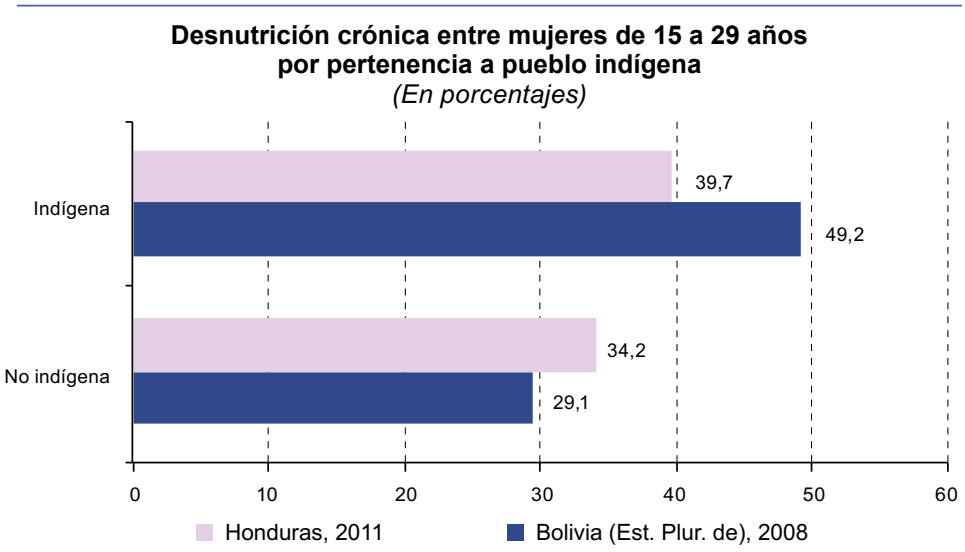

Fuente: Elaborado a partir de datos de las Encuestas de Demografía y Salud de los respectivos países.

Como ya se mencionó, llama la atención el alto porcentaje de jóvenes, ya sean indígenas o no, que no tienen seguro de salud. En el caso de las jóvenes indígenas, incluso las que tienen seguro de salud enfrentan otras barreras para recibir atención médica: inaccesibilidad geográfica (la mayor parte de la oferta de servicios médicos, particularmente especialidades como la salud mental, se centra en zonas urbanas), barreras lingüísticas (si el personal de salud no habla su idioma) y barreras culturales (en vista de la generalizada subvaloración de las creencias de salud no occidentales o tradicionales).

\section{Falta de cobertura de salud entre mujeres de 15 a 29 años por pertenencia a pueblo indígena} (En porcentajes)

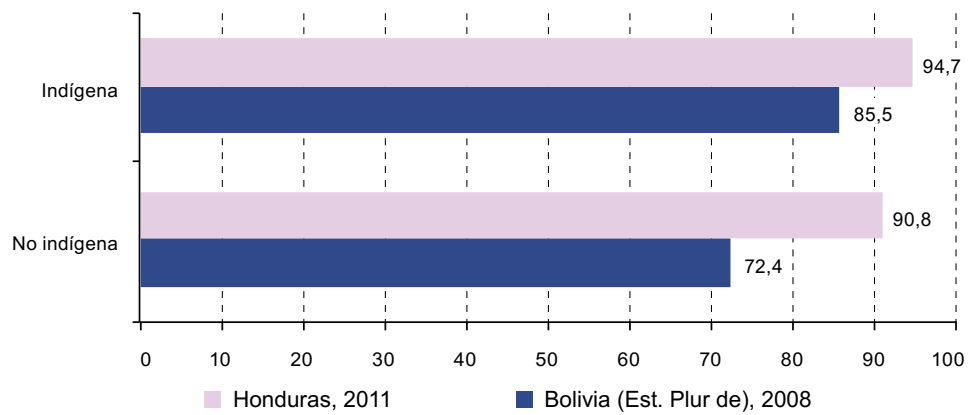

Fuente: Elaborado a partir de datos de las Encuestas de Demografía y Salud de los respectivos países.

Las brechas en salud sexual y reproductiva entre jóvenes indígenas y no indígenas han sido ampliamente documentadas por numerosos estudios en diversos ámbitos del tema. La iniciación sexual, la maternidad adolescente, la atención del parto, la mortalidad materna y los conocimientos sobre la 
Recuadro II.2 (continuación)

transmisión del VIH y otras infecciones de transmisión sexual muestran patrones sistemáticamente diferentes en el caso de los jóvenes, según si pertenecen a un pueblo indígena o no (CEPAL/OPS, 2011, y Pasqualini y Llorens, 2010). Por ejemplo, el distorsionado o escaso conocimiento sobre el VIH, sumado a la percepción de que esta es una enfermedad foránea que no les atañe, es particularmente preocupante en vista del aumento de la migración de los jóvenes indígenas del campo a la ciudad, donde la prevalencia del VIH tiende a ser más alta (CEPAL/OPS, 2011).

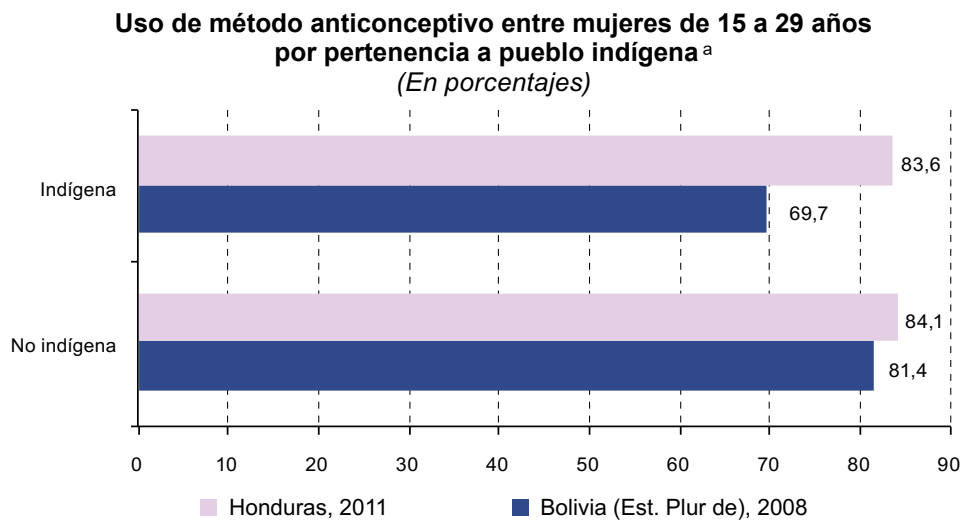

Fuente: Elaborado a partir de datos de las Encuestas de Demografía y Salud de los respectivos países.

a Entre mujeres no embarazadas que han tenido relaciones sexuales en las últimas 4 semanas.

En las cifras presentadas, se confirma una tendencia de las jóvenes indígenas a tener peores indicadores de salud que las jóvenes no indígenas en estado nutricional, salud sexual y reproductiva, y acceso a atención médica. Sin embargo, es importante notar que las brechas son mucho más pronunciadas en Bolivia (Estado Plurinacional de) que en Honduras, lo que marca diferencias entre jóvenes indígenas de un país y otro y, posiblemente, de diferentes pueblos indígenas dentro de un mismo país. Entender estos matices es elemental para diseñar mejores políticas y programas para cerrar las brechas en salud.

Un importante reto para visibilizar los temas de salud entre jóvenes indígenas es la falta de información y análisis. El sesgo mencionado en el texto es aún más marcado en esta población: si bien existen estudios sobre la salud sexual y reproductiva de los jóvenes indígenas, son pocos los que consideran otros temas de salud, como la salud mental (CEPAL/ OPS, 2011). En cuanto a los datos estadísticos, aunque los censos incluyen preguntas sobre etnia y raza, generalmente no contienen preguntas sobre salud. En las Encuestas de Demografía y Salud, que son la base para las cifras presentadas anteriormente, no todos los países recopilan información sobre etnias y los que efectivamente lo hacen se basan en el idioma hablado y no en la autoidentificación. 
Recuadro II.2 (conclusión)

Para responder a estas brechas en salud se requieren políticas y programas que respondan a las necesidades específicas y a las realidades de vida de los jóvenes indígenas, y que además valoren y respeten los conocimientos y aportes de la medicina tradicional (Rodríguez, 2012). No obstante, ya que la salud se vincula estrechamente con otras áreas en las que los jóvenes indígenas también se ven desaventajados y excluidos (educación, vivienda y acceso a un trabajo decente, entre otras), se requieren acciones coordinadas y articuladas de inclusión social que incorporen los temas étnicos y de raza de manera transversal.

Fuente: Elaboración propia sobre la base de Comisión Económica para América Latina y el Caribe (CEPAL)/Organización Panamericana de la Salud (OPS), "Salud de la población joven indígena en América Latina: Un panorama general” (LC/R.2171), Santiago, 2011; R. Martínez y A. Palma, "Seguridad alimentaria y nutricional en cuatro países andinos: una propuesta de seguimiento y análisis", serie Políticas Sociales, N 187 (LC/L.3750), Santiago, CEPAL, 2014; D. Pasqualini y A. Llorens (comps.), Salud y bienestar de los adolescentes y jóvenes: una mirada integral, Buenos Aires, OPS, 2010; y E. Rodríguez, "Salud pública, políticas sociales y desarrollo humano de adolescentes y jóvenes indígenas en América Latina: experiencias acumuladas y desafíos a encarar", 2012.

a Esta cifra se calculó sumando los datos disponibles de los censos de la ronda del año 2000 para 14 países de la región: Argentina, Bolivia (Estado Plurinacional de), Brasil, Chile, Costa Rica, Ecuador, Guatemala, Honduras, México, Nicaragua, Panamá, Paraguay, Perú y Venezuela (República Bolivariana de). La cantidad actual de jóvenes indígenas seguramente supera esta cifra, ya que no se contabiliza, por falta de datos, a los indígenas jóvenes de Colombia, El Salvador y la República Dominicana.

\section{Otros temas de salud en la población juvenil: el uso de drogas y la salud mental}

Como se mencionó en la sección C, la salud de los jóvenes con frecuencia se concibe desde un enfoque limitado, que obstaculiza una comprensión más holística del estado de salud de la juventud y el desarrollo de políticas y programas que atiendan estas realidades más complejas. El estado nutricional de los jóvenes (tanto el sobrepeso como otros trastornos nutricionales), el uso problemático de sustancias lícitas e ilícitas, la salud mental, las enfermedades crónicas (como la diabetes) y la salud ocupacional, entre otros, son temas de los cuales se sabe comparativamente poco. En esta sección se presenta un panorama del uso de sustancias lícitas e ilícitas y de la salud mental de los jóvenes, y ambos temas se sitúan en la problemática de la exclusión social y la desigualdad.

\section{El uso de drogas lícitas e ilícitas}

En el imaginario social, ser joven se asocia con crisis: crisis interna al intentar definirse y construir una identidad propia y crisis externa al tratar de encontrar su lugar en el mundo. Con relación a esto último, la noción de crisis en la juventud también se vincula con el contraste entre las aspiraciones de la persona joven y las posibilidades de realización que le ofrece la sociedad en la que vive (Pasqualini y Llorens, 2010). 
En el campo de la salud, se tiende a percibir a la juventud como una etapa de riesgo y transgresión (Krauskopf, 2000). Desde esta perspectiva más bien negativa y restringida del período juvenil, se focaliza la atención sobre los jóvenes según el problema específico que padecen. Como consecuencia, las intervenciones se enfocan sobre el individuo y omiten el papel de los contextos socioeconómicos y socioculturales en estos comportamientos. Pese a que esta postura ha empezado a cambiar un poco, aún persiste en el área del consumo de drogas lícitas e ilícitas.

Aunque son múltiples los factores por los cuales los jóvenes pueden tener conductas abusivas con las sustancias (desde influencias genéticas, familiares o de pares hasta características individuales), en esta sección se propone que el consumo de dichas sustancias está muy relacionado con los contextos socioculturales y que dicho consumo adquiere significación para los usuarios ${ }^{3}$.

Los elementos que desencadenan el inicio del consumo de sustancias se encuentran a nivel del individuo y en las relaciones interpersonales con los pares. Si bien las toxicomanías son consideradas como psicopatologías con un fuerte arraigo orgánico por el nivel de dependencia que ejercen en el organismo, tensionando en gran medida la voluntad de las personas (ver Reith, 2004), antes de la adicción encontramos escenarios de exposición al consumo definidos por la cultura y las relaciones interpersonales. En este ámbito, los procesos de construcción identitaria juegan un importante papel de mediación entre los jóvenes y el consumo de sustancias. Esta influencia está dada, en parte, por el posicionamiento del consumo de drogas legales en los medios de comunicación, como el cine, el fútbol o la publicidad.

A nivel social, la precariedad y exclusión social tienen su propia dinámica en torno al uso y la distribución de sustancias lícitas e ilícitas. Las condiciones precarias e inestables en el hogar, la vida en situación de calle o la itinerancia entre el hogar, las instituciones de acogida, de tratamiento o de reclusión y la calle constituyen escenarios especialmente riesgosos para los jóvenes en cuanto al abuso y las adicciones a diversas sustancias. Las problemáticas que los aquejan refuerzan la exclusión social desde una fuerte estigmatización como sujetos marginales, adictos y violentos, que no solo se manifiesta en las interacciones cotidianas, sino también en los servicios de salud que deberían acogerlos.

El abuso de drogas lícitas e ilícitas es un grave problema de salud pública debido a sus extensos efectos adversos tanto a nivel personal

Se entiende por consumo indebido o abusivo aquel que implica daños potenciales para la salud del consumidor, su capacidad de inserción productiva, su autoestima, la estabilidad de su familia y la defensa de su comunidad (Hopenhayn, de Rementería y Sunkel, 1999). 
como social. El consumo de drogas lícitas, como el tabaco y el alcohol, tiene consecuencias nocivas para la salud a nivel orgánico que se gestan silenciosamente durante la juventud, pero muestran sus efectos hacia el final de esta etapa, durante la adultez o entrada la tercera edad. Los problemas orgánicos resultantes pueden adquirir múltiples expresiones, pero suelen estar asociados con enfermedades hepáticas en el caso del alcohol y con el cáncer de pulmón y diversas enfermedades respiratorias en el caso del tabaco. Las consecuencias del abuso de drogas ilícitas en la salud del individuo suelen articularse con la psicología evolutiva para generar discursos que apuntan a los efectos que dicho consumo tiene en el desarrollo neurológico y cognitivo de niños, adolescentes y jóvenes. Más allá de los efectos biológicos de las sustancias ilícitas sobre el individuo, otra consecuencia de su consumo abusivo es que algunos jóvenes con adicciones se vinculan con las redes de distribución de estas sustancias. De este modo, quedan expuestos a escenarios de violencia interpersonal y criminalidad, lo que abre otra arista del problema que será tratada en el capítulo III. Por otra parte, el abuso de sustancias también puede perjudicar las relaciones familiares y entre pares.

El abuso de drogas lícitas e ilícitas entre jóvenes también tiene importantes costos directos e indirectos para la sociedad. Estos pueden resumirse en años de vida productivos perdidos entre los jóvenes con dependencia, costos asociados al sistema de justicia penal y costos de salud y tratamiento. El costo del tratamiento para el consumo de drogas es muy inferior a lo que serían los costos de salud y sociales de la dependencia. Según estimaciones realizadas en los Estados Unidos, cada dólar invertido en programas de tratamiento de la adicción produce un retorno de entre cuatro y siete dólares relacionado solo a la reducción de delitos vinculados a las drogas, los costos para el sistema de justicia penal y el robo (National Institute on Drug Abuse, 2009). Estos "ahorros" se suman a los ahorros significativos para la persona, descritos en el párrafo anterior.

La falta de datos comparables plantea un gran problema para analizar el uso de sustancias entre jóvenes latinoamericanos y caribeños ${ }^{4}$. En las encuestas nacionales de juventud se aborda el tema en detalle y se examina, por ejemplo, el uso de drogas por estrato socioeconómico o residencia (urbana y rural), pero estas encuestas no son comparables entre sí. Para ofrecer un panorama de lo que sucede a nivel regional, en este capítulo se utilizan datos provenientes de la Encuesta Mundial de Salud a Escolares de la OMS (2010a). Se trata de una encuesta realizada entre estudiantes de secundaria que utiliza un proceso de muestreo

Se puede decir que este problema no solo está presente en el análisis del uso de drogas, sino que, en general, los datos y la información estadística de salud sobre este grupo poblacional son escasos. 
estandarizado, una metodología común y módulos con preguntas estandarizadas, lo que facilita la comparación de un país a otro. Además, esta encuesta tiene la ventaja de haber sido aplicada en varios países de la región, incluidos muchos de la subregión caribeña ${ }^{5}$. Pese a no permitir un análisis desagregado por nivel socioeconómico, es una buena fuente de información, ya que el uso de sustancias a estas edades tempranas puede hacer referencia a mayores problemas con sustancias en el futuro, lo que, a su vez, puede interferir con los estudios o la inserción laboral.

Como se observa en el gráfico II.8, los datos revelan que la prevalencia del uso de tabaco es variable en los países de la región: del 4,9\% en Anguila al 25,5\% en la Argentina. A grandes rasgos, la prevalencia tiende a ser superior en los cuatro países latinoamericanos incluidos que en los países caribeños, aunque un porcentaje importante de estudiantes en Jamaica declara haber fumado cigarrillos recientemente (24,6\%). Es llamativo que la iniciación al cigarrillo ocurre a edades muy tempranas: entre los estudiantes fumadores, la mayoría probó su primer cigarrillo a los 14 años o antes (véase el gráfico II.9).

Gráfico II.8

América Latina y el Caribe (15 países): estudiantes que fumaron cigarrillos 1 o más días en los últimos 30 días

(En porcentajes)

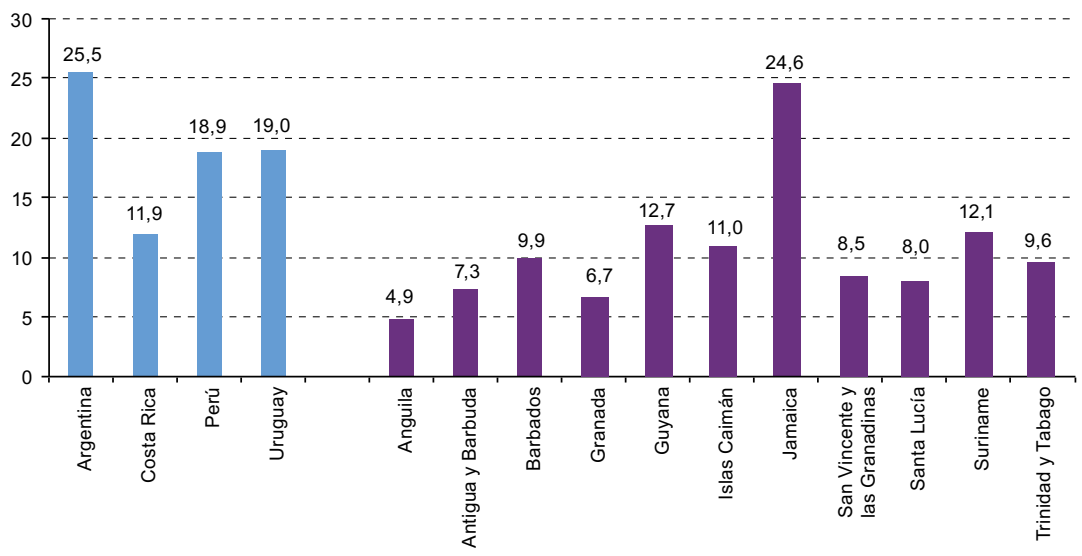

Fuente: Organización Mundial de la Salud (OMS), Encuesta Mundial de Salud a Escolares, 2010 para Anguila (2009), Antigua y Barbuda (2009), Argentina (2007), Barbados (2011), Costa Rica (2009), Granada (2008), Guyana (2010), Islas Caimán (2007), Jamaica (2010), Perú (2010), San Vicente y las Granadinas (2007), Santa Lucía (2007), Suriname (2009), Trinidad y Tabago (2011), Uruguay (2006).

Para mayor información acerca de la encuesta véase [en línea] http://www.who.int/chp/gshs/es/. La encuesta contiene datos de 18 países en la región: Anguila, Antigua y Barbuda, Argentina, Barbados, Costa Rica, Dominica, Granada, Guatemala, Guyana, Islas Caimán, Jamaica, Montserrat, Perú, San Vicente y las Granadinas, Santa Lucía, Suriname, Trinidad y Tabago y Uruguay. 


\section{Gráfico II.9}

América Latina y el Caribe (15 países): estudiantes fumadores que probaron su primer cigarrillo a los 14 años o antes

(En porcentajes)

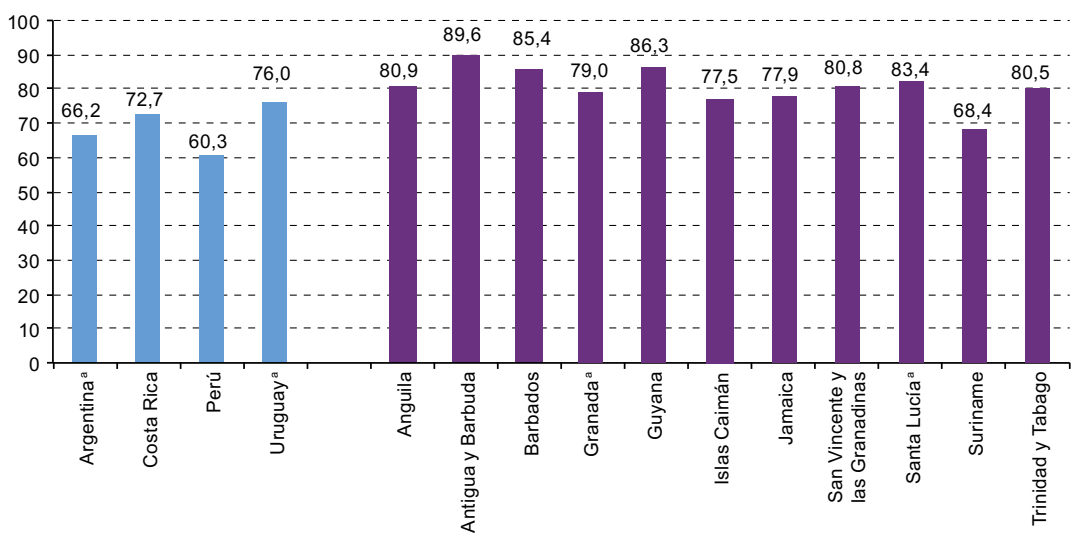

Fuente: Organización Mundial de la Salud (OMS), Encuesta Mundial de Salud a Escolares, 2010 para Anguila (2009), Antigua y Barbuda (2009), Argentina (2007), Barbados (2011), Costa Rica (2009), Granada (2008), Guyana (2010), Islas Caimán (2007), Jamaica (2010), Perú (2010), San Vicente y las Granadinas (2007), Santa Lucía (2007), Suriname (2009), Trinidad y Tabago (2011), Uruguay (2006).

a Tenían 13 años o menos cuando probaron cigarrillos por primera vez.

Al igual que en el consumo de tabaco, existe variabilidad en el consumo de alcohol entre los estudiantes de la región (véase el gráfico II.10). Sin embargo, salvo en contadas excepciones, la prevalencia del consumo de alcohol excede al $30 \%$, o sea 1 en 3 estudiantes declara haber consumido por lo menos un trago de alcohol en los últimos 30 días. Esto sitúa al alcohol como la sustancia más consumida por los jóvenes en este conjunto de países. Como con el cigarrillo, la iniciación al alcohol ocurre a edades tempranas (véase el gráfico II.11). Entre los estudiantes que han consumido alcohol recientemente, la mayoría consumió su primer trago antes de los 14 años.

Por motivos culturales, estos datos no necesariamente señalan un patrón de abuso, ya que muchos jóvenes consumen alcohol desde tempranas edades dentro del hogar como parte rutinaria de las comidas. Sin embargo, cuando se indaga sobre el consumo de alcohol hasta quedar en estado de embriaguez, un alto porcentaje de estudiantes responden afirmativamente (véase el gráfico II.12).

Por último, en el gráfico II.13 se observa la prevalencia del consumo de drogas ilícitas entre estudiantes de secundaria. Se constata que el consumo de estas sustancias tiende a ser más elevado entre estudiantes de países del Caribe que en América Latina. 


\section{Gráfico II.10 \\ América Latina y el Caribe (18 países): estudiantes que han consumido por lo menos un trago de alcohol 1 o más días en los últimos 30 días \\ (En porcentajes)}

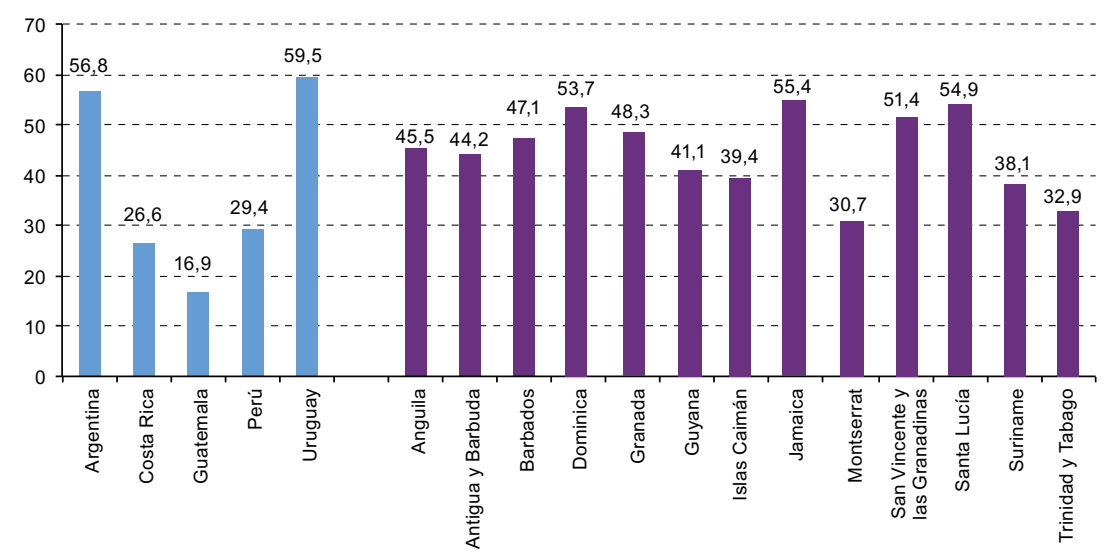

Fuente: Organización Mundial de la Salud, Encuesta Mundial de Salud a Escolares, 2010 para Anguila (2009), Antigua y Barbuda (2009), Argentina (2007), Barbados (2011), Costa Rica (2009), Dominica (2009), Granada (2008), Guatemala (2009), Guyana (2010), Islas Caimán (2007), Jamaica (2010), Montserrat (2008), Perú (2010), San Vicente y las Granadinas (2007), Santa Lucía (2007), Suriname (2009), Trinidad y Tabago (2011), Uruguay (2006).

\section{Gráfico II.11 \\ América Latina y el Caribe (11 países): estudiantes que han consumido alcohol y probaron su primer trago a los 14 años o antes}

(En porcentajes)

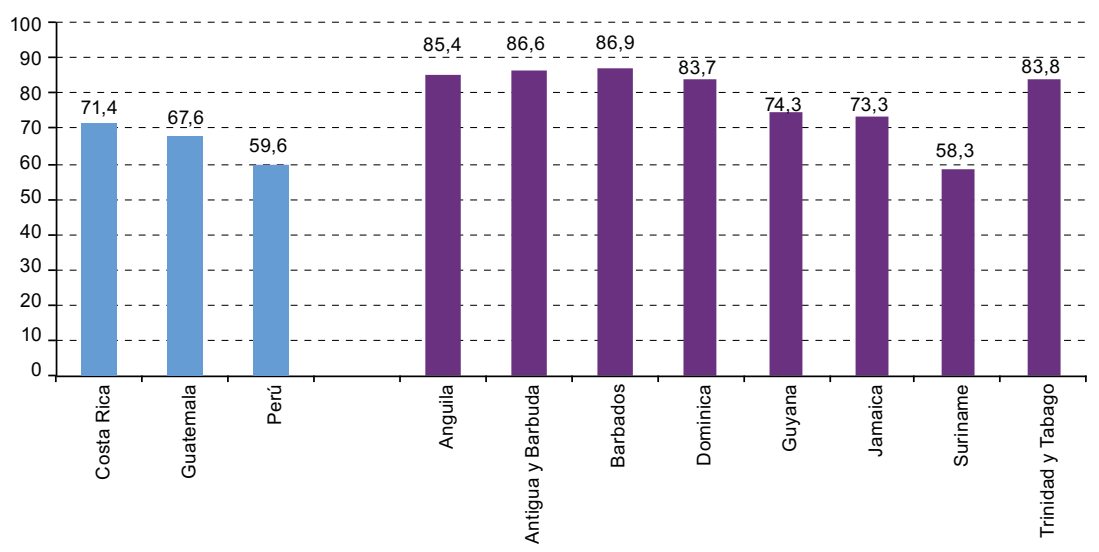

Fuente: Organización Mundial de la Salud, Encuesta Mundial de Salud a Escolares, 2010 para Anguila (2009), Antigua y Barbuda (2009), Barbados (2011), Costa Rica (2009), Dominica (2009), Guatemala (2009), Guyana (2010), Jamaica (2010), Perú (2010), Suriname (2009), Trinidad y Tabago (2011). 


\section{Gráfico II.12}

América Latina y el Caribe (18 países): estudiantes que han consumido tanto alcohol hasta quedar borrachos una o más veces en su vida

(En porcentajes)

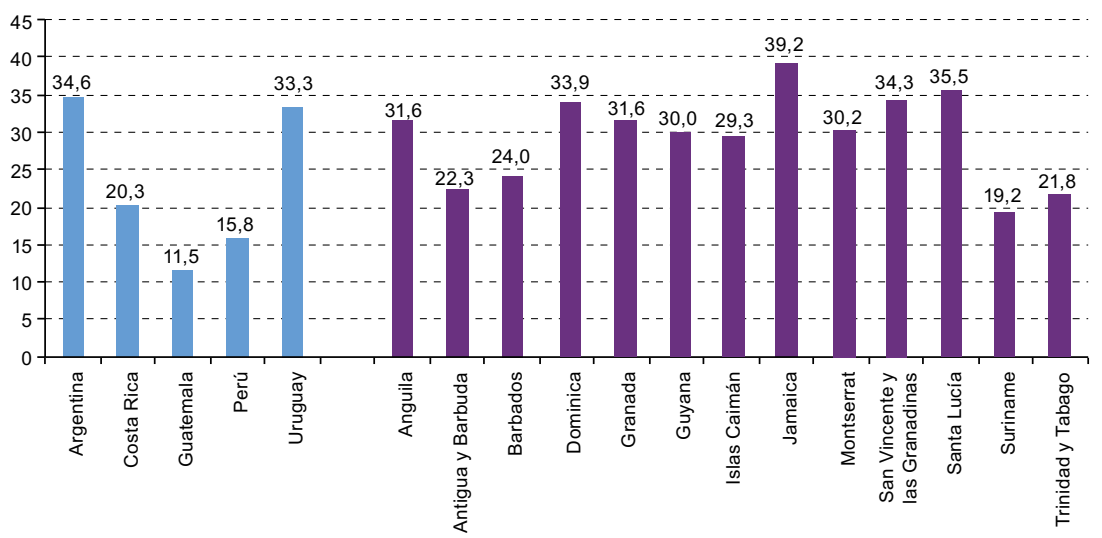

Fuente: Organización Mundial de la Salud, Encuesta Mundial de Salud a Escolares, 2010 para Anguila (2009), Antigua y Barbuda (2009), Argentina (2007), Barbados (2011), Costa Rica (2009), Dominica (2009), Granada (2008), Guatemala (2009), Guyana (2010), Islas Caimán (2007), Jamaica (2010), Montserrat (2008), Perú (2010), San Vicente y las Granadinas (2007), Santa Lucía (2007), Suriname (2009), Trinidad y Tabago (2011), Uruguay (2006).

\section{Gráfico II.13 \\ América Latina y el Caribe (15 países): estudiantes que han consumido drogas, como marihuana, cocaína o éxtasis, una o más veces en su vida (En porcentajes)}

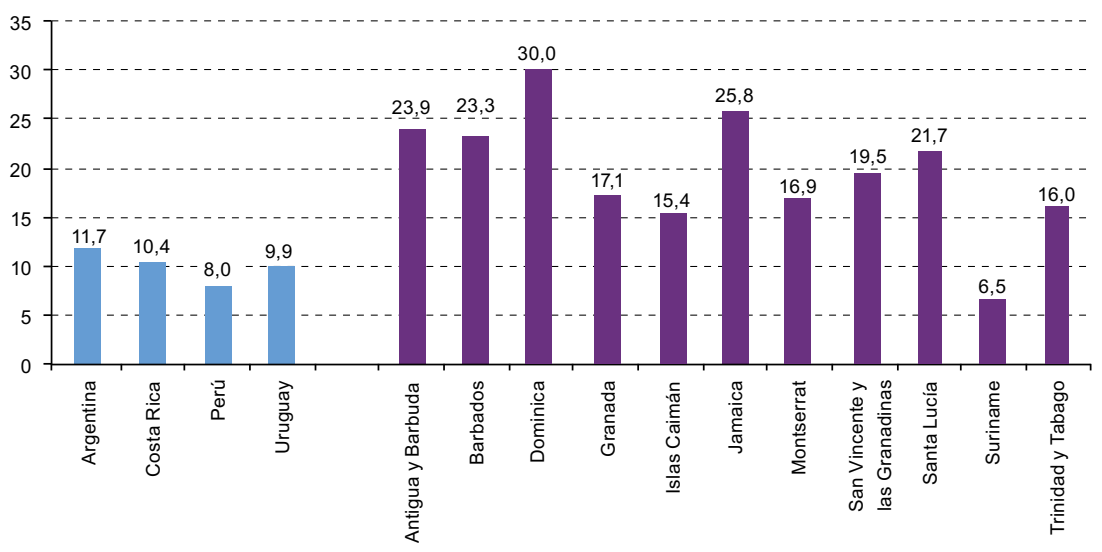

Fuente: Organización Mundial de la Salud, Encuesta Mundial de Salud a Escolares, 2010 para Antigua y Barbuda (2009), Argentina (2007), Barbados (2011), Costa Rica (2009), Dominica (2009), Granada (2008), Islas Caimán (2007), Jamaica (2010), Montserrat (2008), Perú (2010), San Vicente y las Granadinas (2007), Santa Lucía (2007), Suriname (2009), Trinidad y Tabago (2011), Uruguay (2006). 
En resumen, tanto en América Latina como en el Caribe de habla inglesa, el consumo de alcohol supera ampliamente el consumo de tabaco y de drogas ilícitas. En América Latina, el consumo de tabaco es mayor que el consumo de drogas ilícitas, mientras que en el Caribe de habla inglesa se observa lo opuesto, con un mayor porcentaje de estudiantes que declara usar drogas. En virtud de que la encuesta fue realizada en escuelas y, por definición, no recoge las características de adolescentes que no asisten a estos centros educativos, es razonable pensar que las cifras presentadas subestiman la prevalencia de tabaquismo y el consumo de alcohol y drogas ilícitas.

Los jóvenes que usan tabaco y alcohol indican que empezaron a consumir estas sustancias a temprana edad, en la mayoría de los casos antes de los 14 años. Esto sugiere que los mensajes de prevención y las iniciativas de salud pública contra el alcohol y el tabaquismo que se enfocan en adolescentes están llegando demasiado tarde. Por último, aunque estas tendencias no necesariamente indican un consumo abusivo, como ya se mencionó, muchos estudiantes admiten haber bebido alcohol en exceso, lo que es problemático. Respecto del consumo de drogas ilícitas, es necesario señalar que los datos de la encuesta no permiten un análisis más fino sobre el uso de diversos tipos de drogas ilícitas, pues, si bien es cierto que todas son nocivas en algún grado, también hay variaciones en los efectos perjudiciales que pueden tener.

Si bien los medios y las políticas se centran en el uso problemático de sustancias ilícitas en la juventud, en particular la marihuana y la cocaína (y sus derivados, como la pasta base), las drogas más consumidas por los jóvenes, y las que generan mayores problemas en esta etapa de la vida y a futuro, son el alcohol y el tabaco. El hecho de que sean drogas legales no las hace menos nocivas y sus víctimas se distribuyen entre aquellos cuya salud se ve afectada irreversiblemente y quienes bajo el efecto del alcohol se exponen, y exponen a terceros, a situaciones de riesgo, tales como conductas sexuales riesgosas y conducir bajo la influencia del alcohol (CEPAL/OIJ, 2008).

La participación de jóvenes en escenarios de violencia, tema que se revisará en el capítulo III, también se articula con el consumo abusivo de drogas lícitas e ilícitas. En particular, el consumo de alcohol está vinculado con comportamientos agresivos y delitos violentos (Parker y Auerhahn, 1998). Por otra parte, los jóvenes con dependencia de drogas ilícitas pueden recurrir a robos y asaltos para financiar su adicción, o involucrarse en escenarios concretos de producción y distribución de sustancias ilícitas, lo que puede exponerlos a situaciones de violencia en tanto victimarios o víctimas.

Los datos utilizados en esta investigación no permiten desagregarlos por condición socioeconómica. Sin embargo, los resultados de encuestas nacionales de juventud realizadas en la región proporcionan datos que ofrecen un panorama de algunos patrones. En países tan diversos en términos económicos, sociales y culturales como Chile y Guatemala, 
son los jóvenes de estratos altos los que más declaran usar sustancias ilícitas (INJUV, 2013; SESC/CONJUVE/INE, 2011). Esto vuelve compleja la imagen del joven pobre y drogadicto, y puede estar relacionado con la disponibilidad de un mayor ingreso por parte de los jóvenes económicamente aventajados. No obstante, el consumo juvenil de drogas puede estar asociado a diversos procesos en diferentes entornos socioeconómicos. En el caso de los jóvenes de estratos bajos puede reflejar falta de oportunidades, frustraciones ante un sistema educativo que no responde a sus necesidades o conflictos en el entorno familiar. Además, los jóvenes con dependencia de sustancias ilícitas de estratos bajos ven restringidas las posibilidades para acceder a un tratamiento, por lo que las adicciones se tornan especialmente debilitantes y problemáticas.

Se entiende que el uso abusivo de sustancias es un efecto y una causa de exclusión social. En la ausencia de factores de protección, elementos como la pobreza, la desigualdad, una realidad laboral con oferta principalmente en el mercado informal, la escasez de vivienda, modelos escolares que no siempre responden a sus necesidades, y nuevas configuraciones familiares pueden generar contextos de vulnerabilidad para el uso abusivo de sustancias.

A la vez, los jóvenes con dependencia de sustancias son estigmatizados y excluidos, lo que tiene secuelas negativas tanto para su salud como para las probabilidades de recibir tratamiento adecuado para superar dicha dependencia. En varias investigaciones en este ámbito se establece una diferencia entre el estigma a nivel interpersonal y a nivel estructural (Hatzenbuehler y Link, 2014; Link y Phelan, 2014). El estigma estructural se define como "condiciones societales, normas culturales y políticas institucionales que restringen las oportunidades, los recursos y el bienestar de los individuos o grupos estigmatizados" (Hatzenbuehler y Link, 2014, pág. 2). La estigmatización es, entonces, uno de los factores que genera exclusión social y su acción se ve legitimada por condiciones estructurales.

\section{La salud mental de los jóvenes: no hay salud sin salud mental}

Otro grupo de la población juvenil que enfrenta el estigma es aquel integrado por jóvenes con problemas de salud mental. Existe una fuerte relación entre los problemas de salud mental y otros problemas de salud, y también entre los problemas de salud mental y los problemas más generales vinculados al desarrollo juvenil. En particular, los problemas de salud mental están asociados con el rendimiento escolar, el uso y abuso de sustancias, la violencia, y la salud sexual y reproductiva. Por ello, la salud mental tiene un impacto significativo en el desarrollo de los jóvenes y repercute directamente en la posibilidad de vivir una vida plena y lograr una integración económica y social. 
En América Latina y el Caribe, los estudios epidemiológicos de salud mental entre jóvenes son escasos y poco comparables por las diferencias en los instrumentos de medición, el rango etario considerado y los períodos de referencia. Sin embargo, tal como se demostró mediante el análisis de la carga de morbilidad (véase el cuadro II.1), los problemas de salud mental tienen un peso importante entre los jóvenes, especialmente entre las mujeres pertenecientes a ese grupo etario.

Pese a que las mujeres tienden a tener más personas cercanas que los hombres (Fuhrer y otros, 1999), lo que constituye un importante factor protector contra los problemas de salud mental, se evidencia un patrón diferenciado por sexo donde estos problemas parecen afectarles más que a los varones. Este hallazgo coincide con otros estudios llevados a cabo a nivel internacional. Por ejemplo, en una muestra de 15 países, Seedat y otros (2009) informan que las mujeres tienen una prevalencia más elevada de trastornos de internalización, como la depresión y la ansiedad, en tanto que los hombres presentan más trastornos de externalización, como el abuso de sustancias y conducta antisocial.

Aún se desconocen las contribuciones específicas de diversos factores biológicos y psicosociales a la salud mental y el desarrollo de problemas de salud mental en mujeres y hombres. La investigación sobre género y salud mental sugiere que la experiencia de discriminación de género, las concepciones de la masculinidad y la feminidad, los estresores y las estrategias diferenciadas de mitigación del estrés, la vulnerabilidad social y económica de las mujeres, y la experiencia de violencia de género tienen gran incidencia (Gaviria y Rondon, 2010). Un sesgo en el diagnóstico de los problemas de salud mental también puede estar contribuyendo a la mayor prevalencia de estos problemas entre las mujeres.

Es importante señalar que los problemas de salud mental también se vinculan de manera indirecta con otras de las principales causas de la carga de morbilidad entre jóvenes. En algunos estudios se ha demostrado, por ejemplo, que los jóvenes con problemas de salud mental tienen mayor riesgo de contraer VIH que aquellos que no padecen estos problemas (Donenberg y Pao, 2005). También es cierto que existe un estrecho vínculo entre los problemas de salud mental, en particular los trastornos depresivos mayores, y la autolesión (Teti y otros, 2014). El suicidio es, sin duda, la manifestación más grave del mal estado de salud mental.

Los datos sobre tasas de suicidio deben interpretarse con cautela, ya que este tipo de muerte podría atribuirse a otras causas por razones culturales o para evitar el estigma asociado al suicidio, entre otros motivos (OMS, 2002). Este panorama de subregistro de los suicidios se suma a las dificultades para contar con datos confiables sobre las conductas suicidas que no terminan en desenlaces fatales. Además, se ha documentado la escasez de datos sobre el suicidio y la salud mental entre ciertas subpoblaciones de jóvenes, como los jóvenes indígenas y 
las mujeres (CEPAL/OPS, 2011; Gaviria y Rondon, 2010). A pesar de estas dificultades de registro, el fenómeno existe y es preocupante entre los jóvenes latinoamericanos, pues en algunos países de la región exhibe una tendencia al alza (Quinlan-Davidson y otros, 2014).

Mediante el uso de los datos de la Encuesta Mundial de Salud a Escolares se puede indagar acerca de la ideación y planificación del suicidio entre estudiantes de secundaria en la región. Se aprecia que las jóvenes declaran haber considerado el suicidio con mayor frecuencia que los varones en todos los países para los cuales existe información (véase el gráfico II.14). Mientras que en algunos países, como Montserrat y el Perú, la brecha entre varones y mujeres es llamativa, en otros es menos notable (Jamaica y San Vicente y las Granadinas). Resulta alarmante constatar que en nueve países de la región, más de una en cinco jóvenes indicó que había considerado suicidarse y en seis países la cifra asciende a una en cuatro.

\section{Gráfico II.14 \\ América Latina y el Caribe (17 países): estudiantes que han considerado el suicidio}

(En porcentajes)

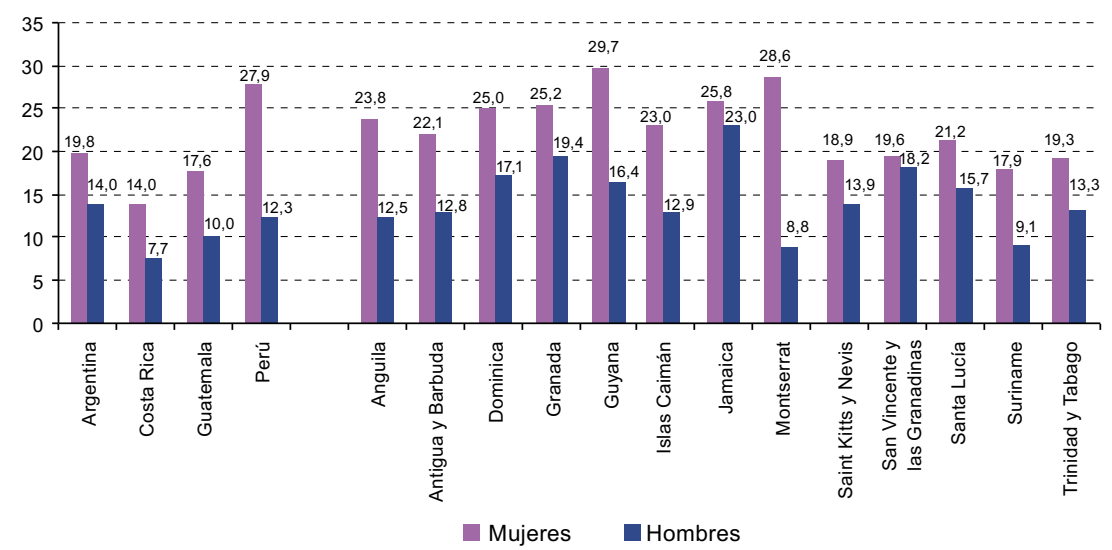

Fuente: Organización Mundial de la Salud (OMS), Encuesta Mundial de Salud a Escolares, 2010 para Anguila (2009), Antigua y Barbuda (2009), Argentina (2007), Barbados (2011), Costa Rica (2009), Dominica (2009), Granada (2008), Guyana (2010), Islas Caimán (2007), Jamaica (2010), Montserrat (2008), Perú (2010), Saint Kitts y Nevis (2011), San Vicente y las Granadinas (2007), Santa Lucía (2007), Suriname (2009), Trinidad y Tabago (2011).

Aunque el porcentaje de jóvenes que declara la planificación de un suicidio tiende a ser un poco inferior al porcentaje de quienes han considerado llevarlo a cabo, todavía alcanza niveles preocupantes en muchos países (véase el gráfico II.15). Al igual que tener la idea de suicidio, la planificación es, en casi todos los países, superior entre mujeres que entre varones. Estos resultados concuerdan con estudios que han mostrado que las mujeres intentan suicidarse y experimentan ideación suicida más que los hombres, aunque ellos tienen tasas superiores de suicidio (Teti y otros, 2014). 


\section{Gráfico II.15 \\ América Latina y el Caribe (17 países): estudiantes que han hecho un plan de suicidio}

(En porcentajes)

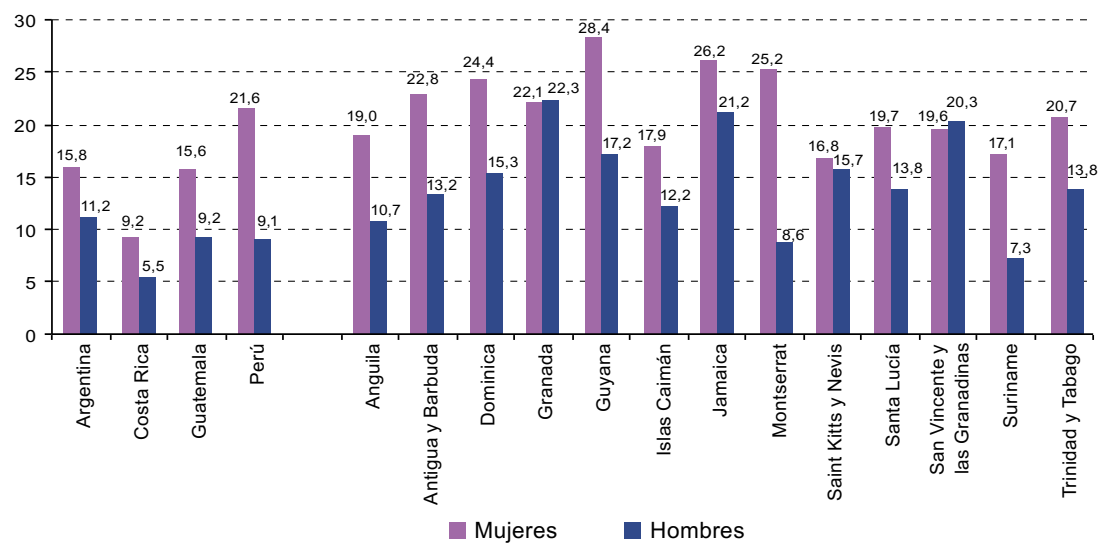

Fuente: Organización Mundial de la Salud (OMS), Encuesta Mundial de Salud a Escolares, 2010 para Anguila (2009), Antigua y Barbuda (2009), Argentina (2007), Barbados (2011), Costa Rica (2009), Dominica (2009), Granada (2008), Guyana (2010), Islas Caimán (2007), Jamaica (2010), Montserrat (2008), Perú (2010), Saint Kitts y Nevis (2011), San Vicente y las Granadinas (2007), Santa Lucía (2007), Suriname (2009), Trinidad y Tabago (2011).

Independientemente del sexo, los problemas de salud mental tienen un impacto significativo en las posibilidades de inclusión social de los jóvenes. Como señala la CEPAL (2014b), los jóvenes con problemas de salud mental pueden enfrentar grandes obstáculos para completar sus estudios debido al bajo rendimiento académico, los problemas de disciplina y asistencia y, con el tiempo, la deserción escolar. Esta trayectoria escolar los deja mal preparados para incorporarse al mercado de trabajo, lo que implica una débil inserción laboral posterior. Los problemas de salud mental durante la adolescencia y la juventud también pueden afectar el desarrollo de relaciones seguras y saludables con sus pares, padres y otros. Se ha demostrado que los problemas de salud mental afectan la autoestima de los jóvenes y su interacción social, y que incluso aumentan sus posibilidades de sufrir lesiones personales y dañarse a sí mismos y a otros (Bradshaw, O’Brennan y McNeely, 2008).

Se reconoce que la causa de problemas de salud mental en la juventud es multifactorial. La pobreza, el hecho de trabajar o vivir en la calle, y de vivir circunstancias tales como el acoso escolar, eventos traumáticos y experiencias de conflicto y posconflicto son importantes factores de riesgo para la salud mental de los jóvenes (Naciones Unidas, 2014). Tal y como se indica en un informe de la OMS sobre salud mental y desarrollo (OMS, 2010b), existe una relación de retroalimentación entre la vulnerabilidad y la salud mental, lo que la vuelve más compleja. De la misma forma, la relación entre la pobreza y los problemas de salud mental es de retroalimentación: las personas que viven en situación de pobreza experimentan altos niveles de 
estrés y trauma, así como exclusión social, y tienen bajo niveles de acceso a atención médica, lo que agrava el riesgo y la gravedad de los problemas de salud mental. También es cierto que las personas con problemas de salud mental pueden estar más expuestas al riesgo de pobreza debido a un mal rendimiento en el ámbito educacional, a una débil inserción laboral, a los altos costos de atención médica, al estigma y a la exclusión social.

Sin embargo, como destacan Patel y otros (2007), la mayoría de los jóvenes no llegan a desarrollar un problema de salud mental, ni siquiera quienes enfrentan muchas adversidades y múltiples factores de riesgo. Ello apunta a la importancia de elementos protectores que mitigan el efecto de los factores de riesgo y deben fortalecerse para promover la salud mental entre la juventud. El sentido de conexión y pertenencia, los bajos niveles de conflicto y el apoyo social son algunos de estos elementos protectores (Patel y otros, 2007). El contexto familiar también es de suma importancia, ya que para aumentar la resiliencia en la juventud es fundamental contar con el apoyo de los padres.

\section{E. Políticas y programas: promoción de una vida saludable ${ }^{6}$}

Según el informe más reciente del Fondo de Población de las Naciones Unidas (UNFPA), Estado de la población mundial 2014, el número de personas jóvenes ha alcanzado un record histórico (UNFPA, 2014). En América Latina y el Caribe, los jóvenes representan más del $25 \%$ de la población (CEPAL/UNFPA, 2012). Para lograr que alcancen su máximo potencial de ser los líderes de mañana, es necesario invertir ahora en áreas clave para su desarrollo integral, como la salud.

Los jóvenes de la región no representan un grupo homogéneo. Tal como se plantea en el documento La hora de la igualdad: Brechas por cerrar, caminos por abrir (CEPAL, 2010), urge visibilizar la heterogeneidad de situaciones, contextos y circunstancias que enfrenta la juventud en los escenarios latinoamericanos. En este capítulo, de hecho, se han constatado realidades de salud muy diversas para jóvenes de diferentes estratos socioeconómicos.

Como lo expresa la CEPAL, la coyuntura de democracia, desarrollo e implementación de derechos implica asegurar la igualdad de acceso y medios para la educación, la salud, el empleo y la seguridad social, de modo de enfrentar las grandes desigualdades sociales y económicas que plagan la región (CEPAL, 2010). Para ello, es preciso implementar políticas orientadas a disminuir la vulnerabilidad y desigualdad social que afecta

La revisión de políticas relacionadas con el tema de salud presentada en esta sección no es un compendio exhaustivo. Se basa en una búsqueda en los sitios web de los ministerios de salud y educación, así como de las instituciones de juventud, de los países que cuentan con este tipo de políticas. 
a ciertos segmentos y grupos sociales, tales como la juventud. Al asegurar esta igualdad de acceso y medios se fomentará una participación más proactiva en la sociedad y se facilitará una realización más plena de potencialidades y proyectos de vida (CEPAL, 2014c).

\section{Las políticas y los programas en materia de salud: una revisión}

A pesar de que los jóvenes tienden a enfermarse menos y mueren en menor cantidad que las personas que se encuentran en otras etapas de la vida, constituyen el grupo poblacional que enfrenta mayores riesgos de salud asociados a factores exógenos. Sus necesidades de salud específicas suelen ser invisibles en las políticas sectoriales convencionales y a menudo sucede que un gran número de políticas de salud para jóvenes no están enfocadas específicamente en ellos, sino que incluyen a la juventud y a algunos de sus segmentos junto con otros grupos etarios de la población.

Muchas de las políticas de salud dirigidas a este grupo poblacional están vinculadas a las escuelas, por lo que son de carácter intersectorial. Brindar conocimientos preventivos para detener o disminuir las relaciones sexuales sin protección y el uso y abuso de drogas lícitas e ilícitas es el principal eje en torno al cual trabajan muchos programas sociales impulsados, en su mayoría, por las carteras de educación y de salud. En esta línea, los programas se enfocan sobre todo en jóvenes que se encuentran en etapa escolar sin que, necesariamente, hayan tenido relaciones sexuales o consuman algún tipo de sustancia.

Existen también políticas de índole más general e impulsadas desde los ministerios de salud que incluyen a la población joven (véase el cuadro II.2). La mayoría de estas políticas proponen una mirada integral sobre la salud desde una perspectiva de derechos. Algunas hacen mención explícita de los temas de salud sobre los que buscan incidir y aunque en algunas se hace referencia a la salud mental, este no es el eje central de ninguna de ellas. Estas políticas tienden a referirse genéricamente a la "salud". Otros ejes bajo los cuales se diseñan e implementan muchos de los programas de salud para jóvenes de diferentes países de la región son los que promueven el acceso universal a los sistemas de salud (véase el cuadro II.2). Parte del trabajo de estos programas consiste en hacer un llamado basado en el respeto a la confidencialidad, el anonimato y la cercanía de los servicios.

El hecho de que existan instituciones que aborden con relativa especificidad los asuntos vinculados con la juventud no es garantía de que se estén poniendo en marcha políticas integrales e inclusivas de las demandas de los jóvenes (CEPAL/UNFPA, 2012). Falta un acceso real a los beneficios del sistema de salud pública. El menosprecio, la imposición de horarios o las difíciles condiciones impuestas a los jóvenes para obtener algún medicamento o tratamiento son algunos de los obstáculos de los servicios médicos en los diferentes países de la región (CEPAL/OIJ, 2008). 


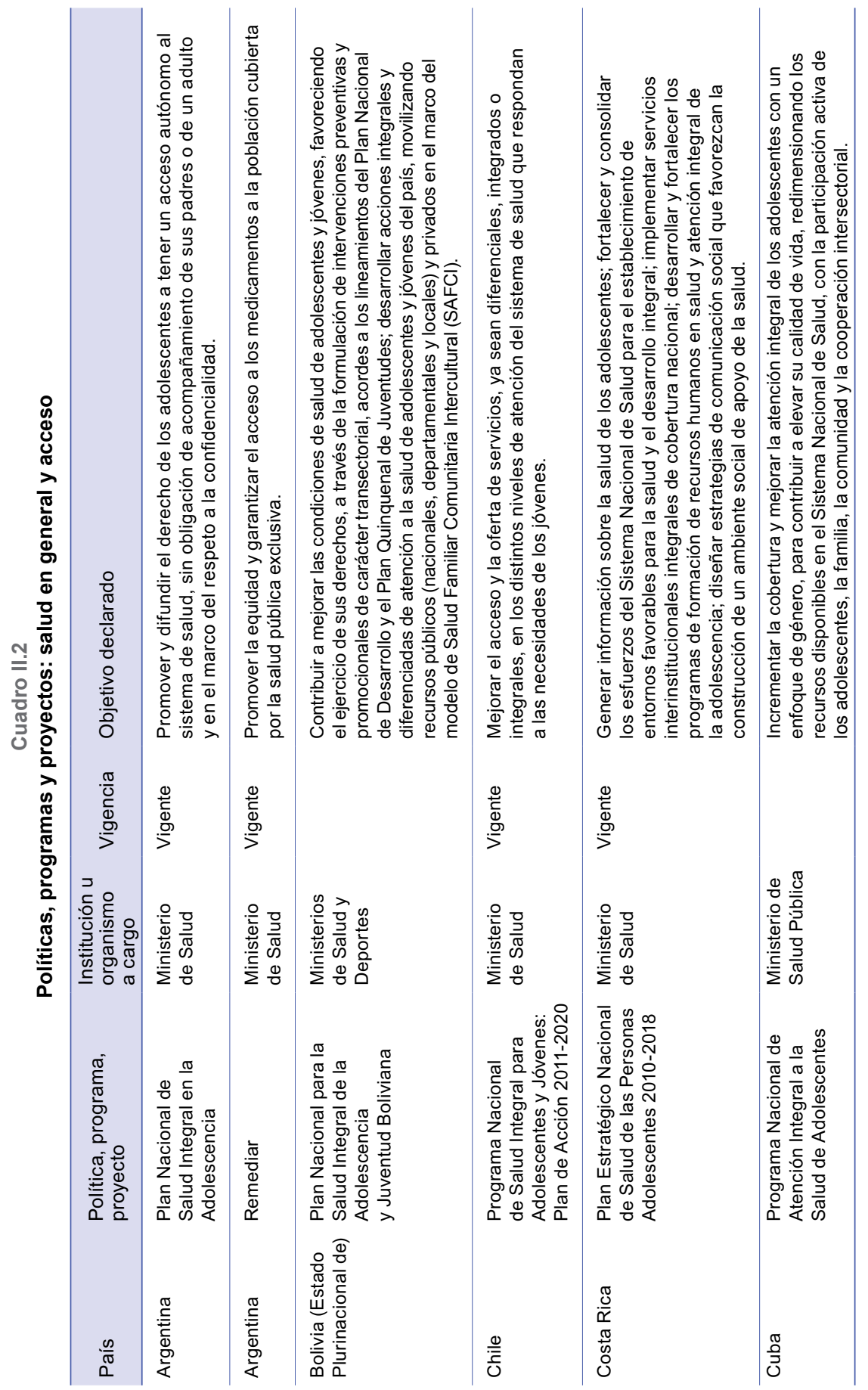




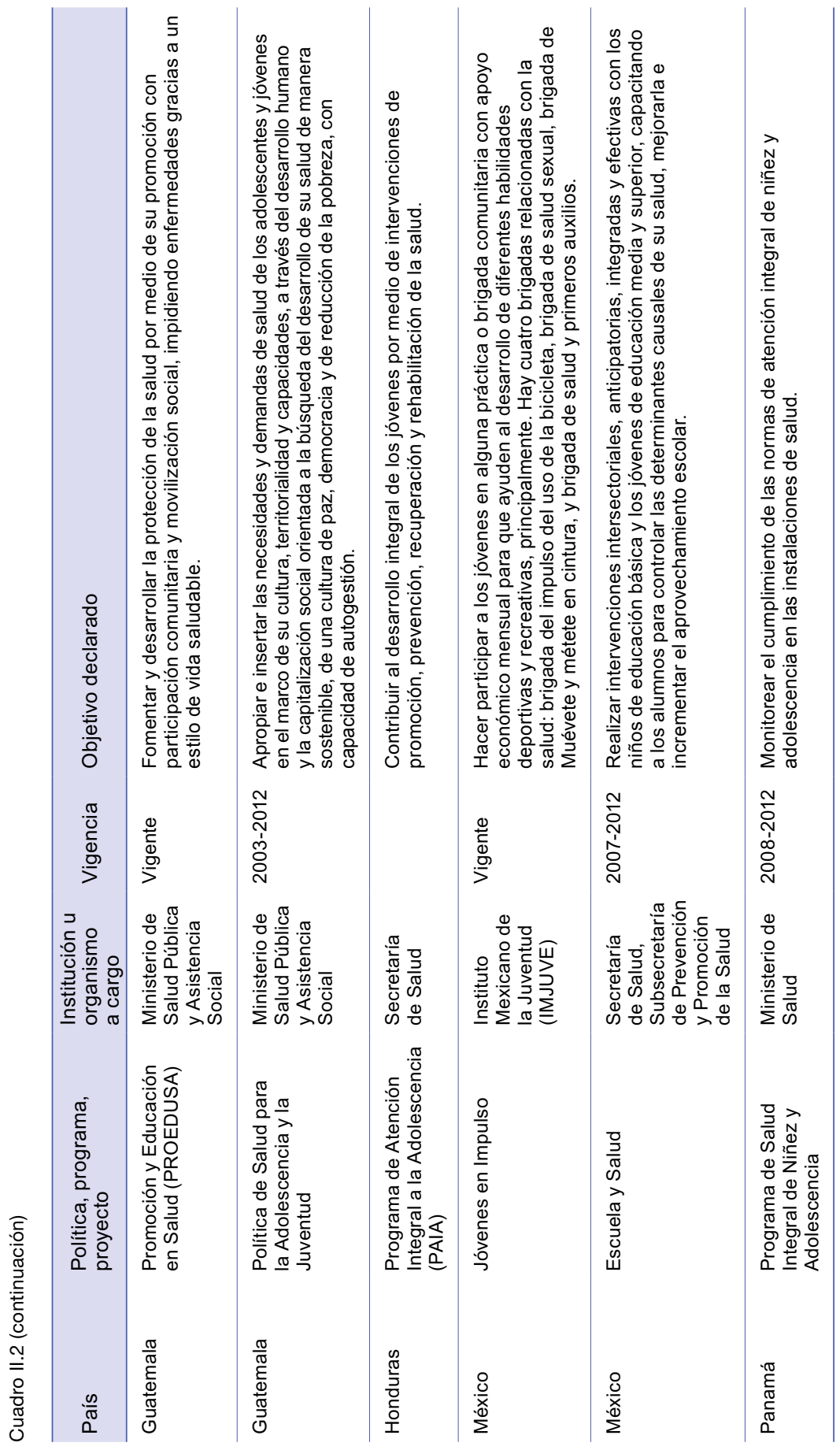




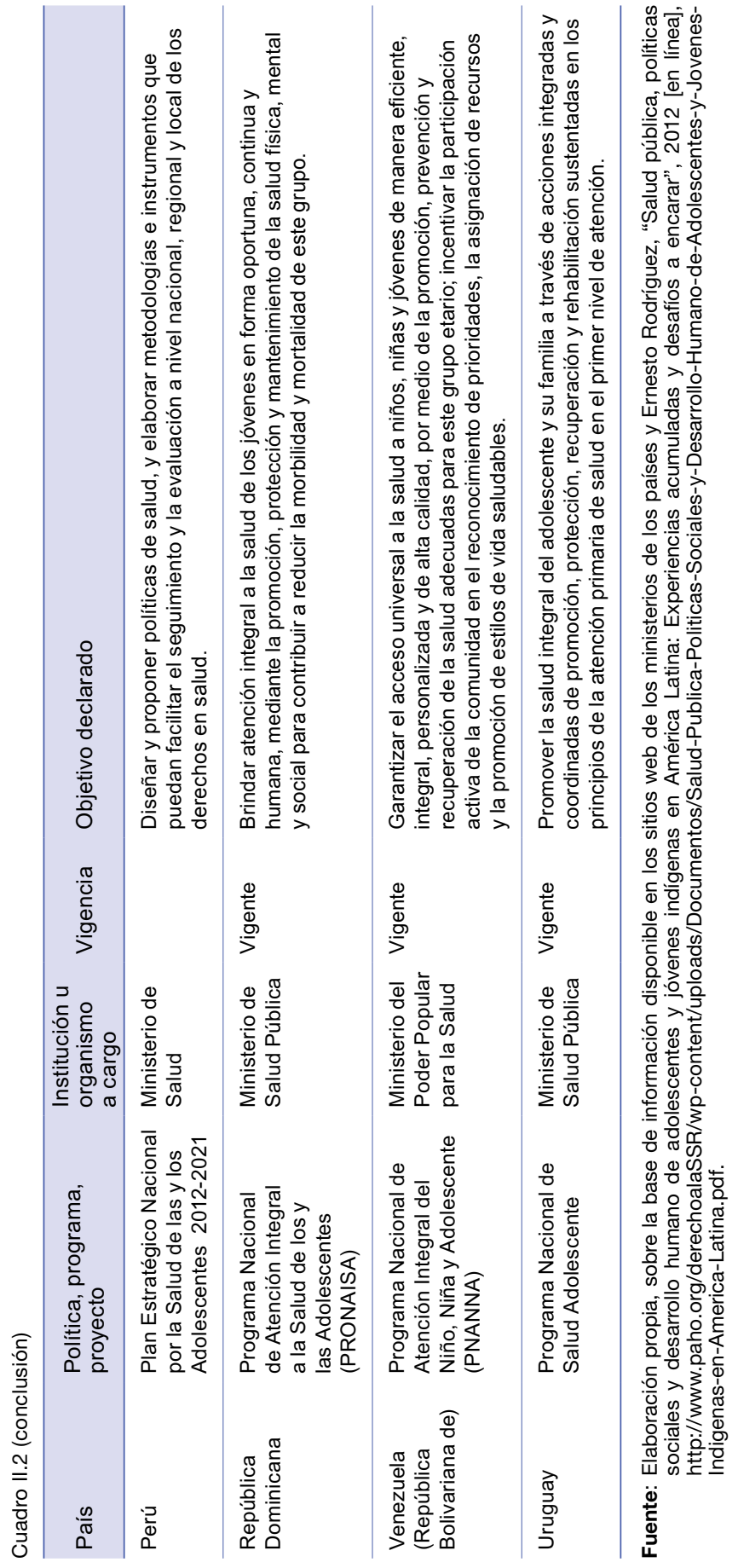


En el caso de la salud sexual y reproductiva (véase el cuadro II.3), muchos de los programas que buscan promover una sexualidad responsable entre los jóvenes son de carácter informativo. Se enfocan en transmitir conocimientos sobre la importancia del uso de preservativos o de la prevalencia y modos de transmisión del VIH u otras enfermedades de transmisión sexual y temas relacionados. Este tipo de información es muy necesaria, pero los conocimientos solos no van a incidir en la adopción de conductas que puedan llegar a proteger la salud. Un ejemplo claro es el uso de anticonceptivos: pese a que el conocimiento de los métodos de anticoncepción es casi universal en América Latina, muchos jóvenes no acceden a ellos ni los utilizan (CEPAL/OIJ, 2008). Hacen falta, entonces, intervenciones de tipo práctico, donde se facilite el acceso a métodos de anticoncepción, así como a estrategias de negociación dentro de la pareja que permitan mantener prácticas sexuales más seguras.

Como se mencionó en la sección correspondiente, la maternidad temprana está muy vinculada a las expectativas, los planes y las oportunidades de las jóvenes. En este sentido, se requieren políticas que abarquen la prevención del embarazo de una manera más amplia, no solo como un problema de educación sexual y reproductiva, y la disponibilidad y el uso de anticonceptivos, sino que atiendan a las oportunidades y los procesos de inclusión social de las jóvenes para que puedan desarrollar y llevar a cabo sus planes de vida.

Junto con los programas de prevención, se requieren programas que ayuden a las adolescentes que quedan embarazadas a finalizar el ciclo educativo. Es fundamental que las adolescentes embarazadas o madres cuenten con una red de apoyo que las motive a continuar con sus estudios y con programas integrales que provean apoyo económico y de cuidados, asesoría y atención psicosocial. Por último, es imperativo combatir la discriminación que enfrentan las adolescentes embarazadas y madres en el ámbito escolar.

En vista de la complejidad e interrelación de los factores que llevan al uso problemático de drogas y alcohol entre los jóvenes, para prevenir su consumo se requiere una perspectiva multidisciplinaria que abarque esta complejidad, incluyendo los contextos y espacios en que dicho consumo emerge. Por lo general, las políticas de la región (véase el cuadro II.4) no adoptan este enfoque, sino que se centran en el individuo: apuntan principalmente a fortalecer las capacidades de los jóvenes para resistir el uso de drogas, pero no al entorno en el que ellos se desenvuelven. 


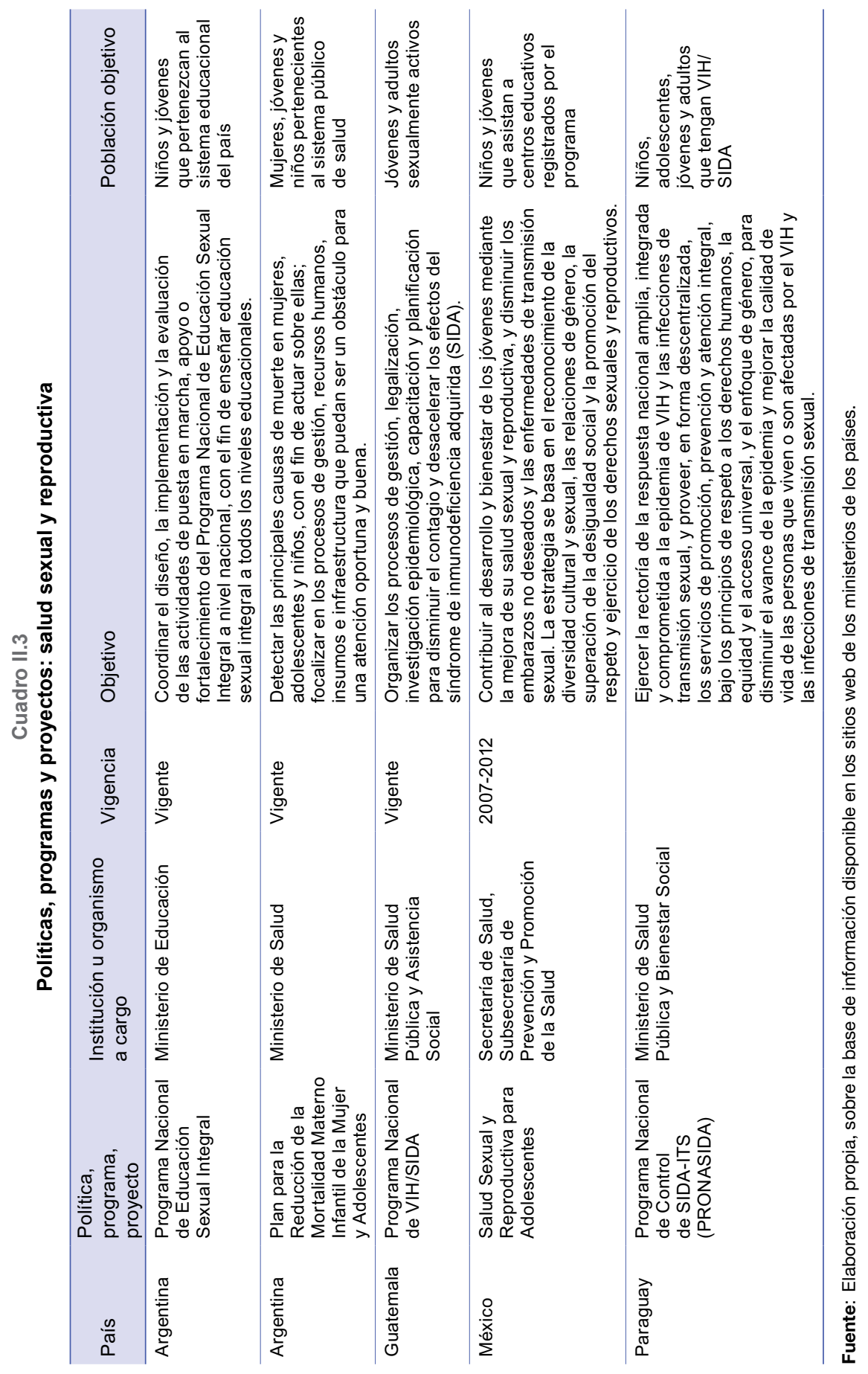




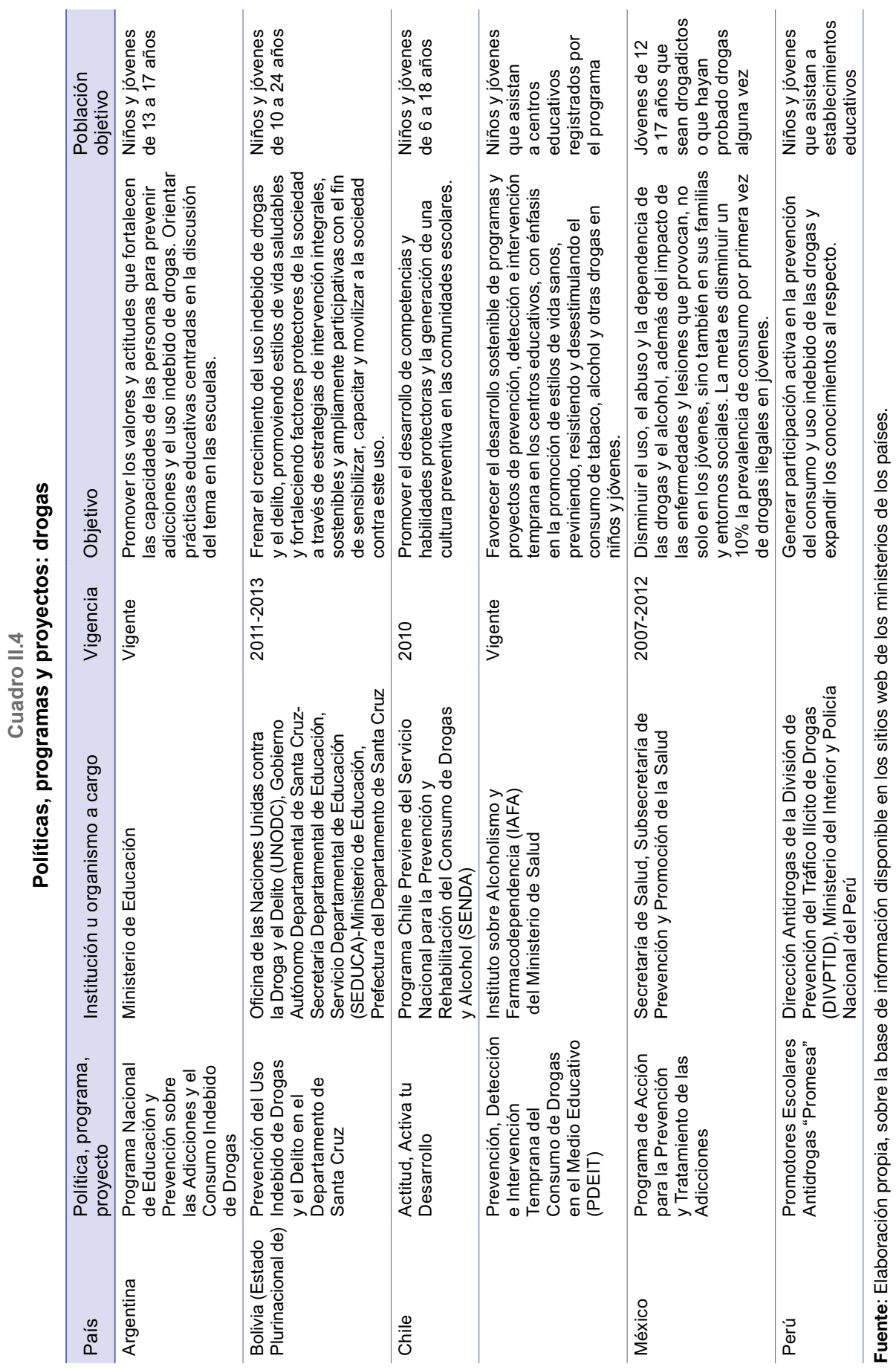


Pese a que el alcohol y el tabaco son las sustancias más usadas por los jóvenes, existen pocas políticas enfocadas a su uso, particularmente en el caso del cigarrillo. Además, teniendo en cuenta que son un público especialmente atractivo tanto para la industria del alcohol como para las tabacaleras, la política de salud debe estar articulada con una fuerte regulación de estos sectores.

Con relación a aquellos jóvenes que ya se encuentran en situación de dependencia de drogas, hay posturas, particularmente impulsadas por los medios, que se adhieren a visiones alarmistas que buscan armar una cruzada contra las drogas y los "drogadictos" (Hopenhayn y otros, 2002). Este abordaje es contraproducente. Los jóvenes que tienen una relación abusiva con las drogas o el alcohol enfrentan una situación difícil y requieren apoyo y no ser estigmatizados o discriminados. Nuevamente, son pocas las iniciativas que buscan proveer tratamiento para los jóvenes con dependencia de estas sustancias.

Esta realidad se sitúa en un contexto donde las políticas de control de drogas ilícitas son cada día más cuestionadas y donde se abre cada día un debate más intenso acerca de la necesidad de una política de drogas más eficaz, centrada en la salud y la seguridad. Esto requeriría un cambio de enfoque y una reorientación de las políticas y los recursos para promover intervenciones sociales y de salud, con el fin de reducir la demanda y buscar alternativas al encarcelamiento para infractores dependientes de drogas, dejando de lado leyes punitivas que no han tenido resultado (OEA, 2014). Según datos recientes de la Organización de los Estados Americanos (OEA, 2013), 12 países de la región han despenalizado el consumo personal o reducido las sanciones por posesión de drogas respecto de la marihuana. Cabe destacar que estas iniciativas no han incrementado el consumo y han reducido la carga sobre los consumidores y el sistema judicial.

\section{Las políticas y los programas en materia de salud: ¿qué se podría mejorar?}

Este breve resumen de las políticas de salud evidencia algunos vacíos. El hecho de que muchos de los programas de salud estén vinculados a las escuelas, aunque intuitivo, es problemático, ya que excluye a jóvenes que están afuera del sistema educativo y que, justamente, enfrentan múltiples desafíos para tener un buen estado de salud. Por otra parte, son pocas las políticas que incluyen a la población mayor de 19 años y, menos aún, a los mayores de 24 años. Como señala Rodríguez (2011), sería ideal implementar políticas públicas que adopten una perspectiva generacional y que acompañen a las personas a lo largo de todo el ciclo de vida. Esto 
es especialmente relevante en el caso de la salud, ya que es una condición que se desarrolla a lo largo de la vida y cada etapa influye en la siguiente. Esto se ve claramente en el caso de la salud mental, pues los problemas que aquejan a las mujeres jóvenes en este ámbito continúan en la adultez, etapa donde también se evidencia una mayor prevalencia de problemas de salud mental entre las mujeres.

Se constata una escasez de programas dirigidos específicamente a la salud mental. En algunas evaluaciones llevadas a cabo en la región se han identificado grandes déficits en la oferta de servicios de salud mental y recursos dirigidos a este ámbito, tanto en términos de recursos financieros como de recursos humanos especializados para proveer tratamientos (OPS, 2009; Rodríguez, 2007 y 2010). Además, se advierte que la distribución de los pocos servicios existentes está muy concentrada en las zonas urbanas. Todo esto provoca una brecha en el tratamiento de los problemas de salud mental entre quienes necesitan dicho tratamiento y quienes lo reciben, la que es más aguda entre los jóvenes que entre los adultos (Rodríguez, 2010). Por otra parte, en algunas investigaciones se ha destacado que la estructura de los servicios de salud mental no corresponde a las necesidades de los jóvenes con estos problemas, ya que los servicios ofrecidos se centran en trastornos graves, pero poco comunes (Belfer y Rohde, 2005).

Como señala la CEPAL (2014b), para atender las necesidades de los jóvenes con problemas de salud mental se requieren estrategias de prevención y tratamiento adecuadas a sus realidades. Para promover la salud mental en la población joven, las intervenciones de prevención deben apuntar a ser universales y considerar programas enfocados a poblaciones de alto riesgo. Resultan especialmente prometedores, por ejemplo, los programas que buscan promover competencias, como regulación emocional, habilidades sociales y resolución de conflictos. Algunos modelos de prevención están orientados a nivel de la familia, la escuela, el trabajo y la comunidad, mientras que otros responden a una noción de multinivel.

Otra observación general respecto de las políticas de salud dirigidas a los jóvenes es que se centran en prevención primaria (buscan reducir o eliminar la posibilidad de que los jóvenes adopten conductas que pueden perjudicar su salud), con poca oferta de prevención secundaria o terciaria ${ }^{7}$. Aun cuando existen programas orientados al tratamiento y la rehabilitación, la accesibilidad económica y geográfica, así como el miedo a la exclusión y la estigmatización, actúan como barreras de uso de estos servicios por parte de los jóvenes. La falta de reconocimiento, por parte de los propios jóvenes, de problemas de salud mental o de adicciones también

\footnotetext{
La prevención primaria busca evitar la adquisición de una enfermedad o problema, mientras que la prevención secundaria apunta a detectar una enfermedad o problema en etapas precoces para impedir su progresión, con énfasis en poblaciones vulnerables. La prevención terciaria incluye medidas dirigidas al tratamiento y la rehabilitación de una enfermedad o problema de salud.
} 
obstaculiza la utilización de servicios de salud mental, lo que apunta a la necesidad de visualizar y desestigmatizar esta problemática y concientizar sobre su reconocimiento.

Finalmente, dada la interrelación entre los temas de salud (salud sexual y reproductiva, salud mental y uso abusivo de drogas y alcohol), es necesario construir propuestas de políticas que sean más integradas. Además de los contenidos sustantivos, la manera en que se transmite la información también debe adecuarse a las realidades de los jóvenes. Hay que recurrir, por ejemplo, a las redes sociales para reforzar mensajes de prevención o para facilitar el acceso a un tratamiento y su seguimiento posterior. Otra estrategia que algunos de los programas utilizan, y que puede ser eficaz, es el modelo de educación por pares, en el que los pares ejercen como educadores en sesiones sobre salud.

Este abordaje más holístico buscaría, además, fortalecer los factores protectores en la vida de los jóvenes, especialmente de aquellos que enfrentan otras condiciones de exclusión, y no solo centrarse en la reducción de riesgos. No se trata de destacar una estrategia por sobre otras, pero cuando se implementan en conjunto es más probable que los comportamientos que conllevan riesgos para la salud de los jóvenes se reduzcan de manera significativa.

De este modo, para crear entornos que favorezcan buenos estados de salud que faciliten la inclusión social es importante ofrecer conocimientos y estrategias para que los jóvenes puedan tomar buenas decisiones respecto de su salud. Al mismo tiempo, se pone énfasis en la necesidad de incidir sobre los riesgos y los factores de protección que surgen donde ellos se desenvuelven (contexto familiar, escolar y comunitario).

\section{Recomendaciones}

Las observaciones bosquejadas se sintetizan en las siguientes recomendaciones para fortalecer las respuestas de políticas, a fin de contribuir al mejoramiento de la salud de los jóvenes en América Latina y el Caribe.

\section{Mejorar la información acerca de las juventudes latinoamericanas en el ámbito de la salud, con el fin de desarrollar políticas basadas en evidencia}

Como se manifestó a lo largo de este capítulo, los datos relacionados con la salud de los jóvenes son escasos, no solo desde el punto de vista de la epidemiología, sino también respecto del uso y la satisfacción con los servicios de atención médica. Sin esta información, es difícil elaborar políticas que respondan a las necesidades de salud de la juventud y mucho menos monitorear y evaluar si estas han sido exitosas. Aunque varios países de la región han realizado encuestas nacionales de juventud, si 
se trata de instancias aisladas que no tienen seguimiento a lo largo del tiempo, será difícil entender cómo evoluciona la salud de la población joven o monitorear el impacto de las políticas y los programas que se implementaron para mejorar la salud de esta población ${ }^{8}$.

\section{Fortalecer servicios específicamente dirigidos a jóvenes, sensibles a las diferencias culturales y con especial énfasis en la confidencialidad}

Los servicios de prevención, atención y tratamiento de los jóvenes deben adaptarse a sus realidades (a su etapa de desarrollo psicoemocional y a su entorno social, económico, cultural y familiar) y, desde luego, han de enfocarse en los temas de salud de mayor relevancia en este grupo poblacional. $\mathrm{Al}$ proveer estos servicios, es imprescindible respetar la autonomía de los jóvenes en la toma de decisiones y asegurar la confidencialidad.

\section{Profundizar la intersectorialidad de las políticas}

Pese a los estrechos vínculos entre los sectores de salud y educación, la salud de los jóvenes también puede promoverse desde otros sectores. Se recomienda fomentar una mayor coordinación institucional a nivel nacional y local entre las instancias responsables de la juventud y aquellas que desarrollan programas o proyectos que, directa o indirectamente, atañen al sector juvenil (educación, salud, seguridad, empleo y demás). De ese modo, se evita que las "políticas de juventud" sean tan solo una lista de políticas sectoriales y se refuerzan mutuamente.

\section{Aumentar los recursos destinados a promover la salud entre los jóvenes}

A medida que la población de la región envejece, la distribución de recursos públicos se dirigirá a atender las necesidades de la población de adultos mayores, en detrimento de otros grupos etarios, sobre todo en el sector de la salud (Rossel, 2013). En virtud de ello, y debido a que, en proporción, habrá menos jóvenes en el futuro, es necesario invertir para que estos puedan contribuir plenamente al desarrollo económico y social de sus comunidades y países. Se trata no solo de invertir recursos financieros, sino también de asegurar que el personal de salud esté capacitado para trabajar con la población juvenil.

\section{Bibliografía}

Anand, Sudhir y Kara Hanson (1997), “Disability-adjusted life years: A critical perspective", Journal of Health Economics, vol. 16, N 6, Amsterdam, Elsevier.

Belfer, Myron Lowell y Luis Augusto Rohde (2005), “Child and adolescent mental health in Latin America and the Caribbean: Problems, progress, and policy research", Revista Panamericana de Salud Pública, vol. 18, Nº 4/5.

8 Para mayor información véase [en línea] http://www.celaju.net/herramientas-de-trabajo/ encuestas-nacionales-de-juventud/. 
Bradshaw, Catherine P., Lindsey M. O’Brennan y Clea A. McNeely (2008), "Core competencies and the prevention of school failure and early school leaving", New Directions for Child and Adolescent Development, vol. 2008, $\mathrm{N}^{\circ} 122$, Wiley.

CEPAL (Comisión Económica para América Latina y el Caribe) (2014a), América Latina y el Caribe en la agenda para el desarrollo después de 2015: Reflexiones preliminares basadas en la trilogía de la igualdad (LC/L.3843), Santiago. (2014b), Panorama Social de América Latina 2014 (LC/G.2635-P), Santiago. Publicación de las Naciones Unidas, Nº de venta: S.14.II.G.6. (2014c), Pactos para la igualdad: Hacia un futuro sostenible (LC/G.2639), Santiago. (2010), La hora de la igualdad: Brechas por cerrar, caminos por abrir (LC/G.2432 (SES.33/3)), Santiago.

CEPAL/CELADE (Comisión Económica para América Latina y el Caribe/Centro Latinoamericano y Caribeño de Demografía-División de Población de la CEPAL) (2010), "Mortalidad", Observatorio Demográfico, No 9 (LC/G.2490-P), Santiago. Publicación de las Naciones Unidas, Nº de venta: S.11.II.G.34.

CEPAL/OIJ (Comisión Económica para América Latina y el Caribe/Organización Iberoamericana de Juventud) (2008), Juventud y cohesión social en Iberoamérica. Un modelo para armar (LC/G.2391), Santiago, octubre.

CEPAL/OPS (Comisión Económica para América Latina y el Caribe/Organización Panamericana de la Salud) (2011), "Salud de la población joven indígena en América Latina: Un panorama general" (LC/R.2171), Santiago.

CEPAL/UNFPA (Comisión Económica para América Latina y el Caribe/Fondo de Población de las Naciones Unidas) (2012), Informe regional de población en América Latina y el Caribe 2011: Invertir en Juventud (LC/G.2391), Santiago.

CEPAL/UNICEF (Comisión Económica para América Latina y el Caribe/Fondo de las Naciones Unidas para la Infancia) (2007), "Maternidad adolescente en América Latina y el Caribe: Tendencias, problemas y desafíos", Desafíos. Boletín de la Infancia y Adolescencia sobre el Avance de los Objetivos de Desarrollo del Milenio, $\mathrm{N}^{\circ} 4$ [en línea] http://repositorio.cepal.org/bitstream/handle/11362/35990/ desafios_4_esp_Final_es.pdf?sequence $=1$.

Donenberg, Geri R. y Maryland Pao (2005), "Youths and HIV/AIDS: Psychiatry's role in a changing epidemic", Journal of the American Academy of Child $\mathcal{E}$ Adolescent Psychiatry, vol. 44, No 8.

Fuhrer, Rebecca y otros (1999), "Gender, social relations and mental health: Prospective findings from an occupational cohort (Whitehall II study)", Social Science $\mathcal{E}$ Medicine, vol. 48, No 1, Amsterdam, Elsevier.

Gaviria, Silvia y Marta B. Rondon (2010), “Some considerations on women's mental health in Latin America and the Caribbean", International Review of Psychiatry, vol. $22, \mathrm{~N}^{\mathrm{o}} 4$.

Guzmán, José Miguel y otros (2006), “The demography of Latin America and the Caribbean since 1950", Population, vol. 61.

Hatzenbuehler, Mark L. y Bruce G. Link (2014), "Introduction to the special issue on structural stigma and health", Social Science E Medicine, vol. 10 [en línea], http:/ / dx.doi.org/10.1016/j.socscimed.2013.12.017.

Hopenhayn, Martin, Iban de Rementería y Guillermo Sunkel (1999), "Criterios básicos para una política de prevención y tratamiento de drogas en Chile", serie Políticas Sociales, N 34 (LC/L.1247-P), Santiago, Comisión Económica para América Latina y el Caribe (CEPAL). Publicación de las Naciones Unidas, Nº de venta: S.99.II.G.49. 
Hopenhayn, Martín y otros (2002), "Prevenir en drogas: Enfoques integrales y contextos culturales para alimentar buenas prácticas", serie Politicas Sociales, N 61 (LC/L.1789-P) Santiago, Comisión Económica para América Latina y el Caribe (CEPAL). Publicación de las Naciones Unidas, $N^{\circ}$ de venta: S.02.II.G.103.

INJUV (Instituto Nacional de Juventud) (2013), 7ma Encuesta Nacional de Juventud 2012, Santiago.

Institute for Health Metrics and Evaluation [en línea] http://vizhub.healthdata. org/gbd-compare.

Krauskopf, Dina (2000), Participación social y desarrollo en la adolescencia, San José, Fondo de Población de las Naciones Unidas (UNFPA).

Link, Bruce G. y Jo Phelan (2014) "Stigma power", Social Science E Medicine, vol. 103 [en línea], http:/ /dx.doi.org/10.1016/j.socscimed.2013.07.035.

(1995), "Social conditions as fundamental causes of disease", Journal of Health and Social Behavior, vol. 35, American Sociological Association.

Maddaleno, Matilde, Paola Morello y Francisca Infante-Espínola (2003), "Salud y desarrollo de adolescentes y jóvenes en Latinoamérica y el Caribe: Desafíos para la próxima década", Salud Pública de México, vol. 45, suplemento 1, Cuernavaca, Instituto Nacional de Salud Pública.

Marmot, Michael y Richard G. Wilkinson (2006), Social Determinants of Health, Nueva York, Oxford University Press.

Martínez, Rodrigo y Amalia Palma (2014), “Seguridad alimentaria y nutricional en cuatro países andinos: una propuesta de seguimiento y análisis", serie Políticas Sociales, N 187 (LC/L.3750), Santiago, Comisión Económica para América Latina y el Caribe (CEPAL).

Naciones Unidas (2014), Mental Health Matters: Social Inclusion of Youth with Mental Health Conditions, Nueva York.

Näslund-Hadley, Emma y Georgina Binstock (2011), “El fracaso educativo: Embarazos para no ir a clases", Notas Técnicas, $N^{\circ}$ IDB-TN-281, Washington, D.C., Banco Interamericano de Desarrollo (BID).

(2010), "The miseducation of Latin American girls: Poor schooling makes pregnancy a rational choice", Notas Técnicas, $\mathrm{N}^{\circ}$ IDB-TN-204, Banco Interamericano de Desarrollo (BID).

National Institute on Drug Abuse (2009), Principles of Drug Addiction Treatment: A Research-Based Guide, segunda edición.

Neumayer, Eric y Thomas Plümper (2007), "The gendered nature of natural disasters: The impact of catastrophic events on the gender gap in life expectancy, 1981-2002", Annals of the Association of American Geographers, vol. 97, No 3.

Nishikiori, Nobuyuki y otros (2006), "Who died as a result of the tsunami? Risk factors of mortality among internally displaced persons in Sri Lanka: A retrospective cohort analysis", BMC Public Health, vol. N ${ }^{\circ} 6$.

OEA (Organización de los Estados Americanos) (2014), El informe de drogas de la OEA: 16 meses de debates y consensos, Washington, D.C. (2013), El problema de las drogas en las Américas, Washington, D.C.

OMS (Organización Mundial de la Salud) (2010a), Encuesta Mundial de Salud a Escolares 2010.

(2010b), Salud mental y desarrollo: Poniendo el objetivo en las personas con problemas de salud mental como un grupo vulnerable, Ginebra [en línea] http:/ / www.who.int/mental_health/policy/mhtargeting/en/.

(2002), Informe mundial sobre la violencia y la salud, Ginebra. 
(1948), "Constitución de la Organización Mundial de la Salud" [en línea] http:/ / www.who.int/governance/eb/constitution/es/.

OPS (Organización Panamericana de la Salud) (2015), Informe sobre la situación de la seguridad vial en la región de las Américas, Washington, D.C. [en línea] http:/ / unasev.gub.uy/wps/wcm/connect/unasev/5fb3f2d1-ffdc-40f1-bd4382de1794ed60/OMS_OPS_Informe+sobre+la+situaci\%C3\%B3n+de+la+Seguri $\mathrm{dad}+\mathrm{Vial}+\mathrm{de}+\mathrm{las}+\mathrm{Am} \% \mathrm{C3} \%$ A9ricas_2015.pdf?MOD=AJPERES\&CONVERT_ $\mathrm{TO}=$ url \&CACHEID $=5 \mathrm{fb} 3 \mathrm{f} 2 \mathrm{~d} 1-\mathrm{ffdc}-40 \mathrm{f} 1-\mathrm{bd} 43-82 \mathrm{de} 1794 \mathrm{ed} 60$.

(2010), Salud sexual y reproductiva y VIH de los jóvenes y adolescentes indígenas en Bolivia, Ecuador, Guatemala, Nicaragua y Perú, Washington, D.C.

(2009), “WHO-AIMS Country Reports" [en línea] http://new.paho.org/hq/ index.php?option=com_content\&task=view\&id=445\&Itemid=1106\&lang=en y http://www.who.int/mental_health/who_aims_country_reports/en/index.html.

Oviedo, Myriam y María Cristina García (2011), “El embarazo en situación de adolescencia: Una impostura en la subjetividad femenina", Revista Latinoamericana de Ciencias Sociales, Niñez y Juventud, vol. 9, № 2.

Parker, Robert Nash y Kathleen Auerhahn (1998), "Alcohol, drugs, and violence", Annual Review of Sociology, vol. 24.

Pasqualini, Diana y Alfredo Llorens (comps.) (2010), Salud y bienestar de los adolescentes y jóvenes: Una mirada integral, Buenos Aires, Organización Panamericana de la Salud (OPS).

Patel, Vikram y otros (2007), "Mental health of young people: A global public-health challenge", The Lancet, vol. 369, Nº 9569 [en línea], http:/ / search.proquest.com/ docview / 199076575 ? accountid $=41816$.

Pilgrim, Nanlesta y Robert Blum (2012), "Protective and risk factors associated with adolescent sexual and reproductive health in the English-speaking Caribbean: A literature review", Journal of Adolescent Health, vol. 50, $\mathrm{N}^{\mathrm{o}} 1$.

Quinlan-Davidson, M. y otros (2014), "Suicide among young people in the Americas", Journal of Adolescent Health, vol. 54, Nº 3 .

Reith, Gerda (2004), "Consumption and its discontents: Addiction, identity and the problems of freedom", The British Journal of Sociology, vol. 55, $\mathrm{N}^{\circ} 2$, Wiley.

Rico, Maria Nieves y Daniela Trucco (2014), "Adolescentes: Derecho a la educación y al bienestar futuro", serie Políticas Sociales, N 190 (LC/L.3791), Santiago, Comisión Económica para América Latina y el Caribe (CEPAL) [en línea], http:/ / www.unicef.org/lac/Adolescentes_derecho_educacion_bienestar_futuro.pdf.

Rodríguez, Ernesto (2012), "Salud pública, políticas sociales y desarrollo humano de adolescentes y jóvenes indígenas en América Latina: Experiencias acumuladas y desafíos a encarar" [en línea], http://www.paho.org/derechoalaSSR/wpcontent/uploads/Documentos/Salud-Publica-Politicas-Sociales-y-DesarrolloHumano-de-Adolescentes-y-Jovenes-Indigenas-en-America-Latina.pdf. (2011), "Políticas de juventud y desarrollo social en América Latina: Bases para la construcción de respuestas integradas", Documento de Trabajo, VIII Foro de Ministros de Desarrollo Social de América Latina (San Salvador, 11 y 12 de julio de 2011).

Rodríguez V., Jorge (2014), “La reproducción en la adolescencia y sus desigualdades en América Latina. Introducción al análisis demográfico, con énfasis en el uso de microdatos censales de la ronda de 2010", Documento de Proyecto (LC/W.605) Santiago, Comisión Económica para América Latina y el Caribe (CEPAL). 
(2012), “La reproducción en la adolescencia en América Latina: Viejas y nuevas vulnerabilidades", Realidad Datos y Espacio. Revista Internacional de Estadística y Geografía, vol. 3, N² 2, Instituto Nacional de Estadística y Geografía. (2008), Reproducción adolescente y desigualdades en América Latina y el Caribe: Un llamado a la reflexión y a la acción, Santiago, Comisión Económica para América Latina y el Caribe (CEPAL).

Rodríguez, Jorge J. (2010), "Mental health care systems in Latin America and the Caribbean", International Review of Psychiatry, vol. 22, $\mathrm{N}^{\circ} 4$. (2007), La reforma de los servicios de salud mental: 15 años después de la Declaración de Caracas, Washington, D.C., Organización Panamericana de la Salud (OPS) [en línea], http:/ /www.ops-oms.org.pa/Lz_HAA/Doc/Agenda.pdf.

Rossel, Cecilia (2013), "Desbalance etario del bienestar. El lugar de la infancia en la protección social en América Latina", serie Políticas Sociales, Nº 176 (LC/L.3574), Santiago, Comisión Económica para América Latina y el Caribe (CEPAL).

Seedat, Soraya y otros (2009), "Cross-national associations between gender and mental disorders in the World Health Organization World Mental Health Surveys", Archives of General Psychiatry, vol. 66, N 7 .

SESC/CONJUVE/INE (Secretaria Ejecutiva del Servicio Cívico/Consejo Nacional de Juventud/ Instituto Nacional de Estadística) (2011), Primera Encuesta Nacional de Juventud en Guatemala (ENJU 2011), Ciudad de Guatemala.

Teti, Germán y otros (2014), "Systematic review of risk factors for suicide and suicide attempt among psychiatric patients in Latin America and Caribbean", Revista Panamericana de Salud Publica, vol. 36, $\mathrm{N}^{\circ} 2$.

UNFPA (Fondo de Población de las Naciones Unidas) (2014), Estado de la población mundial 2014. El poder de 1800 millones: Los adolescentes, los jóvenes y la transformación del futuro, Nueva York, Naciones Unidas, noviembre.

Viner, R.M. y otros (2012), "Adolescence and the social determinants of health", The Lancet, vol. 379, $\mathrm{N}^{\circ} 9826$ [en línea] http://search.proquest.com/docview/1015 610268 ? accountid $=41816$. 


\section{Capítulo III \\ Inclusión y contextos de violencia}

Humberto Soto

Daniela Trucco ${ }^{1}$

\section{A. Violencia y juventud ${ }^{2}$}

Los países de América Latina y el Caribe no pueden afrontar los retos y desafíos para avanzar en el camino de la igualdad y alcanzar mayores niveles de inclusión social juvenil en materia de reducción de la pobreza, educación, empleo o salud sin tomar en cuenta de manera integral los elementos de contexto prevalecientes en la región. La transición demográfica, el proceso de urbanización, el avance tecnológico y la inseguridad alimentaria son solo algunos de dichos elementos, entre los que se destacan especialmente la inseguridad humana y la violencia.

En los últimos años, los importantes avances de los países de la región en materia de desarrollo, incluidos algunos muy positivos para los jóvenes, han convivido paradójicamente con aumentos de los índices de violencia e inseguridad. A diferencia de lo que ocurre en otras regiones

Los autores agradecen los aportes conceptuales y estadísticos de los consultores Sebastián Möller, Carlos Mario Perea y Matías Sálces. También agradecen los comentarios y sugerencias de Néstor López del Instituto Internacional de Planeamiento de la Educación (IIPE) de la Organización de las Naciones Unidas para la Educación, la Ciencia y la Cultura (UNESCO), Buenos Aires.

2 Gran parte de esta revisión conceptual fue desarrollada en el Panorama Social de América Latina 2014 (CEPAL, 2014). 
del mundo, en América Latina y el Caribe, los Estados conviven en paz, pero observan una violencia extrema en la sociedad civil, al punto de convertirse en la zona con la mayor tasa de homicidios del mundo (UNODC, 2014, pág. 22).

La violencia (intencional y no intencional) constituye la primera causa de muerte en la población de 15 a 50 años de la región. Asimismo, 7 de los 14 países más violentos del mundo están en América Latina y el Caribe: Belice, Colombia, El Salvador, Guatemala, Honduras, Jamaica y Venezuela (República Bolivariana de). Entre 2000 y 2010, la tasa de homicidios aumentó un $11 \%$, mientras que en la mayoría de las regiones del mundo descendió o se mantuvo constante. Por otra parte, en los países que cuentan con información disponible se observa que los robos casi se han triplicado en los últimos 25 años. Además, en un día típico en América Latina, 460 personas, principalmente mujeres, sufren las consecuencias de la violencia sexual (PNUD, 2013).

Este contexto de violencia e inseguridad afecta de manera particular a la población juvenil. Como se detalló en el capítulo II, la violencia es la principal causa de muerte entre los jóvenes. En este capítulo se mostrará que ese hecho es solo la cara más visible de una problemática que afecta a los jóvenes de distintas maneras, al verse a menudo involucrados en manifestaciones de violencia, ya sea como víctimas o como autores, en ámbitos que van desde lo familiar hasta lo colectivo, y con causas y consecuencias muy diversas, en su mayoría muy propias de esa etapa de la vida.

Esta aparente mayor prevalencia de las manifestaciones violentas entre la juventud ha transformado el fenómeno en un estigma, que presenta al joven - por la etapa de vida en la que se encuentra- como delincuente y violento, distorsionando la mirada sobre el problema y sus posibles soluciones.

\section{Multidimensionalidad de la violencia: manifestaciones en la juventud}

El concepto de violencia es multidimensional, ya que se manifiesta en diversos ámbitos y espacios, y afecta de distinta manera y con diversos tipos de consecuencias a los actores involucrados. Debido a esta complejidad, un análisis del contexto de violencia en el entorno juvenil requiere definir un marco ordenador que permita estructurarlo. El marco ordenador utilizado en este capítulo se basa en la complementariedad de dos de las tipologías de violencia más utilizadas en la investigación sobre el tema en los últimos años: la propuesta por Galtung (1990) y la derivada del modelo ecológico desarrollado por Bronffenbrenner en 1979 y retomada por la Organización Mundial de la Salud (OMS) en 2002. 
La tipología propuesta por Galtung facilita la identificación de los actores (perpetradores y víctimas) y las formas en que se ejerce violencia mediante los tipos que define: directa (perpetrada entre individuos de manera personal), estructural (perpetrada en el colectivo con base en la desigualdad de la sociedad) y cultural o simbólica (perpetrada hacia personas o grupos mediante la imposición de formas de pensar o percepciones).

\section{Recuadro III.1 \\ Tipología de violencia propuesta por Galtung, 1990}

La tipología de Galtung permite distinguir las dinámicas en los procesos de violencia y propone los siguientes tipos:

Violencia directa: es la más visible y se concreta mediante actos violentos (físicos, verbales o psicológicos) con la intención de dañar a una persona o grupo, y puede estar dirigida a personas, a una colectividad o a la naturaleza.

Violencia estructural: se refiere a las desigualdades plasmadas en la estructura de la sociedad, las cuales excluyen, e incluso eliminan paulatinamente, a ciertos grupos al no ofrecerles posibilidades de alimentación, vivienda, salud, empleo, seguridad y recreo, entre otras. Se manifiesta mediante la exclusión social, la desigualdad socioeconómica, el racismo, la desigualdad por razón de sexo o cualquier otra forma de discriminación que menoscabe el bienestar humano.

Violencia cultural o simbólica: implica la imposición y reproducción de un sistema de pensamiento y percepciones que legitiman un orden social desigual, como el explicado anteriormente. Según Galtung, esto puede llevarse a cabo de dos formas: trastocando los criterios de juicio moral sobre las prácticas violentas o invisibilizando estas prácticas de modo que no pueda producirse ningún juicio crítico (Galtung, 1990).

Fuente: Johan Galtung, "Cultural violence", Journal of Peace Research, vol. 27, № 3, SAGE, 1990.

La tipología utilizada por la OMS a partir del modelo ecológico se usa para complementar la de Galtung, ya que permite identificar con mayor claridad los ámbitos en que se ejerce la violencia, así como sus posibles consecuencias, mediante los tipos que define: autoinfligida (comportamiento suicida y autolesiones), interpersonal (en la familia, hacia menores, la pareja o ancianos, y en la comunidad, entre conocidos o entre extraños) y colectiva (social, política o económica) ${ }^{3}$.

Esta clasificación de la violencia es particularmente utilizada por la Secretaría de la Integración Social Centroamericana (SISCA) y la Dirección de Seguridad Democrática del Sistema de la Integración Centroamericana (SICA) en su Marco Estratégico para la Prevención de la Violencia. 


\section{Recuadro III.2}

Tipología basada en el modelo ecológico (OMS, 2002)

El llamado "modelo ecológico", desarrollado por Bronffenbrenner en 1979 e incorporado más tarde por el Informe mundial sobre la violencia y la salud de la OMS (2002), es útil como modelo de análisis para comprender el fenómeno, ya que lo plantea como algo muy complejo que surge de la correlación de muchos factores de influencia individuales y específicos de contexto, que son relevantes en el entorno vital de los jóvenes. El modelo permite analizar los factores que influyen en el comportamiento (o que aumentan el riesgo de cometer o padecer actos violentos), clasificándolos en cuatro niveles que posteriormente definen los tres tipos de violencia. Los niveles son:

- Factores biológicos y de la historia personal que influyen en el comportamiento de los individuos y aumentan sus probabilidades de convertirse en víctimas o perpetradores de actos violentos. Entre los factores que pueden medirse $o$ rastrearse se encuentran las características demográficas (edad, educación e ingresos), los trastornos psíquicos o de personalidad, las toxicomanías y los antecedentes de comportamientos agresivos o de haber sufrido maltrato.

- Relaciones más cercanas, como las mantenidas con la familia, los amigos, las parejas y los compañeros, investigando cómo estas aumentan el riesgo de sufrir o perpetrar actos violentos. En la violencia juvenil, por ejemplo, tener amigos que cometan o alienten actos violentos puede elevar el riesgo de que un joven los sufra o los perpetre.

- Contextos comunitarios donde se desarrollan las relaciones sociales, como las escuelas, los lugares de trabajo y el vecindario, intentando identificar las características de estos ámbitos que aumentan el riesgo de actos violentos. A este nivel, dicho riesgo puede estar influido por factores como la movilidad de residencia (por ejemplo, el hecho de que las personas de un vecindario tiendan a permanecer en él durante largo tiempo o se trasladen con frecuencia), la densidad de población, los altos niveles de desempleo o la existencia de tráfico de drogas en la zona.

- Factores de carácter general relativos a la estructura de la sociedad que contribuyen a crear un clima donde se alienta o se inhibe la violencia, como la posibilidad de conseguir armas, y las normas sociales y culturales. Entre estas se incluyen las que conceden prioridad a los derechos de los progenitores sobre el bienestar de sus hijos, consideran el suicidio una opción personal más que un acto de violencia prevenible, reafirman la dominación masculina sobre las mujeres y los niños, y respaldan el uso excesivo de la fuerza policial contra los ciudadanos o apoyan los conflictos políticos. Otros factores más generales en este nivel son las políticas sanitarias, económicas, educativas y sociales que contribuyen a mantener las desigualdades económicas o sociales entre los grupos de la sociedad.

Fuente: Organización Mundial de la Salud (OMS), Informe mundial sobre la violencia y la salud, Washington, D.C., 2002.

La complementariedad de estas tipologías se establece a través de las combinaciones de las clases de violencia definidas en ambas. 
En el cuadro III.1 se muestra la forma matricial en que se ordenan las manifestaciones de violencia en la juventud.

\section{Cuadro III.1}

Manifestaciones de violencia en la juventud clasificadas de acuerdo con la complementariedad de las tipologías de Galtung y del modelo ecológico

\begin{tabular}{|c|c|c|c|c|}
\hline & & \multicolumn{3}{|c|}{ Tipología del modelo ecológico } \\
\hline & & Autoinfligida & Interpersonal & Colectiva \\
\hline \multirow{3}{*}{ 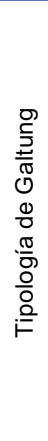 } & Directa & $\begin{array}{l}\text { Autolesiones y } \\
\text { suicidio }\end{array}$ & $\begin{array}{l}\text { Agresiones físicas o } \\
\text { psicológicas en el contexto } \\
\text { familiar, de o hacia la } \\
\text { pareja o amistades } \\
\text { cercanas }\end{array}$ & $\begin{array}{l}\text { Agresiones físicas o } \\
\text { psicológicas hacia } \\
\text { compañeros de escuela } \\
\text { (acoso o matonaje escolar } \\
\text { y ciberacoso), vecinos, } \\
\text { autoridades o pandillas }\end{array}$ \\
\hline & Estructural & Autoexclusión & $\begin{array}{l}\text { Discriminación en el ámbito } \\
\text { familiar o cercano por } \\
\text { características adscritas } \\
\text { (por ejemplo, filiación a } \\
\text { grupos minoritarios) }\end{array}$ & Exclusión social \\
\hline & Cultural/simbólica & Baja autoestima & $\begin{array}{l}\text { Exclusión asociada a } \\
\text { conceptos arraigados en la } \\
\text { cultura (por ejemplo, roles } \\
\text { tradicionales de género) }\end{array}$ & Estigmatización \\
\hline
\end{tabular}

Fuente: Elaboración propia.

La violencia directa autoinfligida, en la cual la persona es a la vez víctima y victimario, es un problema conductual con gran relevancia entre adolescentes y jóvenes, y generalmente se presenta en el ámbito familiar del hogar, con consecuencias que pueden llegar a ser extremas cuando conduce al suicidio (véanse más detalles sobre las estadísticas de problemas de salud mental y conductas suicidas en el capítulo II).

La violencia directa interpersonal puede ubicar al joven como víctima o perpetrador cuando se presenta en el ámbito familiar y es cometida por padres contra los hijos o por la pareja. También puede manifestarse en otros ámbitos, por parte de otros jóvenes o adultos, ya sean conocidos o no, con diversas consecuencias tanto físicas como psicológicas que afectan el desarrollo de los jóvenes y muchas veces modelan su comportamiento en otros ámbitos.

La violencia directa colectiva también puede poner a los jóvenes en posición de víctimas o victimarios al presentarse en entornos escolares o comunitarios, ya sea que se ejerza desde grupos juveniles hacia individuos (que pueden ser jóvenes o no) o desde grupos de vecinos o autoridades hacia individuos o grupos juveniles. Dos casos particulares de este tipo de violencia se han vuelto relevantes en el entorno juvenil: i) el enfrentamiento violento entre grupos de jóvenes, que puede tener notorias consecuencias sociales cuando, por ejemplo, se da entre 
pandillas y ii) el acoso o matonaje (bullying) escolar que se perpetra desde las redes sociales (ciberacoso o cyberbullying). Más adelante en este capítulo se profundizará en estos casos.

La violencia estructural permite identificar la forma en que se desarrollan los mecanismos de inclusión o exclusión y que muchas veces incluyen normas o legislaciones que avalan la exclusión de ciertos grupos, lo que es particularmente relevante entre los jóvenes. Si bien es importante cuando se da de forma autoinfligida, manifestándose a través de la autoexclusión, esta violencia generalmente viene acompañada de un proceso previo de exclusión que la motiva. Por ello, la violencia estructural adquiere particular importancia entre los jóvenes cuando es interpersonal (principalmente en el ámbito cercano) y colectiva, pues da lugar a un escenario de discriminación y exclusión social juvenil. Cabe señalar que si bien los jóvenes tienden a ser más víctimas que victimarios, en muchas ocasiones se presentan procesos de discriminación y exclusión social entre los mismos jóvenes que ponen a algunos de ellos en posición de perpetradores de diversas manifestaciones de violencia, como son los actos de delincuencia o vandalismo juveniles.

La violencia simbólica, que en general va más allá de las manifestaciones y puede conducir a la legitimación de la violencia en las relaciones sociales, adquiere, al igual que en el caso anterior, mayor trascendencia en las poblaciones jóvenes. Se presenta de manera interpersonal, en el ámbito familiar (por ejemplo, en la normalización de los roles tradicionales de género y la aceptación de la violencia intrafamiliar), o de manera colectiva, al llevar a la discriminación de ciertos grupos por rechazos culturalmente arraigados, como la pertenencia a determinada clase social, a una minoría (étnica, sexual u otra) o incluso a una organización juvenil de cierto tipo (pandilla), lo que agrava el estigma juvenil aludido con anterioridad.

El ordenamiento de las manifestaciones de violencia expuesto permite establecer las bases para realizar un análisis más detallado de las manifestaciones que tienen mayor relevancia para los procesos de inclusión juvenil. Debido a que la intención de este documento no se limita a analizar las manifestaciones de la violencia entre los jóvenes, sino que apunta a buscar alternativas para revertir este proceso, se ha considerado fundamental profundizar en dos aspectos de gran trascendencia. En primer lugar, se revisarán las posibles causas de las manifestaciones de violencia para tratar de entender por qué ocurren y cuáles son las mejores formas de evitarlas. En segundo término, se ahondará en los ámbitos o espacios en los que se expresan estas manifestaciones para conocer con mayor detalle dónde ocurren y, de ese modo, tener elementos para diseñar iniciativas para su reversión. 


\section{Multicausalidad de la violencia: factores facilitadores ${ }^{4}$}

Por su carácter multidimensional, la violencia es un fenómeno ubicuo, con múltiples factores de riesgo asociados (en distintos niveles), tanto en lo que respecta al perpetrador del acto violento como a los sujetos afectados (CEPAL/OIJ, 2008; OMS, 2002). En particular, la violencia que afecta a los jóvenes en su calidad de víctimas o victimarios es el resultado de un complejo entramado de factores de riesgo que se presentan en un determinado momento. Dichos factores de riesgo también pueden ser considerados factores posibilitadores o facilitadores de actitudes conducentes a la violencia.

A continuación se detallan algunos de los factores de riesgo (o posibilitadores) más mencionados en los análisis de la literatura internacional, que son de carácter más general y pueden llegar a motivar varias de las manifestaciones de violencia en la juventud ${ }^{5}$.

\section{a) La creciente desigualdad y la exclusión}

Varios estudios coinciden en que mientras la pobreza parece ser un factor agravante en todo tipo de violencia, la desigualdad y la creciente polarización económica-social muestran una asociación mucho más sistemática con los niveles de violencia, principalmente entre los jóvenes. Se ha encontrado que las comunidades más violentas son aquellas que muestran cierto "abandono" o falta de presencia por parte del Estado, como infraestructura en mal estado o carencia de servicios públicos (falta de alumbrado, de calles pavimentadas o de centros de salud, entre otros). De modo que quizás sea más adecuado hablar de un entorno social o comunitario de pobreza que de pobreza de las familias.

Un ejemplo es el caso de las pandillas que, como forma organizada de violencia colectiva (que se analizará más adelante), surgen en los barrios más abandonados por las instituciones del Estado, ya sea que estos estén integrados por las familias más pobres o no (Cruz 2004, pág. 287, citado en Escotto, 2015). En un estudio realizado en El Salvador se encontró que las comunidades más afectadas por las pandillas no son las que están integradas por las personas con menos ingresos, o "los más pobres de los pobres", sino aquellas en donde la carencia de recursos por parte de sus integrantes es más bien relativa (Cruz 2004, pág. 286, citado en Escotto, 2015).

Esto tiene estrecha relación con la tensión entre la expansión del consumo simbólico y la restricción del consumo material. Algunos autores

Este acápite se basa en el trabajo de Teresita Escotto (Escotto, 2015).

En este apartado se mencionan solo los factores de riesgo más reconocidos por especialistas en la materia. Los factores de riesgo, que operan a distintos niveles, pueden ser de varios tipos: sociales, económicos, culturales, políticos, situacionales, estructurales e institucionales. 
hablan de un desfase dramático entre las aspiraciones a una vida mejor y las oportunidades reales de lograrlo que viven grandes grupos de la población (Briceño y Zubillaga, 2001, pág. 171, citado en Escotto, 2015). En una sociedad cada vez más globalizada, las aspiraciones de consumo y bienestar inmediato van en aumento en las nuevas generaciones, en parte promovidas por el acceso generalizado a los medios de comunicación y la información. Pese a haber alcanzado niveles educativos y de bienestar impensados para sus progenitores, una parte importante de la población juvenil se enfrenta a una desilusión respecto de las posibilidades laborales a las que puede acceder (véase el capítulo II). Esa misma frustración de expectativas puede ser un mecanismo que gatille conductas violentas.

\section{b) Las secuelas de conflictos civiles}

Algunos países de América Latina y el Caribe han sufrido procesos sociohistóricos particulares que han determinado la raigambre de la violencia en su matriz cultural y en las prácticas de sus habitantes. Destacan en especial los períodos de transición posbélica y posdictatorial, donde la idea de violencia política comienza a relacionarse con otros tipos de violencia. De acuerdo con un estudio reciente del Banco Mundial, existen dos hipótesis principales acerca de la forma en que los conflictos de la región pudieron contribuir a un mayor nivel de violencia en el caso de Centroamérica, una de las subregiones que concentra los índices de violencia más alarmantes. Por una parte, la guerra pudo haber creado una cultura de la violencia entre la población en cuanto tendencia a depender de la violencia para arreglar los problemas, la que ha permeado entre los jóvenes. Más allá de esto, podría ser que las víctimas tiendan a vengarse o a aplicar la ley por mano propia. Por otra parte, el reciente conflicto armado pudo contribuir a un mayor nivel de violencia debido al traslado de armas de fuego y municiones a la región (Banco Mundial, 2011, pág. 21, citado en Escotto, 2015).

Según esta misma fuente, estudios independientes indican que en 2007 se encontraron en Centroamérica cerca de 4,5 millones de armas pequeñas, la gran mayoría de las cuales eran ilegales. Es de notar que, de acuerdo con este informe, muchos años después del fin de las últimas guerras civiles centroamericanas, las importaciones de armas aumentaron en los seis países de la subregión.

\section{c) El tráfico de drogas}

El tráfico de drogas fomenta la violencia de muchas formas, "incluyendo peleas entre organizaciones traficantes ( $y$ dentro de ellas), peleas entre traficantes y oficiales de la policía, aumento en la disponibilidad de las armas de fuego, y el debilitamiento del sistema de justicia penal al desviar recursos judiciales o corrompiendo el sistema 
judicial en sí" (Banco Mundial, 2011, pág. 11). El ajuste de cuentas mediante la modalidad del sicariato se ha convertido en una situación común, donde resalta la participación de jóvenes. De particular relevancia en esta región es el tráfico de cocaína, por el gran volumen de dinero asociado a esta actividad criminal, lo que genera una serie de distorsiones que se discutirán con mayor profundidad más adelante.

\section{d) Los procesos migratorios y las deportaciones}

El caso de la migración hacia los Estados Unidos es particularmente relevante, ya que este es el principal destino de la población emigrante de América Latina y el Caribe. Según el censo de 2010, en los Estados Unidos residían 21,2 millones de personas nacidas en algún país de la región, de las cuales el 55,2\% eran de origen mexicano, el 14,3\% eran de procedencia centroamericana, el 12,8\% tenía origen sudamericano y el 17,5\% eran de origen caribeño. Si se compara la población residente en los Estados Unidos con la población total de algunos países, se observa que la importancia relativa es mayor en el caso centroamericano. Por ejemplo, 1 de cada 5 salvadoreños, 1 de cada 10 mexicanos y 1 de cada 15 hondureños residen en los Estados Unidos. La quinta parte de los emigrantes son jóvenes de entre 15 y 29 años (CEPAL, 2014). Los procesos migratorios de Centroamérica a los Estados Unidos se iniciaron en la década de 1960 y se acentuaron en períodos de conflicto interno en países como El Salvador, Guatemala y Honduras.

En los primeros años de este proceso migratorio, a su arribo al territorio estadounidense, los jóvenes migrantes centroamericanos eran rechazados y segregados socialmente por los jóvenes de otras nacionalidades. Ello motivó que los jóvenes migrantes centroamericanos crearan pandillas para contrarrestar de forma violenta la exclusión social de que eran objeto. A finales de la década de 1980, el Servicio de Inmigración y Naturalización estadounidense empezó a deportar a jóvenes pandilleros, proceso que se acentuó en la década de 1990 a través del Violent Gang Task Force. Estos procesos de deportación condujeron a que muchos de los jóvenes que habían formado parte de esas pandillas replicaran dichos modelos de organización violenta a su retorno a los países de origen, lo que dio origen a gran parte de las pandillas más violentas que operan en la actualidad en Centroamérica (Savanije, 2007, pág.12, en Murcia, 2015).

$\mathrm{Si}$ bien los procesos migratorios han disminuido en intensidad, todavía continúan, y los jóvenes son uno de los segmentos de la población con mayores probabilidades de movilización, exponiéndose con ello a la violencia, la discriminación y los riesgos sanitarios. En casos extremos, las mujeres jóvenes pueden convertirse en víctimas de tráfico con fines de prostitución (SEGIB/OIJ, 2008, pág. 31, citado en Escotto, 2015). Los efectos adversos de la migración — principalmente de la migración internacionalpueden ser trascendentales en la vida de los migrantes jóvenes, quienes, al 
emprender el viaje migratorio, pueden enfrentarse a situaciones peligrosas y de violencia. Además, en el país de destino pueden ver limitados sus derechos y quedar expuestos a abusos por parte de los empleadores, a dificultades de acceso a servicios y a situaciones de discriminación y marginalización (CEPAL, 2014).

\section{e) La violencia intrafamiliar}

De acuerdo con los especialistas, un factor asociado a los comportamientos violentos es la transmisión intergeneracional del maltrato familiar: quienes presenciaron relaciones violentas en sus padres tienen mayores probabilidades de seguir estos modelos de respuesta, así como los estereotipos de rol para cada sexo en dicha interacción. Las formas violentas de crianza y el maltrato o abandono de los padres no solo contribuyen al desarrollo de conductas antisociales y autoagresivas, así como a la baja autoestima y la desesperanza, sino que limitan la posibilidad de los hijos de internalizar pautas de control y autocontrol, lo que se traduce en la incapacidad de manejar los sentimientos agresivos (Larraín, 2002, pág. 15, citado en Escotto, 2015).

\section{f) La falta de sentido de pertenencia de los jóvenes}

La falta de sentido de pertenencia - entendida como ausencia de adhesión a valores compartidos o a formas reconocidas de participación, carencia de disposición al reconocimiento de los otros en lo referente a percepciones sobre discriminación o nuevas prácticas comunicativas, y falta de confianza en las estructuras sociales y en las opciones de futuro- es causa importante de algunas manifestaciones de violencia. Se ha señalado, por ejemplo, que "la falta de identidad" ha motivado a que "muchas personas jóvenes se unan a maras debido a la ausencia de modelos positivos a seguir tanto en el hogar como en sus comunidades y a ser socialmente excluidos (de oportunidades de educación y de empleo)" (Banco Mundial, 2011, pág. 19, citado en Escotto, 2015).

Cabe destacar que esta falta de sentido de pertenencia también puede ser consecuencia de la violencia y no solo causa de ella. Esto puede conducir a un círculo vicioso que es necesario romper. Desde un enfoque sociológico, la violencia puede ser vista como causa y efecto de la desintegración social vivida en una agrupación humana. Causa, porque la violencia provoca y refuerza la división y la desconfianza entre las personas, llevando a la construcción de formas de convivencia que restringen la interacción humana mediante el uso de mecanismos de discriminación y marginación; y efecto, porque es un síntoma de una injusta combinación de factores materiales e inmateriales que hacen que las personas vayan perdiendo el sentido de pertenencia a una sociedad (Universidad Centroamericana José Simeón Cañas, 2011, citado en Escotto, 2015). 
Uno de los rasgos culturales arraigados en los países de la región, en algunos más que en otros, es que la forma privilegiada para resolver los conflictos sea a partir de la violencia. Esto se da desde la esfera íntima hasta espacios comunitarios y colectivos, y moldea prácticas desde la infancia. En muchos países, los medios de comunicación refuerzan esa imagen y premian el comportamiento violento que los televidentes aprenden y después imitan. Las acciones violentas son presentadas como alternativas idóneas para la resolución de conflictos, con lo que pueden contribuir a modelar el comportamiento cotidiano (Krauskopf, 2002, pág. 12, citado en Escotto, 2015). En algunas oportunidades, los medios presentan a los miembros de las maras o pandillas como ejemplos a seguir y también ocurre que las imágenes de las barras de los equipos deportivos que destruyen y se comportan de modo violento en los estadios son destacadas como modelos de comportamiento juvenil y varonil.

\section{g) La estigmatización de la juventud}

Ciertos grupos juveniles, como los miembros de pandillas o jóvenes de sectores urbanos vulnerables, tienden a ser estigmatizados negativamente. "En el imaginario colectivo y en los medios de comunicación tiende a estigmatizarse al joven, varón, urbano y de sectores populares como potencial amenaza y signo de violencia" (CEPAL, 2008a, pág. 23). Estas expresiones de violencia simbólica tienden a reforzar procesos de exclusión y terminan siendo una profecía autocumplida: el hecho de nacer y crecer en ciertos barrios convierte a los jóvenes en personas sin oportunidades de participar en una sociedad que los discrimina y, por lo mismo, su modo de integración se da a través de grupos y comportamientos violentos.

\section{h) La desafiliación institucional}

Los adolescentes y jóvenes desertan de la escuela por muchas razones, entre las que se encuentran las presiones económicas familiares. Cuando el sistema los expulsa porque no ofrece condiciones adecuadas para que continúen estudiando, contribuye a potenciar los factores de riesgo. Esta situación es particularmente relevante cuando se relaciona con un ambiente de violencia, un manejo inadecuado de los conflictos entre jóvenes, así como entre los jóvenes y el personal de los centros educativos, la falta de atención a necesidades especiales de estudiantes con problemas de aprendizaje o comportamiento, y el uso de la violencia por parte de las autoridades escolares en contra del alumnado. Más adelante nos referiremos en mayor profundidad el ámbito escolar como un contexto específico de violencia que enfrentan jóvenes y adolescentes.

Esto, sumado a la frustración de quienes buscan incorporarse a un mercado laboral que no les ofrece un empleo digno y decente, vuelve a los jóvenes más proclives al riesgo de convertirse en perpetradores de 
violencia. Estos jóvenes ven con muy poca esperanza la inserción positiva en el mercado laboral. La mayoría de los pocos trabajos que encuentran no reúnen las condiciones necesarias para constituir un trabajo decente y el respeto a los derechos laborales fundamentales sigue siendo un sueño para muchos jóvenes trabajadores.

La situación en que se encuentra el núcleo duro de exclusión juvenil (aquellos jóvenes que no estudian ni están empleados, pero que tampoco realizan otras actividades) alude a una situación de ruptura de los vínculos que permiten la formación de capacidades y la participación en el capital social. En la medida en que el mercado laboral y el sistema educativo son los espacios más importantes de inclusión, esto puede constituirse en un factor de riesgo que incremente la propensión de los jóvenes a perpetrar algunas manifestaciones de violencia. La aceptación de su propia marginación por parte de estos jóvenes los dispone a la vulnerabilidad y los condiciona a reproducir la pobreza y la exclusión, los expone a riesgos en el ámbito de la salud reproductiva y, en algunos casos, los convierte en potenciales participantes en actividades transgresoras (SEGIB/OIJ, 2008, pág. 33, citado en Escotto, 2015)6.

Es importante señalar que los factores facilitadores de la violencia descritos tienen un carácter más general, y que cada una de las manifestaciones de violencia puede estar asociada, a su vez, con otros factores de índole más particular que la motiven. También es necesario reconocer que ninguno de los factores facilitadores de la violencia en la juventud mencionados es cien por ciento explicativo ni actúa de manera aislada, por lo que hacer frente a uno de ellos sin actuar sobre los demás ni tomarlos en cuenta nunca podrá tener el efecto deseado de reducir la violencia. Al contrario, podría ser contraproducente y contribuir a su escalamiento.

Puesto que en este tema se conjugan elementos de espectro nacional, como las condiciones generales de contexto económico y social (niveles de desigualdad, tráfico de drogas, dinámica demográfica, acceso a la educación y el empleo e, incluso, antecedentes históricos en materia de conflictos civiles), con aspectos de índole más particular, como el entorno familiar, cultural y de sentido de pertenencia de los individuos, se destaca la necesidad de abordar el tema desde diversos puntos de partida bajo un enfoque integral.

En este sentido, para hacer frente a los factores de riesgo es necesario generar "factores de protección" que disminuyan (o logren eliminar) los efectos más graves de los primeros y, de esa manera, contribuyan a reducir la violencia. Los factores de protección deberán ser cuidadosamente identificados y trabajados con el fin de crear las condiciones idóneas

Véase el capítulo II. 
para promover contextos de convivencia pacífica en el ámbito familiar, comunitario y social. Este punto motiva un análisis más detallado de los ámbitos o espacios donde se manifiesta la violencia que afecta a los jóvenes y que se verá a continuación.

\section{Ubicuidad de la violencia: espacios o ámbitos que enfrenta la juventud}

En los últimos años, en América Latina y el Caribe se pasó de un escenario de violencia colectiva (en un contexto de dictaduras y guerras civiles) a otro donde la violencia interpersonal parece adquirir mayor notoriedad mediática y más atención como objeto de estudio (Imbusch, Misse y Carrión, 2011, pág. 98). Fundamentalmente, esta atención ha girado en torno al concepto de crimen, cuya definición resulta compleja, y a la estigmatización de las personas que habitan en sectores asediados por la violencia. El crimen es un fenómeno definido por el derecho penal, de modo que una conducta puede ser considerada criminal en un caso y en otro solo resultar reprobable, sin llegar a constituir un delito. Los jóvenes enfrentan diversos espacios o ámbitos de violencia que no se limitan a crímenes de alta connotación pública y afectan sus alternativas y oportunidades de desarrollo.

Los factores facilitadores descritos, y que han influido en el surgimiento de los actuales escenarios de violencia, plantean la necesidad de que, en el análisis sobre violencia desde una perspectiva multidimensional con enfoque en la población juvenil, se considere la existencia de una estrecha relación con los procesos de exclusión social, tanto para víctimas como para perpetradores, donde el vínculo entre violencia y contexto se alimenta y retroalimenta, de modo que los entornos sociales, territoriales y familiares pueden llegar a propiciar resoluciones violentas en los jóvenes (CEPAL/OIJ, 2008).

A partir de la complementariedad de tipologías propuesta (Galtung y enfoque sistémico), los espacios de manifestación de los distintos tipos de violencia en la juventud son vastos. Prácticamente ningún sitio está libre de violencia, pues esta puede darse tanto en espacios cerrados e íntimos, como el hogar, la escuela o el lugar de trabajo, como en ámbitos públicos, como las instituciones y los medios de comunicación (incluso Internet). Es importante analizar las especificidades que tiene cada uno de dichos espacios como sitios propensos a la violencia.

La información sobre violencia en distintos ámbitos es difícil de analizar de manera comparada a nivel regional. Sin embargo, los datos generados a partir de estudios de caso o de encuestas específicamente diseñadas para estos fines muestran elevados índices de violencia en el ámbito familiar y escolar, pero también en espacios públicos. De 
acuerdo con la encuesta Latinobarómetro de 2008, para el promedio de una selección de 18 países, entre el 25\% y el 29\% de los jóvenes percibían que vivían situaciones de violencia en el contexto escolar, familiar, entre pandillas y entre vecinos. Destaca el caso del Brasil, donde más de la mitad de las personas jóvenes encuestadas declaraban vivir en contextos de violencia en espacios tan próximos como la escuela (véase el cuadro III.2).

\section{Cuadro III.2}

América Latina (18 países): percepción de presencia de violencia en distintos ámbitos, población de 16 a 29 años, 2008

(En porcentajes)

\begin{tabular}{|c|c|c|c|c|}
\hline & $\begin{array}{c}\text { En las } \\
\text { escuelas }\end{array}$ & $\begin{array}{c}\text { En las } \\
\text { familias }\end{array}$ & $\begin{array}{c}\text { Entre } \\
\text { vecinos }\end{array}$ & $\begin{array}{c}\text { Entre } \\
\text { pandillas }\end{array}$ \\
\hline Argentina & 29 & 20 & 16 & 20 \\
\hline Bolivia (Estado Plurinacional de) & 28 & 32 & 23 & 28 \\
\hline Brasil & 52 & 40 & 42 & 38 \\
\hline Chile & 26 & 27 & 15 & 29 \\
\hline Colombia & 33 & 32 & 25 & 21 \\
\hline Costa Rica & 24 & 25 & 23 & 19 \\
\hline Ecuador & 19 & 19 & 17 & 18 \\
\hline El Salvador & 25 & 17 & 19 & 26 \\
\hline Guatemala & 33 & 35 & 34 & 34 \\
\hline Honduras & 32 & 28 & 25 & 24 \\
\hline México & 33 & 34 & 27 & 26 \\
\hline Nicaragua & 29 & 22 & 28 & 30 \\
\hline Panamá & 29 & 32 & 34 & 28 \\
\hline Paraguay & 20 & 18 & 18 & 18 \\
\hline Perú & 28 & 27 & 20 & 32 \\
\hline República Dominicana & 35 & 28 & 32 & 28 \\
\hline Uruguay & 29 & 21 & 14 & 21 \\
\hline Venezuela (República Bolivariana de) & 29 & 32 & 31 & 34 \\
\hline América Latina $^{a}$ & 29 & 27 & 25 & 26 \\
\hline
\end{tabular}

Fuente: Comisión Económica para América Latina y el Caribe (CEPAL), sobre la base de tabulaciones especiales de la encuesta Latinobarómetro de 2008.

a Promedio simple de los resultados de los 18 países incluidos en la medición.

Como se ha descrito, la juventud de la región enfrenta contextos y manifestaciones de la violencia en distintos ámbitos, lo que a su vez se origina en una multiplicidad de factores. En las siguientes secciones se busca analizar con mayor profundidad algunos de los ámbitos y manifestaciones de violencia considerados de gran impacto para los 
jóvenes y que además han adquirido especial notoriedad a partir de su difusión por los medios de comunicación. De manera particular se abordará la relación entre género y violencia en la juventud, considerando distintos ámbitos y manifestaciones y analizando el entorno pandilleril. A continuación, en un ámbito más comunitario, se revisarán las manifestaciones de violencia directa interpersonal y colectiva en las escuelas en tanto espacios de socialización esencial de las generaciones de adolescentes y jóvenes. Por último, se analizarán las manifestaciones de violencia colectiva que sufren muchas de las ciudades de la región con formas de violencia organizada (en especial, el tema de las pandillas y organizaciones juveniles violentas).

\section{B. Género y violencia en la juventud}

A nivel mundial y regional existe abundante información acerca de la prevalencia de manifestaciones de violencia en contra de la mujer en todos los grupos de edad. Por su trascendencia, y dado que muchas de las manifestaciones de violencia tienen consecuencias particulares entre las poblaciones jóvenes, es relevante analizar cuál es la relación entre género y violencia en la juventud, ya que la violencia contra la mujer se da en todos los espacios y en todas las dimensiones y tipos de violencia considerados (véase el cuadro III.1).

En términos generales, el análisis de las convergencias entre género, juventud y violencia ha sido restringido, y son pocos los estudios que se enfocan en determinar si el hecho de ser mujer $u$ hombre establece un nivel diferente de riesgo de ser víctima o victimario de determinada manifestación de violencia entre los jóvenes. Los análisis que buscan identificar si ser joven es un factor diferenciador en el nivel de riesgo de perpetrar actos de violencia de género son todavía más escasos ${ }^{7}$.

En esta sección se buscará analizar si el género es un factor facilitador de la violencia; es decir, si el género define per se un nivel diferenciado de riesgo de ser víctima o perpetrador de la violencia. También se pretende analizar si ser joven es un factor facilitador en la perpetración de actos de violencia de género; particularmente, si los hombres jóvenes son más propensos a realizar actos de violencia en contra de las mujeres. Por último, se profundizará de modo particular sobre el caso de violencia contra las mujeres en el contexto de las pandillas, donde estos factores se potencian de manera considerable.

El Informe mundial sobre la violencia y la salud realizado en 2002 por la Organización Mundial de la Salud (OMS, 2002) es un ejemplo de los pocos estudios referentes al tema, que, por ende, se vuelve una referencia obligada. 


\section{El género como factor de riesgo de ser víctima o victimario de violencia en la juventud}

La violencia en contra de las mujeres es conceptualizada como "todo acto de violencia basado en la pertenencia al sexo femenino que tenga o pueda tener como resultado un daño o sufrimiento físico, sexual o psicológico para la mujer, así como las amenazas de tales actos, la coacción a la privación arbitraria de la libertad, tanto si se producen en la vida pública como en la vida privada" (Naciones Unidas, 1993) ${ }^{8}$. Debido a que considera múltiples aspectos sociológicos que incluyen factores de índole cultural y familiar arraigados por mucho tiempo, esta es una de las manifestaciones de violencia más complejas de analizar y se considera un flagelo que es necesario erradicar de nuestras sociedades.

Existe información estadística que permite formular algunas conclusiones parciales sobre la hipótesis de que el sexo del individuo puede ser un factor determinante en la propensión a ser víctima de algún tipo de violencia. Por ejemplo, para el caso de la consecuencia más contundente de la violencia, que es la pérdida de la vida, en el repositorio de información del Observatorio Mundial de la Salud se reportan cifras estimadas, a partir de registros administrativos para 2012, que muestran que la mortalidad por lesiones intencionales entre hombres jóvenes (15 a 29 años) en América Latina y el Caribe es 8,5 veces mayor que entre las mujeres del mismo rango etario (OMS, 2013). Esto refleja una mayor propensión de los hombres jóvenes a sufrir las consecuencias de la violencia en esta manifestación particular, conclusión compartida en la gran mayoría de los estudios de violencia juvenil.

Al profundizar en el análisis, se observa que el 17\% de las muertes por lesiones intencionales de hombres jóvenes fueron autoinfligidas (suicidio), mientras que en las mujeres jóvenes dicho porcentaje asciende al 37,8\%. Si bien esto no significa que las mujeres jóvenes se suiciden más que los hombres jóvenes (la tasa de suicidio muestra una relación de tres suicidios de hombres jóvenes por cada suicidio de mujeres jóvenes), sí muestra evidencia que permite analizar cualitativamente la razón por la cual, una vez considerado el nivel diferenciado de riesgo de muerte por lesiones intencionales, existe una diferencia en el nivel relativo de violencia autoinfligida en las mujeres jóvenes.

En el caso de las manifestaciones de violencia asociadas con actos de delincuencia, la información disponible en el Barómetro de las Américas (Proyecto de Opinión Pública de América Latina (LAPOP))

\footnotetext{
8 Esta es la definición del Artículo 1 de la Declaración sobre la Eliminación de la Violencia contra la Mujer de las Naciones Unidas [en línea] http://www.ohchr.org/SP/ProfessionalInterest/ Pages/ViolenceAgainstWomen.aspx.
} 
para 2012 ofrece indicios de que, en los países de América Latina donde se llevó a cabo la encuesta, las mujeres jóvenes son más propensas a ser víctimas de violación o asalto sexual que las mujeres de otras edades y que los hombres jóvenes. Los datos de dicha fuente de información también ofrecen indicios de que las mujeres jóvenes son más propensas a ser secuestradas que los hombres jóvenes (véase el cuadro III.3). Se habla de indicios, pues la información muestra un bajo porcentaje de personas que declara haber sido víctima de violencia sexual y de secuestro. En este sentido, hay que tener en cuenta que uno de los problemas es la falta de denuncia y el subregistro en diversos instrumentos de recolección de información de este tipo de manifestaciones de violencia en la región, pues todavía existen patrones culturales machistas que tienden a adjudicar responsabilidad a la propia víctima en el hecho, como si ella lo hubiera provocado o buscado.

Cuadro III.3

América Latina (18 países): personas que han sufrido actos delincuenciales en los 12 meses previos a la encuesta, según tipo de acto, sexo y edad, $201{ }^{\text {a }}$

(En porcentajes)

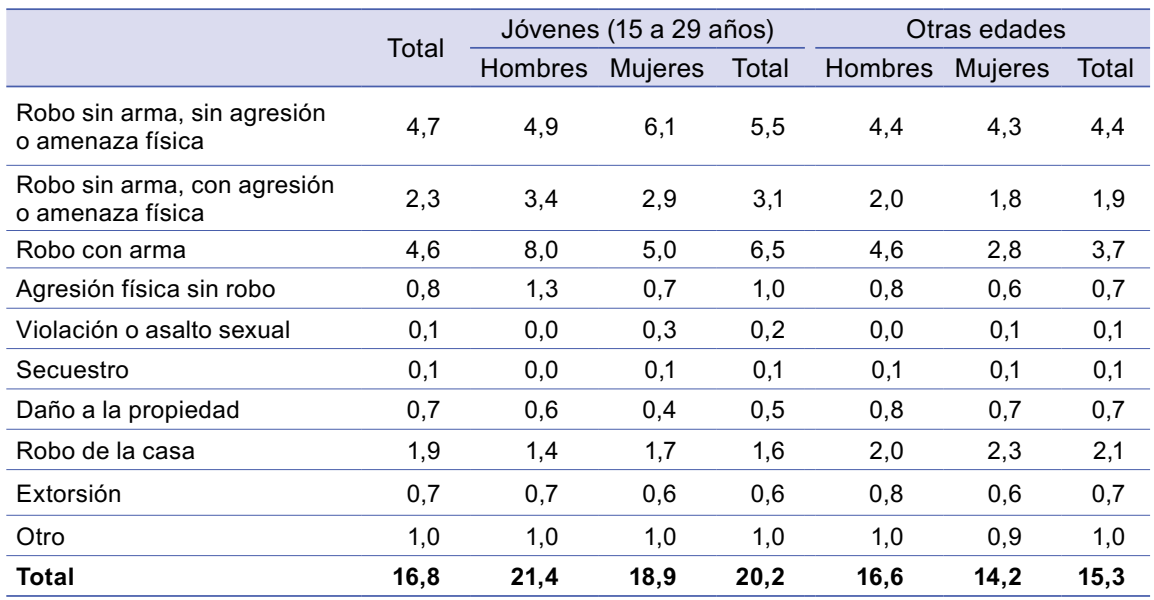

Fuente: Proyecto de Opinión de Pública de América Latina (LAPOP), Barómetro de las Américas, (2012).

a Argentina, Bolivia (Estado Plurinacional de), Brasil, Chile, Colombia, Costa Rica, Ecuador, El Salvador, Guatemala, Honduras, México, Nicaragua, Panamá, Paraguay, Perú, República Dominicana, Uruguay y Venezuela (República Bolivariana de).

En referencia a manifestaciones de violencia asociadas con la victimización directa hacia las mujeres, la información de las encuestas de salud y demografía de algunos países de la región que han incluido preguntas sobre el tema muestra porcentajes variables, que van del $10 \%$ al $30 \%$ de mujeres que son víctimas de empujones o golpes por parte de su pareja, sin evidencia clara de que las mujeres jóvenes tengan una mayor 
propensión a recibirlos que las mujeres de otras edades ${ }^{9}$. En el caso de las agresiones sexuales, particularmente las relaciones sexuales forzadas, se observa que las mujeres jóvenes sí son más propensas a esta manifestación de la violencia, principalmente cuando se trata de violencia por parte de sus parejas, con porcentajes de prevalencia en rangos del 5\% al 11\%. Cabe destacar que en el caso de la agresión perpetrada por personas que no son las parejas de las mujeres, si bien el porcentaje es significativamente más reducido (lo que resalta la trascendencia que tiene la violencia en la pareja), también existe evidencia de que las mujeres jóvenes son más propensas a recibir dichas agresiones.

En general, es difícil encontrar información que permita analizar otras manifestaciones de violencia, como las asociadas a la trata de personas o las relativas a la violencia sexual y psicológica, al maltrato intrafamiliar (de padres o madres a hijos e hijas), a la violencia escolar o a la violencia colectiva, entre otros temas, a fin de mostrar si existe una relación significativa y diferenciada acerca del riesgo de ser víctimas de violencia entre las mujeres jóvenes y los hombres jóvenes con relación a otros grupos etarios. En la mayoría de los casos se intuye, o se conoce a partir de estudios cualitativos, que la diferencia existe. Sin embargo, la generación de datos para corroborarlo cuantitativamente aún está pendiente ${ }^{10}$.

Cabe señalar que si bien, en general, las fuentes de información disponibles no permiten establecer si el sexo del individuo puede ser un factor determinante en la propensión a ser perpetrador de la mayoría de las manifestaciones de violencia, los datos del Estudio mundial sobre el homicidio muestran una marcada tendencia al señalar, para esa manifestación específica de violencia, que el $95 \%$ de los homicidas a nivel mundial son hombres (UNODC, 2014) ${ }^{11}$.

Esta tendencia se confirma al analizar la información proveniente de las encuestas dirigidas a mujeres víctimas de violencia y de la gran mayoría de los estudios de violencia de género de corte cualitativo. A partir de ello, se establece como conclusión generalizada que, en la gran mayoría de los casos y sin distinción de grupos etarios, la violencia en contra de las mujeres es perpetrada por hombres, lo que refuerza la necesidad de realizar un análisis más comprehensivo que transversalice el enfoque de género en la violencia juvenil.

Se dispone de información para Bolivia (Estado Plurinacional de) (2008), Colombia (2010), Haití (2012), Honduras (2012), el Perú (2012) y la República Dominicana (2007).

10 Este reto se exacerba en el caso de la manifestación más extrema de la violencia de género: el femicidio. Esto se debe a la escasez de registros disponibles al respecto a causa de las dificultades de tipificación.

11 En el diagnóstico de la violencia juvenil en El Salvador se señala la misma cifra del 95\% de victimarios homicidas hombres en ese país (Alianza Joven Regional, 2010). 


\section{La juventud como factor en la perpetración de la violencia de género}

Se ha podido identificar una clara relación diferencial entre el sexo de los perpetradores y de las víctimas de la violencia de género, notoriamente desproporcionada hacia la perpetración masculina y la victimización femenina. Ello sustenta la apuesta de que un cambio cultural generacional, dirigido a la sensibilización hacia la no violencia en contra de las mujeres por parte de los hombres y a la erradicación de la normalización de dicho tipo de violencia por parte de las mujeres y de la sociedad en general, permitirá que los índices de violencia en contra de las mujeres disminuyan.

No obstante, no pareciera haber evidencia de que este tipo de violencia sea menor en los grupos más jóvenes, lo que muestra que no se está logrando la transmisión intergeneracional del mensaje a favor del respeto al derecho a una vida libre de violencia entre los jóvenes de la región. Los datos de las encuestas de salud y demografía de algunos países de la región muestran que entre un $15 \%$ y un $40 \%$ de las mujeres jóvenes vieron a su padre golpear a su madre en su niñez, lo que implica que al crecer, estas mujeres puedan llegar a considerar normal que sus parejas las golpeen o maltraten. Cabe destacar que la proporción de mujeres mayores de 29 años que fueron testigo de esta situación es significativamente mayor que en el caso de las mujeres jóvenes, lo que constituye un indicador positivo para el proceso de reducción de la violencia contra la mujer.

La información de las mismas encuestas muestra que, sin diferencia notoria entre mujeres jóvenes o de más edad, la mayoría de quienes han sufrido algún tipo de maltrato por parte de sus parejas no solicita ayuda. Esto nuevamente es reflejo del proceso de doble victimización que llegan a padecer las mujeres cuando, al solicitar ayuda tras haber sido maltratadas, y debido a convenciones sociales, pueden llegar a ser estigmatizadas por el mismo hecho. Un aspecto relevante que se refleja en los mismos datos es que las mujeres jóvenes, ante un escenario de maltrato, tienden a solicitar más ayuda de sus padres que las mujeres de mayor edad, lo que refleja la importancia de la sensibilización intergeneracional y del apoyo de la familia en esta problemática.

\section{La violencia contra la mujer en las pandillas}

La información sobre el papel de las mujeres en las pandillas es, en general, reducida y se asocia con los resultados de algunos estudios de caso que lo documentan. En algunos de estos estudios, realizados en 2006 en El Salvador, Guatemala y Honduras, se documentó la presencia mayoritaria de hombres e incluso un marcado descenso de la participación activa de las mujeres en las pandillas (Aguilar, 2006; Ranum, 2006 y Andino, 2006, citados 
en Aguilar y Carranza, 2008). En uno de dichos estudios se señala que las mujeres en general suelen representar menos de una cuarta parte de los integrantes de estos grupos (Demoscopía, 2007, citado en Bravo, 2013).

Salvo contadas excepciones, las mujeres que pertenecen a las pandillas no cumplen las mismas funciones que los hombres en las actividades de estas organizaciones. Lo habitual es que las mujeres se involucren con las pandillas atendiendo a los roles tradicionales de género, en actividades que van desde la procuración de alimentos hasta el encubrimiento y la protección, la custodia de armas o el cuidado de heridas. En general, no son consultadas para la toma de decisiones en lo que concierne a las pandillas, son castigadas si cometen infidelidad y se les restringe la posibilidad de escoger pareja dentro de la misma pandilla. En ocasiones, tienen un rol de sumisión sexual en un contexto donde, en la mayoría de los casos, los pandilleros no buscan relacionarse de manera estable con una mujer $y$, si se lo llegan a plantear, buscan a una mujer fuera de la pandilla (Lacayo, 2015).

En algunos estudios que han buscado profundizar sobre el papel de las mujeres en las pandillas se ha documentado que una forma en que las pandillas han planteado atraer a los jóvenes es mediante la oferta de acceso fácil a dinero, poder y sexo. En el último caso, esto se concreta mediante la afiliación a la pandilla de mujeres, principalmente adolescentes. Por lo general, se trata de jóvenes que provienen de una realidad de escasas oportunidades y entornos familiares poco promisorios ( $y$, en muchos casos, con antecedentes de agresión de pareja o intrafamiliar). En una búsqueda de emancipación, las jóvenes son atraídas por un escenario de promiscuidad que está lejos de ser liberador. Estas mujeres se vuelven propiedad de las pandillas y los pandilleros ejercen sobre ellas una violencia sexual manifiesta mediante la violación o el abuso colectivo (Rubio, 2008).

Si bien esta es una temática que requiere mayor profundización en cuanto a su manifestación más tangible, en los pocos estudios de caso donde se aborda el tema se refleja de manera contundente la magnificación de la desigualdad de género en las pandillas y, en cierta medida, se pone de manifiesto la necesidad de explorar el tema de violencia sexual generado en este contexto en contra de las mujeres, principalmente adolescentes, que llegan a involucrarse con las pandillas.

\section{Violencia escolar}

Un alto porcentaje de los jóvenes pasa gran parte de su vida cotidiana en un centro educativo. Como se observa en el cuadro III.2, alrededor del $30 \%$ de la juventud afirma que vive situaciones de violencia en ese espacio. En diversos estudios realizados desde los años setenta 
hasta la fecha se ha analizado la violencia escolar como un tema de suma relevancia para la formación de las nuevas generaciones. Particularmente, porque la presencia de comportamientos violentos contradice lo que se espera de la escuela, en tanto espacio seguro y protegido que busca formar a las nuevas generaciones en conductas y valores ciudadanos y democráticos (Román y Murillo, 2011). Una conclusión derivada de los estudios estriba en la importancia de distinguir entre la violencia que llega a la escuela desde espacios sociales externos y la que se genera dentro de la propia institución.

En un sentido amplio, la presencia de violencia en las escuelas, de forma similar a lo que ocurre con la violencia en otros ámbitos, tiene como trasfondo las propias transformaciones sociales que experimenta la sociedad en su conjunto. Los cambios ocurridos en las últimas décadas, impulsados por el proceso de globalización que redefine los espacios y el territorio, la mundialización de los centros de decisión y poder, y la creciente prevalencia del mercado y del consumo en la cotidianeidad de las personas, han sido muy significativos. Sumado a la penetración de las nuevas tecnologías de la información y las comunicaciones (TIC), esto ha tenido un especial impacto en la vida de adolescentes y jóvenes (López, 2011). Además, existen en la región procesos de masificación de la educación que han ampliado de manera considerable la diversidad de la población escolar. La institución escolar, conservadora por naturaleza, no ha podido acoger plenamente algunos de estos cambios.

A pesar de que los factores facilitadores de la violencia varían de acuerdo con las particularidades de cada territorio, se identifican dos factores culturales comunes a todos los países de la región. El primero tiene relación con un tipo de violencia simbólica, asociado a una cultura generalizada que valida la violencia como la vía privilegiada de resolución de conflictos. Uno de los roles que, justamente, debería cumplir el sistema educativo es promover un cambio de actitudes y valoraciones en las nuevas generaciones, que validen la existencia del conflicto, pero permitan abordarlo sin el uso de violencia (IIDH, 2011).

El segundo factor común a los países de la región, también simbólico, se relaciona con la discriminación y baja tolerancia a las diferencias en sociedades que son muy desiguales. La escuela, especialmente a nivel de enseñanza secundaria, tuvo en su origen un carácter opcional y selectivo, de formación de élites. La apertura del espacio escolar hacia grandes diversidades socioculturales ha generado una tensión con la tradición cultural de competencia y discriminación, que dificulta la tolerancia de las diferencias y la convivencia en los establecimientos educativos. Como plantea López, "es un desajuste en términos valorativos entre el alumno que se quisiera tener, y aquel que efectivamente está en el aula día a día. No sólo se constata que los nuevos alumnos son diferentes, 
sino además se hace visible que esa diferencia genera malestar, y más aún, es connotada y valorada negativamente" (López, 2011, pág. 236). Por otra parte, la baja tolerancia a la diferencia también se expresa entre los propios estudiantes, que imitan comportamientos discriminatorios y violentos de sus padres y entornos cercanos fuera de la escuela, como violencia directa o simbólica a nivel interpersonal en el espacio escolar (véase el cuadro III.1).

Las manifestaciones de violencia en el espacio educativo son diversas y hay que comprenderlas dentro del conjunto de relaciones interpersonales en que ocurren y del distinto grado de intensidad o gravedad de los actos. En este sentido, es necesario diferenciar entre aquellos actos de violencia que se dan desde los adultos (la autoridad escolar) hacia los estudiantes, los que se dan desde los estudiantes (y también sus padres) hacia los docentes y las autoridades escolares, y la violencia entre pares. Debido a que la violencia entre pares es la que ha adquirido mayor relevancia en los últimos años gracias a la exaltación que han hecho los medios de comunicación - al conceptualizarla como acoso o matonaje escolar-, este es el tipo de violencia escolar que se aborda en mayor profundidad en esta sección.

El concepto de acoso o matonaje escolar (también conocido como bullying) refiere a distintas situaciones de intimidación, acoso, abuso, hostigamiento y victimización que ocurren reiteradamente entre escolares. Consiste en agresiones físicas o psicológicas que se dan de manera repetida y por tiempos extendidos, que implican y tienen consecuencias distintas, aunque igualmente preocupantes, para todos los estudiantes que se ven envueltos en tales comportamientos. En estas situaciones hay que comprender que están involucrados tres tipos de actores distintos: la víctima, el perpetrador y los testigos (Román y Murillo, 2011). Son hechos que comúnmente ocurren durante la adolescencia, en pleno proceso de construcción de la identidad, donde el perpetrador del acto requiere de testigos para que las agresiones sirvan a su propio proceso de reafirmación identitaria.

De acuerdo con un informe sobre violencia escolar de Plan Internacional y el Fondo de las Naciones Unidas para la Infancia (UNICEF) (Eljach, 2011), las agresiones entre pares en la infancia son algo común e incluso normal en la etapa de desarrollo y socialización. Estos procesos deben ir acompañados de un apoyo adulto que ponga guías y límites al comportamiento. El uso de violencia en la etapa adolescente es diferente porque es un acto consciente. En muchos casos puede ser interpretado como un acto de reconocimiento y validación de sí mismo, a partir de la confrontación y el desprecio por el otro. Por lo mismo, se requieren testigos. Quienes eligen este camino para afirmar su identidad suelen ser adolescentes que no han obtenido el reconocimiento necesario en su 
propio entorno (familiar o escolar) o no tuvieron guías y límites adecuados en su proceso formativo que limitaran este tipo de comportamientos.

A la hora de diseñar estrategias de intervención que sean efectivas para tratar el problema, es muy importante considerar también al victimario y no trabajar, como ocurre habitualmente, de manera exclusiva con la víctima, como si esta fuera la responsable de ser objeto de violencia por su inadecuada adaptación social. Es necesario considerar que las acciones que realiza el victimario también suelen responder a un conjunto de factores problemáticos de su propio desarrollo. Las actitudes discriminatorias que muchas veces terminan en comportamientos violentos de adolescentes, provienen de imitaciones y aprendizajes del mundo adulto de su entorno inmediato (Eljach, 2011). Por ello, además de aplicar sanciones, es necesario brindar apoyo y trabajar recursos personales de manejo de conflictos y tolerancia. Además, educar al grupo de escolares en su papel protector de la víctima al momento de ser testigos puede ser una estrategia muy efectiva para controlar este tipo de comportamientos en la escuela.

\section{Violencia escolar entre pares: algunas cifras}

En algunos estudios sobre el tema se indica que la violencia física en las escuelas ha disminuido, pero lo que ha ido en aumento es la violencia psicológica o emocional. Este tipo de acoso y hostigamiento entre pares suele ser muy dañino porque permanece oculto y pasa desapercibido al no dejar huellas físicas (Eljach, 2011). Al igual que ocurre en otros ámbitos de la violencia, es difícil encontrar estadísticas comparadas para los países de la región. Una de las pocas estadísticas disponibles en el tema específico de la violencia entre pares es la que recoge la Encuesta Mundial de Salud a Escolares, en la que han participado 23 países de América Latina y el Caribe durante la década de 2000. Estos datos muestran que, en promedio, el $28 \%$ de los escolares que participan del estudio declaran haber sido víctimas de acoso escolar durante el último mes. Es decir que alrededor de un tercio de los estudiantes señala que enfrenta este problema de modo relativamente cotidiano en su vivencia escolar (véase el gráfico III.1).

Una medición indirecta con base en la recopilación de estudios nacionales sobre violencia en las escuelas, realizada por el estudio de Plan Internacional y el UNICEF (Eljach, 2011), muestra que entre el 50\% y el $70 \%$ de la población estudiantil declara haber sido víctima o testigo de situaciones de agresión entre pares durante su vida escolar. Si bien las preguntas del cuadro III.4 no son comparables, la información recopilada a partir de encuestas de juventud a nivel nacional coincide con esta tendencia, especialmente en el caso de los más jóvenes (adolescentes de entre 15 y 19 años), que son quienes asisten en altas proporciones al sistema escolar. Las cifras son de magnitudes similares para los casos de Guatemala (69\%) 
y el Perú (51\%) porque, a diferencia de la encuesta chilena, las preguntas incluyen el haber sido testigos y víctimas. En el caso de la encuesta chilena, los valores coinciden con las tendencias de victimización del gráfico III.1.

\section{Gráfico III.1 \\ América Latina y el Caribe (23 países): población de entre 11 y 17 años que declara haber sufrido bullying (acoso escolar) en el último mes}

(En porcentajes)

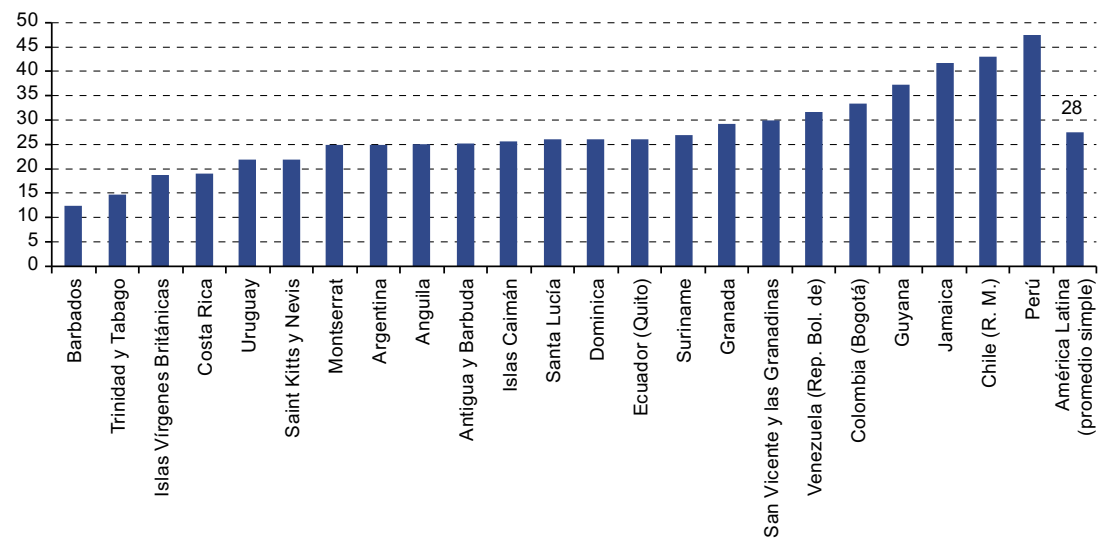

Fuente: Comisión Económica para América Latina y el Caribe (CEPAL), sobre la base de tabulaciones especiales de la Encuesta Mundial de Salud a Escolares (GSHS) de la Organización Mundial de la Salud.

Nota: Para Chile, Colombia, el Ecuador y Venezuela (República Bolivariana de) solo se consideraron los casos de la Región Metropolitana de Santiago, Bogotá, Quito y Barinas, respectivamente. Los años reales para cada país son: 2003 para Venezuela (República Bolivariana de); 2005 para Chile; 2006 para el Uruguay; 2007 para la Argentina, Colombia, el Ecuador, las Islas Caimán, Santa Lucía, y San Vicente y las Granadinas; 2008 para Granada y Montserrat; 2009 para Anguila, Antigua y Barbuda, Costa Rica, Dominica, las Islas Vírgenes Británicas y Suriname; 2010 para Guyana, Jamaica y el Perú; y 2011 para Barbados, Saint Kitts y Nevis y Trinidad y Tabago.

\section{Cuadro III.4}

Chile, Guatemala y Perú: jóvenes de 15 a 29 años que declaran presencia de violencia física en su escuela o lugar de estudio, según tramo de edad

(En porcentajes)

\begin{tabular}{lccc}
\hline Tramo de edad & $\begin{array}{c}\text { Chile: ¿Has sido víctima } \\
\text { de violencia física } \\
\text { en alguna de estas } \\
\text { situaciones? } \\
\begin{array}{c}\text { En la escuela o lugar } \\
\text { de estudios }\end{array}\end{array}$ & $\begin{array}{c}\text { Guatemala: Durante } \\
\text { el último año escolar, } \\
\text { ¿ha ocurrido en su } \\
\text { escuela, colegio o instituto, } \\
\text { violencia física } \\
\text { entre alumnos? }\end{array}$ & $\begin{array}{c}\text { Perú: ¿Cuáles son los } \\
\text { problemas más frecuentes } \\
\text { que se dan o se han dado } \\
\text { en tu centro educativo? } \\
\text { Violencia física } \\
\text { entre alumnos }\end{array}$ \\
\hline 15 a 19 años & 39 & 69 & 51 \\
\hline 20 a 24 años & 36 & 21 & 27 \\
\hline 25 a 29 años & 26 & 9 & 22 \\
\hline
\end{tabular}

Fuente: Comisión Económica para América Latina y el Caribe (CEPAL), sobre la base de tabulaciones especiales de la Séptima Encuesta Nacional de Juventud realizada en Chile, 2012; de la Primera Encuesta Nacional de Juventud en Guatemala (ENJU), 2011; y de la Primera Encuesta Nacional de la Juventud Peruana (ENAJUV), 2011. 
En varios de estos estudios nacionales se concluye que la violencia no es un fenómeno circunscrito a las escuelas más pobres, sino que se produce en todos los niveles socioeconómicos y en proporciones similares en escuelas públicas y privadas. Incluso hay hallazgos de mayor prevalencia de ciertos tipos de conductas violentas en escuelas con alto poder adquisitivo (Eljach, 2011). Los tipos de violencia que ocurren son de diversa índole y no necesariamente son los mismos para varones que para mujeres. La información disponible permite distinguir las agresiones físicas como el tipo preponderante de violencia masculina, mencionada en promedio en el 20,9\% de los casos, mientras que para las jóvenes destacan las burlas por su aspecto físico en el 23,5\% de los casos. Se trata de tipos de violencia que reflejan comportamientos y discriminaciones asociadas a los roles y desigualdades de género tradicionales.

\section{Gráfico III.2 \\ América Latina y el Caribe (23 países): tipos de bullying (acoso escolar) sufridos por la población de 11 a 17 años que declara haber sido víctima en el último mes, según sexo \\ (En porcentajes)}

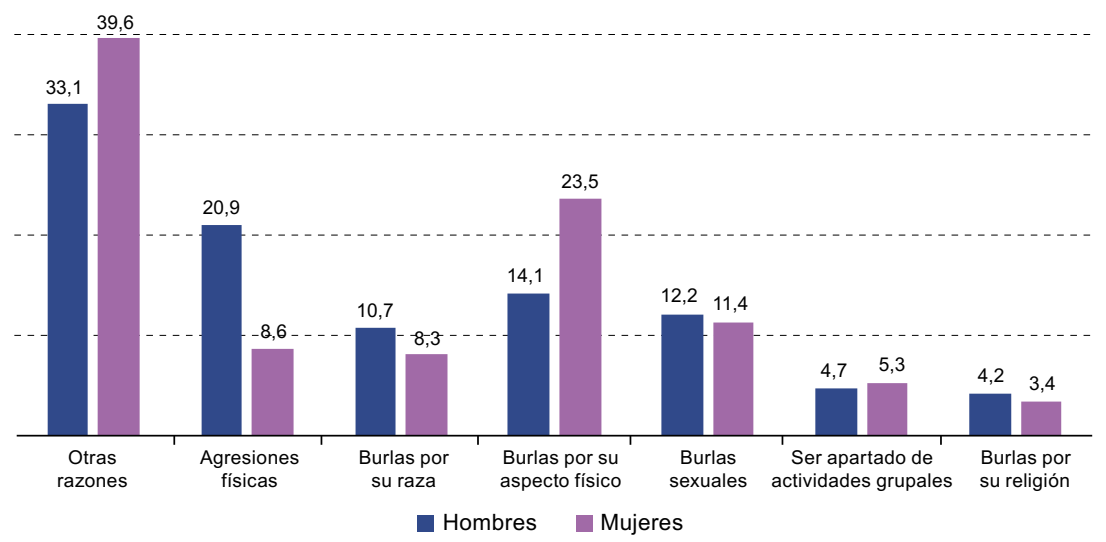

Fuente: Comisión Económica para América Latina y el Caribe (CEPAL), sobre la base de tabulaciones especiales de la Encuesta Mundial de Salud a Escolares (GSHS) de la Organización Mundial de la Salud.

Nota: Para Chile, Colombia, el Ecuador y Venezuela (República Bolivariana de) solo se consideraron los casos de la Región Metropolitana de Santiago, Bogotá, Quito y Barinas, respectivamente. Los años reales para cada país son: 2003 para Venezuela (República Bolivariana de); 2005 para Chile; 2006 para el Uruguay; 2007 para la Argentina, Colombia, el Ecuador, las Islas Caimán, Santa Lucía, y San Vicente y las Granadinas; 2008 para Granada y Montserrat; 2009 para Anguila, Antigua y Barbuda, Costa Rica, Dominica, las Islas Vírgenes Británicas y Suriname; 2010 para Guyana, Jamaica y el Perú; y 2011 para Barbados, Saint Kitts y Nevis y Trinidad y Tabago. La categoría "Otras razones" agrupa una diversidad de causales de violencia diferentes que no pueden clasificarse en un tipo particular.

Esta información confirma lo que se ha encontrado en diversos estudios realizados a nivel internacional: que la presencia de la violencia 
escolar es un fenómeno bastante generalizado en todos los países y estratos sociales y no se trata de eventos aislados en ciertos tipos de escuelas o países (Román y Murillo, 2011). Los resultados de distintos estudios realizados, especialmente en países desarrollados, pero también en América Latina, han demostrado los efectos negativos que tiene sobre las víctimas la violencia entre pares en el ámbito escolar. Entre ellos se mencionan el menor desempeño académico, el deterioro en la motivación y los problemas de autoestima y desarrollo psicosocial (Román y Murillo, 2011).

\section{Recuadro III.3}

\section{Alcances sobre el bullying o matonaje escolar homofóbico en América Latina}

Una de las tantas aristas del bullying o matonaje escolar se relaciona con la orientación sexual o identidad de género de cada joven. El llamado bullying homofóbico es, en muchas situaciones, una agresión que se origina en supuestos relacionados con diversas etiquetas que discriminan a hombres y mujeres por orientación sexual o identidad de género real o percibida (UNESCO, 2013). Asimismo, las etiquetas que dependen de la orientación sexual o identidad de género percibida o real de cada joven se vuelven formas transversales de violentar a muchos estudiantes. Este matonaje escolar se puede realizar tanto en la sala de clases como a través de las redes sociales. Aun cuando la seguridad de los sistemas de comunicación electrónica ha mejorado, en muchos casos, el acoso cibernético o ciberacoso es un espacio que permite que, desde el anonimato, el agresor o la agresora se desvincule de la responsabilidad y las consecuencias de enfrentar directamente a quien desea agredir.

El acoso escolar homofóbico no es solo una arremetida entre pares. En varios países, de hecho, son los profesores quienes aíslan a un estudiante cuando tiene una orientación sexual o identidad de género diferente del resto. La escuela y la educación impartida constituyen un espacio que permite que los jóvenes desarrollen conocimientos y habilidades que mejoren sus condiciones futuras. No obstante, también son el principal lugar donde se lleva a cabo el acoso escolar homofóbico. Destaca, de esta manera, como un escenario que permea en el desarrollo social y psicológico del alumnado.

El matonaje escolar afecta negativamente la salud y el bienestar de los estudiantes. Las burlas, la provocación, el uso de apodos hirientes, la manipulación psicológica, la violencia física y la exclusión social son formas bajo las cuales se realiza el acoso escolar. Además, este no solo aqueja a estudiantes que tengan una orientación sexual o identidad de género diferente del resto, sino que muchas veces afecta a jóvenes que no son lesbianas, gais, bisexuales, transgénero ni intersexuales (LGTBI).

Las agresiones provocadas por el acoso escolar homofóbico impactan directamente en la salud mental y física de las víctimas. En muchas ocasiones, los jóvenes que han sido violentados terminan dañándose a sí mismos e incluso suicidándose. 
Recuadro III.3 (conclusión)

\section{Algunas buenas prácticas para afrontar el bullying homofóbico en América Latina}

- Brasil: Brasil sin homofobia (2004) es un programa en el que se incluye el programa de Escuelas sin Homofobia, que busca, de manera interdisciplinaria y multitudinaria, combatir la homofobia en los establecimientos educacionales, realizar investigaciones cualitativas sobre la homofobia en las escuelas y crear material de capacitación para estudiantes y docentes.

- Chile: El Movimiento por la Diversidad Sexual (MUMS), con el auspicio de diversas municipalidades, realiza talleres en diferentes establecimientos educacionales de Santiago con el fin de abordar el acoso y la violencia escolar en contextos de respeto a la diversidad sexual.

- El Salvador: La iniciativa impartida por la Secretaría de Inclusión Social junto con el Ministerio de Educación busca concientizar sobre el problema del acoso escolar y estimular a los directores de las escuelas para enfrentar los casos de discriminación y acoso escolar homofóbico.

- México: La Fundación hacia un Sentido de la Vida (FUNSEVIDA) es un grupo de apoyo para padres, madres, familiares y amigos que creó el video "Homofobia y VIH: lo que las madres y padres dicen" donde se presentan sus testimonios. También elaboró un proyecto en seis escuelas de la ciudad de Jalapa sobre cómo reconocer el acoso escolar homofóbico y qué hacer para enfrentarlo. Se realizaron más de 50 talleres de capacitación para educadores, apoderados y estudiantes de secundaria.

Es así como esta acción comienza a reproducirse desde las estructuras relacionadas con la identidad de género en las que los jóvenes fueron criados. La discriminación reside en las actividades que realiza cada estudiante y que no pertenecen, convencionalmente, al género con el que ha sido identificado por sus compañeros.

Por esto, el desafío de las escuelas consiste en establecer normas de comportamiento claras y estrictas, apoyar social y pedagógicamente a sus alumnos, acoger y explicitar las diferencias de género, crear espacios de denuncia y juicios justos, asistir a cada estudiante que es víctima o victimario, y velar por que cada iniciativa antidiscriminación promulgada por estudiantes y docentes sea bien recibida.

Resulta primordial que el ambiente educacional sea seguro, respetuoso y libre de discriminación. Crear un espacio de cooperación, tanto dentro como fuera de la sala de clases, es tarea de todas las personas que estudian, enseñan, trabajan o administran la escuela. La misión de estos escenarios de solidaridad es eliminar insultos, sexismos, lenguaje despectivo, términos y modelos de conducta negativos que choquen con el libre derecho de los jóvenes para educarse.

Fuente: Comisión Económica para América Latina y el Caribe (CEPAL), sobre la base de Organización de las Naciones Unidas para la Educación, la Ciencia y la Cultura (UNESCO), "Respuestas del sector de educación frente al bullying homofóbico", Publicación de la serie Buenas políticas y prácticas para la educación en VIH y salud, Cuadernillo, N 8, Santiago, 2013. 


\section{El factor tecnológico en la ecuación}

Como se analizará en mayor profundidad en el capítulo V, la era digital y el uso de Internet, en especial de las redes sociales, cada vez están más presentes en la vida cotidiana de las personas en la región, en particular en el caso de la población juvenil. Internet es una plataforma que abre un amplio abanico de posibilidades y oportunidades que dependen del lugar de acceso, la calidad de la conexión y las habilidades de quien la utiliza. Pese a la existencia de brechas muy relevantes, es difícil negar que adolescentes y jóvenes forman parte de un entorno con gran presencia tecnológica, que es reforzada en las escuelas y, en muchos de los casos, en los hogares.

Inevitablemente, este contexto ha transformado de forma positiva, y también negativa, algunos elementos clave que afectan el proceso de desarrollo de los jóvenes. El aumento de la cantidad y disponibilidad de información desafía y transforma las maneras de aprender, así como las habilidades que hay que ir desarrollando para aprender mejor. También cambian las maneras de relacionarse, ya que permite, por ejemplo, la interacción con otros desde el anonimato, la accesibilidad a gran cantidad de personas, la comunicación inmediata, el establecimiento de comunidades virtuales y el archivado automático de la interacción (Pavez, 2014). Además, abre canales de participación antes inexistentes: Internet y las redes sociales han jugado un importante papel en muchos movimientos sociales, estudiantiles y juveniles en la región y en el mundo (véase el capítulo V).

Estas transformaciones generan oportunidades y también riesgos en las vivencias de la adolescencia y juventud. Es relevante preguntarse por los límites y riesgos que involucra el uso de Internet, sobre todo en la población más joven debido a su limitada capacidad de autorregulación y susceptibilidad a la presión social (O'Keefee y Clarcke-Pearson, 2011, citado en Pavez, 2013). Algunos de los riesgos más conocidos y mediatizados son la captación de niños para fines sexuales (grooming), el acecho de adultos hacia menores de edad con fines sexuales y el ciberacoso. Este último se describe como un tipo de acoso, ya sea en la forma de hostigamiento, persecución, denigración, violación de intimidad, exclusión o suplantación de identidad a través de Internet $u$ otros medios electrónicos, por un grupo o un individuo de forma repetida contra una persona que no se puede defender (Smith y otros, 2008, citado en Pavez, 2014). Si bien, como se revisaba en las secciones anteriores, la violencia y los abusos de todo tipo no son novedad en el contexto escolar, sí lo es la forma que van tomando, especialmente gracias a Internet. Esto se debe a que la velocidad de expansión del mensaje, la amplitud de la audiencia y su difusión forman parte de un fenómeno sin precedentes que pone en jaque a los sistemas educativos que no están preparados para enfrentarlos y que convierten a las plataformas en línea en elementos "contundente(s) en la destrucción emocional" (UNICEF, 2011, citado en Pavez, 2014). 
El ciberacoso presenta características que lo vuelven no solo más permanente en el tiempo, sino también más dañino que el matonaje presencial. Por ejemplo, los agresores pueden ocultar su identidad, lo que aumenta su impunidad y hace más difícil la defensa de la víctima. También pueden aumentar de manera exponencial y la humillación puede alcanzar audiencias mucho más extensas. Se trata de un fenómeno con una alta velocidad de difusión $y$, aunque se descarta una agresión física directa, le da un carácter público a la ofensa, lo que aumenta la vulnerabilidad de la víctima (Cerezo-Ramírez, 2012, citado en Pavez, 2013).

Como se trata de un fenómeno emergente, son pocos los estudios en los que se han abordado los casos de acoso escolar por Internet en América Latina. Un país pionero en la medición de este tipo de comportamientos es el Brasil, donde se estima que un 33\% de un total de 5.827 escolares encuestados afirmó que algún amigo o amiga había sido víctima de ciberacoso en 2009, y que un 30\% fue víctima de malos tratos por Internet, que incluyeron hablar mal de ellos a través de las redes sociales, difundir fotos embarazosas de ellos o sus familias, robar sus claves y suplantarlos en redes sociales (Eljach, 2011). En la Argentina, un estudio realizado en conjunto por Microsoft y el Instituto Nacional contra la Discriminación, la Xenofobia y el Racismo (INADI) concluyó que el 16\% de los escolares encuestados recibió alguna vez intimidaciones o amenazas y que el 15\% sufrió algún tipo de discriminación a través de una red social (UNICEF, 2011).

En Chile, los casos también van en aumento. En la Encuesta Nacional de Violencia Escolar, para la cual se entrevistó a 49.637 alumnos de entre 12 y 17 años en 2009, se dio cuenta de que el 8\% fue víctima de acoso escolar por Internet. Una situación preocupante es el círculo vicioso que se da entre víctimas y victimarios, puesto que el $48,3 \%$ de aquellos que reconocieron agredir a otros niños por Internet son también víctimas de violencia escolar grave. Esta situación es todavía más acentuada entre las mujeres, donde el $61,4 \%$ de las causantes de matonaje en línea a otras compañeras fueron, a su vez, víctimas de acoso escolar presencial o por Internet (Sepúlveda, 2012, citado en Pavez, 2013).

En un contexto en que el derecho a la privacidad, la honra y la reputación resultan vulnerables cuando no hay un marco normativo que los resguarde en el mundo digital y donde se expanden prácticas como el ciberacoso, surgen posiciones polarizadas frente al tema, en las que proteger contra empoderar y restringir contra desarrollar capacidades son algunas de las premisas. Sin embargo, niños, niñas, adolescentes y jóvenes son sujetos de derecho a los que se debe una protección económica, social y cultural integral, por lo que se debería dejar de lado una visión victimizadora cuando utilizan la red. Habría que buscar rescatar las oportunidades y ventajas de ser parte del mundo digital, protegiéndose de los riesgos. Se trata de un terreno poco explorado, pero pareciera haber 
consenso en cuanto a apuntar al sistema educativo como respuesta, no solo para promover el acceso a las TIC, sino también para desarrollar habilidades digitales (Pavez, 2014, pág. 5). La escuela se enfrenta al desafío de transformarse en un espacio donde se oriente y se entreguen pautas de conductas, herramientas y capacidades que permitan disminuir riesgos y aumentar las ventajas del uso de las TIC para las nuevas generaciones.

\section{Violencia colectiva en la ciudad ${ }^{12}$}

Dadas las grandes tensiones y dificultades que significa para algunos países, la dimensión urbana de la violencia, con factores facilitadores asociados con la criminalidad y el narcotráfico, es de las más visibles y preocupantes en la región. Tiene gran influencia en las alternativas de desarrollo e inclusión social de la juventud, al establecer un escenario más propicio para el involucramiento de los jóvenes, ya sea como victimarios o como víctimas, en las manifestaciones de violencia asociadas con la criminalidad (véase el cuadro III.1). De acuerdo con el último informe de la Oficina de las Naciones Unidas contra la Droga y el Delito (UNODC, 2014), en promedio, el $30 \%$ de los homicidios que ocurren en el continente americano están relacionados con el crimen organizado o de pandillas, lo que contrasta con el porcentaje de homicidios asociados a esta causa en Asia, Europa y Oceanía, donde es inferior al 1\% (CEPAL, 2014).

El miedo, la inmediata expresión de la inseguridad y de la cohesión social debilitada, está muy presente en la sociedad contemporánea, cada vez menos capaz de generar cohesión. A lo largo de la historia, todas las sociedades en algún momento han depositado sus miedos en alguna entidad, por lo general una población a la que se convierte en objeto de estigma y, por tanto, de rechazo y exclusión. En la actualidad, esa población la constituyen los jóvenes, en particular los que viven en las extensas zonas pobres que componen las ciudades latinoamericanas.

El estigma se crea sobre una base simbólica que se traslada con gran facilidad del joven pobre al joven criminal, lo que cierra más puertas a su inclusión. El marero (pandillero centroamericano), tatuado hasta el rostro y con un gesto tremendamente agresivo, encarna como nadie el arquetipo del pánico urbano. Su figura y el empleo que han hecho de ella los medios de comunicación mundial ponen en evidencia el estigma contemporáneo que sufre esa población donde la sociedad actual, tras un juicio que no se basa necesariamente en la evidencia, proyecta su miedo a la inseguridad.

Esta estigmatización de la juventud, basada en el contexto de inseguridad y violencia actual, paradójicamente es, per se, una manifestación

12 Gran parte de esta sección fue elaborada para el Panorama Social de América Latina 2014 (CEPAL, 2014) y se utilizaron insumos preparados por el consultor Carlos Mario Perea. 
más de la violencia estructural colectiva. Cabe entonces preguntarse: ¿qué tanto se sostiene el estigma que la sociedad de la inseguridad le ha asignado a los jóvenes?

\section{El homicidio como la máxima expresión de la violencia directa}

Poco se sabe acerca de los perpetradores de los actos violentos y su distribución etaria. Las estadísticas son limitadas y de difícil acceso y su registro es deficitario, en parte por los altos niveles de impunidad que hay en muchos de los países de la región. En el caso de México, por ejemplo, según los datos publicados, la tasa de sentenciados por homicidio en 2008 era relativamente similar entre jóvenes de 16 a 29 años (10,7 por 100.000 habitantes) y adultos de entre 30 y 44 años (9,6 por 100.000 habitantes), y significativamente inferior para el grupo de adultos de 45 a 59 años (5,2 por 100.000 habitantes) ${ }^{13}$. Las cifras de víctimas de actos de violencia extrema, como el homicidio, constituyen una aproximación más general al grado de participación en hechos violentos. Se supone que cuanto mayor es la participación en organizaciones violentas, más riesgo existe de convertirse en víctima.

La mirada comparada de la participación de jóvenes en homicidios, y en particular su grado de victimización, respecto de la misma situación entre las personas de 30 a 44 años y de 45 a 59 años, no sustenta el estigma asignado a los jóvenes. Por ejemplo, en el caso de la tasa de mortalidad por violencia interpersonal considerando las muertes por asaltos con armas de fuego, armas cortantes y otros medios, los datos sobre América Latina y el Caribe entre 1990 y 2010 no reflejaban diferencias significativas entre jóvenes de 15 a 29 años y personas de 30 a 44 años (véase el gráfico III.3). Las dos curvas mantienen una relativa paridad y, pese a que entre $1995 \mathrm{y}$ 2005 la participación de los adultos fue menor, las diferencias no llegaron a ser estadísticamente significativas.

Si se analiza esta misma información a nivel nacional, considerando los países que se han visto más afectados por olas de violencia en los últimos años (con tasas de homicidio superiores a 27 cada 100.000 habitantes), se puede apreciar que la victimización de la población juvenil es variable. No se observa como regla general que sean las víctimas principales de homicidio, sino que todo depende del país, del momento y del contexto de violencia general al que se enfrente cada sociedad. Por ejemplo, la tasa de mortalidad por homicidio según grupo etario del Brasil, Colombia y Venezuela (República Bolivariana de) (los tres países sudamericanos con un nivel de violencia más elevado) muestra una proporción mayoritaria de población juvenil afectada durante las últimas dos décadas (véase el gráfico III.4).

13 Estadísticas judiciales en materia penal disponibles a través del sitio en Internet del Instituto Nacional de Estadística y Geografía (INEGI), véase [en línea] http://www.inegi.org.mx/. 
Gráfico III.3

América Latina y el Caribe: tasa de mortalidad por violencia interpersonal, según tramos de edad, 1990-2010

(En número de muertes por 100.000 habitantes)

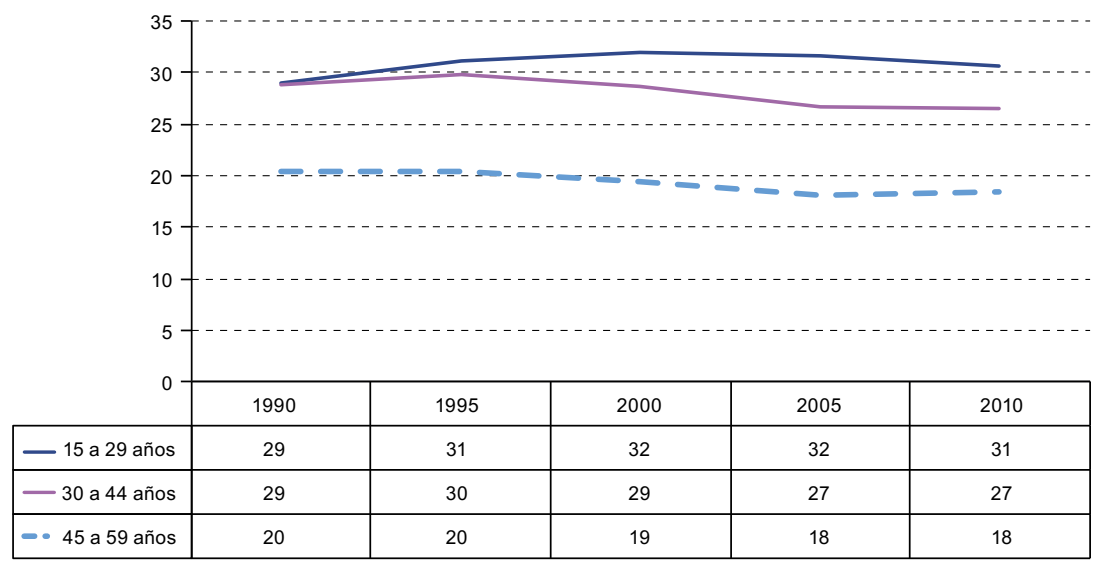

Fuente: Instituto para la Medición y Evaluación de la Salud [en línea] http://vizhub.healthdata.org/gbdcompare/ y Comisión Económica para América Latina y el Caribe (CEPAL), Panorama Social de América Latina 2014 (LC/G.2635-P), Santiago, 2014. Publicación de las Naciones Unidas, $\mathrm{N}^{\circ}$ de venta: S.14.II.G.6.

Gráfico III.4

Brasil, Colombia y Venezuela (República Bolivariana de): tasa de mortalidad por violencia interpersonal, según tramos de edad, 1990-2010 a

(En número de muertes por 100.000 habitantes)

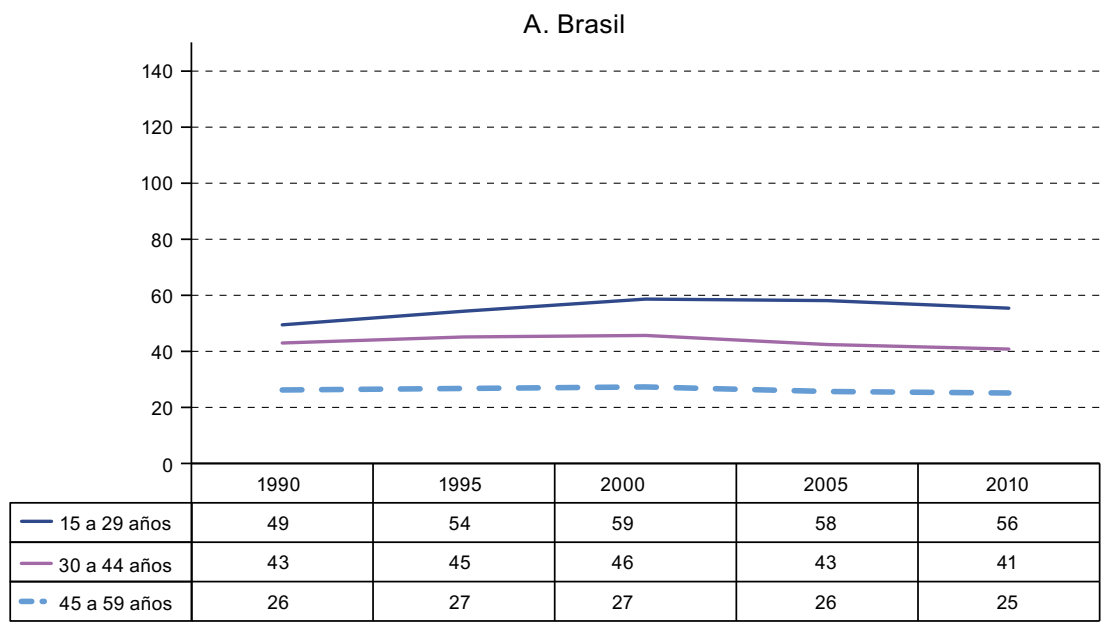


Gráfico III.4 (conclusión)

B. Colombia

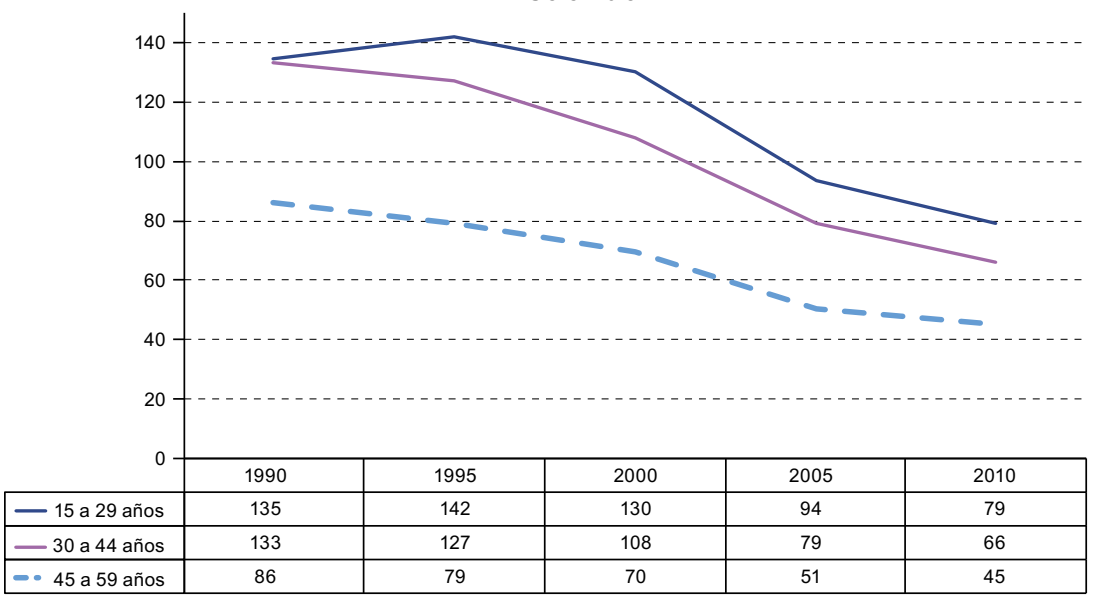

C. Venezuela (República Bolivariana de)

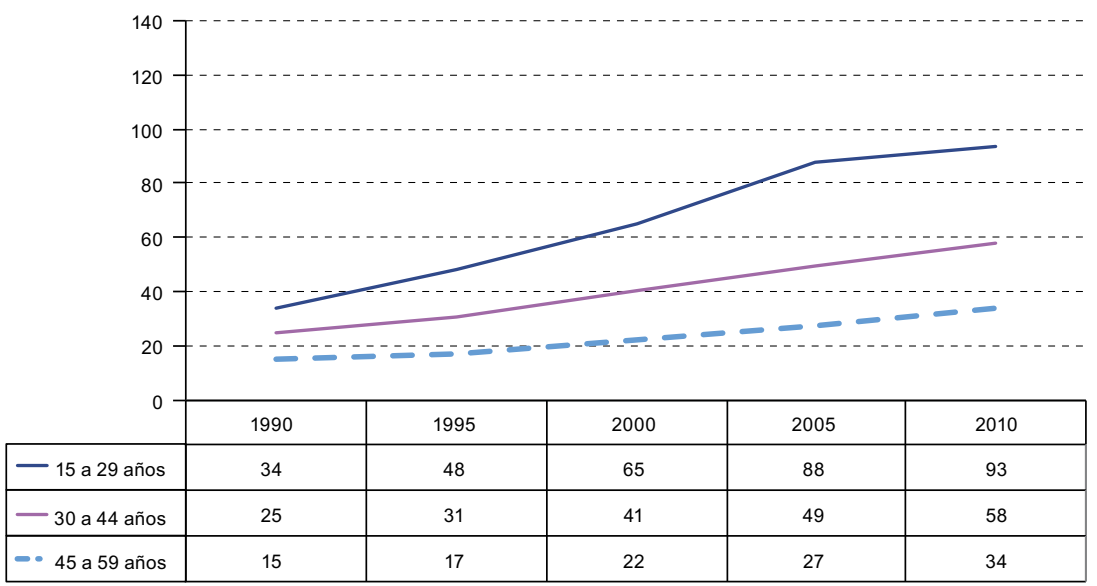

Fuente: Instituto para la Medición y Evaluación de la Salud [en línea] http://vizhub.healthdata.org/gbdcompare/ y Comisión Económica para América Latina y el Caribe (CEPAL), Panorama Social de América Latina 2014 (LC/G.2635-P), Santiago, 2014. Publicación de las Naciones Unidas, $\mathrm{N}^{\circ}$ de venta: S.14.II.G.6.

a Las diferencias entre grupos etarios son estadísticamente significativas, a excepción de la diferencia entre los segmentos de 15 a 29 años y de 30 a 44 años de Colombia.

Aun cuando se considera el contexto social de estos países, en relación con la presencia de actores violentos de gran envergadura asociados con las dinámicas del narcotráfico y de organizaciones criminales, las dominaciones territoriales violentas (narcotraficantes en Río de Janeiro o guerrillas en Colombia) no terminan de explicar la situación. El caso centroamericano lo confirma, pues el aumento de la violencia vinculado a la presencia de esos actores no ha implicado un mayor nivel 
de participación de los jóvenes como víctimas de actos homicidas, como se esperaría en virtud del estigma. Los casos de El Salvador, Guatemala, Honduras y México lo corroboran: son las personas de 30 a 44 años quienes hasta el año 2000 exhibían un nivel de participación levemente superior (que no alcanza a ser significativo en términos estadísticos) (véase el gráfico III.5). En la última década, cuando los niveles de violencia general registran un aumento, se han ido incorporando segmentos juveniles de manera más paritaria.

\section{Gráfico III.5}

El Salvador, Guatemala, Honduras y México: tasa de mortalidad por violencia interpersonal, según tramos de edad, 1990-2010 ${ }^{a}$ (En número de muertes por 100.000 habitantes)

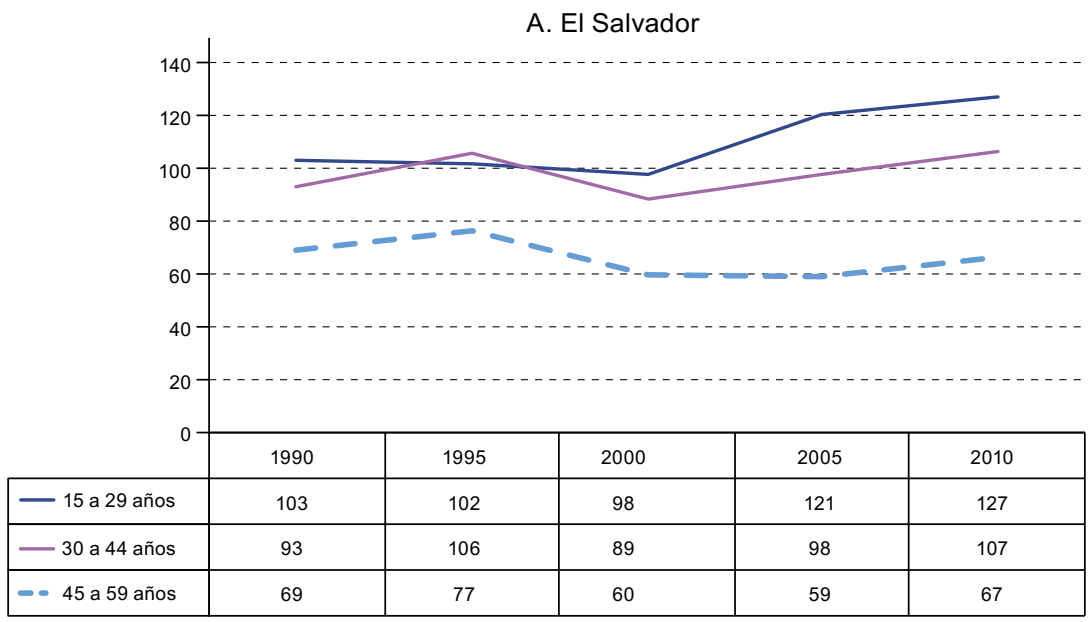

B. Guatemala

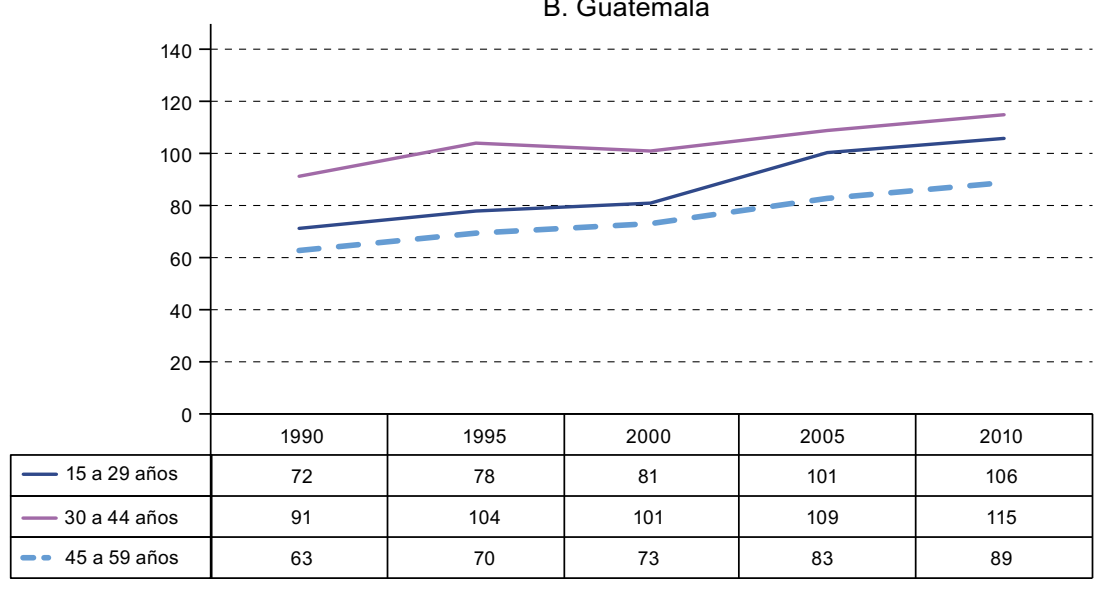


Gráfico III.5 (conclusión)

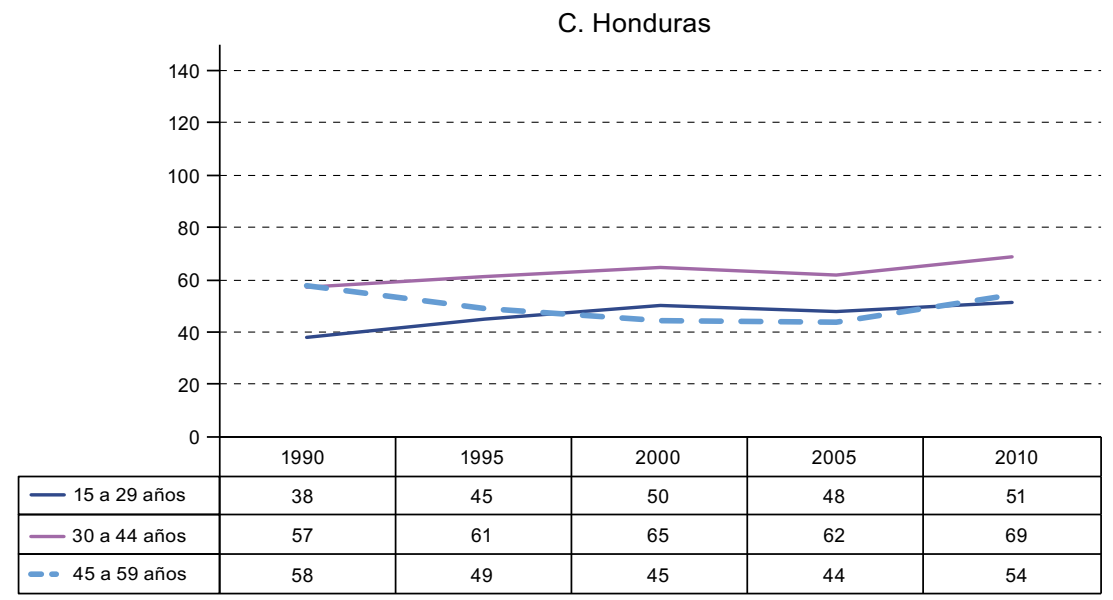

D. México

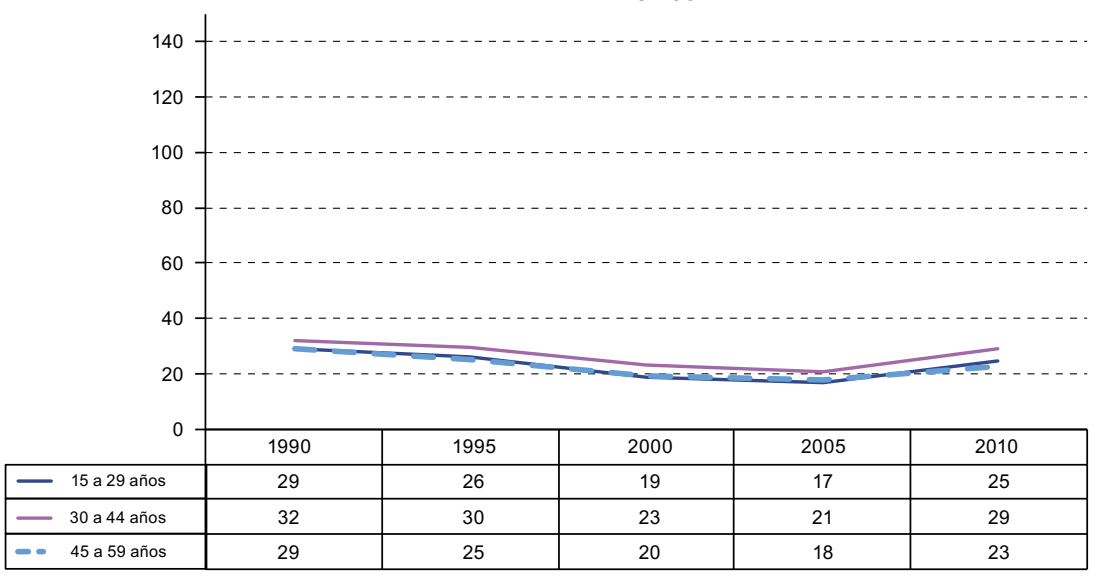

Fuente: Instituto para la Medición y Evaluación de la Salud [en línea] http://vizhub.healthdata.org/gbdcompare/.

a Las diferencias en las tasas de mortalidad de los jóvenes no son estadísticamente diferentes a las de los otros grupos de edad en ninguno de los países.

Así, mientras que en los países de América del Sur con mayor grado de violencia mueren más jóvenes por causas violentas, en las naciones del centro del continente con las mismas características, el fenómeno se da principalmente entre los adultos o es compartido con los jóvenes. Cabe destacar que existe una considerable diferencia entre las tasas de homicidios de los dos subcontinentes: en Centroamérica es de 37 por 100.000 habitantes y en América del Sur es de 16 por 100.000 habitantes (UNODC, 2012). Estos datos no sustentan la teoría de que existe una mayor 
participación juvenil en hechos violentos, ya que la victimización homicida recae esencialmente sobre las personas de entre 15 y 44 años. Se pone de manifiesto, no obstante, un contexto muy complicado para la integración de las juventudes en algunas ciudades de la región. No hay duda de que los jóvenes forman parte del contexto de violencia, pero esta violencia es un fenómeno generalizado que involucra al conjunto de la sociedad, incluida de igual manera la población adulta.

\section{Formas organizadas de participar en la violencia: las pandillas y el narcotráfico}

La aproximación estadística a los grados de participación en conductas violentas a partir de las cifras de víctimas indica que el estigma sobre el joven violento no proviene tanto de la magnitud de su intervención en actos de violencia como de la forma en que interviene. La figura más resaltada por los medios de comunicación tiene que ver con las formas organizadas de violencia urbana entre jóvenes (principalmente varones) denominadas pandillas, "maras", "clicas" o "combos", según el país. Los calificativos atribuidos a este tipo de jóvenes en el imaginario colectivo son de juventud "desviada" o "desadaptada".

En el Panorama Social de América Latina 2008 (CEPAL, 2008b), se planteaba que los estudios indican que la gran mayoría de los perpetradores de actos violentos son jóvenes en contextos urbanos de la misma edad y sexo que sus víctimas; en la mayor parte de los casos, varones que actúan en grupo. Este tipo de violencia organizada surge de agrupamientos locales que se construyen en el marco de situaciones de marginalidad y comportamientos disruptivos: las pandillas. Estas son bandas que desarrollan subculturas propias y luchan entre sí por el control territorial. En algunas ciudades se trata de agrupaciones numerosas de jóvenes que llevan a cabo diversos tipos de delitos en su entorno inmediato, pero también acciones de intimidación o disuasión a terceros (CEPAL, 2008b).

La información recogida por el estudio del Proyecto de Opinión Pública de América Latina (LAPOP) de 2012 muestra que alrededor de un tercio de la población tiene la percepción de que su barrio está afectado por este tipo de organizaciones (véase el cuadro III.5). La proporción es algo mayor en el caso de los jóvenes (un 35\% en promedio frente al $31 \%$ de los adultos). Cabe destacar que los que denuncian mayores niveles de presencia de pandillas no son los ciudadanos de los países del triángulo del norte de Centroamérica (El Salvador, Guatemala y Honduras), donde destaca la presencia de maras en las principales urbes, sino los de otros países de la zona, como Panamá y, particularmente, la República Dominicana (donde esta percepción ha ido creciendo en los últimos años). 
Cuadro III.5

América Latina y el Caribe (18 países): percepción de la incidencia de pandillas o maras en los barrios, según sus residentes, por país y tramo etario, 2012

(En porcentajes)

\begin{tabular}{lcc}
\hline País & 16 a 29 años & 30 años y más \\
\hline Guyana & 19 & 14 \\
\hline Haití & 20 & 19 \\
\hline Jamaica & 25 & 20 \\
\hline Belice & 28 & 27 \\
\hline Nicaragua & 28 & 24 \\
\hline Paraguay & 30 & 24 \\
\hline Honduras & 31 & 26 \\
\hline México & 33 & 35 \\
\hline Guatemala & 36 & 31 \\
\hline Uruguay & 37 & 35 \\
\hline Brasil & 37 & 40 \\
\hline El Salvador & 38 & 32 \\
\hline Costa Rica & 39 & 32 \\
\hline Perú & 40 & 35 \\
\hline Ecuador & 41 & 38 \\
\hline Colombia & 42 & 33 \\
\hline Panamá & 43 & 45 \\
\hline República Dominicana & 55 & 48 \\
\hline América Latina y el Caribe a & 35 & $\mathbf{3 1}$ \\
\hline
\end{tabular}

Fuente: Comisión Económica para América Latina y el Caribe (CEPAL), sobre la base de tabulaciones especiales de la encuesta bianual del Proyecto de Opinión Pública de América Latina (LAPOP), 2012.

a Promedio simple de los resultados de los 18 países incluidos en la medición.

La participación juvenil en distintas formas organizadas de violencia urbana es indudable en la región. El papel de la pandilla en términos territoriales dentro de las ciudades es una de las características que genera mayor sensación de inseguridad en la población en general, porque afecta directamente la convivencia. La figura del pandillero parado en una esquina, desafiliado de las instituciones en las que por su edad debería estar participando (tradicionalmente, la escuela o el empleo), alimenta el estigma del joven violento que representa una amenaza al orden ciudadano y al proyecto cultural de ciudad, al basar su soberanía en el barrio (Perea, 2008). La territorialización del poder criminal organizado se asocia con los niveles de segregación y "guetización" de muchas de las urbes latinoamericanas.

La pandilla emerge como un efecto directo de la violencia estructural, la exclusión y la marginación del proceso de desarrollo de la sociedad. Los especialistas en temas de juventud han manifestado durante décadas que la pandilla es una organización que ofrece una alternativa de inclusión social a una parte de las juventudes latinoamericanas. Cuando 
lo que existe es pobreza, muy pocas alternativas de inserción laboral y una débil presencia del Estado y de las instituciones en general, lo único que queda para dar sentido de futuro a la vida de muchos jóvenes es el grupo de pares en el barrio. La pandilla les provee de poder, de ingresos monetarios, de un espacio y de un sentido de pertenencia que ninguna otra institución social les ofrece. Como señalaba la CEPAL (2008b), el hecho de pertenecer a una pandilla opera como una "inclusión en la exclusión": muchas pandillas actúan como microsistemas de integración social que reflejan, compensan y refuerzan la desintegración con respecto a la sociedad. Sin embargo, Reguillo señala que este tipo de organizaciones ha cambiado en los últimos años y ha pasado de ser un espacio central de pertenencia a uno de supervivencia: "Las grupalidades juveniles en contextos de exclusión y pobreza parecen operar para muchos de sus integrantes como lugar de mínimas seguridades y confianzas (precarias)" (Perea, 2008, pág. 9).

No se puede entender este fenómeno sin comprender la historia sociopolítica y cultural de cada territorio donde emergen estas organizaciones. Esas coordenadas influyen en los modos de organizarse, en el poder de reclutamiento que tienen las organizaciones criminales sobre las juventudes y en el tipo de dominio territorial que ejercen. Es importante analizar la pertenencia a estos grupos y los niveles de violencia en que se traducen algunas de sus acciones de dominio, que se enmarcan en una multiplicidad de procesos sociales facilitadores de este tipo de inclusión social alternativa de una parte de los jóvenes de la región. En la literatura se han identificado muchos factores facilitadores de la incorporación de ciertos grupos juveniles en colectivos territoriales violentos. Algunos tienen que ver con el debilitamiento del tejido social, con secuelas de una historia de violencia civil, con la disponibilidad de armas de fuego, con procesos de desigualdad y marginación crecientes, con la desafiliación institucional de ciertos grupos de jóvenes o con un sistema educativo expulsor y discriminatorio, entre otros factores ya mencionados al comienzo de este capítulo.

Hay un factor que es importante tener en cuenta, al ser común a varios países de la región -en especial los que han sufrido ciclos alarmantes de violencia- y que además es característico de América Latina y el Caribe: el tráfico de cocaína. En las últimas décadas, este se ha convertido en el mercado ilegal dominante en ciudades marcadas por la violencia (como Medellín en Colombia, Río de Janeiro en el Brasil, Ciudad Juárez en México y, recientemente, en las ciudades del triángulo del norte centroamericano). Es un mercado del que derivan importantes márgenes de ganancias y que ordena otro conjunto de actividades ilegales (Perea, 2014). En muchas de estas ciudades no hay posibilidad alguna de competir desde el mercado legal, y aún menos desde el Estado, con ofertas económicas 
de inclusión laboral para jóvenes de poblaciones marginales. En algunos países, como los centroamericanos y México, los cárteles tienden cada vez más a "subcontratar" los servicios de las pandillas para realizar actividades ligadas al plagio y al sicariato, y sobre todo para sus luchas, para las que deben reclutar más gente en poco tiempo y con menos recursos. Por su incidencia en los niveles de conflictividad y su efecto multiplicador de violencia, el tráfico de cocaína ha tenido un papel protagónico en la región.

Aunque según Perea (2014) el narcotráfico no agota el tema de la criminalidad en América Latina y el Caribe, tampoco puede ser comprendido como una forma más del crimen organizado. El tráfico de cocaína ha tenido un papel protagónico en toda la región en cuanto a su efecto sobre los niveles de conflictividad; es decir, por su efecto multiplicador de violencia. Del análisis de este autor emerge con claridad la idea de que a mayor grado de acumulación monetaria en las redes del narcotráfico, se generan mayores niveles de violencia social. El tráfico de cocaína es el que acarrea los mayores niveles de rentabilidad en la región, que se ha convertido en el centro de producción mundial de la sustancia.

Una de las principales dimensiones para comprender los grados de violencia que enfrentan las juventudes marginadas en las urbes de la región tiene que ver con la ubicación de su país y ciudad en los eslabones de la cadena del negocio del narcotráfico. Perea (2014) describe que son cuatro los principales eslabones que componen esta cadena: producción, procesamiento, comercio y consumo. A medida que se avanza en estos eslabones, aumentan los niveles de rentabilidad. Los campesinos que producen los cultivos de cocaína (concentrados en países como Bolivia (Estado Plurinacional de), Colombia y el Perú) reciben apenas el 1\% del total de las ventas. Los márgenes de rentabilidad aumentan exponencialmente hacia el final de la cadena de negocio y las mayores ganancias se generan en el eslabón final del comercio. Las personas que integran del eslabón de paso, que transportan la cocaína desde la zona de producción hacia los países intermedios, reciben aproximadamente el 9\% de las ganancias, mientras que quienes la depositan en los mayores escenarios de consumo (eslabón final) alcanzan a percibir el $25 \%$. La venta minorista que viene después, en los propios mercados de consumo, recibe un $65 \%$ de la renta del tráfico, pero está repartida entre una mayor cantidad de personas, no organizaciones o cárteles (Perea, 2014). Por lo tanto, es el escenario de comercio mayorista final el que acumula mayores rentas en menos manos (en los años noventa estuvo concentrado en Colombia y actualmente se concentra en los cárteles mexicanos).

El hecho de que esta sea una actividad ilegal, donde no hay regulaciones instituidas para intermediar los conflictos, provoca el uso de la violencia. A mayores niveles de ganancias, mayores son los conflictos $\mathrm{y}$, por lo mismo, los grados de violencia involucrados para demarcar las 
relaciones de poder entre las organizaciones. Según plantea Perea (2014), los incidentes grandes y organizados de violencia se han desplegado en el eslabón final del comercio, donde se acumulan las mayores masas monetarias; tal ha sido el caso de Colombia y ahora de México. Las crisis que experimentan los países con Estados más frágiles, como los países del triángulo norte centroamericano, son evidentes. Desde que Colombia dejó de ser el epicentro, estos países se han visto principalmente afectados por los cambios en las rutas del tráfico de cocaína hacia los Estados Unidos. Actualmente, el 95\% de la cocaína que entra a los Estados Unidos transita por México o sus aguas territoriales, y se estima que entre el $60 \%$ y el $90 \%$ del producto pasa antes por la región centroamericana (Banco Mundial, 2011, citado en Escotto, 2015).

El modo en que estas organizaciones se insertan en cada ciudad y cada país depende mucho de sus instituciones y su tejido social, así como de las estructuras de poder de las propias organizaciones criminales. Ello determina el tipo de inserción social que se dé a nivel territorial y el grado de involucramiento de las juventudes locales. No obstante, es uno de los rasgos centrales de las crisis de violencia a las que la región de América Latina y el Caribe debe atender como bloque frente al mundo y frente al consumo de drogas (que ocurre principalmente en países externos a la región). Como dice Perea, esta multimillonaria actividad privatiza el poder y alimenta la precariedad de la justicia de muchos países. Además, agrava la desigualdad y la segregación y contribuye a aumentar la estigmatización de las juventudes pobres y la inseguridad ciudadana (Perea, 2014).

Entender a la juventud en el marco del estigma de la violencia distorsiona el juicio sobre la raíz del problema y justifica aproximaciones equivocadas para su prevención y solución. El estigma limita la comprensión sobre las distintas realidades y contextos que enfrentan la mayoría de los jóvenes en la región y justifica políticas que ven el comportamiento disruptivo de algunas juventudes como característica endógena al ciclo de vida. Como se ha visto a lo largo del capítulo, las causalidades son múltiples $\mathrm{y}$, en particular aquellas que tienen que ver con violencias urbanas de mayor envergadura, están asociadas a comportamientos dirigidos desde el mundo adulto y son parte de un contexto de ilegalidad y crimen que los desborda. Ello está ocurriendo en una sociedad que no ha logrado incluir a sus nuevas generaciones.

\section{E. Las alternativas hacia una convivencia pacífica}

Las alternativas para revertir el contexto actual de violencia y sus consecuencias negativas para la juventud deben plantearse bajo una visión integral que considere la complejidad descrita en el presente 
capítulo y que se refleja en la multiplicidad de factores facilitadores de cada una de las manifestaciones de violencia. Algunos de estos factores son generales, como los relacionados con los contextos socioeconómicos o las transformaciones sociales, y otros son más simbólicos. Entre estos últimos se pueden mencionar rasgos culturales de la región, como los roles tradicionales de género y la aceptación de la violencia y la resolución violenta de conflictos.

Esta complejidad, que involucra también una diversidad de actores y escenarios de violencia, implica la necesidad de plantear acciones en distintos ámbitos, como la promoción del cierre de brechas de exclusión y el diseño de políticas nacionales a favor de la población con menos acceso a los beneficios del crecimiento económico, así como la ruptura con visiones culturalmente arraigadas que fomentan la discriminación y la exclusión, la apertura de espacios de inclusión (educación y empleo) y muchos otros que desincentiven la violencia. Es necesario reconocer también que muchas manifestaciones de violencia ya están produciéndose y que se requiere implementar estrategias de prevención y control, atendiendo a los grupos en riesgo de sufrir violencia y a los grupos en riesgo de perpetrarla, e incluso a los que ya lo han hecho.

Es mucho lo que se puede y debe hacer, y en un contexto de recursos limitados es importante priorizar acciones identificando lo que es más urgente. Asimismo, es importante ver lo que se ha hecho, analizarlo y, en caso de ser efectivo, continuarlo e incluso replicarlo en otras latitudes, pero siempre tomando en cuenta la necesidad de coordinación de acciones bajo un enfoque integral y considerando las especificidades territoriales, dado que, como se mencionó previamente, las iniciativas aisladas podrían tener efectos contraproducentes.

En el caso de la identificación de las prioridades, es importante conocer lo que los mismos jóvenes proponen, pues ellos son los actores principales de esta tarea. Tal como se plantea en el Panorama Social de América Latina 2014 (CEPAL, 2014), es importante asegurar la presencia y el involucramiento de adolescentes y jóvenes en la formulación, ejecución, vigilancia y validación de políticas públicas multisectoriales en todos los niveles, con presupuestos sostenibles y considerando contextos y realidades particulares. La inadecuación de políticas para la juventud tiene costos significativos para todos, tanto porque agravan los problemas descritos en las secciones anteriores como por las consecuencias de no incluir adecuadamente a esta población en las iniciativas de desarrollo económico, con lo que se desaprovecha su creatividad y energía, al tiempo que se vulnera su derecho a la participación. Es decir, se pierde un círculo virtuoso y se potencia un círculo vicioso. 


\section{La visión de los jóvenes sobre un entorno libre de violencia}

En torno al debate mundial frente al planteamiento de nuevas metas de desarrollo, en los últimos años se han celebrado distintos foros de participación de las juventudes con el objeto de identificar cuáles son los principales desafíos que enfrentan a nivel regional. De acuerdo con la heterogeneidad de los grupos representados, las prioridades son diversas, aunque hay cierta coincidencia en algunos de los temas esenciales y críticos para el desarrollo pleno de las juventudes en la región. Uno de ellos es, justamente, la posibilidad de vivir en ambientes exentos de violencia (CEPAL, 2014).

En los foros se ha planteado la necesidad de impulsar políticas públicas para sensibilizar a la juventud sobre la cultura de la paz, así como para eliminar toda forma de violencia hacia las mujeres mediante programas y procesos de prevención y educación a hombres y mujeres en todas las etapas de la vida, y reconociendo el femicidio como expresión máxima de la violencia hacia las mujeres y como un delito que debe ser tipificado en las legislaciones (Naciones Unidas, 2014). Algunas de las principales peticiones de las mujeres jóvenes son: incremento del gasto fiscal para prevenir y combatir la violencia de género, más facilidades de acceso a seguridad y atención de salud en caso de haber sido violentadas, programas de reparación y legislaciones sobre discriminación y racismo.

Otro tema importante para muchos jóvenes es la protección frente a la violencia en espacios virtuales, como el matonaje y el acoso por la vía de Internet y de las redes sociales. En algunos foros se plantea también que los Estados deben avanzar en un paradigma de seguridad que proteja a los jóvenes y no actúe en contra de ellos de modo represivo, lo que supone evitar todo tipo de violencia institucional y garantizar plenamente sus derechos.

En el consenso global alcanzado en uno de los foros mundiales, las juventudes reconocen la importancia de su papel en la prevención y resolución de conflictos, entendiendo que es una condición indispensable para el desarrollo de sociedades pacíficas, inclusivas y seguras. Dicho reconocimiento de la importancia de su función se ha visto reflejado en la conformación de agrupaciones juveniles enfocadas específicamente en la prevención de la violencia (por ejemplo, grupo de jóvenes contra la violencia en Centroamérica).

En síntesis, los jóvenes proponen apostar por estrategias de sensibilización buscando modificar la visión cultural hacia una cultura de 
paz y enfocar esfuerzos en la prevención de la violencia de género y la violencia escolar, pero sin dejar de considerar el resto de los elementos que conforman el contexto actual de violencia.

\section{Políticas y programas que abordan la violencia en la juventud}

En lo que respecta a acciones que ya estén ejecutándose, en el último Informe sobre la situación mundial de la prevención de la violencia (OMS/UNODC/PNUD, 2014), se recopiló información sobre las iniciativas generales en materia de leyes, políticas y programas que han emprendido varios países de la región en este ámbito (véase el cuadro III.6). De estos resultados se desprenden las siguientes consideraciones respecto del desarrollo de políticas y estrategias orientadas a la violencia y la juventud en los países de la región.

\section{a) La disponibilidad de información}

Del informe mencionado se desprende que la gran mayoría de los países de la región no cuenta con un sistema de información que permita generar diagnósticos certeros respecto de la prevalencia de la violencia en el país. Solo 4 de los 19 países analizados disponen de encuestas nacionales que aborden el tema de la violencia que no termina en muerte.

En este sentido, cabe destacar que los homicidios, para los que hay gran disponibilidad de información, son solo un indicador de la violencia, pero hay expresiones no fatales de la violencia que se viven dentro de las familias, en instituciones escolares, en la ciudad y en otros espacios de la vida cotidiana, que deben enfrentarse de manera integral. Disponer de información sobre esas expresiones no fatales es de gran relevancia para abordar de manera adecuada la violencia juvenil y plantear políticas y programas pertinentes.

\section{b) Los planes de acción y las normativas nacionales}

El desarrollo de un plan de acción a nivel nacional es un paso clave para la prevención efectiva de la violencia. Es una manera de articular lo que los diversos sectores de la política pública pueden hacer para enfrentar las raíces del problema en forma integral. El informe muestra que más del $80 \%$ de los países de la región ha avanzado en la generación de planes de acción nacional que aborden el tema de violencia juvenil a pesar de no contar con información estadística detallada al respecto (esto se ubica por encima del promedio internacional que llega al 53\%). 


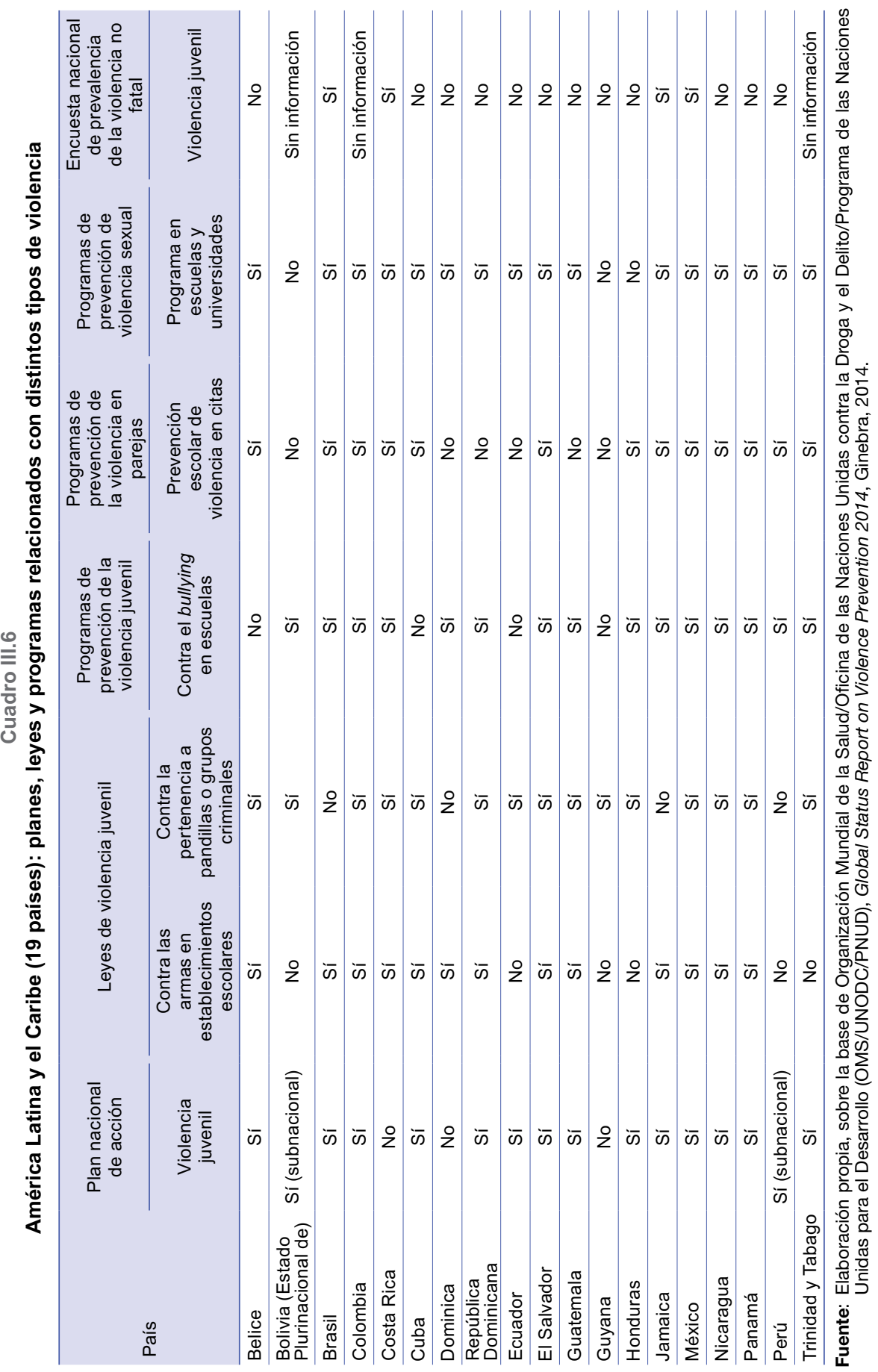


La mayoría de los países ha avanzado también en la promulgación de normativa y leyes específicas contra la violencia, un paso importante para establecer las normas de comportamiento aceptables y construir sociedades seguras. Principalmente, dichas leyes se han enfocado a limitar la tenencia de armas en los establecimientos educativos, así como la pertenencia a pandillas o grupos organizados que ejerzan violencia. El informe plantea que muchas de estas leyes en realidad no se aplican, lo que resalta la importancia de que los esfuerzos nacionales se concentren en avanzar hacia el real ejercicio de la legislación vigente, fortaleciendo los mecanismos y recursos institucionales para lograr entornos más seguros (OMS/UNODC/PNUD, 2014).

De acuerdo con la revisión realizada por la Organización Panamericana de la Salud (OPS, 2006), en muchos de los planes nacionales de juventud se incluye una preocupación por los temas de violencia que afectan a los jóvenes. Sin embargo, esta se presenta desde un punto de vista genérico, con poca centralidad y jerarquía. Por lo tanto, desde estos instrumentos se cuenta con pocas herramientas precisas para poder encarar los temas de violencia juvenil con respuestas oportunas y pertinentes (OPS, 2006).

\section{c) Los programas de prevención de la violencia}

En lo que respecta a los programas de prevención de la violencia en la población juvenil, de acuerdo con los hallazgos del informe, las estrategias puestas en marcha a nivel internacional apuntan a la formación de aptitudes para la vida y la prevención de la intimidación. La mayoría de los países está implementando algún programa contra el acoso o matonaje escolar (véase el cuadro III.6), y en el caso de la violencia contra la mujer, la estrategia principal se enfoca en cambiar las normas sociales y culturales.

Muchos de los países de la región también abordan la violencia escolar y de género desde la óptica de la formación de las nuevas generaciones. Para ello, tienen como enfoques predominantes la construcción de ciudadanía y la promoción de valores democráticos entre jóvenes y también en sus entornos comunitarios. Muchos de los programas se abordan desde y hacia los entornos escolares, y se destacan aquellos que utilizan la mediación entre pares como una de las herramientas efectivas de formación y resolución de conflictos.

Entre los programas enfocados a la violencia escolar se distinguen tres grandes tipos: los que buscan generar información, los que buscan promover la convivencia escolar y los que se enfocan en la promoción de derechos, dentro de los cuales se incluye el derecho a un entorno libre de violencia. En el primer caso, se han identificado acciones implementadas en los últimos diez años que buscan estudiar en profundidad la problemática 
de violencia en las escuelas, destacándose programas como el Observatorio Argentino de Violencia en las Escuelas en la Argentina y el Observatorio sobre la Violencia y Convivencia en la Escuela en el Perú.

En el caso de acciones que tienen por objeto consolidar a las escuelas como espacios seguros libres de violencia mediante la promoción de la convivencia y la prevención interna, se han identificado programas como el Programa Nacional de Mediación Escolar en la Argentina; la Política de Convivencia Escolar hacia una educación de calidad para todos en Chile; el Programa para la Gestión del Conflicto Escolar y la Alianza para la Paz, Educación para la Paz en Colombia; El Cole en Nuestras Manos y el Festival Estudiantil de las Artes en Costa Rica; la campaña Aprender sin Miedo, el Plan Escuela Segura y el Plan de Prevención Escolar en El Salvador; el Programa Nacional Escuela Segura, el Programa Nacional para Abatir y Eliminar la Violencia Escolar y el proyecto Abriendo Escuelas para la Equidad en México; el programa De la Violencia a la Convivencia, la Mesa contra el Acoso en la Escuela y el programa Fiscales Escolares en el Perú, y el Dispositivo Bicentenario de Seguridad va a la Escuela en Venezuela (República Bolivariana de).

Algunas de las estrategias más destacadas basadas en la institución escolar son las que promueven la apertura de la escuela hacia la comunidad (Escuelas Abiertas en Guatemala y el Brasil). Los siguientes son los elementos centrales identificados por el estudio de la OPS (2006) para la efectividad de estos programas: los jóvenes y las comunidades locales se apropian del espacio escolar y, por lo tanto, lo protegen en lugar de atacarlo; al convertirse en un espacio amigable para la comunidad en su conjunto, se genera mayor atracción para el retorno de desertores; al ofrecer herramientas de aprendizaje para la vida (no excluyente), se generan procesos de mayor empatía en el proceso educativo.

Como programas que apuntan a la promoción de la garantía de los derechos de los jóvenes, con particular énfasis en contextos de violencia escolar, se pueden mencionar los siguienres: el Programa Nacional por los Derechos de la Niñez y la Adolescencia en la Argentina; el proyecto Construyendo Ciudadanía en Chile; el Plan Nacional Decenal de Educación - Educación en y para la paz, la convivencia y la ciudadanía en Colombia, y el programa Defensoras y Defensores Escolares en Venezuela (República Bolivariana de).

En el ámbito de la violencia de género y del maltrato infantil también han existido algunas intervenciones. En este caso se destacan el Programa de Capacitación y Tratamiento de la Violencia Familiar, Maltrato Infantil y Abuso Sexual en la Argentina; el Plan Distrital para la Atención Integral a Víctimas de Violencia y Abuso Sexual de Colombia, y el Programa de prevención y lucha contra la violencia juvenil y de género desde la educación y defensa de los derechos humanos en El Salvador. 
Otros programas que atañen a la juventud y fueron creados para prevenir la violencia son los que trabajan con "policías comunitarias". Algunos países han desarrollado programas a nivel de ciudades (Bogotá, Sao Paulo, Belo Horizonte), mientras que otros cuentan con programas importantes a nivel nacional, como es el caso de Nicaragua. El modelo de prevención de violencia de Nicaragua articula todos los ministerios que tienen injerencia en acciones de prevención y atención a la violencia en el marco de un "Modelo de Responsabilidad Compartida" en el que participan. Incluye también el apoyo de la ciudadanía a través de los Gabinetes de la Familia, la Comunidad y la Vida conformados por habitantes de las mismas comunidades. En el marco de este modelo, la Policía articula un modelo "preventivo, proactivo y comunitario" que incluye la profesionalización permanente del cuerpo policial y la coordinación con la policía voluntaria y dos entidades adicionales - la Comisaría de la Mujer y la Niñez y la Dirección de Asuntos Juveniles- que atienden de manera particular la violencia juvenil. Entre las acciones de la Dirección de Asuntos Juveniles se encuentra la intervención cercana a jóvenes que tienen conductas violentas y a jóvenes involucrados en actividades de pandillas o que tienen conflictos con la ley. El propósito es atender a estos jóvenes mediante una estrategia pacífica aplicando un protocolo de seis pasos (tregua, diagnóstico, atención, armisticio, desmovilización y reinserción social), en virtud del compromiso de los mismos jóvenes, de sus familias y de la comunidad.

De acuerdo con lo señalado por la OPS (2006), las experiencias de policías comunitarias de América Latina que han sido evaluadas logran incrementar la confianza pública en la policía y acercarse a la comunidad. No necesariamente disminuyen las tasas de abuso policial, porque para ello es necesario acompañar estos programas con estrategias de reentrenamiento y con sistemas de monitoreo y alarma temprana frente a infracciones reiteradas por algunos policías. Las evidencias son menos claras en relación con la disminución de los actos de violencia y delincuencia. En algunos países también se han implementado programas que promueven vías de inserción social para los jóvenes que se encuentran en situaciones marginales, en riesgo de cometer actos de violencia o que ya los hayan cometido. Este es el caso del Programa de prevención con niños, niñas y adolescentes en riesgo de desarrollar carreras delictuales de Chile; el programa Escola Aberta en el Brasil; el Programa para Fortalecer Medidas de Protección a Adolescentes Infractores en el Ecuador; Jóvenes Protagonistas y Escuelas Abiertas y la Liga Atlética Juvenil en Guatemala. Mediante la promoción de actividades como talleres artísticos o la práctica de deportes entre los jóvenes, estos programas fomentan la convivencia para prevenir la delincuencia juvenil o el consumo de drogas. 
Por último, pueden identificarse algunos programas implementados en los últimos diez años que buscan prevenir la violencia juvenil sin enfocarse en ningún ámbito específico. Este es el caso del proyecto Desarrollo Juvenil y Prevención de la Violencia en la República Dominicana. También hay programas que son de índole general, pero que permean al grupo juvenil, como el proyecto de desarrollo de competencias ciudadanas para prevenir la violencia y construir democracia en Colombia, el Programa de Seguridad Integral de Panamá, el programa ¿Violencia? ¡No gracias! de la República Dominicana y el Programa de promoción del derecho al buen trato en Venezuela (República Bolivariana de).

Cabe señalar que algunos de estos programas ya no se encuentran vigentes. Esto se puede deber a su asociación a los ciclos políticos de los países (períodos de gobierno) o a restricciones presupuestarias. Algunos programas han tenido más éxito, como es el caso de los enfocados a los esquemas de escuelas abiertas y de promoción de la cultura de paz, mientras que otros no han tenido los resultados esperados, como los que promueven espacios específicos de participación juvenil. En este último caso, son más efectivas las iniciativas que promueven la inserción laboral y el fomento a la participación ciudadana (Rodríguez, 2006).

\section{d) La influencia del estigma asignado a la juventud}

Mención especial merece el impacto que ha tenido el estigma de la violencia como una condición juvenil en la definición de políticas. El estigma, surgido en los años ochenta y vigente en el imaginario colectivo y cultural, en gran parte se ha visto reforzado por los mensajes que destacan los medios de comunicación y ha conducido a que en muchos países se debata reducir la edad de imputabilidad por delitos. La preocupación por la edad penal forma parte del desasosiego que produce un contexto de inseguridad que genera angustia entre la ciudadanía, que conduce a una opinión pública proclive a reclamar por castigos fuertes para los adolescentes, justificando que son conscientes de sus actos y por ello no se les puede exonerar de la responsabilidad penal que tienen al emprender una vida criminal.

En este sentido, es importante recordar que las políticas o estrategias de Estado de sobrecriminalización, represión, falta de apego a la ley, imputación penal adolescente y otras, que fueron impulsadas con fuerza en la década de 2000, resultaron contraproducentes, ya que los niveles de violencia siguieron aumentando.

La alternativa es implementar políticas hacia la inclusión juvenil que incorporen mecanismos de comunicación y reflexión conjunta sobre las causas de la victimización y la violencia juvenil, y que permitan transitar hacia una cultura de paz a partir de la internalización de la idea básica de no negar el conflicto, pero sí afirmar que siempre es posible resolverlo de forma no violenta. 
La negociación y la resolución pacífica tendrían que formar parte de la educación formal y no formal, lo que permitiría brindar a las nuevas generaciones herramientas sobre los modos de relacionarse, comprender al otro y resolver desacuerdos sin llegar a la violencia. El Estado debe ser capaz de transmitir modelos de cultura de la paz a través de las policías, de los sistemas de justicia, de la transparencia, del apoyo a la comunidad y de sus instituciones en general (CEPAL, 2014).

\section{Recomendaciones para la inclusión juvenil en contextos de violencia}

Para lograr un proceso de reversión del contexto de violencia actual, las dimensiones de la violencia que han sido planteadas en el presente capítulo tienen que verse reflejadas en una diversidad de enfoques de intervención. Ello implica considerar el diseño de políticas integrales que, mediante una presencia más sólida del Estado, se enfoquen en las múltiples causas bajo estrategias articuladas a distintos niveles, con la incorporación de la perspectiva territorial. Asimismo, también es necesario que estas políticas consideren estrategias de largo plazo que posibiliten recuperar aspectos de contexto social generalizado, como la cultura de resolución no violenta de conflictos que permita reducir la violencia mediante la voluntad de los actores violentos de dejar de serlo. También se requiere el reconocimiento de la responsabilidad compartida entre todos los actores sociales y propiciar la existencia de un escenario de confianza institucional, sobre todo en instituciones como la policía.

En este sentido, se plantean algunas recomendaciones de índole general. La primera es que los enfoques de intervención que se definan deben establecer con claridad la forma en que se harán cargo de la problemática en cada una de las dimensiones. Este aspecto permitirá evitar duplicidades de intervención y enfocar mejor los esfuerzos. Tal como lo plantea la OPS (2006), es imprescindible asumir que la violencia es un fenómeno estructural y muy complejo, por lo que hay que intentar superar enfoques de políticas muy comunes en la región que tienden a ser simplistas y que se limitan a otorgar respuestas puramente represivas, o bien campañas de corte moralista, asimilando, muchas veces de manera mecánica, la situación de pobreza con la condición de violencia.

La segunda recomendación general estriba en la importancia de establecer un mecanismo de coordinación entre las diversas instancias públicas que trabajan con temas de violencia y población juvenil, buscando su complementariedad para lograr un enfoque integral de la política nacional en relación con esta problemática. Para ello es indispensable que exista un espacio de coordinación interinstitucional.

Estas dos recomendaciones iniciales forman la base del diseño de respuestas con enfoques integrales e integrados que, como menciona Rodríguez, han sido las más pertinentes al buscar "incidir en la propia 
cultura ciudadana, y apostando a la sostenibilidad correspondiente en el tiempo y en el espacio, acotando en paralelo el alcance de las respuestas de corto plazo" (Rodríguez, 2006, pág. 3). Es recomendable priorizar las respuestas de largo plazo, fomentando los valores de paz, tolerancia y resolución pacífica de los conflictos. La agenda de seguridad debería ser complementaria a esta perspectiva y apostar a la pacificación en el marco del respeto a los derechos humanos (Alvarado, Rodríguez y Vommaro, 2013).

Una tercera recomendación se basa en la necesidad de avanzar en sistemas de información nacionales que permitan revelar el verdadero alcance del problema e identificar a las poblaciones más afectadas, lo que posibilitará un mejor enfoque de las intervenciones y el monitoreo de sus avances.

Un cuarto aspecto que es importante considerar es la mejora en la capacidad de las instituciones a cargo del diseño, implementación y coordinación de las acciones en torno al conocimiento de métodos adecuados de diseño, monitoreo y evaluación que permitan identificar adecuadamente las estrategias útiles. Parte de los elementos necesarios para cubrir este punto radica en relevar la agenda de juventudes a un nivel que permita la asignación adecuada de recursos para la mejora de capacidades para una implementación pertinente y sostenible desde las instituciones del Estado, así como un claro tratamiento de la violencia en la juventud incorporado en los planes nacionales de juventud o de seguridad ciudadana que establezcan funciones claramente definidas para las distintas instituciones.

La quinta recomendación general consiste en promover una mayor y mejor coordinación, para evitar duplicidad de esfuerzos, entre todos los actores que llevan a cabo programas y proyectos de atención a la juventud y de prevención de la violencia. Entre ellos se encuentran las instancias nacionales, las autoridades municipales, las organizaciones de la sociedad civil y los organismos de cooperación internacional (ya sean bilaterales o multilaterales). En este sentido, cabe señalar que las acciones de la sociedad civil y los organismos de cooperación internacional han jugado un papel particularmente relevante en la prevención de la violencia, aunque a pequeña escala. De esta manera, se recomienda que estas respuestas integrales se apoyen mucho en el capital social a nivel comunitario. Para mejorar el desempeño de las estrategias a nivel local habría que buscar sinergias y posibles complementariedades entre las instituciones del Estado y las redes sociales a nivel comunitario (OPS, 2006).

Como sexta recomendación general se plantea la importancia de reconocer al joven como actor principal en las intervenciones, cumpliendo funciones preponderantes en su diseño e implementación, de forma que se apodere de dichas acciones. Este es el modelo que se reconoce como de mayor éxito en el tratamiento de la violencia en la juventud (Rodríguez, 2006). 
Ya en el ámbito específico de los enfoques de intervención -y partiendo de la premisa de que la prevención de la violencia es, en general, más eficiente que las acciones de control de esta-, Buvinic, Morrison y Orlando enumeran un conjunto de recomendaciones encaminadas a la prevención de la violencia, ordenadas de acuerdo con el tipo de prevención que abordan, y que se mencionan a continuación ${ }^{14}$.

\section{a) Estrategias de prevención primaria}

Es importante reducir los factores de riesgo que aumentan las posibilidades de que una persona o un grupo de personas sea víctima o actúe de manera violenta mediante estrategias de corto, mediano y largo plazo. En el caso de las medidas de corto y mediano plazo se recomienda considerar:

- Estrategias de reducción de riesgos próximos, como consumo de alcohol y drogas, o porte de armas.

- Implementación de campañas de sensibilización y educación a la población en general, con especial énfasis en la juventud, que permitan la promoción de una cultura de paz desde distintos escenarios, incluido el modelamiento de prácticas: en el sistema educativo y en los medios de comunicación, en los espacios laborales y en el seno familiar (la sensibilización a padres y madres debería considerarse de gran trascendencia).

- La escuela es una de las instituciones clave en estos procesos. A partir de los estudios que se han hecho de experiencias exitosas, se relevan ciertas variables relevantes para permitir una mayor efectividad de los programas. Se recomiendan las medidas de democratización de las relaciones de gestión escolar y el establecimiento de relaciones positivas entre estudiantes y profesores; la preparación de la comunidad educativa para enfrentar el conflicto de manera adecuada, con una actitud proactiva y evitando la impunidad; y el involucramiento de la familia y la comunidad educativa en general (OPS, 2006).

- Los medios de comunicación también pueden tener un papel preponderante en la sensibilización. En general, se destaca el impacto masivo que tienen los medios desde un aspecto negativo y contrario a la promoción de la prevención de la violencia, porque suelen enfatizar la difusión de actos de violencia y estigmatizar a los jóvenes pobres en la forma en que presentan las noticias policiales (OPS, 2006). Habría que hacer un esfuerzo para trabajar con los medios de comunicación en un sentido inverso.

14 Véase más información en Buvinic, Morrison y Orlando (2005). 
- Evaluación de las legislaciones sobre violencia en torno al tratamiento que se da a la violencia en la juventud, con el objeto de incorporar o generar elementos orientadores o rectores de la actuación de las instituciones ante manifestaciones de violencia en espacios escolares y no escolares, bajo un enfoque de garantía de derechos y con claridad de normas e implicaciones para los jóvenes que transgreden la ley.

Con relación a las medidas de largo plazo se recomienda considerar:

- El apoyo a iniciativas en distintos niveles de gobierno (gubernamentales, de la sociedad civil o de la cooperación internacional) en materia de inclusión social juvenil, desde los ámbitos de la educación, el empleo y la participación, mediante la apertura de espacios de inclusión en estos ámbitos, con estrategias como becas escolares y apoyo al primer empleo, entre otras discutidas más en profundidad en los capítulos anteriores.

\section{b) Estrategias de prevención secundaria}

La prevención secundaria se enfoca en los grupos más vulnerables y que ya han sido afectados por la violencia, por ejemplo, personas involucradas con pandillas, que viven en la calle o con adicciones.

- Mejora en el diseño e implementación de las iniciativas que se concentran en actividades tales como asistencia psicosocial, atención a jóvenes con problemas de adicción a drogas o alcohol, y desmovilización de jóvenes pandilleros.

- Fortalecimiento de las estrategias de tratamiento de la violencia estudiantil en las escuelas mediante protocolos que establezcan las hojas de ruta de atención considerando los derechos de la niñez y la adolescencia y tomando en cuenta el interés superior del niño en menores de 18 años.

- Las instituciones policiales tambiénjuegan un papel fundamental y hay que trabajar intensamente para cambiar la mentalidad predominante en la región, donde el imaginario del joven pobre como delincuente en potencia, al que hay que vigilar y castigar, tiene un efecto muy negativo sobre la confianza y legitimidad de estas instituciones en los barrios y localidades. Hay que trabajar para que esta sea una institución a la que se puede recurrir para obtener protección (OPS, 2006).

\section{c) Estrategias de prevención terciaria}

La prevención terciaria tiene un enfoque restaurativo, consistente en la rehabilitación y reinserción social de personas que están en conflicto 
con la ley, ya que han incurrido en la violencia, o en la restauración de daños a las víctimas.

- Diseño e implementación de una política social que promueva la responsabilidad penal (sanción), pero también la reinserción social mediante mecanismos de inclusión de los jóvenes en los espacios educativos o productivos, considerando la violencia como un fenómeno significativo para los mecanismos de inclusión formales cuando se infringe la ley.

- Judicialización de la violencia con fortalecimiento de los sistemas de justicia, abriendo espacios para la denuncia y el adecuado seguimiento de los procesos, tanto para los victimarios como para las víctimas. En este ámbito se incluye una mejor capacidad de la Policía en el manejo de las denuncias, en las herramientas de investigación y en el procesamiento y conductas con los implicados.

- Promoción de iniciativas que atiendan a la población juvenil en conflicto con la ley. Esto abarca a todos los jóvenes encarcelados o en centros de internamiento que carecen de oportunidades para reinsertarse a la vida (social, económica y política) del país una vez que cumplan su condena. Hay que reconocer que se trata de personas con derecho a que se les trate con dignidad y a que se les entreguen herramientas para desarrollar capacidades y habilidades que les permitan llevar una vida digna y productiva una vez que recuperen su libertad.

Antes de concluir, no se puede dejar de resaltar la importancia de identificar y "replicar" las experiencias exitosas o buenas prácticas en materia de inclusión social juvenil en otros países de la región, así como la relevancia de la cooperación Sur-Sur y de la difusión de estudios o diagnósticos realizados por universidades $u$ organizaciones no gubernamentales (ONG) que contribuyan a una mejor comprensión de la problemática, sobre todo en las siguientes áreas: deserción escolar; crimen organizado, narcotráfico y aumento en el consumo de drogas; suicidios en la niñez y la adolescencia; precariedad en el empleo juvenil; violencia intrafamiliar; migraciones juveniles transnacionales; retorno de jóvenes deportados y rehabilitación y reinserción de jóvenes en conflicto con la ley. Estos estudios pueden ayudar a identificar alternativas útiles para la preparación de los planes de acción de las políticas públicas que buscan reducir el involucramiento de la juventud en las múltiples dimensiones de la violencia descritas en este capítulo, favoreciendo la promoción de un concepto de inclusión social más amplio, que incida en el desarrollo con igualdad, particularmente en el desarrollo de todos los jóvenes de la región en un entorno libre de violencia. 


\section{Bibliografía}

Aguilar, Jeanette y Marlon Carranza (2008), “Las maras y pandillas como actores ilegales de la región", ponencia preparada en el marco del Informe Estado de la Región en desarrollo humano sostenible, San Salvador.

Alianza Joven Regional (2010), "Diagnóstico de la violencia juvenil en El Salvador", San Salvador.

Alvarado, Sara Victoria, Ernesto Rodríguez y Pablo Vommaro (2013), Informe CLACSO-UNESCO: Políticas de inclusión social de jóvenes en América Latina. Situación, desafios y recomendaciones para la acción [en línea] http:/ /www.celaju. net/informe-unesco-clacso-politicas-publicas-de-juventud-e-inclusion-socialen-america-latina-y-el-caribe/.

Banco Mundial (2011), Crimen y violencia en Centroamérica. Un desafío para el desarrollo [en línea] http://siteresources.worldbank.org/INTLAC/Resources/FINAL_ VOLUME_I_SPANISH_CrimeAndViolence.pdf.

Bravo, Rebeca G. (2013), Maras en Centroamérica y México (Costa Rica, Guatemala, Honduras, Nicaragua, Panamá, El Salvador), Madrid, Comisión Española de Ayuda al Refugiado (CEAR).

Buvinic, Mayra, Andrew Morrison y María Beatriz Orlando (2005), "Violencia, crimen y desarrollo social en América Latina y el Caribe", Papeles de Población, $\mathrm{N}^{\circ}$ 43, Universidad Autónoma del Estado de México.

CEPAL (Comisión Económica para América Latina y el Caribe) (2014), Panorama Social de América Latina 2014 (LC/G.2635-P), Santiago. Publicación de las Naciones Unidas, $\mathrm{N}^{\circ}$ de venta: S.14.II.G.6.

(2008a), "Situación y desafíos de la juventud en Iberoamérica", documento presentado en la XVIII Cumbre Iberoamericana de Jefes de Estado y de Gobierno de Iberoamérica, San Salvador.

(2008b), Panorama Social de América Latina 2008 (LC/G.2402-P), Santiago. Publicación de las Naciones Unidas, $\mathrm{N}^{\circ}$ de venta: S.08.II.G.89.

CEPAL/OIJ (Comisión Económica para América Latina y el Caribe/Organización Iberoamericana de Juventud) (2008), Juventud y cohesión social en Iberoamérica. Un modelo para armar (LC/G.2391), Santiago, octubre.

Dammert, Lucía y otros (2010), Crimen e Inseguridad: Indicadores para las Américas, Santiago, FLACSO Chile/Banco Interamericano de Desarrollo (BID).

Eljach, Sonia (2011), Violencia escolar en América Latina y el Caribe: Superficie y fondo, Ciudad de Panamá, Plan Internacional/Fondo de las Naciones Unidas para la Infancia (UNICEF), noviembre.

Escotto, Teresita (2015), “Juventudes en Centroamérica en contextos de inseguridad y violencia: Realidades y retos para su inclusión social", por aparecer.

Fleitas Ortiz de Rozas, Diego M., Germán Lodola y Hernán Flom (2014), Delito y violencia en América Latina y el Caribe: Perfil de los países de la región, Buenos Aires, Asociación para Políticas Públicas.

Galtung, Johan (1990), “Cultural violence”, Journal of Peace Research, vol. 27, N³, SAGE.

IIDH (Instituto Interamericano de Derechos Humanos) (2011), Informe interamericano de la educación en derechos humanos: Un estudio en 19 países. Desarrollo en las políticas de convivencia y seguridad escolar con enfoque de derechos, San José. 
Imbusch, Peter, Michel Misse y Fernando Carrión (2011), "Violence research in Latin America and the Caribbean: A literature review", International Journal of Conflict and Violence, vol. $5, \mathrm{~N}^{\circ} 1$.

INJUV (Instituto Nacional de Juventud) (2012), Séptima Encuesta Nacional de Juventud, Santiago.

Lacayo, Nadine (2015), “Inclusión social juvenil en contextos de violencia. Estudio de caso Nicaragua", inédito.

LAPOP (Proyecto de Opinión Pública de América Latina) (2012), “Base de datos del Barómetro de las Américas" [en línea] http:/ /lapop.ccp.ucr.ac.cr/Lapop.html.

LLECE (Laboratorio Latinoamericano de Evaluación de la Calidad de la Educación) (2013), Análisis del clima escolar: ¿Poderoso factor que explica el aprendizaje en América Latina y el Caribe?, Oficina Regional de Educación de la UNESCO para América Latina y el Caribe (OREALC).

López, Néstor (2011), "El desprecio por ese alumno", Escuela, identidad y discriminación, Néstor López (coord.), Buenos Aires, Instituto Internacional de Planeamiento de la Educación (IIPE) de la Organización de las Naciones Unidas para la Educación, la Ciencia y la Cultura (UNESCO), Buenos Aires.

Murcia, Walter (2015), "Pandillas en El Salvador: propuestas y desafíos para la inclusión social juvenil en contextos de violencia urbana", en prensa.

Naciones Unidas (2014), "ECOSOC Forum on Youth 2014. \#Youth2015: Realizing the Future They Want" [en línea] http://www.un.org/en/ecosoc/youth2014/ pdf/background_note.pdf.

(1993), "Declaración sobre la Eliminación de la Violencia contra la Mujer de las Naciones Unidas" [en línea] http: / / www.ohchr.org/SP/ProfessionalInterest/ Pages/ViolenceAgainstWomen.aspx.

OMS (Organización Mundial de la Salud) (2013), "Global Health Observatory Data Repository" [en línea] http:/ /apps.who.int/gho/data/node.main\#. (2002), Informe mundial sobre la violencia y la salud, Washington, D.C.

OMS/UNODC /PNUD (Organización Mundial de la Salud/Oficina de las Naciones Unidas contra la Droga y el Delito/Programa de las Naciones Unidas para el Desarrollo) (2014), Global Status Report on Violence Prevention 2014, Ginebra.

OPS (Organización Panamericana de la Salud) (2006), Políticas públicas y marcos legales para la prevención de la violencia relacionada con adolescentes y jóvenes. Estado del arte en América Latina 1995-2004, Washington, D.C.

Ortega, Daniel y otros (2014), Por una América Latina más segura: Una nueva perspectiva para prevenir y controlar el delito, Bogotá, Corporación Andina de Fomento, junio.

Pavez, María Isabel (2014), "Los derechos de la infancia en la era de Internet: América Latina y las nuevas tecnologías", serie Políticas Sociales, N 210 (LC/L.3894), Santiago, Comisión Económica para América Latina y el Caribe (CEPAL). (2013), "Juventud latinoamericana y el uso y apropiación de redes sociales: Desafíos e interrogantes", Santiago, inédito.

Perea Restrepo, Carlos (2014), "La muerte próxima. Vida y dominación en Río de Janeiro y Medellín", Análisis Político, vol. 27, № 80.

(2008), ¿Qué nos une? Jóvenes, cultura y ciudadanía, Medellín, La Carreta.

PLAN (2008), Learn without Fear: The Global Campaign to End Violence in Schools.

PLAN Internacional/UNICEF (Fondo de las Naciones Unidas para la Infancia) (2013), Construcción de una caja de herramientas y análisis de legislación y políticas públicas: Para la protección de los niños, niñas y adolescentes contra todo tipo de violencias en las escuelas, Ciudad de Panamá. 
PNUD (Programa de las Naciones Unidas para el Desarrollo) (2013), Informe regional de desarrollo humano 2013-2014. Seguridad ciudadana con rostro humano: Diagnóstico y propuestas para América Latina, Nueva York, noviembre.

Rodino, Ana María (2013), "Safety and peaceful coexistence policies in Latin American schools: Human rights perspective", Sociología, Problemas e Práticas, N 71.

Rodríguez, Ernesto (2006), Jóvenes, violencias y cultura de paz en América Central: Enfoques, dilemas y respuestas a desplegar en el futuro.

Román, Marcela y Francisco Javier Murillo (2011), “América Latina: Violencia entre estudiantes y desempeño escolar", Revista CEPAL, N 104 (LC/G.2498-P), Santiago, Comisión Económica para América Latina y el Caribe (CEPAL).

Rubio, Mauricio (2008), "La pandilla proxeneta, violencia y prostitución juvenil en Centroamérica", URVIO. Revista Latinoamericana de Seguridad Ciudadana, $\mathrm{N}^{\mathrm{O}} 4$, Quito, FLACSO Ecuador.

SENAJU (Secretaría Nacional de la Juventud) (2011), Primera Encuesta Nacional de la Juventud Peruana (ENAJUV 2011), Lima.

SESC/CONJUVE/INE (Secretaría Ejecutiva del Servicio Cívico/Consejo Nacional de la Juventud/Instituto Nacional de Estadística) (2011), Primera Encuesta Nacional de Juventud en Guatemala (ENJU 2011), Ciudad de Guatemala.

UNESCO (Organización de las Naciones Unidas para la Educación, la Ciencia y la Cultura) (2013), "Respuestas del sector de educación frente al bullying homofóbico", Publicación de la serie Buenas políticas y prácticas para la educación en VIH y salud, Cuadernillo, $\mathrm{N}^{\circ} 8$, Santiago.

UNICEF (Fondo de las Naciones Unidas para la Infancia) (2014), Hidden in Plain Sight: a Statistical Analysis of Violence against Children, Nueva York, septiembre. (2011), “Internetsegura.Sin riesgonidiscriminación” [enlínea]http:/ /internet. inadi.gob.ar/wp-content/uploads/2011/12/internet-segura.pdf.

UNODC (Oficina de las Naciones Unidas contra la Droga y el Delito) (2014), Global Study on Homicide 2013: Trends, Contexts, Data, Viena. (2012), Global Study on Homicide 2011: Trends, Contexts, Data, Viena.

Zurita Rivera, Úrsula (2012), "Las escuelas mexicanas y la legislación sobre la convivencia, la seguridad y la violencia escolar", Educación y Territorio, vol. 2, $\mathrm{N}^{\mathrm{o}} 1$, junio. 
Capítulo IV

\section{El acceso de los jóvenes a la cultura en la era digital en América Latina}

Guillermo Sunkel ${ }^{1}$

\section{Introducción}

En las últimas décadas se ha reunido evidencia sustantiva sobre el papel de la cultura en el desarrollo (UNESCO, 2010). La comunidad internacional ha constatado que la cultura contribuye de forma efectiva a las políticas, estrategias y programas que tienen por objeto el desarrollo económico y social inclusivo, la sostenibilidad medioambiental, la armonía, la paz y la seguridad. De ahí que la cultura ha pasado a ser concebida como un motor y un facilitador del desarrollo sostenible. El valor de la cultura para el desarrollo ha sido reconocido recientemente por el Equipo de Tareas del Sistema de las Naciones Unidas sobre la Agenda para el Desarrollo Después de 2015 (UNESCO, 2012).

A partir de este reconocimiento, se sostiene que la cultura está vinculada, entre otros aspectos del desarrollo, a la inclusión social. En la perspectiva de la Comisión Económica para América Latina y el Caribe (CEPAL), "la inclusión social permite la realización y el disfrute progresivos de derechos que son fundamentales para alcanzar muchas de las aspiraciones de una sociedad segura, saludable y próspera en todo el planeta" (CEPAL, 2014b, pág. 6). La cultura, como la educación o la salud, constituye un ámbito de ejercicio de derechos respecto del cual también se generan procesos de

El autor desea agradecer a Andrés Espejo por el procesamiento de la información estadística y a Matías Salcés por la recopilación de datos sobre programas culturales. 
exclusión. El acceso de los jóvenes a la cultura —que constituye uno de los derechos culturales fundamentales- es una condición para la generación de oportunidades que posibiliten la expresión del sujeto de manera que este se desarrolle en toda su plenitud y participe activamente en la sociedad.

La inclusión en el ámbito de la cultura requiere promover el acceso a la cultura de los jóvenes en situación de exclusión, riesgo o vulnerabilidad, desde una perspectiva de consumo cultural y, de este modo, posibilitar que puedan expresarse, continuar creciendo como personas, transformar su situación e incidir en la sociedad. Ejercer el derecho de acceso y participación en la cultura contribuye al desarrollo humano y al bienestar de la juventud. Además, la participación en la vida cultural y la libertad de expresión artística son fundamentales para forjar sociedades inclusivas e igualitarias (Observatorio Bizkaia, 2012, pág. 6).

Plantear una definición única de cultura no es nada fácil. Se trata de uno de los conceptos más complejos de las ciencias sociales, en torno al cual se han desarrollado debates que se prolongan hasta hoy. Al intentar reconstruir la historia del concepto se aprecia cómo el término es abordado de distinta forma según los distintos campos de conocimiento y las diferentes escuelas (CEPAL/OEI, 2014, pág. 28). En la actualidad, es necesario reconocer que existe una tensión entre la noción antropológica de cultura y la noción cultural de Estado: mientras que para los Estados la cultura es un sector específico, en la visión antropológica no hay acciones humanas ni políticas públicas que no contengan en sí mismas dimensiones culturales constitutivas (CEPAL/OEI, 2014, pág. 15).

En este capítulo se asume la noción de cultura como un sector específico que incluye un amplio espectro de actividades. Estas abarcan desde las actividades artísticas - como las artes escénicas o visuales-, incluido el patrimonio material e inmaterial, hasta las industrias culturales o creativas (cinematográfica, editorial y musical, entre otras). El sector cultural actualmente también incluye a las nuevas tecnologías de la comunicación, o tecnologías digitales, en la medida en que estas han tenido un profundo impacto en las formas de producción, circulación y consumo de los bienes culturales. En todo caso, lo que distingue a las diversas actividades consideradas en el sector cultural y les da cierta unidad es que en todas ellas el valor simbólico predomina sobre el valor de cambio.

Dada la creciente importancia que las tecnologías digitales han adquirido en la vida cotidiana de la generación joven, sobre todo en las últimas décadas, es importante considerarlas en el concepto de cultura que aquí se utiliza. De hecho, si bien los cambios tecnológicos han tenido un impacto en toda la sociedad, este ha sido especialmente fuerte en la juventud y ha llegado a modificar su forma de estar en el mundo, su experiencia del espacio y del tiempo, y sus relaciones sociales. 
El propósito central de este capítulo es examinar el acceso de los jóvenes a la cultura en la era digital en América Latina. Utilizamos la noción de acceso para referirnos específicamente a la dimensión de los usuarios, y no a los creadores o gestores culturales. Por una parte, esta aproximación se vincula con el tema de los derechos culturales, pues el acceso es, precisamente, un derecho fundamental. La exclusión del acceso de los jóvenes a la cultura - por ejemplo, debido a barreras socioeconómicas o educativas- es una vulneración de ese derecho. Se trata, por tanto, de examinar si existe equidad en el acceso; es decir, si los jóvenes ejercen ese derecho. Por otra parte, esta aproximación se vincula con la noción de "consumo cultural" que examina la cultura desde la óptica de los públicos y no, como era tradicional, a partir de la obra o de la "producción" de los objetos culturales. Los consumos culturales, como se señala más adelante, no obedecen a las preferencias de los individuos, sino que se relacionan con aspectos de la estructura de clases.

La principal fuente de información utilizada en este capítulo es el módulo de cultura del Latinobarómetro 2013, realizado por encargo de la Organización de Estados Iberoamericanos para la Educación, la Ciencia y la Cultura (OEI), que incluye un conjunto de preguntas específicas sobre cultura y consumos culturales ${ }^{2}$. Estas preguntas se refieren, entre otras cosas, a la lectura de libros y diarios, la asistencia al cine y al teatro, la visualización de videos, la escucha de música grabada, el uso de la computadora, el correo electrónico e Internet, así como de las redes sociales, los lugares de conexión a Internet, las actividades realizadas cuando la persona se conecta a Internet, la visita a sitios patrimoniales, la participación en celebraciones comunitarias, la asistencia a recitales de música, el tiempo dedicado a ver televisión y el tiempo dedicado a escuchar radio.

Si bien el módulo de cultura encargado por la OEI ha permitido analizar los actuales consumos culturales juveniles, es importante resaltar la precariedad de las estadísticas sobre cultura. Debido a que en esta base de datos no existen series de tiempo, no es posible realizar análisis de tendencias ni desagregaciones por algunas variables sociodemográficas que permitan distinguir entre adolescentes y jóvenes, o entre consumos en el ámbito urbano y rural. Por otra parte, las encuestas de consumo cultural o las encuestas de juventud de los países presentan serios problemas de comparabilidad y, por tanto, son fuentes muy limitadas para presentar una visión regional.

En la sección A de este capítulo se examina si se han producido cambios intergeneracionales en los patrones de consumo cultural y si existen brechas intrageneracionales en el acceso a los bienes culturales. En la sección B se analiza si los jóvenes de la región tienen un acceso equitativo a

La información recogida a través de este módulo es utilizada en el presente documento con autorización del Secretario General de la OEI. 
los medios digitales o si existen brechas de acceso y de uso que impiden que una proporción significativa de la juventud aproveche las oportunidades que brindan estos medios en el ámbito de la cultura en la era digital. En la sección $C$ se revisa el papel de los medios digitales en la promoción del acceso a la cultura y el desarrollo de nuevas formas de acceso a los bienes y servicios culturales. Por último, en la sección D se presentan algunos tipos de programas culturales ilustrativos y se describen algunas de las principales iniciativas impulsadas desde el Estado y la sociedad civil.

\section{A. Acceso a bienes culturales}

¿Cuáles son las características de los patrones de consumo cultural de los jóvenes y cómo se compara este consumo con el de los adultos? ¿Cuán desigual es el acceso a bienes culturales entre jóvenes de distintos países y regiones, y entre jóvenes de diferentes estratos sociales? Para abordar estas interrogantes es necesario tener en claro tres conceptos básicos.

En primer lugar, hay que considerar que el consumo cultural se realiza en el denominado "tiempo libre". Este se define como el tiempo que queda después de la carga de trabajo remunerado y no remunerado (CEPAL, 2013), y en el caso de los jóvenes se incluye el estudio. El tiempo libre es limitado y contempla, entre otras, actividades escogidas libremente que contribuyen al bienestar de las personas y que se vinculan con el descanso, el ocio, las actividades recreativas y creativas, y la convivencia familiar y con amigos. El consumo cultural es central en el uso del tiempo libre.

En segundo término, los patrones de consumo cultural no obedecen a diferencias arbitrarias en las preferencias de los individuos, sino que se relacionan con aspectos de la estructura de clases que inciden en la reproducción intergeneracional de los intereses culturales que afectan y moldean las preferencias estéticas (Palma y Aguado, 2010; DiMaggio y Useem, 1978b). El contexto familiar y la socialización temprana a través del arte pueden aumentar la frecuencia de la asistencia a actos culturales. El nivel de educación formal es otro factor que incide en la participación en actividades artísticas y culturales (DiMaggio y Useem, 1978a, pág. 64). Según Bourdieu, la estratificación socioeconómica y el patrón de consumo cultural tienen una relación directa. La participación de algunos grupos en ciertas actividades, como las bellas artes, es un signo de distinción social, una señal que indica y refuerza la pertenencia a un estatus socioeconómico (superior) (Bourdieu, 1984).

Como tercer punto, como se ha señalado, hay que considerar que el consumo cultural supone el acceso a bienes culturales, pero dicho acceso no asegura la apropiación. Este requiere destrezas y habilidades que son adquiridas a través de la socialización familiar y la educación formal. Es 
decir, el consumo cultural requiere de capital cultural. La noción de capital cultural hace referencia a competencias culturales o "corpus de conocimiento cultural que proporcionan modos de consumo cultural particulares, que se distinguen y que conforman a una relativamente sofisticada clasificación de la cultura y de los bienes simbólicos" (Lee citado en Gayo, 2011, pág. 12). El capital cultural expresa conocimiento, gustos y disposiciones culturales especialmente asociadas al ámbito artístico (Gayo, 2011, pág.10). Además, el capital cultural es un activo para ejercer ciudadanía activa y también para comunicarse en la sociedad de la información (Hopenhayn, 2008, pág. 61). Es, por tanto, un recurso clave para la inclusión social.

En el gráfico IV.1 se da cuenta del acceso de distintos segmentos etarios de la población latinoamericana a diversos bienes culturales. Se distinguen tres segmentos: los jóvenes (16 a 29 años), los adultos (30 a 50 años) y los adultos mayores (51 años y más) ${ }^{3}$. La información indica que el acceso a los bienes culturales decrece con la edad: las personas jóvenes tienen una mayor participación en el consumo cultural, seguidas por los adultos y los adultos mayores.

\section{Gráfico IV.1 \\ América Latina (18 países): personas que han utilizado, visto o participado en alguna actividad cultural, según tramo de edad ${ }^{a}$}

(En porcentajes)

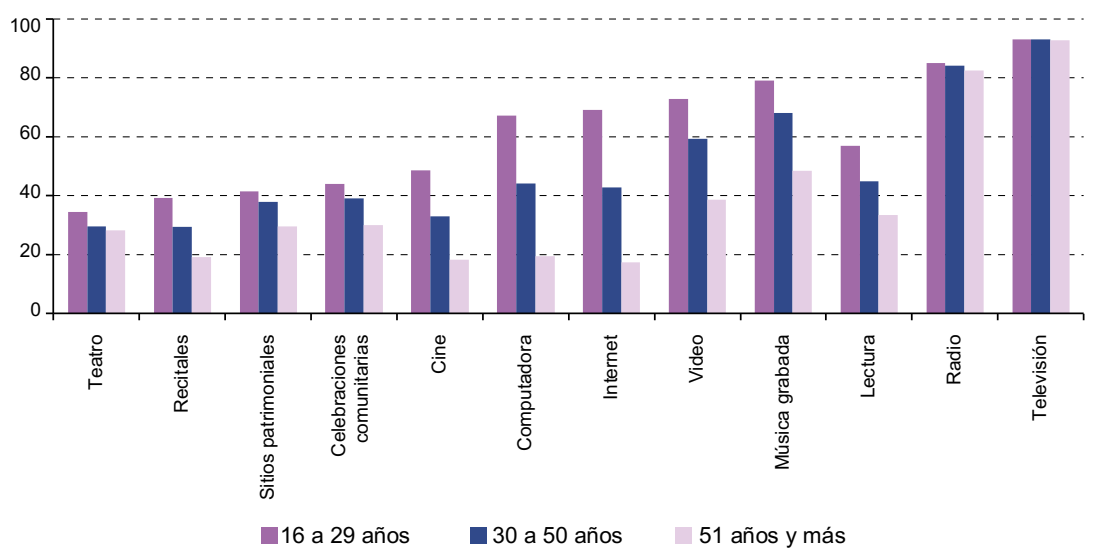

Fuente: Comisión Económica para América Latina y el Caribe (CEPAL), sobre la base de tabulaciones especiales de la encuesta Latinobarómetro, 2013.

a Las preguntas por frecuencia no son exactamente iguales para todos los bienes culturales. Por ejemplo, en la asistencia a salas de cine, la visualización de videos y la escucha de música grabada las frecuencias son: diariamente, al menos una vez por semana, al menos una vez al mes, al menos una vez al trimestre y menos de una vez cada tres meses. En el uso de la computadora, no obstante, la pregunta distingue entre varias veces al día, al menos una vez al día, al menos una vez por semana, al menos una vez al mes y al menos una vez al trimestre. En el uso de Internet se distingue entre todos los días, ocasionalmente, casi nunca o nunca.

La calificación de personas de 51 años y más como "adultos mayores" se utiliza solo a efectos de simplificar la presentación. 
Los jóvenes tienen mayor acceso que los adultos y los adultos mayores a todas las actividades culturales consideradas (con la excepción de la televisión, donde todos acceden por igual). En promedio, son el segmento que más lee libros (un $57 \%$ lee libros) con cierta frecuencia, frente a un $33 \%$ de los adultos mayores), que más asiste a recitales de música (un $40 \%$ de los jóvenes ha ido o asiste a un recital de música con cierta frecuencia, frente a un $22 \%$ de los adultos mayores), que más va al cine (un $49 \%$ ha ido o va al cine con cierta frecuencia, frente al $18 \%$ de los adultos mayores), que más ve videos (un $73 \%$ ve videos con cierta frecuencia, frente al 39\% de los adultos mayores) y que más escucha música grabada (un $80 \%$ frente al $48 \%$ de los adultos mayores).

Este mayor acceso de la actual generación joven a las actividades culturales sugiere que nuevos sectores sociales -en especial jóvenes de clase media y, en alguna medida, de sectores de bajos recursos- están accediendo a consumos que tradicionalmente estaban restringidos a un público de elite, como el teatro, los museos o los recitales de música. También están accediendo a bienes de la industria cultural como el libro, el cine, la música grabada o el video.

La información indica, además, que los jóvenes son el segmento que más utiliza las tecnologías digitales: un $67 \%$ usa computadoras "con algún grado de frecuencia", comparado con un 19\% de los adultos mayores, y el $69 \%$ usa Internet "con algún grado de frecuencia", comparado con un 17\% de los adultos mayores".

Las notorias diferencias mencionadas reflejan la existencia de una brecha intergeneracional en el consumo cultural, en el sentido de que la actual generación joven en América Latina tiene mayores niveles de acceso a los bienes y servicios culturales que las generaciones adultas. Ello implica que una mayor proporción de jóvenes está ejerciendo el derecho de acceso y participación en la cultura, que es fundamental para alcanzar muchas de las aspiraciones de sociedades más justas y equitativas. El ejercicio de los derechos culturales se asocia con los mayores niveles educativos logrados por la población joven en las últimas décadas, lo que ha ampliado las capacidades de personas en situación de exclusión o vulnerabilidad. A su vez, estos mayores niveles educativos son un factor clave para modificar la reproducción intergeneracional de los intereses culturales de manera de conseguir una distribución menos desigual del capital cultural (véanse más detalles sobre los avances educativos en la región en el capítulo I).

Es importante resaltar que si bien ha habido avances en términos del acceso de los jóvenes a la cultura, estos son aún insuficientes. A diferencia de

La categoría "con algún grado de frecuencia" incluye desde "varias veces al día" hasta "al menos una vez al trimestre" (es decir que no solo se consideran los usuarios frecuentes). 
las actividades culturales que tienen lugar en el espacio privado y que registran altos niveles de participación (televisión, radio, video, computadora e Internet), las que se desarrollan en el espacio público (teatro, cine, sitios patrimoniales o recitales de música) registran niveles de participación relativamente bajos (véase el gráfico IV.1). Partiendo de la base de que existen diferencias entre países, solo un $34 \%$ de los jóvenes de América Latina ha presenciado una obra de teatro, un $39 \%$ ha ido a recitales de música, un $44 \%$ ha participado en celebraciones comunitarias y un $49 \%$ ha asistido al cine con cierta frecuencia.

Estos niveles relativamente bajos de participación en prácticas culturales que tienen lugar en espacios públicos indican la existencia de limitaciones al acceso. Las barreras de acceso a las actividades culturales que se desarrollan en el espacio público (teatro, cine, lugares patrimoniales o recitales de música) son de tipo económico, educativo y geográfico, dado que la oferta cultural tiende a estar concentrada en las grandes ciudades. Indudablemente, algunas de estas barreras (como las económicas) también operan en el caso de actividades que se realizan en el espacio privado (computadoras e Internet). Ello indica que para que la cultura se constituya en un ámbito clave de inclusión social en los países de la región se requiere de políticas orientadas a remover los obstáculos que limitan el acceso generalizado a ella.

En el gráfico IV.2 se da cuenta del acceso de los jóvenes a diversos bienes culturales según tres grupos de países (o subregiones): Cono Sur (Argentina, Chile y Uruguay); región andina (Bolivia (Estado Plurinacional de), Colombia, Ecuador y Perú) y Centroamérica (Costa Rica, El Salvador, Guatemala, Honduras, Nicaragua y Panamá), además del Brasil y México. La información indica que, pese a los avances, aún persisten grandes desigualdades en el acceso de la población joven al capital cultural en los países de la región.

Los jóvenes de los países centroamericanos tienen menor acceso que los jóvenes de las restantes subregiones en todas las actividades culturales consideradas (con la excepción de asistencia a recitales). Además, en algunos de estos países el acceso a los bienes culturales está muy por debajo de los promedios de la subregión (tal es el caso de El Salvador, Guatemala, Honduras y Nicaragua). Por ejemplo, el 22\% de los jóvenes hondureños participan en celebraciones comunitarias, el $26 \%$ va al cine, el $15 \%$ asiste al teatro, el $13 \%$ acude a recitales de música, el $41 \%$ ve videos, el 33\% usa computadoras y el 36\% se conecta a Internet. En consecuencia, el ejercicio de los derechos culturales de los jóvenes en estos países se encuentra muy restringido, posiblemente debido a los menores niveles educativos, la magnitud de la pobreza, los problemas de integración social y la escasa oferta de bienes culturales.

En contraste, los niveles de acceso de los jóvenes de Costa Rica y Panamá a los bienes culturales son muy superiores al promedio de esa subregión. Por ejemplo, el $54 \%$ de los jóvenes panameños participa en celebraciones comunitarias, el $72 \%$ va al cine, el $40 \%$ asiste al teatro, el $41 \%$ acude a recitales de música, el $81 \%$ ve videos, el $70 \%$ usa computadoras y el $74 \%$ se conecta a Internet. 
Gráfico IV.2

Jóvenes (16 a 29 años) que han utilizado, visto o participado en alguna actividad cultural, según grupos de países

(En porcentajes)

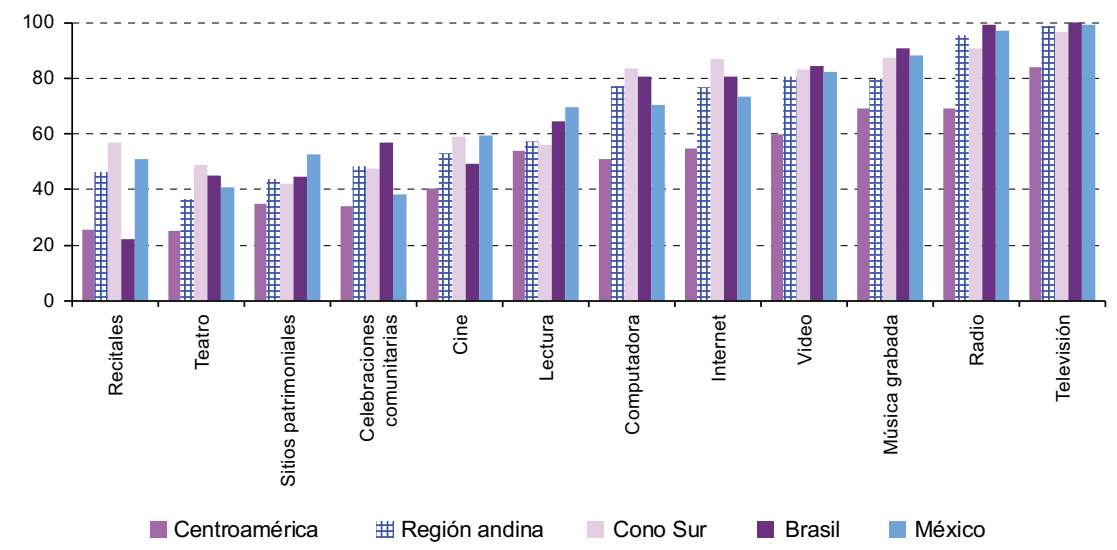

Fuente: Comisión Económica para América Latina y el Caribe (CEPAL), sobre la base de tabulaciones especiales de la encuesta Latinobarómetro, 2013.

Las diferencias en el acceso según subregiones son notorias. El hecho de que la juventud en Centroamérica exhiba niveles de acceso inferiores a los de las demás subregiones y países mencionados en todas las actividades culturales consideradas plantea una situación crítica en términos del ejercicio de los derechos culturales. Ahora bien, si se revisan las diversas actividades culturales, también hay diferencias o brechas intrageneracionales en las subregiones donde se observan mayores niveles de acceso. Por ejemplo, los jóvenes del Cono Sur muestran más acceso a Internet, computadoras, recitales y teatro, la juventud brasileña exhibe los mayores niveles de consumo de música, radio y video, y los mexicanos tienen los niveles más elevados de consumo de lectura y cine.

Las desigualdades en el acceso de la juventud a los bienes culturales sin duda se asocian con el nivel socioeconómico y educativo. De acuerdo con el informe Cultura y desarrollo económico en Iberoamérica, en algunos países de la región se ha ido ampliando el acceso a bienes culturales tradicionalmente restringidos a públicos de elite, como los museos, el teatro, los conciertos y recitales de música. No obstante, el nivel socioeconómico y educativo de las personas aún condiciona el acceso a estos bienes culturales y genera desigualdades (CEPAL/OEI, 2014, págs. 230-244). Por tanto, la mayor participación de públicos juveniles en las diversas expresiones artísticas continúa siendo un desafío desde el punto de vista del acceso a la cultura.

Algo similar ocurre con los bienes generados por la industria cultural. Según el citado informe, la lectura de libros está muy asociada con el nivel 
educativo (a mayor nivel educativo, mayor frecuencia de lectura de libros) y el nivel socioeconómico (a mayor nivel socioeconómico, mayor frecuencia de lectura de libros), lo que implica que estos factores continúan limitando el acceso de las personas que se encuentran en situación de mayor vulnerabilidad social y económica (CEPAL/OEI, 2014, pág. 248). El mismo proceso se observa en el consumo de otros bienes culturales, como el cine. En este caso, cuanto mayor es el nivel socioeconómico y de estudios, mayor es la asistencia y la frecuencia de asistencia al cine (CEPAL/OEI, 2014, pág. 259).

A continuación se plantean algunos elementos que se desprenden del análisis realizado.

- Una mayor proporción de jóvenes está ejerciendo el derecho de acceso y participación en la cultura, lo que es fundamental para forjar sociedades inclusivas e igualitarias. Esta democratización del acceso a los bienes culturales da cuenta de una brecha intergeneracional en el consumo cultural, que se encuentra asociada a los mayores niveles educativos de las actuales generaciones jóvenes.

- Existen brechas intrageneracionales que se manifiestan en el acceso desigual de la juventud a los bienes culturales en los países de la región. Principalmente, aunque no de manera exclusiva, estas desigualdades se asocian a factores socioeconómicos y educativos.

- América Latina es una región con un desarrollo muy desigual en términos de oportunidades de acceso a la cultura: hay países donde los jóvenes tienen una alta participación en varias de las actividades culturales consideradas y otros (como algunos países centroamericanos) donde el acceso está muy limitado.

- El mayor acceso de los jóvenes a la cultura sin duda contribuye a la inclusión social de las nuevas generaciones. Sin embargo, existen obstáculos que limitan el acceso de muchos jóvenes que se mantienen alejados de la cultura por factores socioeconómicos y educativos o por la falta de tiempo libre. Aún persisten, por lo tanto, grandes desafíos para que efectivamente la cultura se constituya en un ámbito clave de inclusión social, lo que requiere de políticas orientadas a remover esos obstáculos.

\section{B. Acceso y uso de medios digitales}

"Al hablar de rupturas generacionales, se mencionan los años '60 como paradigmáticos. No está mal en más de un sentido, pero refleja la mirada de quienes hoy somos adultos y fuimos jóvenes en aquellos años. Hoy nos encontramos frente a una brecha de magnitud similar o mayor, solo que no es ideológica y política sino que está ligada a lo tecno-cultural" (Balardini, 2014, pág. 2). 
En la sección A se examinó el acceso a diversos bienes culturales, entre los cuales se encontraban los medios digitales (la computadora e Internet). La profundización del análisis del acceso y uso de las tecnologías digitales que se realizará en esta sección se debe a varios motivos. En primer lugar se destaca la importancia que los medios digitales han pasado a tener en la vida de los jóvenes, hasta llegar a modificar su forma de estar en el mundo y sus relaciones sociales. En segundo término, porque el uso de las tecnologías digitales es una condición necesaria para aprovechar las oportunidades que estas brindan, incluso en el ámbito de la cultura. Como tercer punto hay que destacar que el uso de las tecnologías digitales genera nuevos modos de acceso a la cultura, con lo cual se reorganizan los consumos culturales y se reestructura el campo cultural. Por último, porque el uso de las nuevas tecnologías también es, entre otras cosas, una práctica cultural.

¿Tienen los jóvenes de la región un acceso equitativo a los medios digitales o, por el contrario, existen brechas de acceso y de uso que impiden que una proporción significativa de la juventud aproveche las oportunidades que brindan estos medios? ¿Se ha producido una profundización de brechas con la masificación de las tecnologías digitales? Para abordar estas interrogantes son necesarios un par de alcances conceptuales 6 .

El primero alude a la noción de brecha digital: la diferencia entre las personas que tienen acceso a las tecnologías digitales y las que no lo tienen (OCDE, 2001). Recientemente han surgido nuevos planteamientos que buscan ampliar y profundizar este concepto. La OCDE, por ejemplo, ha advertido sobre el surgimiento de una "segunda brecha digital": la diferencia entre quienes cuentan con las habilidades y competencias necesarias para hacer un uso efectivo de las tecnologías digitales y aquellos que no (OCDE, 2010). Asimismo, quienes plantean el concepto de segunda brecha digital afirman que dichas competencias dependen del capital económico, social y cultural de las personas. Al respecto, Selwyn utiliza la noción de "arcoíris de acceso", haciendo alusión a la existencia de matices a partir de los cuales se genera el proceso de acceso a las tecnologías digitales. Por lo tanto, la brecha no está exclusivamente limitada al acceso físico, sino también a cómo las personas usan las tecnologías de la información y las comunicaciones (TIC). El autor dice que el acceso a la tecnología es inútil sin las habilidades, los conocimientos y el apoyo para utilizarla de manera eficaz (Selwyn, 2004, pág. 348). En consecuencia, afirma que la brecha digital hace alusión tanto al acceso físico como a la capacidad de utilizar las tecnologías digitales y de darles un sentido.

En segundo lugar, se trata de la noción de cultura digital. La cultura digital se caracteriza, fundamentalmente, por entornos materiales

Véase un análisis, desde el ámbito educativo, de los temas que se tratan en esta sección en Sunkel, Trucco y Espejo (2014). 
electrónicos y entornos simbólicos digitales, es decir, numerizados en código binario (Lévy, 2007). En la cultura digital, los entornos materiales decisivos están integrados por computadoras y equipos informáticos, así como por redes de computadores y telecomunicaciones. Los entornos simbólicos digitales comprenden la inmensa gama de informaciones y contenidos digitalizados que residen y circulan en los entornos materiales. A su vez, los entornos simbólicos interpretativos se refieren a los significados, las interpretaciones, las representaciones y los conocimientos correspondientes a los entornos simbólicos digitales o que tienen que ver con legitimaciones, objetivos o valores relacionados con ellos (Lévy, 2007).

En el gráfico IV.3 se da cuenta de la frecuencia de uso de computadoras en tres grupos etarios de la población latinoamericana: jóvenes, adultos y adultos mayores. Se observa claramente que son los jóvenes quienes usan las computadoras con mayor frecuencia. Si se suman las categorías "varias veces al día" y "al menos una vez al día", se obtiene que un $44 \%$ de los jóvenes son usuarios frecuentes. Esta cifra cuadruplica con creces la de los adultos mayores $(10 \%)$ y es muy superior a la de los adultos $(26 \%)$. Por otra parte, se verifica que una alta proporción de adultos mayores $(81 \%)$ nunca usa la computadora.

\section{Gráfico IV.3 \\ América Latina (18 países): frecuencia de uso de la computadora, según grupos de edad \\ (En porcentajes)}

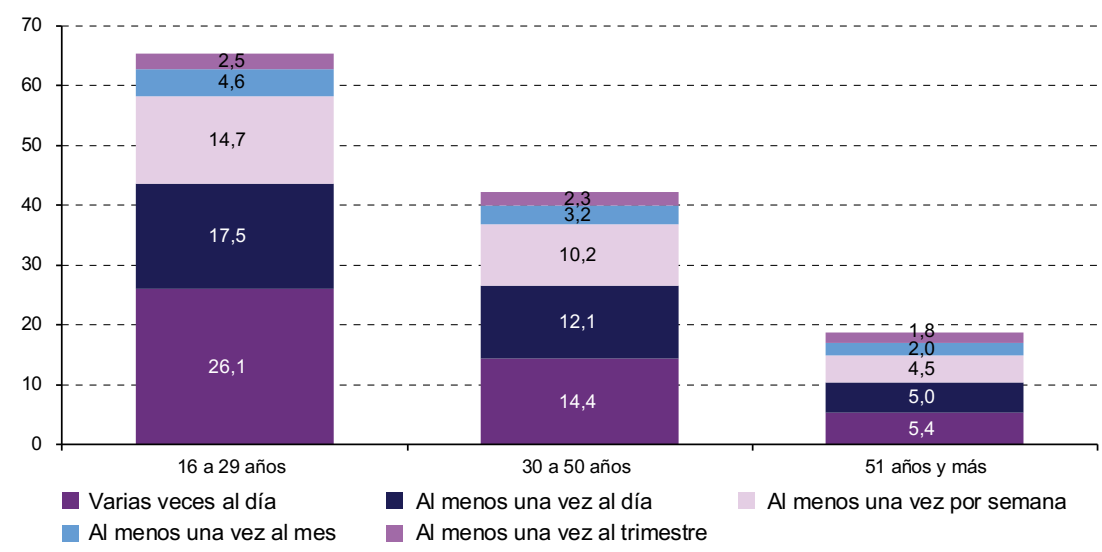

Fuente: Comisión Económica para América Latina y el Caribe (CEPAL), sobre la base de tabulaciones especiales de la encuesta Latinobarómetro, 2013.

En el gráfico IV.4 se muestra la frecuencia de uso de Internet en los mismos grupos etarios. Algo más de un tercio de los jóvenes (35\%) usa 
Internet "todos los días", comparado con un 19\% de los adultos y solo un $7 \%$ de los adultos mayores. La proporción de jóvenes usuarios frecuentes de Internet es menor que la de usuarios frecuentes de computadoras (44\%), posiblemente debido al costo de la conexión ${ }^{7}$. Ese 35\% de la población joven que se conecta a diario a Internet se encuentra plenamente integrado en la cultura digital. Por su parte, el 26\% que la usa "ocasionalmente" también tiene un alto grado de cercanía y se encuentra altamente familiarizado con los códigos de la cultura digital.

\section{Gráfico IV.4 \\ América Latina (18 países): frecuencia de uso de Internet, según grupos de edad} (En porcentajes)

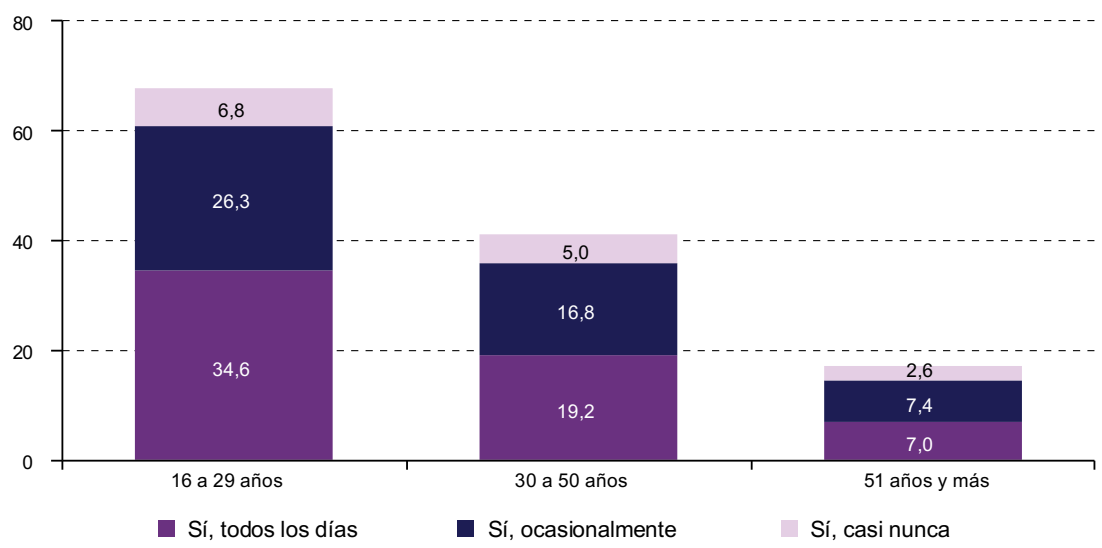

Fuente: Comisión Económica para América Latina y el Caribe (CEPAL), sobre la base de tabulaciones especiales de la encuesta Latinobarómetro, 2013.

A partir de la información presentada, se puede deducir que existe una profunda brecha intergeneracional en términos de acceso a los medios digitales. A diferencia de los adultos y de los adultos mayores, una proporción significativa de los jóvenes de la región tiene acceso frecuente a las tecnologías digitales ${ }^{8}$. La brecha digital intergeneracional puede ser conceptualizada en términos de la distinción entre "nativos" e "inmigrantes" digitales. Piscitelli afirma que los estudiantes actuales son hablantes nativos del lenguaje de la televisión interactiva, las computadoras, los videojuegos e Internet, mientras que los mayores, por más tecnófilos que sean (o se crean), nunca sobrepasan la categoría de inmigrantes digitales, o de hablantes más o menos competentes en esa segunda lengua. Sostiene que el hecho de que lo digital sea una segunda

\footnotetext{
Véase más información en CEPAL (2010).

8 También es importante notar que, en el promedio regional, alrededor de un tercio de los jóvenes latinoamericanos (32\%) nunca usa Internet (véase el gráfico IV.4).
} 
lengua para los inmigrantes se nota en todo lo que hacen; es un acento que matiza todas sus actividades y que se refleja fundamentalmente en su vida académica y profesional. Los adultos ingresan a Internet cuando no encuentran un libro que aborde el problema que les interesa; antes de usar un aparato leen el manual; antes de ejecutar un programa necesitan saber qué tecla apretar. Los nativos digitales funcionan del modo contrario: hacen primero y se preguntan después (Piscitelli, 2009, pág. 46).

La noción de nativos digitales sugiere, entonces, que la actual generación joven ha experimentado un cambio radical respecto de sus predecesores, los denominados "inmigrantes digitales". Los jóvenes de hoy constituyen la primera generación formada en los nuevos avances tecnológicos. Ellos se han acostumbrado por inmersión, al encontrarse rodeados, desde la infancia, de computadoras, videos y videojuegos, música digital, telefonía móvil y otros entretenimientos y herramientas afines. Piensan y procesan la información de modo significativamente distinto a sus predecesores (los inmigrantes digitales) y tienen mayor destreza en el manejo y la utilización de la tecnología. Los nativos digitales han nacido y se han formado utilizando la particular "lengua digital" de juegos por computadora, video e Internet (Balardini, 2004).

En el gráfico IV.5 se presenta la frecuencia de uso de Internet entre la juventud latinoamericana según nivel socioeconómico. Se observa que, si bien los jóvenes actuales pueden caracterizarse, grosso modo, como "nativos digitales", existe una brecha digital intrageneracional. Casi la mitad de los jóvenes de estrato alto (48\%) de la región usa Internet todos los días y un $28 \%$ lo hace en forma ocasional. Esto implica que, en promedio, aproximadamente tres de cada cuatro de estos jóvenes tienen un alto grado de familiaridad con los códigos de la cultura digital; se trata, claramente, de nativos digitales. Sin embargo, la frecuencia de uso disminuye de manera significativa según el nivel socioeconómico. Así, poco más de un cuarto de los jóvenes de clase media (27\%) usa Internet todos los días y un $28 \%$ la usa ocasionalmente, lo que implica que algo más de la mitad de esta población se encuentra inmersa en la cultura digital. Por su parte, solo el 13\% de jóvenes de los sectores más pobres usa Internet todos los días y el 18\% la usa ocasionalmente. Esto significa que menos de un tercio de la juventud en situación de vulnerabilidad se encuentra inmerso en los entornos simbólicos digitales.

Más allá de los promedios regionales, existen diferencias significativas por países en la frecuencia de uso de Internet. Por ejemplo, casi dos tercios (61\%) de los jóvenes chilenos de estrato bajo y más de la mitad (55\%) de los jóvenes argentinos de estrato bajo son usuarios de Internet (incluidos quienes la usan "todos los días" y "ocasionalmente"). Esto implica que una proporción importante de jóvenes que se encuentran en situación de vulnerabilidad en 
estos países tiene acceso a los medios digitales y que se trata de países con un proceso muy avanzado de inclusión digital. Ello plantea un gran contraste con lo que se observa en algunos países de Centroamérica donde, por ejemplo, solo el $8 \%$ de los jóvenes salvadoreños, el $9 \%$ de los hondureños y el $9 \%$ de los nicaragüenses de estrato bajo son usuarios de Internet. Estas cifras indican que amplios sectores de la juventud de estos países se encuentran excluidos del acceso a las tecnologías digitales.

\section{Gráfico IV.5 \\ Jóvenes (16 a 29 años): frecuencia de uso de Internet, según nivel socioeconómico ab}

(En porcentajes)

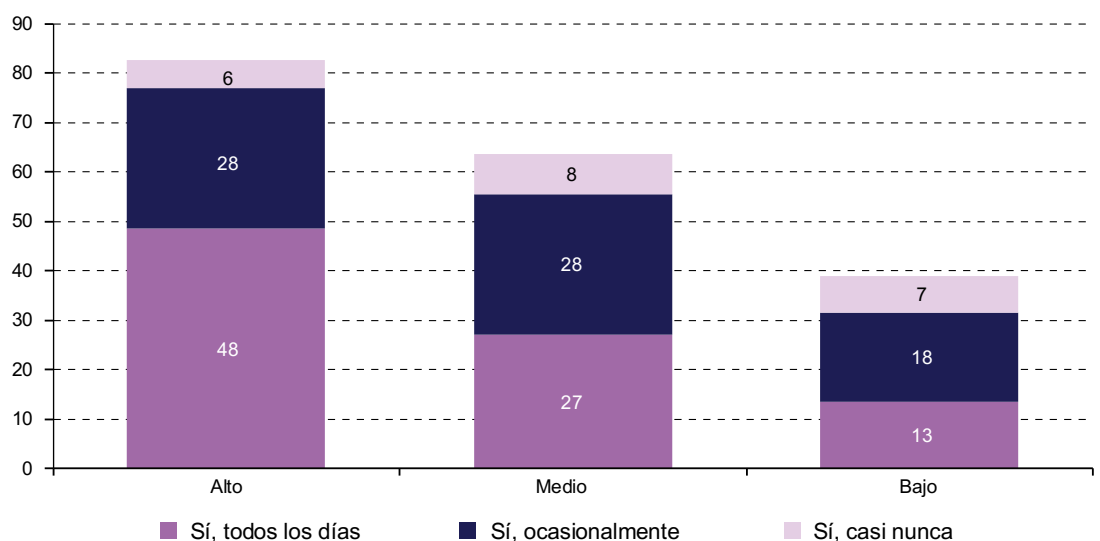

Fuente: Comisión Económica para América Latina y el Caribe (CEPAL), sobre la base de tabulaciones especiales de la encuesta Latinobarómetro, 2013.

a Se excluye la categoría "nunca".

b En el Latinobarómetro, el nivel socioeconómico de las personas se basa en la autopercepción de los encuestados. En la pregunta se solicita al encuestado que en su apreciación considere algunos aspectos de sus condiciones de vida.

La brecha digital intrageneracional también está asociada con las diferentes posibilidades de acceso a la tecnología. En este sentido, se destaca que el hogar es el lugar donde se accede a la tecnología con mayor frecuencia e intensidad, pues posibilita una conexión permanente. En el gráfico IV.6 se muestra que las diferencias de acceso en el hogar por nivel socioeconómico son significativas: los jóvenes de sectores altos tienen casi cuatro veces más posibilidades de tener conexión a Internet en el hogar que los de sectores bajos, diferencia que se encuentra asociada al costo de la conexión. El cibercafé es una opción para quienes no tienen acceso desde el hogar, pero es limitada en términos de frecuencia e intensidad de uso. El uso de Internet en el trabajo encuentra mayores restricciones aún. 


\section{Gráfico IV.6 \\ América Latina (18 países): lugar de conexión a Internet de los jóvenes (16 a 29 años), según nivel socioeconómico ${ }^{a}$}

(En porcentajes)

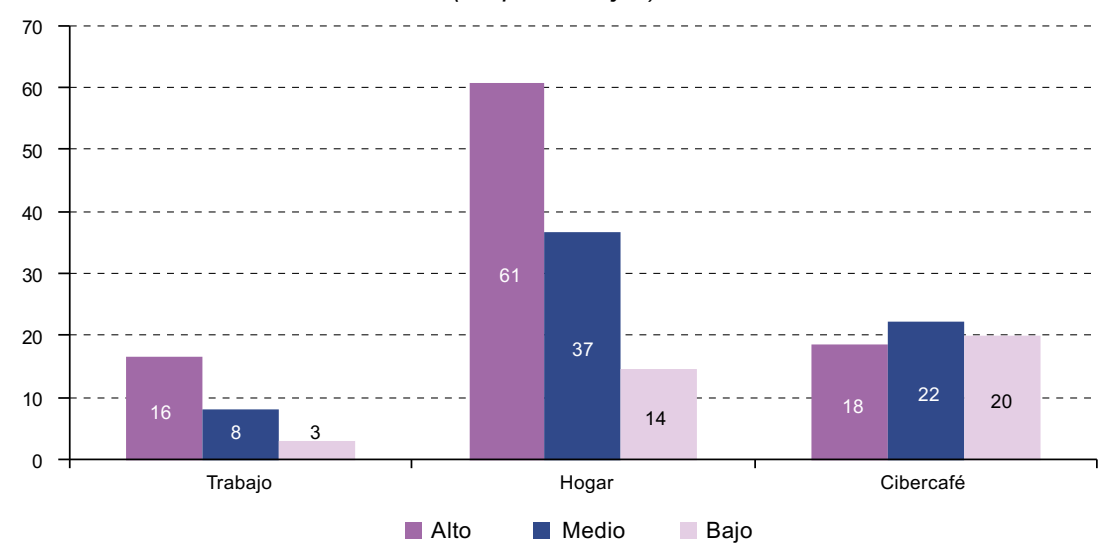

Fuente: Comisión Económica para América Latina y el Caribe (CEPAL), sobre la base de tabulaciones especiales de la encuesta Latinobarómetro, 2013.

a En el Latinobarómetro, el nivel socioeconómico de las personas se basa en la autopercepción de los encuestados. En la pregunta se solicita al encuestado que en su apreciación considere algunos aspectos de sus condiciones de vida.

A continuación se plantean algunos elementos que se desprenden del análisis realizado.

- Existe una brecha digital intergeneracional que implica que, a diferencia de los adultos y de los adultos mayores, una proporción significativa de los jóvenes de la región tiene acceso a las tecnologías digitales y las usa con frecuencia. La juventud está incorporada en la cultura digital en una proporción mucho mayor que los adultos debido a su carácter de nativos digitales, por ser una generación formada en los avances tecnológicos.

- Se destaca también la existencia de una brecha digital intrageneracional que implica que no todos los jóvenes acceden de igual manera a los medios digitales. Estas desigualdades en el acceso a los medios digitales se encuentran asociadas, entre otros, a factores socioeconómicos. Como se ha visto, la frecuencia de uso disminuye significativamente según el nivel socioeconómico, lo que implica que quienes pertenecen a sectores más pobres tienen menos acceso a la cultura digital. A su vez, esto se encuentra asociado al hecho de que el hogar es el sitio que permite acceder a la tecnología con mayor frecuencia e intensidad, lo que tiende a concentrarse en los sectores de mayores ingresos debido a los costos de conexión. 
- La brecha entre los jóvenes que tienen acceso a las oportunidades de las tecnologías digitales y aquellos que están excluidos - es decir, la brecha de acceso- continúa siendo un tema crítico en América Latina a pesar de los enormes esfuerzos realizados para combatirla. En algunos países de la región son muchos los jóvenes que se encuentran excluidos de los medios digitales y quedan fuera de la "tecno-cultura", lo que impide que puedan aprovechar las oportunidades que brindan estos medios, con la posible consecuencia de una profundización de la brecha.

- Los avances logrados en algunos países de la región, asociados fundamentalmente a la masificación del acceso y al desarrollo de una infraestructura de redes digitales, conllevan nuevos desafíos. Para estos países, al igual que para los países más desarrollados, el problema principal ya no es el acceso -o la disponibilidad de dispositivos digitales conectados a Internet-, sino los usos y la apropiación de las nuevas tecnologías. Esto es lo que se ha denominado la segunda brecha digital - o brecha de usos- y que hace referencia a las diferencias existentes entre grupos según sus capacidades o habilidades para utilizar las tecnologías de forma eficaz. El desafío ahora consiste en detener la profundización de la segunda brecha que es, en definitiva, donde se juega la posibilidad de que la juventud aproveche las oportunidades que brindan las nuevas tecnologías.

\section{Acceso a bienes culturales a través de las tecnologías digitales}

El acceso y uso de los medios digitales son condiciones necesarias para aprovechar las oportunidades que brindan las nuevas tecnologías, incluso en el ámbito de la cultura. Desde esta perspectiva, interesa examinar el papel de los medios digitales en la promoción del acceso a la cultura y su contribución al ejercicio de los derechos culturales. ¿Contribuyen las tecnologías digitales a la democratización del acceso a la cultura? ¿Generan oportunidades para la promoción del acceso a la cultura o más bien han generado nuevas brechas entre los jóvenes?

Para abordar estas interrogantes es necesario considerar que la digitalización - que es el fundamento de la cultura digital — ha tenido un fuerte impacto en la producción y circulación de los diversos ámbitos del sector cultural. Ello incluye desde el patrimonio (museos o artes escénicas, por ejemplo) hasta las industrias culturales (editorial, música o cine), incluidos los medios de comunicación (radio y televisión). La industria musical fue pionera en este proceso y es ejemplo de la profundidad que 
ha tenido el impacto de la digitalización. Al respecto, se ha señalado que la verdadera revolución que trajeron los avances tecnológicos de fines de la década de 1990 a la industria musical se asocia con el enorme potencial que desató el ascenso y la divulgación del soporte digital alrededor del mundo $\mathrm{y}$, principalmente, con las posibilidades que proporciona la distribución digital de contenidos a través de la red (Palmeiro, 2004). Entre los factores que hicieron posible esta revolución se destaca la capacidad de los discos duros de las computadoras personales de almacenar miles de canciones mediante la utilización de sofisticadas técnicas de compresión de archivos de audio (como el MP3) y reproducción con excelente calidad, y la popularización de conexiones a Internet de alta velocidad que proveyeron el ancho de banda necesario para distribuir música de forma rápida y eficaz en los hogares.

El paradigma digital altera radicalmente la esencia de las grabaciones musicales. El proceso de digitalización las transforma de bienes tangibles (como discos compactos, cintas o discos de vinilo) a meras secuencias de ceros y unos comprendidas en un archivo digital. La distribución digital de música rompe con las estructuras establecidas al permitir que los usuarios elijan, almacenen y consuman su música preferida de manera inmediata y sin moverse de su casa. Asimismo, la digitalización posibilita la copia perfecta de los temas a costo cero (Palmeiro, 2004).

El impacto de la digitalización en la producción y distribución de los diversos bienes culturales es objeto de un creciente número de investigaciones. Un ejemplo de estas investigaciones es "Los museos en la era digital. Uso de las nuevas tecnologías antes, durante y después de visitar un museo, centro cultural o galería de arte", un estudio realizado por Dosdoce.com donde se pretende analizar cómo los museos, los centros culturales y las galerías de arte pueden aprovechar mejor las tecnologías de última generación con el fin de mejorar sus servicios y prestaciones, así como sus materiales y contenidos de manera virtual, enriqueciendo la experiencia de los espectadores en la visita (Dosdoce.com, 2013). Otro ejemplo es la colección de trabajos contenidos en el Anuario AC/E de cultura digital. Focus 2014: Uso de las nuevas tecnologías en las artes escénicas (AC/E, 2014), que tiene por objeto principal examinar el impacto de las nuevas tecnologías en las artes escénicas. En particular, se analiza la manera en que la cultura digital está cambiando la forma de diseñar, producir y exhibir teatro9.

Los medios digitales también han generado nuevas maneras de acceder a la cultura y ello ha dado pie a un acceso mediatizado digitalmente a una amplia gama de bienes y servicios culturales. En el gráfico IV.7 se da cuenta del uso de Internet para realizar actividades culturales en

Véanse algunos ejemplos de investigaciones sobre el impacto de las tecnologías digitales en las industrias culturales en Dosdoce.com (2011), IFPI (2014) y De Luca (2009). 
tres grupos etarios de la población latinoamericana: jóvenes, adultos y adultos mayores. Se distinguen actividades relacionadas con las industrias culturales (música, cine o libros), patrimonio (museos), artes escénicas y otras actividades (buscar información, comprar o reservar entradas) ${ }^{10}$.

\section{Gráfico IV.7 \\ América Latina (18 países): personas que han utilizado Internet para realizar alguna actividad cultural, según tramo de edad}

(En porcentajes)

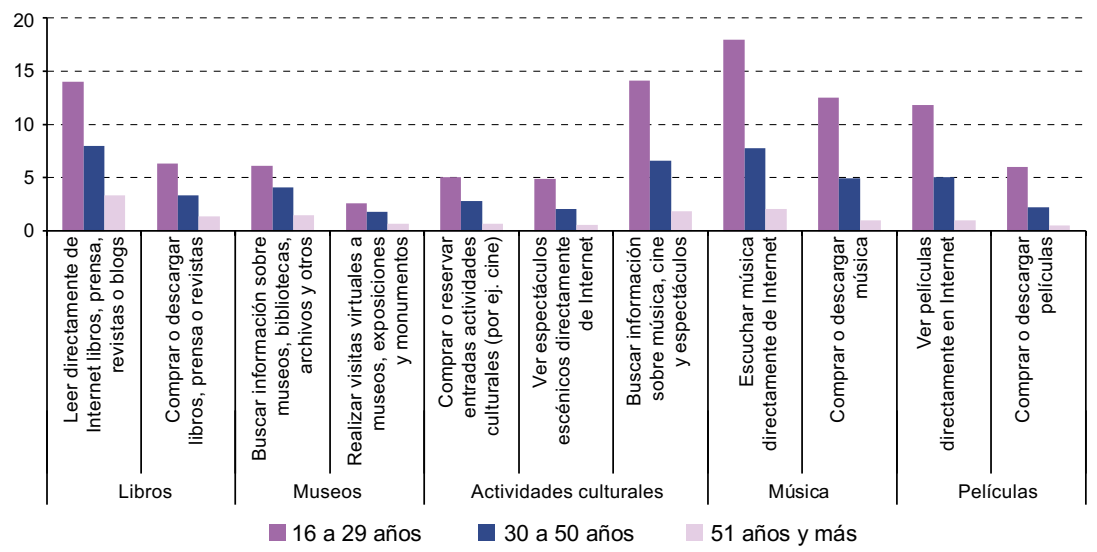

Fuente: Comisión Económica para América Latina y el Caribe (CEPAL), sobre la base de tabulaciones especiales de la encuesta Latinobarómetro, 2013.

La información indica que en Internet estas actividades culturales son realizadas en mayor proporción por los jóvenes, seguidos de los adultos y los adultos mayores. Según datos del Latinobarómetro, en promedio, los jóvenes latinoamericanos son el segmento que más escucha música (18\%), lee libros (14\%) y ve películas $(12 \%)$ por Internet. A su vez, son el segmento que más compra o descarga música (13\%), libros $(6 \%)$ y películas $(6 \%)$ por esta misma vía. Los jóvenes también recurren mucho a Internet para buscar información sobre música, cine y espectáculos (14\%) $\mathrm{y}$, aunque de forma incipiente, son el segmento que más ve espectáculos escénicos $(5 \%)$ y realiza visitas virtuales a museos o exposiciones (3\%).

En el gráfico IV.7 también se observa que algunas actividades culturales son realizadas en Internet por una proporción de personas mucho

10 Cabe destacar que las actividades culturales que se realizan por Internet consideradas en el estudio del Latinobarómetro son más diversas que las consideradas en la sección sobre modos "tradicionales" de acceso a los bienes culturales. Además de prácticas tales como leer libros, ver cine o videos, escuchar música, asistir a recitales, obras de teatro u otros eventos, las actividades culturales que se realizan mediante Internet incluyen comprar o descargar (actividad que solo es posible realizar en Internet) libros, música o películas, buscar información sobre música, cine y espectáculos, y comprar o reservar entradas. 
mayor que otras. Las actividades culturales que más realizan los jóvenes son escuchar música, buscar información sobre música, cine y espectáculos, comprar o descargar música, leer libros y ver películas. Las restantes actividades - comprar o descargar libros, comprar o descargar películas y buscar información sobre museos y bibliotecas- las realizan de forma aún muy incipiente.

La proporción de personas que utiliza Internet para acceder a la cultura es menor que la proporción de personas que accede de modo "tradicional", es decir, sin mediación digital. Sin embargo, la tendencia al alza es significativa y se hace cada vez más relevante, producto de la masificación de Internet y de la generación de nuevos servicios que promueven el acceso a la cultura (véase el recuadro IV.1).

A su vez, estos procesos están generando cambios en los modos de consumo de los bienes culturales. La rapidez en el crecimiento y la expansión de servicios que permiten ver películas a través de Internet, por ejemplo, ha generado nuevas formas en las que el cine llega al espectador. Si bien la noción de que ver una película es una suerte de ritual compartido desde el inicio de la cinta, que además implica comentarla a la salida de la sala de cine, ya se encontraba en crisis previo a Internet producto de la masificación del video, el DVD y la televisión de pago, no hay duda de que Internet ha contribuido decisivamente a esta crisis. La región vive tiempos poscinematográficos en que la relación con las imágenes está cambiando a pasos acelerados y las películas ya no son ni significan lo mismo que para las generaciones anteriores.

\section{Recuadro IV.1}

\section{Servicios de acercamiento a la cultura a través de Internet}

Ante la importancia que ha adquirido la práctica de escuchar música en Internet $-y$ también como una forma de hacer frente a las descargas ilegales-, se han desarrollado servicios de suscripción que proporcionan streaming (flujo o transmisión) de música mediante una tarifa plana mensuala. Uno de estos servicios es Spotify, "una aplicación empleada para la reproducción de música vía streaming. [...] El programa fue lanzado el 7 de octubre de 2008 al mercado europeo, mientras que su implantación en otros países se realizó a lo largo de 2009. La empresa sueca, que tiene su sede en Estocolmo, Suecia, ha firmado acuerdos con las discográficas Universal Music, Sony BMG, EMI Music, Hollywood Records y Warner Music entre otras". En marzo de 2013 contaba con más de 24 millones de usuarios registrados, de los cuales más de 6 millones eran de pago ${ }^{b}$.

Grooveshark y Deezer son servicios que también proporcionan streaming de música por suscripción con los que se está consiguiendo que cada vez más usuarios paguen por la música que escuchan: "de hecho, muchos están abandonando los servicios piratas para pasar a formar parte de un entorno legal de la música que compensa a los artistas y a los titulares de derechos" (IFPI, 2014, pág. 7). 
Recuadro IV.1 (conclusión)

El cine ha seguido una línea similar. Ante la importancia de Internet como espacio para ver cine $-y$ también como un modo de hacer frente a las descargas ilegales-, se han creado servicios de suscripción que proporcionan, mediante una tarifa plana mensual, streaming multimedia (principalmente, películas y series) a demanda por Internet. Uno de estos servicios es Netflix, que se encuentra disponible en América Latina desde 2011 y ofrece al suscriptor un catálogo con una enorme cantidad de películas y series que pueden verse en distintos dispositivos conectados a Internet, como computadoras, tabletas o televisores. Cabe destacar que el modelo de suscripción está logrando que cada vez más consumidores paguen por las películas y series que ven. Esto ha tenido como resultado que muchas personas comiencen a abandonar los servicios piratas para pasar a formar parte de un entorno legal.

Fuente: Federación Internacional de la Industria Fonográfica (IFPI), Informe de la música digital de la IFPI 2014, 2014, y Wikipedia.

a "El streaming (también denominado transmisión, lectura en continuo, difusión en flujo, lectura en tránsito, difusión en continuo, descarga continua o mediaflujo) es la distribución digital de multimedia a través de una red de computadoras, de manera que el usuario consume el producto (generalmente archivo de video o audio) en paralelo mientras se descarga. La palabra streaming se refiere a una corriente continua, que fluye sin interrupción. [...] Esto se contrapone al mecanismo de descarga de archivos, que requiere que el usuario descargue por completo los archivos para poder acceder a su contenido. El término se aplica habitualmente a la difusión de audio o video". Véase [en línea] http://es.wikipedia.org/wiki/Streaming.

b Véase [en línea] http://es.wikipedia.org/wiki/Spotify.

También se destacan los cambios que Internet ha generado en los modos de lectura, particularmente entre la juventud. Se trata de cambios en los protocolos de lectura: el paso "de la lectura plana a la lectura esférica", como lo denomina Beatriz Sarlo, que se encuentra asociado a la competencia que enfrenta el libro por parte del hipertexto, un texto móvil al que se puede entrar desde cualquier punto y que tiene caminos distintos para remitir de una parte a otra o de palabras a imágenes y sonidos. Como advierte Sarlo, "la página, tal como el libro nos acostumbró a la idea de página, ya no existe en el hipertexto, que es solo un conjunto de x pantallas, no ordenadas por sucesión fija, a las que podemos acceder y articular de diferentes modos, siguiendo nexos de asociación, de jerarquía, de secuencia, de tema o de capricho" (Sarlo, 1998, pág. 70). Se llega así a un cambio en los protocolos de lectura, una mutación profunda del acto de leer que alcanza su mayor impacto precisamente en los jóvenes, que tienen más cercanía, o empatía, con las nuevas tecnologías de la comunicación. Según Martín-Barbero, esta empatía "va de la enorme capacidad de absorción de información vía televisión o juegos computarizados - que erosiona la autoridad de la escuela como única instancia legítima de transmisión de saberes- a la facilidad para entrar y manejarse en la complejidad de las redes informáticas" (MartínBarbero, 1998, pág. 35). En contraste con la resistencia de los adultos a la cultura del hipertexto, los jóvenes no solo muestran más pericia instrumental 
para navegarlo, sino también más afinidad expresiva, pues "es en sus relatos e imágenes, en sus sonoridades, fragmentaciones y velocidades que encuentran su ritmo y su idioma" (Martín-Barbero, 1998, pág. 35).

En este nuevo modo de acceso a la cultura posibilitado por Internet - un acceso mediado digitalmente que representa una alternativa a las formas tradicionales - también existe una brecha intergeneracional. Los jóvenes tienen mayores niveles de acceso a la cultura a través de Internet que las generaciones adultas $\mathrm{y}$, por tanto, también ejercen el derecho de acceso y participación en la cultura a través de los medios digitales ${ }^{11}$. $\mathrm{Si}$ en el caso de los modos tradicionales de consumo cultural el acceso juvenil se encuentra asociado a los mayores niveles educativos logrados por esta población en las últimas décadas, en el nuevo modo de acceso este se encuentra asociado a una nueva forma de capital cultural, un "capital tecno-cultural" que existe en las actitudes y disposiciones de los individuos hacia la tecnología y, particularmente, en ciertas competencias, conocimientos y habilidades (O'Keeffe citada en Gayo, 2011, pág. 11).

Las habilidades digitales son centrales para dicho capital tecnocultural y entre ellas hay dos que se destacan especialmente (Claro, 2008). En primer lugar están las habilidades funcionales, generalmente conceptualizadas como "alfabetización digital", que consideran un conjunto de competencias necesarias para utilizar algunas aplicaciones de estas tecnologías, entre las que se pueden señalar el procesador de palabras, la planilla de cálculo, el correo electrónico y el navegador de Internet. En segundo término tenemos las "habilidades digitales para el aprendizaje" que van más allá del manejo funcional de ciertas aplicaciones para referirse a un uso creativo de estas y que permiten la adquisición de nuevos conocimientos. Aquí se incluyen, entre otras, la habilidad para navegar, buscar, evaluar críticamente y dar sentido a la información obtenida a través de los medios digitales.

El capital tecno-cultural conformado por estos dos tipos de habilidades digitales es fundamental para tener acceso y participar en actividades culturales a través de Internet. La juventud actual, cuya vida doméstica ha estado permeada por las nuevas tecnologías, se encuentra aquí en una clara posición de ventaja. Por otra parte, esto sugiere que la tendencia a utilizar Internet como un nuevo modo de acceso a la cultura -más incipiente en algunas actividades y más desarrollada en otras- abre la posibilidad de que participen jóvenes que antes no participaban por razones económicas, de distancia geográfica u otras y, por tanto, que los nuevos medios contribuyan a masificar el acceso a la cultura.

11 Cabe destacar que el porcentaje de adultos mayores que realiza actividades culturales por Internet es muy marginal en todas las actividades consideradas. 
En el gráfico IV.8 se da cuenta de las actividades culturales que realizan los jóvenes en Internet según tres grupos de países (o subregiones): Cono Sur (Argentina, Chile y Uruguay), región andina (Bolivia (Estado Plurinacional de), Colombia, Ecuador y Perú) y Centroamérica (Costa Rica, El Salvador, Guatemala, Honduras, Nicaragua y Panamá). Además, se considera por separado la información para el Brasil y México. Los datos indican que existen grandes desigualdades intrageneracionales en el uso de Internet como modo de acceso a la cultura en los distintos países de la región.

\section{Gráfico IV.8 \\ América Latina (18 países): jóvenes (16 a 29 años) que han utilizado Internet para realizar alguna actividad cultural, según grupos de países}

(En porcentajes)

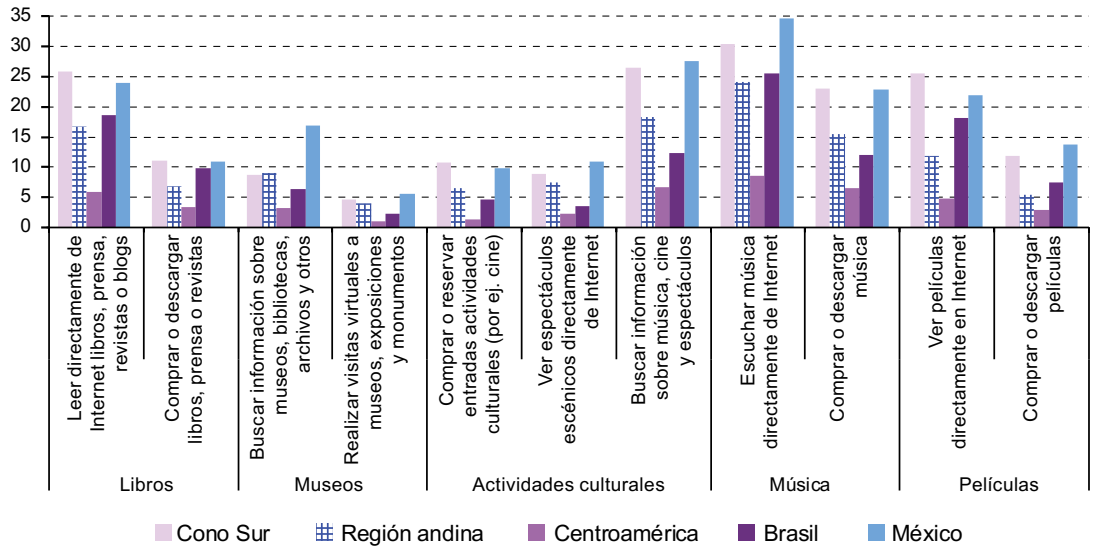

Fuente: Comisión Económica para América Latina y el Caribe (CEPAL), sobre la base de tabulaciones especiales de la encuesta Latinobarómetro, 2013.

En comparación con los de las otras subregiones, los jóvenes de los países centroamericanos son los que menos utilizan Internet como modo de acceso a la cultura en todas las actividades consideradas. La información indica que la escucha, compra o descarga de música, libros y películas desde Internet es un fenómeno muy incipiente en esta subregión, particularmente en países como El Salvador, Guatemala, Honduras y Nicaragua. Esto coincide con la información presentada anteriormente tanto respecto de los consumos culturales como del desarrollo digital en los países.

El uso de Internet como modo de acceso a la cultura en las restantes subregiones es mayor que el observado en Centroamérica, aunque entre ellas existen diferencias. Se destaca el uso de Internet como modo de acceso por parte de los jóvenes mexicanos y del Cono Sur. Por ejemplo, el 35\% de la juventud de México y el 30\% de los jóvenes del Cono Sur escuchan música por Internet, mientras que la lectura de libros por este medio llega al $24 \%$ y 
al 26\%, respectivamente. En México, un 22\% de los jóvenes ve películas por Internet y este porcentaje sube al $25 \%$ en el Cono Sur. Sin duda, estos niveles de uso de Internet para realizar actividades culturales son significativos y reflejan una tendencia que se encuentra en pleno desarrollo.

Lamentablemente, no se dispone de información que permita realizar un análisis más detallado de los factores que inciden en las brechas intrageneracionales en el uso de Internet como modo de acceso a la cultura. Sin embargo, las posibilidades de aprovechar las oportunidades que brinda Internet en el ámbito de la cultura están necesariamente condicionadas por el acceso y uso de los medios digitales. Como se ha visto, existen desigualdades en el acceso a los medios digitales y, por lo tanto, hay una brecha entre quienes tienen acceso a las oportunidades y quienes están excluidos. La desigualdad en el acceso se profundiza aún más en la medida en que muchos jóvenes no tienen las habilidades digitales necesarias para aprovechar las oportunidades. En consecuencia, la ampliación del acceso a la cultura a través de Internet es un desafío asociado al cierre de la brecha digital y a la masificación del capital tecno-cultural.

A continuación se plantean algunos elementos que se desprenden del análisis realizado.

- Existe una tendencia creciente a utilizar Internet como un nuevo modo de acceso a la cultura que se caracteriza por estar mediatizado digitalmente. Internet permite a un número muy significativo de personas realizar una amplia gama de actividades culturales. Asimismo, se puede señalar que se están produciendo cambios en los modos de consumo cultural. Se trata de un proceso en desarrollo en el que se están generando nuevos servicios que promueven el acceso a la cultura.

- La tendencia a utilizar Internet como modo de acceso a la cultura está liderada por las personas jóvenes. Ello genera una brecha digital intergeneracional que se expresa en un uso de Internet para acceder a los bienes culturales mucho menor en el caso de los adultos. Esto demuestra que una proporción significativa de la juventud está ejerciendo el derecho de acceso y participación en la cultura a través de los medios digitales.

- El uso de Internet como modo de acceso a la cultura se encuentra asociado a un capital tecno-cultural conformado por habilidades digitales. Este es un recurso distinto al utilizado en los modos tradicionales de acceso a los bienes culturales, ya que se asocia con mayores niveles educativos de la generación joven, y a los medios digitales, ya que alude a las capacidades de la juventud en tanto nativos digitales. Se trata de un tipo de capital cultural que abre la posibilidad de que participen en la 
cultura los jóvenes que antes no lo hacían (por ejemplo, por razones de distancia geográfica), pero que también se encuentra desigualmente distribuido en los hogares.

- En los países de la región existen grandes desigualdades intrageneracionales en el uso de Internet como modo de acceso a la cultura. Mientras que en algunos países los jóvenes comienzan a tener una amplia participación en determinadas actividades culturales a través de Internet, en otros, como es el caso de algunos países centroamericanos, el acceso todavía es muy limitado. Estas desigualdades son reflejo de diferencias de otro tipo, como el nivel de expansión de las nuevas tecnologías.

- El uso de Internet como nueva forma de acceder a la cultura no sustituye los modos tradicionales de consumo cultural. Los medios digitales más bien abren una nueva posibilidad de acceso a estos bienes y es muy posible que esto acerque la cultura a personas que antes se encontraban excluidas. Lo interesante es que, en relación con otros segmentos etarios, una mayor proporción de jóvenes ejerce el derecho de acceso a la cultura tanto en los modos tradicionales como en la nueva forma mediatizada digitalmente.

\section{Programas culturales: promoción del bienestar}

El análisis previo revela un mayor acceso a la cultura por parte de los jóvenes en comparación con los adultos asociado con mayores niveles educativos de la generación joven y también con la existencia de un capital tecno-cultural conformado por ciertas habilidades digitales. Esto se manifiesta en una democratización del acceso y del ejercicio de los derechos culturales. Sin embargo, debido a que aún persisten obstáculos que limitan el acceso de muchos jóvenes a la cultura, existen desafíos para que la cultura se constituya en un ámbito clave de inclusión social.

¿Se han desarrollado políticas o programas culturales orientados a la promoción del acceso a la cultura y al ejercicio de los derechos culturales? ¿Se ha utilizado la cultura como recurso para la inclusión social de la juventud? ¿Se han puesto en marcha programas orientados a la inclusión digital que posibiliten una distribución más equitativa del capital tecno-cultural?

En los países de la región en general no existen políticas culturales a nivel nacional para los jóvenes y, más específicamente, dirigidas a su acceso a la cultura (Interarts, 2012). En cambio, hay una diversidad de programas, 
proyectos o iniciativas que buscan promover su acceso a la cultura y facilitar procesos de inclusión social. En el ámbito público estas iniciativas se vinculan principalmente con los institutos de la juventud, los ministerios o consejos de cultura, los ministerios de educación y los municipios.

Es posible diferenciar distintos tipos de programas culturales por temas y en un estudio reciente se distinguen los siguientes: formación artística, formación y desarrollo audiovisual, espacios públicos para la cultura joven, inclusión social y mejoras educativas y de salud, y derechos humanos, incluidos los derechos culturales (Interarts, 2012). En este capítulo se presentan tres tipos de programas que están vinculados a los temas que han sido tratados: aquellos orientados a la promoción del acceso a la cultura, al uso del arte y la cultura como mecanismo de inclusión social, y al desarrollo de habilidades digitales para la producción y la expresión cultural ${ }^{12}$.

Es importante resaltar que no se han considerado otros tipos de programas culturales (por ejemplo, los programas de formación, de desarrollo de espacios públicos para la cultura joven o de gestión cultural) que pueden ser relevantes al problema, pero que escapan a la perspectiva que acá se ha desarrollado. Tampoco se han tomado en cuenta las políticas orientadas al cierre de la brecha digital que provienen de ámbitos distintos a la cultura (por ejemplo, las políticas de las TIC en educación u otras políticas de inclusión digital que forman parte de la agenda digital de los países).

Los tipos de programas que acá se presentan no dan cuenta de los distintos tipos de proyectos que es posible llevar a cabo en el ámbito de la cultura y ni siquiera abarcan todo lo que se realiza con relación al acceso a la cultura. Estos tipos de programas tampoco concentran el mayor número de iniciativas. Por otra parte, las pocas iniciativas que se describen solo tienen como propósito ilustrar las acciones que se realizan en el marco de un determinado tipo de programa cultural ${ }^{13}$.

12 No se pudo identificar programas orientados al uso de Internet como medio de acceso a bienes culturales.

13 En general, los proyectos que se describen son realizados desde el sector público o a través de alianzas público-privadas y también se incluyen algunas iniciativas del tercer sector. Para identificar las iniciativas se realizó una búsqueda en los sitios web oficiales de institutos de la juventud y ministerios de cultura de los países. Además, se han utilizado los escasos documentos existentes con información de proyectos culturales considerados como buenas prácticas, entre los que se puede mencionar: "Acceso de los jóvenes a la cultura en Iberoamérica: Tendencias, obstáculos y experiencias" (Interarts, 2012); Cultura, común denominador para el desarrollo. 18 prácticas exitosas (OEA, 2011); Arte para la inclusión y la transformación social. Documento de experiencias e iniciativas en este ámbito (Observatorio Bizkaia, IV Factoría Creativa, 2011), y el Fondo Internacional para la Diversidad Cultural, a cargo de la Organización de las Naciones Unidas para la Educación, la Ciencia y la Cultura (UNESCO), que apoya proyectos que tengan por objeto propiciar la creación de un sector cultural dinámico, principalmente a través de actividades que faciliten la introducción o elaboración de políticas y estrategias que protejan y promuevan la diversidad de las expresiones culturales. Véase [en línea] http://www.unesco.org/new/es/culture/themes/ cultural-diversity/diversity-of-cultural-expressions/international-fund/. 


\section{Promoción del acceso a la cultura}

Las iniciativas de promoción del acceso a la cultura se caracterizan por fomentar la inclusión social a través de la democratización del acceso y, en particular, por facilitar el acceso a la cultura a jóvenes que se encuentran imposibilitados por razones socioeconómicas o educativas. Con el objeto de caracterizar esta orientación de política, a continuación se consideran tres casos emblemáticos.

Un proyecto que ilustra bien esta orientación de política es el Abono Cultural del Uruguay. A través del proyecto Socio Espectacular de las instituciones teatrales El Galpón y Circular de Montevideo, y en convenio con el Banco de Previsión Social (BPS), el Instituto Nacional de la Juventud (INJU) creó una tarjeta (Abono Cultural), asociada a la Tarjeta Joven, que facilita el acceso a la cultura durante un año a jóvenes pertenecientes a instituciones educativas públicas, tanto de enseñanza formal como no formal, que se encuentran excluidos total o parcialmente del consumo de bienes y servicios culturales. El proyecto, que se inició en 2009 y brinda servicios a 5000 jóvenes, tiene por objeto democratizar el acceso a bienes y servicios culturales, tales como teatro, cine, espectáculos deportivos, musicales, carnaval y otras expresiones culturales. Se parte de la base de que la democratización del acceso a la diversidad de bienes culturales resulta un factor decisivo en los procesos de integración social. Los destinatarios son estudiantes seleccionados de secundaria, centros juveniles o aulas pedagógicas que intentan culminar su educación (Interarts, 2012) ${ }^{14}$.

Cultura Viva para la Nueva Lima es otro proyecto que se inserta en esta orientación. Implementada por la Subgerencia de Cultura de la Municipalidad de Lima, esta convocatoria para artistas se propone fortalecer la producción cultural existente en la ciudad y contribuir a la construcción de una mayor conciencia ciudadana en la capital. En el marco de esta iniciativa, cada semana se ofrecen distintos espectáculos e intervenciones artístico-culturales en los espacios públicos de libre acceso a toda la comunidad. El proyecto financia a actores y actrices, artistas plásticos y visuales, músicos, bailarines, creadores audiovisuales y narradores - ya sean profesionales, aficionados o estudiantes- cuyas propuestas de producción sean seleccionadas. Los temas que pueden abordar son: democracia, equidad de género, goce de la diversidad, integridad, identidades culturales, preservación del medioambiente, derechos humanos y lucha por el cambio (Interarts, 2012).

El Plan Nacional de Lectura de Panamá busca articular, divulgar, fortalecer, formar y promover acciones a favor de la lectura entre niños, jóvenes y adultos de todas las regiones, respetando la diversidad, con el fin de formar hombres y mujeres con conciencia crítica. Entre sus

${ }_{14}$ Véase [en línea] http://www.socioespectacular.com.uy/abono.html. 
líneas de acción se encuentran: la lectura como tema de política pública; acciones para la formación de actores en promoción cultural; estímulo a la creación de materiales de lectura; acciones para mejorar las bibliotecas (infantiles, públicas, escolares, universitarias y especializadas); acciones para fortalecer la lectura y la escritura en el sistema educativo; los medios de comunicación y la lectura. Este proyecto iniciado en 2008 abarca todo el territorio nacional y es gestionado por diversas instituciones públicas y privadas. Entre las diversas actividades realizadas para fomentar la lectura (como congresos y ferias) se destacan por su carácter innovador los círculos de lectura, los cafés literarios, la siembra de lectores y las caravanas de lectura (Interarts, 2012) ${ }^{15}$.

Por último, cabe destacar los proyectos que buscan acercar el arte al público (también llamados "de formación de públicos"). En esta línea se destacan los festivales de teatro, que han tenido un importante papel en la masificación de esta expresión cultural. Aunque no está orientado específicamente a un público joven, un ejemplo destacado es el Festival Teatro a Mil que se celebra cada mes de enero en Santiago de Chile desde 1994. Con una oferta que ha crecido sostenidamente en el tiempo, el festival ha logrado convertir las calles de Santiago en un escenario al aire libre. Desde su creación hace más de 20 años, millones de personas tienen la oportunidad de ver teatro durante un mes completo, lo que ha contribuido de manera significativa a acercar este arte al público ${ }^{16}$.

\section{El arte y la cultura como mecanismo para la inclusión social}

Las iniciativas que se enmarcan en esta segunda orientación se caracterizan por promover la inclusión social de jóvenes en situación de vulnerabilidad a partir de su participación en actividades artísticas y culturales. Estas parten del supuesto de que la expresión constituye una dimensión y un derecho fundamental de las personas, y la expresión artística y cultural es una vía privilegiada para que todas las personas, y en particular quienes se encuentran en situación de vulnerabilidad, desarrollen esa dimensión y ejerzan ese derecho de manera individual y colectiva (Observatorio Bizkaia, 2012, pág. 6). A continuación se destacan algunas experiencias.

Dunna: Alternativas creativas para la paz es un proyecto implementado por la Fundación Granitos de Paz, en conjunto con el Ministerio de Cultura de Colombia y la Institución Educativa República del Líbano, que ilustra bien esta orientación. Su objetivo es aplicar un modelo de intervención en

15 Véase [en línea] http://www.binal.ac.pa.

16 En esta línea, el Fondo Internacional para la Diversidad Cultural de la UNESCO ha financiado recientemente el proyecto Theatre4Youth de Sudáfrica, una iniciativa de acercamiento del teatro al público joven. 
salud mental a través de la psicoterapia de danza y movimiento para el manejo de la depresión y la ansiedad en los adolescentes de poblaciones vulnerables del país. Las sesiones consisten en diversos ejercicios que utilizan el movimiento como un proceso creativo que favorece la integración emocional, cognitiva, social y física del individuo. El proyecto parte de la hipótesis de que el manejo de las problemáticas de salud mental facilita la reconciliación de los participantes a nivel personal y social, al tiempo que contribuye a la creación de una nueva sociedad orientada a la paz, la tolerancia y la armonía en Colombia (Interarts, 2012).

Otro proyecto que se enmarca en esta orientación es el Circo Social del Sur (CSS) de Buenos Aires, una organización sin fines de lucro que interviene en los sectores más vulnerables y busca la transformación personal y social a través del arte. El público beneficiario son niños, niñas y jóvenes que viven en hogares pobres con carencias de nutrición y serios riesgos ambientales y sanitarios. El proyecto toma la cultura y el arte circense como estrategia para generar nuevas formas de producción, pertenencia, educación y organización comunitaria, así como potenciadoras del desarrollo de las capacidades de creación y autonomía de los colectivos de niños, niñas y jóvenes con que trabaja. El Circo Social del Sur realiza actividades en diversas organizaciones comunitarias de base en la Villa 21-24 y Ciudad Oculta. Por medio de las diferentes disciplinas artísticas se generan espacios comunitarios de pertenencia, aprendizaje y participación (Observatorio Bizkaia, IV Factoría Creativa, 2011).

Una tercera iniciativa que ilustra esta orientación es el proyecto YIP-Colombianos Renaciendo en el Hip-Hop, que se inserta en una línea de trabajo de prevención de conductas relacionadas con delitos o violencia, y se articula con el Plan de desarrollo distrital Bogotá positiva: Para vivir mejor. El proyecto surgió de una organización de cooperación internacional, Young in Prison International (YiP IN) en los Países Bajos, que venía implementando estrategias similares en otros países y desarrollando actividades a través del hip-hop. Su objetivo es aportar a la reintegración social de jóvenes infractores de la ley y fomentar conductas no delictivas. El público objetivo del proyecto lo conforman mujeres y hombres jóvenes que se encuentran recluidos en diversos centros de Bogotá y otros municipios del departamento de Cundinamarca por infracción a la ley penal o en fase pospenal, en rehabilitación de drogas o internos de instituciones para niños abandonados o víctimas de abuso. El proyecto aplica la metodología de formación de alto impacto Ayara, que incluye formación en las cuatro expresiones artísticas del hip-hop (grafiti, breakdance, rap y DJ), así como orientación psicosocial para el fortalecimiento de habilidades personales en temas de autoestima, capacidades sociales y resolución de conflictos. Además, el programa ofrece capacitación en áreas relacionadas como la capoeira, confección de moda para hip-hoperos y medios de comunicación (técnicas audiovisuales y periodismo). 
La elección de esta metodología para trabajar con jóvenes que se encuentran en las condiciones ya descritas se basa en el hecho de que Bogotá, al igual que otras ciudades de Colombia, carece de programas atractivos para la prevención y reinserción de los jóvenes ${ }^{17}$.

Cabe destacar que el proyecto YIP está incluido en el Banco de Buenas Prácticas en Prevención del Delito en América Latina y el Caribe del Centro de Estudios en Seguridad Ciudadana del Instituto de Asuntos Públicos de la Universidad de Chile, en colaboración con el Banco Interamericano de Desarrollo (BID) y el Open Society Institute ${ }^{18}$. Otro proyecto incluido en ese Banco, y que se inserta en la línea de cultura para la inclusión social juvenil, es Escuelas para la convivencia en El Salvador. Este proyecto incluye una metodología atractiva para la juventud que se centra en el deporte, el arte y la cultura, la resolución de conflictos, la cuestión de género y la capacitación para el empleo.

Otra iniciativa destacable es la Conchalí Big Band en Santiago de Chile. Este proyecto educativo comienza en 1994 cuando la Corporación Municipal de Conchalí, una de las comunas con mayor índice de riesgo social de la Región Metropolitana, crea una serie de talleres artísticos y deportivos. El proyecto convoca a adolescentes y jóvenes de 12 a 18 años a participar como músicos en una gran orquesta de jazz. Esta iniciativa, con más de 20 años de existencia, ha logrado incorporar a más de 400 adolescentes y jóvenes a la música, incentivándolos para que se dediquen a ella profesionalmente. La participación en eventos musicales y el desarrollo de habilidades para tocar un instrumento, así como el aprendizaje de otras actividades en el campo de la cultura, contribuyen a generar disciplina en las personas jóvenes, y ello constituye un factor facilitador del buen desempeño escolar y laboral (CEPAL/OIJ, 2014).

Por último, cabe destacar la Sinfonía por el Perú, un programa de inclusión social y prevención que, en el marco del sistema de orquestas juveniles e infantiles de ese país, busca, por medio de la música, acercar a los jóvenes a sus talentos, motivarlos a un mejor desarrollo y alejarlos de la violencia. El proyecto, inaugurado en 2011, surge como una iniciativa del gobierno peruano para superar la violencia que afecta a la población infantil y juvenil, entregándoles herramientas de expresión y un espacio para desarrollarse de manera sana y segura. El trabajo que realiza la Sinfonía por el Perú implica traducir el arte y la educación en un lenguaje que tiene sentido para la juventud y que es incorporado a través de la diversión y expresado mediante sus propias creaciones musicales. De este modo, es posible habilitar entornos que escapen de los contextos de creciente violencia e inseguridad a los que se ven expuestos los jóvenes.

17 Véase [en línea] http://seguridadenbarrios.cl/buenaspracticasenprevencion.org/bbp_docs/ 04_proyecto_yip_colombia.pdf

18 Véase [en línea] http://seguridadenbarrios.cl/buenaspracticasenprevencion.org/bbp.html 


\section{Desarrollo de habilidades digitales para la producción y la expresión cultural}

La promoción del desarrollo de habilidades digitales para la producción y la expresión cultural implica una inversión en capital tecno-cultural. Algunos de los proyectos vinculados a esta iniciativa buscan aportar a la inclusión social juvenil a través del empleo. A continuación se consideran tres casos ilustrativos.

El proyecto Formación para jóvenes indígenas en la industria audiovisual en Guatemala ejemplifica esta orientación y fue implementado por el Instituto de Relaciones Internacionales e Investigaciones para la Paz (IRIPAZ), una organización guatemalteca sin fines de lucro, con el apoyo del Fondo Internacional para la Diversidad Cultural (FIDC) de la UNESCO. Los participantes, pertenecientes a las etnias maya, garífuna y xinca, aprendieron producción audiovisual, escritura de guiones, dirección cinematográfica, iluminación y fotografía, uso de la cámara, edición y posproducción en un nuevo centro de formación audiovisual establecido en la Universidad de San Carlos. También se impartieron clases sobre los derechos culturales de los pueblos indígenas, la igualdad de género y el desarrollo de capacidades para la comunidad. Gracias a las pasantías en TV Maya, los estudiantes tuvieron la oportunidad de adquirir experiencia práctica. En estos momentos, el centro continúa organizando breves talleres gratuitos sobre comunicación audiovisual intercultural. Una vez finalizado el curso, los alumnos graduados emprendieron rumbos profesionales muy diversos: algunos como directores gráficos de televisión, otros como movilizadores culturales en sus comunidades o animadores culturales en el Ministerio de Cultura y Deportes. Del curso también surgieron grupos artísticos indígenas que hoy producen cortometrajes y videos musicales acerca de sus culturas, y distribuyen sus creaciones principalmente a través de Internet y las redes sociales, aunque alguna televisión local también ha emitido sus producciones. Otros alumnos del centro de formación iniciaron su propio negocio de comunicación. "Destinos cruzados", el primer cortometraje realizado íntegramente por un equipo de jóvenes indígenas, fue uno de los resultados estelares de la formación. En septiembre de 2012 fue presentado en el festival de cine Ícaro de Guatemala y en la actualidad el equipo realizador trabaja en una versión ampliada que incorporará cinco piezas musicales. Una de las participantes señaló: "Además de enseñarnos tecnología, los medios audiovisuales nos permiten expresar nuestra identidad cultural... para mostrar la realidad de nuestras comunidades xinca, garífuna y maya. Estamos comenzando, y gracias a este proyecto hemos recibido una importante oportunidad formativa"19.

19 Véase[enlínea]http://www.unesco.org/new/es/culture/themes/cultural-diversity/diversityof-cultural-expressions/international-fund/. 
Un segundo proyecto iniciado en 2004 en esta misma línea es Wapikoni Mobile. Se trata de una iniciativa dirigida inicialmente a las comunidades de las Primeras Naciones de Quebec, en el Canadá, en la que participaron el Consejo de la Nación Atikamekw y el Consejo de la Juventud de las Primeras Naciones de Quebec y Labrador. Wapikoni Mobile consiste en un estudio itinerante que visita comunidades y capacita a jóvenes en diversos medios audiovisuales. El proyecto desarrolló un enfoque educativo para satisfacer las demandas regionales y encarar los graves problemas que enfrentan las comunidades de las Primeras Naciones, tales como violencia doméstica, suicidio y adicciones. Hasta 2012, Wapikoni Mobile había llevado a cabo múltiples capacitaciones en naciones y comunidades autóctonas (incluidos talleres de creación y producción de video y música) y realizado cerca de 360 grabaciones musicales y 450 cortometrajes, algunos traducidos a varios idiomas. En el marco del proyecto también se organizaron conferencias y cientos de actividades de divulgación en festivales, y se obtuvieron más de 40 galardones nacionales e internacionales. Paralelamente, se instalaron algunos estudios permanentes para continuar con las capacitaciones. El primero de estos estudios fue Wetomaci, inaugurado en 2006. La pedagogía de los talleres se basa en el concepto del aprendizaje práctico o "aprender haciendo". Lo que se busca a largo plazo es que los participantes afirmen su identidad mediante el lenguaje, el desarrollo de sus habilidades y la apropiación de herramientas de comunicación para poner fin a su aislamiento y crear una red con los realizadores de las Primeras Naciones y otros lugares a fin de combatir los prejuicios entre inmigrantes. A más diez años de su fundación, Wapikoni Mobile se constituye como un referente de creación de documentales e intervenciones multidisciplinarias a nivel continental (OEA, 2011).

Por último, Habla es otro proyecto en esta misma línea que se ha implementado en Bangladesh y el Perú. Desarrollada en colaboración con la Fundación Anesvad, la iniciativa da voz a las personas y las comunidades, y permite explicar su situación de vida mediante la técnica del video. Como se describe desde la propia organización: "Lanzamos el Proyecto Habla, una iniciativa pionera en comunicación social que consiste en la elaboración de videos comunitarios, grabados con teléfonos móviles por las poblaciones vulnerables con las que trabajamos, para que ellas mismas documenten su realidad. La comunicación al servicio de la comunidad. Una iniciativa pionera en comunicación social con la que buscamos que las poblaciones vulnerables con las que trabajamos cuenten su realidad, en primera persona, a través de grabaciones hechas con el teléfono móvil. El Proyecto Habla es un ejercicio documental y participativo, un dinamizador social que persigue concienciar y sensibilizar sobre los problemas de los países del Sur y su lucha por el acceso a la salud (por ejemplo, la lucha contra la tuberculosis). También quiere generar una corriente crítica que contribuya a revertir las situaciones de desigualdad e injusticia social que se producen en el mundo y que impiden el acceso a los derechos básicos" (Observatorio Bizkaia, IV Factoría Creativa, 2011). 


\section{Sugerencias}

Del análisis realizado se desprenden ciertas sugerencias para la formulación de propuestas de política orientadas a la promoción del acceso y la participación juvenil en la cultura, una cuestión fundamental para el bienestar de los jóvenes. A continuación se presentan algunas de estas sugerencias.

\section{a) Precisar la institucionalidad desde la cual puedan implementarse políticas y programas culturales orientados a los jóvenes}

Como se ha destacado, en los países de la región no existen políticas culturales para la juventud a nivel nacional ni políticas dirigidas al acceso y la participación de los jóvenes en la cultura. Tampoco existe una institucionalidad desde la cual estas políticas puedan implementarse. En el ámbito público, las iniciativas existentes se vinculan principalmente con los institutos de la juventud, los ministerios o consejos de cultura, los ministerios de educación y los municipios. En este sentido, es necesario pensar la articulación entre las instituciones que contribuyan a mejorar la situación de la juventud desde el ámbito de la cultura. Ello permitiría incorporar las diversas iniciativas existentes - muchas de las cuales son de pequeña escala - en políticas de mayor envergadura. También es necesario pensar en la necesidad de desarrollar alianzas público-privadas y con el tercer sector.

\section{b) Garantizar el acceso y la participación cultural de los jóvenes latinoamericanos}

Con relación a las generaciones adultas, una mayor proporción de jóvenes está actualmente ejerciendo el derecho de acceso y participación en la cultura, lo que se encuentra asociado a los mayores niveles educativos con que cuentan. Sin embargo, estos avances son insuficientes, ya que existen obstáculos que limitan a muchos jóvenes que aún se encuentran alejados del acceso y la participación en la cultura por factores socioeconómicos y educativos. Para garantizar el acceso y la participación de la juventud latinoamericana en la cultura se requiere de políticas orientadas a remover esos obstáculos y a una redistribución del capital cultural.

\section{c) Utilizar la cultura como un recurso clave de inclusión social de jóvenes vulnerables}

La cultura ofrece herramientas para luchar contra la pobreza y amplía las capacidades y oportunidades de los grupos vulnerables. En el marco de las políticas públicas, la cultura puede ser utilizada como un 
valioso recurso de inclusión de jóvenes en situación de riesgo social por su cercanía con la violencia, la delincuencia, el narcotráfico o el consumo de drogas, entre otros. La cultura es un "lugar" clave para realizar intervenciones de este tipo porque es atractiva para la juventud, pero también porque genera capacidades que fomentan la participación, la resolución de conflictos y la resiliencia.

\section{d) Contribuir a la redistribución del capital tecno-cultural}

Como se ha visto, no todos los jóvenes tienen acceso a las tecnologías digitales. En muchos países de la región, sin embargo, el problema principal es la brecha de capacidades o habilidades para utilizar las tecnologías de forma eficaz: la denominada "segunda brecha digital". Para aprovechar las oportunidades que brindan las nuevas tecnologías en el ámbito de la cultura es necesario disponer de un capital tecno-cultural conformado por ciertas habilidades digitales. La cultura es un "lugar" clave para contribuir a la redistribución de ese capital tecno-cultural capacitando a la juventud en el uso de estas habilidades digitales para la producción y expresión cultural. Además, con ello se contribuye a la reducción de la segunda brecha digital.

\section{e) Mejorar los sistemas de información sobre la juventud en el ámbito de la cultura}

La formulación de políticas requiere de información. Sin embargo, como se ha señalado, la cultura es un campo que se caracteriza por la precariedad de las estadísticas. Las encuestas nacionales de juventud podrían recabar información sobre los hábitos y comportamientos de los jóvenes en este ámbito y constituirse en una fuente útil de datos si se incluyera un módulo con preguntas clave al respecto. Para garantizar la comparabilidad, se requeriría que las encuestas de juventud de los diferentes países incluyan un mismo conjunto de preguntas.

\section{f) Elaborar orientaciones específicas para algunos países centroamericanos}

A lo largo de este capítulo se ha visto que Centroamérica presenta un desarrollo muy desigual en términos de oportunidades de acceso a la cultura, incluido el acceso a las tecnologías digitales. En este sentido, se destaca que los jóvenes de algunos países centroamericanos se encuentran muy rezagados en términos del acceso y la participación cultural, lo que implica que sus derechos culturales se encuentran muy restringidos. Si bien las sugerencias anteriores son válidas para estos países, dadas sus particularidades, se requeriría elaborar algunas orientaciones específicas. 


\section{Bibliografía}

AC/E (Acción Cultural Española) (2014), Anuario AC/E de cultura digital. Focus 2014: Uso de las nuevas tecnologías en las artes escénicas [en línea] http:/ / www. accioncultural.es/es/publicacion_digital_anuario_ac_e_cultura_digital_ focus_2014.

Balardini, Sergio (2014), “Viejas y nuevas formas de ser joven”, Diálogos del SITEAL, mayo.

(2004), "De deejays y ciberchabones. Subjetividades juveniles y tecnocultura", Revista de Estudios sobre Juventud, año 8, $N^{\circ} 20$.

Bourdieu, Pierre (1984), Distinction: A Social Critique of the Judgement of Taste, Harvard University Press.

CEPAL (Comisión Económica para América Latina y el Caribe) (2014a), Panorama Social de América Latina 2014 (LC/G.2635-P), Santiago. Publicación de las Naciones Unidas, $\mathrm{N}^{\circ}$ de venta: S.14.II.G.6.

(2014b), "América Latina y el Caribe en la Agenda para el Desarrollo después de 2015: Reflexiones preliminares basadas en la trilogía de la igualdad" (LC/L.3843), Santiago.

(2013), Panorama Social de América Latina 2013 (LC/G.2580), Santiago. Publicación de las Naciones Unidas, $N^{\circ}$ de venta: S.14.II.G.6.

(2010), "Avances en el acceso y uso de las tecnologías de la información y la comunicación en América Latina y el Caribe 2008-2010", Documento de Proyectos, $N^{\circ} 316$ (LC/W.316), Santiago.

CEPAL/OEI (Comisión Económica para América Latina y el Caribe/Organización de Estados Iberoamericanos para la Educación, la Ciencia y la Cultura) (2014), Cultura y desarrollo económico en Iberoamérica, Madrid.

(2012), "Avanzar en la construcción de un espacio cultural compartido. Desarrollo de la Carta Cultural Iberoamericana" [en linea] http://www.culturasiberoamericanas. org/documentos_trabajo.php.

CEPAL/OIJ (Comisión Económica para América Latina y el Caribe/Organización Iberoamericana de Juventud) (2014), Invertir para transformar. La juventud como protagonista del desarrollo, Santiago, octubre.

(2004), La juventud en Iberoamérica, tendencias y urgencias (LC/L.2180), Santiago.

Claro, Magdalena (2008), "ICT related skills and competencies. Approaches to identification, definition and assessment in the Chilean context", inédito.

De Luca, Luiz Gonzaga Assis (2009), A hora do cinema digital. Democratização e globalização do audiovisual, São Paulo, Imprensa Oficial.

DiMaggio, Paul y Michael Useem (1978a), "Cultural democracy in a period of cultural expansion: The social composition of arts audiences in the United States", Social Problems, vol. 26, N², Oxford, Oxford University Press. (1978b), "Social class and arts consumption", Theory and Society, vol. 5, $N^{\circ} 2$, Springer.

Dosdoce.com (2013), “Los museos en la era digital. Uso de las nuevas tecnologías antes, durante y después de visitar un museo, centro cultural o galería de arte" [en línea] http://www.dosdoce.com/articulo/estudios/3820/museos-en-laera-digital/. 
(2011), "Indústria editorial 2.0: tendències, oportunitats $i$ reptes davant la digitalització del llibre".

Gayo, Modesto (dir.) (2011), "Consumo cultural y desigualdad de clase, género y edad: Un estudio comparado en Argentina, Chile y Uruguay", Avances de Investigación, $\mathrm{N}^{\circ}$ 62, Madrid, Fundación Carolina.

Hopenhayn, Martín (2008), "Inclusión y exclusión social en la juventud latinoamericana", Pensamiento Iberoamericano, $\mathrm{N}^{\mathrm{o}} 3$, Madrid.

IFPI (Federación Internacional de la Industria Fonográfica) (2014), Informe de la música digital de la IFPI 2014.

Interarts (2012), “Acceso de los jóvenes a la cultura en Iberoamérica. Tendencias, obstáculos y experiencias" [en línea] http://www.interarts.net/descargas/ interarts1241.pdf.

Lévy, Pierre (2007), Cibercultura: La cultura de la sociedad digital, Barcelona, Anthropos Editorial.

Martín-Barbero, Jesús (1998), “Jóvenes: Des-orden cultural y palimpsestos de identidad", Viviendo a toda. Jóvenes, territorios culturales y nuevas sensibilidades, Humberto Cubides, María Cristina Laverde y Carlos Eduardo Valderrama (eds.), Bogotá, Siglo del Hombre Editores.

Música Popular, "Conchalí Big Band" [en línea], www.musicapopular.cl/3.0/ index2.php?op=Artista\&id=487.

Observatorio Bizkaia (2012), "Arte para la inclusión y la transformación social" [en línea] www.3sbizkaia.net.

Observatorio Bizkaia, IV Factoría Creativa (2011), Artepara la inclusión y la transformación social. Documento de experiencias e iniciativas en este ámbito [en línea] http:// www.3sbizkaia.org/Archivos / Documentos /Enlaces /1174_Documento\%20 de\%20experiencias.pdf.

OCDE (Organización de Cooperación y Desarrollo Económicos) (2010), Are the New Millennium Learners Making Their Grade? Technology Use and Educational Performance in PISA, París. (2001), Understanding the Digital Divide, París.

OEA (Organización de los Estados Americanos) (2011), Cultura, común denominador para el desarrollo. 18 Prácticas exitosas [en línea] http://scm.oas.org/pdfs/2012/ CIDI03698S01.pdf.

Palma, Luis Antonio y Luis Fernando Aguado (2010), "Economía de la cultura. Una nueva área de especialización de la economía", Revista de Economía Institucional, vol. 12, N ${ }^{\mathrm{o}} 22$, Bogotá, Universidad Externado de Colombia.

Palmeiro, César (2004), "La industria discográfica y la revolución digital”, Buenos Aires, Universidad de Buenos Aires.

Piscitelli, Alejandro (2009), Nativos digitales, Santillana.

Sarlo, Beatriz (1998), "Del plano a la esfera: Libros e hipertextos", Cultura, medios y sociedad, Jesús Martín-Barbero y Fabio López de la Roche (eds.), Bogotá, Universidad Nacional de Colombia.

Selwyn, Neil (2004), "Reconsidering political and popular understandings of the digital divide", New Media \& Society, vol. 6, N 3, SAGE.

Sinfonía por el Perú [en línea] www.sinfoniaporelperu.org. 
Sunkel, Guillermo, Daniela Trucco y Andrés Espejo (2014), La integración de las tecnologías digitales en las escuelas de América Latina. Una mirada multidimensional, Libros de la CEPAL, N 124 (LC/G.2607-P), Santiago, Comisión Económica para América Latina y el Caribe (CEPAL). Publicación de las Naciones Unidas, $\mathrm{N}^{\circ}$ de venta: S.14.II.G.10.

UNESCO (Organización de las Naciones Unidas para la Educación, la Ciencia y la Cultura) (2012), "Culture: a Driver and an Enabler of Sustainable Development", Equipo de Tareas del Sistema de las Naciones Unidas sobre la Agenda de las Naciones Unidas para el Desarrollo Después de 2015. (2010), The Power of Culture for Development, París. 
Capítulo V

\section{Participación política, apego a la democracia y temas prioritarios de las personas jóvenes en América Latina, 2000-2013}

Carlos F. Maldonado Valera ${ }^{1}$

\section{Introducción}

La desigualdad y la inclusión social son dos grandes retos para América Latina en general y para las personas jóvenes en particular. Como se apunta en el marco de análisis del presente libro, la participación política es uno de los ejes principales para la inclusión social de los jóvenes, junto con la educación, el empleo, la salud, la cultura y una vida libre de violencia. Esto en virtud de que la participación política constituye en sí misma un derecho humano fundamental, así como una vía esencial para alcanzar, mediante su ejercicio, el goce efectivo de otros derechos humanos. Por esa razón, el enfoque de derechos, eje orientador de las políticas públicas para encaminarlas hacia la garantía de derechos, también está vinculado con la apertura de posibilidades concretas de participación para todas las personas.

Oficial de Asuntos Sociales de la División de Desarrollo Social de la CEPAL. El autor agradece el apoyo y los importantes aportes a este capítulo de Matías Sálces, asistente de investigación de la División de Desarrollo Social, así como los comentarios y observaciones sumamente útiles de Andrés Espejo, Fabiana Pierre, Humberto Soto, Guillermo Sunkel, Daniela Trucco y Heidi Ullmann. El contenido final es de responsabilidad exclusiva del autor. 
Al igual que en otras regiones del mundo, en numerosos estudios de la Comisión Económica para América Latina y el Caribe (CEPAL), así como de otros organismos y especialistas, se ha señalado la lejanía y falta de confianza de las personas jóvenes de América Latina respecto de la política, y su menor participación en tanto votantes y candidatos en las elecciones, en los partidos políticos y en las organizaciones sociales tradicionales que canalizan las demandas y expresan los intereses de los distintos grupos sociales (IDEA Internacional, 2013; CEPAL/OIJ, 2008; CEPAL/UNFPA, 2011). Con frecuencia, y con base en la división un tanto arbitraria de la mayoría de edad como criterio de ejercicio pleno de la ciudadanía política, los jóvenes, en especial aquellos que son menores de edad, tienden a ser considerados por el orden establecido como sujetos de las políticas, mas no como sujetos políticos activos (Reguillo, 2003). Incluso es usual que cuando tienen la edad requerida para votar, sus prioridades sean consideradas centrales por los responsables políticos solo cuando el conjunto de los electores los considera prioritarios o, si se quiere, cuando "los padres votan por los intereses de sus hijos" (UNFPA, 2014, pág. 7). Como ha señalado la Unión Interparlamentaria, organismo conformado por legisladores de todo el mundo, cuando se comparan con los ciudadanos de otros grupos etarios, se observa que los jóvenes también enfrentan diversos obstáculos o barreras muy concretas para participar activamente en la vida política y electoral por las vías convencionales (véase el recuadro V.1).

En contrapartida, la juventud tiende a mostrarse indiferente e incluso a rechazar las formas tradicionales de acción política, al tiempo que es un actor protagonista de movilizaciones informales o no convencionales. Los jóvenes utilizan y aprovechan de forma novedosa y creativa nuevos canales de comunicación y coordinación, como las redes sociales virtuales, y en ocasiones consiguen generar extensos procesos de cambio en la política y en las políticas. De hecho, actuando en red o participando en discusiones colectivas o "virales", muchos jóvenes hoy se inventan y se descubren como sujetos políticos; es decir, como ciudadanos. Al respecto, podría evocarse el papel central de la juventud en el movimiento estudiantil de 2011 en Chile, la irrupción del Movimiento \#Yosoy132 durante la campaña presidencial de México en 2012 o, si nos remontamos algunos años atrás, su papel en el proceso que llevó a la convocatoria a una Asamblea Constituyente en Colombia en 1990-1991. No en vano, el 15 de septiembre de 2014, Día Internacional de la Democracia, el Secretario General de las Naciones Unidas se refirió especialmente a la imperiosa necesidad de vincular más estrechamente a la juventud con la participación política como vía de renovación y consolidación de las democracias en todas las latitudes ${ }^{2}$.

En 2007, con el fin de alentar a los gobiernos a fortalecer los programas nacionales dedicados a promover y consolidar la democracia, la Asamblea General de las Naciones Unidas declaró mediante la resolución A/62/7 el 15 de septiembre de cada año como Día Internacional de la Democracia. Véase [en línea] http://www.un.org/es/events/democracyday/. 
Recuadro V.1

Algunos factores limitantes de la participación de las personas jóvenes en la vida política de las democracias contemporáneas

Los jóvenes no son tomados en serio por el sistema político y son considerados inmaduros e inexperimentados.

Las personas jóvenes enfrentan obstáculos legales para participar en la política, desde la edad mínima requerida para votar hasta la edad mínima para ser votado. En muchos países, las personas de entre 16 y 21 años, y en algunos casos hasta los 25 años (lo que representa una proporción significativa de la población joven), no pueden ser parte de la vida política.

Las mujeres y hombres jóvenes involucrados en la política no siempre tienen acceso a las redes sociales de los políticos de mayor edad, que suelen ser de difícil acceso para nuevos actores.

Los jóvenes involucrados en la política enfrentan mayores retos financieros en comparación con sus pares de mayor edad y con más tiempo en la vida política.

La imagen que las personas jóvenes tienen de la política como conflictiva y corrupta les resulta poco atractiva, al igual que la imagen que tienen de los principales líderes políticos.

Fuente: Unión Interparlamentaria (UIP), Taking Democracy to Task, Ginebra, 2014.

Como se verá, la discusión sobre la participación de las personas jóvenes en la vida política ocurre en un contexto regional que presenta ciertas especificidades. Pese a la gran diversidad de trayectorias políticas que registra la región, la mayoría de los países comparte el legado conformado por extensos períodos de gobierno autoritario o dictatorial seguidos por una recuperación paulatina de la democracia electoral a partir de los años ochenta. En la mayoría de los casos, incluso, la fase más reciente de vida en democracia ha sido la de mayor duración y estabilidad. A la vez, persisten evidentes retos para traducir la igualdad jurídica y formal entre los ciudadanos, que está inscrita en las leyes, en mecanismos concretos y efectivos de inclusión y de igualdad social, sobre todo para las nuevas generaciones. La elevada desigualdad que caracteriza a la región plantea entonces un cuestionamiento al valor y a las tareas pendientes de la vida en democracia en tanto vehículo efectivo de inclusión. La duda sobre el sentido de democracias en donde la igualdad es más una ficción jurídica que una condición social de los ciudadanos cuestiona cotidianamente el valor de la democracia y tensiona el apego de las personas con respecto a los principios y valores democráticos.

Las dos últimas décadas muestran, no obstante, un panorama muy diverso en cuanto a las trayectorias políticas de los países, con casos recientes de cambios de orden constitucional de la mano de liderazgos carismáticos en algunos (Bolivia (Estado Plurinacional de), Ecuador y Venezuela (República Bolivariana de)), el arribo y la permanencia de 
nuevas coaliciones gobernantes de centro-izquierda en otros (Argentina, Brasil, El Salvador, Nicaragua, Perú y Uruguay), y, por último, casos en donde el orden político instaurado durante las transiciones a la democracia ha cambiado poco (Chile y Colombia), a veces con signos sostenidos de una legitimidad decreciente y con prolongadas crisis (o incluso el colapso) de los antiguos sistemas de partidos (Costa Rica, Guatemala, Honduras, México y Paraguay) (Luna, 2014).

A la vez, cuando menos en América del Sur, y en comparación con el momento de recuperación de la democracia en las décadas de 1980 y 1990, la última década constituyó una fase de gran dinamismo económico, traducido en progresos tangibles en la dimensión social y económica, así como también en nuevas y mayores expectativas por parte de la ciudadanía. Esa mejoría y esas nuevas expectativas, más allá de la dimensión formal y electoral, hoy interpelan con mayor fuerza la necesidad de afianzar la calidad de las democracias (Morlino, 2014).

En ese contexto, tras dos décadas o más de vida en democracia, ¿qué evidencia se puede recoger hoy acerca del apego de los jóvenes a la participación política en general y a la democracia en América Latina? ¿Cuál ha sido su evolución en el tiempo? ¿Es posible esbozar patrones similares en toda la región? ¿Son la política y la vida democrática consideradas vehículos de inclusión y mayor igualdad por parte de los jóvenes? ¿Cuáles son las prioridades de política pública de las personas jóvenes? ¿Se han mantenido en el tiempo divergencias claras entre los patrones característicos de jóvenes y adultos? En el presente capítulo se intentará reunir algunos elementos de respuesta a estas preguntas.

Para ello, sobre la base de información del Latinobarómetro (2000-2013) y de bibliografía secundaria, a continuación se ofrece un panorama regional de la valoración y la participación juvenil en la vida pública. Tal opción tiene ventajas y limitaciones metodológicas que conviene explicitar desde el inicio. Las encuestas Latinobarómetro son encuestas de opinión basadas en muestras nacionales significativas, pero con una representatividad limitada de la población juvenil y, por lo tanto, no implican una concordancia necesaria con las opiniones de la mayoría de los jóvenes. Sin embargo, existen pocas fuentes de información que permitan comparar en los mismos términos y temáticas a los países de la región, y menos todavía en dos puntos del tiempo. Por lo tanto, sopesando ambos aspectos y privilegiando la búsqueda y la comparación a nivel regional, los principales énfasis y aportes consisten en ofrecer un panorama no estático, procurando abordar su evolución en el tiempo (entre 2000 y 2013) y contrastando los patrones de participación de las personas de entre 16 y 29 años con los 
de las personas de 30 años y más. Sin pretender una representatividad exhaustiva, se intenta aportar al debate y a la profundización de la investigación en torno a la participación política de los jóvenes y sus principales preocupaciones, en el contexto de las democracias recientes y las desiguales que caracterizan a la región.

Como se verá en las siguientes secciones, en la mayoría de los países, los jóvenes votan con menor frecuencia que los adultos, desconfían en mayor medida de instituciones como el Congreso o los partidos en comparación con otras instituciones, se manifiestan insatisfechos con el funcionamiento de la democracia y, en la mayoría de los casos, creen con menor intensidad que antes que esta constituya siempre la mejor forma de gobierno. No obstante, el panorama de la región es heterogéneo y varios indicadores apelan a un contraste no siempre tan marcado entre adultos y jóvenes. Por ejemplo, las personas jóvenes no se muestran mucho menos interesadas en la política que los adultos, como tampoco ignoran el importante papel del Congreso o los partidos para el buen funcionamiento de la democracia, ni son indiferentes a una serie de temas e intereses por los que se declaran más dispuestos a movilizarse que las personas adultas. De hecho, la mayor disposición a movilizarse a favor de diversos temas y su protagonismo en nuevas formas de movilización constituyen una llamada de atención sobre la necesidad de ampliar los espacios de participación de las personas jóvenes con miras a una mayor inclusión social.

\section{A. Participación electoral y movilización de las personas jóvenes}

El interés de los jóvenes por la política es bajo, aunque no mucho menor que el de los adultos de 30 años y más (véase el gráfico V.1). Los datos disponibles del Latinobarómetro en 2013 revelan que el 72\% de los jóvenes se declaraba poco o nada interesado en la política y el promedio para la población adulta era prácticamente idéntico $(71 \%)^{3}$. Tales porcentajes iban desde un $88 \%$ en el caso de Chile hasta un $66 \%$ en el caso del Paraguay, y Venezuela (República Bolivariana de) era el único país en donde la mitad de los jóvenes se declaraba poco o nada interesado. El grado de interés de los jóvenes comparado con el de la población adulta varía de un país a

Promedio simple para 18 países de la región sobre la base de la encuesta Latinobarómetro 2013. La pregunta se plantea en el cuestionario de la siguiente forma: “¿Cuán interesado está usted en la política?". Originalmente, la pregunta cuenta con seis alternativas de respuesta: "no sabe", "no responde", "muy interesado", "algo interesado", "poco interesado", "nada interesado". A los efectos de la presentación de los datos, no obstante, las opciones fueron recodificadas en "muy o algo interesado" y "poco o nada interesado". 
otro. Destacan Chile y el Uruguay como los países donde se observa mayor desinterés de la población juvenil respecto de los adultos. También hay una serie de países donde los jóvenes declaran mayor interés que los mayores de 30 años, como es el caso de Bolivia (Estado Plurinacional de), Colombia, Costa Rica, Nicaragua (donde el desinterés de toda la población por la política es de los menos elevados) y el Perú. No obstante, las diferencias entre adultos y jóvenes suelen ser modestas y - con la excepción de la República Bolivariana de Venezuela- el rasgo dominante parece ser un desinterés generalizado por el tema.

\section{Gráfico V.1 \\ América Latina (18 países): poco o ningún interés en la política de los jóvenes de 16 a 29 años y los adultos de 30 años y más, 2013 ${ }^{\text {a }}$}

(En porcentajes)

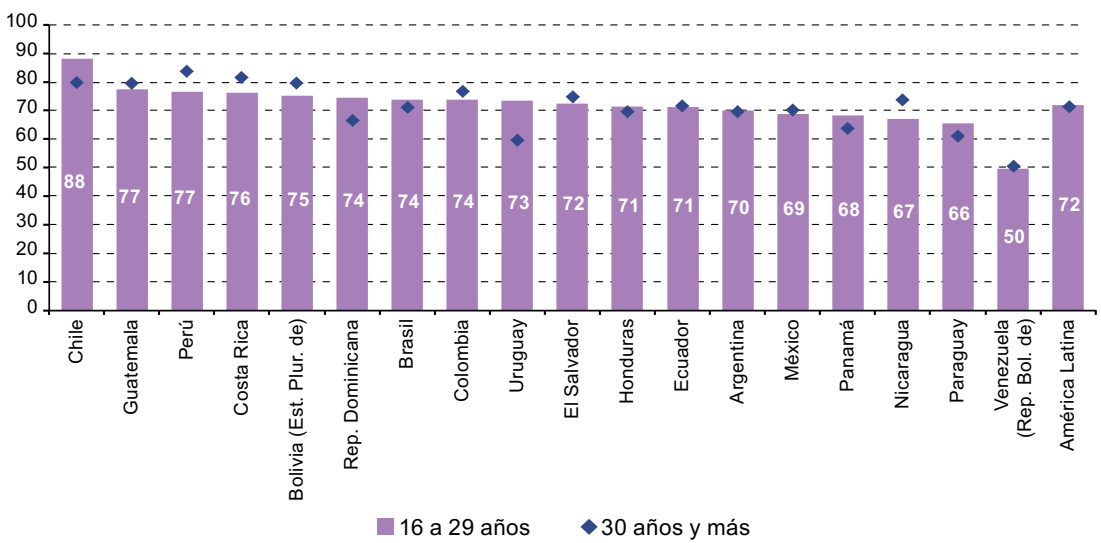

Fuente: Comisión Económica para América Latina y el Caribe (CEPAL), sobre la base de tabulaciones especiales de la encuesta Latinobarómetro de 2013.

Nota: La pregunta se plantea en el cuestionario de la siguiente forma: "¿Cuán interesado está usted en la política?". Originalmente, la pregunta cuenta con seis alternativas de respuesta: "no sabe", "no responde", "muy interesado", "algo interesado", "poco interesado" y "nada interesado". A los efectos de la presentación de los datos, no obstante, las opciones fueron recodificadas en "muy o algo interesado" y "poco o nada interesado".

a Los países están presentados en orden descendente, según el porcentaje de jóvenes que declararon en 2013 estar poco o nada interesados por la política.

Un segundo indicador mucho más claro de participación política se relaciona con el voto en las últimas elecciones presidenciales: los jóvenes declaran mayoritariamente haber votado, pero con mucha menor frecuencia que los adultos. Esto se debe a un fenómeno de exclusión por razones de edad, pero también de autoexclusión en el caso de quienes tienen la edad y cumplen los requisitos administrativos, pero deciden no votar. Destacan negativamente los casos de Chile y de varios países centroamericanos donde los jóvenes que votan están cerca o por debajo del $50 \%$ (véase el gráfico V.2). 


\section{Gráfico V.2}

América Latina (17 países): jóvenes y adultos que declaran haber votado en la última elección presidencial, 2000-2013 ${ }^{\text {a }}$

(En porcentajes)

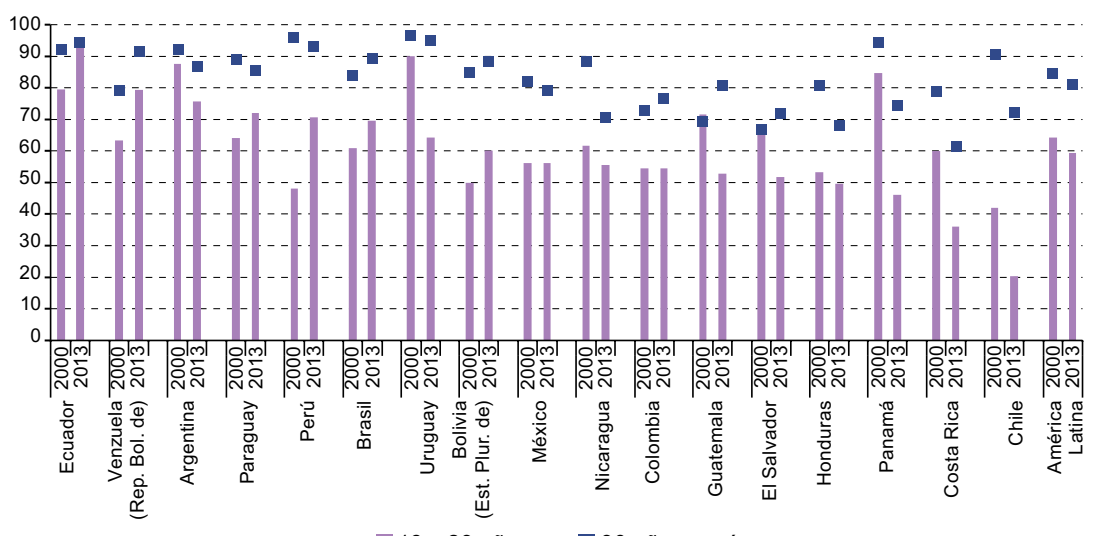

16 a 29 años $\quad \square 0$ años y más

Fuente: Comisión Económica para América Latina y el Caribe (CEPAL), sobre la base de tabulaciones especiales de la encuesta de Latinobarómetro de 2000 y 2013.

Nota: Los valores que suman el total de casos que no votaron incluyen también a quienes no pudieron asistir, quienes no cumplen con los requisitos para votar y quienes no quisieron votar, entre otros.

a Los países están presentados en orden descendente, según el porcentaje de jóvenes que declararon en 2013 haber votado en la última elección presidencial.

En términos de la evolución de la participación electoral declarada por la población joven, es relevante destacar algunos países donde la reducción del porcentaje ha sido muy elevada en la última década, como es el caso de Chile y el Uruguay en el Cono Sur, lo que coincide con el menor interés por la política, y de Costa Rica, El Salvador, Guatemala y Panamá en Centroamérica. Por el contrario, hay algunos países como Bolivia (Estado Plurinacional de), el Ecuador, el Perú y Venezuela (República Bolivariana de), donde la tendencia ha sido la opuesta en la última década y se observa un notable incremento de la participación juvenil en el voto.

La baja frecuencia con que los jóvenes encuestados declaraban en 2013 trabajar para un partido o candidato, porcentaje que oscilaba entre poco más de $14 \%$ en el caso del Brasil y apenas un 3\% en Chile (véase el gráfico V.3), es otra indicación del poco interés juvenil en la política convencional. En prácticamente todos los casos, los adultos de 30 años y más declaraban en mayor medida haber trabajado para un partido o candidato, con diferencias más marcadas en Costa Rica, Honduras, Panamá y la República Dominicana. Con la excepción de los casos mencionados, el contraste entre personas jóvenes y adultas no es tan marcado en la mayoría de los países: a nivel de la región, el promedio en el caso de las personas jóvenes era del 8\%, ligeramente menor al 10\% observado entre los adultos. 


\section{Gráfico V.3}

América Latina (18 países): frecuencia de trabajo para un partido político

o candidato, por tramo de edad, $2013^{\text {a }}$

(En porcentajes)

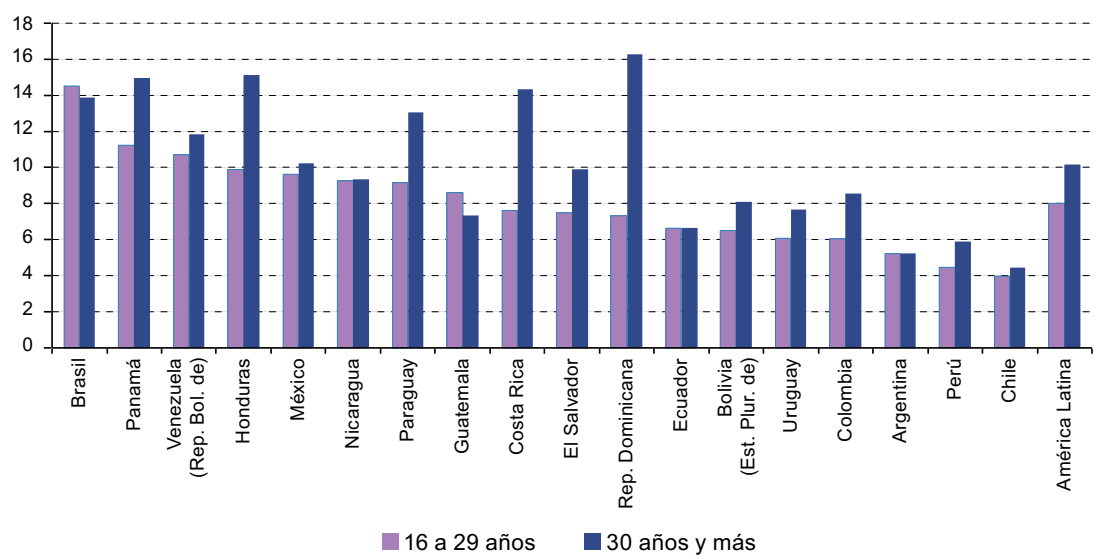

Fuente: Comisión Económica para América Latina y el Caribe (CEPAL), sobre la base de tabulaciones especiales de la encuesta Latinobarómetro de 2013.

a Los países están presentados en orden descendente, según el porcentaje de jóvenes que en 2013 declararon trabajar con frecuencia para algún partido o candidato.

Más allá de la esfera propiamente política, en numerosos estudios también se ha señalado un distanciamiento de la participación en otro tipo de organizaciones. En las publicaciones de la Organización de las Naciones Unidas para la Educación, la Ciencia y la Cultura (UNESCO), se destaca que "la inmensa mayoría de los jóvenes latinoamericanos y caribeños se encuentra al margen de las asociaciones y los movimientos juveniles existentes (entre un $5 \%$ y un $20 \%$ según los países, siendo abrumadora mayoría las organizaciones deportivas y religiosas), en lo que podría considerarse una transición a nuevas formas de participación juvenil y de entender el compromiso o actuar ciudadanos" (CEPAL, 2014, pág. 162).

En el caso de los jóvenes, la movilización social, el ejercicio del voto o la autoexclusión de ambas acciones son un indicador de actitudes, ya sea de adhesión, indiferencia o aversión a la vida pública y la democracia. Al mismo tiempo, en el caso de los jóvenes menores de edad, no votar también puede expresar situaciones de exclusión política cuando se trata de personas no necesariamente indiferentes o adversas a la participación electoral, pero impedidas de participar debido a los requisitos etarios para acceder a la ciudadanía política plena. En principio, no obstante, la movilización social no tiene restricciones formales equiparables. Una aproximación a esta es el porcentaje de jóvenes que declaraba haber participado en una manifestación al menos una vez en el último año (véase 
el gráfico V.4). A nivel regional, en el período 2000-2013, dicho porcentaje se mantuvo en torno al $26 \%$, con una frecuencia levemente mayor en comparación con los adultos de 30 y más años.

\section{Gráfico V.4 \\ América Latina (17 países): jóvenes y adultos que declaran haber participado en manifestaciones al menos una vez en el último año, 2000-2013 ${ }^{\text {a }}$ (En porcentajes)}

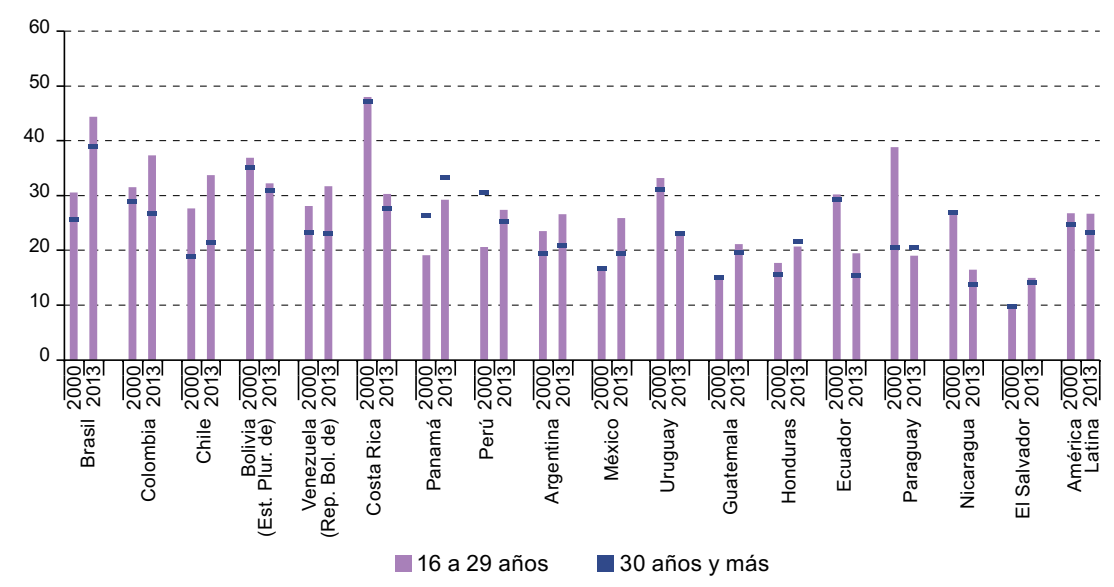

Fuente: Comisión Económica para América Latina y el Caribe (CEPAL), sobre la base de tabulaciones especiales de la encuesta Latinobarómetro de 2000 y 2013.

a Los países están presentados en orden descendente, según el porcentaje de jóvenes que en 2013 declararon haber participación en al menos una manifestación.

No obstante, la región presenta gran heterogeneidad. En 2013, el porcentaje que declaraba haber participado en una manifestación al menos una vez en el último año oscilaba entre un $44 \%$ en el Brasil y un $15 \%$ en El Salvador. En 11 países, dicho porcentaje aumentó, mientras que en 6 mostró una considerable reducción. Destacan los casos de Bolivia (Estado Plurinacional de), el Brasil, Chile, Colombia, Costa Rica y Venezuela (República Bolivariana de), con niveles de participación en manifestaciones del 30\% o más. Por el contrario, en la mayoría de los países centroamericanos se apreciaban niveles más bajos, en torno al $20 \%$ o menos. La participación en manifestaciones en Costa Rica, aunque continua siendo relativamente elevada en comparación con otros países, bajó casi 18 puntos porcentuales entre 2000 y 2013.

Ahora bien, ¿qué tan vasto es el contingente de jóvenes que está fuera de la participación electoral y la movilización social? En diversos estudios se ha buscado asociar participación electoral con movilización social (FLACSO/IDEA Internacional, 2013) con el fin de identificar a aquellos jóvenes que: i) votan y se movilizan; ii) votan, 
pero no se movilizan; iii) no votan, pero se movilizan; iv) no votan y no se movilizan (los que serían una suerte de "marginales" de la política). Quienes votan y se movilizan en forma simultánea ejercen una estrategia de "voz" en la esfera pública, con una participación política convencional como electores, pero también a través de una participación directa como ciudadanos movilizados (Hirschman, 1995). Quienes solo votan sin movilizarse corresponden a un perfil de "voz con lealtad", en el sentido de que tienen una participación como electores, cumpliendo con uno de los deberes básicos de los ciudadanos en democracia, mas no al grado de participar en alguna movilización colectiva. Por el contrario, quienes se movilizan pero no votan representan un grupo con una estrategia de "voz sin lealtad", en el sentido de que participan de forma activa y directa en la vida pública aunque no necesariamente a partir de una adhesión a las modalidades convencionales de participación electoral $1^{4}$. Por último, quienes no votan ni se movilizan son un grupo "al margen" y se encuentran alejados de la participación electoral y de la movilización social, ya sea por indiferencia, por insatisfacción con los canales existentes de participación o por estar excluidos de estos. Lo expuesto no implica que en este último grupo y en los demás deban descartarse la creación y el uso activo de otros canales de expresión y búsqueda de sentido.

Contrastar los patrones de participación de jóvenes y adultos de 30 y más años en el período 2000-2013 arroja luz sobre el orden de magnitud entre diferentes actitudes hacia la participación política y en qué medida puede vislumbrarse entre los jóvenes una categoría de personas que no votan ni se manifiestan (los que se encuentran en una situación "al margen"). Como se aprecia en el gráfico V.5, en la región predominan dos grandes grupos entre las personas jóvenes: el mayor corresponde a quienes solamente votan (un $42 \%$ en 2013), seguido por el grupo "al margen", que no vota ni se moviliza (un 31,3\% en 2013). En tercer lugar, aparecen quienes votan y han participado en una manifestación al menos una vez (un 17,4\% en 2013), seguidos finalmente por quienes no votan, pero sí se han manifestado $(9,3 \%)$. El principal cambio observado durante el período es un leve aumento del porcentaje de quienes no votan ni se movilizan (del $27,3 \%$ al $31,3 \%$ ) y un descenso de quienes solo votan (del $45,9 \%$ al $42,0 \%$ ). El principal elemento distintivo con respecto a los adultos de 30 años y más es un contingente mucho menor que está al margen, como también una importancia marginal de quienes no votan y han participado exclusivamente mediante la movilización.

\footnotetext{
En el caso del grupo de jóvenes menores de edad, podría encontrarse quienes desearían votar, pero no pueden debido a los requisitos etarios o administrativos requeridos para ejercer el derecho a voto.
} 


\section{Gráfico V.5}

América Latina (promedio simple de 17 países): jóvenes y adultos que declaran haber votado en la última elección y haber participado en una manifestación al menos una vez en el último año, 2000-2013

(En porcentajes)

A. Jóvenes de 16 a 29 años

2000

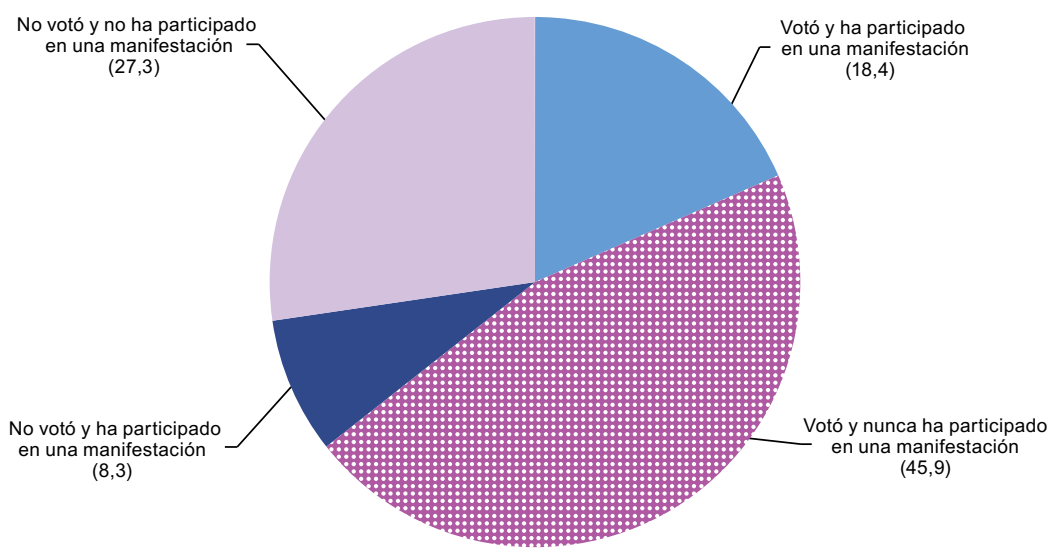

2013

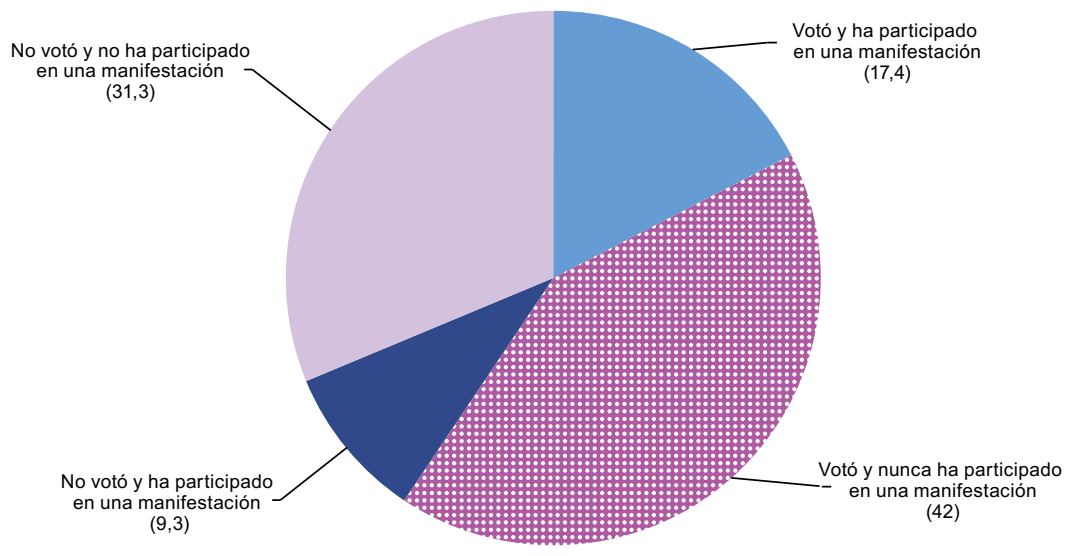


Gráfico V.5 (conclusión)

B. Adultos (30 años y más)

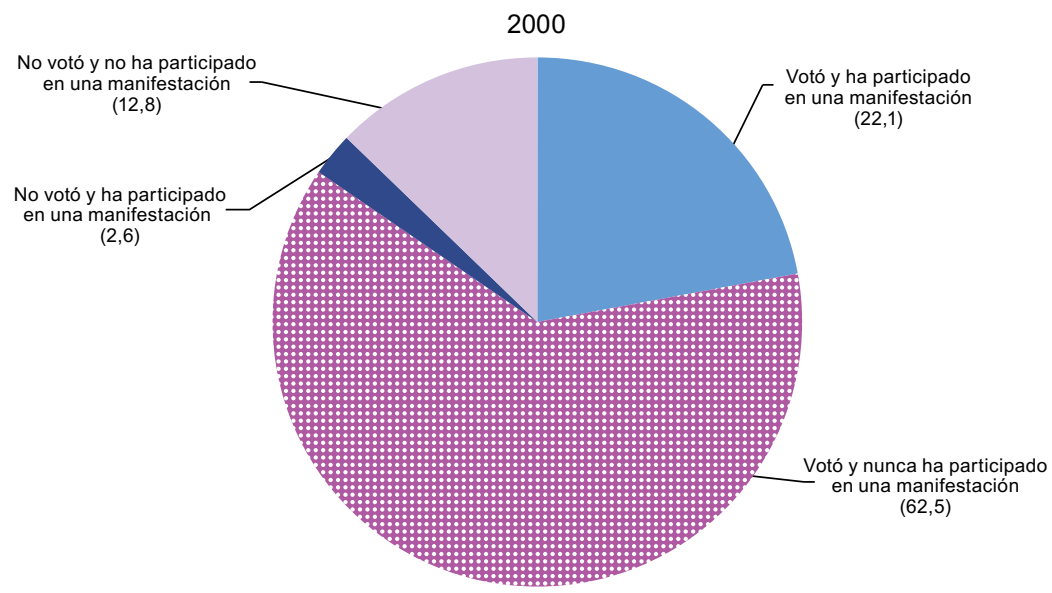

2013

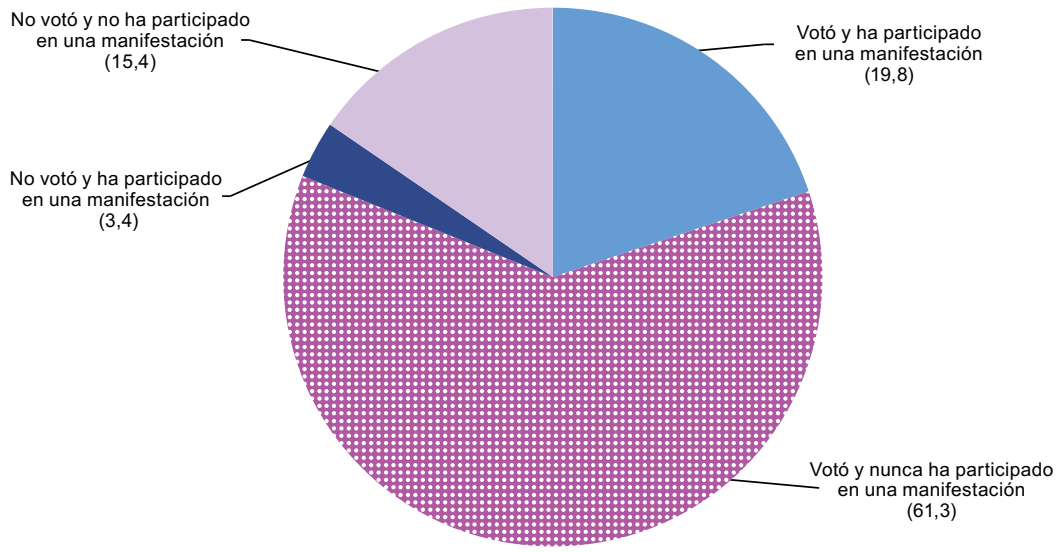

Fuente: Comisión Económica para América Latina y el Caribe (CEPAL), sobre la base de tabulaciones especiales de la encuesta Latinobarómetro de 2000 y 2013.

Nota: Los valores que suman el total de casos que no votaron incluyen también a quienes no pudieron asistir, quienes no cumplen con los requisitos para votar y quienes no quisieron votar, entre otros.

El contingente de personas que se mantienen al margen, así como el de jóvenes que no votan, pero han participado en alguna manifestación, varía considerablemente de un país a otro (véase el gráfico V.6). Destaca el caso de Chile, donde en 2013 un 54\% de los jóvenes no había votado ni se había movilizado, así como los de la mayoría de los países centroamericanos en los que dicho porcentaje oscila entre 
el 38\% y el $48 \% 5$. En el otro extremo se encuentran la Argentina, el Brasil, el Ecuador y Venezuela (República Bolivariana de), con porcentajes comparativamente más bajos. En casi todos los casos, y en ambos puntos del tiempo, los porcentajes de jóvenes que no votan y no se movilizan eran mayores que los de los adultos, lo que confirma una mayor distancia - por exclusión o autoexclusión- de la participación política. Sin embargo, la evolución en el tiempo de quienes no votan ni se han movilizado revela tendencias encontradas. En un grupo importante de países de Centroamérica y del Cono Sur (Argentina, Chile, Costa Rica, El Salvador, Guatemala, Nicaragua, Panamá y Uruguay), dicho porcentaje aumentó considerablemente. De la misma forma, el porcentaje de este grupo se redujo notablemente en cinco países sudamericanos: Bolivia (Estado Plurinacional de), Brasil, Ecuador, Perú y Venezuela (República Bolivariana de). Por último se destaca el caso de Chile, donde un porcentaje elevado ( $26 \%$ ) de jóvenes declaraba no votar, pero sí haberse movilizado, un rasgo que se describe en el recuadro V.3.

\section{Gráfico V.6 \\ América Latina (17 países): jóvenes y adultos que no votaron en la última elección, según si declaran haber participado en una manifestación al menos una vez en el último año, 2000-2013 ${ }^{\text {a }}$} (En porcentajes)

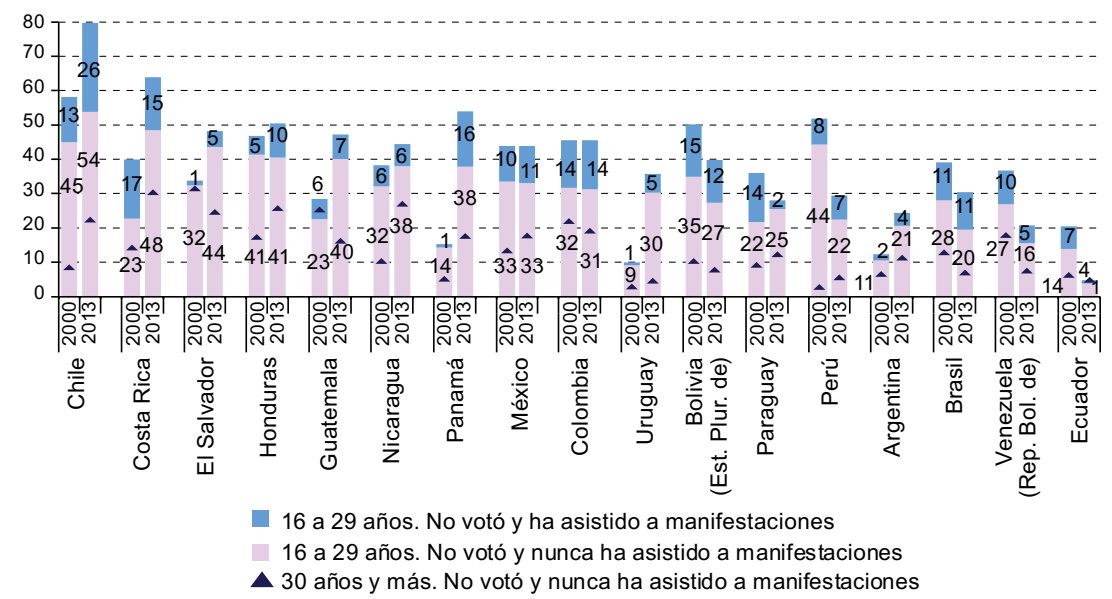

Fuente: Comisión Económica para América Latina y el Caribe (CEPAL), sobre la base de tabulaciones especiales de la encuesta Latinobarómetro de 2000 y 2013.

a Los países están presentados en orden descendente, según el porcentaje de jóvenes que en 2013 declaró no haber votado y no haberse manifestado.

En el caso de Chile, sin embargo, hay que tener en cuenta que entre ambas mediciones se implementó un cambio en la ley sobre votaciones. Se cambió el sistema de inscripción voluntaria al registro electoral por uno automático para todos los ciudadanos mayores de 18 años y se pasó de un sistema de votación obligatoria a un sistema de votación voluntaria. Esto puede reflejar el significativo aumento de personas que dejaron de votar, tanto entre la juventud como en la población general. 
Lo expuesto muestra que existe un margen para ampliar la participación política de los jóvenes. Para ello podrían buscarse vías tanto para la movilización como para la participación electoral, especialmente en algunos países que además exhiben un proceso de creciente distanciamiento con la política convencional en la última década. Este punto se retoma más adelante en relación con las recomendaciones que permitirían levantar las barreras discernibles en cada contexto, comenzando por equiparar la edad para votar y ser candidato, entre otros aspectos. También apunta a la pregunta acerca de cómo estos patrones de participación política se vinculan con actitudes individuales, los niveles de confianza en las instituciones y el apego a la democracia, características que pueden conformarse de manera muy distinta en cada país. La evolución en esta materia ha sido más bien negativa en países del Cono Sur (Argentina, Chile y Uruguay) y de Centroamérica, y positiva en los casos del Brasil, el Ecuador y Venezuela (República Bolivariana de).

En suma, entre las personas jóvenes hay signos claros de desafección hacia la participación política convencional, aunque no necesariamente más intensos que entre los adultos, ya que el interés por la política es muy escaso y la frecuencia de trabajo en los partidos políticos es baja en ambos grupos de edad. Hay diferencias más notorias en la participación electoral, pues los jóvenes votan con menor frecuencia $y$, comparativamente, se sitúan al margen de la participación convencional y no se han movilizado.

\section{B. Actitudes individuales, confianza en las instituciones y apego a la democracia}

La aparente desafección de las personas jóvenes hacia la participación política convencional se ve reflejada en un alto grado de cuestionamiento y desconfianza hacia las instituciones, pese a que en diversos estudios se ha subrayado la actitud individual más positiva u optimista de las personas jóvenes en comparación con los adultos, que confían en que sus habilidades y capacidades van a redundar en mejores condiciones futuras tanto para ellos mismos como para sus países (OIJ y otros, 2013; CEPAL/ UNFPA, 2011). Como se verá a continuación, en los últimos años se ha confirmado un descenso en la confianza de los jóvenes en las instituciones, especialmente las políticas, así como un menor apego a la democracia.

Si se consideran algunos datos, como la apreciación de la situación económica del país y las perspectivas económicas para el siguiente año, ese rasgo de desapego y desconfianza se corrobora y mantiene en el tiempo. Estas opiniones, por definición subjetivas, no se correlacionan solamente con la evolución de las condiciones materiales de existencia expresadas, por ejemplo, en las tasas de crecimiento económico o los niveles absolutos 
de pobreza, sino también con la sensación de empoderamiento o agencia y la apreciación de las condiciones propias con respecto a las de otras personas y del país (Corporación Latinobarómetro, 2013).

Con respecto a la apreciación sobre la situación económica del país, se observa una actitud más positiva por parte de las personas jóvenes en ambos puntos del tiempo en comparación con la población de 30 años y más (véase el gráfico V.7). Por una parte, se destaca que la percepción sobre la situación económica de cada país entre 2000 y 2013 mejoró a nivel regional. En general, el porcentaje que la consideraba mala cayó considerablemente y aumentó el de quienes consideraban la situación como regular o buena. En ambas tendencias, no obstante, se observan diferencias entre jóvenes y no jóvenes. En general, los primeros tienden a considerar la situación como mala con menor frecuencia y como buena o regular con mayor frecuencia en ambos puntos del tiempo.

\section{Gráfico V.7}

América Latina (promedio simple de 17 países): apreciación de la situación económica del país, 2000-2013

(En porcentajes)

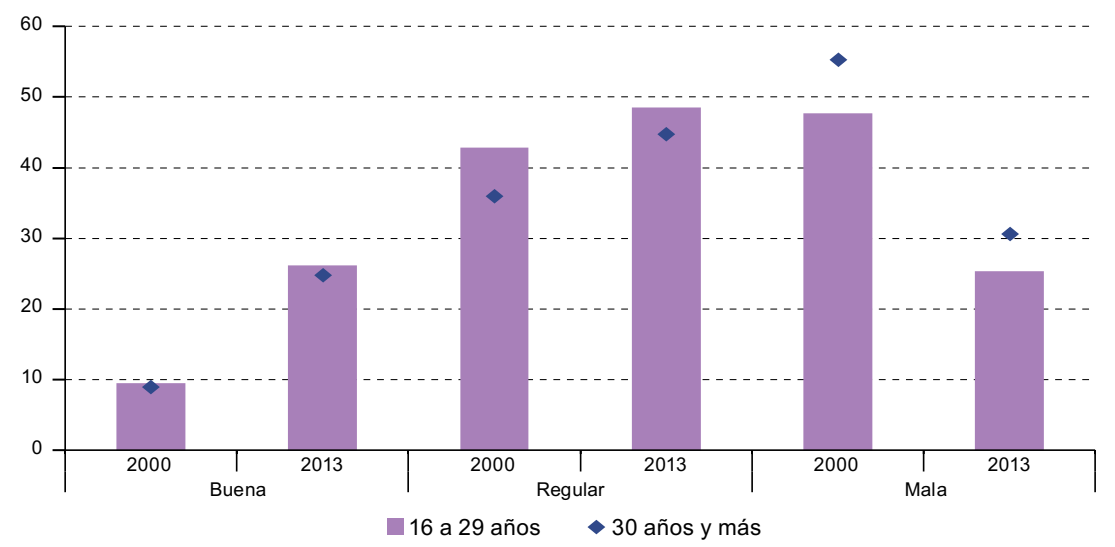

Fuente: Elaboración propia, sobre la base de procesamientos especiales de la encuesta Latinobarómetro de 2000 y 2013.

Con respecto a la apreciación sobre la situación económica personal y familiar para los siguientes 12 meses en 2013, destaca una actitud más positiva por parte de las personas jóvenes (véase el gráfico V.8). En la mayoría de los países, la expectativa de que dicha situación sería positiva superaba el 50\%, con la excepción de El Salvador, Honduras y Venezuela (República Bolivariana de). Por otra parte, tales expectativas eran más frecuentes entre los jóvenes que entre los no jóvenes, con excepción del Paraguay y Venezuela (República Bolivariana de). 


\section{Gráfico V.8}

América Latina (18 países): apreciación de la situación económica personal y familiar como mejor o un poco mejor para los siguientes 12 meses, según país y tramo etario, $2013^{a}$

(En porcentajes)

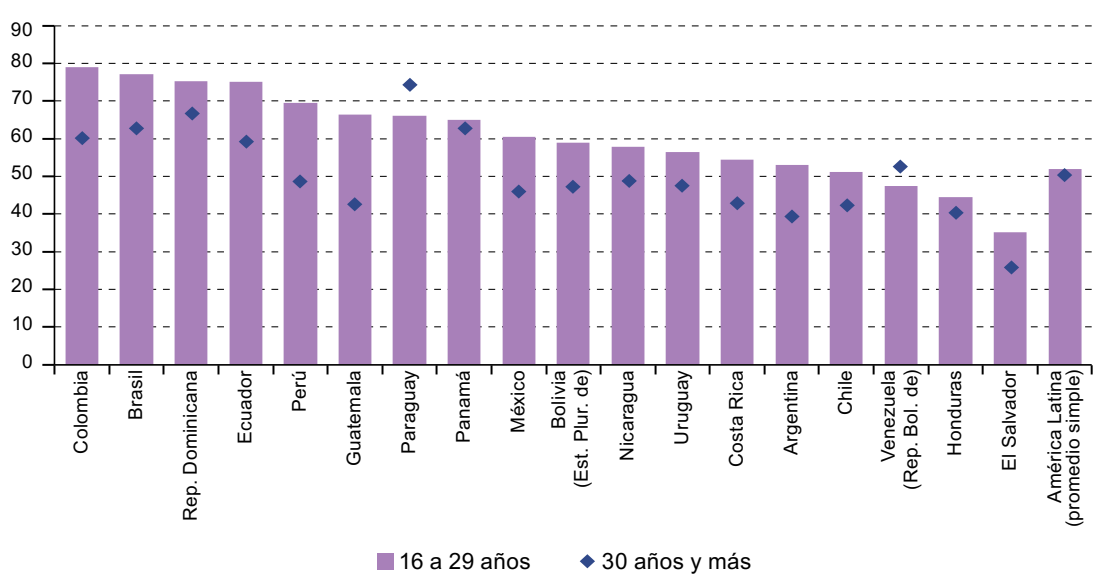

Fuente: Elaboración propia, sobre la base de procesamientos especiales de la encuesta Latinobarómetro 2013. a Los países están presentados en orden descendente, según el porcentaje de jóvenes que consideraban que la situación económica sería mejor o un poco mejor.

Como se mencionó, la actitud juvenil relativamente optimista a nivel individual sigue estando acompañada por una considerable desconfianza y desapego hacia diversas instituciones sociales y, sobre todo, políticas. El Congreso y los partidos políticos despiertan mucha menos confianza entre las personas jóvenes en comparación no solo con otras instituciones tradicionalmente legítimas, como la Iglesia (que, a pesar de ello, despierta menos confianza que en el pasado), sino también con los medios de comunicación (televisión) o instituciones como las Fuerzas Armadas o la Policía (véase el gráfico V.9). Con excepción de la Iglesia, la comparación para la primera década de 2000 muestra una leve mejoría en términos de esta evaluación negativa. La caída de la confianza en la Iglesia es mayor entre los adultos que entre las personas jóvenes, al tiempo que el aumento en la confianza es ligeramente superior en el caso de la televisión y las Fuerzas Armadas. En cualquier caso, durante el período se mantuvo la característica de que, entre estas instituciones, el Congreso y los partidos políticos despertaban, comparativamente, menos niveles de confianza tanto entre adultos como entre jóvenes. 


\section{Gráfico V.9}

América Latina (promedio simple de 17 países): personas de 16 a 29 años y de 30 años y más que declaran tener mucha o ninguna confianza en instituciones seleccionadas, 2000-2013

(En porcentajes)

A. Mucha confianza

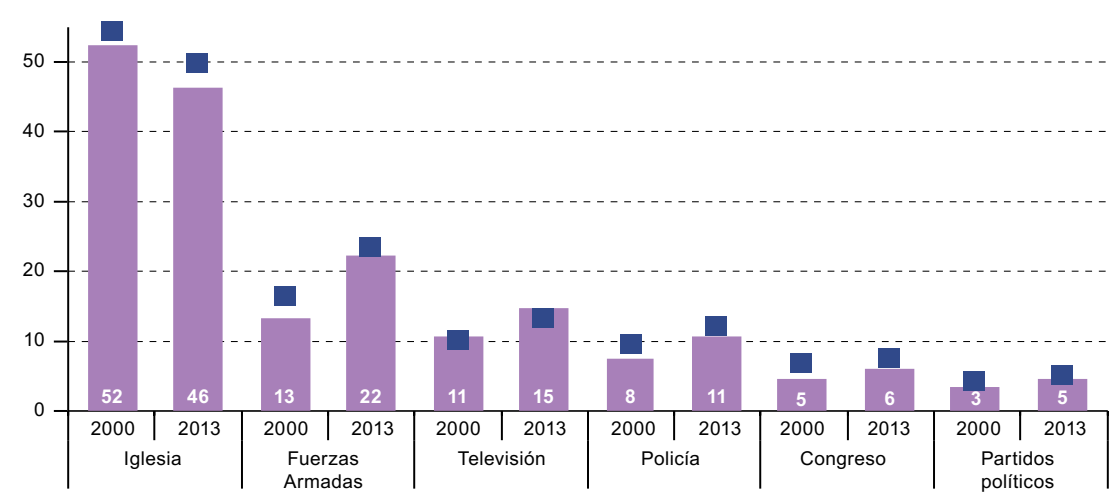

B. Ninguna confianza

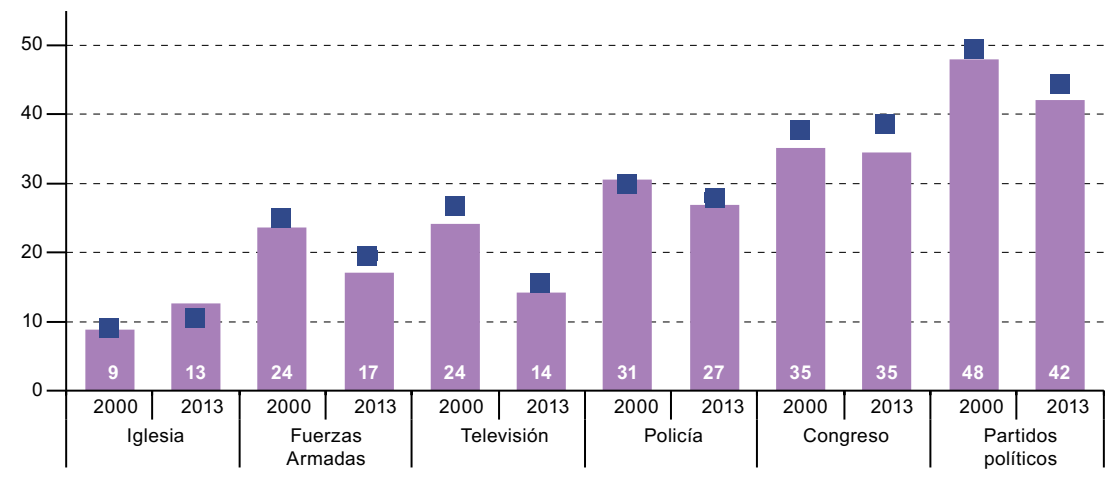

16 a 29 años $\square 30$ años y más

Fuente: Elaboración propia, sobre la base de procesamientos especiales de la encuesta Latinobarómetro de 2000 y 2013. 
El porcentaje de encuestados jóvenes que consideran que una democracia puede funcionar sin el Congreso o los partidos políticos expresa el poco aprecio por dos instituciones básicas de la democracia representativa cuya función es la representación plural de los intereses de las personas, a la vez que un contrapeso necesario frente al poder ejecutivo. Sin embargo, la falta de confianza en el Congreso y los partidos no opaca totalmente su valor. A nivel de la región, el 56\% y el $53 \%$ de las personas jóvenes consideraba, con una gran heterogeneidad entre países, que una democracia no puede funcionar sin estos actores. Algunas particularidades a nivel de los países son llamativas. En el caso del Congreso, sobresalen el Ecuador y Venezuela (República Bolivariana de), donde el porcentaje que lo consideraba necesario pasó de un nivel muy bajo a un nivel muy alto y mayoritario, del $28 \%$ al $78 \%$ y del $30 \%$ al $58 \%$, respectivamente. Con los partidos ocurre algo parecido, ya que se registra un considerable aumento del $26 \%$ al $84 \%$ en Venezuela (República Bolivariana de) y del $27 \%$ al $57 \%$ en el Ecuador. En contraste, en varios países de Centroamérica (Costa Rica, El Salvador y Panamá) y del Cono Sur (Chile y Uruguay) se observa un marcado descenso en ambos indicadores.

En suma, una mirada a los niveles de confianza de los jóvenes encuestados por Latinobarómetro en 2000 y 2013 revela que se mantienen patrones de muy baja confianza hacia las instituciones propiamente políticas, en comparación con instituciones como la Iglesia y las Fuerzas Armadas, o medios de comunicación como la televisión.

Una pregunta fundamental en los estudios de opinión es la apreciación de la democracia como mejor forma de gobierno en cualquier circunstancia, en contraposición con la aceptación de gobiernos autoritarios en ciertos casos, o bien con la indiferencia entre una u otra forma de gobierno. Mientras que la apreciación de la primera alternativa evoca un apego positivo hacia la democracia por encima de cualquier circunstancia o coyuntura de crisis, la segunda opción refleja actitudes más ambivalentes en el sentido de que el quiebre de la democracia puede ser aceptable, cuando menos en ciertas situaciones extremas, lo que implica que esta no siempre es vista como la mejor o única forma legítima de gobierno. La tercera alternativa (indiferencia) indica otro tipo de ambivalencias, como una falta notable de interés y apego por la vida política en sí, o incluso una aversión a la política y un cuestionamiento a la legitimidad de cualquier orden político. A continuación se exploran las preferencias de los jóvenes en la región. 
Con respecto al apego a la democracia, en general, los jóvenes la consideran como la mejor forma de gobierno con una frecuencia similar a la de los adultos (véase el gráfico V.10), con la excepción de Chile y el Uruguay, donde las personas adultas muestran mayor apego. El porcentaje de jóvenes de la región que consideraba la democracia como mejor forma de gobierno pasó del 57,7\% al 53,7\%. En 2013, menos de la mitad de los jóvenes de ocho países consideraba la democracia como mejor forma de gobierno (Brasil, El Salvador, Guatemala, Honduras, México, Nicaragua, Panamá y Paraguay). Además, entre 2000 y 2013, ese nivel de apoyo se redujo en la mayoría de los países. Sobresale un grupo de países con un descenso de entre 6 y 32 puntos porcentuales (Bolivia (Estado Plurinacional de), Costa Rica, El Salvador, Honduras, México, Nicaragua, Panamá, Perú y Uruguay). Solamente en el Brasil, el Ecuador y Venezuela (República Bolivariana de) se observaron aumentos importantes (véanse los gráficos V.10 y V.11).

\section{Gráfico V.10 \\ América Latina (17 países): apoyo a la democracia como mejor forma de gobierno, entre los jóvenes de 16 a 29 años y los mayores de 30 años, 2013 a}

(En porcentajes)

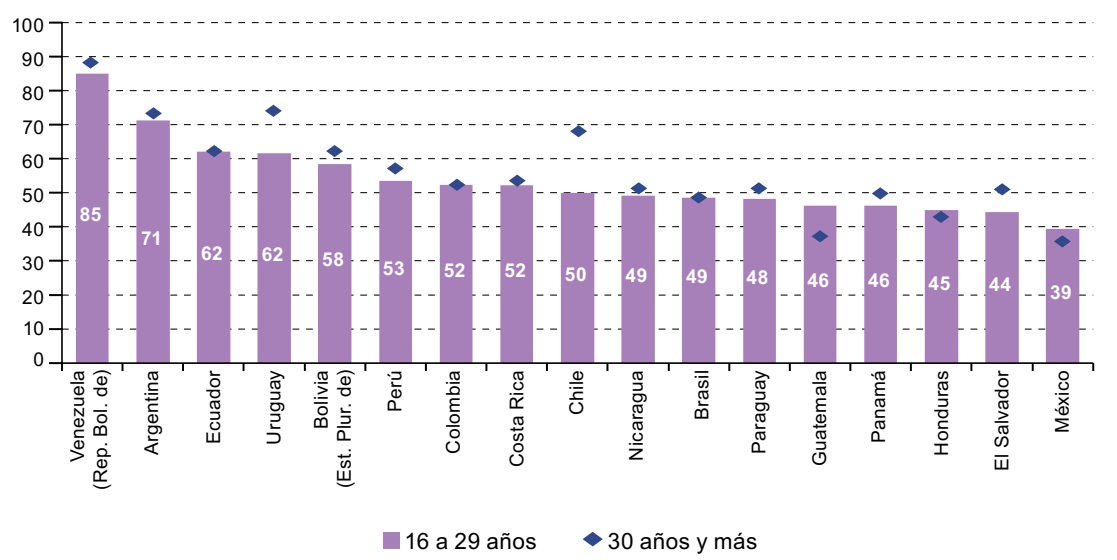

Fuente: Comisión Económica para América Latina y el Caribe (CEPAL), sobre la base de tabulaciones especiales de la encuesta Latinobarómetro 2013.

Nota: La pregunta se plantea en el cuestionario de la siguiente forma: “¿Con cuál de las siguientes frases está Ud. más de acuerdo?". Las alternativas de respuesta son: "La democracia es preferible a cualquier otra forma de gobierno", "En algunas circunstancias, un gobierno autoritario puede ser preferible a uno democrático" y "A la gente como uno, nos da lo mismo un régimen democrático que uno no democrático". Para la encuesta de 2013, las categorías "no sabe" y "no responde" completan el $100 \%$ de los casos.

Los países están presentados en orden descendente, según el porcentaje de jóvenes que declararon a la democracia como preferible a cualquier forma de gobierno en 2013. 
Gráfico V.11

América Latina (17 países): evolución del apoyo a la democracia como mejor forma de gobierno, entre los jóvenes de 16 a 29 años, 2000 y $2013^{\text {a }}$

(En porcentajes)

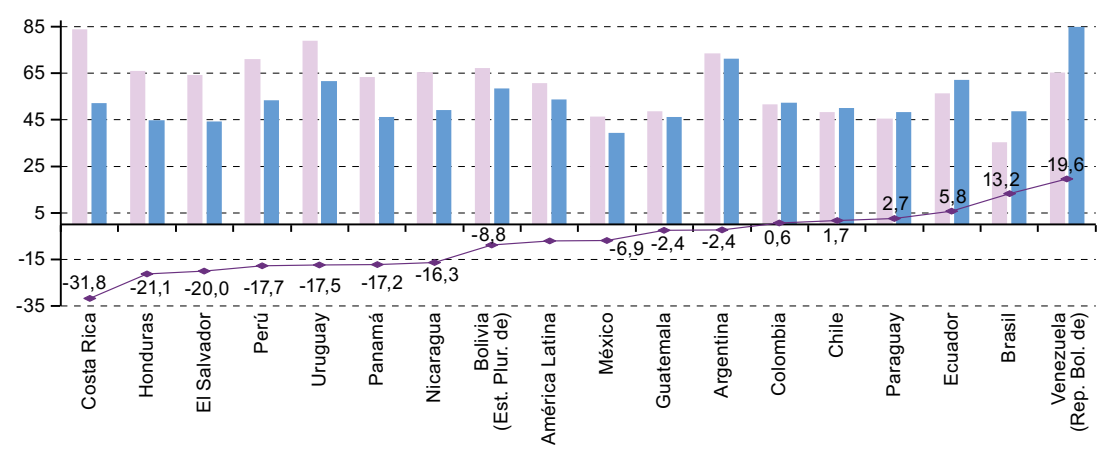

La democracia es preferible a cualquier otra forma de gobierno, 2000

- La democracia es preferible a cualquier otra forma de gobierno, 2013

- Crecimiento o disminución en el apoyo a la democracia de 2000 a 2013

Fuente: Comisión Económica para América Latina y el Caribe (CEPAL), sobre la base de tabulaciones especiales de la encuesta Latinobarómetro de 2000 y 2013.

Nota: La pregunta se plantea en el cuestionario de la siguiente forma: “¿Con cuál de las siguientes frases está Ud. más de acuerdo?". Las alternativas de respuesta son: "La democracia es preferible a cualquier otra forma de gobierno", "En algunas circunstancias, un gobierno autoritario puede ser preferible a uno democrático" y "A la gente como uno, nos da lo mismo un régimen democrático que uno no democrático". Los datos de la República Dominicana no fueron considerados, ya que presenta solo cifras para 2013. Para la encuesta de 2013, las categorías "no sabe" y "no responde" completan el $100 \%$ de los casos.

a Los países están presentados en orden descendente, según la caída en el apoyo a la democracia.

En el gráfico V.12 se muestra una manera de sintetizar estas trayectorias. Por una parte, por encima de la línea diagonal sobresalen los países en donde la preferencia entre los jóvenes por la democracia como mejor forma de gobierno aumentó en el período 2000-2013. Entre las trayectorias positivas destacan los casos del Brasil, el Ecuador y Venezuela (República Bolivariana de), donde en 2013 el apoyo a la democracia aumenta considerablemente. Por debajo de dicha línea están los países en donde el apoyo a la democracia como mejor forma de gobierno se redujo en el período. Entre estos se destacan Costa Rica, El Salvador, Honduras, México, Nicaragua y Panamá en Centroamérica, y Bolivia (Estado Plurinacional de), el Perú y el Uruguay en América del Sur.

Pero esa apreciación se relativiza al observar el nivel de apoyo inicial y final. Los países situados a la izquierda del eje vertical y por debajo del eje horizontal del gráfico V.12 mantuvieron en el período 2000-2013 un nivel de apoyo a la democracia como mejor forma de gobierno inferior al $50 \%$. En el Brasil, el apoyo a la democracia pasó del 35\% al 48\%, pero el país se mantuvo en el grupo de países de relativo bajo apoyo. Si bien los países 
que en 2013 presentaban un apoyo por debajo del 50\% llaman la atención, los casos más preocupantes son los de aquellos que en ambos puntos del tiempo presentaron esa característica. En México, por ejemplo, el apoyo a la democracia como mejor forma de gobierno era del 45\% en 2000 y en 2013 se redujo aún más, al 39\%. De la misma forma, los países situados a la derecha del eje vertical y por encima del eje horizontal son países que, a pesar de sus trayectorias individuales, mantienen un nivel de apoyo a la democracia por encima del 50\%. Pese a los marcados descensos observados en Costa Rica y el Uruguay, ambos países se mantuvieron en este grupo. En el recuadro V.2 se analiza en mayor detalle el caso de Costa Rica.

\section{Gráfico V.12 \\ América Latina (17 países): cambio en el apoyo a la democracia como mejor forma de gobierno, entre los jóvenes de 16 a 29 años, 2000-2013}

(En porcentajes)

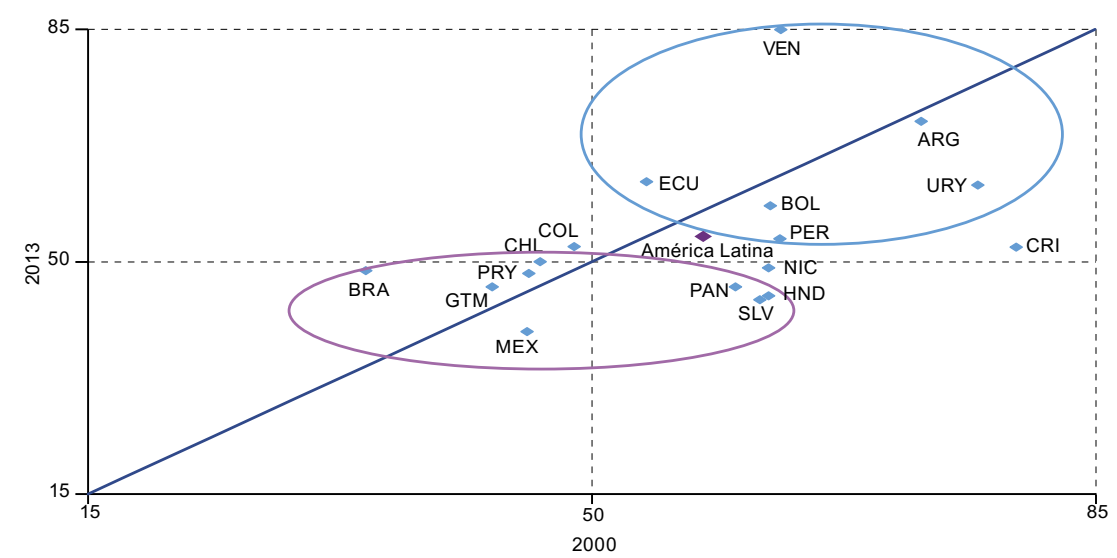

Fuente: Comisión Económica para América Latina y el Caribe (CEPAL), sobre la base de tabulaciones especiales de la encuesta Latinobarómetro de 2000 y 2013.

Nota: La pregunta es planteada en el cuestionario de la siguiente forma: "¿Con cuál de las siguientes frases está Ud. más de acuerdo?". Las alternativas de respuesta son: "La democracia es preferible a cualquier otra forma de gobierno", "En algunas circunstancias, un gobierno autoritario puede ser preferible a uno democrático" y "A la gente como uno, nos da lo mismo un régimen democrático que uno no democrático". Los datos de la República Dominicana no fueron considerados, ya que presenta solo cifras para 2013. Para la encuesta de 2013, las categorías "no sabe" y "no responde" completan el $100 \%$ de los casos.

Un indicador revelador de un apoyo de baja intensidad a la democracia es el cambio en el porcentaje de jóvenes que se declaran satisfechos con el funcionamiento de la democracia (véase el gráfico V.13). A nivel de la región, este porcentaje ascendía a solo el $36 \%$ en 2000 y se mantuvo en un $39 \%$ en 2013 . Por encima de la línea diagonal se encuentran diez países donde el nivel de satisfacción con la democracia aumentó (Argentina, Bolivia (Estado Plurinacional de), Brasil, Chile, Ecuador, El Salvador, Nicaragua, Paraguay, Perú y Uruguay). Por debajo 
de dicha línea hay cinco países, en su mayoría centroamericanos, donde ese nivel de satisfacción descendió (Costa Rica, Guatemala, Honduras, México y Venezuela (República Bolivariana de)). En 2013, con la excepción de la Argentina, el Ecuador, Nicaragua y el Uruguay, la mayoría de las personas jóvenes se declaraba insatisfecha. Al mismo tiempo, la satisfacción con la democracia se redujo en cinco países, sobre todo de Centroamérica.

\section{Recuadro V.2 \\ Costa Rica: desapego juvenil hacia la participación electoral y la democracia, 2013}

En la Encuesta Nacional de Juventudes 2013 y diversos estudios sobre abstencionismo y participación se ratifica que desde fines de 1990 los niveles de confianza y de participación convencional entre la juventud de Costa Rica han disminuido. Según García Fernández y otros (2005), el análisis de las causas del ausentismo electoral en los últimos 50 años permite identificar tres períodos. En primera instancia, los años cincuenta marcan el proceso de consolidación de un nuevo sistema político-electoral. Para la década de 1960 se estabilizó una proporción de abstencionistas en torno a una quinta parte de los ciudadanos, situación que no muestra grandes fluctuaciones hasta la elección de 1998, cuando el abstencionismo llegó al 30\% del padrón electoral. En la elección de 2002 se registró una mayor proporción de jóvenes que no habían votado nunca en comparación con los adultos, en tanto que disminuía la magnitud de quienes votan siempre. Así, muchas de las personas jóvenes que declaraban nunca haber votado se abstuvieron de hacerlo en 2002, o bien incluso en 1998 y 2002, de tal forma que no votaron la primera o las primeras dos veces que tuvieron oportunidad de hacerlo.

La encuesta citada revela, al igual que Latinobarómetro 2013, una valoración decreciente de la democracia como mejor forma de gobierno entre las personas de 15 a 35 años (tramo etario asociado con la juventud en las encuestas de ese país) y un aumento de la indiferencia hacia ese tema. También se observó un descenso en los niveles de confianza hacia los gobernantes de dicho país.

Costa Rica: valoración del sistema democrático por las personas 2007 y jóvenes de 15 a 35 años, según la Encuesta Nacional de Juventudes 2013 (En porcentajes)

\begin{tabular}{|c|c|c|c|c|c|c|}
\hline \multirow[t]{2}{*}{ Pregunta } & \multicolumn{2}{|c|}{ De acuerdo } & \multicolumn{2}{|c|}{$\begin{array}{l}\text { Ni de acuerdo ni } \\
\text { en desacuerdo }\end{array}$} & \multicolumn{2}{|c|}{ En desacuerdo } \\
\hline & 2007 & 2013 & 2007 & 2013 & 2007 & 2013 \\
\hline $\begin{array}{l}\text { "La democracia es el mejor } \\
\text { sistema político que existe" }\end{array}$ & 52,4 & 37,4 & 9,5 & 17,1 & 12,2 & 14,8 \\
\hline $\begin{array}{l}\text { "Tengo confianza } \\
\text { en los gobernantes } \\
\text { costarricenses" }\end{array}$ & 14,1 & 10,7 & 14,2 & 15,6 & 34,1 & 30,5 \\
\hline
\end{tabular}

Fuente: Elaboración propia, sobre la base de los resultados de la primera y segunda Encuesta Nacional de Juventudes de Costa Rica, 2007 y 2013. 
Recuadro V.2 (conclusión)

Según diversos estudios, el aumento de la abstención se explica fundamentalmente mediante variables políticas: el malestar con la política y el distanciamiento de los partidos tradicionales. La pérdida de simpatía hacia los partidos tradicionales se agudizó a partir de 1990 y se destaca que hay una mayor pérdida de seguidores cuando los partidos han estado en el gobierno. El desapego partidario tiende a concentrarse, en el caso de los dos principales partidos, en un sector social relativamente alto, con mayor nivel educativo y mejor situación económica y laboral. Un factor explicativo tiene que ver con las diversas experiencias de vida de una generación respecto de la de sus padres. Hay diferencias, por ejemplo, en la fortaleza de las lealtades partidarias según la cercanía temporal de los eventos que dieron origen al sistema de partidos. En el caso costarricense, las principales fuerzas políticas de la segunda mitad del siglo XX nacen del conflicto armado de 1948. Los jóvenes actuales no solo no vivieron ese proceso, sino que sus padres tampoco lo recuerdan. En una investigación sobre la elección de 1998, Fournier, Cortés y Zeledón (1999) hallaron evidencia del debilitamiento de la tradición política familiar. En la elección de 2002, Gutiérrez Espeleta y otros autores situaron la ruptura con la tradición electoral como el principal factor explicativo de los resultados de ese año y plantearon que es más probable que esa ruptura se originara en las personas más jóvenes, que no tienen vínculos afectivos con las fuerzas políticas de 1948. Otro factor es la experiencia de las personas jóvenes con respecto a los mayores, ya que los primeros no tienen la vivencia o el recuerdo del período de mayor eficacia del Estado de bienestar (década de 1970) y podrían no tener una percepción tan favorable del Estado como las generaciones de ciudadanos de la segunda mitad del siglo XX. Por otra parte, sus condiciones de incorporación al mundo laboral han sido más difíciles que las vividas por las generaciones anteriores.

Por último, en comparación con otros países de la región, Costa Rica históricamente presenta una cultura política con una fuerte adhesión a la democracia (Alfaro-Redondo, Vargas-Cullel y Seligson, 2015). Sin embargo, en las últimas tres décadas, ese nivel de adhesión ha disminuido de manera notoria.

Fuente: Elaboración propia, sobre la base de Jorge E. Segura Arias "Gobiernos locales y participación de las personas jóvenes en puestos de elección popular en Costa Rica, 2010", Revista Derecho Electoral, № 15, enero-junio de 2013; Consejo Nacional de Política Pública de la Persona Joven, Segunda Encuesta Nacional de Juventudes: Informe de principales resultados, San José [en línea] http://www.cpj.go.cr/component/ docman/doc_download/41-segunda-encuesta-nacional-de-juventudes-informe-deprincipales-resultados-costa-rica-2013; Fondo de Población de las Naciones Unidas (UNFPA), 1era encuesta nacional de juventud: Costa Rica 2008. Informe integrado, San José, 2009 [en línea] http://www.cpj.go.cr/docs/encuesta/Informe-final-encuesta.pdf; Jorge Raúl García Fernández y otros, Abstencionistas en Costa Rica: ¿Quiénes son y por qué no votan?, Editorial de la Universidad de Costa Rica, 2005 [en línea] http:// biblioteca.clacso.edu.ar/Costa_Rica/iis-ucr/20120725041855/abstencion.pdf; Gerardo Berthin, Explorando la dinámica de la participación política juvenil en la gobernabilidad local en América Latina, Centro Regional para América Latina y El Caribe, Ciudad de Panamá, 2013; Ronald Alfaro-Redondo, Jorge Vargas-Cullell y Mitchell A. Seligson, "Cultura política en Costa Rica: El declive de largo plazo de las actitudes que favorecen una democracia estable continúa", Perspectivas desde el Barómetro de las Américas: 2015, N ${ }^{\circ} 111$ [en línea] http://www.vanderbilt.edu/lapop/insights/IO911es_V2.pdf; Ana Lucía Gutiérrez Espeleta y otros, "Resquebrajándose una tradición electoral”, Revista de Ciencias Sociales, No 98, San José [en línea] http://163.178.170.74/wp-content/ revistas/98/04-.pdf; y Marco Fournier, Alberto Cortés y Fernando Zeledón, "Elección nacional de 1998: Encuesta de opinión. Informe final”, Maestría Centroamericana en Ciencias Políticas de la Universidad de Costa Rica, 1999. 


\section{Gráfico V.13}

América Latina (17 países): cambio en la cantidad de jóvenes de 16 a 29 años que se declaraban satisfechos con el funcionamiento de la democracia, 2000-2013 ${ }^{\text {a }}$

(En porcentajes)

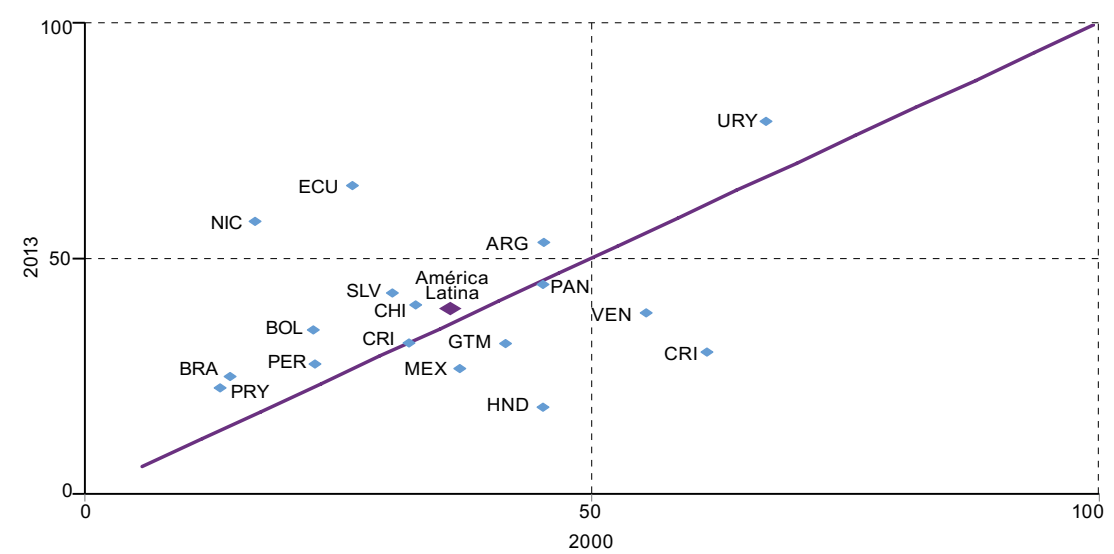

Fuente: Comisión Económica para América Latina y el Caribe (CEPAL), sobre la base de tabulaciones especiales de la encuesta Latinobarómetro de 2000 y 2013.

Nota: La pregunta es planteada en el cuestionario de la siguiente forma: “¿Con cuál de las siguientes frases está Ud. más de acuerdo?". Las alternativas de respuesta son: "La democracia es preferible a cualquier otra forma de gobierno", "En algunas circunstancias, un gobierno autoritario puede ser preferible a uno democrático" y "A la gente como uno, nos da lo mismo un régimen democrático que uno no democrático". Los datos de la República Dominicana no fueron considerados, ya que presenta solo cifras para 2013. Para la encuesta de 2013, las categorías "no sabe" y "no responde" completan el $100 \%$ de los casos.

Si se consideran las otras alternativas a la democracia como mejor forma de gobierno (indiferencia a la forma de gobierno o preferencia por un gobierno no democrático), en la mayoría de los casos predomina la indiferencia (véase el gráfico V.14). En 2013, hasta un 35\% de los jóvenes en México se declaraban indiferentes a la forma de gobierno. Un rasgo positivo es que en los países con niveles relativamente elevados de apoyo a una solución autoritaria en 2000, se observan marcados descensos hacia 2013. Este es el caso del Brasil (del 27\% al 18\%), Chile (del 18\% al $12 \%$ ), Colombia (del 23\% al 16\%), el Paraguay (del 38\% al 31\%) y Venezuela (República Bolivariana de) (del 23\% al 9\%). El considerable aumento del porcentaje de jóvenes que favorecerían en algunas circunstancias un gobierno autoritario ocurre solo en el Perú (del 11\% al 19\%) y en tres países de Centroamérica: Costa Rica (del 7\% al 18\%), El Salvador (del 12\% al 20\%) y Nicaragua (del 7\% al 21\%). 


\section{Gráfico V.14 \\ América Latina (17 países): apoyo a la democracia como mejor forma de gobierno, entre los jóvenes de 16 a 29 años, 2000-2013}

(En porcentajes)

\section{A. 2000}

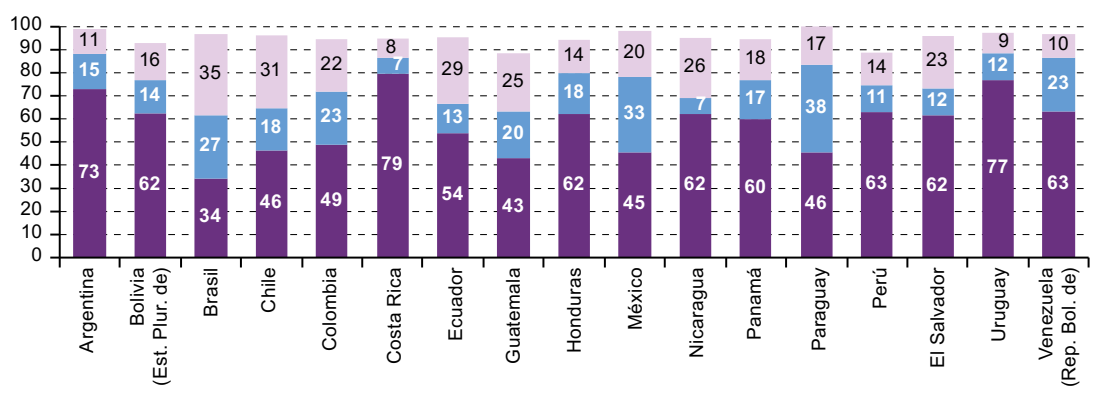

- La democracia es preferible a cualquier otra forma de gobierno

Un gobierno autoritario puede ser preferible a uno democrático

Nos da lo mismo un régimen democrático que uno no democrático

\section{B. 2013}

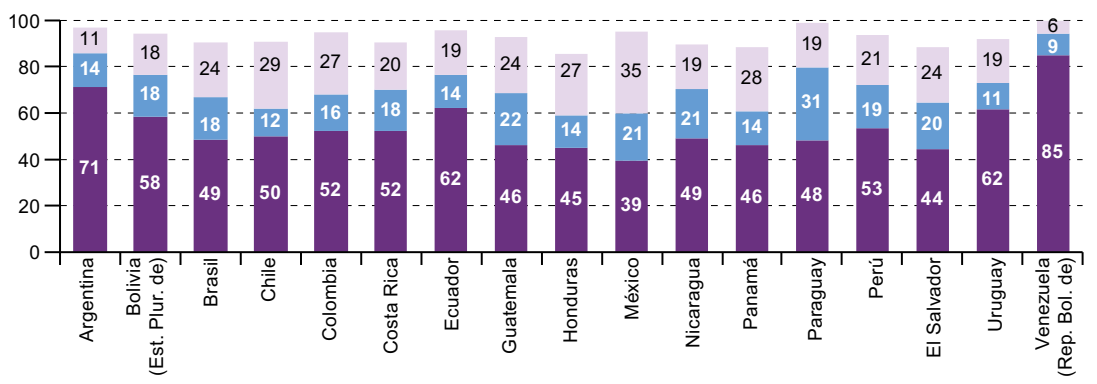

- La democracia es preferible a cualquier otra forma de gobierno

En algunas circunstancias, un gobierno autoritario puede ser preferible

A la gente como uno, nos da lo mismo un régimen democrático o uno autoritario

Fuente: Comisión Económica para América Latina y el Caribe (CEPAL), sobre la base de tabulaciones especiales de la encuesta Latinobarómetro de 2000 y 2013.

Nota: La pregunta es planteada en el cuestionario de la siguiente forma: “¿Con cuál de las siguientes frases está Ud. más de acuerdo?". Las alternativas de respuesta son: "La democracia es preferible a cualquier otra forma de gobierno", "En algunas circunstancias, un gobierno autoritario puede ser preferible a uno democrático" y "A la gente como uno, nos da lo mismo un régimen democrático que uno no democrático". Los datos de la República Dominicana no fueron considerados, ya que presenta solo cifras para 2013. Para la encuesta de 2013, las categorías "no sabe" y "no responde" completan el $100 \%$ de los casos. 
Un último indicador acerca de la valoración de la capacidad representativa de las democracias es la percepción sobre quién gobierna realmente el país (véase el gráfico V.15). En 2013, en la mayoría de los países, un $70 \%$ o más de las personas jóvenes consideraba que quienes gobiernan son los grupos poderosos en su propio beneficio. Solo en tres países los jóvenes consideraban que se gobernaba para el bien de todo el pueblo (Ecuador, Nicaragua y Uruguay), mientras que Bolivia (Estado Plurinacional de), El Salvador y Venezuela (República Bolivariana de) muestran niveles intermedios, por debajo del $70 \%$, con un $55 \%$, un $59 \%$ y un $60 \%$, respectivamente. Todos estos países comparten como rasgo común la llegada y permanencia en el poder de nuevas coaliciones situadas a la izquierda del espectro político, la mayoría de las veces de la mano de liderazgos carismáticos a partir de 2000. En este tema, las opiniones poco optimistas de los jóvenes concuerdan con las de los adultos de 30 años y más. En tal sentido, esta evolución es concordante con estudios que han señalado que si los períodos de amplia deslegitimación de los partidos políticos apresuraron el colapso del sistema partidario con el consiguiente surgimiento de fuertes liderazgos apartidarios, el momento posterior, si se viera acompañado de altos niveles de movilización o contestación social, podría dar surgimiento a nuevas vinculaciones partidarias estables (PNUD/AECID, 2014). No obstante, en la mayoría de los países prevalece una visión poco convencida de que sus gobiernos estaban orientados a favorecer a la mayoría.

\section{Gráfico V.15}

América Latina (18 países): jóvenes de 16 a 29 años y adultos de 30 años y más que consideran que son los grupos poderosos y no el pueblo quienes gobiernan su país, $\mathbf{2 0 1 3}^{\text {a }}$

(En porcentajes)

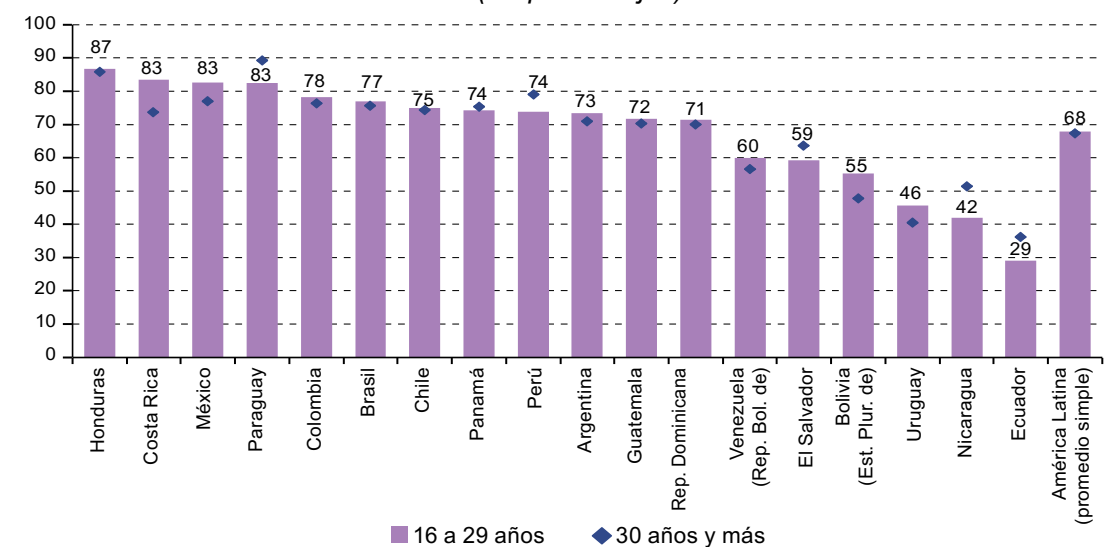

Fuente: Comisión Económica para América Latina y el Caribe (CEPAL), sobre la base de tabulaciones especiales de la encuesta Latinobarómetro de 2013.

Nota: La pregunta es planteada en el cuestionario de la siguiente forma: "En términos generales, ¿diría usted que (país) está gobernado por unos cuantos grupos poderosos en su propio beneficio, o que está gobernado para el bien de todo el pueblo?".

a Los países están presentados en orden descendente, según el porcentaje de jóvenes que declararon que gobiernan los grupos poderosos en su propio beneficio en 2013. 
En suma, el aprecio de los jóvenes por la democracia como mejor forma de gobierno, según lo retrata Latinobarómetro en 2000-2013, ratifica una tendencia a la baja en varios casos, a favor, sobre todo, de la indiferencia por la forma de gobierno, con algunas excepciones como el Brasil, el Ecuador y Venezuela (República Bolivariana de). Particularmente preocupantes son los casos de países centroamericanos y México, donde los niveles de aprecio por la democracia ya eran bajos en 2000 y han seguido descendiendo. No hay que perder de vista, sin embargo, que cada trayectoria nacional responde a dinámicas y ciclos políticos propios que pesan sobre las actitudes de distintos grupos, destacándose cambios en las coaliciones gobernantes que pueden relegitimar o desprestigiar a la democracia como forma de gobierno, y aminorar o atizar tanto la indiferencia como la aceptación de soluciones autoritarias.

En ese escenario, ¿con qué se identifica la democracia? La democracia representativa engloba una tensión perenne entre libertad individual y búsqueda de igualdad entre las personas (Bobbio, 1996). La libertad individual implica una serie de mecanismos de salvaguarda de los derechos de las personas contra la arbitrariedad del Estado, de las organizaciones privadas y públicas, y de otras personas, mientras que la igualdad entre las personas supone asegurar condiciones de existencia y de interacción que generen resultados o niveles de goce de derechos similares. En consecuencia, la forma en que las personas entienden la democracia se inclina por uno u otro polo. A comienzos de la década de 2000, diversos estudios de opinión en América Latina apuntaban a que en esta región, recientemente democratizada, las preferencias manifestadas por las personas tendían a posicionarse más hacia la igualdad, en el sentido de expectativas de igualdad entre las personas y de mejoras de tipo socioeconómico, al menos en comparación con lo observado entonces en América del Norte (Moreno, 2001). También se señalaba una tendencia a que los jóvenes asocien la democracia más frecuentemente con nociones de libertad, protección de las minorías y la libertad de expresión, en lugar de elementos de tipo material o electoral (Moreno, 2001).

Una manera de abordar este tema es explorar el tipo de condiciones que las personas jóvenes asocian con la democracia. Al respecto, en la encuesta Latinobarómetro de 2013 se ofrecen varias preguntas en las que se pide asociar a la democracia con distintos elementos. En cada una de estas preguntas coexisten opciones vinculadas con la libertad individual, el ejercicio del poder político, el bienestar material de las personas y la orientación de las políticas públicas. De acuerdo con esta batería de preguntas, a nivel regional, en cada una de las consultas, la opción más mencionada (pero no necesariamente mayoritaria en términos absolutos) estuvo relacionada con aspectos ligados con la libertad individual y de expresión (véase el gráfico V.16). 


\section{Gráfico V.16 \\ América Latina (18 países): promedio de las cuatro características principales atribuidas por los jóvenes a la democracia, 2013}

(En porcentajes)

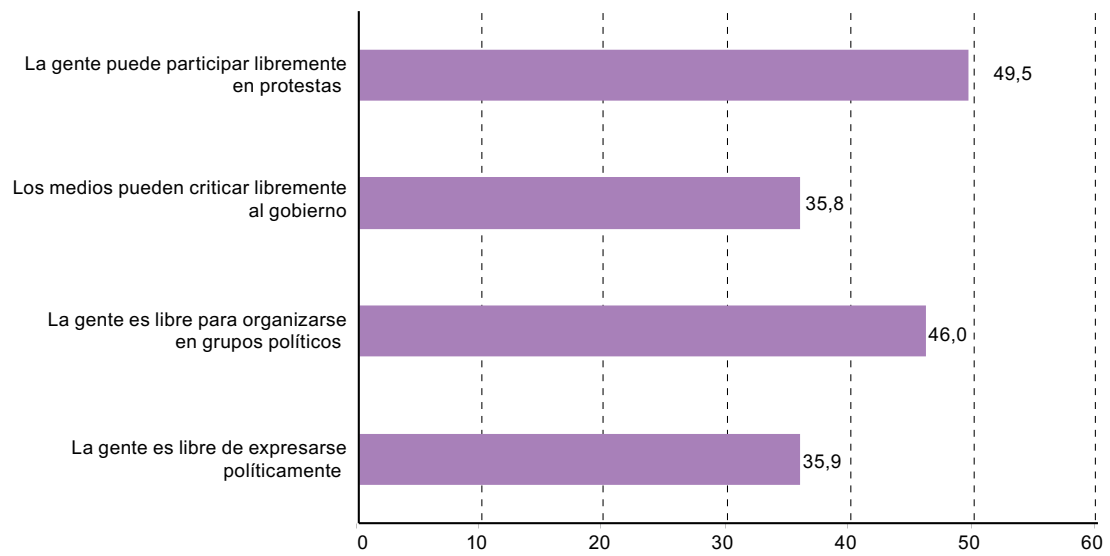

Fuente: Comisión Económica para América Latina y el Caribe (CEPAL), sobre la base de tabulaciones especiales de la encuesta Latinobarómetro de 2013.

Nota: La pregunta en el cuestionario se plantea de la siguiente forma: "Si tuviera que elegir solo una de las cuatro frases siguientes, ¿cuál elegiría como la más representativa de las características de la democracia?". Cada característica pertenece y suma el $100 \%$ de una sola pregunta, por lo que se preguntó lo mismo cuatro veces a los encuestados. No obstante, cada pregunta tenía cuatro alternativas de respuesta (sin contar "no responde", "no entiende la pregunta" y "no puede elegir").

A nivel de países, no obstante se observan algunas variaciones $y$, sobre todo, una diversidad polisémica en cuanto a la noción de democracia. En el cuadro V.1 se muestran las preferencias de alternativas propuestas a la pregunta "Si tuviera que elegir solo una de las cuatro frases siguientes, ¿cuál elegiría como la más representativa de las características de la democracia?". En general, la más mencionada tiene que ver con la libertad: "Los medios pueden criticar libremente al gobierno". En segundo lugar, la característica más mencionada por los jóvenes tuvo que ver con aspectos materiales: "El gobierno asegura oportunidades laborales para todos", mención preferente en los casos de México y el Paraguay. También sobresalen los casos del Ecuador, El Salvador y la República Dominicana, donde la segunda mención correspondía a la opción "El gobierno refuerza la ley y el orden". En el Uruguay, por último, la segunda opción más mencionada era: "Múltiples partidos compiten de manera limpia en las elecciones".

Ante este panorama heterogéneo, pero en general de baja participación, desapego hacia las instituciones políticas y frágil apoyo a la democracia en muchos países, ¿qué tanto están redefiniendo la movilización directa y por vías no convencionales las modalidades tradicionales de participación de las personas jóvenes? 


\section{Cuadro V.1}

América Latina (18 países): promedio de las cuatro características principales que atribuyen los jóvenes a la democracia, 2013

(En porcentajes)

\begin{tabular}{|c|c|c|c|c|}
\hline País & $\begin{array}{l}\text { Los medios } \\
\text { pueden criticar } \\
\text { libremente al } \\
\text { gobierno }\end{array}$ & $\begin{array}{l}\text { El gobierno asegura } \\
\text { oportunidades } \\
\text { laborales para todos }\end{array}$ & $\begin{array}{l}\text { El gobierno } \\
\text { refuerza } \\
\text { la ley y el } \\
\text { orden }\end{array}$ & $\begin{array}{l}\text { Múltiples partidos } \\
\text { compiten de } \\
\text { manera limpia en } \\
\text { las elecciones }\end{array}$ \\
\hline Argentina & 42,4 & 19,4 & 9,7 & 19,1 \\
\hline $\begin{array}{l}\text { Bolivia (Estado } \\
\text { Plurinacional de) }\end{array}$ & 35,7 & 20,9 & 15,5 & 10,2 \\
\hline Brasil & 48,4 & 14,6 & 12,4 & 12,1 \\
\hline Colombia & 34,5 & 22,5 & 20,2 & 17,1 \\
\hline Costa Rica & 38,6 & 18,3 & 15,4 & 17,1 \\
\hline Chile & 26,5 & 23,0 & 15,8 & 11,1 \\
\hline Ecuador & 30,1 & 21,8 & 29,6 & 8,6 \\
\hline El Salvador & 36,4 & 14,1 & 27,8 & 9,2 \\
\hline Guatemala & 31,7 & 27,1 & 22,2 & 12,7 \\
\hline Honduras & 50,2 & 18,8 & 8,0 & 10,7 \\
\hline México & 29,6 & 30,1 & 16,6 & 15,5 \\
\hline Nicaragua & 35,7 & 24,3 & 17,2 & 14,5 \\
\hline Panamá & 40,9 & 15,1 & 11,9 & 20,8 \\
\hline Paraguay & 22,8 & 28,5 & 15,7 & 15,4 \\
\hline Perú & 43,1 & 20,4 & 14,5 & 10,3 \\
\hline República Dominicana & 29,1 & 16,5 & 26,8 & 21,2 \\
\hline Uruguay & 31,8 & 19,2 & 11,6 & 22,8 \\
\hline $\begin{array}{l}\text { Venezuela (República } \\
\text { Bolivariana de) }\end{array}$ & 37,3 & 17,5 & 17,3 & 15,6 \\
\hline América Latina & 35,8 & 20,7 & 17,1 & 14,7 \\
\hline
\end{tabular}

Fuente: Comisión Económica para América Latina y el Caribe (CEPAL), sobre la base de tabulaciones especiales de la encuesta Latinobarómetro de 2013.

Nota: La pregunta se plantea en el cuestionario de la siguiente forma: "Si tuviera que elegir solo una de las cuatro frases siguientes, ¿cuál elegiría como la más representativa de las características de la democracia?". Cada característica pertenece y suma el $100 \%$ de una sola pregunta, por lo que se preguntó lo mismo cuatro veces a las y los encuestados. No obstante, cada pregunta tenía cuatro alternativas de respuesta (sin contar "no responde", "no entiende la pregunta" y "no puede elegir"). El total porcentual por renglón no suma el $100 \%$ debido a que se omiten del cuadro los porcentajes relativamente más bajos de las alternativas "No entiende la pregunta" y "No puede elegir", con el fin de simplificar la exposición de la información.

\section{La participación no convencional y las nuevas plataformas de expresión, movilización e incidencia}

El distanciamiento de los jóvenes del sistema político y de la competencia electoral no debe opacar nuevos modos de participación no convencional de las personas jóvenes con un creciente potencial contestatario y de influencia en la agenda pública. En los últimos años han surgido en la región fuertes movimientos sociales liderados por la juventud, lo que supone un llamado de atención respecto de su interés de ser escuchados y de participar activamente en el desarrollo de sus sociedades. Emergen 
así nuevas formas de movilización y organización juvenil donde las herramientas tecnológicas constituyen un elemento clave, en particular las redes sociales. Estas se encuentran entre las plataformas de Internet preferidas en América Latina: de los 12 países del mundo donde las redes sociales son más utilizadas, 5 son de la región y los usuarios, en su mayoría, son adolescentes y jóvenes (CEPAL, 2014).

El modelo comunicativo propuesto por las redes sociales es opuesto al de los medios de comunicación tradicionales de tipo masivo que dirigen un mensaje unitario a un grupo indefinido de individuos. En las redes sociales, son los usuarios quienes tienen la posibilidad de crear y difundir mensajes a un número también indeterminado de personas, y esa interactividad se ve acentuada por su capacidad de crear redes y de establecer contactos. Este modelo implica un cambio sustancial en la forma en que las personas interactúan, tanto entre sí como con las instituciones, ya sea individualmente, en comunidades o en movimientos (Pavez, 2014). Tales redes sociales cumplen una función de creciente protagonismo en cuanto al modo en que los adolescentes y jóvenes ejercen influencia y plantean opiniones, inquietudes e ideas, dando paso a nuevas formas de organización que han generado movimientos sociales y comunidades (PNUD, 2013).

En los últimos años se ha consumado una triple revolución de la mano de la masificación del acceso a Internet, el surgimiento de las redes sociales virtuales como nuevos espacios y protagonistas de la interacción social, y la explosión en el uso y acceso a dispositivos digitales portátiles (celulares y tabletas). La nueva generación en América Latina es protagonista de este proceso, en el sentido de ser, simultáneamente, nativa democrática y nativa digital. Bianchi dice que habría una nueva generación de activistas que hacen un ejercicio novedoso de estos espacios y herramientas a su alcance. Estos actores son, aunque no exclusivamente, jóvenes que tienen naturalizadas las prácticas democráticas, pero que desafían el statu quo (Bianchi, 2014).

En comparación con los adultos, esto confirma una mayor tendencia de las personas jóvenes a mantenerse al margen de la participación electoral y convencional. Al mismo tiempo, no obstante, entre quienes deciden participar se observa una tendencia más marcada a movilizarse directamente por vías distintas al voto. Esto se refleja en la Primera Encuesta Nacional de Juventud de Guatemala de 2011, en donde se muestra que los jóvenes de menor edad declaran participar en organizaciones de apoyo de causas específicas (véase el gráfico V.17).

El caso de Chile es particular pues, tal y como se vio en las secciones anteriores, presenta simultáneamente niveles muy altos de desapego a la participación electoral y a la movilización entre las personas jóvenes, junto con un aumento notable del porcentaje de jóvenes que en el período 2000-2013 declaró movilizarse, pero no votar. En parte, estos rasgos son coincidentes con los datos de la Encuesta Nacional de Juventud de 2012 de ese país (véase el recuadro V.3). 


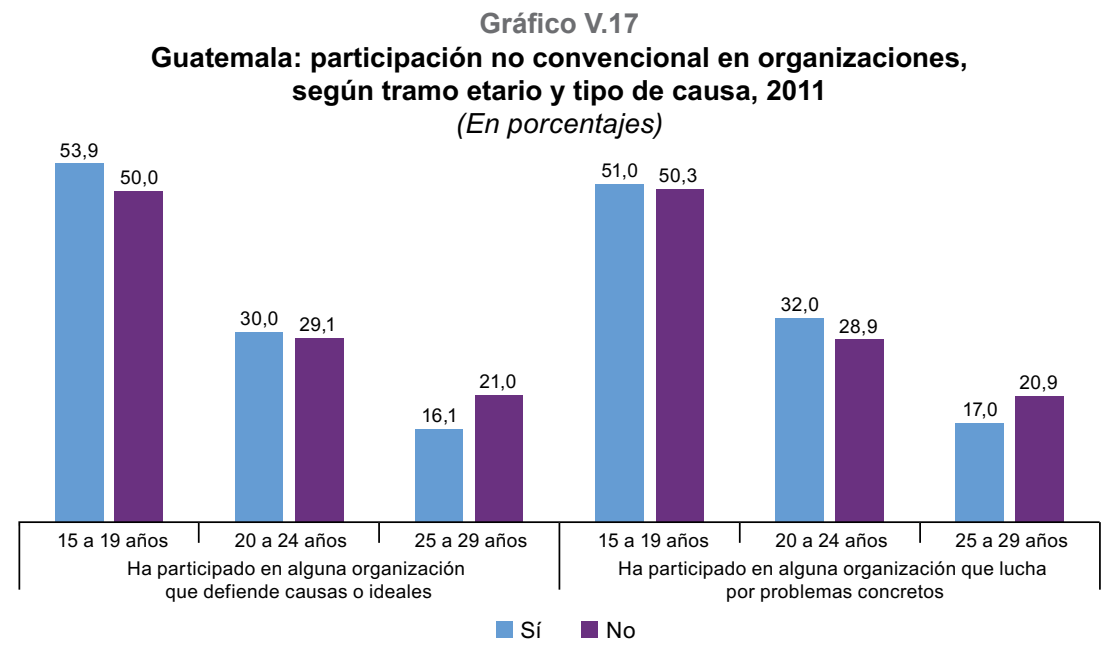

Fuente: Comisión Económica para América Latina y el Caribe (CEPAL), sobre la base de tabulaciones especiales de la Primera Encuesta Nacional de Juventud en Guatemala (ENJU), 2011.

\section{Recuadro V.3 \\ Chile: algunos rasgos de la movilización no convencional de las personas jóvenes, 2012}

Desde el retorno a la democracia en Chile, la asociatividad, entendida como la participación en organizaciones sociales intermedias de diverso tipo, ha sido baja (Ríos Tobar y Ajenjo Martínez, 2014). Ocurre lo contrario en el caso de la participación política menos convencional, como la asistencia a marchas. Diversos estudios muestran que los jóvenes, a diferencia de los adultos, prefieren la movilización social, la "política de la calle", la protesta y la acción política directa (Flisfisch y Miranda, 2014). Entre 2011 y 2012 surgió en Chile un amplio movimiento estudiantil en el cual participó un gran número de jóvenes, en especial pertenecientes al mundo universitario de las grandes aglomeraciones urbanas.

Al respecto, los datos de la Séptima Encuesta Nacional de Juventud presentan algunos resultados reveladores (véanse los siguientes gráficos). El primero es que la gran mayoría de los jóvenes chilenos no participan en este tipo de movilización. De las tres modalidades de participación no convencional consideradas, ellos declaran haber participado con mayor frecuencia en marchas, seguido por paros y tomas (un $23 \%$, un $18 \%$ y un $10 \%$, respectivamente). Entre quienes sí optan por movilizarse por estas vías, la mayoría son varones de entre 15 y 24 años, pertenecientes a los estratos más altos, que en principio tienen mayor acceso a la educación universitaria, y de áreas urbanas (escenario privilegiado del movimiento estudiantil en las principales ciudades en donde se encuentran los centros universitarios). Esto indicaría que durante el período correspondiente a dicha encuesta, para un contingente importante de jóvenes sin edad para votar, la movilización no convencional constituyó una importante vía de participación política. 
Chile: participación juvenil en diferentes tipos de acciones políticas no convencionales durante los últimos 12 meses, según tramo etario, estrato social, sexo y área geográfica, 2012

(En porcentajes)

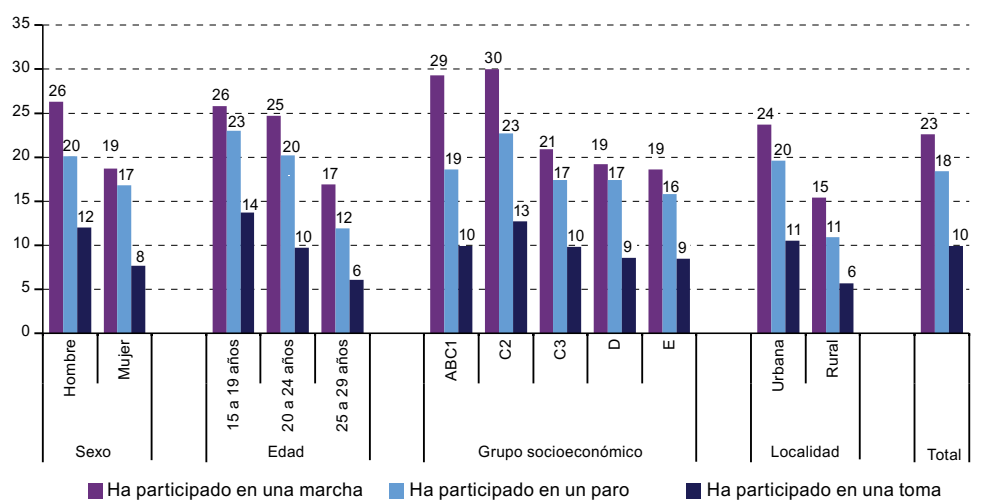

Fuente: Encuesta Nacional de Juventud 2012.

\section{Chile: participación de las personas jóvenes en diferentes tipos de acciones políticas no convencionales durante los últimos 12 meses, según subgrupo etario \\ (En porcentajes)}

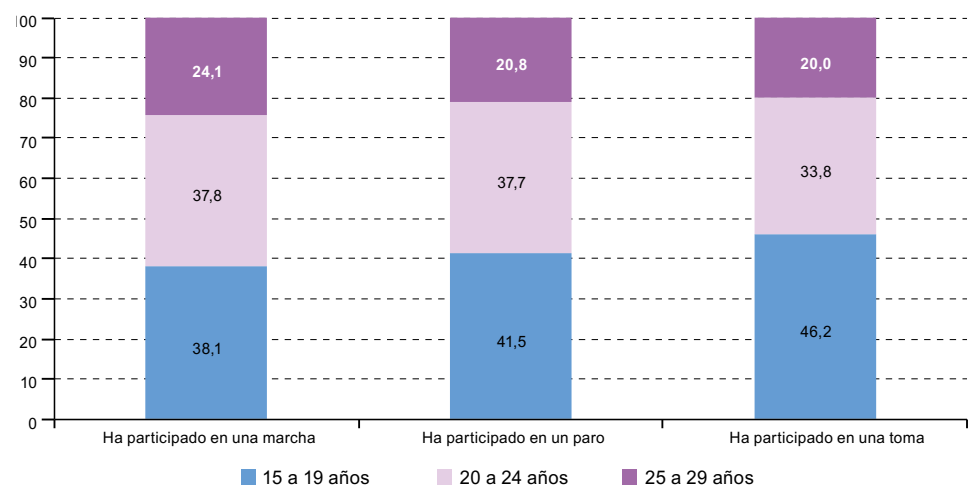

Fuente: Encuesta Nacional de Juventud 2012.

Fuente: Elaboración propia, sobre la base de Instituto Nacional de la Juventud (INJUV), 7ma Encuesta Nacional de Juventud 2012, Santiago, 2013; Marcela Ríos Tobar y Felipe Ajenjo Martínez, "Evolución de la participación social y política en Chile", Electoras y electores, movimientos, partidos, Ángel Flisfisch (comp.), Santiago, FLACSO Chile, 2014; y Ángel Flisfisch y Lucía Miranda, "Análisis comparativo de niveles de confianza en instituciones y agentes políticos: Chile y América Latina", Electoras y electores, movimientos, partidos, Ángel Flisfisch (comp.), Santiago, FLACSO Chile, 2014. 
Como contraparte de los bajos indicadores de participación política convencional en Chile, se puede citar el peso del movimiento estudiantil de 2011. Este instaló en la agenda pública temas que los actores políticos tradicionales habían esquivado o abordado parcialmente, como, por ejemplo, poner fin efectivo al lucro en todo el sistema educativo y en especial en la educación universitaria, un principio que estaba presente en el marco legislativo formal, pero que en la práctica no era respetado. A pesar de las negativas o soluciones propuestas por el gobierno de turno, las manifestaciones lograron un amplio y prolongado apoyo al que se sumaron miles de familias y otros sectores sociales, con lo que se produjeron movilizaciones excepcionalmente numerosas y mediatizadas. Por otra parte, en la mayoría de las encuestas de opinión se revelaba un apoyo nacional a las principales causas enarboladas por el movimiento estudiantil, respaldo que se mantuvo en el tiempo. No obstante los cambios de gabinete y la aplicación de algunas medidas gubernamentales significativas, la necesidad de una completa reordenación del sistema educativo y de una reforma tributaria para recaudar los fondos necesarios quedó instalada en la agenda pública. Tal fue la importancia de los temas planteados por el movimiento, que buena parte de ellos estuvo en el centro de la siguiente campaña presidencial y en el programa de la coalición que ganó dicha elección. Otro hecho notable fue que buena parte de los líderes surgidos del movimiento estudiantil - personas jóvenes menores de 25 años- logró incorporarse a diversos partidos o actuar de manera independiente para lanzar candidaturas al poder legislativo en 2013, y varios de ellos llegaron a ocupar escaños en la Cámara de Diputados. En tal sentido, el movimiento estudiantil de 2011 presenta el interés adicional de haber contribuido al surgimiento de nuevos líderes jóvenes que accedieron a puestos de elección popular y que adquirieron una incidencia concreta sobre la toma de decisiones.

Otro caso llamativo fue protagonizado por jóvenes mexicanos con el movimiento \#yosoy132, organizado por universitarios en medio de la campaña presidencial de 2012 (véase el recuadro V.4).

El Brasil es otro de los países donde el descontento social se ha expresado y articulado en parte mediante el uso de Internet. Desde junio de 2013, los medios de comunicación informaron de decenas de miles de personas, en su mayoría jóvenes universitarios, que se han manifestado por asuntos tales como los altos precios del transporte público o los costos del Mundial de Fútbol, lo que dio paso a una de las mayores olas de protestas en muchos años. Este movimiento, que también utilizó las redes sociales, principalmente Facebook, ponía de relieve la necesidad de satisfacer nuevas demandas de inclusión social de muchos estudiantes y personas jóvenes, en el sentido de que el transporte público es esencial para permitir el goce efectivo de oportunidades educativas y laborales, sobre todo en los grandes contextos urbanos. Al igual que en el caso del movimiento mexicano, sus integrantes aseguran que se trata de una organización horizontal sin afiliaciones partidistas ni liderazgos definidos (Pavez, 2014). 


\section{Recuadro V.4 \\ México: el movimiento \#yosoy132 durante la campaña presidencial de 2012}

En el contexto de la campaña presidencial y legislativa de 2012 en México, irrumpió con fuerza un movimiento liderado por jóvenes estudiantes universitarios, tanto de instituciones públicas como privadas, en torno a exigencias como la democratización de los medios de comunicación, la celebración de un tercer debate entre los candidatos presidenciales y el rechazo a lo que percibían como la imposición de un candidato presidencial por parte de diversos medios masivos de comunicación.

El lunes 14 de mayo ocurrió un incidente durante un acto de campaña en la Universidad Iberoamericana en donde varios estudiantes protestaron por el operativo policial y la presencia de público externo favorable a uno de los candidatos. La cobertura mediática del acto enfatizó el hecho de que las protestas no provenían de los estudiantes de dicha universidad, sino de elementos externos Frente a lo que consideraron una tergiversación de la realidad, un grupo de alumnos de esa institución privada realizó y difundió un video con 131 estudiantes que mostraban la credencial que indicaba su nombre y número de matrícula para mostrar que ellos efectivamente estuvieron allí. El video logró una amplia difusión a partir de la red social YouTube y unos minutos más tarde incluso llegó a ser tendencia (trending topic) en Twitter (véase [en línea] http://www.youtube.com/ watch? $\mathrm{v}=\mathrm{P} 7 \mathrm{XbocXsFkl)}$.

Este movimiento logró extenderse casi inmediatamente a otras universidades con la respuesta de otros estudiantes que mediante Twitter se manifestaron para identificarse como el estudiante número 132, razón de la utilización del símbolo \#, por lo que se denominó \#Yosoy132. Es así como el movimiento dio lugar a manifestaciones públicas que llamaban a los estudiantes a mantenerse informados, a los medios a no manipular la información y entregarla de forma independiente y neutral, y a la realización de foros públicos con acceso a todos los jóvenes que quisieran participar. También organizaron un debate al que invitaron a todos los candidatos presidenciales y en el que se utilizó una nueva forma de moderación que incluía preguntas recogidas por Twitter y enlaces vía Skype. Fue gracias al potencial inclusivo de esa tecnología que su mensaje sobrepasó la esfera del público que ya estaba interesado en la política y llegó a una audiencia mayor, tan variada como desconocida. En definitiva, este movimiento que utilizó exitosamente las redes sociales virtuales no solo canalizaba la indignación de muchos electores ante la percepción de una cobertura mediática sesgada.

El impacto inicial del movimiento también se explica por llenar un vacío de información y de participación experimentado por muchos jóvenes y electores. Se destaca que mucho tiene que ver en el surgimiento de \#Yosoy132 la escasez de canales formales de participación a través de partidos políticos y la poca voluntad de la clase política de expandir los canales disponibles (González, 2012, pág. 99). Una vez terminada la coyuntura electoral, el movimiento perdió fuerza, lo que muestra la dificultad de consolidar este tipo de movilizaciones e inscribirlas en el largo plazo mediante la construcción de nuevas formas organizacionales.

Fuente: Elaboración propia, sobre la base de Luis Josué González, “\#YoSoy132. Participación política 2.0 en México", Diálogo Político, № 2, 2012. 
Estos movimientos, manifestaciones y organizaciones sociales no tradicionales, donde los jóvenes ejercen un liderazgo clave, se caracterizan por nuevas formas de comunicación, convocatoria y participación. Se organizan a través de las redes sociales y acaparan la atención, tanto de los medios de comunicación masivos como de sus gobiernos (Pavez, 2014). Esos mismos rasgos conspiran contra su permanencia en el tiempo. No obstante, constituyen una modalidad nueva y recurrente de movilización con objetivos puntuales que pueden tener un gran impacto. Su importancia estriba en su carácter complementario ante la inadecuada o insuficiente representación de los jóvenes y de su pluralidad por los canales convencionales de la democracia representativa. Más en general, estas modalidades abonan a una conflictividad social que obliga a los sistemas políticos a atender demandas y dar respuestas a asuntos que son ignorados, o incluso bloqueados, por los canales institucionales formales (Calderón Gutiérrez, 2011 y 2012). Por ello, es importante explorar qué temas son susceptibles de movilizar a las personas jóvenes y cuáles perciben como los problemas más urgentes.

\section{Temas que movilizan a la juventud y sus prioridades para la agenda pública}

Los temas que llaman a las personas jóvenes a movilizarse ofrecen una mirada complementaria a lo que se ha venido tratando en este capítulo. En principio, a partir de los resultados de la encuesta de 2013, los jóvenes en general se mostraban muy dispuestos, en comparación con los adultos, a movilizarse a favor de varios temas mencionados en Latinobarómetro (véase el gráfico V.18). A la vez, se declaraban "nada dispuestos" en menor proporción que los adultos a movilizarse en todos esos temas. Los asuntos que mayor interés despiertan entre la juventud son la educación y la salud, seguidos por la búsqueda de mejores salarios y mejor trabajo, la protección de los derechos democráticos, la propiedad de la tierra y la explotación de los recursos naturales. Se observa que los temas prioritarios están relacionados con las oportunidades individuales (salud, educación, salario y trabajo) y son los que concitan mayor entusiasmo en comparación con causas más intangibles como la protección de los derechos democráticos. Al mismo tiempo, asuntos de lucha social "tradicional", como la propiedad de la tierra o la explotación de los recursos naturales, temas vinculados tanto con discusiones generales sobre la apropiación de los ingresos generados mediante esa actividad como por sus efectos sobre el medioambiente, despiertan menos entusiasmo. 


\section{Gráfico V.18 \\ América Latina (promedio simple de 18 países): jóvenes de 16 a 29 años y adultos de 30 años y más que declaran estar muy dispuestos o nada dispuestos a movilizarse a favor de asuntos seleccionados, 2013 a (En porcentajes)}

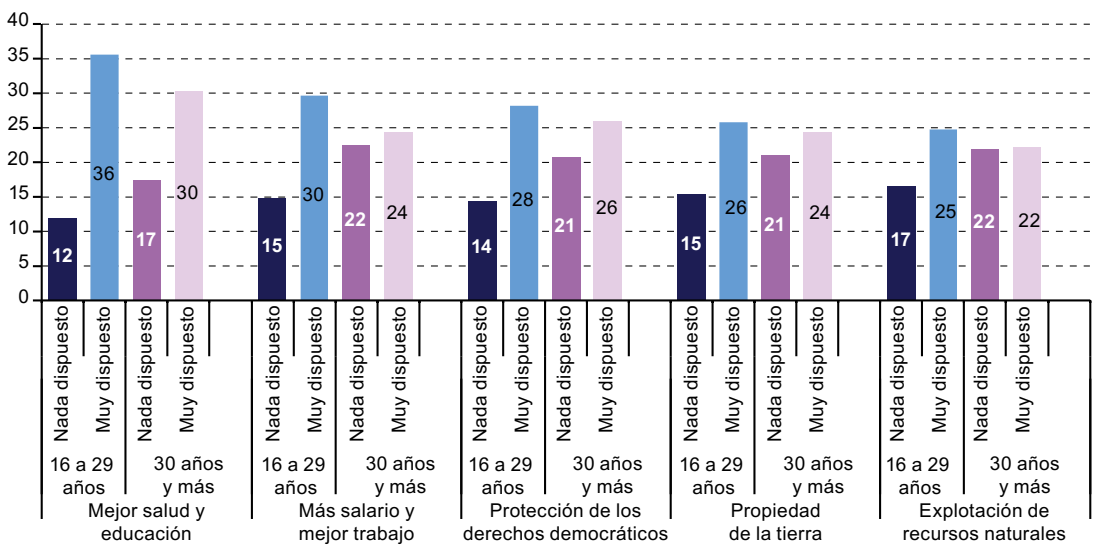

Fuente: Comisión Económica para América Latina y el Caribe (CEPAL), sobre la base de tabulaciones especiales de la encuesta Latinobarómetro de 2013.

a Con el fin de captar la intensidad relativa de cada tema, solo se consideran quienes responden estar muy dispuestos o nada dispuestos a movilizarse, pues entre ambas opciones el cuestionario de Latinobarómetro 2013 incluye ocho niveles intermedios.

Si bien el panorama por país es diverso, en general se repite el mismo orden de prioridad otorgado a los distintos temas, así como las brechas ya mencionadas con respecto a las personas de 30 años y más. Si consideramos el porcentaje de quienes se declaran nada dispuestos a movilizarse, los patrones relevados son similares y más marcados, en el sentido de que, salvo en el caso de algunos países, son los adultos de 30 años y más quienes se declaran con mayor frecuencia nada dispuestos a movilizarse con respecto a esos mismos temas (véase el gráfico V.19) ${ }^{6}$. En otras palabras, la falta de confianza, la mayor indiferencia y la menor participación electoral convencional no implican per se una menor disposición por parte de las personas jóvenes para movilizarse. En el caso de la salud y la educación, los adultos de 30 años y más se muestran con mayor frecuencia nada dispuestos a movilizarse, salvo en el caso de Honduras y Panamá. No hay excepciones en el caso de la movilización por más salario y mejor trabajo, como tampoco por la protección de los derechos democráticos. Con respecto a la propiedad de la tierra y la explotación de los recursos naturales, solo en Panamá la opción "nada dispuestos" era ligeramente superior entre los jóvenes de 16 a 29 años. Esto plantea también una menor aversión a la movilización entre los menores de 30 años encuestados, un rasgo concomitante con el mayor optimismo señalado anteriormente.

Si se mira el porcentaje de personas jóvenes y no jóvenes que se declaran muy dispuestas a movilizarse a favor de estos asuntos, los patrones son similares. 


\section{Gráfico V.19}

América Latina (promedio simple de 18 países): jóvenes de 16 a 29 años y adultos de 30 años y más que se declaran nada dispuestos a movilizarse a favor de asuntos seleccionados, $2013^{\text {a }}$

(En porcentajes)

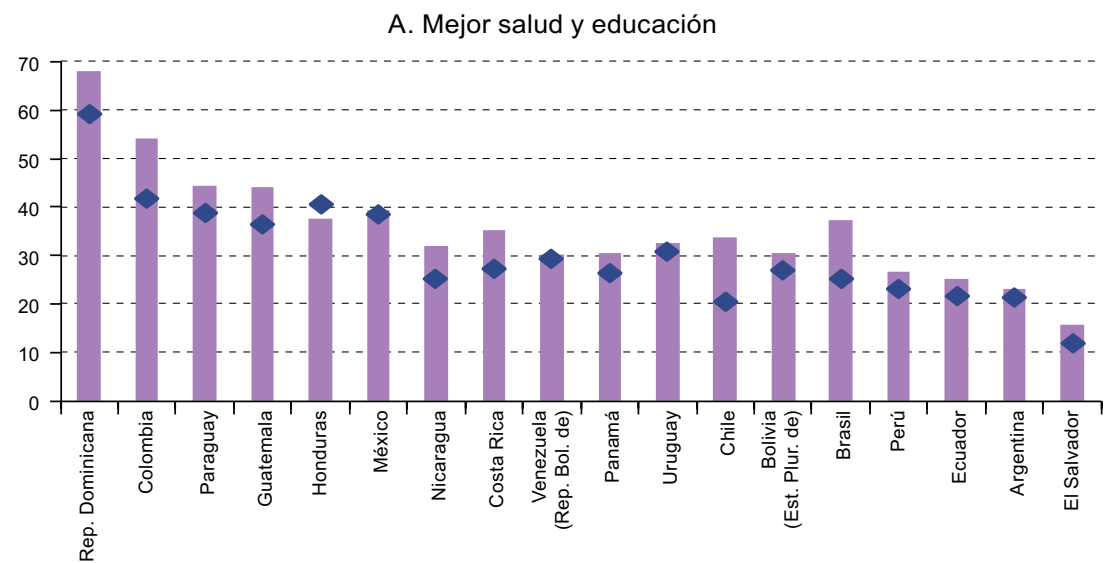

B. Más salario y mejor trabajo

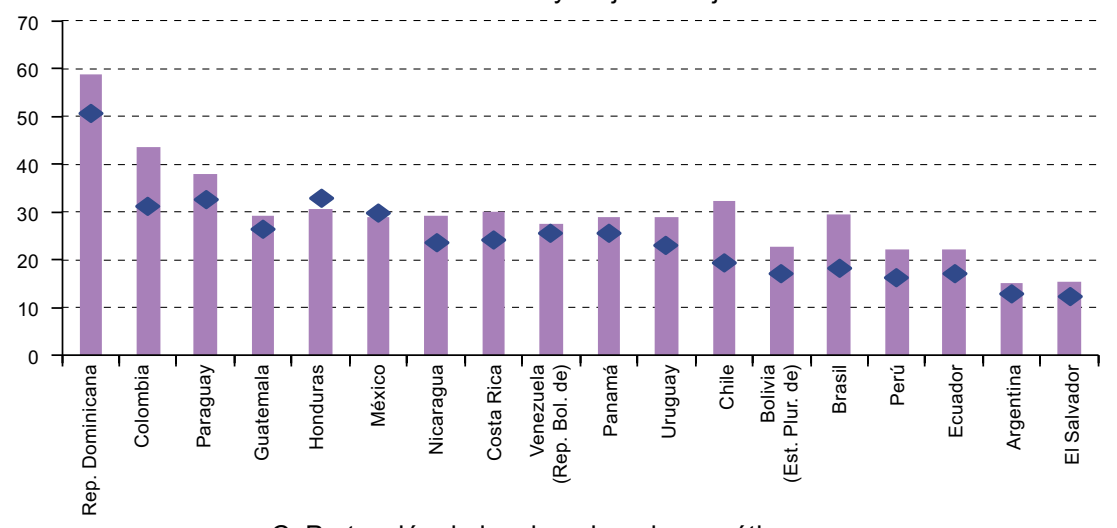

C. Protección de los derechos democráticos

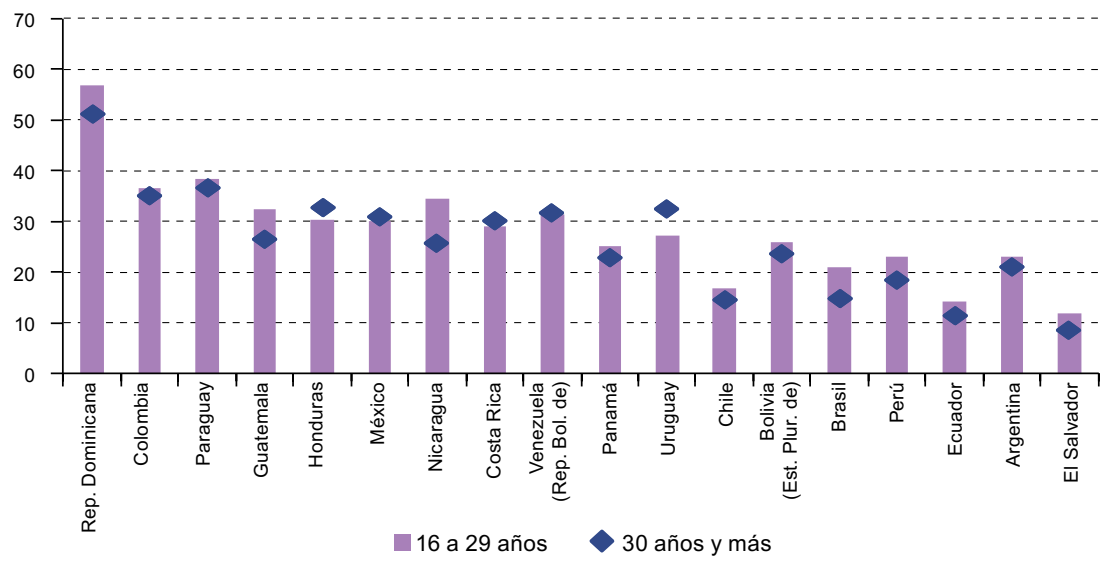


Gráfico V.19 (conclusión)

\section{Propiedad de la tierra}

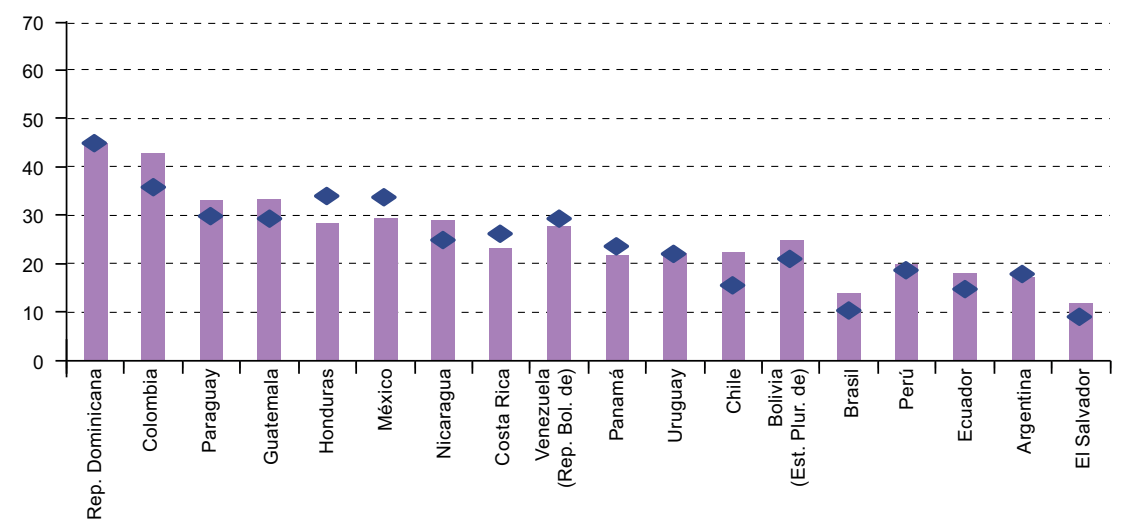

E. Explotación de los recursos naturales

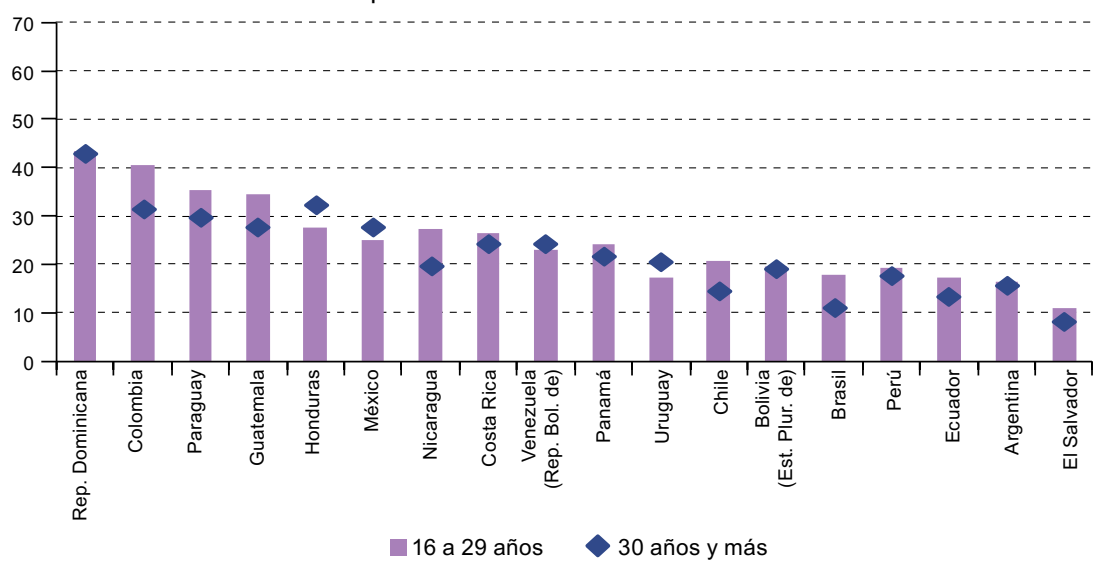

Fuente: Comisión Económica para América Latina y el Caribe (CEPAL), sobre la base de tabulaciones especiales de la encuesta Latinobarómetro de 2013.

a Con el fin de captar la intensidad relativa de cada tema, solamente se consideran quienes responden estar nada dispuestos a movilizarse.

Además de revisar la postura de los jóvenes hacia la participación política convencional y no convencional y hacia la democracia, así como los temas que más los incitan a movilizarse, conviene tener en cuenta cuáles son los principales temas en términos de la agenda pública y su evolución en los últimos años. A nivel de la región, los principales problemas identificados por las personas jóvenes cambiaron entre 2000 y 2013 (véase el gráfico V.20). En 2000, los temas identificados como prioritarios fueron la desocupación y el desempleo $(21,2 \%)$, la educación $(20,7 \%)$ y la corrupción $(9,7 \%)$. A estos los seguían de cerca la pobreza con un $8,1 \%$ y la delincuencia con un $7,7 \%$. En 2013, en cambio, los tres temas más destacados fueron la delincuencia (23\%), la desocupación y el 
desempleo (15,9\%), y la educación y la corrupción (ambos con un 6,3\%). De este modo, solo el desempleo y la desocupación se ha mantenido como un tema de gran preocupación, mientras que la delincuencia ganó terreno durante el período analizado.

\section{Gráfico V.20 \\ América Latina (17 países): promedio de percepción sobre el problema más importante en el país, según los jóvenes de 16 a 29 años, 2000 y 2013 \\ (En porcentajes)}
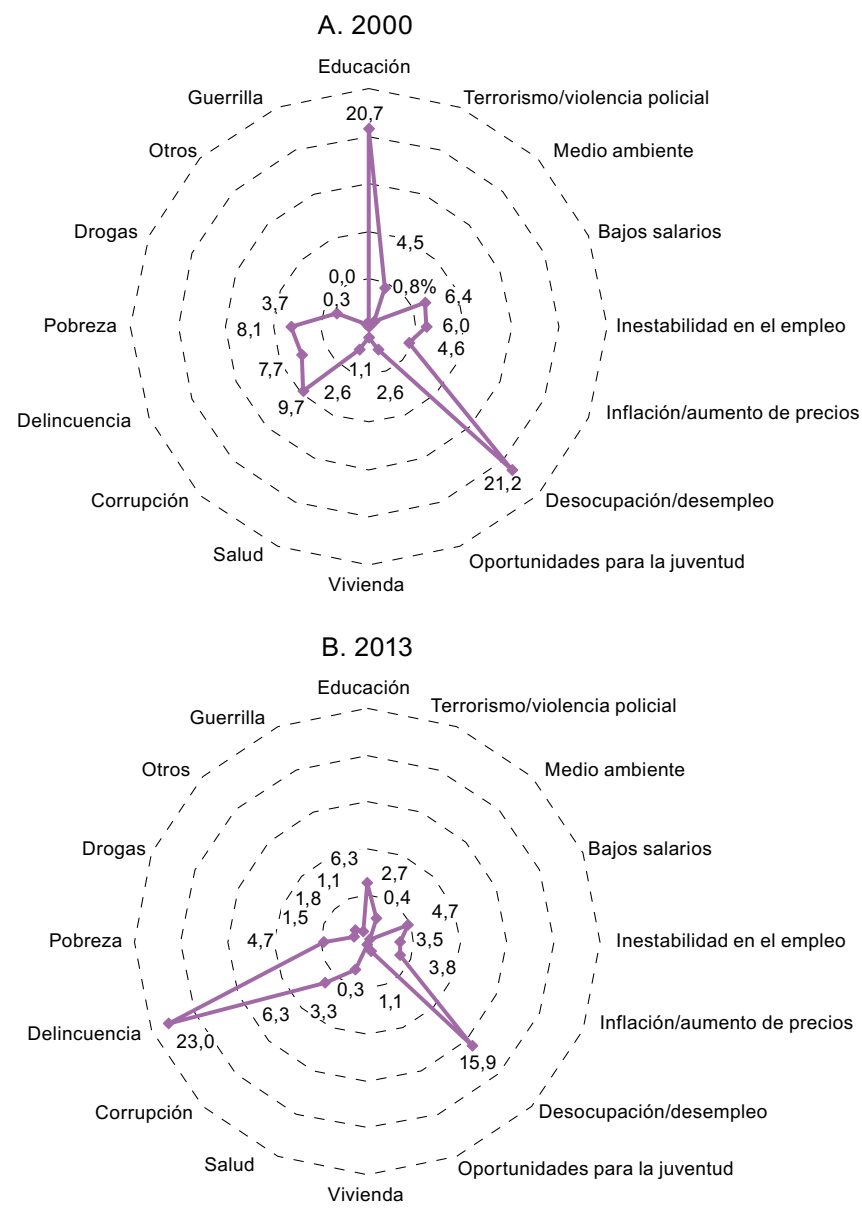

Fuente: Comisión Económica para América Latina y el Caribe (CEPAL), sobre la base de tabulaciones especiales de la encuesta Latinobarómetro de 2000 y 2013.

Nota: En el cuestionario, la pregunta se plantea de la siguiente forma: "De la lista de problemas que le voy a mostrar, ¿cuál considera Ud. que es el más importante en el país?". A fin de hacer comparables los casos para ambos años, solo se consideraron las alternativas de respuesta estudiadas en la encuesta de 2000. Esto quiere decir que las opciones "no sabe", "no responde", "ninguno", "transporte", "violación de los derechos humanos", "narcotráfico", "desabastecimiento", "calentamiento global", "servicios básicos", "economía/problemas financieros", "situación política", "distribución del ingreso", "discriminación racial”, "problemas limítrofes", "problemas con países vecinos" y "problemas energéticos" completan el 100\% de los casos encuestados para 2013. 
Si bien cada país presenta sus particularidades, también se observan ciertas regularidades que conviene relevar (véase el cuadro V.2). En 2000, la educación estaba entre los dos problemas considerados más importantes en 13 de 16 países para los que se cuenta con información. Por su parte, la desocupación y el desempleo también estaban presentes en la mayoría de los países (11 países).

Cuadro V.2

América Latina (17 países): los dos problemas más importantes mencionados por jóvenes de 16 a 29 años, 2000 y 2013

\begin{tabular}{|c|c|c|}
\hline País & 2000 & 2013 \\
\hline \multirow{2}{*}{ Argentina } & Desocupación y desempleo & Delincuencia y seguridad pública \\
\hline & Educación & Inflación y aumento de precios \\
\hline \multirow{2}{*}{$\begin{array}{l}\text { Bolivia (Estado } \\
\text { Plurinacional de) }\end{array}$} & Educación & Delincuencia y seguridad pública \\
\hline & Desocupación y desempleo & La economía y problemas financieros \\
\hline \multirow{2}{*}{ Brasil } & Desocupación y desempleo & Problemas de salud \\
\hline & Drogas & Problemas de la educación ${ }^{a}$ \\
\hline \multirow{2}{*}{ Chile } & Desocupación y desempleo & Problemas de la educación \\
\hline & Inestabilidad en el empleo & Delincuencia y seguridad pública \\
\hline \multirow{2}{*}{ Colombia } & 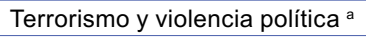 & Desocupación y desempleo \\
\hline & Desocupación y desempleo & Violencia y pandillas \\
\hline \multirow{2}{*}{ Costa Rica } & Educación & Corrupción \\
\hline & Corrupción & Desocupación y desempleo \\
\hline \multirow{2}{*}{ Ecuador } & Educación & Delincuencia y seguridad pública \\
\hline & Corrupción & Desocupación y desempleo \\
\hline \multirow{2}{*}{ El Salvador } & Pobreza & Delincuencia y seguridad pública $^{\text {a }}$ \\
\hline & Educación & Bajos salarios \\
\hline \multirow{2}{*}{ Guatemala } & Educación & Delincuencia y seguridad pública ${ }^{a}$ \\
\hline & Bajos salarios & Desocupación y desempleo \\
\hline \multirow{2}{*}{ Honduras } & Educación & Desocupación y desempleo \\
\hline & Delincuencia $^{a}$ & 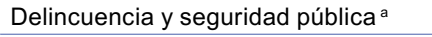 \\
\hline \multirow{2}{*}{ México } & Inflación y aumento de precios & Delincuencia y seguridad pública \\
\hline & Educación & Desocupación y desempleo \\
\hline \multirow{2}{*}{ Nicaragua } & Educación & Desocupación y desempleo \\
\hline & Desocupación y desempleo & Bajos salarios \\
\hline \multirow{2}{*}{ Panamá } & Desocupación y desempleo & Transporte \\
\hline & Educación & Bajos salarios \\
\hline \multirow{2}{*}{ Paraguay } & Desocupación y desempleo & Desocupación y desempleo \\
\hline & Educación ${ }^{a}$ & Delincuencia y seguridad pública \\
\hline \multirow{2}{*}{ Perú } & Desocupación y desempleo & Delincuencia y seguridad pública \\
\hline & Educación & Pobreza \\
\hline \multirow{2}{*}{ Uruguay } & Desocupación y desempleo & Delincuencia y seguridad pública \\
\hline & Bajos salarios & Desocupación y desempleo \\
\hline \multirow{2}{*}{$\begin{array}{l}\text { Venezuela (República } \\
\text { Bolivariana de) }\end{array}$} & Educación & Delincuencia y seguridad pública \\
\hline & Desocupación y desempleo & $\begin{array}{l}\text { Desabastecimiento, falta de alimentos } \\
\text { y acaparamiento }\end{array}$ \\
\hline
\end{tabular}

Fuente: Elaboración propia, sobre la base de tabulaciones especiales de la encuesta Latinobarómetro de 2000 y 2013.

a Dependiendo del año de la encuesta, estas categorías se nombran de distinta manera, pero se asume que significan lo mismo. 
Para 2013, en 13 de los 16 países, la delincuencia y la seguridad pública (incluidas las pandillas) estaba presente entre los dos temas más importantes. El desempleo y la desocupación fueron mencionados en nueve países, al tiempo que otros asuntos se señalaban con menor frecuencia, como los problemas económicos y financieros, la corrupción y la educación. En suma, a nivel de los países hay cierta coincidencia con lo observado a nivel regional, en el sentido de que los problemas de desempleo y desocupación se han mantenido como un tema prioritario para las personas jóvenes encuestadas en 2000 y 2013, al tiempo que los problemas ligados con la delincuencia han pasado a formar parte de las principales preocupaciones mencionadas en 2013.

\section{E. Políticas y programas para favorecer la participación y movilización de las personas jóvenes}

La participación política juvenil y su involucramiento en los debates y en la conversación pública en general, así como su eventual movilización activa, son procesos que difícilmente podrían cambiar de forma radical en virtud de medidas o políticas específicas. Resulta difícil imaginar un aumento de dicho involucramiento "por decreto" o fundado en medidas puntuales. La participación surge de un interés por el ámbito público, y el voto y la movilización proceden de una toma de conciencia de su importancia por parte de las personas, así como de la disposición a asumir los eventuales costos de volverse un ciudadano activo.

Por ello, la participación y la movilización de la juventud se generan a partir de ciertas demandas y causas específicas en un momento dado, a veces marcando a una generación, pero no necesariamente asegurando el involucramiento sostenido de ese grupo etario en el futuro (véanse los recuadros V.3 y V.4). En cierta medida, cada nueva generación de jóvenes va buscando y encontrando un lugar en el contexto que le tocó en suerte: con más o menos crecimiento económico, con mayores o menores tensiones redistributivas, y con mayor o menor incorporación en la agenda pública y gubernamental de los temas que les preocupan. Al mismo tiempo, los patrones de desapego hacia la participación y la democracia por parte de los jóvenes han llevado a numerosos estudios (incluido el presente ejercicio) a plantear que, si bien hay situaciones nacionales particulares que ameritan un examen en profundidad, el problema común a todos los países en esta materia es la inclusión de los jóvenes en la operación y los procesos de la democracia representativa.

En los cuadros V.3 y V.4 se aprecia una mirada somera a algunos programas implementados en la región que buscan fomentar la 
participación política y social de jóvenes. En general, las acciones pueden clasificarse en dos grandes categorías: los programas centrados en organizar instancias de diálogo y de participación orientados a las personas jóvenes en materia política (véase el cuadro V.3) y los programas que buscan impulsar directamente la participación política juvenil (véase el cuadro V.4).

\section{Cuadro V.3}

Programas centrados en la generación de instancias y procesos de diálogo y comunicación política para las personas jóvenes

\begin{tabular}{|c|c|c|c|}
\hline País & $\begin{array}{l}\text { Política, programa } \\
\text { o proyecto }\end{array}$ & $\begin{array}{l}\text { Institución u } \\
\text { organismo a } \\
\text { cargo }\end{array}$ & Objetivo \\
\hline Argentina & $\begin{array}{l}\text { Mutuales del } \\
\text { Bicentenario }\end{array}$ & $\begin{array}{l}\text { Dirección } \\
\text { Nacional de } \\
\text { Juventud }\end{array}$ & $\begin{array}{l}\text { Crear canales y condiciones para profundizar la } \\
\text { participación y la organización social y política } \\
\text { de la juventud. Dirigida a jóvenes de entre } 21 \text { y } \\
36 \text { años en más de } 40 \text { mutuales a nivel nacional. }\end{array}$ \\
\hline \multirow[t]{2}{*}{ Brasil } & Estação Juventude & $\begin{array}{l}\text { Secretaría } \\
\text { Nacional de } \\
\text { Juventud }\end{array}$ & $\begin{array}{l}\text { Instaurar espacios públicos de atención a } \\
\text { jóvenes de entre } 15 \text { y } 29 \text { años de sectores } \\
\text { vulnerables del país. }\end{array}$ \\
\hline & $\begin{array}{l}\text { Participatório } \\
\text { (Observatório } \\
\text { Participativo da } \\
\text { Juventude) }\end{array}$ & $\begin{array}{l}\text { Secretaría } \\
\text { Nacional de } \\
\text { Juventud }\end{array}$ & $\begin{array}{l}\text { Promover la participación en ambientes } \\
\text { virtuales, movilizar a la juventud y producir redes } \\
\text { de conocimiento. }\end{array}$ \\
\hline Chile & $\begin{array}{l}\text { Escuelas de } \\
\text { ciudadanía }\end{array}$ & $\begin{array}{l}\text { Instituto } \\
\text { Nacional de } \\
\text { la Juventud } \\
\text { (INJUV) del } \\
\text { Ministerio de } \\
\text { Desarrollo } \\
\text { Social }\end{array}$ & $\begin{array}{l}\text { Generar en los jóvenes un mayor compromiso y } \\
\text { participación democrática, cívica y ciudadana. } \\
\text { Fomentar su cultura cívica mediante el } \\
\text { desarrollo de actividades prácticas de } \\
\text { participación ciudadana, de modo de encontrar } \\
\text { nuevos líderes jóvenes interesados en participar } \\
\text { en el mejoramiento de su entorno. Dirigida a } \\
\text { más de } 10.500 \text { estudiantes de } 4^{\circ} \text { medio de } \\
\text { establecimientos municipales particulares- } \\
\text { subvencionados o particulares en } 60 \text { Escuelas } \\
\text { de Ciudadanía. }\end{array}$ \\
\hline Colombia & $\begin{array}{l}\text { Mesa Nacional } \\
\text { de Consejeros y } \\
\text { Consejeras }\end{array}$ & $\begin{array}{l}\text { Colombia } \\
\text { Joven, } \\
\text { programa } \\
\text { presidencial } \\
\text { para el } \\
\text { Sistema } \\
\text { Nacional de } \\
\text { Juventud }\end{array}$ & $\begin{array}{l}\text { Ser una instancia para la interlocución } \\
\text { y concertación ante las entidades } \\
\text { gubernamentales de Colombia como } \\
\text { representante de procesos juveniles y prácticas } \\
\text { de organizaciones juveniles, para la garantía, } \\
\text { cumplimiento, goce o restablecimiento efectivo } \\
\text { de derechos de las juventudes, la ampliación } \\
\text { de sus capacidades y de las oportunidades de } \\
\text { acceso a un desarrollo integral y sustentable. } \\
\text { Dirigida a los jóvenes que participan en } \\
\text { organizaciones juveniles y políticas del país. }\end{array}$ \\
\hline Ecuador & $\begin{array}{l}\text { Proceso de } \\
\text { articulación de los } \\
\text { jóvenes para su } \\
\text { participación política } \\
\text { en el Ecuador }\end{array}$ & $\begin{array}{l}\text { Secretaría } \\
\text { Nacional de } \\
\text { Gestión de la } \\
\text { Política }\end{array}$ & $\begin{array}{l}\text { Garantizar los espacios para la participación } \\
\text { política de los jóvenes a nivel nacional que } \\
\text { busquen participar en la política. }\end{array}$ \\
\hline
\end{tabular}

Fuente: Elaboración propia, sobre la base de políticas y programas implementados por los institutos de juventud de la región. 


\section{Cuadro V.4 \\ Programas que buscan promover directamente la participación política de las personas jóvenes}

\begin{tabular}{|c|c|c|c|}
\hline País & $\begin{array}{l}\text { Política, } \\
\text { programa o } \\
\text { proyecto }\end{array}$ & $\begin{array}{l}\text { Institución u organismo } \\
\text { a cargo }\end{array}$ & Objetivo \\
\hline Chile & $\begin{array}{l}\text { P.A.I.S. Joven } \\
\text { (Programa de } \\
\text { Apoyo a Iniciativas } \\
\text { Sociales Jóvenes) }\end{array}$ & $\begin{array}{l}\text { Instituto Nacional de la } \\
\text { Juventud (INJUV) del } \\
\text { Ministerio de Desarrollo } \\
\text { Social junto con el } \\
\text { Ministerio de Planificación }\end{array}$ & $\begin{array}{l}\text { Fomentar la participación juvenil para el } \\
\text { desarrollo del país. Dirigida a jóvenes } \\
\text { que quieran participar o ya participen en } \\
\text { política. }\end{array}$ \\
\hline Colombia & $\begin{array}{l}\text { Innovación } \\
\text { Social creada por } \\
\text { Jóvenes }\end{array}$ & $\begin{array}{l}\text { Colombia Joven, } \\
\text { programa presidencial } \\
\text { para el Sistema Nacional } \\
\text { de Juventud }\end{array}$ & $\begin{array}{l}\text { Fomentar una cultura de innovación } \\
\text { entre los jóvenes de } 14 \text { a } 28 \text { años } \\
\text { para que se conviertan en agentes de } \\
\text { cambio en sus comunidades y participen } \\
\text { activamente en la consolidación de la } \\
\text { paz en Colombia. }\end{array}$ \\
\hline \multirow[t]{2}{*}{$\begin{array}{l}\text { Costa } \\
\text { Rica }\end{array}$} & $\begin{array}{l}\text { Democracia } \\
\text { Participativa }\end{array}$ & $\begin{array}{l}\text { Agencia Española de } \\
\text { Cooperación Internacional } \\
\text { para el Desarrollo } \\
\text { (AECID) }\end{array}$ & $\begin{array}{l}\text { Promover una sociedad equitativa, } \\
\text { fortalecer las instituciones del Estado } \\
\text { para profundizar el acercamiento entre } \\
\text { estas y los ciudadanos, y mejorar } \\
\text { la gestión pública. Incrementar } \\
\text { las capacidades de los colectivos } \\
\text { vulnerables para su mejor integración y } \\
\text { participación social. }\end{array}$ \\
\hline & $\begin{array}{l}\text { Participación } \\
\text { Ciudadana }\end{array}$ & $\begin{array}{l}\text { Comisión Nacional para } \\
\text { el Mejoramiento de la } \\
\text { Administración de Justicia } \\
\text { (CONAMAJ) }\end{array}$ & $\begin{array}{l}\text { Fortalecer el vínculo entre el poder } \\
\text { judicial y la ciudadanía para democratizar } \\
\text { la gestión judicial y optimizar la } \\
\text { administración de justicia. Reforzar } \\
\text { el sistema democrático costarricense } \\
\text { y el conocimiento de necesidades y } \\
\text { posibilidades de la sociedad civil en } \\
\text { relación con el poder judicial. Mejorar } \\
\text { la respuesta del sistema judicial a } \\
\text { las necesidades locales y fortalecer } \\
\text { los vínculos entre la comunidad y las } \\
\text { instituciones del sector judicial. }\end{array}$ \\
\hline Ecuador & $\begin{array}{l}\text { Diálogo con } \\
\text { los gobiernos } \\
\text { autónomos y } \\
\text { descentralizados } \\
\text { en el Ecuador }\end{array}$ & $\begin{array}{l}\text { Secretaría Nacional de } \\
\text { Gestión de la Política }\end{array}$ & $\begin{array}{l}\text { Apoyar la gobernabilidad en los } \\
\text { territorios en el marco del proceso de } \\
\text { reforma democrática del Estado. }\end{array}$ \\
\hline México & Impulso México & $\begin{array}{l}\text { Instituto Mexicano de la } \\
\text { Juventud (IMJUVE) de la } \\
\text { Secretaría de Desarrollo } \\
\text { Social (SEDESOL) }\end{array}$ & $\begin{array}{l}\text { Estimular la creatividad, el capital social, } \\
\text { la conformación y la participación de } \\
\text { grupos y organizaciones juveniles a } \\
\text { través del ejercicio de sus derechos y } \\
\text { el apoyo a las diversas acciones que } \\
\text { emprendan a favor del desarrollo integral } \\
\text { de los jóvenes de entre } 12 \text { y } 29 \text { años. }\end{array}$ \\
\hline \multirow[t]{2}{*}{ Perú } & Cuota de Jóvenes & $\begin{array}{l}\text { Comisión Permanente del } \\
\text { Congreso de la República }\end{array}$ & $\begin{array}{l}\text { Promover la participación activa de los } \\
\text { menores de } 29 \text { años en los gobiernos } \\
\text { locales, representados por las } \\
\text { municipalidades. }\end{array}$ \\
\hline & $\begin{array}{l}\text { Ley del Consejo } \\
\text { Nacional de la } \\
\text { Juventud }\end{array}$ & $\begin{array}{l}\text { Comisión Permanente del } \\
\text { Congreso de la República }\end{array}$ & $\begin{array}{l}\text { Establecer el marco normativo e } \\
\text { institucional que oriente las acciones } \\
\text { del Estado y de la sociedad en } \\
\text { materia de política juvenil y que } \\
\text { permita impulsar las condiciones } \\
\text { de participación y representación } \\
\text { democrática de las personas de entre } \\
15 \text { y } 29 \text { años, sin discriminación alguna } \\
\text { que afecte sus derechos, obligaciones } \\
\text { y responsabilidades, orientados a la } \\
\text { promoción y el desarrollo integral } \\
\text { de la juventud. }\end{array}$ \\
\hline
\end{tabular}


Cuadro V.4 (conclusión)

\begin{tabular}{|c|c|c|c|}
\hline País & $\begin{array}{l}\text { Política, } \\
\text { programa o } \\
\text { proyecto }\end{array}$ & $\begin{array}{l}\text { Institución u organismo } \\
\text { a cargo }\end{array}$ & Objetivo \\
\hline Uruguay & $\begin{array}{l}\text { Fondo de } \\
\text { Iniciativas } \\
\text { Juveniles }\end{array}$ & $\begin{array}{l}\text { Instituto Nacional de } \\
\text { la Juventud (INJU) del } \\
\text { Ministerio de Desarrollo } \\
\text { Social }\end{array}$ & $\begin{array}{l}\text { Apoyar e incentivar el protagonismo } \\
\text { y la participación juvenil de carácter } \\
\text { asociativo. Fortalecer e impulsar la } \\
\text { capacidad y el tejido asociativo de las } \\
\text { organizaciones, grupos y colectivos } \\
\text { juveniles, como estrategia para facilitar su } \\
\text { incidencia pública y política en la agenda } \\
\text { del país. Fomentar las expresiones } \\
\text { juveniles en su mayor diversidad } \\
\text { mediante la estimulación de propuestas } \\
\text { inclusivas en su conformación grupal y en } \\
\text { las acciones a emprender. Generar una } \\
\text { experiencia de articulación e interlocución } \\
\text { entre colectivos juveniles como } \\
\text { antecedente para la conformación de } \\
\text { las mesas locales y departamentales de } \\
\text { juventud. Dirigido a jóvenes de entre } 15 \\
\text { y } 29 \text { años de todo el país que presenten } \\
\text { proyectos sociales. }\end{array}$ \\
\hline
\end{tabular}

Fuente: Elaboración propia, sobre la base de políticas y programas implementados por los institutos de juventud de la región.

En su mayoría, los primeros son implementados por los institutos o las secretarías de juventud de los países, mientras que los segundos dependen de instancias más diversas, del poder legislativo o judicial, así como de organismos de gobierno dependientes del poder ejecutivo. Son muestra de que existen esfuerzos y experiencias para tratar de reducir la distancia que suele separar a las personas jóvenes de la participación social y política. Como se apunta a continuación, aunque estos programas tienen valor y es deseable que cuenten con cobertura y financiamiento, hay muchos otros ámbitos de acción que pueden explorarse.

Conviene hacer una reflexión más general, más allá de las políticas sectoriales de juventud. Dada la información analizada acerca de los patrones de participación convencional y no convencional de los jóvenes, y sobre la base de una revisión de la experiencia internacional, es posible delinear algunas orientaciones para que el contexto institucional y el funcionamiento del sistema político estén lo más abiertos posible a los aportes y a la participación de las personas jóvenes. Se trata de medidas que van desde adaptaciones del marco jurídico nacional y electoral hasta cambios que favorecen la apertura a las personas jóvenes de espacios de diálogo, participación e incidencia a nivel comunitario, en los partidos y las organizaciones de la sociedad civil. Los avances simultáneos en esos ejes estratégicos deberían conformar un contexto político e institucional más abierto a la incorporación de los jóvenes como actores de la política.

Entre las medidas para fomentar el interés y la participación de la juventud señaladas en diversos informes se cuentan la consolidación de currículos escolares con información sobre el funcionamiento de los 
sistemas electorales y los canales de participación, así como la realización de parlamentos juveniles o sesiones especiales del poder legislativo abiertas a la participación juvenil (Beetham, 2006; UIP, 2014). En el recuadro V.5 se detallan algunas medidas concretas señaladas recientemente por la Unión Interparlamentaria para fomentar el interés y la participación política de las personas jóvenes. Más que argumentar que todas sean de utilidad en cualquier contexto, lo que importa es tener presente el amplio abanico de alternativas como punto de partida para determinar la viabilidad de su puesta en práctica en casos específicos.

\section{Recuadro V.5 \\ Medidas concretas orientadas a fomentar la participación política de las personas jóvenes}

Establecer cuotas para jóvenes en los Parlamentos y los partidos políticos.

Establecer cuotas a nivel local para que puedan emerger y consolidarse nuevos liderazgos políticos a nivel nacional.

Estudiar la posibilidad de reducir la edad mínima para votar y para ser votado.

Igualar la edad mínima requerida para ser votado con la edad mínima para votar.

Considerar la posibilidad de formar partidos políticos para jóvenes, siempre que así lo permita el marco constitucional y legal de cada país.

Dado que con frecuencia se vota por candidatos similares, y que cuantos más representantes jóvenes haya en el Parlamento, más votarán las personas jóvenes, incluir más candidatos de ese tramo etario en las listas legislativas de los partidos y para puestos ejecutivos.

Establecer Comités de Juventud en los Parlamentos y habilitarlos para analizar cualquier proyecto de legislación o de política, tengan o no efectos directos o explícitos sobre la juventud.

Monitorear la implementación de las políticas orientadas a la juventud, dedicar fondos para políticas de educación y capacitación de jóvenes, y tomar en cuenta a la juventud al momento de preparar los presupuestos nacionales.

Incluir a las personas jóvenes en los debates internacionales y no solamente en los foros dedicados a la juventud.

Introducir programas de capacitación para políticos jóvenes con el fin de mitigar la falta de experiencia política de los jóvenes.

Establecer programas de posgrado o de formación universitaria para jóvenes aspirantes a participar activamente en la vida política con el propósito de compensar su relativa falta de experiencia.

Incluir la participación activa de los jóvenes en la toma de decisiones de política, la gobernanza y la paz, en el marco de los Objetivos de Desarrollo Sostenible, tal como lo solicitó el Foro de la Juventud del Consejo Económico y Social de las Naciones Unidas.

Fuente: Unión Interparlamentaria (UIP), Taking Democracy to Task, Ginebra, 2014. 
A la luz de estas recomendaciones y del panorama de la región en torno a los requisitos etarios para poder ejercer el voto (véase el cuadro V.5), es notable que en 19 de 24 países considerados de América Latina y el Caribe las condiciones de elegibilidad al poder legislativo exijan una edad superior a la edad para votar. En 11 países (Argentina, Bolivia (Estado Plurinacional de), Brasil, Colombia, Haití, Paraguay, Perú, República Dominicana, Santa Lucía, Trinidad y Tabago y Uruguay), la edad requerida para la Cámara de Diputados es de 25 años o más, barrera que, de facto, deja fuera toda posibilidad de participación a una porción elevada de la población joven. Además, en el caso de los países con cámaras altas o senados, los requerimientos de edad para pertenecer a estos órganos son todavía más elevados. De hecho, en 9 de los 13 países con Cámara Alta (Argentina, Bolivia (Estado Plurinacional de), Brasil, Chile, Colombia, México, Paraguay, Santa Lucía y Uruguay), toda la población joven queda fuera al establecerse rangos de edad de 30 años o más para ser electo. En contraste, solo en cuatro países, la edad mínima requerida para votar coincide con la edad mínima para ser votado al Congreso (Granada, Guatemala, Guyana y Suriname). Por lo tanto, con miras a ampliar las posibilidades jurídicas para la elección de representantes jóvenes, en la mayoría de los países habría razones para discutir cuando menos una reducción del desfase entre ambos requisitos.

Otro ámbito de intervenciones que pueden delinearse en cada país alude a acciones y reformas que favorezcan la participación juvenil, no solo a nivel normativo, sino también a lo largo del ciclo electoral, como se ha planteado en un estudio global reciente sobre el tema (PNUD, 2013). Ello implica incidir sistemáticamente en el desarrollo de las capacidades requeridas para que candidatos jóvenes puedan interactuar con menos disparidades de recursos y de experiencia. Para ello es importante mantener abiertos canales de participación e incidencia permanentes a nivel comunitario, pues ese suele ser un nivel privilegiado para la formación inicial de capacidades de liderazgo político y social.

Un tercer campo estratégico para el desarrollo de capacidades consiste en que las intervenciones o programas centrados en las personas jóvenes estén guiados o gestionados por ellas mismas (por ejemplo, a nivel de la gestión de proyectos, la colaboración con iniciativas encabezadas por jóvenes y la inclusión sistemática de menores de 29 años en los procesos de diálogo o consulta nacionales y locales). Con el fin de privilegiar acciones que estén efectivamente vinculadas con los intereses y prioridades presentes en cada contexto, tales iniciativas deben adaptarse a las condiciones nacionales o locales, así como a la diversidad de situaciones de las personas jóvenes. En el recuadro V.6 se identifican algunas medidas que pueden favorecer la participación de las personas jóvenes en las distintas fases del ciclo electoral, en donde interactúan la normativa electoral, la reglamentación interna de los partidos políticos y las normas y prácticas de las organizaciones de la sociedad civil. 
Cuadro V.5

América Latina y el Caribe (24 países): edad mínima para votar y para ser elegido al poder legislativo nacional

\begin{tabular}{|c|c|c|c|c|}
\hline País & Cámara & Escaños & Edad Para Ser Votado & Edad Para Votar \\
\hline \multirow{2}{*}{ Argentina } & Senado & 74 & 30 años & \multirow{2}{*}{18 años } \\
\hline & Diputados & 257 & 25 años & \\
\hline \multirow{2}{*}{$\begin{array}{l}\text { Bolivia (Estado } \\
\text { Plurinacional de) }\end{array}$} & Senado & 36 & 35 años & \multirow{2}{*}{18 años } \\
\hline & Diputados & 130 & 25 años & \\
\hline \multirow{2}{*}{ Brasil } & Senado & 81 & 35 años & \multirow{2}{*}{16 años } \\
\hline & Diputados & 513 & 25 años & \\
\hline \multirow{2}{*}{ Colombia } & Senado & 102 & 30 años & \multirow{2}{*}{18 años } \\
\hline & Diputados & 165 & 25 años & \\
\hline Costa Rica & Asambleístas & 57 & 21 años & 18 años \\
\hline \multirow{2}{*}{ Chile } & Senado & 38 & 40 años & \multirow{2}{*}{18 años } \\
\hline & Diputados & 120 & 21 años & \\
\hline Ecuador & Asambleístas & 137 & 18 años & 16 años \\
\hline Guatemala & Diputados & 158 & 18 años & 18 años \\
\hline Honduras & Diputados & 128 & 21 años & 18 años \\
\hline \multirow{2}{*}{ México } & Senado & 150 & 30 años & \multirow{2}{*}{18 años } \\
\hline & Diputados & 500 & 21 años & \\
\hline Nicaragua & Asambleístas & 92 & 21 años & 16 años \\
\hline \multirow{2}{*}{ Paraguay } & Senado & 45 & 35 años & \multirow{2}{*}{18 años } \\
\hline & Diputados & 125 & 25 años & \\
\hline Perú & Diputados & 130 & 25 años & 18 años \\
\hline \multirow{2}{*}{ Uruguay } & Senado & 30 & 30 años & \multirow{2}{*}{18 años } \\
\hline & Diputados & 99 & 25 años & \\
\hline Dominica & Asambleístas & 31 & 21 años & 18 años \\
\hline \multirow{2}{*}{ Granada } & Senado & 13 & \multirow{2}{*}{18 años } & \multirow{2}{*}{18 años } \\
\hline & Diputados & 16 & & \\
\hline Guyana & Asambleístas & 65 & 18 años & 18 años \\
\hline \multirow{2}{*}{ Haití } & Senado & 30 & \multirow{2}{*}{25 años } & \multirow{2}{*}{18 años } \\
\hline & Diputados & 95 & & \\
\hline \multirow{2}{*}{ Jamaica } & Senado & 21 & \multirow{2}{*}{21 años } & \multirow{2}{*}{18 años } \\
\hline & Diputados & 63 & & \\
\hline \multirow{2}{*}{ Santa Lucía } & Senado & 11 & \multirow{2}{*}{30 años } & \multirow{2}{*}{18 años } \\
\hline & Diputados & 18 & & \\
\hline Saint Kitts y Nevis & Asambleístas & 16 & 21 años & 18 años \\
\hline Suriname & Asambleístas & 51 & 18 años & 18 años \\
\hline $\begin{array}{l}\text { República } \\
\text { Dominicana }\end{array}$ & Diputados & 190 & 25 años & 18 años \\
\hline & Senado & 31 & & \\
\hline Irınıdad y labago & Diputados & 42 & 25 anos & 18 anos \\
\hline
\end{tabular}

Fuente: Elaboración propia sobre la base de los registros electorales oficiales de los países y María García, "Jóvenes políticos en los parlamentos latinoamericanos", Elites Parlamentarias Latinoamericanas. Boletín Datos de Opinión, N 6, Universidad de Salamanca, 2009 [en línea] http://americo.usal.es/ oir/elites/Boletines_Analisis/6_Garc\%C3\%ADa.pdf; Mariana Llanos y Detlef Nolte, "Los Congresos en América Latina: Legislaturas reactivas, potencialmente activas", Política, $\mathrm{N}^{\circ} 47$, Santiago, Universidad de Chile [en línea] http://www.revistapolitica.uchile.cl/index.php/RP/issue/view/1651. 


\section{Recuadro V.6}

Intervenciones estratégicas para potenciar y fortalecer la participación y movilización política de las personas jóvenes en las distintas etapas del ciclo electoral

\section{Medidas en el período preelectoral}

A nivel de las organizaciones de la sociedad civil, la vida comunitaria y el debate público

- Alentar la continua participación de la juventud e impartir educación cívica en escuelas y universidades.

- Diseñar programas de capacitación, como incubadoras de proyectos, para la formación de valores democráticos, el desarrollo de cualidades de liderazgo, trabajo en equipo y sobre el papel de las personas jóvenes como ciudadanos y agentes de cambio en sus sociedades.

- Apoyar el desarrollo comunitario y las organizaciones de voluntarios encabezadas por jóvenes.

- Brindar apoyo flexible con bajas barreras de acceso a proyectos juveniles innovadores y de pequeña escala.

- Salvar la brecha digital utilizando teléfonos celulares y espacios de radio dedicados a la discusión de temas específicos por parte de personas jóvenes.

- Utilizar plataformas virtuales para compartir conocimientos y establecer contactos entre jóvenes movilizados políticamente.

A nivel de los partidos políticos

- Alentar medidas de acción afirmativa, tales como cuotas de jóvenes y mujeres en los partidos políticos.

- Apoyar el desarrollo de fuertes alas juveniles en los partidos políticos.

- Brindar fomento de capacidad para afiliados jóvenes de partidos políticos en un contexto multipartidario.

- Abordar por separado las necesidades de capacitación y mentoría de las personas jóvenes que militan en un partido.

2. Medidas para fomentar la participación y movilización de los jóvenes durante el ciclo electoral

- Asegurar la participación de la juventud en todas las fases de las campañas de educación al votante.

- Implementar métodos atractivos y estrategias multimedia para atraer la atención de la juventud.

- Incluir a la juventud en comités de asesoramiento de los organismos o tribunales electorales como personal de locales de votación y observadores electorales, así como fondos de apoyo a proyectos de observación electoral.

- Desarrollar herramientas interactivas en línea para llegar a los votantes jóvenes que saben usar computadoras. 
Recuadro V.6 (conclusión)

\section{Medidas para fomentar la participación y movilización política de las personas jóvenes durante la fase poselectoral}

- Hacer que se escuchen las voces de la juventud en el Parlamento y en el gobierno.

- Facilitar el funcionamiento de consejos o parlamentos juveniles nacionales dirigidos por jóvenes.

- Invitar a grupos de jóvenes a visitar y conocer el trabajo cotidiano de los Parlamentos nacionales.

- Iniciar esquemas de pasantías para estudiantes en los Parlamentos.

- Capacitar y apoyar a los miembros jóvenes del Parlamento.

- Iniciar y apoyar los consejos de jóvenes a nivel local.

Fuente: Programa de las Naciones Unidas para el Desarrollo (PNUD), Mejorando la participación política de la juventud a lo largo del ciclo electoral. Guía de buenas prácticas, Nueva York, 2013 [en línea] http://www.undp.org/content/dam/undp/library/ Democratic\%20Governance/Electoral\%20Systems\%20and\%20Processes/SP_UNYouth_Guide-LR.pdf.

Por último, cabe mencionar que varias de estas medidas han sido evocadas por las propias personas jóvenes en múltiples foros. Por ejemplo, en la Declaración de Juventud del IV Foro de Jóvenes de las Américas de abril de 2015, los jóvenes participantes identificaron las siguientes prioridades: "Proponemos cuotas electorales juveniles que aseguren nuestra participación e incidencia, institucionalizar mecanismos de debate permanente, TICs sociales, consultas vinculantes y la participación en el ciclo de las políticas públicas. Además evaluar aquellos que existan para reformarlos hacia el futuro, brindando adicionalmente educación ciudadana sobre liderazgo, participación pública, gestión y control político y social" (VII Cumbre de las Américas, 2015, pág. 7).

\section{F. Conclusiones}

Tras el período más largo de vida en democracia para la mayoría de los países de América Latina, las percepciones de las personas en torno a su participación política muestran, en la mayoría de los casos, un importante déficit de legitimidad. Esto se suma a las dificultades y deudas de los regímenes democráticos de la región, en los que persiste una gran tensión entre democracias que, más allá de la esfera electoral y formal, coexisten con sociedades altamente desiguales. En la gran mayoría de los países, por ejemplo, se mostró que más de dos tercios de los jóvenes y adultos consideraban que gobernaban los poderosos en su propio beneficio. Desde esa perspectiva, la democracia está lejos de ser percibida como un mecanismo de inclusión, de igualación o de mejoría individual. 
A la vez, las actitudes y percepciones de los jóvenes exploradas en este capítulo expresan cambios en los últimos años, probablemente de la mano de las trayectorias particulares de cada país, en especial sus ciclos políticos y económicos. De un país a otro se corroboran rasgos generales ya identificados por numerosos estudios, como una menor confianza en las instituciones sociales y sobre todo políticas, menores niveles de participación convencional y electoral, bajo interés en la política, una mayor indiferencia a la mostrada por los no jóvenes hacia la democracia como mejor forma de gobierno y una tendencia a asociar la democracia con la libertad individual y de expresión, entre otros aspectos. Pero algunas de estas características no son exclusivas de las personas jóvenes: en muchos contextos nacionales, jóvenes y adultos comparten un bajo interés en la política y una elevada desconfianza hacia las instituciones políticas.

También en las encuestas se observa un mayor optimismo juvenil y una actitud en principio más entusiasta que la de los adultos para movilizarse a favor de temas como la salud, la educación y mejores empleos y oportunidades. Esto coincide con una mayor disposición de los jóvenes a manifestarse directamente mediante movilizaciones y otras vías, aun cuando la mayoría se muestre indiferente o reticente a participar. En comparación con los adultos, entre las personas jóvenes suele haber un contingente mayor que no vota (por exclusión etaria o por autoexclusión) ni se ha movilizado nunca. Al mismo tiempo, los jóvenes han sido protagonistas de modalidades no convencionales de movilización que pueden incidir en la agenda pública y que desempeñan un papel central en el planteamiento de demandas postergadas $u$ omitidas por los canales convencionales de participación. Otro elemento coincidente a nivel de la región apunta a los temas de mayor preocupación para las personas jóvenes y su evolución en el tiempo. En 2000, los problemas considerados más apremiantes eran la desocupación y el desempleo, la educación y la corrupción. Trece años después irrumpen los problemas de delincuencia y seguridad pública, el desempleo se mantiene como tema de interés y, en menor medida, se mencionan la educación y la corrupción.

Por otra parte, como se ha tratado de mostrar, el perfil del ciudadano joven en la región no se ha mantenido estático ni ha evolucionado en un único sentido. Más allá de los rasgos generales ya mencionados, se observan grandes variaciones de un país a otro. Hay países caracterizados por niveles de confianza, participación y apego a la democracia relativamente altos (Argentina, Costa Rica, Uruguay y Venezuela (República Bolivariana de)) y otros, como el Brasil, Chile, México y varios países centroamericanos, que presentan niveles más bien bajos en ambos puntos del tiempo. No obstante, las trayectorias de unos y otros han sido muy diversas. En algunos casos hay múltiples indicios de una 
caída simultánea de la participación electoral y la movilización, así como de la confianza en las instituciones políticas, en la democracia y en las capacidades de respuesta de los gobiernos, entre otros aspectos. Tal es el caso de México, el Paraguay y la mayoría de los países de Centroamérica, en donde se destaca Costa Rica por el elevado nivel inicial de confianza y apego a la democracia que caracterizaba a ese país en 2000. El caso del Uruguay también es notable, ya que muestra elevados niveles iniciales de apego y confianza en la democracia en 2000 y un posterior descenso, aunque en menor medida que en Costa Rica.

También hay casos en los que, en torno al año 2000, se presentaban niveles muy bajos de confianza y apego juvenil en esas dimensiones y que han aumentado para 2013, como ocurrió en el Brasil y, muy claramente, en el Ecuador y Venezuela (República Bolivariana de). Esto sugiere una hipótesis en el sentido del peso de ciclos económicos favorables y de procesos de alternancia política o de refundación constitucional que mitigaron la elevada desconfianza y la baja participación de las personas jóvenes prevalecientes alrededor de 2000 en varios países. Este parecería ser el caso de la Argentina, el Brasil, Colombia, el Ecuador, Venezuela (República Bolivariana de) y, en menor medida, el Uruguay. Lo que ocurre en Chile es más ambiguo, ya que se mantuvo entre los países en donde las personas jóvenes presentan indicios de menor confianza hacia la política y la democracia, y una mayor tendencia a recurrir a la movilización por parte de una minoría importante. Lo expuesto apunta a que, a diferencia de lo que otros estudios señalan en virtud de un análisis fijo en el tiempo, la actitud de las personas jóvenes y sus patrones de participación política no están destinados a seguir una pauta unívoca, sino que los cambios de trayectoria, positivos y negativos, son posibles. Si bien el elevado y creciente desapego juvenil en unos casos (México y Centroamérica) resulta preocupante, en otros, sobre todo en América del Sur, el panorama fue más positivo.

Al respecto, se argumentó que existe un abanico de opciones relativas a normas, políticas y programas centrados en el fomento de la participación, organización y movilización de las personas jóvenes. También se planteó que una orientación general debería consistir en abrir espacios y eliminar barreras a la participación de las personas jóvenes, no con la premisa de revertir mecánicamente los patrones de exclusión o autoexclusión de los canales convencionales de participación, sino de permitir que cada contexto político e institucional sea capaz de incorporar sus movilizaciones y aportes. Un punto de partida en casi todos los países sería abrir la discusión sobre las condiciones de elegibilidad: la distancia, a veces muy grande, que separa a las edades requeridas para poder votar y ser votado. 


\section{Bibliografía}

Beetham, David (2006), Parliament and Democracy in the Twenty-First Century. A Guide to Good Practice, Ginebra, Unión Interparlamentaria.

Bianchi, Matías (2014), Democracia en los márgenes de la democracia. Activismo en América Latina en la era digital, Asuntos del Sur.

Bobbio, Norberto (1996), Liberalismo y democracia, Ciudad de México, Fondo de Cultura Económica.

Calderón Gutiérrez, Fernando (coord.) (2012), “La protesta social en América Latina", Cuadernos de Prospectiva Politica, N ${ }^{\circ}$, Buenos Aires, Siglo Veintiuno Editores, julio.

(2011), Los conflictos sociales en América Latina, Programa de las Naciones Unidas para el Desarrollo (PNUD)/Fundación UNIR Bolivia, septiembre.

CEPAL (Comisión Económica para América Latina y el Caribe) (2014), Panorama Social de América Latina 2014 (LC/G.2635-P), Santiago. Publicación de las Naciones Unidas, $\mathrm{N}^{\circ}$ de venta: S.14.II.G.6.

CEPAL/OIJ (Comisión Económica para América Latina y el Caribe/Organización Iberoamericana de Juventud) (2008), Juventud y cohesión social en Iberoamérica. Un modelo para armar (LC/G.2391), Santiago, octubre.

CEPAL/UNFPA (Comisión Económica para América Latina y el Caribe/Fondo de Población de las Naciones Unidas) (2011), Informe Regional de Población en América Latina y el Caribe 2011. Invertir en Juventud (LC/G.2391), Santiago.

Corporación Latinobarómetro (2013), Informe 2013, Santiago, noviembre.

FLACSO/IDEA Internacional (Facultad Latinoamericana de Ciencias Sociales/ Instituto Internacional para la Democracia y la Asistencia Electoral) (2013), Youth and Political Participation in Latin America. Current State and Challenges, Santiago, noviembre.

Hirschman, Albert (1995), Bonheur privé, action publique, París, Fayard.

IDEA Internacional (2013), Annual Democracy Forum 2013. Youth Participation in Politics and Elections. Background Paper, Instituto Internacional para la Democracia y la Asistencia Electoral.

Luna, Juan Pablo (2014), "Partidos políticos y pactos sociales en América Latina", inédito.

Moreno, Alejandro (2001), "Democracy and mass belief systems in Latin America", Citizen Views of Democracy in Latin America, Roderic Ai Camp (ed.), Pittsburgh, University of Pittsburgh Press.

Morlino, Leonardo (2014), La calidad de las democracias en América Latina. Informe para IDEA Internacional, San José, Instituto Internacional para la Democracia y la Asistencia Electoral.

OIJ (Organización Iberoamericana de Juventud) y otros (2013), El futuro ya llegó. $1^{a}$ encuesta iberoamericana de juventudes. Informe ejecutivo, Madrid, julio.

Pavez, María Isabel (2014), "Los derechos de la infancia en la era de internet. América Latina y las nuevas tecnologías", serie Políticas Sociales, N 210 (LC/L.3894), Santiago, Comisión Económica para América Latina y el Caribe (CEPAL), septiembre.

PNUD (Programa de Naciones Unidas para el Desarrollo) (2013), Informe Regional de Desarrollo Humano 2013-2014. Seguridad ciudadana con rostro humano: Diagnóstico y propuestas para América Latina, Nueva York, noviembre. 
PNUD/AECID (Programa de las Naciones Unidas para el Desarrollo/Agencia Española de Cooperación Internacional para el Desarrollo) (2014), Ciudadanía política. Voz y participación ciudadana en América Latina, Buenos Aires, Siglo Veintiuno Editores, febrero.

Reguillo, Rossana (2003), “Ciudadanías juveniles en América Latina”, Última Década, vol. 11, No 19, Santiago, Centro de Estudios Sociales (CIDPA), noviembre.

UIP (Unión Interparlamentaria) (2014), Taking Democracy to Task, Ginebra, octubre. UNFPA (Fondo de Población de las Naciones Unidas) (2014), Estado de la población mundial 2014. El poder de 1800 millones: Los adolescentes, los jóvenes y la transformación del futuro, Nueva York, Naciones Unidas, noviembre.

VII Cumbre de las Américas (2015), “Declaración de Juventud. IV Foro de Jóvenes de las Américas: Jóvenes socios para la prosperidad" [en línea] http:// cumbredelasamericas.pa/declaracion-de-juventud-iv-foro-de-jovenes-de-lasamericas-jovenes-socios-para-la-prosperidad/. 



\section{Capítulo VI \\ Reflexiones finales}

En el año 2013, el Secretario General de las Naciones Unidas nombró al primer Enviado del Secretario General para la Juventud a fin de fortalecer el compromiso del sistema de las Naciones Unidas con los jóvenes. Creó a la vez un grupo de trabajo con la tarea de elaborar un plan estratégico global para la juventud que reuniera a diversos organismos de las Naciones Unidas para mejorar la coherencia y la sinergia de las actividades de todo el sistema de la Organización en áreas clave relacionadas con el desarrollo juvenil. Estas medidas han permitido avanzar en el conocimiento y la comprensión de los desafíos y problemas que enfrenta la juventud actualmente. Se plantean dos retos para la sociedad en su conjunto: la necesidad de responder a las demandas de los jóvenes en los diferentes espacios donde su voz no tiene eco, debiendo esa respuesta estar orientada a garantizar sus derechos, y la importancia de considerar a los jóvenes como actores fundamentales para el desarrollo haciéndolos partícipes de ese proceso (CEPAL, 2014).

Los esfuerzos que ha hecho la CEPAL por avanzar en este sentido son de larga trayectoria. El primer y segundo informe iberoamericano de juventud, presentados en 2004 y 2008 conjuntamente por la CEPAL y la Organización Iberoamericana de Juventud (CEPAL/OIJ, 2004 y 2008), contribuyeron a la elaboración de visiones, diagnósticos y políticas de juventud en el espacio iberoamericano. A partir de la reflexión propuesta en estos informes, se identificaron una serie de tensiones y paradojas que enfrentan los jóvenes en sus procesos de desarrollo y de inclusión social, que se han establecido como referentes de la discusión de juventud a nivel regional. En comparación con generaciones anteriores, se les reconoce 
como una población más educada, pero con menores oportunidades laborales; con más acceso a la información que nunca antes, pero con pocas oportunidades de acceder al poder en espacios de representación; más saludable, pero al mismo tiempo con menor reconocimiento de la política pública a sus necesidades de salud específicas, y con altos niveles de acceso al consumo simbólico, pero muchas restricciones para materializarlo. Para conciliar estas paradojas y lograr que todos los jóvenes de la región puedan hacer efectivos sus derechos alcanzando una plena inclusión en la sociedad, realizar su potencial y contribuir a construir sociedades más igualitarias y productivas, se requieren políticas que consideren al sujeto joven en su integralidad.

En los capítulos que preceden se analizó la inclusión desde el punto de vista de algunas dimensiones de la vida de los jóvenes y se extrajeron los principales retos que deberían abordarse para avanzar hacia la formulación de políticas que permitan cerrar las brechas objetivas de inclusión social juvenil. Aunque el análisis se centró principalmente en las desigualdades de ingreso y las brechas intergeneracionales, las brechas de género, las desigualdades étnicas y las territoriales son otros campos fértiles para profundizar el análisis e intervenir con políticas.

Este diagnóstico contribuye a un rico corpus de conocimiento sobre la situación de los jóvenes en América Latina y el Caribe que se va afinando cada vez más y que abre una discusión sobre algunos temas que han sido hasta ahora poco atendidos. Además, aporta un análisis de las políticas al yuxtaponer la realidad de la inclusión social de los jóvenes con las políticas existentes que responden (o no) a estas realidades. A partir de las recomendaciones elaboradas en cada uno de los ámbitos de acción, se identifican algunos retos comunes.

En primer lugar, se señala la necesidad de contar con mejores sistemas de información que permitan monitorear las situaciones de vida y las percepciones de este conjunto de la población en cada país y territorio, y de que esta información sea utilizada para tomar decisiones de inversión pública en la juventud de manera más informada. Por otra parte, se propone avanzar en la promulgación de normativa y regulaciones que protejan y promuevan la realización de los derechos sociales de los jóvenes, por ejemplo, el acceso a servicios de salud y educación, la oportunidad de un trabajo decente y la posibilidad de participar en los procesos de toma de decisiones de interés público. Finalmente, un reto de gran relevancia es la articulación, con una mirada integral, de los distintos sectores de la política pública involucrados.

En el presente análisis se constató la relevancia y, en algunos casos, la ausencia de esta mirada integral y multidimensional sobre la juventud en las políticas que abordan este ciclo de la vida. Por ejemplo, considerando 
el eje principal de inclusión social de la población joven, la educación y el empleo, se pudo observar que las políticas de estas dos áreas tienen poca vinculación entre sí, y en ninguno de los dos ámbitos se abarca de una manera central o comprensiva el tema de la familia y las tareas del cuidado. Justamente en esta etapa de la vida es cuando la necesidad de conciliar la educación con el empleo es más fuerte, y el peso de las responsabilidades familiares y de cuidado puede truncar las trayectorias educacionales y laborales de los jóvenes, especialmente de las mujeres. De la misma manera, se releva la importancia de articular entre los sectores de salud, educación y seguridad el tema de la violencia que enfrenta la juventud en su proceso de desarrollo e inclusión, para aplicar estrategias de real prevención y acompañamiento de la población juvenil.

Para lograr políticas que respondan a la multidimensionalidad y la integralidad del ser joven y promuevan su inclusión en la sociedad, se requiere un contexto institucional propicio. El marco institucional determina en gran medida el tipo de políticas que pueden implementarse para promover la inclusión social de los jóvenes, su alcance y su efectividad. Hay tres dimensiones de la institucionalidad que son factores determinantes en este proceso: los entes coordinadores de la temática, el marco normativo y la existencia de políticas o planes nacionales de juventud.

Es importante reconocer que la concepción de la juventud es una construcción social y, por tanto, las definiciones etarias, características y roles que se le otorguen varían de acuerdo con los factores históricos y culturales de cada sociedad. Además, los países tienen que tener en consideración que las transiciones y trayectorias vitales de los jóvenes son heterogéneas, se desarrollan de distinta manera y en distintos tiempos, y no necesariamente siguen un modelo de trayectoria lineal (CEPAL/OIJ/IMJUVE, 2014).

Por lo tanto, lo primero a tener en cuenta al analizar el contexto institucional es la perspectiva sobre juventud que se toma en las políticas y programas como punto de partida. Tal como se ha planteado en los informes iberoamericanos de juventud (CEPAL/OIJ, 2004, 2008; CEPAL/ OIJ/IMJUVE, 2014), la complejidad a la que remite el término juventud y la manera de definirlo determina la variabilidad de la concepción de las políticas con que se aborda el tema. Más allá del rango etario establecido, que en la mayoría de los países se sitúa entre los 15 y 24 años o entre los 15 y 29 años de edad, lo que va a determinar en gran medida la implementación de las políticas es la definición sustancial que se tenga de este segmento y dónde se sitúa, es decir, qué lugar ocupan los jóvenes dentro de la sociedad, qué roles se les asigna y qué otros les son vedados (CEPAL/OIJ/IMJUVE, 2014).

De acuerdo con un estudio realizado por Dina Krauskopf (2003), incluido en los informes iberoamericanos de juventud (CEPAL/OIJ, 2008; 
CEPAL/OIJ/IMJUVE, 2014), es posible identificar cuatro grandes paradigmas que han dominado en los supuestos estatales respecto del término juventud, incidiendo, por tanto, en la definición de las políticas para los jóvenes (véase el cuadro VI.1).

\section{Cuadro VI.1}

Paradigmas de la fase juvenil en los enfoques de políticas y programas

\begin{tabular}{|c|c|c|c|c|}
\hline $\begin{array}{l}\text { Paradigma de } \\
\text { la fase juvenil }\end{array}$ & Políticas & $\begin{array}{l}\text { Características } \\
\text { de los } \\
\text { programas }\end{array}$ & Tipos & Objetivos \\
\hline \multirow{5}{*}{$\begin{array}{l}\text { Transición a la } \\
\text { adultez } \\
\text { (etapa de } \\
\text { preparación) }\end{array}$} & $\begin{array}{l}\text { Orientadas a la } \\
\text { preparación para la } \\
\text { adultez }\end{array}$ & \multirow{5}{*}{$\begin{array}{l}\text { Universales } \\
\text { Indiferenciados } \\
\text { Aislados }\end{array}$} & \multirow{5}{*}{$\begin{array}{l}\text { Programas } \\
\text { educativos } \\
\text { Programas de } \\
\text { uso del tiempo } \\
\text { libre y actividades } \\
\text { deportivas, } \\
\text { recreativas o } \\
\text { culturales }\end{array}$} & $\begin{array}{l}\text { Integración de } \\
\text { los jóvenes }\end{array}$ \\
\hline & $\begin{array}{l}\text { adultez } \\
\text { Extensión de la } \\
\text { cobertura educativa }\end{array}$ & & & \multirow[t]{2}{*}{$\begin{array}{l}\text { Potenciamiento } \\
\text { de factores } \\
\text { protectores de } \\
\text { la adolescencia }\end{array}$} \\
\hline & \multirow{2}{*}{$\begin{array}{l}\text { Tiempo libre sano y } \\
\text { recreativo, con baja } \\
\text { cobertura }\end{array}$} & & & \\
\hline & & & & \multirow{2}{*}{$\begin{array}{l}\text { Prevención de } \\
\text { la violencia en la } \\
\text { etapa predelictiva }\end{array}$} \\
\hline & Servicio militar & & & \\
\hline \multirow{4}{*}{$\begin{array}{l}\text { Riesgo y } \\
\text { transgresión } \\
\text { (etapa } \\
\text { problemática } \\
\text { para la } \\
\text { sociedad) }\end{array}$} & \multirow{4}{*}{$\begin{array}{l}\text { Compensatorias } \\
\text { Sectoriales } \\
\text { (predominantemente } \\
\text { justicia y salud) } \\
\text { Focalizadas }\end{array}$} & \multirow{2}{*}{$\begin{array}{l}\text { Asistencialidad } \\
\text { y control de } \\
\text { problemas } \\
\text { específicos }\end{array}$} & $\begin{array}{l}\text { Programas de } \\
\text { rehabilitación }\end{array}$ & \multirow{4}{*}{$\begin{array}{l}\text { Control social de } \\
\text { sectores juveniles } \\
\text { movilizados } \\
\text { Prevención de la } \\
\text { violencia }\end{array}$} \\
\hline & & & $\begin{array}{l}\text { Programas de } \\
\text { reinserción social }\end{array}$ & \\
\hline & & $\begin{array}{l}\text { Relevancia } \\
\text { a la juventud } \\
\text { urbano-popular }\end{array}$ & $\begin{array}{l}\text { Programas en } \\
\text { torno al sistema } \\
\text { carcelario }\end{array}$ & \\
\hline & & $\begin{array}{l}\text { Dispersión } \\
\text { de ofertas }\end{array}$ & & \\
\hline \multirow{5}{*}{$\begin{array}{l}\text { La juventud } \\
\text { ciudadana } \\
\text { (etapa de } \\
\text { desarrollo } \\
\text { social) }\end{array}$} & \multirow{5}{*}{$\begin{array}{l}\text { Articuladas en la } \\
\text { política pública } \\
\text { Intersectoriales } \\
\text { Inclusión de los } \\
\text { jóvenes como } \\
\text { sujetos explícitos de } \\
\text { derechos políticos, } \\
\text { sociales, culturales } \\
\text { y económicos }\end{array}$} & \multirow{5}{*}{$\begin{array}{l}\text { Integrales } \\
\text { Participativos } \\
\text { Extensión de } \\
\text { alianzas entre } \\
\text { programas y } \\
\text { ejecutores }\end{array}$} & $\begin{array}{l}\text { Políticas nacionales } \\
\text { de reducción }\end{array}$ & $\begin{array}{l}\text { Estrategia } \\
\text { comunitaria }\end{array}$ \\
\hline & & & de la pobreza & \multirow{2}{*}{$\begin{array}{l}\text { Prevención de la } \\
\text { violencia } \\
\text { Estrategias } \\
\text { participativas }\end{array}$} \\
\hline & & & $\begin{array}{l}\text { Programas de } \\
\text { transferencia } \\
\text { directa o }\end{array}$ & \\
\hline & & & $\begin{array}{l}\text { condicionada } \\
\text { de recursos }\end{array}$ & \multirow[t]{2}{*}{ Capital social } \\
\hline & & & $\begin{array}{l}\text { Programas de } \\
\text { voluntariado }\end{array}$ & \\
\hline \multirow{4}{*}{$\begin{array}{l}\text { La juventud } \\
\text { como actor } \\
\text { estratégico del } \\
\text { desarrollo } \\
\text { (etapa de } \\
\text { formación } \\
\text { y aporte } \\
\text { productivo) }\end{array}$} & \multirow{2}{*}{$\begin{array}{l}\text { Articuladas en } \\
\text { política pública } \\
\text { Intersectoriales }\end{array}$} & \multirow{2}{*}{$\begin{array}{l}\text { Equidad y } \\
\text { transversalidad } \\
\text { institucional }\end{array}$} & $\begin{array}{l}\text { Programas } \\
\text { de empleo de }\end{array}$ & \multirow{4}{*}{$\begin{array}{l}\text { Prevención de } \\
\text { la violencia } \\
\text { Inserción al } \\
\text { mercado laboral } \\
\text { Capital económico }\end{array}$} \\
\hline & & & & \\
\hline & \multirow{2}{*}{$\begin{array}{l}\text { Orientadas a la } \\
\text { incorporación de la } \\
\text { juventud como capital } \\
\text { humano y desarrollo } \\
\text { de capital social }\end{array}$} & $\begin{array}{l}\text { Enfrentamiento } \\
\text { de la exclusión }\end{array}$ & $\begin{array}{l}\text { Programas de } \\
\text { capacitación }\end{array}$ & \\
\hline & & $\begin{array}{l}\text { Aporte juvenil a } \\
\text { estrategias de } \\
\text { desarrollo }\end{array}$ & $\begin{array}{l}\text { Programas } \\
\text { de desarrollo } \\
\text { productivo y } \\
\text { empresarial }\end{array}$ & \\
\hline
\end{tabular}

Fuente: Comisión Económica para América Latina y el Caribe (CEPAL)/Organización Iberoamericana de Juventud (OIJ), Juventud y cohesión social en Iberoamérica: un modelo para armar (LC/G.2391), Santiago, 2008, sobre la base de D. Krauskopf, "La construcción de las políticas de juventud en Centroamérica", Políticas públicas de juventud en América Latina: políticas nacionales, O. Dávila (comp.), Viña del Mar, CIDPA Ediciones. 
Todos estos paradigmas aparecen en distintos momentos de las últimas tres décadas, pero no se excluyen entre sí. Hoy coexisten en la política y el discurso públicos, y con frecuencia se combinan y fusionan de distintas maneras. De cada uno de estos enfoques se desprenden opciones en cuanto a la formulación de las políticas y el carácter de los programas orientados a la juventud (CEPAL, 2009; CEPAL/OIJ/IMJUVE, 2014). En los dos últimos enfoques, el de ciudadanía juvenil y el de la juventud como actor estratégico del desarrollo, se considera a los jóvenes como actores sociales, perspectiva que las Naciones Unidas y este libro promueven. Se intenta evitar asumir el primer paradigma porque a partir de este no se considera a la persona joven un sujeto de derechos y de bienestar en su etapa de vida actual, sino solo en cuanto será un adulto en el futuro. El segundo conduce a una mirada restringida y estigmatizante sobre la población juvenil, que puede originar soluciones de política pública limitadas en el sentido de proporcionar a las nuevas generaciones las capacidades que requieren para participar en un proceso de desarrollo dirigido a establecer condiciones de igualdad.

En cuanto a las instituciones gubernamentales coordinadoras de los temas relativos a la juventud, existen muy diversas modalidades (véase el anexo VI.A1). En la región se pueden identificar ministerios (Nicaragua, República Dominicana y Venezuela (República Bolivariana de)), viceministerios (Bolivia (Estado Plurinacional de) y Costa Rica), secretarías de juventud (Brasil, Paraguay y Perú), subsecretarías, institutos (Chile, El Salvador, Honduras, México y Uruguay), direcciones (Argentina y Ecuador), consejos nacionales de juventud (Guatemala) y otros. Como señaló la CEPAL (2009), en general, los objetivos de estas instancias incluyen al menos cuatro tareas: el conocimiento sistemático de la realidad juvenil; la profesionalización de su personal técnico; la innovación en el diseño y la ejecución de programas, y el desarrollo de capacidades comunicacionales para promover consensos entre la clase dirigente y la opinión pública. En el anexo VI.A1 se presentan los principales objetivos o misiones establecidos en varias de las entidades coordinadoras de los temas de juventud en la región. La mayoría declara como principal misión coordinar y articular las políticas, programas y acciones de juventud. Algunas también se consideran interlocutores del Estado en el diálogo con las organizaciones juveniles de la sociedad civil.

La mayor parte de las instituciones de juventud de América Latina y el Caribe tienen su propio sitio web (un 90\% de los países). En general publican noticias relacionadas con temas de juventud e información sobre políticas y programas que están implementándose en el país. Un poco más de la mitad de estos sitios (60\%) presenta información sobre las leyes y normativa relacionadas, alrededor de un $40 \%$ contiene publicaciones vinculadas a investigaciones sobre juventud realizadas por las propias 
instituciones y otros organismos, y menos del 30\% cuenta con información estadística relativa a la juventud de su país.

Independientemente de la variedad de las modalidades y las tareas que llevan a cabo para promover el desarrollo de la población juvenil en sus respectivos países, las instituciones tienden a ser débiles, especialmente cuando se comparan con la solidez de los ministerios sectoriales relacionados, como los de educación, trabajo y salud. Esta debilidad nace de su limitado poder político, los escasos recursos con los que cuentan para ejecutar sus funciones y el poco impacto de sus esfuerzos. Ante este panorama, se hace necesario reflexionar sobre las funciones esenciales que deberían cumplir. En este sentido, se propone que las entidades a cargo de los temas de la juventud se enfoquen en asumir un rol de coordinación y articulación de esfuerzos, para dinamizar los procesos, lograr visibilizar estas cuestiones en las políticas sectoriales e impulsar una mirada integral sobre la juventud en los diferentes sectores. Sin embargo, se reconoce que realizar esta función de coordinación será difícil, considerando la asimetría de poder entre los entes rectores del tema y los ministerios sectoriales. Por lo tanto, se requiere apoyo político de alto nivel para enfatizar y visibilizar el tema de la juventud en los ministerios sectoriales, y paralelamente reforzar y empoderar a los entes rectores correspondientes.

Claramente, fortalecer la articulación entre los actores gubernamentales que trabajan para promover el desarrollo juvenil debe ser una prioridad, ya que los programas desarticulados no solo son más ineficientes en el uso de los (pocos) recursos disponibles, sino también más costosos. Esta realidad justifica la implementación de políticas y programas integrales coordinados por las instancias de juventud, concertados entre los actores involucrados y diseñados de acuerdo con una lógica de atención a los grupos juveniles ubicados en sus entornos respectivos. También resulta necesario fortalecer las instancias locales (sobre todo municipales) para llevar a cabo iniciativas de inclusión social juvenil que contemplen una mayor participación comunitaria, tanto en su diseño como en su ejecución.

Un segundo componente clave de la institucionalidad es la existencia de una normativa sobre juventud (véase el anexo VI.A2). Estas normativas, en forma de leyes o decretos, crean instituciones, manifiestan derechos, identifican objetivos, establecen metas, asignan recursos y distinguen niveles de responsabilidad y de articulación con los actores. Al establecer un marco jurídico en el ámbito de la juventud, la sociedad expresa su compromiso de atender las necesidades de esta población y articula la forma de abarcar esas necesidades. Por otra parte, obliga a los diferentes niveles del poder ejecutivo a definir políticas y programas para cumplir con los objetivos establecidos y a dirigir recursos del presupuesto público para esos fines. De esta manera, el marco jurídico proporciona 
estabilidad, permanencia de criterios, institucionalidad y recursos para las políticas públicas de juventud. No obstante, la existencia de una normativa no garantiza su aplicación; su ejecución requiere una política o plan nacional de juventud. El papel de una política o plan nacional de juventud también es crítico porque proporciona una visión para todos los programas y actividades relacionadas con la juventud de un país, construyendo e instalando a su vez una visión sobre lo que significa ser joven en el contexto histórico específico.

Durante el Primer Foro Mundial de Políticas para la Juventud, se consensuaron lineamientos básicos para dichas políticas ${ }^{1}$. Según el Compromiso de Bakú, las políticas de juventud deberían cumplir con las siguientes características:

- Basarse en derechos (haber sido elaboradas e implementadas en un marco de derechos humanos acorde con los compromisos globales y regionales de los países);

- Ser inclusivas (asegurar la igualdad de oportunidades para que cada joven pueda lograr su máximo potencial en la vida, posibilitando la participación ciudadana de todas las personas y eliminando las barreras de exclusión, particularmente de los grupos vulnerables);

- Ser participativas (ser formuladas, desarrolladas, implementadas, monitoreadas y evaluadas con la participación significativa de personas jóvenes y todos los interesados a nivel local y nacional, de contextos rurales y urbanos, y de todos los contextos de desarrollo, incluidas las situaciones posteriores a un conflicto y de transición);

- Tener perspectiva de género (facilitar acciones específicas que promuevan la igualdad de género, asegurando que las jóvenes se hallen en pie de igualdad con los varones, y abordar las disparidades basadas en el género que puedan surgir en cualquier contexto, desde el político hasta el socioeconómico y cultural);

- Ser integrales (encarar el desarrollo de la juventud con una perspectiva holística, mediante la colaboración entre sectores de la política, ministerios y otras entidades relevantes, y proveer un marco estratégico integrado que oriente la legislación y las medidas que afecten a este grupo etario);

\footnotetext{
El Compromiso de Bakú fue el resultado del Primer Foro Mundial sobre Políticas para la Juventud, organizado por las Naciones Unidas, que se celebró en dicha ciudad entre el 28 y el 30 de octubre 2014. Esta reunión convocó a más de 700 participantes de 165 países y tenía por objetivo proporcionar una plataforma para que diversos actores interesados evaluaran el desarrollo, la implementación y el monitoreo de las políticas de juventud, compartieran experiencias e identificaran brechas y desafíos sobre la materia.
} 
- Basarse en el conocimiento y la evidencia (desarrollarse y actualizarse periódicamente sobre la base de la recolección, el análisis y la difusión de información tanto cualitativa como cuantitativa respecto de la situación, las necesidades, los desafíos y las oportunidades de los jóvenes en un contexto determinado);

- Contar con recursos suficientes (disponer de recursos adecuados, transparentes y especialmente asignados para su implementación, monitoreo y evaluación, así como maximizar los recursos disponibles mediante la coordinación entre los actores interesados), y

- Incluir procesos de rendición de cuentas (ser formuladas y ejecutadas desde el nivel local y nacional, y regularmente monitoreadas y evaluadas según metas e indicadores específicos de desarrollo juvenil y con la activa participación de personas jóvenes).

En la región, muchos países han desarrollado estrategias en las que se asumen las perspectivas de la juventud como un espacio de la ciudadanía o del joven un actor estratégico del desarrollo, y que incluyen elementos del Compromiso de Bakú (véase el anexo VI.A3). Sin embargo, se observa que las políticas propuestas desde los sectores que conciernen a la población joven no necesariamente incorporan esta perspectiva, sino que parten más bien de un enfoque de la juventud como un período de transición o como una etapa de transgresión y riesgo. Esto da lugar a dos cursos paralelos de las políticas de juventud en la región: las políticas impulsadas por los entes rectores del tema de juventud que proponen una respuesta integrada, por una parte, y las políticas sectoriales en juventud, por la otra, que operan con visiones de la población juvenil no convergentes (Rodríguez, 2011).

Además, pese a los avances en materia de políticas y planes de juventud, la asignación de recursos a este sector en los presupuestos públicos aún son insuficientes y, en algunos casos, se evidencian desfases entre el presupuesto y los objetivos de dichos planes. Por ejemplo, como señala Rodríguez (2011), en los documentos de las políticas públicas de juventud se prioriza a los jóvenes excluidos, la inserción laboral, la construcción de ciudadanía y la prevención de la violencia, mientras que en los presupuestos públicos se sigue priorizando a los jóvenes integrados y la educación formal, y se destinan algunos recursos a la salud, pero relativamente pocos a la inserción laboral y la prevención de la violencia (Rodríguez, 2010).

La mayor parte de estos esfuerzos de institucionalización de las acciones hacia la juventud se han establecido a partir de la década de 2000. Todo lo anterior permite constatar la paulatina preocupación de los gobiernos de la región por dar visibilidad y orientación a las acciones 
dirigidas a la juventud, y la toma de conciencia sobre la importancia de la legislación y las políticas adecuadas para responder a las necesidades, aspiraciones y demandas de los jóvenes. Sin embargo, la existencia de una normativa sobre temas de juventud y un plan o política para ejecutar esa normativa es una condición necesaria pero no suficiente para promover la inclusión de los jóvenes, ya que, a pesar de estos avances y compromisos, una serie de desafíos dificultan la efectiva implementación de estas medidas.

En primer lugar, en la actualidad, las políticas nacionales de juventud son gestionadas por los entes coordinadores respectivos, que, como se mencionó previamente, cuentan con recursos y poder político limitados. Al mismo tiempo, los ministerios sectoriales tienden a actuar de forma independiente en temas que afectan a los jóvenes. Esta fragmentación representa una barrera significativa para la ejecución, el seguimiento y, en última instancia, la eficacia de la política.

Otro desafío se relaciona con el financiamiento, un tema que ha recibido atención a nivel global. La Agenda de Acción de Addis Abeba de la Tercera Conferencia Internacional sobre la Financiación para el Desarrollo representa el primer instrumento internacional en que se reconoce explícitamente que invertir en juventud es esencial para lograr un desarrollo inclusivo, equitativo y sostenible para presentes y futuras generaciones ${ }^{2}$. Este mensaje tiene eco en trabajos de la CEPAL y otras organizaciones que promueven el desarrollo juvenil en la región. En sus informes más recientes (CEPAL/UNFPA, 2012; CEPAL/OIJ/IMJUVE, 2014), la CEPAL ha avanzado en el análisis de la inversión social que se requiere para las políticas y estrategias relativas a la juventud, con el fin de brindar una real garantía de sus derechos. En CEPAL/UNFPA (2012) se plantea que la voluntad política expresada en los acuerdos y consensos internacionales no necesariamente se materializa en políticas o programas específicos que garanticen las condiciones para que los jóvenes logren incrementar sus capacidades y realizar autónomamente sus proyectos de vida. De acuerdo con las estimaciones preparadas en el último informe de juventud (CEPAL/OIJ/IMJUVE, 2014), alrededor de 2012 la inversión social total en la región equivalía al 19,1\% del PIB (unos 660.000 millones de dólares). Del total de gasto público en inversión social, las estimaciones indican que la región destina alrededor de 102.000 millones de dólares a programas sociales cuyos beneficiarios directos o indirectos son los jóvenes (183.000 millones de dólares a precios de 2005, expresados en paridad de poder adquisitivo). Tal como se plantea en la edición 2014 del Panorama Social de América Latina (CEPAL, 2014), dado

La Tercera Conferencia Internacional sobre la Financiación para el Desarrollo, organizada por las Naciones Unidas, se celebró entre el 13 y 16 de julio de 2015 en la ciudad de Addis Abeba, Etiopía. El documento final, la Agenda de Acción de Addis Abeba está disponible [en línea] http://www.un.org/ga/search/view_doc.asp?symbol=A/CONF.227/L.1. 
que los márgenes actuales de expansión del gasto público son menores, es necesario mejorar la planificación de los gastos, junto con el desarrollo y fortalecimiento de los mecanismos de evaluación, con el propósito de aumentar la eficacia y eficiencia del uso de los recursos.

En tercer lugar, los canales de participación para que los jóvenes puedan cumplir un papel activo en la formulación, la implementación, el monitoreo y la evaluación de las políticas son insuficientes y no logran captar de una manera inclusiva y eficiente la voz de la juventud. Aunque existen algunas vías de participación a través de organizaciones de jóvenes, estas generalmente carecen de recursos, y la coordinación entre ellas tiende a ser débil o nula. Frecuentemente, en la implementación de políticas públicas, no se propicia la participación de los jóvenes de manera continua a lo largo del proceso, sino solo en las etapas finales y de manera ad hoc. Además, estas instancias de participación solo tienen lugar cuando se trata de políticas que están directamente vinculadas a la población juvenil y no en otros ámbitos. Fortalecer la participación de los jóvenes es imprescindible para que todas las decisiones sean más relevantes, sostenibles y legítimas.

Desarrollar e implementar políticas públicas de juventud incluyentes y participativas no es una tarea sencilla, sino que implica un esfuerzo y un compromiso concertados. Se requiere llevar a cabo consultas entre jóvenes y organizaciones de jóvenes, una coordinación eficaz y sostenible entre los ministerios, recursos suficientes y la integración de la política nacional de la juventud en los planes nacionales de desarrollo. No obstante, como se ha planteado a lo largo de este libro, invertir en esta etapa del ciclo de vida y lograr la plena inclusión de los jóvenes es crucial para el proceso de desarrollo orientado a la construcción de capacidades y oportunidades que permitan alcanzar mayores niveles de igualdad en América Latina y el Caribe.

\section{Bibliografía}

CEPAL (Comisión Económica para América Latina y el Caribe) (2014), Panorama Social de América Latina, 2014 (LC/G.2635-P), Santiago. (2009), Panorama Social de América Latina, 2008 (LC/G.2402-P), Santiago.

CEPAL/OIJ (Comisión Económica para América Latina y el Caribe/Organización Iberoamericana de Juventud) (2008), Juventud y cohesión social en Iberoamérica: un modelo para armar (LC/G.2391), Santiago, octubre.

(2004), La juventud en Iberoamérica: tendencias y urgencias (LC/L.2180), Santiago, octubre. 
CEPAL/OIJ/IMJUVE (Comisión Económica para América Latina y el Caribe/ Organización Iberoamericana de Juventud/Instituto Mexicano de la Juventud) (2014), Invertir para transformar: la juventud como protagonista del desarrollo, Madrid, septiembre.

CEPAL/UNFPA (Comisión Económica para América Latina y el Caribe/Fondo de Población de Naciones Unidas) (2012), Invertir en juventud: Informe Regional de Población en América Latina y el Caribe 2011 (LC/G.2391), Santiago.

Krauskopf, Dina (2003), "La construcción de políticas dejuventud en Centroamérica”, Políticas públicas de juventud en América Latina: políticas nacionales, O. Dávila (comp.), Viña del Mar, CIDPA Ediciones.

Rodríguez, Ernesto (2011), “Políticas de juventud y desarrollo social en América Latina: bases para la construcción de respuestas integradas", documento presentado en el VIII Foro de Ministros de Desarrollo Social de América Latina, San Salvador, 11 y 12 de julio [en línea] http:/ /www.unesco.org/new/fileadmin/MULTIMEDIA/ HQ/SHS/pdf/Youth\%20Policies\%20and\%20Social\%20Development\%20-\%20 Building\%20Integrated\%20Responses\%20ES.PDF. (2010), "Políticas públicas de juventud en América Latina: avances concretados y desafíos a encarar en el Marco del Año Internacional de la Juventud", serie Debates SHS, $\mathrm{N}^{\mathrm{o}} 1$, mayo, Organización de las Naciones Unidas para la Educación, la Ciencia y la Cultura (UNESCO).

SNJ/CLACSO (Secretaría Nacional de Juventud del Brasil/Consejo Latinoamericano de Ciencias Sociales) (2014), Juventud, participación y desarrollo social en América Latina y el Caribe. 


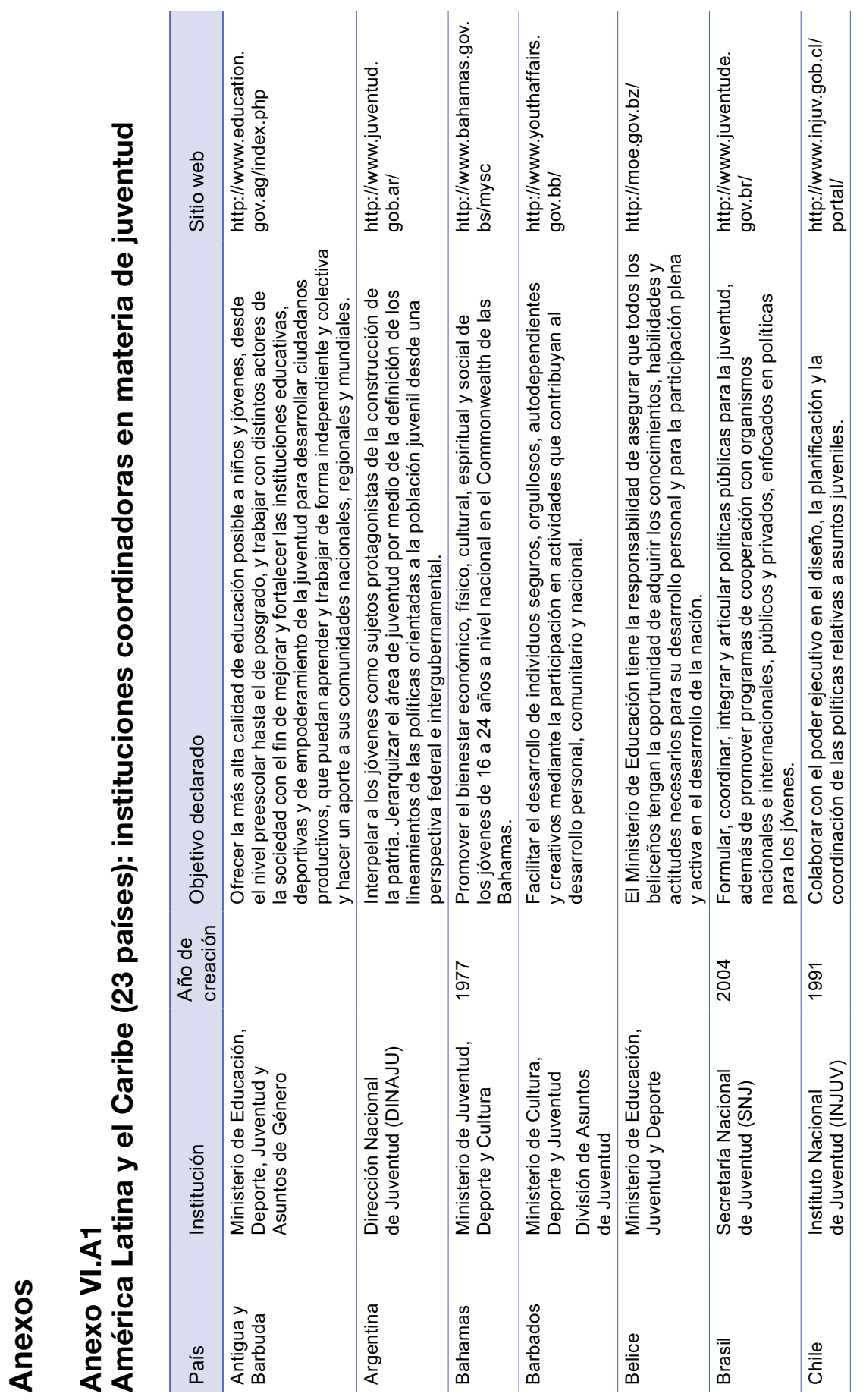




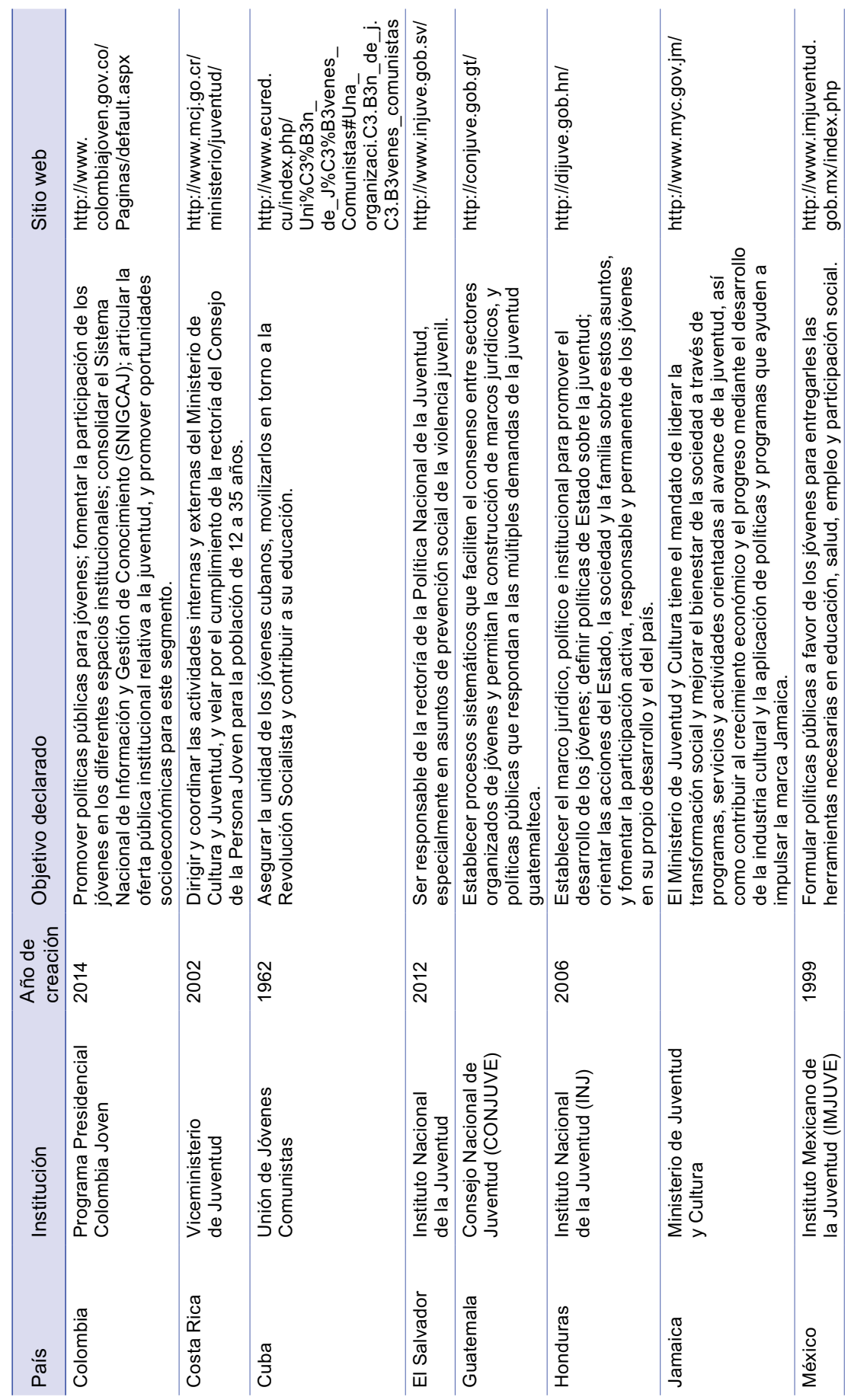




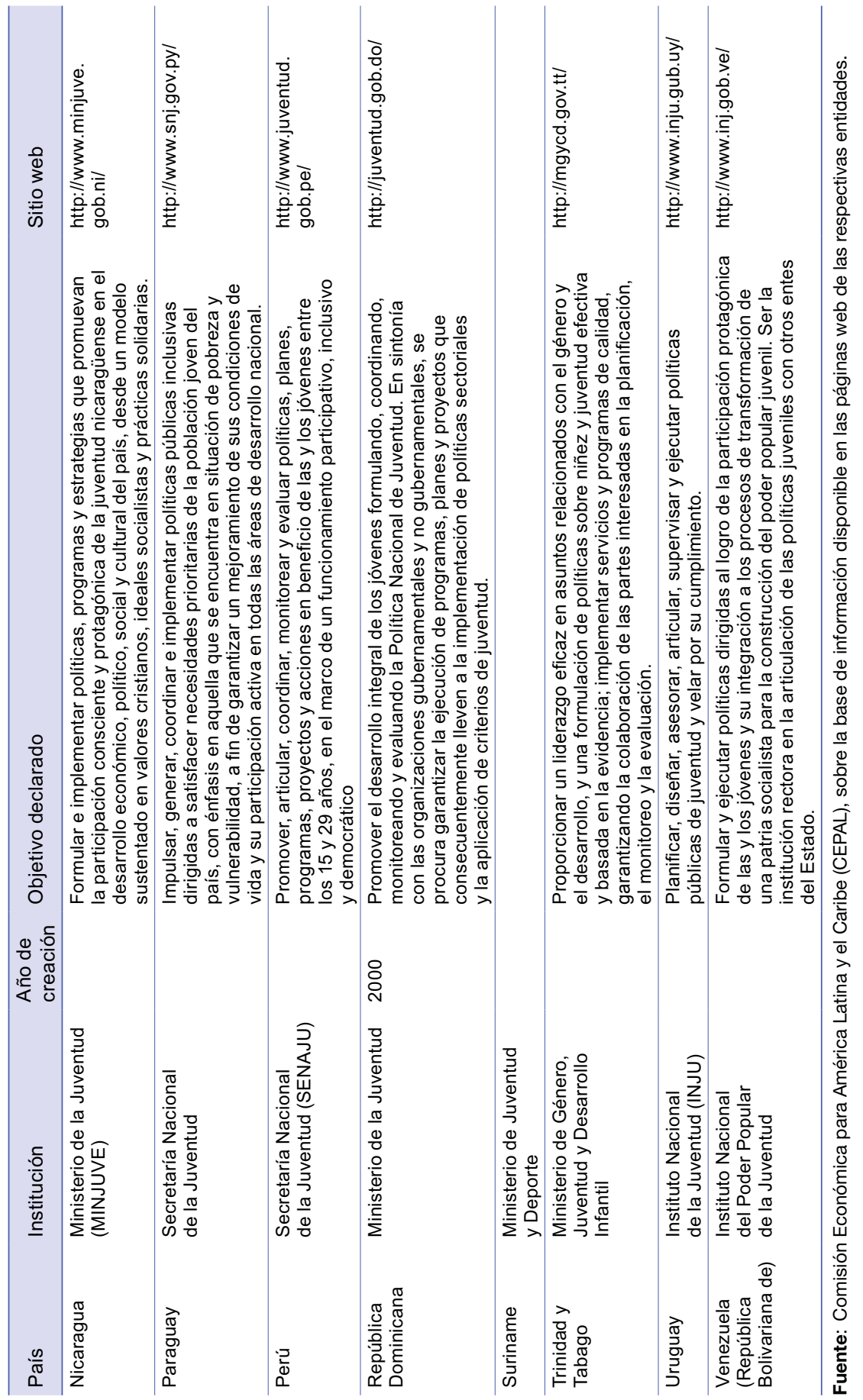




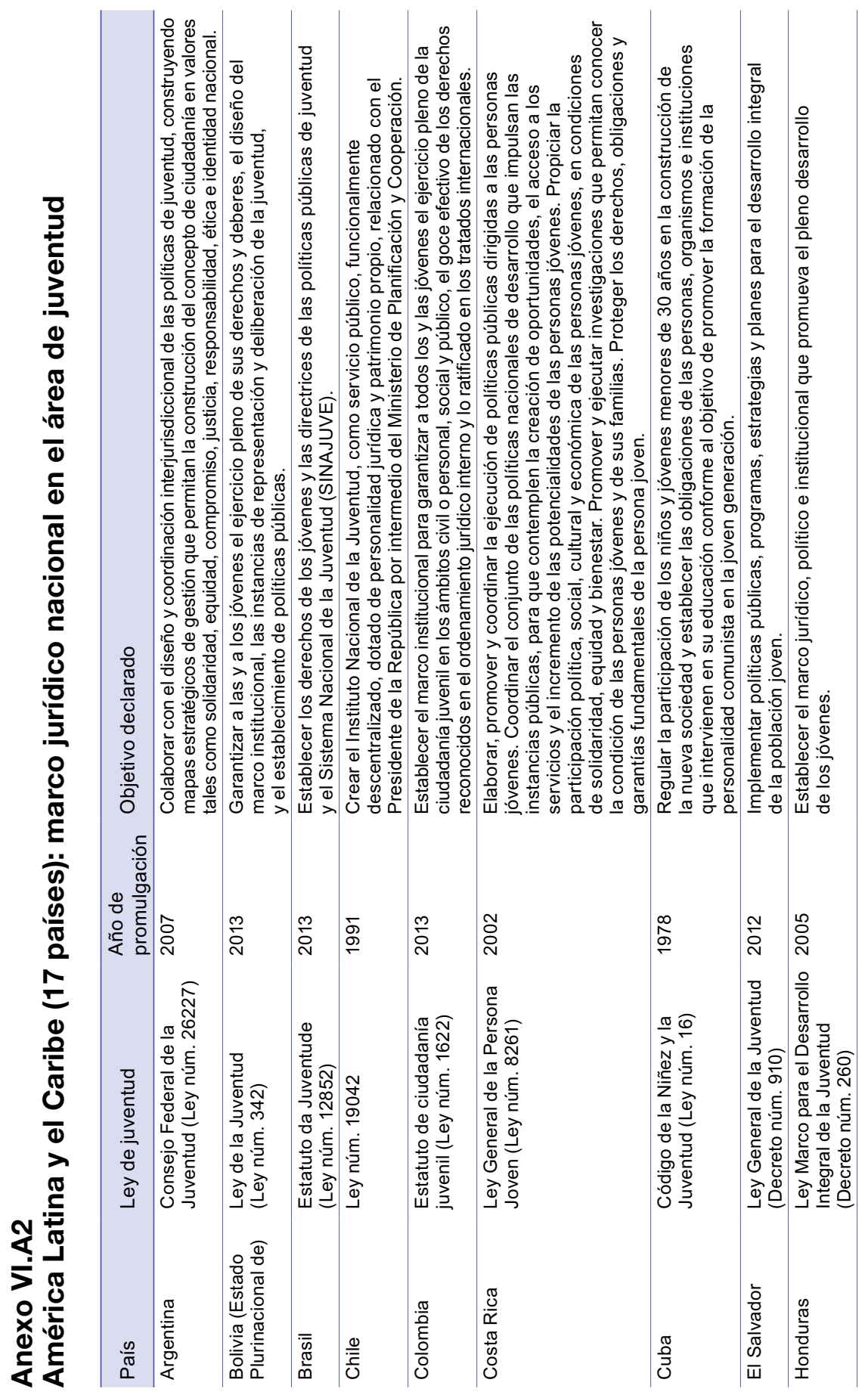




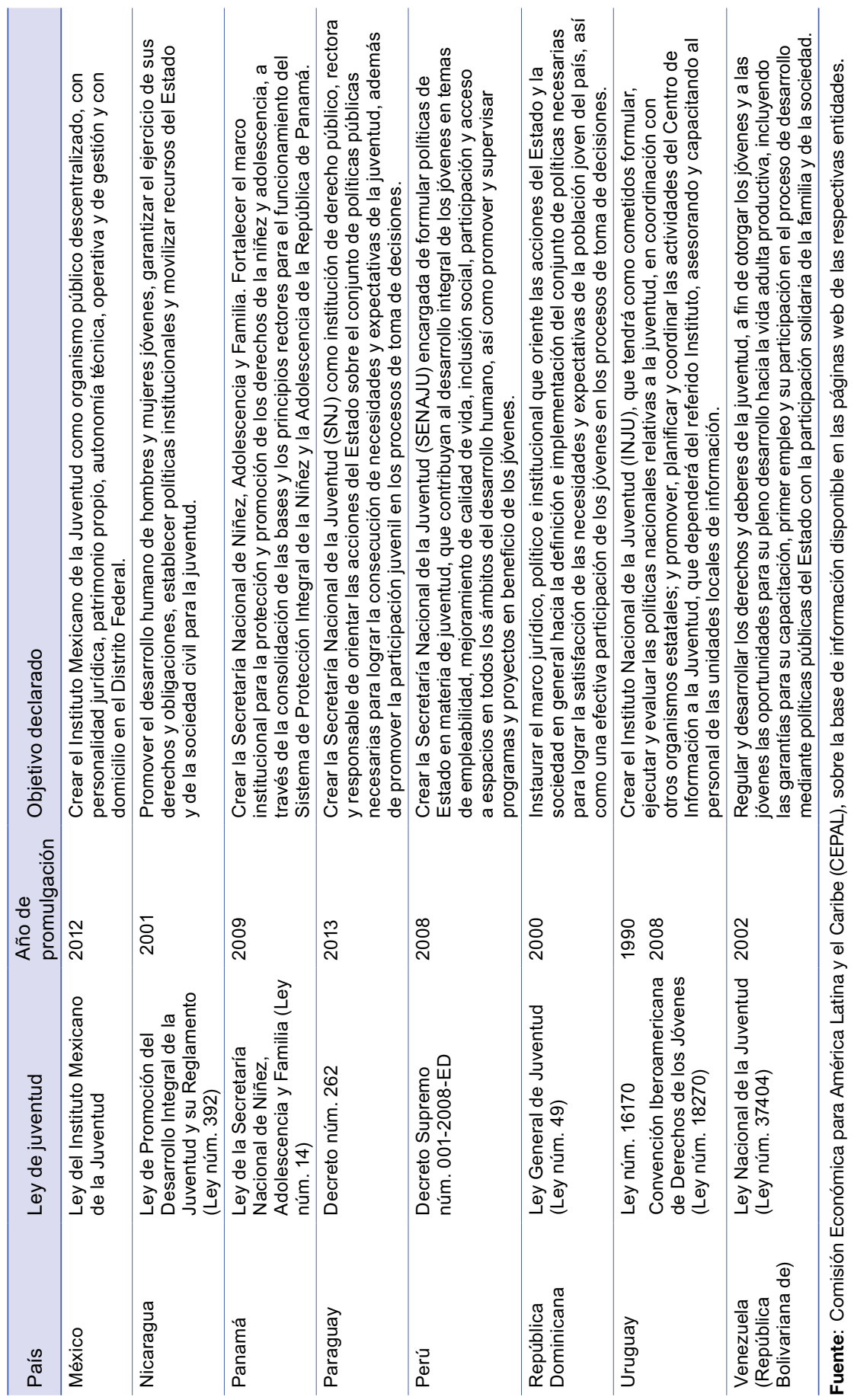




\section{Anexo VI.A3 \\ América Latina y el Caribe (15 países): documentos de las políticas nacionales de juventud}

\begin{tabular}{|c|c|c|}
\hline País & Documento & Sitio web \\
\hline $\begin{array}{l}\text { Antigua y } \\
\text { Barbuda }\end{array}$ & $\begin{array}{l}\text { Política Nacional de Juventud: } \\
\text { Empoderar Hoy a los Líderes de } \\
\text { Mañana }\end{array}$ & $\begin{array}{l}\text { http://www.youthpolicy.org/national/Antigua_- } \\
\text { Barbuda_2007_National_Youth_Policy.pdf }\end{array}$ \\
\hline Bahamas & Política Nacional de Juventud & \\
\hline Barbados & Política Nacional de Juventud & $\begin{array}{l}\text { http://www.youthpolicy.org/national/ } \\
\text { Barbados_2011_National_Youth_Policy.pdf }\end{array}$ \\
\hline Brasil & $\begin{array}{l}\text { Política Nacional de Juventud: } \\
\text { Directrices y Perspectivas }\end{array}$ & $\begin{array}{l}\text { http://library.fes.de/pdf-files/bueros/ } \\
\text { brasilien/05611.pdf }\end{array}$ \\
\hline Chile & $\begin{array}{l}\text { Chile se Compromete con los } \\
\text { Jóvenes: Plan de Acción en } \\
\text { Juventud }\end{array}$ & $\begin{array}{l}\text { http://extranet.injuv.gob.cl/cedoc/Estudios } \% 20 \\
\text { del\%20INJUV/ESTUDIOS\%20PDF/Evaluacion_ } \\
\text { de_la_Reforma_Escolar.pdf }\end{array}$ \\
\hline Colombia & $\begin{array}{l}\text { Política Nacional de Juventud: } \\
\text { Bases para el Plan Decenal de } \\
\text { Juventud } 2005-2015\end{array}$ & $\begin{array}{l}\text { http://cdim.esap.edu.co/BancoMedios/ } \\
\text { Documentos\%20PDF/programa\%20 } \\
\text { presidencial\%20colombia\%20joven.pdf }\end{array}$ \\
\hline Costa Rica & $\begin{array}{l}\text { Política Pública de } \\
\text { la Persona Joven }\end{array}$ & $\begin{array}{l}\text { http://www.cpj.go.cr/images/POLITICA_ } \\
\text { PUBLICA_DE_LA_PERSONA_ } \\
\text { JOVEN_2014_-_2019.pdf }\end{array}$ \\
\hline Ecuador & $\begin{array}{l}\text { Agenda de Igualdad para } \\
\text { la Juventud, 2012-2013 }\end{array}$ & $\begin{array}{l}\text { http://www.youthpolicy.org/national/ } \\
\text { Ecuador_2012_Youth_Equality_Policy.pdf }\end{array}$ \\
\hline El Salvador & $\begin{array}{l}\text { Política Nacional de Juventud } \\
\text { 2011-2024 y Plan de Acción } \\
\text { 2011-2014 }\end{array}$ & $\begin{array}{l}\text { http://planipolis.iiep.unesco.org/upload/Youth/ } \\
\text { El\%20Salvador/El_Salvador_Politica\%20 } \\
\text { Nacional\%20de\%20Juventud\%20de\%20EI\%20 } \\
\text { Salvador\%202011-2024.pdf }\end{array}$ \\
\hline Guatemala & Política de Juventud 2012-2020 & http://conjuve.gob.gt/descargas/pnj.pdf \\
\hline Honduras & $\begin{array}{l}\text { Política Nacional de Juventud } \\
\text { 2007-2021: Por una Ciudadanía } \\
\text { Plena }\end{array}$ & $\begin{array}{l}\text { http://planipolis.iiep.unesco.org/upload/Youth/ } \\
\text { Honduras/Honduras_2007_National_Youth__ } \\
\text { Policy.pdf }\end{array}$ \\
\hline México & $\begin{array}{l}\text { Programa Nacional de Juventud } \\
\text { 2014-2018 }\end{array}$ & $\begin{array}{l}\text { http://www.dof.gob.mx/nota_detalle.php?codigo } \\
=5343095 \& \text { fecha=30/04/2014 }\end{array}$ \\
\hline Nicaragua & $\begin{array}{l}\text { Plan de Acción de la Política } \\
\text { Nacional para el Desarrollo } \\
\text { Integral de la Juventud 2005-2015 }\end{array}$ & $\begin{array}{l}\text { http://planipolis.iiep.unesco.org/upload/Youth/ } \\
\text { Nicaragua/Nicaragua_National_Youth_Policy.pdf }\end{array}$ \\
\hline Panamá & $\begin{array}{l}\text { Política Pública de Juventud } \\
\text { de Panamá }\end{array}$ & $\begin{array}{l}\text { http://planipolis.iiep.unesco.org/upload/Youth/ } \\
\text { Panama/Panama_2004_National_Youth_Policy.pdf }\end{array}$ \\
\hline Paraguay & Plan Nacional de Juventud & http://www.mec.gov.py/cms_v2/adjuntos/7259 \\
\hline Perú & $\begin{array}{l}\text { Plan Estratégico Nacional de la } \\
\text { Juventud 2014-2021: Rumbo al } \\
\text { Bicentenario }\end{array}$ & $\begin{array}{l}\text { http://juventud.gob.pe/media/publications/Plan- } \\
\text { Nacional-Juventud-Documento-Trabajo.pdf }\end{array}$ \\
\hline $\begin{array}{l}\text { República } \\
\text { Dominicana }\end{array}$ & $\begin{array}{l}\text { Política Pública Nacional para } \\
\text { el Desarrollo de la Juventud } \\
\text { Dominicana 2008-2015 }\end{array}$ & \\
\hline $\begin{array}{l}\text { Trinidad y } \\
\text { Tabago }\end{array}$ & $\begin{array}{l}\text { Política Nacional de Juventud } \\
2012-2017\end{array}$ & $\begin{array}{l}\text { http://www.youthpolicy.org/national/Trinidad_ } \\
\text { Tobago_2012_National_Youth_Policy.pdf }\end{array}$ \\
\hline Uruguay & $\begin{array}{l}\text { Plan de Acción de Juventudes } \\
\text { 2015-2025 }\end{array}$ & $\begin{array}{l}\text { http://www.inju.gub.uy/innovaportal/v/26838/5/ } \\
\text { innova.front/plan_de_accion_de_- } \\
\text { juventudes_2015-2025 }\end{array}$ \\
\hline $\begin{array}{l}\text { Venezuela } \\
\text { (República } \\
\text { Bolivariana de) }\end{array}$ & Misión Jóvenes de la Patria & $\begin{array}{l}\text { http://www.youthpolicy.org/wp-content/uploads/ } \\
\text { library/2013_Venezuela_Youth_Policy_Spa.pdf }\end{array}$ \\
\hline
\end{tabular}

Fuente: Comisión Económica para América Latina y el Caribe (CEPAL), sobre la base de la información disponible en las páginas web de las respectivas entidades. 



\section{Publicaciones recientes de la CEPAL ECLAC recent publications}

\section{www.cepal.org/publicaciones}

\section{Informes periódicos / Annual reports}

También disponibles para años anteriores / Issues for previous years also available

- Estudio Económico de América Latina y el Caribe 2015, 204 p. Economic Survey of Latin America and the Caribbean 2015, 196 p.

- La Inversión Extranjera Directa en América Latina y el Caribe 2015, 150 p. Foreign Direct Investment in Latin America and the Caribbean 2015, $140 \mathrm{p}$.

- Anuario Estadístico de América Latina y el Caribe 2014 / Statistical Yearbook for Latin America and the Caribbean 2014, $238 \mathrm{p}$.

- Balance Preliminar de las Economías de América Latina y el Caribe 2014, 92 p. Preliminary Overview of the Economies of Latin America and the Caribbean 2014, 92 p.

- Panorama Social de América Latina 2014, $296 \mathrm{p}$. Social Panorama of Latin America 2014, 284 p.

- Panorama de la Inserción Internacional de América Latina y el Caribe 2014, 148 p. Latin America and the Caribbean in the World Economy 2014, $140 \mathrm{p}$.

\section{Libros y documentos institucionales / Institutional books and documents}

- La nueva revolución digital: de la Internet del consumo a la Internet de la producción, 2015, 98 p. The new digital revolution: From the consumer Internet to the industrial Internet, 2015, 98 p.

- Panorama fiscal de América Latina y el Caribe 2015: dilemas y espacios de políticas, 2015, 128 p. Fiscal Panorama of Latin America and the Caribbean 2015: Policy space and dilemmas. Executive Summary, 2015, 14 p.

- La economía del cambio climático en América Latina y el Caribe: paradojas y desafíos del desarrollo sostenible, 2014, $96 \mathrm{p}$.

The economics of climate change in Latin America and the Caribbean: Paradoxes and challenges of sustainable development, 2014, 92 p.

- El desafío de la sostenibilidad ambiental en América Latina y el Caribe: textos seleccionados de la CEPAL 2012-2014, 2015, 148 p.

- Los pueblos indígenas en América Latina: avances en el último decenio y retos pendientes para la garantía de sus derechos, 2014, 410 p.

- Pactos para la igualdad: hacia un futuro sostenible, 2014, 340 p. Covenants for Equality: Towards a sustainable future, 2014, 330 p.

- Integración regional: hacia una estrategia de cadenas de valor inclusivas, 2014, 226 p. Regional Integration: Towards an inclusive value chain strategy, 2014, 218 p. Integração regional: por uma estratégia de cadeias de valor inclusivas, 2014, 226 p.

- Prospectiva y desarrollo: el clima de la igualdad en América Latina y el Caribe a 2020, 2013, 72 p. 
- Comercio internacional y desarrollo inclusivo: construyendo sinergias, 2013, 210 p. International trade and inclusive development: Building synergies, 2013, 200 p.

- Cambio estructural para la igualdad: una visión integrada del desarrollo, 2012, 330 p. Structural Change for Equality: An integrated approach to development, 2012, 308 p.

- La hora de la igualdad: brechas por cerrar, caminos por abrir, 2010, 290 p.

Time for Equality: Closing gaps, opening trails, 2010, 270 p.

A Hora da Igualdade: Brechas por fechar, caminhos por abrir, 2010, 268 p.

\section{Libros de la CEPAL / ECLAC books}

136 Instrumentos de protección social: caminos latinoamericanos hacia la universalización, Simone Cecchini, Fernando Filgueira, Rodrigo Martínez, Cecilia Rossel (eds.), 2015, 510 p.

135 Rising concentration in Asia-Latin American value chains: Can small firms turn the tide? Osvaldo Rosales, Osvaldo, Keiji Inoue, Nanno Mulder (eds.), 2015, 282 p.

134 Desigualdad, concentración del ingreso y tributación sobre las altas rentas en América Latina, Juan Pablo Jiménez (ed.), 2015, $172 \mathrm{p}$.

133 Desigualdad e informalidad: un análisis de cinco experiencias latinoamericanas, Verónica Amarante, Rodrigo Arim (eds.), 2015, 526 p.

132 Neoestructuralismo y corrientes heterodoxas en América Latina y el Caribe a inicios del siglo XXI, Alicia Bárcena, Antonio Prado (eds.), 2014, 452 p.

131 El nuevo paradigma productivo y tecnólogico: la necesidad de políticas para la autonomía económica de las mujeres, Lucía Scuro, Néstor Bercovich (eds.), 2014, 188 p.

130 Políticas públicas para la igualdad de género: un aporte a la autonomía de las mujeres, María Cristina Benavente, Alejandra Valdés, 2014, 134 p.

\section{Copublicaciones / Co-publications}

- Gobernanza global y desarrollo: nuevos desafíos y prioridades de la cooperación internacional, José Antonio Ocampo (ed.), CEPAL/Siglo Veintiuno, Argentina, 2015, 286 p.

- Decentralization and Reform in Latin America: Improving Intergovernmental Relations, Giorgio Brosio and Juan Pablo Jiménez (eds.), ECLAC / Edward Elgar Publishing, United Kingdom, 2012, $450 p$.

- Sentido de pertenencia en sociedades fragmentadas: América Latina desde una perspectiva global, Martín Hopenhayn y Ana Sojo (comps.), CEPAL / Siglo Veintiuno, Argentina, 2011, 350 p.

\section{Coediciones / Co-editions}

- Perspectivas económicas de América Latina 2015: educación, competencias e innovación para el desarrollo, CEPAL/OCDE, 2014, $200 \mathrm{p}$.

Latin American Economic Outlook 2015: Education, skills and innovation for development, ECLAC,/ CAF/OECD, 2014, $188 p$.

- Regional Perspectives on Sustainable Development: Advancing Integration of its Three Dimensions through Regional Action, ECLAC-ECE-ESCAP-ESCWA, 2014, 114 p.

- Perspectivas de la agricultura y del desarrollo rural en las Américas: una mirada hacia América Latina y el Caribe 2014, CEPAL / FAO / IICA, 2013, 220 p. 


\section{Cuadernos de la CEPAL}

101 Redistribuir el cuidado: el desafío de las políticas, Coral Calderón Magaña (coord.), 2013, 460 p.

101 Redistributing care: The policy challenge, Coral Calderón Magaña (coord.), 2013, 420 p.

\section{Documentos de proyecto / Project documents}

- La economía del cambio climático en el Perú, 2014, 152 p.

- La economía del cambio climático en la Argentina: primera aproximación, 2014, 240 p.

- La economía del cambio climático en el Ecuador 2012, 2012, 206 p.

\section{Cuadernos estadísticos de la CEPAL}

42 Resultados del Programa de Comparación Internacional (PCI) de 2011 para América Latina y el Caribe. Solo disponible en CD, 2015.

41 Los cuadros de oferta y utilización, las matrices de insumo-producto y las matrices de empleo. Solo disponible en CD, 2013.

\section{Series de la CEPAL / ECLAC Series}

Asuntos de Género / Comercio Internacional / Desarrollo Productivo / Desarrollo Territorial / Estudios Estadísticos / Estudios y Perspectivas (Bogotá, Brasilia, Buenos Aires, México, Montevideo) / Studies and Perspectives (The Caribbean, Washington) / Financiamiento del Desarrollo/ Gestión Pública / Informes y Estudios Especiales / Macroeconomía del Desarrollo / Manuales / Medio Ambiente y Desarrollo / Población y Desarrollo/ Política Fiscal / Políticas Sociales / Recursos Naturales e Infraestructura / Seminarios y Conferencias.

\section{Revista CEPAL / CEPAL Review}

La Revista se inició en 1976, con el propósito de contribuir al examen de los problemas del desarrollo socioeconómico de la región. La Revista CEPAL se publica en español e inglés tres veces por año.

CEPAL Review first appeared in 1976, its aim being to make a contribution to the study of the economic and social development problems of the region. CEPAL Review is published in Spanish and English versions three times a year.

\section{Observatorio demográfico / Demographic Observatory}

Edición bilingüe (español e inglés) que proporciona información estadística actualizada, referente a estimaciones y proyecciones de población de los países de América Latina y el Caribe. Desde 2013 el Observatorio aparece una vez al año.

Bilingual publication (Spanish and English) proving up-to-date estimates and projections of the populations of the Latin American and Caribbean countries. Since 2013, the Observatory appears once a year. 


\section{Notas de población}

Revista especializada que publica artículos e informes acerca de las investigaciones más recientes sobre la dinámica demográfica en la región. También incluye información sobre actividades científicas y profesionales en el campo de población.

La revista se publica desde 1973 y aparece dos veces al año, en junio y diciembre.

Specialized journal which publishes articles and reports on recent studies of demographic dynamics in the region. Also includes information on scientific and professional activities in the field of population. Published since 1973, the journal appears twice a year in June and December.

Las publicaciones de la CEPAL están disponibles en: ECLAC publications are available at: www.cepal.org/publicaciones

También se pueden adquirir a través de: They can also be ordered through: www.un.org/publications

United Nations Publications PO Box 960

Herndon, VA 20172

USA

Tel. (1-888)254-4286

Fax (1-800)338-4550

Contacto / Contact. publications@un.org

Pedidos / Orders: order@un.org 


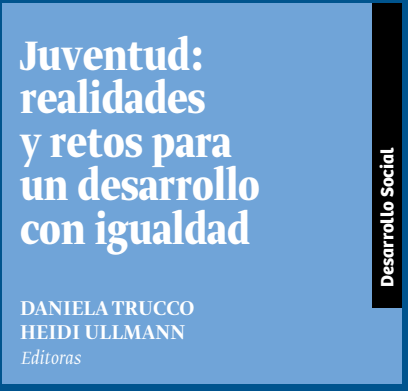

En este libro se ilustra la situación de los jóvenes de América Latina y el Caribe en términos de sus oportunidades de inclusión social, con el fin de aportar al fortalecimiento de las políticas de juventud de la región. La integración de la población juvenil en los procesos de desarrollo es crucial para avanzar hacia sociedades más igualitarias, no solo por el número que representan los jóvenes en relación con el resto de la población, sino por sus implicancias en términos de tasas de dependencia, necesidades y problemáticas propias de este período de la vida.

La propuesta de la CEPAL apunta a comprender el proceso de inclusión social desde una perspectiva de derechos que trascienda el eje básico de educación y empleo. Para ello incorpora otras dimensiones de la inclusión social que son también fundamentales para que la juventud avance no solo en los parámetros objetivos de la inclusión, sino también en los subjetivos, sintiéndose parte de una sociedad que se construye en conjunto.

El libro se ordena a partir de un análisis de las principales brechas de inclusión en distintos ámbitos clave de esta etapa de la vida. Así, desde un enfoque de políticas sectoriales coordinadas, se aborda la educación y la transición hacia el empleo; el acceso a la salud y algunas consideraciones relevantes para este grupo de edad; los contextos de creciente violencia que enfrenta la juventud; el ámbito cultural, con particular atención a la cultura digital, y la participación política de los jóvenes. En el último capítulo, tomando en cuenta las recomendaciones derivadas del análisis de cada ámbito y la situación general de institucionalidad, normativa e inversión social de la región, se presenta una discusión más integral sobre la política social dirigida a la juventud. 